UNIVERSIDAD NACIONAL DE LA PLATA

FACULTAD DE HUMANIDADES Y CIENCIAS DE LA EDUCACIÓN

SECRETARÍA DE POSGRADO

\title{
Valoración e investigación en el continuo de la experiencia
}

Desde el pragmatismo de John Dewey

al debate sobre el ideal de ciencia libre de valores

\author{
Livio Mattarollo \\ Centro de Investigaciones en Filosofía \\ IdIHCS, UNLP/CONICET
}

Tesis para optar por el grado de Doctor en Filosofía

Directora: Dra. María Cristina Di Gregori

CIeFi, IdIHCS, FaHCE, UNLP/CONICET

Co-director: Dr. Federico E. López

CIeFi, IdIHCS, FaHCE, UNLP/CONICET

Ensenada, 8 de octubre de 2019 


\section{AGRADECIMIENTOS}

Esta investigación y sus resultados han sido posibles por el apoyo de distintas instituciones y por el trabajo de muchas personas. Agradezco al Consejo Nacional de Investigaciones Científicas y Técnicas por haber financiado mis estudios durante 5 años. Agradezco a la Universidad Nacional de La Plata en su conjunto y al Centro de Investigaciones en Filosofía, radicado en el Instituto de Investigaciones en Humanidades y Ciencias Sociales (UNLP / CONICET), por haberme ofrecido un lugar de trabajo y especialmente un lugar de encuentro. En el marco de la Facultad de Humanidades y Ciencias de la Educación agradezco al Doctorado en Filosofía, por su atento y amable trato durante mi tránsito por la carrera; a la Pro-Secretaría de Relaciones Internacionales, por haberme permitido realizar un intercambio académico ciertamente enriquecedor en la Facultad de Artes y Filosofía de la Universidad de Gent, Bélgica; y a la Biblioteca, gran aliada en esta tarea.

Agradezco a mis compañeras/os y amigas/os del Grupo de Estudios Pragmatistas, Victoria Sánchez, Leopoldo Rueda, María Bibiloni y Analía Melamed, por las horas de reflexión compartidas y sus jugosos aportes en reuniones, cursos, congresos e incluso a la distancia. Agradezco también a Federico López, con quien he trabajado codo a codo durante estos últimos años y cuyo conocimiento de la obra de Dewey ha propiciado un salto de calidad en mis propias lecturas e interpretaciones. Reservo un agradecimiento muy especial a Cristina Di Gregori, quien guía mi trabajo desde 2011. Su mirada filosófica rigurosa y aguda junto con su total entusiasmo, generosidad, disposición y compromiso son elementos sin los cuales mi investigación no habría avanzado un solo paso.

Agradezco a mi familia por su apoyo incondicional. Finalmente, agradezco a Ludmila: su lugar durante el proceso de investigación y escritura ha sido infinitamente más importante de lo que soy capaz de explicitar. A todas y todos les debo los aciertos que pudieran aparecer en las próximas páginas. Las omisiones, errores e imprecisiones, por supuesto, son mi entera responsabilidad. 


\section{CONTENIDO}

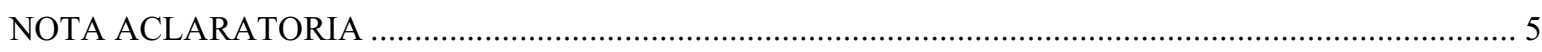

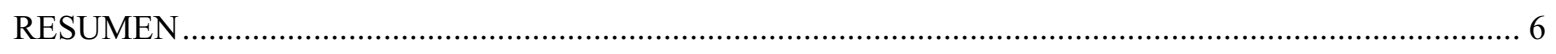

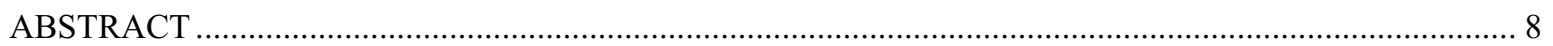

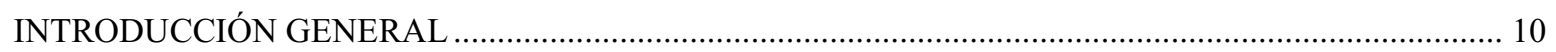

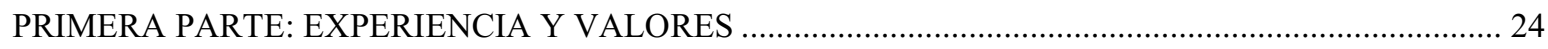

CAPÍTULO 1: PUNTOS DE PARTIDA (Y DE LLEGADA) .................................................................... 25

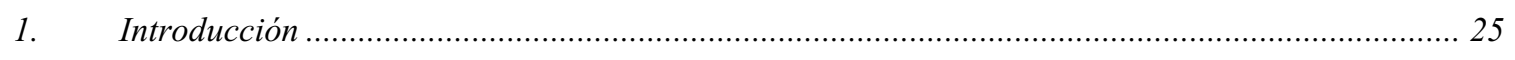

2. John Dewey y una novedosa concepción de la experiencia ........................................................ 26

3. Hacia la concepción deweyana del valor ............................................................................... 32

3.1. El impacto del darwinismo y los sentidos del naturalismo .................................................. 32

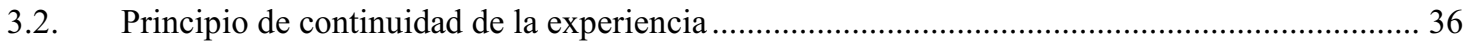

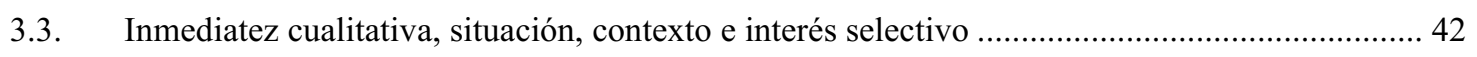

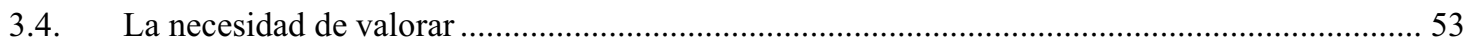

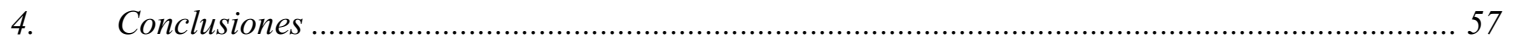

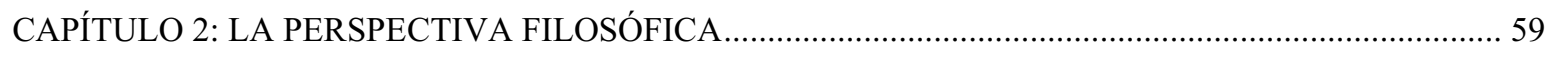

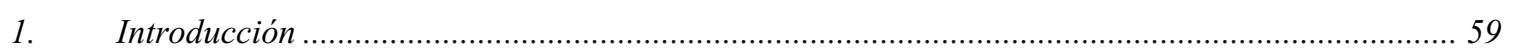

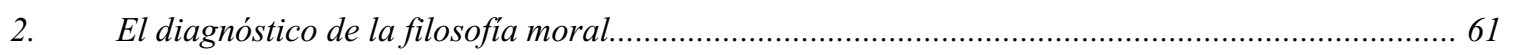

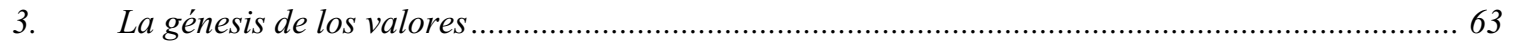

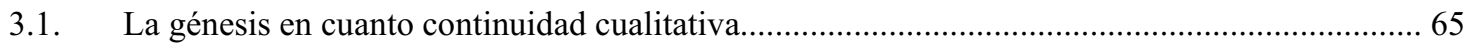

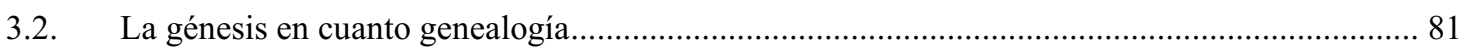

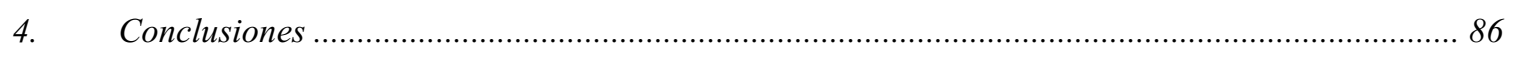

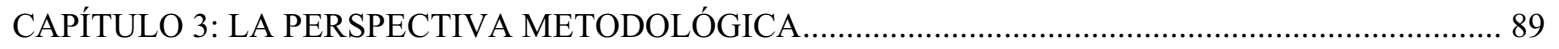

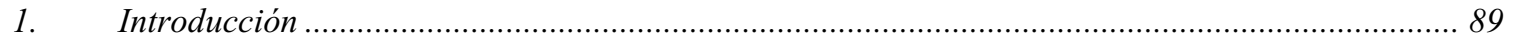

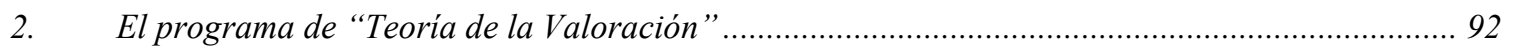

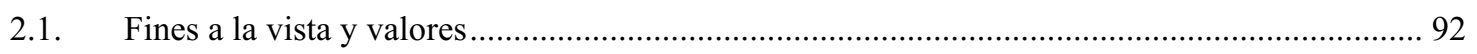

2.2. La tesis de la continuidad medios-fines en el continuo de valoración .......................................... 96

3. Críticas y aclaraciones sobre el sentido deweyano de normatividad .......................................... 104

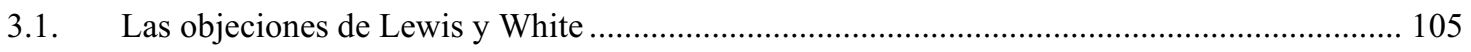

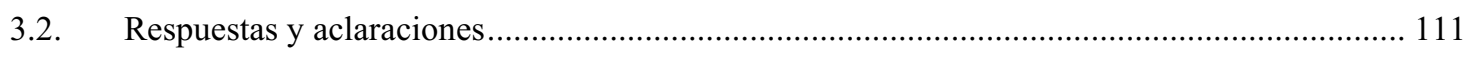

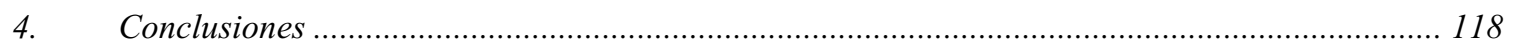

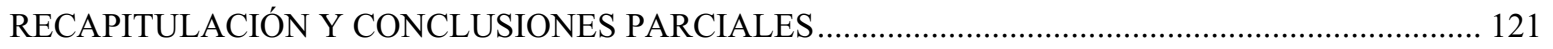




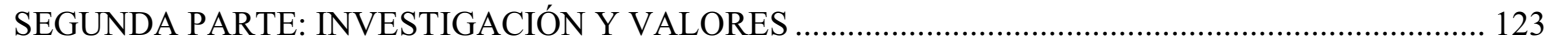

CAPÍTULO 4: LA INVESTIGACIÓN CIENTÍFICA COMO PRÁCTICA ………........................................ 124

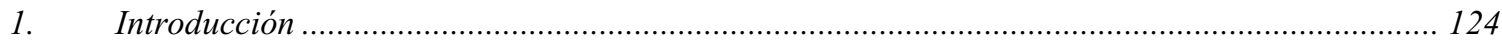

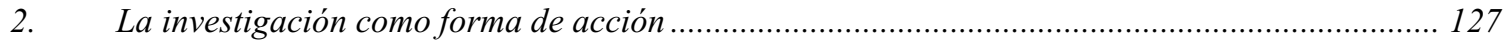

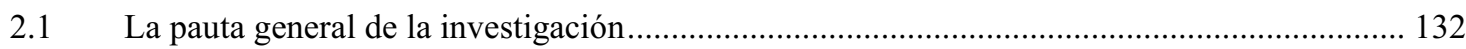

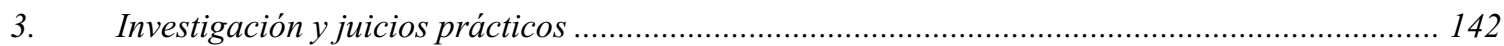

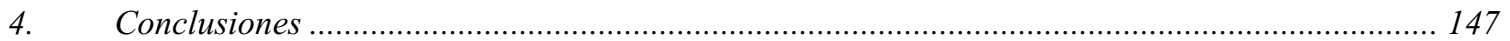

CAPÍTULO 5: LA RECONSTRUCCIÓN DE LAS CONTINUIDADES...................................................... 149

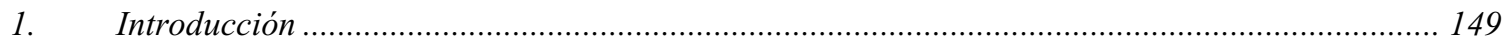

2. El carácter contextual de la investigación ............................................................................... 151

3. Continuidad procedimental y continuidad material ............................................................... 156

3.1. El carácter bidireccional de la continuidad material............................................................... 163

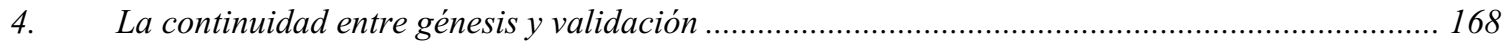

5. Del desplome de la dicotomía hecho/valor a la organización de la investigación......................... 172

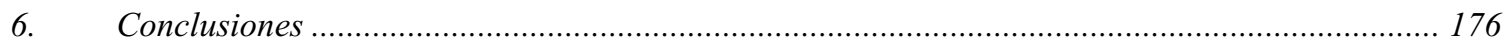

CAPÍTULO 6: FILOSOFÍA POLÍTICA DE LA CIENCIA EN CLAVE DEWEYANA................................. 179

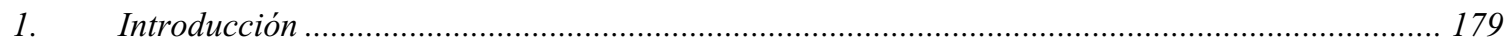

2. La democracia como forma de vida y su justificación epistémica .............................................. 180

3. Ciencia, expertos y constitución de la opinión pública .......................................................... 190

4. Dewey, en camino a una filosofia política de la ciencia ............................................................ 201

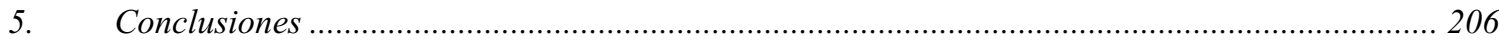

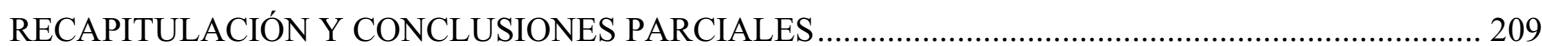

TERCERA PARTE: APORTES AL DEBATE SOBRE EL IDEAL DE CIENCIA LIBRE DE VALORES 212 COMENTARIOS PRELIMINARES: UN MAPA DEL DEBATE .............................................................. 213

CAPÍTULO 7: HEATHER DOUGLAS Y SU RECHAZO AL IDEAL ....................................................... 225

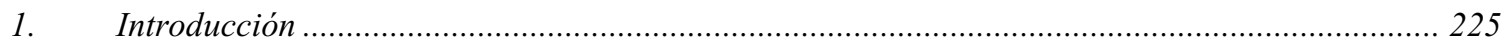

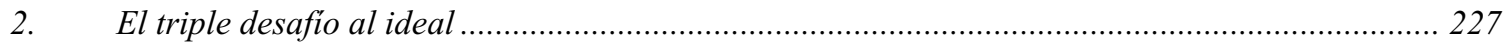

3. Rechazando el ideal: riesgo inductivo y terreno moral de la ciencia ........................................... 231

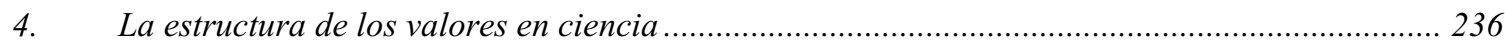

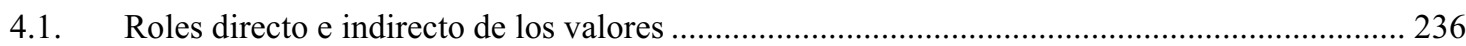

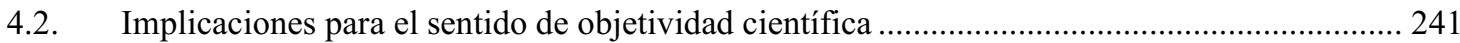

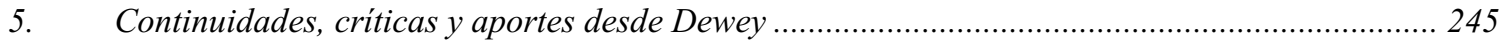

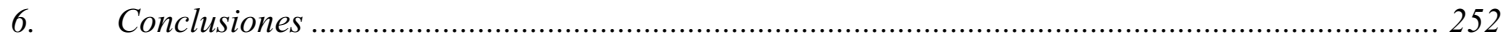

CAPÍTULO 8: PHILIP KITCHER, CIENCIA BIEN ORDENADA Y DEMOCRACIA ….......................... 255

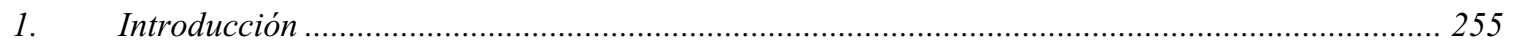


2. El ideal de ciencia bien ordenada: fundamentos epistémicos ................................................. 257

3. El ideal de ciencia bien ordenada: fundamentos políticos y meta-éticos................................... 262

3.1. En tono rawlsiano: la primera versión del ideal........................................................ 262

3.2. En tono deweyano: la segunda versión del ideal ......................................................... 268

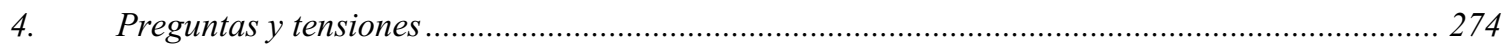

5. Algunas reconsideraciones - o qué aportaría un enfoque deweyano consecuente ........................ 278

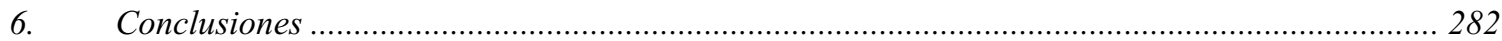

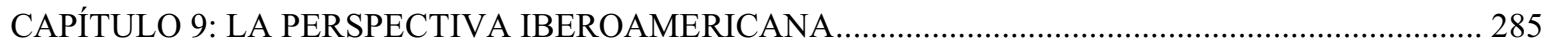

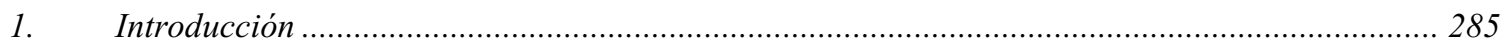

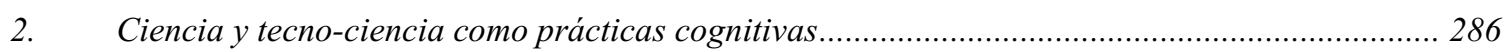

2.1 Del "reduccionismo heredado" a la acción científica ...................................................... 286

$2.2 \quad$ La revolución tecno-científica ................................................................................... 294

3. Concepción de valor y fundamentos filosóficos de la axiología ................................................299

4. Hacia un nuevo modelo (pragmatista) de racionalidad ............................................................. 304

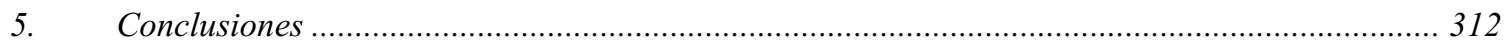

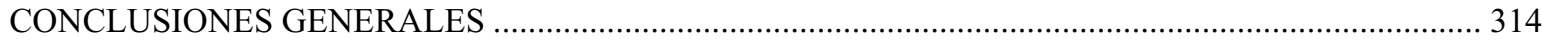

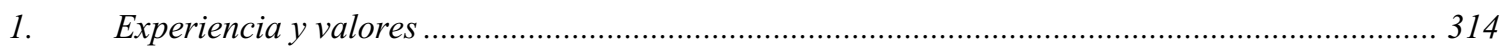

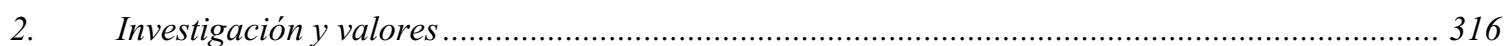

3. Aportes al debate sobre el ideal de ciencia libre de valores ................................................... 320

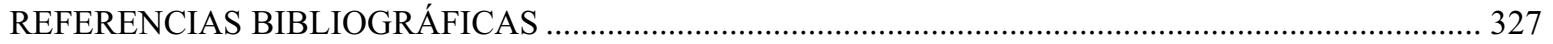




\section{NOTA ACLARATORIA}

Todas las citas y referencias siguen la Sexta Edición del manual de estilo de la American Psychological Association. Por su parte, las citas y referencias a los textos de John Dewey son a las versiones en español, cuando las hubiera. Caso contrario, las traducciones de los fragmentos son propias. Asimismo, para aquellos textos que no cuentan con traducción al español he optado por conservar sus títulos en inglés. Como es habitual en la literatura especializada, se remitirá a la edición canónica de las obras completas: The Collected Works of John Dewey 1882-1953 (1967-1987). The Early Works, 1882-1898 (1967-1972); The Middle Works, $1899-1924$ (1976-1983); The Later Works, 1925-1953 (1981-1991). Carbondale: Southern Illinois University Press. Así, se indicará EW (The Early Works), MW (The Middle Works) o LW (The Later Works), seguido del correspondiente número de volúmen. Luego, para aquellos títulos que cuenten con traducción al español la referencia combinará ambos estilos, por ejemplo (Dewey, 1950, p. 123. LW.12.108). Para aquellos textos que no cuenten con traducción al español la referencia será a las obras completas, por ejemplo (LW.6.20). La única excepción a esta clave de citación es el libro Unmodern Philosophy and Modern Philosophy (2012) cuya edición y publicación es posterior a The Collected Works of John Dewey.

Por su parte, las traducciones de las múltiples citas de textos de Heather Douglas y de Philip Kitcher son propias. Respecto de aquellos artículos escritos originalmente en inglés, la aclaración sobre la traducción queda incluida en la propia referencia. Habida cuenta de las limitaciones de toda traducción, tanto para los textos de Dewey como para la bibliografía crítica y las fuentes contemporáneas he optado por incluir entre corchetes algunos términos de la frase en inglés que según entiendo pueden facilitar la comprensión de la cita en cuestión. 


\section{RESUMEN}

El objetivo general de esta tesis es ofrecer un análisis de las relaciones entre las teorías de la valoración y de la investigación de John Dewey a efectos de considerar en qué medida el planteo del pragmatista permite afirmar que hay legítima presencia de valores morales, sociales y políticos en la investigación científica y qué aportes pueden hacerse desde allí al debate actual sobre el ideal de ciencia libre de valores. La tesis aparece dividida en tres partes, orientadas a (i) reconstruir las ideas deweyanas en torno al valor y la valoración; (ii) analizar la teoría de la investigación de Dewey a la luz de la pregunta por sus componentes valorativos; y (iii) abordar algunas intervenciones críticas del ideal de ciencia libre de valores desde el marco teórico deweyano.

La primera parte tiene como punto de inicio un estudio del concepto de experiencia, a la base de toda la reflexión filosófica de Dewey, análisis orientado a identificar los aspectos pertinentes para la comprensión de las ideas del pragmatista en torno a los valores y la valoración. En este marco se ponen de relieve tres aspectos principales: que la experiencia debe comprenderse en términos de transacción entre organismo y ambiente, que presenta una matriz cualitativa-apreciativa y que hay continuidad tanto entre sus niveles primario o inmediato y secundario o reflexivo como entre las distintas experiencias reflexivas. Asimismo, de acuerdo con la insoslayable impronta naturalista de la filosofía deweyana, se observa que cualquier reflexión en torno a los valores debe inscribirlos en el curso de experiencia. Así, la tarea filosófica en materia de valores y valoración pasa por dar cuenta de la génesis y la genealogía de los valores y también por ofrecer una pauta metodológica para la correcta o inteligente formación de los valores. Este análisis permite subrayar que los valores deben comprenderse en continuidad con el nivel primario de experiencia y que deben ser el resultado de una deliberación inteligente e informada por el mejor conocimiento disponible. En suma, se afirma que para Dewey no hay valoración en sentido distintivo sin investigación.

La segunda parte busca identificar en qué puntos de la investigación científica, de acuerdo con el planteo de Dewey, hay efectiva y legítima presencia de valores. Para ello, el recorrido comienza por recuperar la pauta general de la investigación, teniendo en cuenta que Dewey define a esta última -tanto a nivel del sentido común como científico, sin 
perjuicio de sus diferencias- como la transformación controlada de una situación indeterminada en otra unificada. Una vez identificado este aspecto, se consideran las continuidades entre investigación científica y valoración, en distintos sentidos: contextual, procedimental y material. Asimismo, se consideran los argumentos de Dewey sobre la imposibilidad de distinguir tajantemente entre ámbitos de génesis y validez del conocimiento, sobre la superación de la dicotomía hecho/valor y sobre el rol de la cooperación en la investigación científica (estos últimos desde la perspectiva de Putnam). Desde aquí se afirma que, así como no hay valoración sin investigación, tampoco hay investigación sin valoración. Por último, se ofrece un análisis de las relaciones propuestas por Dewey entre investigación científica, opinión púbica y democracia, a efectos de señalar que en cuanto actividad pública la ciencia debe tener ciertas regulaciones por parte del público $\mathrm{y}$, a su vez, que la plena comunicación de los resultados de las investigaciones científicas es condición para la conformación de ese mismo público competente y activo.

La tercera parte aborda el debate contemporáneo sobre el ideal de ciencia libre de valores a la luz del marco teórico deweyano. Para ello, en primer lugar se ofrece un breve estado de la discusión y luego se abordan en sendos capítulos (i) los argumentos de Heather Douglas en favor de la inclusión de valores morales y sociales en caso de que la investigación reporte consecuencias extra-epistémicas; (ii) el ideal de ciencia bien ordenada y su inextricable relación con la democracia elaborado por Philip Kitcher; y (iii) las consideraciones sobre ciencia y tecnociencia en cuanto prácticas cognitivas atravesadas por un pluralismo axiológico y sobre la noción de racionalidad valorativa presentadas por los filósofos iberoamericanos Javier Echeverría y León Olivé. En este contexto, se arguye que los principales aportes del marco teórico deweyano están dados por su concepción de valor en cuanto resultado de una deliberación inteligente, su concepción amplia de investigación que impide abstraerla del curso de experiencia, por un profundo sentido de continuidad entre valores e investigación y por una novedosa concepción política de público, elementos que en su conjunto reclaman por una consideración responsable sobre los fines y valores de la ciencia. En virtud de lo dicho, se afirma entonces que el pensamiento deweyano ofrece elementos consistentes y sólidos para una filosofía política del conocimiento científico.

PALABRAS CLAVE: Experiencia - Valores - Investigación - Ciencia - Ideal de ciencia libre de valores - Democracia 


\begin{abstract}
The main purpose of this thesis is to provide an analysis of the links between two theories advanced by John Dewey: his theory of valuation and his theory of inquiry. The aim of this analysis is twofold: firstly, to consider in what sense his philosophical position allows to claim that moral, social and political values play a legitimate role within scientific inquiry and secondly, to identify what contributions could be made from a Deweyan perspective to the current debate about value-free science ideal. The study is divided into three parts, each of which intend to: (i) reconstruct Dewey's ideas about value and valuation; (ii) analyze Dewey's theory of inquiry in the light of the question concerning its valuation-elements; and (iii) address some criticisms against the value-free science ideal taking into account Dewey's view.

The starting point of the first part is an analysis of a crucial element in Dewey's philosophy, that is, the concept of experience, in order to identify the pertinent aspects for the understanding of the pragmatist's ideas about values and valuation. In this context, three main aspects are highlighted: firstly, experience must be understood in terms of transaction between the organism and the environment, secondly, that experience presents a qualitative-appreciative matrix and thirdly, that there is a continuity both between its primary or immediate level and its secondary or reflective level, as well as between different reflective experiences. Likewise, according to the naturalist feature of deweyan philosophy, it is argued that any reflection on values must be rooted into the course of experience. Thus, the philosophical task regarding values and valuation is not only to explain the genesis and genealogy of values but also to offer a methodological guideline for the correct formation of values. This analysis allows for both highlighting this point and that values must be understood in continuity with the primary level of experience and must be the result of intelligent deliberation while also be informed by the best available knowledge. To put it simply, it is argued that according to Dewey there is no genuine valuation without inquiry.

The second part focuses on identifying at which points of the scientific inquiry is there an effective and legitimate presence of values according to Dewey's view. In order to achieve this goal, this part focuses on Dewey's general pattern of inquiry taking into
\end{abstract}


account that he defines inquiry -both with respect to common sense and scientific inquiryas the controlled transformation of an indeterminate situation into a unified whole. After pointing this out, the continuities between scientific research and assessment are considered with regard to different dimensions: contextual, procedural and material dimensions. Likewise, Dewey's arguments against genesis/validity dichotomy as well as his understanding of the fact/value dichotomy and the role of cooperation in scientific research are considered (the last two introduced through Hilary Putnam's view). Thus, it is claimed that just as there is no valuation without scientific inquiry, there is no scientific inquiry without valuation. Finally, it is offered an analysis of the relations proposed by Dewey between scientific inquiry, public opinion and democracy, in order to point out firstly, that as a public activity, science should be subject to regulations by the public and secondly, that free and full communication of scientific inquiries' results is the precondition of the existence of a genuine and effective public .

The third part addresses the contemporary debate on the ideal of value-free science in the light of Dewey's point of view. In this regard, a brief state of mainstream positions is offered. After that, different particular approaches are addressed: (i) Heather Douglas' arguments in favor of the inclusion of moral and social values in the case-scenario that investigation reports extra-epistemic consequences; (ii) Philip Kitcher's the ideal of wellordered science and its deep relationship with democracy; and (iii) Javier Echeverría and León Olivé's views on science and techno-science as cognitive practices signed by an axiological pluralism and their idea about a kind of rationality based on values. Within this context, it is argued that the main contributions of Dewey's theoretical framework are given by several key points: his conception of values as a result of intelligent deliberation, his broad conception of inquiry, a deep sense of continuity between scientific inquiry and valuation, and a novel and fruitful political conception of public. All of these elements demand for a careful and serious consideration about the ends and values of science. By virtue of all these reasons, it is claimed that Dewey offers consistent and solid grounds for a political philosophy of scientific knowledge.

KEYWORDS: Experience - Values - Inquiry - Science - Free-value science ideal Democracy 


\section{INTRODUCCIÓN GENERAL}

A lo largo de la tradición y sobre la base de la férrea dicotomía teoría-práctica, las posiciones dominantes en filosofía tendieron a focalizar sus indagaciones respecto del conocimiento en su dimensión estrictamente teórica, en cuanto contemplación y vía de acceso a verdades eternas e inmutables, y relegaron al conocimiento práctico a un segundo orden, esto es, como un conocimiento cualitativamente inferior. En la contemporaneidad, esta perspectiva cristaliza en la identificación de la filosofía del conocimiento con la versión standard de la filosofía de la ciencia y en el modo en que ésta priorizó el análisis lógico de las teorías científicas por sobre cualquier otro tipo de consideración. Así, junto con la consolidación progresiva de otras dicotomías, a saber, hecho-valor (de reconocida herencia moderna), epistémico-extraepistémico y justificación-descubrimiento, la pregunta por la dimensión valorativa, moral y política del conocimiento en general y del conocimiento científico en particular fue virtualmente expulsada del ámbito de la reflexión filosófica rigurosa y quedó en manos de la sociología o de la historia de la ciencia.

A diferencia de esta visión, en el presente estudio sostengo que es necesario recuperar la referida pregunta por el componente valorativo del conocimiento para desarrollar un abordaje filosófico que determine los ámbitos de incidencia efectiva de los valores tradicionalmente denominados extra-epistémicos en la investigación científica. Esto implica identificar las condiciones bajo las cuales es legítimo y deseable considerarlos como aspectos intrínsecos a la actividad científica, en dos niveles: por un lado, en referencia a la validez del conocimiento y, por el otro, al desarrollo de la ciencia en cuanto actividad pública -entendiendo por esto último la elección de problemas a resolver o temas a investigar, los modos, alcances y restricciones de su aplicación, etc. En principio, y sigo aquí la observación de Ricardo Gómez (2014, p. 13), la pregunta acerca de la presencia de valores tradicionalmente considerados extra-epistémicos parecería tener una obvia respuesta positiva si se considera la dimensión "externa" de la ciencia. Sin embargo, sucedería lo contrario para la dimensión "interna", de validez del conocimiento. En este contexto surgen tres preguntas fundamentales: (i) ¿la determinación de la validez del conocimiento está efectivamente libre de valores sociales, éticos, políticos? (ii) ¿cómo debería entenderse y articularse la presencia de los así llamados valores extra-epistémicos 
en la dimensión pública de la ciencia? y (iii) ¿es legítima y deseable la presencia de valores tradicionalmente denominados extra-epistémicos en esas dos aristas o dimensiones de la investigación científica?

Partiendo de estos interrogantes, en lo que sigue presento un análisis del tema desde el marco teórico de John Dewey con el propósito de sostener dos grandes afirmaciones. Por un lado, que su perspectiva respecto de la investigación en general y de la investigación científica en particular brinda respuestas con sólidos fundamentos filosóficos a las preguntas antedichas, ofreciendo razones para sostener que hay efectiva, legítima y deseable presencia de valores en las dos dimensiones señaladas por Gómez y para sentar las pautas de una filosofía política del conocimiento científico. Por otro lado, que su perspectiva permite elaborar una fundamentación consistente y enriquecedora de la posición de algunas intervenciones en la discusión actual sobre el ideal de ciencia libre de valores, a saber: la de Heather Douglas, la de Philip Kitcher y, en el ámbito iberoamericano, la de León Olivé y Javier Echeverría.

Considerando la intención general indicada, adopto y propongo articular dos enfoques metodológicos: por un lado el de reconstrucción histórica, que busca describir y ubicar a los filósofos en sus propios términos y contextos intelectuales; y por otro lado el de reconstrucción racional, que permite recuperar los argumentos filosóficos como interlocutores válidos en discusiones contemporáneas -siempre y cuando se advierta el peligro del anacronismo (Cf. Rorty, 1984, pp. 69 y ss.). ${ }^{1}$ En este sentido, vale recordar entonces que Dewey forma parte de la tradición del pragmatismo clásico estadounidense, cuyo núcleo principal mas no exclusivo aparece vinculado al Departamento de Filosofía de la Universidad de Harvard hacia finales del Siglo XIX. En términos generales, la evolución del pragmatismo puede dividirse en dos grandes épocas. La primera de ellas, entre 1880 y 1914, es conocida como "Edad de Oro" y tiene entre sus representantes principales a Josiah

\footnotetext{
1 De acuerdo con Rorty, las reconstrucciones histórica y racional parecen llevar a un dilema: o bien la actividad se limita a la reconstrucción contextual y argumentativa, o bien se imponen léxicos, términos y problemas ajenos al filósofo y a su tiempo. Sin embargo, de acuerdo con Rorty esto no constituye un dilema pues deben hacerse ambas reconstrucciones, sólo que por separado. En este punto considero más interesante la posición de María Isabel Sant Cruz, para quien una reconstrucción histórica no puede hacerse sino desde el presente al tiempo que una reconstrucción racional descontextualiza en demasía, por lo cual ambos enfoques son igualmente necesarios y pertinentes (Santa Cruz, 2003, pp. 139-145). En ese sentido corre la articulación de enfoques aquí propuesta.
} 
Royce, William James, Charles Sanders Peirce y George Santayana. En este período se suceden dos grandes líneas de pensamiento: inicialmente el idealismo absoluto, de la mano de Royce, y posteriormente la línea pragmatista, en especial a partir de los ensayos gnoseológicos de Peirce y de algunas conferencias programáticas de James. Tanto el darwinismo y su repercusión filosófica como el kantismo y su insistencia en tomar a la experiencia como único horizonte del conocimiento marcan la ruta intelectual de esta fase de la "Edad de Oro". Asimismo, rápidamente se observa un movimiento de expansión de las ideas pragmatistas a nivel nacional en lugares como Michigan, Chicago y Columbia con los trabajos de Dewey y de George Herbert Mead, y a nivel internacional en Inglaterra e Italia, de la mano de Ferdinand Schiller y Mario Calderoni, respectivamente.

La segunda época se inicia tras la finalización de la Primera Guerra Mundial. A ella pertenecen Ralph Barton Perry, Alfred Whitehead y Clarence Irwing Lewis, entre otros. Signados por la profesionalización de la filosofía, estos pensadores añaden dos elementos fundamentales: por un lado, sistematizan los análisis en teoría de la valoración, profundizando la impronta humanista de la primera época; por el otro, toman a la lógica formal como objeto de estudio y postergan a la psicología como disciplina auxiliar de la filosofía. Tal vez sea Lewis quien representa el punto más alto de esta segunda época, dado el indudable rigor de su producción en materia de lógica, teoría del conocimiento y teoría de la valoración. Asimismo, Lewis fue alumno de James y Royce, fue un profundo estudioso de las obras de Peirce y Dewey y también fue profesor de filósofos contemporáneos como William van Orman Quine, Donald Davidson o Nelson Goodman, de modo que es un nexo entre los padres del pragmatismo y algunos de los más destacados filósofos norteamericanos de la segunda mitad del siglo XX. En este breve recuento vale indicar también que en los últimos años se ha hecho un esfuerzo muy interesante por visibilizar el aporte de filósofas pragmatistas contemporáneas a Dewey como Charlotte Perkins Gilman y Jane Addams, dedicadas especialmente a la filosofía política y social (al respecto, Cf. Miras Boronat, 2019).

Más allá de estas relaciones intelectuales, cuesta identificar al pragmatismo como una escuela de filosofía en la medida en que no existe un núcleo duro de tesis propias de todos sus integrantes, que éstos no reconocen fuentes históricas comunes y que cultivan diversas orientaciones intelectuales. No obstante, hay ciertos puntos de coincidencia, entre 
los cuales es imprescindible mencionar el esfuerzo por superar las dicotomías filosóficas tradicionales entre teoría y práctica o lógica objetiva del conocimiento puro y lógica subjetiva de los valores, junto con su posición falibilista que es a la vez anti-fundacionalista y anti-escéptica, sus críticas a cualquier forma de esencialismo y sus cuestionamientos a las teorías del conocimiento de herencia racionalista o empirista clásica. En pocas palabras, estos pensadores comparten una mirada que asocia estrechamente las interpretaciones generales sobre la experiencia, el conocimiento y el carácter valorativo de toda acción. Esta lectura general les permite romper con las barreras disciplinarias y moverse con cierta facilidad entre el análisis metodológico o conceptual y teorías más sustantivas sobre conducta, fines y valores; entre la lógica de la investigación científica y la ética o la política; y entre el perfil de pensador abstracto y el reformador social. Bajo esta presentación, que por supuesto no es la única posible, Dewey aparece como el mejor exponente de la actitud pragmatista en particular y de la filosofía estadounidense en general. El nivel de su producción intelectual junto con sus aportes novedosos en el campo de la pedagogía y su compromiso político con muchas causas progresistas le valió un gran reconocimiento: de acuerdo con Sidney Hook, su amigo y discípulo, "John Dewey es el filósofo por antonomasia de los Estados Unidos, no sólo por su origen sino por las estimulantes perspectivas que abre su pensamiento. [...] Resulta difícil encontrar algún aspecto de la cultura de Estados Unidos al que no haya contribuido." (Hook, 2000, p. 19).

También resulta importante indicar en esta breve reseña que el pragmatismo ha sido objeto de profusas críticas y de algunas malas interpretaciones. Uno de los ataques más relevantes proviene de la tradición germánica, que al decir de Hans Joas es protagonista y responsable principal de la "historia de un malentendido" (Cf. 1998, Capítulo 4). En efecto, si bien el pragmatismo fue tópico preponderante del Congreso Mundial de Filosofía de 1907 celebrado en Alemania, las críticas presentadas por Max Scheler en Conocimiento y Trabajo parecen haber instalado un "sentido común filosófico" que lo identifica con la racionalidad calculadora o instrumental. Esta interpretación parece haber permeado en las lecturas posteriores, ensayadas con especial encono por parte de los miembros del Instituto de Investigación Social de Frankfurt. Las reseñas de algunas obras de Dewey escritas por Herbert Marcuse y los pasajes más punzantes de Crítica de la Razón Instrumental de Max 
Horkheimer son claros ejemplos de la insistencia en calificar al pragmatismo como mero instrumentalismo orientado al éxito o utilidad de la acción. En su visión, el pragmatismo constituiría una extrapolación del ideal tecno-científico a todos los ámbitos de la cultura humana y sería la expresión del ideal social burgués consumista que reduce la democracia al modelo económico capitalista -lectura notoriamente deudora del planteo marxista-estructuralista de los frankfurtianos. Este tipo de reduccionismos, al que debe sumarse la interpretación del pragmatismo como "filosofía de la adaptación" favorable al darwinismo social, explica según Joas por qué los vínculos entre pragmatismo y teoría crítica resultaron casi completamente estériles y por qué en el ámbito intelectual alemán pocos pensadores han sido tratados con tanto desdén como Dewey (Cf. Joas, 1998, p. 105 y 133 , respectivamente).

Más allá del interés que efectivamente reviste un estudio de la recepción del pragmatismo por parte de la teoría crítica, en función del tema de la presente investigación es crucial considerar el vínculo entre pragmatismo y empirismo lógico, en la medida en que permite, por un lado, explicar el ocaso del primero como filosofía predominante en el ámbito académico norteamericano y, por el otro, dar cuenta de los orígenes del ideal de ciencia libre de valores. Sobre la primera cuestión, y de acuerdo con George Reisch (2009), los empiristas lógicos emigrados a Estados Unidos producto del ascenso del nazismo en Europa llevaron consigo no sólo sus elaboraciones teóricas sino también sus originarios compromisos culturales, sociales e incluso políticos, sintetizados en el Movimiento de Unidad de las Ciencias y especialmente en la figura de Otto Neurath. El Movimiento fue bien recibido en la ciudad de Nueva York por parte de Hook, Nagel, Morris y del mismo Dewey, quien compartía con Neurath muchas perspectivas progresistas y una lectura de la ciencia como constitutiva de un programa de acción social general. En efecto, el proyecto de la Enciclopedia Internacional de la Ciencia Unificada en tanto órgano de difusión y discusión de las perspectivas del Movimiento cobró un renovado impulso y aún con ciertos vaivenes, las gestiones de Morris y la participación de Dewey fueron determinantes para que en 1938 se edite el primer número en la Universidad de Chicago.

Sin embargo, las modificaciones del escenario político durante y particularmente después de la Segunda Guerra Mundial incidieron en el panorama intelectual norteamericano, que sufrió notorias reconfiguraciones. Las fuertes presiones anticomunistas 
y anticolectivistas lideradas por Joseph McCarthy durante la Guerra Fría hicieron que para fines de la década de 1950 las reflexiones sobre el conocimiento científico adoptaran una forma profesional apolítica, individual y técnica, más adecuada para elaborar una legitimación filosófica de las pretensiones científico-militares del gobierno estadounidense. En consecuencia, y según indica Reisch "[1]o que sobrevivió a la Guerra Fría fue el empirismo lógico sin el Movimiento de Unidad de la Ciencia de Neurath [...]", propiciando un alejamiento de la disciplina respecto de las cuestiones normativas asociadas a la ética o a la política y confinando sus preocupaciones a asuntos exclusivamente teóricos (Reisch, 2009, p. 43. Cursivas en el original). A partir de allí fueron ganando terreno figuras como Carl Hempel o Hans Reichenbach, quien ya en la década de 1930 había escindido los aspectos teóricos y prácticos del conocimiento, y se plantearon distinciones rotundas entre contexto de justificación y de descubrimiento, por un lado, y entre valores epistémicos y extra-epistémicos, por el otro. Como resultado, la dimensión del conocimiento prioritariamente considerada fue la teórica, limitada al contexto de justificación y bajo la forma del análisis lógico y metodológico del lenguaje de las teorías científicas. Por su parte, el pragmatismo y especialmente Dewey en tanto colaborador de la Enciclopedia devinieron objeto de fuertes críticas por parte de esta nueva versión filosófica de las ciencias y resultaron finalmente desplazados del centro de la escena académica norteamericana.

En lo que refiere puntualmente al asunto de los valores, la nueva visión de la ciencia adoptó la teoría emotivista elaborada por Charles Stevenson, fuertemente crítica de las ideas deweyanas sobre el carácter cognitivo de los valores y de la posibilidad de establecer la validez de los procedimientos de la lógica y de la investigación en la formación, elección y justificación de los juicios de valor. En suma, aquello que inicialmente fue una visión filosófica del conocimiento con claros compromisos sociales terminó asentándose en "las heladas laderas de la lógica", por retomar la expresión de Reisch, y a mediano plazo derivó en la fuerte impronta analítica de la filosofía estadounidense (Cf. 2009, Capítulo 18). Como fuera, esta pretendida versión apolítica de la ciencia no puede ocultar algo a esta altura obvio, a saber, que ella misma es política en la medida en que enmascara siempre y por razones políticas una determinada e íntima conexión entre ciencia, contexto y valores 
políticos en aras de una supuesta aunque empobrecida noción de objetividad funcional y legitimadora de fines a todas luces políticos (Cf. Gómez, 2014, p. 219). ${ }^{2}$

Los referidos acontecimientos y sus consecuencias filosóficas representan, además, un punto de partida para la conformación del ideal de ciencia libre de valores. Siguiendo la lectura de Heather Douglas (2009, Capítulo 3), la pretensión de mantener la evaluación y aceptación de teorías científicas tan libre de valores morales y políticos como fuera posible cobró especial vigor a partir de la década de 1960. En línea con la argumentación de Reisch, Douglas señala que en la escena intelectual estadounidense la Guerra Fría reforzó una serie de dicotomías que iban desde democracia o totalitarismo y capitalismo o comunismo hasta lógica científica o valores sociales, éticos y políticos. El estrechamiento progresivo de los intereses de la filosofía de la ciencia y las presiones anteriormente señaladas tendieron a la especificación cada vez más detallada de sus tópicos de estudio y al fortalecimiento de un perfil apolítico heredado por algunos representantes contemporáneos de la disciplina. Como indica Gómez, aquellas visiones que actualmente defienden el ideal de ciencia libre de valores no son más que la rigorización de la versión tradicional de la neutralidad valorativa de la ciencia, entendida como ausencia de valores extra-epistémicos o no-cognitivos en el contexto de justificación, esto es, en la comparación, aceptación o rechazo de teorías (Cf. Gómez, 2014, p. 170). En conclusión, parece haber una línea de continuidad entre la adopción de un perfil técnico y apolítico en la filosofía de la ciencia de posguerra y las versiones contemporáneas que defienden la neutralidad valorativa de la ciencia, entendida nuevamente en términos de teorías.

Si bien estos rasgos lograron consolidarse - no en vano la filosofía de la ciencia así concebida pasó a la historia como la "concepción heredada" o versión standard-, las críticas no demoraron en surgir. En efecto, la corriente historicista en filosofía de la ciencia representada por Norwood Hanson, Stephen Toulmin y Thomas Kuhn o posteriormente la sociología del conocimiento a partir de los estudios de Bruno Latour, Steve Woolgar, Karin

\footnotetext{
${ }^{2}$ Por supuesto, la historia de la recepción del pragmatismo no se agota en estos breves párrafos. Al respecto, no se puede dejar de mencionar a Bertrand Russell, quien a diferencia de la lectura frankfurtiana ubica a Dewey en el marco de las filosofías continentales vinculadas a la síntesis y lo desvincula de la tradición británica analítica. Russell ha sido particularmente crítico de la concepción deweyana de asertabilidad garantizada y ha elaborado una serie de cuestionamientos en "Dewey`s New Logic", su reseña a Lógica. Teoría de la Investigación de Dewey. Allí el británico ha incluido también algunas objeciones agudas a los conceptos deweyanos de experiencia y situación, objeciones que retomaré y analizaré en el Capítulo 1 (Cf. Russell en Schlipp, 1939).
} 
Knorr-Cetina y Andrew Pickering, entre otros, han elaborado serias objeciones a las versiones tradicionales. Más allá de las tensiones que surgen al interior de cada aporte, en particular con respecto al rol que pudo haber tenido la obra de Kuhn como crítica de la versión tradicional o, por el contrario, como consolidación de la misma (Cf. Fuller, 1998), lo cierto es que en las últimas décadas la reflexión filosófica sobre el conocimiento se ha remitido cada vez más al análisis de las prácticas y no sólo a su producto final, sin por ello minimizar la rigurosidad del estudio metodológico de las teorías.

De acuerdo con Ana Rosa Pérez Ransánz y Ambrosio Velasco Gómez (2011, pp. 14-22) y también con Federico López (2014), la redirección de las reflexiones sobre el conocimiento científico también está en clara sintonía con el planteo de los pragmatistas clásicos, en especial con la filosofía de Dewey y su intención de ligar los aspectos teóricos, prácticos y valorativos de la investigación. Estas afirmaciones se inscriben, a su vez, en un contexto general de resurgimiento del pragmatismo, orientado tanto a la reconstrucción de sus tesis clásicas como a nuevos enfoques y desarrollos. En efecto, y más allá de la alusión de Reisch, es la propia línea de filosofía analítica la que recupera algunas tesis originarias del pragmatismo, a partir de los ya mencionados Quine, Davidson y Goodman, junto con los aportes de Wilfrid Sellars y Robert Brandom. Por otra parte, en las últimas décadas el pragmatismo también ha sido recuperado mediante el reconocimiento y la revaloración de su noción de experiencia y la exploración de las consecuencias que la misma implica para diversas concepciones gnoseológicas, éticas y políticas. En ese sentido, los trabajos de Axel Honneth, Hans Joas -ambos vinculados a la tradición de Frankfurt-, Hilary Putnam, Richard Bernstein y Richard Rorty son algunos de los más relevantes en el área y serán considerados atentamente a lo largo de esta investigación. En ellos no solo se recuperan orientaciones filosóficas que se indican como explícitamente deudoras del pragmatismo clásico, sino que además se ofrecen puntos de partida para una necesaria actualización de esta corriente filosófica. ${ }^{3}$

\footnotetext{
${ }^{3}$ Bernstein (1992, p. 835) señala que el resurgimiento del pragmatismo no sólo se circunscribió a la filosofía sino que también alcanzó a la teoría social (con autores como Benjamin Barber, Michael Walzer o William Sullivan), a la sociología (Dimitri Shalin y Eugene Rochberg-Halton), a la crítica literaria (Frank Lentricchia, Richard Poirier) e incluso a la teoría feminista (Nancy Fraser).
} 
Teniendo en cuenta lo dicho, Dewey emerge como una referencia de absoluta relevancia e interés para abordar el tema de este estudio, por dos razones centrales: por un lado, su entramado filosófico conduce a reflexionar en clave ético-política sobre el conocimiento pues considera que el aspecto valorativo es intrínseco a toda actividad humana, incluidas las investigaciones científicas; por el otro, las posiciones partícipes en la discusión sobre el ideal de ciencia libre de valores no cuentan con una teoría filosófica de base como la del pragmatista, por lo cual una reconstrucción de los argumentos de este último puede aportar herramientas conceptuales para una mejor articulación, interpretación y posterior intervención en la discusión contemporánea. En este contexto apunto a contribuir a la comprensión de la importancia y originalidad de la posición de Dewey en el marco del pragmatismo clásico y de sus aportes específicos a la teoría del conocimiento, la ética y la política, así como a vincularlo con corrientes actuales de discusión. Finalmente, busco abrir líneas de investigación que retomen el pensamiento de Dewey y que ofrezcan herramientas conceptuales para una revisión crítica de las prácticas científicas contemporáneas, sin perjuicio de las abundantes y valiosas contribuciones realizadas en los últimos años en torno al carácter valorativo de la producción de conocimiento.

A partir de estos lineamientos generales, los objetivos particulares de esta investigación son (i) clarificar la posición de Dewey respecto del asunto de los valores; ${ }^{4}$ (ii) reconstruir la noción deweyana de investigación científica a la luz de la pregunta por su dimensión valorativa moral, social y política y del vínculo planteado por el autor entre ciencia y política; (iii) analizar los planteos de Douglas, Kitcher, Echeverría y Olivé en cuanto partícipes activos del debate sobre el ideal de ciencia libre de valores; y (iv) establecer las razones por las que es pertinente y fructífero apelar al entramado teórico deweyano para brindar una fundamentación filosófica a dichas posiciones críticas del referido ideal.

\footnotetext{
${ }^{4}$ La expresión "el asunto de los valores" puede parecer demasiado amplia y consecuentemente poco precisa. Sin embargo, encuentra su razón en el intento de evitar dos riesgos: el primero de ellos, señalado en reiteradas oportunidades por Dewey, es el riesgo de referir a estas reflexiones en términos de "teoría del valor" pues ello trae consigo, según indica el pragmatista, una concepción de valor en cuanto entidad metafísica abstracta, contraria a la impronta naturalista de su filosofía; el segundo de ellos, señalado por Pappas (2008) es el riesgo de reducir las consideraciones de Dewey a sus textos sobre los juicios valorativos y más específicamente a Teoría de la Valoración de 1939, dejando por fuera la dimensión cualitativa de los valores. En este orden, bajo la expresión "el asunto de los valores" intentaré incluir y elaborar una visión integral del enfoque deweyano.
} 
En vistas al cumplimiento de estos propósitos, las tareas son (i) reconstruir la concepción deweyana de experiencia, en vistas a identificar los aspectos teóricos relevantes en relación al tema de trabajo; (ii) determinar con precisión aquellos pasajes de las obras de Dewey en los que se trate el tema del valor y de su rol en la investigación científica, a fines de distinguir qué problemas, planteos y perspectivas se abordan; (iii) analizar y sistematizar los principales argumentos esgrimidos en el referido debate sobre el ideal de ciencia libre de valores a efectos de confrontarlos entre sí y con la posición del propio Dewey; y por último (iv) evaluar los desarrollos teóricos contemporáneos a la luz de las consideraciones deweyanas, atendiendo a qué valores son considerados legítimos para incidir en la actividad científica, qué relación se establece entre la dimensión valorativa y la objetividad del conocimiento y finalmente qué rol puede tener la filosofía en la discusión sobre política del conocimiento científico.

Habida cuenta de la metodología propuesta junto con las finalidades y tareas indicadas, la presente tesis queda dividida en tres partes. Bajo el título "Experiencia y valores" la primera parte tiene como objetivo central reconstruir y explicar la posición deweyana respecto de los valores. Así, en el capítulo 1 analizo el concepto de experiencia, transversal a la elaboración filosófica de Dewey, con un doble propósito: por un lado, señalar algunos rasgos centrales que permiten describirla como una novedosa teoría de la experiencia en términos de transacción y, por el otro, identificar aspectos puntuales que son relevantes para el tratamiento de su teoría del valor: la influencia del darwinismo, la tesis de la continuidad de la experiencia, los conceptos de situación, contexto e inmediatez cualitativa y finalmente la fundamentación metafísica de la necesidad de valorar. Según mi lectura, estos elementos permiten afirmar que dado el proceso de naturalización de los viejos respaldos metafísicos trascendentes, eternos e inmutables, la reflexión filosófica sobre los valores queda frente a una tarea de doble perspectiva: la "perspectiva filosófica", que debe inscribir y dar cuenta de la génesis de los valores en el curso de experiencia, y la "perspectiva metodológica", que debe ofrecer una pauta general para la correcta formación de valores. En el capítulo 2 analizo la primera de ellas, prestando especial atención a la dimensión cualitativa del tránsito desde la situación moral hacia la moralidad reflexiva, mientras que en el capítulo 3 analizo la segunda, concentrándome en el programa de la 
teoría de la valoración e indagando tanto las relaciones de Dewey con algunos de los representantes del empirismo lógico como las críticas respecto del sentido de normatividad que se desprende de su posición. Teniendo en cuenta que para Dewey toda conducta inteligente, es decir, toda conducta que no se limite a ser ciegamente impulsiva o mecánicamente rutinaria necesariamente involucra valoraciones, en las conclusiones parciales señalo que el tratamiento de su concepción del valor en las dimensiones cualitativa y metodológica es un eslabón vital al momento de analizar su visión sobre las investigaciones científicas, en la medida en que estas últimas son o aspiran a ser inteligentes. Asimismo, indico que el carácter continuo de la experiencia, en sus distintas facetas o dimensiones, constituye un elemento indispensable para comprender cabalmente la perspectiva deweyana sobre los valores.

La segunda parte, titulada "Conocimiento y valores", se focaliza en concepción deweyana de la investigación científica y el rol que allí juegan los valores, tanto en la propia pauta general de la investigación como en la concepción de la ciencia como actividad fundamentalmente pública, siempre a fines de retomar y ofrecer respuestas en clave deweyana a los interrogantes señalados en el comienzo mismo de esta introducción. En esta línea, en el capítulo 4 me aboco a la concepción deweyana de investigación, enfatizando su aspecto eminentemente práctico dado por la interpretación de la lógica en tanto pauta general de la investigación. En el capítulo 5 analizo distintos sentidos de continuidad entre experiencia e investigación y entre investigación y valoración, los cuales permiten afirmar que la definición normativa de investigación científica supone una instancia de valoración, que no se puede ni es deseable excluir consideraciones valorativas tradicionalmente consideradas extra-epistémicas de la pauta general de la investigación porque estas últimas son parte de la prueba completa de las investigaciones, especialmente en aquellos casos en esas investigaciones generan un círculo amplio de consecuencias que va más allá de lo que inicialmente se consideraría "propiamente" científico, y que la distinción entre génesis y validez o ámbito de descubrimiento y ámbito de justificación no es tan férrea como supone la versión standard de la filosofía de la ciencia. Llegado este punto, y en función de precisar mi propuesta, recupero las observaciones de Helen Longino acerca de la distinción entre valores constitutivos y contextuales de la ciencia, distinción que puesta a la luz de la noción amplia de investigación elaborada por Dewey permitiría 
afirmar que ciertos valores tradicionalmente denominados extra-epistémicos fueran valores constitutivos de la investigación (Cf. Longino, 1983, pp. 7-9 y 1990, pp. 4-7). En definitiva, permitiría desmarcarse de una de las dicotomías más cerradas de la visión filosófica standard de la ciencia mediante la cual se ha distinguido entre elementos propios y ajenos a la ciencia. Asimismo, recupero las consideraciones de Putnam sobre el colapso de la dicotomía hecho/valor, siempre a fin de abonar la tesis de la presencia de valores en la investigación científica, y las consideraciones del mismo Putnam acerca del valor de la cooperación democrática en la investigación -asunto que introduce la dimensión política de la práctica científica.

A partir de allí, en el capítulo 6 evalúo el vínculo entre ciencia y política, aspecto central de la perspectiva deweyana y del presente estudio. Así, luego de recuperar los elementos centrales de la discusión entre Dewey y Walter Lippmann sobre el rol de la opinión pública, remito especialmente a los argumentos presentados por Dewey acerca del carácter público de la ciencia y de su inextricable vínculo con un modo de vida democrático, indico en qué sentido ciencia, opinión pública y democracia se constituyen mutuamente, tal y como indica Ramón del Castillo (2004, p. 24), y sugiero algunas líneas en dirección a una filosofía política del conocimiento en clave deweyana. Una vez presentados estos elementos, en las conclusiones parciales ofrezco las razones por las que considero que la investigación científica no puede concebirse como valorativamente neutral o libre de valores dada su inscripción en el continuo de la experiencia, de matriz valorativa, y dada la legítima incidencia de valores tradicionalmente denominados extra-epistémicos en la instancia misma de validación del conocimiento en cuanto resultado de la investigación; en segundo lugar la investigación científica no puede concebirse al margen de la política dado su carácter distintivamente público y su rol en la construcción de la democracia en cuanto forma de vida, según la concibe Dewey.

Una vez presentado el marco teórico deweyano avanzo hacia la tercera parte, titulada "Aportes al debate sobre el ideal de ciencia libre de valores". En los comentarios preliminares presento un mapa general del debate, identificando las posturas principales y concentrándome especialmente en la defensa del ideal en términos de neutralidad, imparcialidad y autonomía ofrecida por Hugh Lacey. A partir de aquí elaboro tres capítulos 
focalizados en distintos actores de la discusión. En el capítulo 7 abordo los argumentos de Heather Douglas acerca del triple desafío al ideal de ciencia libre de valores y de la aceptabilidad e incluso deseabilidad de incorporar valores éticos y políticos en el seno de la investigación científica, dado su carácter falible. En este marco señalo que la posición de Douglas parece asumir algún tipo de dicotomía entre hecho/valor y aceptar los valores morales y políticos sólo por defecto, esto es, cuando hay riesgos de que los errores de la investigación repercutan en un ámbito extra epistémico, e intento señalar que desde la perspectiva deweyana se puede defender que los juicios valorativos en la pauta general de la investigación tienen lugar por derecho. En el capítulo 8 propongo analizar los argumentos de Philip Kitcher acerca del ideal de ciencia bien ordenada, los cuales llevan a evaluar las razones ofrecidas por el propio Kitcher en favor de la democracia misma y a indicar cómo las tensiones que se identifican pueden ser resueltas apelando al marco teórico de Dewey -al que, de hecho, el mismo Kitcher remite cada vez más a lo largo su obra. De este modo, si la fundamentación de la posición de Douglas puede darse a partir de los argumentos deweyanos sobre el investigador como un práctico y sobre la investigación en cuanto inscripta en un continuo de experiencia más amplio, la fundamentación de la posición de Kitcher puede hacerse a partir de los argumentos deweyanos sobre el vínculo entre ciencia y democracia. Ya en el capítulo 9 analizo algunos aportes realizados desde el ámbito académico iberoamericano, recuperando los aportes de Javier Echeverría y León Olivé acerca de la ciencia y la tecnociencia como prácticas cognitivas y del rol ineludible que en ella tienen los valores tradicionalmente denominados extra-epistémicos. Asimismo, señalo cómo los autores perfilan una noción de racionalidad que incluye la dimensión valorativa como un componente central, en clara sintonía con la perspectiva deweyana. Por último, en las conclusiones generales presento un recuento de las principales líneas de esta investigación, detallo cuáles son los aportes principales del enfoque deweyano al debate sobre el ideal de ciencia libre de valores, señalo qué puntos de las argumentaciones contemporáneas que consideran deseable algún tipo de vínculo entre conocimiento científico y valores morales y políticos pueden ser enriquecidos desde el entramado teórico del pragmatista e indico aquellos temas o líneas que hayan quedado abiertas para futuros tratamientos, a nivel teórico y práctico. 
Permítaseme una última reflexión respecto de la impronta deweyana de esta misma investigación -so riesgo de adelantar ciertos contenidos que encontrarán desarrollo en los capítulos siguientes. Dewey entiende que en tanto indagación de condiciones y consecuencias la valoración es una forma de crítica que implica no solo concentrarse en las condiciones de producción del objeto valioso sino también en sus operaciones futuras. En este marco, “[...] la filosofía no es ni puede ser nada más que esta operación y función crítica vuelta consciente de sí y de lo que implica, ejercida deliberada y sistemáticamente” (1948, p. 328. LW.1.301). Más aún, la filosofía es crítica de las críticas pues analiza las condiciones, relaciones y consecuencias de los propios criterios con la finalidad de explicitar los valores que los fundamentan y someterlos a una ulterior indagación. Asimismo, Dewey considera que el papel principal de la filosofía es abordar reflexiva y críticamente los problemas y conflictos inherentes y más acuciantes de las sociedades, los cuales tienen que ver con conflictos de valor (Cf. LW.8.30). Más aún, Dewey observa que la comprensión y manipulación de la ciencia y de su poderosa capacidad de transformar el mundo es uno de los problemas más apremiantes y complejos de la civilización contemporánea: “Aquí yace el corazón de nuestro problema social actual. La ciencia ha sido utilizada para modificar los actos y actitudes sociales más fundamentales de los hombres. [...]. La potencialidad de la ciencia como el instrumento de control más poderoso que haya existido alguna vez pone a la humanidad ante el desafío más importante." (LW.6.58). En este sentido, pues, considerar el lugar y la función de la ciencia en el amplio y continuo curso de experiencia es para Dewey una tarea más propiamente filosófica que cualquier análisis auto-contenido de la ciencia en cuanto tal (LW.6.20). Las próximas páginas intentan retomar estas indicaciones acerca de cómo y sobre qué temas debe reflexionar la filosofía y se lanzan a lo que estimo es una labor filosófica de urgencia: señalar por qué la investigación científica no puede concebirse al margen de los valores morales, sociales y políticos, por qué estos últimos tienen un lugar legítimo en la investigación, es decir, por qué la ciencia no puede entenderse como un instrumento valorativamente neutral desvinculado de su contexto y de su aplicación, y por qué, en definitiva, la filosofía ofrece herramientas para reflexionar sobre los valores y fines de la actividad científica, en clave eminentemente política. 
PRIMERA PARTE: EXPERIENCIA Y VALORES 


\section{CAPÍTULO 1: PUNTOS DE PARTIDA (Y DE LLEGADA)}

\section{Introducción}

En el capítulo final de Experiencia y Naturaleza (1929) Dewey presenta a la filosofía como la indagación inteligente de las condiciones, relaciones y consecuencias de los objetos tomados como bienes y valores, y también del lugar que éstos ocupan en la organización de nuestra experiencia. De esta manera, el asunto de los valores constituye un tema central en su proyecto filosófico y puede ser tomado, según hipotetizo aquí, como un hilo conductor entre el peculiar sentido deweyano de experiencia, sus reflexiones en el ámbito de la moral y la política y su concepción de investigación científica. Ahora bien, en una perspectiva más amplia, la filosofía de Dewey puede comprenderse como una filosofía de, por y para la experiencia. Esta afirmación ilustra, en primer lugar, el constante llamado del autor a considerar los asuntos y problemas humanos como el tema prioritario de la filosofía. En segundo lugar, ilustra el profundo interés de Dewey en enriquecer progresivamente el curso mismo de la experiencia por vías de la reflexión filosófica -junto con otro tipo de actividades, por supuesto. De esta manera, el concepto de experiencia constituye tanto un punto de partida como un punto de llegada para la filosofía.

Estas observaciones iniciales permiten advertir que la noción de experiencia es transversal a la vasta obra de Dewey. En efecto, el pragmatista la trata desde diferentes perspectivas y con diferentes propósitos, según esté analizando cuestiones relativas a la educación, a la investigación científica, al arte, a la ética o a la política. Atento a esta consideración, en lo que sigue presentaré los rasgos centrales de la noción de experiencia a fines de sentar las bases filosóficas para abordar el problema de la génesis, crítica y formación inteligente de valores en clave deweyana. En la segunda sección del capítulo identificaré ciertos aspectos generales de la noción, enfatizando su carácter vital y transactivo. En la tercera sección, y orientando ya el análisis al tema central de esta investigación, me detendré en tres temas que considero cruciales para la cuestión recién señalada. El primero de ellos es la influencia del darwinismo en el enfoque de Dewey, tanto a nivel filosófico en relación con algunas tesis sustantivas como a nivel meta-filosófico, esto es, acerca de cómo debería entenderse la propia tarea filosófica -tarea que, como se 
señalará, queda íntimamente ligada a reflexiones de orden valorativo. El segundo elemento es la tesis de la continuidad de la experiencia, estrechamente vinculada con la irrenunciable impronta naturalista de la filosofía de Dewey y, a su vez, con la apuesta por el progresivo enriquecimiento de la experiencia. El tercer elemento es el aspecto de inmediatez cualitativa de la experiencia, aspecto que conducirá al análisis de los conceptos de situación y contexto. Estos tres factores, identificados como los principios del naturalismo pragmático, resultan de suma relevancia al momento de explicar la génesis de los valores en el curso de la experiencia, toda vez que permiten dar cuenta de aquél sin apelar a hiatos, apriorismos o intuiciones del bien y permite, al mismo tiempo, incluir la dimensión reflexiva propia del proceso de valoración. Finalmente, presentaré un argumento por el cual se establece que, en un mundo signado por la contingencia, el azar y la inestabilidad, la necesidad de consolidar y refinar los bienes poseídos es, sin más, la necesidad de valorar.

Una vez abordados estos elementos, en las conclusiones señalaré cuáles son a mi juicio las dos perspectivas de la tarea filosófica respecto del valor que se desprenden del enfoque deweyano sobre la experiencia: dar cuenta de la génesis de estos últimos en el curso de la experiencia y ofrecer una metodología para su correcta formación, en los términos de una teoría de la valoración. Este último argumento, espero, dejará indicado el camino de los próximos capítulos del trabajo, bajo la idea de que "[n]adie puede tener la esperanza de comprender la teoría del valor de Dewey si no entiende completamente el significado que él le adscribe al término 'experiencia"” (Smith, 1922, p. 339).

\section{John Dewey y una novedosa concepción de la experiencia}

Dewey perfila su concepción de experiencia en oposición a aquello que identifica como la versión griega clásica y a aquello que identifica como el empirismo moderno. En términos generales la limitación más seria que encuentra Dewey en ambas versiones es la disociación entre experiencia y razón: si Platón considera que la experiencia queda ligada a la práctica ciega y que la razón es lo único que nos puede elevar por sobre los hábitos y costumbres, Berkeley, Locke y Hume cometen el error de suponer un individuo como receptor pasivo de impresiones sin intervención de la razón, al menos en una primera instancia. No obstante, Dewey rescata algunos aspectos interesantes de ambas concepciones: por un lado, la postura clásica enfatiza el carácter social de la experiencia en 
tanto transmisión del conocimiento; por otro lado, los empiristas insisten en la experiencia como juez para cualquier reivindicación de orden gnoseológico e incluso político, encontrando allí ciertas contribuciones para su propia comprensión del tema.

Así las cosas, y reconociendo también su deuda con Bacon y el nuevo método experimental de la ciencia, Dewey afirma que la experiencia es ante todo acción, tanto de un organismo o individuo sobre las cosas que lo rodean como del ambiente, natural a la vez que social, sobre dicho individuo. En “The Need for a Recovery of Philosophy” (1917), pieza crucial para el estudio de la concepción deweyana de experiencia, puede leerse lo siguiente: “[y] la experiencia no es idéntica a la acción mental; es la entera conexión orgánica agente-paciente en todas sus interacciones con el ambiente, natural y social [...] Se sigue con igual fuerza que experiencia no significa primariamente conocimiento, sino maneras de hacer y padecer" (MW.10.26). ${ }^{5}$ Esta definición, una de las tantas ofrecidas por Dewey, permite identificar varios puntos centrales: el carácter vital de la experiencia, su interpretación en términos de transacción y sus diferencias con la tradición filosófica.

Con respecto al primer aspecto, en el mismo ensayo Dewey señala que experimentar significa, ante todo, vivir, y que donde hay vida hay una doble conexión mantenida con el ambiente (MW.10.6-7). En igual sentido corren las ideas expuestas en Unmodern Philosophy and Modern Philosophy, texto que se consideraba perdido y que fue publicado recién en 2012. Allí Dewey define a la experiencia como una función vital [lifefunction] y asienta dos postulados centrales: el término "experiencia" debe ser considerado como sinónimo de vivir [living] o de las ocurrencias de las funciones vitales, al tiempo que estas funciones vitales remiten a aquellos eventos cuya naturaleza está plenamente representada en la vida humana. Más aún, la experiencia como función vital queda definida en términos de "interactividad de factores orgánicos y ambientales", de modo que estas funciones son elementos que sólo por análisis conceptual terminan siendo designados como organismo y ambiente. Justamente en la medida en que estas funciones vitales están siempre "en marcha" [ongoing] -algo que, para Dewey, es evidente prima facie- envuelve

\footnotetext{
5 "The Need for a Recovery of Philosophy" fue publicado como ensayo inaugural del libro Creative Intelligence: Essays in the Pragmatic Attitude (1917), destinado a ser un "manifiesto pragmatista". De acuerdo con Lewis Hahn, este ensayo no sólo constituye el texto insignia de Creative Intelligence sino, por sobre todo, una de las mejores exposiciones del concepto deweyano de experiencia debido a la claridad de la exposición y al modo de construirla por contraste con las visiones ortodoxas (Cf. Hahn, 1980. MW.10.xi).
} 
fases de hacer y padecer, esto es, fases continuas y recíprocas de actividad y pasividad relativas (Dewey, 2012, Capítulo 14). En definitiva, para Dewey la experiencia es "vitalidad elevada", vale decir, completa interpenetración del organismo y el ambiente en un continuo desenvolvimiento de desequilibrios y reajustes dinámicos (Cf. 2008a, p. 21. LW.10.25).

Estas primeras observaciones remiten al aspecto radicalmente activo de la experiencia, para el que Dewey emplea la idea de transacción. Según indican H. S. Thayer y V. T. Thayer (1978. MW.6.xxv), el sentido de esta última noción puede rastrearse hasta el ensayo "El Concepto de Arco Reflejo en la Psicología” de 1896. Más aún, y de acuerdo con Feodor Cruz, es posible que ya en 1876 Dewey haya estado interesado en las implicancias fílosóficas del modelo interaccional propuesto por Maxwell para la física, modelo al que el pragmatista dotará de contenido unos años después, apoyado en la escuela biologicista de psicología prevaleciente durante el primer cuarto del siglo XX en Estados Unidos (Cruz, 1987, p. 17). En efecto, en "Conduct and Experience" de 1930 el término "transacción" parece tener su primera alusión en el sentido que aquí interesa rescatar. Así, plantea Dewey,

[1]a estructura de lo que fuera que sea 'tenido' mediante cualidades inmediatamente presentes es encontrada en los modos recurrentes de interacción que toman lugar entre lo que denominamos organismo, por un lado, y ambiente, por el otro. Esta interacción es el hecho primario, y constituye una trans-acción. Sólo por análisis y abstracción selectiva podemos diferenciar la ocurrencia efectiva en dos factores, uno denominado organismo y el otro, ambiente. (LW.5.220).

La cita precedente resume en pocas líneas dos ideas centrales en la perspectiva de Dewey: la experiencia en cuanto "tenida" [had] por vías de las cualidades inmediatas punto sobre el que volveré más adelante- y la experiencia en cuanto transacción. Según puede advertirse, la transacción supone el carácter integral de la relación organismo y ambiente, al punto que éstos sólo pueden identificarse y diferenciarse de modo analítico. En ese sentido, hacia 1949 Dewey y Arthur Bentley explicitan algunas notas de la idea de transacción. En efecto, y a diferencia de la autoacción como aquella en la cual los objetos actúan bajo sus propias capacidades, y de la interacción como aquella en la cual los objetos, definidos y completos de modo independiente, actúan entre sí en su interconexión causal o 
mecánica, los autores utilizan nuevamente el concepto de transacción para dar cuenta de un tipo particular de vínculo en el que los elementos y su unidad funcional obtienen su carácter específico en el papel que desempeñan dentro de la relación transaccional (Cf. LW.16.102). ${ }^{6}$ Según explica Geiger, “'transacción’ deviene una palabra clave en la obra final de Dewey porque remite a la conexión antes que a la desconexión, al todo antes que a las partes, a la continuidad antes que a la discontinuidad." (Geiger, 1978, p. 16. Cursivas agregadas). A partir de esta caracterización es posible, pues, comprender a la propia experiencia en términos transaccionales. ${ }^{7}$

Considerando las notas recientemente señaladas, aparecen delineadas algunas diferencias centrales entre la concepción deweyana de experiencia y el sentido en que ha sido tomada en la tradición filosófica, diferencias que permiten señalar a la versión pragmatista como francamente novedosa. Siguiendo la lectura que propone Dewey en el referido "The Need for a Recovery of Philosophy", los puntos de oposición son cinco. En primer lugar, la perspectiva tradicional considera a la experiencia principalmente como una cuestión de conocimiento, mientras que ahora aparece como la transacción entre el ser vivo y su entorno físico (y social, para el caso puntual del ser humano), de manera que se tienen experiencias no cognitivas. En segundo término, para Dewey la versión tradicional de la experiencia queda vinculada a lo personal o subjetivo (más allá de las pretensiones de universalidad que efectivamente tienen los empiristas o racionalistas), mientras que su nueva interpretación sugiere un sentido de objetividad en cuanto que la experiencia es el conjunto de acciones y padecimientos concretos de los seres humanos y está expuesta a modificaciones provocadas por sus respuestas. En tercer lugar, la concepción clásica y

\footnotetext{
${ }^{6}$ Es interesante tener en cuenta que en esta obra Dewey y Bentley refieren al uso de la perspectiva transaccional en el campo de la física (más precisamente, a la discusión entre Heinsenberg y Bohr). No obstante, como señala Di Gregori, el empleo de esta idea por parte de Dewey sin referencias a las ciencias físicas permite concluir que el compromiso teórico de Dewey con la noción de transacción ya estaba asumido y elaborado con anterioridad -sin perjuicio de la influencia que efectivamente pudieron haber tenido los desarrollos de las ciencias físicas durante la década de 1940 sobre el texto de Dewey y Bentley (Cf. Di Gregori, 2015, p. 6).

${ }^{7}$ Dewey y Bentley parecen plantear incluso el reemplazo del término "experiencia” por "transacción”: “[...] transaccionalmente empleada, la palabra 'conducta' debería hacer el trabajo que 'experiencia' buscaba hacer en el pasado, y debería hacerlo libre de las aplicaciones vacilantes, vagas y confusas que han hecho finalmente a esta última palabra tan a menudo inservible" (LW.16.260). Asimismo, la concepción de experiencia en términos transaccionales permite trazar interesantes vínculos entre la perspectiva deweyana y algunas de sus lecturas contemporáneas como, por ejemplo, la propuesta por Hans Joas (Cf. Di Gregori, 2013 y 2015).
} 
luego el empirismo moderno vinculan a la experiencia con el pasado, con lo dado, mientras que la nueva noción de experiencia en su forma vital es experimental, es proyección hacia el futuro para cambiar lo dado. De esta manera, pues, la experiencia es tanto contenido, asunto [subject-matter] como método (Cf. Metz, 1969, p. 249, entre otros). En cuarto lugar la tradición compromete a la experiencia con el particularismo, sin conexiones, mientras que la experiencia como actividad de ajuste entre individuo y entorno se caracteriza fundamentalmente por las conexiones y continuidades, por constituirse como una serie de situaciones entrelazadas. Finalmente, el quinto y último ítem indica que la posición tradicional disocia "experiencia" y "pensamiento", mientras que la nueva concepción de la experiencia insiste en reconectar ambos términos y desarrollar una acción inteligente que oriente el comportamiento (Cf. MW.10.6. Para un análisis detallado de las diferencias, Cf. Bernstein, 1979, pp. 209-220 y 2010 pp. 98-112).

Hay otros dos aspectos que merecen referencia en esta reconstrucción inicial. Por un lado, Dewey plantea una distinción entre experiencia primaria o de primer orden, "bruta y macroscópica", llevada adelante de modo habitual y por tanto irreflexiva o producto de apenas un mínimo de reflexión accidental, y experiencia secundaria o reflexiva, "refinada", producto de una indagación persistente y sujeta a reglas o principios (Cf. 1948, p. 10. LW.1.16). En este punto es fundamental tener en cuenta que en la experiencia primaria se encuentran las indeterminaciones que podrán ser definidas como problemas y ofrece los primeros datos para la reflexión propia de la experiencia secundaria y que los resultados de esta última quedarán comprobados en la medida en que se remita nuevamente al curso de experiencia primario y contraste sus conclusiones allí. Según Dewey, adoptar el método empírico para la reflexión filosófica permite inscribirla en el curso de experiencia, forjar criterios para evaluar sus conclusiones y prevenir la aparición de problemas artificiales. Precisamente en esto radica la urgencia de aplicar el método empírico o denotativo en la filosofía como aquel que ubica los productos de la experiencia reflexiva en un camino de regreso que señala y se dirige hacia algo propio de la experiencia primaria en pos de su progresivo enriquecimiento. De acuerdo con Pappas (2018), la insistencia en tomar a la experiencia como punto de partida y de regreso de las elaboraciones reflexivas o teóricas constituye la herencia filosófica más importante recibida de Dewey y sienta las bases para comprender a la experiencia como un método. 
Por otro lado, Dewey postula que hay experiencias que adquieren un carácter de consumación, en tanto $\mathrm{y}$ en cuanto continúan su curso hasta un cumplimiento o culminación y no es objeto de interrupciones extrañas o letargos internos. Esta experiencia en sentido genuino se caracteriza por el libre fluir de sus partes constitutivas, sin vacíos, puntos muertos ni junturas, visto que cada secuencia continúa con aquello que venía sucediendo y se integra en la corriente general de la experiencia. Luego, cualquier conclusión no será una instancia separada e independiente de esa experiencia, sino la consumación del proceso en su totalidad, de un movimiento que llega a completarse. Esto constituye por tanto el sentido estricto de tener una experiencia -la experiencia de esa tormenta, esa campaña política, ese juego de ajedrez, entre tantas otras- frente a aquellas experiencias incompletas, interrumpidas o abandonadas en las que el sujeto no se involucra plenamente, sea por su acción mecánica y poco reflexiva o por la aparición de factores externos que cortan ese discurrir unificado. A partir de las consideraciones previas es posible afirmar que las experiencias genuinas se distinguen por su unidad, integridad y completitud debido a su carácter o cualidad consumatoria. En esta concepción de la experiencia el fin es significativo no por sí mismo sino como integración de las partes que tienen un principio, un desarrollo y un cumplimiento, de manera que las partes se mueven hacia una consumación y no solamente a un cese en el tiempo. ${ }^{8}$

Al momento he señalado algunos aspectos de la noción deweyana de experiencia con la intención de ofrecer una primera caracterización general. No obstante, y teniendo en cuenta lo dicho respecto del carácter transversal de dicho concepto para las elaboraciones filosóficas de Dewey, cualquier estudio enfocado en algún aspecto o tema específico del vasto repertorio deweyano deberá concentrarse en ciertos elementos particulares de la noción de experiencia justamente en vistas al asunto de indagación. Tal es la tarea que emprenderé a continuación en referencia al asunto de los valores.

\footnotetext{
${ }^{8}$ En El arte como experiencia Dewey señala que "ninguna experiencia, de cualquier clase que sea, es una unidad, a menos que tenga cualidad estética." (Dewey, 2008a, p. 47. LW.10.45). Entiendo que el autor utiliza el término "estético" en el marco de su estudio de la experiencia en relación al arte y que, al momento de considerar el aspecto integral de las experiencias genuinas de cualquier índole, resulta más claro comprender el aspecto unificado apelando a la idea de cualidad consumatoria. En relación a esto, Di Gregori y Durán dan cuenta de la filiación entre la propuesta deweyana y las consideraciones de Aristóteles en Poética, respecto de los rasgos propios de una tragedia: principio, medio y fin. (Cf. Di Gregori y Durán, 2008).
} 


\section{Hacia la concepción deweyana del valor}

\subsection{El impacto del darwinismo y los sentidos del naturalismo}

Sin lugar a dudas, una de las influencias más significativas en la filosofía de Dewey ha sido el darwinismo, comprendiendo por este no sólo la propia teoría de la selección natural sino, en un sentido más amplio, los desafíos que supone esta nueva hipótesis científica para la filosofía misma. La publicación de El Origen de las Especies en 1859, el mismo año del nacimiento de Dewey, constituyó un hito o, al decir de Martin Jay, el fósforo que encendió la controversia entre el avance de las perspectivas científicas y la preponderancia del Calvinismo en las mayores universidades de Estados Unidos (Jay, 2002, p. 29). En la trayectoria intelectual del propio Dewey, la adscripción al darwinismo supone una reorientación de su postura filosófica de oposición a los dualismos y de comprensión integrada del sujeto y su experiencia, inicialmente enmarcada en el pensamiento de Hegel y reabsorbida en los primeros años del siglo XX en una perspectiva naturalista (al respecto, Cf. Faerna 1996, p. 181; Jay, 2009, p. 330 y Bernstein, 2010, pp. 54-55). ${ }^{9}$

En 1909 Dewey escribe "La influencia del darwinismo en la filosofía", texto clave para entender sus planteos posteriores respecto del concepto de experiencia y de la función que reviste la filosofía. Dewey reseña inicialmente el concepto de "especie" (eidos, specie) y lo remite en el marco de la filosofía clásica a la forma fija y causa final de los seres vivos, la cual opera a lo largo de los cambios y los liga a un único curso, manteniendo su uniformidad de estructura y función. En este contexto se postula la superioridad de lo fijo y el cambio se subordina como lo defectuoso y no real; en consonancia, el conocimiento adquiere la forma contemplativa, relegando a un segundo plano a todo "saber hacer" o

\footnotetext{
${ }^{9}$ Una síntesis de la biografía de Dewey puede encontrarse en John Dewey: semblanza intelectual de Sidney Hook (2000, pp. 19-33). Los libros The Education of John Dewey de Martin Jay (2002) y Becoming John Dewey de Thomas Dalton (2002) constituyen dos excelentes piezas para el estudio de la trayectoria personal e intelectual del pragmatista. Respecto de la nueva perspectiva filosófica de Dewey, Richard Rorty señala que el pragmatista necesitó deslizarse a una forma de panpsiquismo para conciliar los aportes de Hegel con el inmanentismo evolucionista de Darwin y que, en consecuencia, la filosofía de Dewey conservaría los aspectos menos favorables de ambas influencias: el idealismo hegeliano y el vitalismo darwiniano. Como contrapartida, Rorty propone un "Dewey alternativo" que no sólo podría sino que debería haber tomado el historicismo de Hegel y el positivismo de Darwin para conformar una filosofía pragmatista sin ser empirista radical y naturalista sin ser panpsiquista (Cf. Rorty, 2000). Entre las distintas respuestas a Rorty resulta particularmente interesante la ofrecida por Ángel Faerna, quien evalúa el concepto de naturalismo y propone definirlo como un intento de extender el marco científico al tratamiento de preguntas no científicas que surgen de la experiencia inmediata. A su criterio, esta definición del naturalismo hace justicia a los intereses de Dewey, particularmente en Experiencia y Naturaleza y, se podría agregar, en toda su perspectiva filosófica, permitiendo además tomar a Darwin "en serio" (Cf. Faerna, 2003).
} 
conocimiento práctico. Ahora bien, según Dewey, desde el título mismo de la obra de Darwin puede observarse la nueva impronta intelectual de corte científico (impulsada también por Copérnico, Kepler, Galileo, entre otros), toda vez que la combinación entre "origen" y "especies" supone una tensión y una reconsideración del concepto mismo de especie, tradicionalmente concebido como eterno y por consiguiente sin origen.

Desde mi punto de vista, la lectura de este ensayo permite registrar un nivel metafilosófico y un nivel propiamente filosófico del impacto del darwinismo en la filosofía. Respecto del primero, la incidencia del darwinismo se evidencia en las consideraciones sobre la dirección que debería tomar la disciplina, los problemas que debería atender y el rol que se debería atribuir tanto en relación con su propia historia como con las otras disciplinas intelectuales y científicas. En términos más concretos, los cambios son tres, dando lugar a lo que Cometti denomina "la lección de Darwin" (2015, pp. 8-9):

(i) el interés por las esencias deviene interés por los incrementos en justicia y felicidad a partir de la administración inteligente de las condiciones existentes;

(ii) la explicación de las cualidades y valores de la vida por referencia a metas finales se torna análisis de los usos y significados presentes y generalmente asumidos por el peso de la tradición; y

(iii) la idealización y racionalización del universo bajo la pretensión de legislar $a$ priori pasa a ser estudio de las condiciones y consecuencias específicas de las ideas y valores.

En este sentido, Dewey entiende que la nueva función de la filosofía debe ser, en efecto, identificar e interpretar los conflictos que surgen de la experiencia para posteriormente ensayar soluciones que serán puestas a prueba en el curso mismo de los acontecimientos. Así, la filosofía se asemeja (o debería asemejarse) cada vez más a una diagnosis y prognosis moral y política, lejos de las clásicas pretensiones trascendentales, y debería quedar provista de un creciente sentido de la responsabilidad.

En cuanto al rol que juegan estas ideas al interior de la obra de Dewey, es claro que la impronta darwiniana no sólo tiene un impacto a nivel metafilosófico sino también filosófico, como se evidencia en varias de sus tesis principales. En efecto, el título en principio contradictorio de El origen de las especies trae a colación el problema tradicional 
de "designio vs. azar" o "mente vs. materia". En la medida en que el concepto de especie supone un propósito o finalidad que opera mediante los cambios sensibles pero que en sí mismo no es visible, debe ser entonces una fuerza racional o ideal que es aprehendida por la razón. Dicho de otro modo, si la lógica clásica se apoya en el designio teleológico, el pensamiento se ve forzado a justificar principios trascendentes y valores ideales. Como consecuencia, la versión clásica debe dar la espalda a los hechos concretos de la experiencia, impidiendo que se reconozca y trabaje seriamente sobre los bienes y los males que ella presenta. Así, hay una primera imposición de lo mental por sobre lo material, especialmente si se considera que este argumento del designio sirve tanto para justificar la posibilidad de la ciencia como el valor de los esfuerzos morales y religiosos del hombre. La teoría darwiniana, por su parte, apunta justamente a las bases de esa filosofía teleológica y cósmica, pues al afirmar que todas las adaptaciones se deben a la variación constante de los organismos en favor del ajuste al medio y a la eliminación de aquellas mutaciones que no son útiles para tal propósito, Darwin afirma implícitamente que no hay fuerza causal inteligente que planifique el curso de tales variaciones. De acuerdo con Dewey, el problema "designio vs. azar" tiene en su formulación algunos supuestos que lo vuelven carente de sentido: si se admite que el único conocimiento provechoso surge de los cambios (y sus respectivas consecuencias) por los que se genera nuestro objeto de estudio, entonces la pregunta por lo que queda "más allá" de esos cambios es ininteligible. Por otro lado, la adopción del modelo darwiniano implica dejar atrás al concepto de sustancia o especie como principio regulativo teleológico que explica la inteligibilidad de la naturaleza y la posibilidad de la ciencia. Sobre este punto Dewey considera que "[1]a influencia de Darwin sobre la filosofía radica en haber conquistado para el principio de transición los fenómenos de lo vivo, permitiendo así que la nueva lógica se aplique a la mente, a la moral y a la vida." (Dewey, 2000, p. 54. MW.4.37).

La referencia al darwinismo permite entonces enmarcar algunos elementos fundamentales de la perspectiva de Dewey, a saber: (i) la experiencia en tanto transacción no-teleológica entre organismo y entorno, en la medida en que no es un proceso que se desenvuelve hacia algún fin previamente establecido sino que es un proceso desde, al igual que la evolución en sentido darwiniano; (ii) la continuidad entre las formas y actividades inferiores y superiores; (iii) una concepción eminentemente práctica del conocimiento, en 
tanto instrumento que permite la resolución de problemas surgidos en esa relación transactiva; y (iv) una concepción anti-esencialista, anti-fundacionalista y falibilista para la ética y la política, en la medida en que los valores no tienen un respaldo en alguna entidad eterna e inmutable o trascendente sino que son producto de la deliberación respecto de las consecuencias de las acciones, en su relación medios-fines. ${ }^{10}$ Estos cuatro puntos pueden tomarse como bases de la perspectiva naturalista de Dewey, a las que se debería sumar un último elemento: (v) el respeto por los resultados y el standard científico marcado por el estado concreto de las investigaciones, siempre provisorias e incompletas, clave para no obturar el camino de la reflexión inteligente ni tender hacia el finalismo o el dogmatismo (Cf. "Anti-Naturalism in extremis", LW.15.58). Estos elementos conjugados implican además un rechazo de cualquier versión de formas platónicas, esencias aristotélicas, razones puras kantianas, intuiciones del bien y "todo un conjunto de otros ciudadanos menos prominentes del zoológico filosófico", junto con una fuerte apuesta por situar los problemas, investigaciones y soluciones en el curso de experiencia (Kitcher, 2012, p. xvi).

Las consideraciones precedentes remiten a una de las intenciones fundamentales de la filosofía deweyana: desarrollar instrumentos intelectuales que lleven de manera progresiva la investigación hacia las realidades profunda y totalmente humanas, vale decir, morales. En La Reconstrucción de la Filosofía y considerando tanto los sucesos de la Primera Guerra Mundial como el desajuste entre el avance científico, que ha trocado el concepto de estabilidad por el de orden constante de cambio como eje de su actividad, y la filosofía, que aún se resiste a dejar la necesidad y universalidad de sus valores y principios, Dewey insiste en recuperar el valor programático del darwinismo pues hace caer los dogmas de las especies inmutables, de subordinación de lo individual a lo universal, de lo cambiante a lo fijo, y permite establecer un nuevo método para la vida social y moral.

\footnotetext{
${ }^{10}$ En una apretada pero notoriamente precisa síntesis, Putnam identifica cuatro rasgos centrales a la base de las filosofías de Peirce, James y Dewey: (i) una concepción gnoseológica anti-escéptica, (ii) una concepción epistemológica falibilista, (iii) la tesis según la cual no hay dicotomía fundamental entre hechos y valores, y (iv) la tesis de la primacía de la práctica en la filosofía (Putnam \& Conant, 1994, p. 152). Todos estos elementos se siguen con claridad de la adopción del enfoque naturalista recientemente señalado.
} 


\subsection{Principio de continuidad de la experiencia}

Uno de los puntos centrales del impacto del darwinismo en la filosofía deweyana es la asimilación del principio de continuidad de la experiencia. A este respecto, si bien la idea misma de continuidad aparece en todos los ámbitos de indagación filosófica sobre los que ha trabajado Dewey (Burke, Hester, \& Talisse, 2002, p. xxi), el interés de la sección es identificar y analizar algunos aspectos que estimo relevantes para abordar con posterioridad la pregunta por la génesis de los valores $\mathrm{y}$, más aún, por los vínculos entre valores e investigación científica. Para ello propongo entonces revisar (i) la tesis de la continuidad entre las actividades y formas menos complejas y más complejas; (ii) la noción de afectividad; y (iii) la consideración de los principios de interacción y continuidad como los aspectos longitudinal y lateral de la experiencia.

Tal vez el punto en que más fácilmente se identifique la referida influencia del darwinismo es en la concepción misma de naturaleza planteada por Dewey. En efecto, a lo largo de Experiencia y Naturaleza el pragmatista sostiene que hay distintos niveles de transacciones que si bien tienen características distintivas son continuos entre sí. De esta manera, y siguiendo la lectura de Bernstein (2010b, pp. 113-125), es posible considerar a la naturaleza como "proceso de procesos", esto es, como una serie de transacciones continuas, superpuestas y combinadas. De acuerdo con Dewey, hay distintos niveles en las transacciones naturales, partiendo de la distinción inicial entre cosas vivientes y no vivientes, cuya diferencia más básica no radica en alguna fuerza no-natural que se imponga a la materia sino en que las actividades de lo viviente se caracterizan por un ritmo de necesidad-esfuerzo o petición-satisfacción, esto es, en el modo en que se conectan y operan las energías y en las diferentes consecuencias a que dan lugar una u otra actividad, modo del que carecen las cosas no vivientes. Es así que, reconociendo en la naturaleza niveles diferentes de transacciones en función de su creciente complejidad, cabe admitir los fenómenos en su plena realidad empírica sin recurrir a las rupturas del dualismo en la continuidad histórica, existencial. En consecuencia, no hay cortes abruptos al interior de la naturaleza que necesiten la aplicación de categorías no-naturales para explicarlos. ${ }^{11}$ Por otro

\footnotetext{
${ }^{11}$ Dewey clasifica las transacciones naturales en (i) físico-químicas, transacciones de masa y energía que actúan tendiendo a mantener el tipo de actividad del organismo al que pertenece; aquí Dewey identifica lo físico con lo inanimado; (ii) psico-físicas, denotando en el organismo una actividad que se rige por el ritmo de necesidad-ajuste y satisfacción mencionado recientemente; el prefijo "psico" señala que la actividad física
} 
lado, resulta importante señalar que para Dewey el primer postulado que alimenta una teoría naturalista de la investigación se expresa bajo la tesis de la continuidad entre las actividades y formas inferiores o menos complejas y las actividades y formas superiores o más complejas - tesis sobre la que volveré con más detalle en el capítulo 4, al momento de precisar la pauta general de la investigación (Cf. 1950, pp. 37-38. LW.12.30-31).

Según indica Dewey en "Affective Thought” (1926. LW.2) la tradición filosófica ha marcado una férrea distinción entre los procesos orgánicos y psicológicos por un lado y las manifestaciones culturales en ciencia y arte, por el otro. Esa misma tradición ha operado otras demarcaciones fuertes, tales como la separación de lo estrictamente lógico e intelectual propio de la ciencia, lo emocional e imaginativo de la poesía, la música y, en menor medida, las artes plásticas, y la esfera práctica para el ámbito de la industria y los asuntos políticos. Dicho de otro modo, ha establecido una demarcación entre pensamiento, sentimiento o afectividad y volición que redunda en una segmentación de las actividades vitales. Sin embargo, los avances contemporáneos a Dewey de los estudios sobre distintas funciones biológicas han permitido sustentar la tesis del desarrollo continuo entre las operaciones menos complejas y las operaciones más complejas y han dado sustento a su propia formulación filosófica -en línea con su posición naturalista anteriormente señalada. ${ }^{12}$

La idea de afectividad indica que el organismo tiene una serie de necesidades básicas que no puede satisfacer sino por medio de una actividad que modifique al propio entorno, hasta tanto no se dé lugar a una nueva integración entre el organismo y el

adquiere la actividad o cualidad adicional de obtener del medio una clase de satisfacción para las necesidades superior a otras alternativas (esa capacidad discriminativa conforma la sensibilidad); y (iii) espiritual, distintivo de la experiencia humana en tanto está signado por la capacidad del uso del lenguaje, por la manipulación de signos para representar algo que no esté inmediatamente presente y que desarrolle nuevos signos (Cf. Dewey, Experiencia y Naturaleza, Cap. 7 y Tiles, 1988, pp. 55-59).

${ }^{12}$ La referencia aquí es al texto Psicología del Razonamiento (1923) del biólogo y psicólogo italiano Eugenio Rignano, en donde se afirma que el razonamiento es constituido por la relación recíproca entre dos actividades primordiales de nuestra psiquis, la intelectual y la afectiva, y desarrolla a partir de allí la referida noción de afectividad, base filosófica para dar cuenta de la tesis de continuidad de Rignano. Thomas Dalton señala que si bien Dewey se apoya en las investigaciones de Rignano para trazar puentes entre el dominio de la ciencia y el dominio del arte bajo la consideración de que ambos deben lidiar con el problema común de "transformar energía en ideas", el pragmatista no queda completamente satisfecho con los aportes del italiano al momento de explicar el origen de experiencias nuevas, motivo por el cual termina alejándose de la idea de pensamiento afectivo y acercándose a las teorías de Ernst Mach, Ludwig Boltzmann y James Clerk Maxwell para explicar al menos parcialmente el fenómeno de la percepción estética (Dalton, 2002, pp. 161-162). 
ambiente. En este sentido, la noción de afectividad es coherente con el sentido general otorgado por el autor al concepto de experiencia. El punto novedoso que introduce Dewey en "Affective Thought" es aplicar la noción de afectividad al pensamiento mismo. Así las cosas, el pensamiento queda definido como una fase de la función genérica de ocasionar una nueva relación entre el organismo y su ambiente o condiciones de vida y, al igual que las otras fases de la misma función genérica, está controlado por la necesidad, el deseo y las satisfacciones progresivas. Asimismo, las experiencias pasadas pueden ser retenidas para el momento en que sea necesario ajustar la integración con el ambiente a partir de las necesidades señaladas anteriormente. Ahora bien, esta retención no es intelectual sino que es una cuestión de modificaciones orgánicas, de cambio de disposiciones, actitudes y hábitos. Luego, el material del pensamiento viene del pasado pero su propósito y dirección son futuros (Dewey, LW.2.106).

A partir de estas consideraciones Dewey afirma que las dicotomías filosóficas previamente indicadas resultan de haber aislado al organismo del ambiente y de haber desestimado o desatendido las funciones de las necesidades en la creación de fines o consecuencias a promover. Puesto en otros términos, la tradición filosófica ha ignorado la conexión de los fines propuestos con la función afectiva, expresada en el organismo y extendida y refinada a través de la experiencia, y consecuentemente ha tenido que explicar el surgimiento de las elaboraciones intelectuales y lógicas cada vez más complejas y comprehensivas apelando a elementos externos al propio curso de experiencia y dando lugar, en definitiva, a las mentadas dicotomías.

En virtud de lo dicho, la experiencia en términos de transacción y el vínculo afectivo entre organismo y ambiente son puntos de partida común a todas las actividades vitales y experiencias diferenciales, de modo que permiten establecer una continuidad entre ellas sobre la base de ese elemento compartido y sentar las pautas para una "lógica de la experiencia", tomando en préstamo una expresión del propio Dewey. En este sentido amplio o genérico, su valor radica en poder dar cuenta del paso entre distintas situaciones o funciones propias de la experiencia (MW.2.313). ${ }^{13}$ Así comprendida, la lógica de la

\footnotetext{
${ }^{13}$ La expresión "lógica de la experiencia" aparece en la contribución de Dewey a Studies in Logical Theory de 1903 (más precisamente, en el primer apartado del texto deweyano, titulado "The Relationship of Thought and its Subject-Matter"). En su clásico libro The Necessity of Pragmatism R. W. Sleeper dedica un capítulo completo al análisis de la "lógica de la experiencia" aunque con una perspectiva distinta a la aquí considerada
} 
experiencia permite remover las bases de la referida segmentación de las distintas actividades vitales en la medida en que en todas ellas la satisfacción de las necesidades requiere por igual que el ambiente sea modificado. Para el caso del razonamiento, esto aparece como la necesidad de la experimentación. El punto en común es el principio de la relación entre organismo y ambiente y la satisfacción, por parte del razonamiento, la ciencia y del arte, de las mismas necesidades fundamentales. En palabras del pragmatista, "[p]robablemente llegará un momento en que será universalmente reconocido que las diferencias entre los esquemas lógicos coherentes y las estructuras artísticas en la poesía, la música, y el arte plástico son diferencias técnicas y de especialización antes que diferencias profundamente arraigadas." (LW.2.106).

El tópico de la continuidad de la experiencia es profundizado por Dewey en Experiencia y Educación (1938. LW.13), ofreciendo además una caracterización adicional, a saber, la identificación del aspecto vertical o longitudinal y lateral o latitudinal de la experiencia. En el marco de su discusión con las denominadas "educación conservadora” y “educación progresiva”, Dewey afirma que existe una conexión orgánica entre educación y experiencia y, asimismo, que la nueva filosofía de la educación está comprometida con algún género de filosofía empírica y experimental. Esta tesis lo conduce a plantear la necesidad de una teoría de la experiencia tal que permita desarrollar una sólida filosofía de la experiencia educativa -lo cual constituye, en definitiva, el objetivo principal de Experiencia y Educación. Si bien el análisis de este aspecto del pensamiento deweyano excede los límites de la presente investigación, es justamente aquí donde Dewey introduce una interesante y sugerente observación: "No es suficiente con insistir sobre la necesidad de la experiencia, ni aun de la actividad de la experiencia. Todo depende de la cualidad de la experiencia." (LW.13.13. Traducción levemente modificada. Cf. 2010, p. 73).

\footnotetext{
-sin que ello suponga, al menos en principio, algún tipo de tensión entre ambas. Tras considerar tanto los antecedentes lógicos y psicológicos en Peirce y James como las referencias críticas hechas por Dewey al texto Logik de Lotze (1874, edición en inglés de 1888), Sleeper plantea que con la idea de una lógica de la experiencia Dewey cuestiona aquellas posiciones que consideran la posibilidad de un pensamiento puro, sin relación con ningún objeto - tal es, en efecto, la concepción de lógica sostenida por Lotze. Dicho de otro modo, Sleeper entiende que la apuesta de Dewey es dejar en claro que no se puede concebir al pensamiento por fuera de la experiencia, esto es, no se puede concebir una "lógica sin ontología" -comentario que lo habilita, además, a observar que en estos pasajes Dewey adelanta algunas tesis ontológicas que serán profundizadas en Experiencia y Naturaleza, especialmente acerca del mundo en continua transición (Cf. Sleeper, 1986, Cap. 3).
} 
Dewey identifica dos aspectos para la cualidad de la experiencia: (i) el aspecto inmediato de agrado o desagradado - que será analizado en la próxima sección- y (ii) el principio de continuidad experiencial. Respecto del segundo punto, enfatiza el hecho de que toda experiencia emprendida y sufrida modifica al que actúa y la sufre, afectando a su tiempo, se desee o no, a la cualidad de las experiencias siguientes. El apoyo de este principio es una idea de hábito, no comprendido como un modo más o menos fijo de hacer cosas sino, en un sentido más profundo, como la formación de actitudes emocionales e intelectuales, sensibilidades y modos básicos de satisfacer y responder a las condiciones vitales. Así, el principio de continuidad indica que toda experiencia recoge algo de la anterior y modifica de algún modo la cualidad de la posterior. Asimismo, la experiencia no sólo penetra en el sujeto en la medida en que influye en la formación de sus actitudes de deseo y propósito, sino que toda experiencia modifica, en algún grado, las condiciones objetivas bajo las cuales se ha tenido la experiencia, y esas modificaciones se acumulan con el paso de las generaciones (Cf. Dewey, 2010, p. 78-82. LW.13.18-21).

Como se adelantó, un aspecto fundamental para interpretar el concepto de experiencia es su carácter transactivo, que asigna igual influencia a las condiciones objetivas y a las condiciones internas de la experiencia. Puesto que toda experiencia es un "juego recíproco" entre las dos series de condiciones, considerar conjuntamente o en su interacción ambos tipos de condiciones permite elaborar una nueva definición del concepto de situación, que será analizado en el siguiente parágrafo. Por el momento resulta relevante señalar que para Dewey la afirmación de que los individuos viven en un mundo significa que viven en una serie de situaciones en cuanto interacciones entre un individuo, otras personas y objetos. En efecto, "[1]as concepciones de situación y de interacción son inseparables una de otra. Una experiencia es siempre lo que es porque tiene lugar una transacción entre un individuo y lo que, en el momento, constituye su ambiente [...]" (2010, p. 86. LW.13.25).

En este punto Dewey afirma que "[1]os principios de continuidad e interacción no se pueden separar uno de otro. Son, por decirlo así, los aspectos longitudinal y lateral de la experiencia." (Dewey, 2010, p. 86. LW.13.25. Cursivas en el original). Un modo de interpretar esta afirmación es asignar a cada principio uno de los aspectos. Tal es la lectura de S. Morris Eames, para quien el aspecto longitudinal corresponde al principio de 
continuidad y el aspecto lateral o latitudinal corresponde al principio de interacción (Cf. 2003, p. 11). De esta manera, el vínculo entre las actividades y formas menos complejas y más complejas así como la relación entre experiencias primarias y experiencias reflexivas quedarían representadas por el carácter longitudinal y transactivo de la experiencia, mientras que la relación entre experiencias sucesivas, tal y como la plantea Dewey en Experiencia y Educación, quedaría representada por el aspecto lateral de la experiencia.

A diferencia de esta lectura, que disocia los principios referidos, estimo más adecuado priorizar su carácter “inseparable”, según los caracteriza Dewey. De hecho, estimo que esta distinción de facetas de la continuidad es resultado de un trabajo analítico que como tal establece diferencias a efectos de dar cuenta de un trato con el mundo que es integral y multidimensional y de una noción de experiencia atravesada por condiciones espacio-temporales que, a su vez, gana en profundidad, espesor y densidad cualitativa. Esto constituye, en definitiva, el continuo de la experiencia.

Ahora bien, más allá de esta aclaración, lo cierto es que Dewey mismo propone la distinción entre los aspectos longitudinal y lateral de la continuidad de la experiencia aspectos que, según buscaré argumentar en el capítulo 5, son de notorio interés para pensar las relaciones entre valoración e investigación. En este marco, propongo considerarlos bajo una "interpretación integral" a los fines de dar cuenta del curso de experiencia, en su aspecto latitudinal o lateral, y de la conexión orgánica entre la experiencia primaria y las distintas experiencias reflexivas particulares, en su aspecto longitudinal. Tomar ambos principios como un agregado inextricable permite derivar algunas conclusiones importantes para la comprensión de la teoría deweyana de la experiencia. Por un lado, queda claro que la interacción o transacción es una característica de los distintos tipos de experiencias, sean aquellas que se consuman como una experiencia o aquellas que han quedado truncas, sean aquellas de sentido común, de la investigación científica, de la educación, del arte o de la valoración. Asimismo, dicho carácter lateral habilita a pensar que hay transacción no sólo al interior de cada experiencia particular sino entre distintas experiencias suscitadas en el continuo experiencial. Esta interpretación permite, por tanto, comprender la tesis meliorativa o de posible enriquecimiento cualitativo y progresivo de la experiencia, es decir, la insistencia deweyana acerca de que toda experiencia debería preparar ulteriores 
experiencias de una cualidad más profunda y expansiva al establecer ciertas preferencias o aversiones, al modificar las condiciones objetivas bajo las cuales tendrán lugar experiencias ulteriores o al hacer más fácil o difícil actuar para algún fin determinado Tal es el caso paradigmático de las experiencias educativas, aquellas que provocan curiosidad, fortalecen la iniciativa y crea propósitos y deseos que orienten las acciones futuras. En palabras de Dewey, "[c]ada experiencia es una fuerza en movimiento. Su valor sólo puede ser juzgado sobre la base de aquello hacia lo que se mueve.” (2010, p. 81. LW.13.21).

Por otro lado, la lectura ofrecida refuerza la posición deweyana por la cual todos los niveles de experiencia implican transacción entre organismo y ambiente, sea en las experiencias primarias o en las experiencias reflexivas. De hecho, Dewey pone especial atención sobre estas últimas, a fines de evitar que se mantengan en un plano exclusivamente reflexivo y abstracto y que omitan el camino de regreso a la experiencia, es decir, a fin de evitar que recaigan en aquello que Dewey denomina como la falacia más persistente de la filosofía (Cf. entre otros, LW.6.5. Este punto será analizado con mayor detalle en la sección siguiente). Por otro lado, partir de la experiencia como un factor del hacer y padecer permite entender que el aporte del conocimiento pasa justamente por administrar con inteligencia los elementos para mejorar y enriquecer la experiencia primaria. Es así que para Dewey el método empírico es el único que puede recuperar la amplia integridad de la experiencia para la filosofía porque sólo él toma esa indivisa unidad como salida y llegada de sus reflexiones. Citando nuevamente a Cruz, "[e]n términos de experiencia, continuidad significa integridad." (1987, p. 12). Finalmente, las experiencias reflexivas particulares se apoyan en esta continuidad para enfatizar distintos aspectos específicos y hacerlos el eje del proceso reflexivo que las ocupe, mecanismo que permite explicar la estrategia deweyana del "rodeo" por la experiencia a la hora de analizar actividades que son altamente reflexivas y específicas, tales como la investigación científica, el arte o la propia valoración.

\subsection{Inmediatez cualitativa, situación, contexto e interés selectivo}

Un tercer elemento relevante es el aspecto de inmediatez cualitativa de la experiencia junto con las concomitantes nociones de situación y contexto, claves para comprender el proceso mismo de valoración. Antes de comenzar con el tratamiento de las 
fuentes resulta oportuno hacer dos comentarios que permitirán dar cuenta del interés que reviste el análisis propuesto. Por un lado, parece que la pregunta por la inmediatez ha sido un rasgo distintivo de la filosofía estadounidense en general y del pragmatismo en particular. Así, Santayana se propone dar cuenta de las cualidades en el plano estético y Whitehead busca explicar la presencia universal de aquellas, al tiempo que Peirce reivindica la categoría de primeridad como inmediatez y James postula un flujo inmediato perceptual desde el cual se forjan los conceptos (Bernstein, 2010, p. 130). ${ }^{14}$ Para el caso de Dewey, sus intérpretes clásicos y contemporáneos coinciden en señalar que una cabal comprensión de la teoría de la experiencia implica necesariamente un estudio preciso de su aspecto de inmediatez cualitativa (Bernstein, 1961; S. M. Eames, 2003; Pappas, 2016; Shusterman, 1999; Stuhr, 1979). Por otro lado, esta dimensión de inmediatez cualitativa ha sufrido un proceso de selectividad negativa en la literatura sobre Dewey debido a que la terminología del asunto parece escapar a un análisis riguroso. En efecto, y al igual que el término "experiencia", el término "cualitativo" presenta ciertas asociaciones tradicionales en la historia de la filosofía que frustraron al menos parcialmente los esfuerzos reconstructivos de Dewey, en la medida en que fue generalmente asociado o bien a alguna propiedad metafísica abstracta o bien a algún fenómeno subjetivo -ninguno de los cuales responde a la visión del autor (Pappas, 2016, pp. 441-442). Así, abordar este aspecto es una tarea necesaria al momento de dar cuenta de un elemento central y generalmente poco atendido de la teoría de la experiencia de Dewey.

Considerando estas observaciones, el propósito de la sección es analizar dos ensayos publicados por Dewey en la década de 1930, a saber, "Qualitative Thought" ([1930] LW.5) y "Context and Thought" ([1931] LW.6), sin perjuicio de algunas referencias a otras obras, especialmente a Experiencia y Naturaleza y a Lógica. Teoría de la Investigación ([1938] 1950. LW.12). Como se indicó, para Dewey la experiencia se define como transacción entre organismo y ambiente en una dinámica de desequilibrios y ajustes. Si se leen estas afirmaciones junto con las frases iniciales de "Qualitative Thought"

\footnotetext{
14 Dewey analiza y critica la concepción de peirceana de primeridad en "Peirce's Theory of Quality" (LW.11.86). Al respecto, Robert E. Innis sostiene que hay una línea de continuidad entre la propuesta de Peirce y la de Dewey, a tal punto que este último parece haber escrito una estética general de la cualidad plenamente consistente con la perspectiva peirceana (Cf. Innis, 2011).
} 
por las cuales "el mundo en que inmediatamente vivimos, aquel en que luchamos, somos exitosos o vencidos, es preeminentemente un mundo cualitativo. Aquello por lo que actuamos, sufrimos y disfrutamos son cosas en sus determinaciones cualitativas", entonces resulta absolutamente claro que la dimensión o aspecto cualitativo está a la base misma del hacer y padecer que constituye el sentido más básico de la experiencia (LW.5.243). En este sentido, resulta por demás interesante la expresión "matriz cualitativa" de la experiencia en la medida en que permite observar que este aspecto de inmediatez cualitativa es común a toda experiencia y que es sobre o a partir de él que se podrán construir las experiencias reflexivas particulares (Cf. Innis, 2011).

De acuerdo con Dewey, el problema de los "objetos cualitativos" ha sido trabajado en la metafísica y en la epistemología pero no ha recibido la atención correspondiente en otros ámbitos de la filosofía y, en especial, en la teoría lógica. En este sentido, la metafísica se ha ocupado del status existencial de los objetos cualitativos en tanto opuestos a los objetos de la ciencia física, mientras que la epistemología, habiendo decidido que las cualidades son subjetivas y psíquicas, se ha ocupado de su relación con las propiedades de los objetos externos al sujeto, definidas en términos no cualitativos. Para el caso de la estética, la lógica o la política -y se podría agregar a la valoración en general y a la moral en particular-, el efecto de la referida desatención es o bien negar, al menos implícitamente, que tengan algún fundamento lógico o bien, en el intento de ubicarlas bajo categorías lógicas ya elaboradas, quitarle su significado distintivo y tratarlas como objetos cuasimatemáticos, dejando al pensamiento sin ningún status o control lógico.

Un punto fundamental en el análisis de Dewey es la noción de situación. Con este concepto se pretende indicar que el asunto referido en una proposición existencial es, en última instancia, una existencia compleja unificada [held together] por el hecho de estar dominada y caracterizada por una única cualidad, más allá de su complejidad interna (LW.5.246). ${ }^{15}$ De acuerdo con los ya mencionados Bernstein (1961, pp. 5-8) y Stuhr (1979, pp. 72-76), a la hora de dar cuenta del referido aspecto cualitativo es posible identificar tres aspectos o notas claves:

\footnotetext{
${ }^{15}$ La noción de situación con unidad cualitativa determinada puede rastrearse, cuanto menos, a la ya mencionada contribución de Dewey a Studies in Logical Theory. En efecto, tras señalar que nunca pensamos en abstracto sino acerca de o sobre asuntos determinados, Dewey observa que "[e]n el curso de la experiencia cambiante mantenemos un balance en el movimiento desde situaciones con cualidad afectiva [affectional] a aquellas que son prácticas o apreciativas o reflexivas [...]" (MW.2.311).
} 
(i) las cualidades son directamente experienciadas o tenidas [had] antes que conocidas, en línea con aquella definición inicial de experiencia en términos de "hacer y padecer". ${ }^{16}$ En efecto, Dewey afirma que hay objetos de aprehensión, posesión, uso y goce directo y que si se toma el adjetivo "estético" en un sentido más amplio que en el de la aplicación a lo bello y lo feo -o más bien aisthetico, siguiendo otra clarificadora indicación de Innis para señalar el vínculo aunque no la identificación entre esta aprehensión directa y la elaboración artística, de segundo orden (2011, p. 44)-, es indudable que la cualidad directa, final o encerrada en sí caracteriza a las situaciones (Cf. Dewey, 1948, p. 82. LW.1.82). ${ }^{17}$ Asimismo, uno de los objetivos centrales de Dewey es justamente desarticular la relación tradicionalmente planteada por la filosofía entre inmediatez cualitativa y conocimiento inmediato. La distinción entre tener y conocer es la distinción entre lo directa e inmediatamente presente y la discriminación, clasificación y significación que supone, como mínimo, el proceso de conocimiento. Luego, “[...] experimentar cualidades es una condición necesaria, aunque no suficiente, para obtener conocimiento. Cada ocasión en la que tiene lugar una cualidad es única, aunque las cualidades puedan ser clasificadas y, en consecuencia, servir como signos." (Bernstein, 2010, p. 131). Es en este sentido que, según indica Dewey en El Arte como Experiencia, la experiencia es apreciativa, perceptiva y gozosa [appreciative, perceiving and enjoying] (LW.10.53). ${ }^{18}$

(ii) el locus de las cualidades son las propias situaciones, pues si bien las cualidades son experienciadas y requieren un experienciador, no son subjetivas en el sentido de pertenecer a la conciencia ni son objetivas en el sentido de constituirse como previas o antecedentes a la experiencia sino que pertenecen a la transacción misma entre

\footnotetext{
${ }^{16}$ Aun cuando no aparezca en el diccionario de la RAE, empleo el término "experienciada/o" y sus derivados a fines de diferenciarlo de "experimentado" pues este último remite más a experimentación y consecuentemente a un sentido cognitivo, precisamente aquel que Dewey cuestiona como sentido primigenio de su idea de experiencia.

${ }^{17}$ Por supuesto, un análisis de la dimensión estética de la experiencia supera los objetivos del presente capítulo. Al respecto, Cf. Di Gregori y Durán, 2008 y Di Gregori y Pérez Ransánz, 2010, entre otros.

${ }^{18}$ En su versión castellana de El Arte como Experiencia Jordi Claramonte propone traducir appreciative por "estimativa" (Cf. Dewey, 2008a, p. 54). Por mi parte, prefiero el término "apreciativo" pues respeta literalmente la versión inglesa, se vincula más directamente con la idea deweyana de inmediatez cualitativa y me permite, además, reservar la familia de palabras de "estimar" para una acepción específica de value. Retomaré este punto en el próximo capítulo.
} 
organismo y ambiente, al "encuentro" entre ambos: "Las cualidades no estuvieron nunca en el organismo; siempre fueron cualidades de interacciones en que participan a la vez las cosas extra-orgánicas y los organismos" (Dewey, 1948, p. 213-214. LW.1.198-199. Cursivas en el original). En definitiva, el concepto de situación permite traspasar o superar los dualismos sujeto-objeto o mental-físico en la medida en que esas distinciones son siempre instituidas dentro de la situación como un todo inclusivo. En este mismo sentido, Stuhr señala que preguntar si una cualidad es mental o física supone una incomprensión inicial de la naturaleza de la experiencia cualitativa, de su unidad y de su carácter transactivo (1979, p. 75); y

(iii) hay cualidades ubicuas que permean toda la situación, la demarcan como tal, "corren a través" de cada aspecto o detalle, les da significado y los mantiene integrados en la situación [pervasive and internally integrating quality, LW.5.246]. Asimismo, la cualidad permeante o ubicua no sólo cohesiona los elementos de la situación en un todo sino que le brinda un carácter único en el sentido de indivisible e induplicable (Dewey, 1950, p. 85. LW.12.74). La cualidad es, entonces, la "marca definitoria" de una situación dada (Stuhr, 1979, p. 74). ${ }^{19}$

Para comprender el lugar y la función del concepto de situación resulta interesante atender a ciertos comentarios de "Experience, Knowledge and Value. A Rejoinder", texto escrito por Dewey en respuesta al conjunto de ensayos críticos publicados en The Philosophy of John Dewey por motivo de su octogésimo cumpleaños (Schilpp, 1939). En primer término, y a nivel meta-filosófico, Dewey explica que introducir una noción como la de situación busca ofrecer una alternativa viable tanto al atomismo lógico, cuya consecuencia es la negación de las conexiones en el curso de experiencia, como al monismo absolutista que, en nombre de las relaciones no deja lugar a lo discreto, a lo individual. Según Dewey, esta posición se sigue de su visión naturalista: en la medida en que la experiencia incluye algo experienciado y algún proceso de experienciación, es

\footnotetext{
${ }^{19}$ Tanto Bernstein (1961, p. 7) como Pappas (2016, p. 442) y Stuhr (1979, p. 76) señalan que la cualidad permeante es una cualidad "terciaria", apoyados en algunos pasajes del propio Dewey. No obstante, en Lógica. Teoría de la Investigación Dewey aclara que la referencia a cualidades terciarias no es adecuada porque éstas califican a todos los elementos componentes, a los que se aplican de manera general y absoluta, mientras que la cualidad permeante de una situación no es general sino única, es decir, no en términos de "penoso" o "alegre" sino de "la penosidad" o "la alegría" que caracteriza a una situación única (Cf. Dewey, 1950, p. 86-87. LW.12.76). Esta última explicación resulta, a mi juicio, más aproximada a la idea de cualidad permeante como aquello que hace única a la situación particular.
} 
temporal y espacialmente más extensa e internamente más compleja que cualquier adición de objetos o de cualidades; luego, la experiencia tiene más alcance y contenido que el supuesto por el empirismo particularista pero no llega al punto de lidiar con universales, pues toda transacción es situada: "En otras palabras, la teoría de las situaciones experienciales que se sigue directamente del enfoque biológico-antropológico es por su misma naturaleza una via media entre el pluralismo atomista extremo y los monismos absolutistas [block universe monisms]. Lo que no es sino decir que es genuinamente empírica en un sentido naturalista.” (Dewey en Schilpp, 1939, p. 544. LW.14.29).

En segundo término, y a nivel filosófico, resulta interesante abordar el vínculo que explicita Dewey entre situación y experiencia, para lo cual es necesario reconstruir brevemente las críticas al concepto mismo de situación señaladas por Bertrand Russell en “Dewey’s New Logic” (en Schilpp, 1939, pp. 136-156). Considerando por un lado el concepto de situación en cuanto "todo existencial cualitativo de carácter único" (Dewey, 1950, p. 141. LW.12.125) y por otro lado algunos comentarios respecto de conceptos como ambiente y mundo, tales como "[e]xiste, sin dudas un mundo natural independiente del organismo, pero este mundo es medio ambiente [environment] sólo cuando entra, directa o indirectamente, a formar parte de funciones vitales" (Dewey, 1950, p. 48. LW.12.40), Russell plantea la pregunta por la extensión o alcance de la situación: “¿Cuán extensa [large] es una situación?” (Russell en Schilpp, 1939, p. 139). De acuerdo con Russell, la vinculación entre el principio deweyano de continuidad de la experiencia y el concepto de situación conduce necesariamente a concluir que por situación no se puede comprender menos que "el universo entero". Luego, Dewey queda comprometido con una posición radicalmente holista -posición que, además, Russell vincula con algún resto del hegelianismo propio de la formación inicial del pragmatista. A partir de esta primera conclusión Russell deriva otras dos afirmaciones: (i) que toda investigación es, estrictamente interpretada, un intento de analizar el universo, y (ii) que todo juicio, en definitiva, cualifica a la Realidad como un todo. Si se quieren evitar estas dos conclusiones, arguye Russell, es necesario que se le otorgue más preponderancia a alguna función lógica que permita individualizar particulares en lugar de fundirlos en aquel todo existencial de carácter único (Cf. Russell en Schilpp, 1939, pp. 139-140). 
Frente a estas observaciones Dewey introduce una caracterización de las situaciones en términos de "unidades de experiencia" plurales e individualizadas y que mantienen directa conexión debido al principio de continuidad de la experiencia, en tanto la situación, más allá del carácter único dado por su propia cualidad permeante, contiene dentro de sí algún aspecto que apunta a otras situaciones, según se analizó en la sección previa. El punto central de la respuesta deweyana es la disolución del dualismo "discreto-continuo" por vías de la identificación entre experiencia y funciones vitales [life-functions] pues para el mantenimiento de la vida son igualmente necesarias tanto la atención sobre la situación presente, con los rasgos de unidad e induplicabilidad dados por la cualidad permeante distintiva, como la atención sobre los efectos en las condiciones de las situaciones subsiguientes. En palabras de Dewey, “[d]esde este ángulo, casi todo lo que he escrito es un comentario al hecho de que las situaciones son inmediatas en su ocurrencia directa, y mediadoras y mediadas en el continuo temporal que constituye la vida-experiencia [lifeexperience]." (Dewey en Schilpp, 1939, p. 546. LW.14.30).

Por todo lo dicho, la situación es el gran e inclusivo "asunto" [subject-matter] que contiene y al que, por vías de las distinciones particulares, se refiere el pensamiento. Tal y como indica Faerna, sólo hay pensamiento-en-situación, desde y para la situación (1996, p. 186). Desde aquí se siguen dos puntos de interés. En primer lugar, la situación en cuanto tal no puede ser explicitada sino que se da por sentada como "universo de experiencia" en la medida en que está presente en todas las explicitaciones o distinciones, esto es, en la medida en que es la condición previa del universo de discurso de lo que fuera que se establece explicita o expresamente en proposiciones. Esta observación permite explicar, desde un nuevo ángulo, el indisoluble vínculo entre situación y experiencia: “[e]l lector, esté o no esté de acuerdo con lo que se ha dicho, lo haya comprendido o no, al leer los párrafos anteriores ha tenido una situación experimentada, singularmente cualificada, y la comprensión reflexiva de lo que se decía en los párrafos estaba controlada por la naturaleza de esta situación inmediata. Uno no puede evitar el tener una situación porque esto equivaldría a no tener experiencia, ni siquiera la del desacuerdo.” (Dewey, 1950, p. 85. LW.12.74. Cursivas en el original). En segundo lugar, la situación controla los términos del pensamiento pues éstos son sus distinciones, y su aplicabilidad en aquélla es el test último de su validez. La unidad cualitativa subyacente regula la pertinencia o relevancia y la 
fuerza de cada distinción o relación hecha al interior de la situación; guía la selección o rechazo y la manera de utilización de los términos explícitos; y permite continuar trabajando sobre el problema sin detenernos a pensar cada vez qué es lo que nos ocupa. ${ }^{20}$ Esta última afirmación permite introducir otro aspecto relevante de la teoría de la experiencia para dar cuenta del asunto de los valores: el rol del contexto en el pensamiento, vale decir, a nivel de la experiencia reflexiva, y en la definición del interés selectivo, tal y como lo explicita Dewey en "Context and Thought" (LW.6).

Dewey toma como punto de partida del ensayo un comentario del antropólogo Bronislaw Malinowski respecto de la necesidad de considerar el contexto en conexión con el uso del lenguaje. Si bien esta última afirmación parece válida para el caso del lenguaje/discurso de comunidades "salvajes" [alien and remote savage tribe], Dewey advierte que sería un error pensar que el principio elaborado por Malinowski se aplica solo en esos casos. En efecto, entendemos el significado de lo que se dice en nuestro propio lenguaje no porque la apreciación del contexto sea innecesaria sino lo contrario, porque el contexto está ineludiblemente presente e implícito. Así, el contexto queda incorporado en todo lo dicho y es el árbitro del valor de cada expresión: "No somos explícitamente conscientes del rol del contexto precisamente porque cada una de nuestras expresiones está saturada por aquél a punto de formar el significado de lo que decimos y escuchamos." (Cf. Dewey, LW.6.4). En consecuencia, según Dewey el significado de los símbolos no es inherente a ellos sino derivados en la medida en que no pueden suplir el contexto que les provee significado y comprensión. Si bien la referencia inicial corresponde al estudio del lenguaje, Dewey considera que aquélla contiene en germen la tesis de la indispensabilidad del contexto para el pensamiento y, consecuentemente para una teoría de la lógica, de la filosofía y, me permito agregar, para una concepción del valor.

\footnotetext{
${ }^{20}$ Shusterman toma la distinción entre had y known para elaborar una respuesta a las acusaciones lanzadas por Rorty a Dewey en los ya citados artículos acerca del carácter intrínsecamente fundacionalista de la dimensión cualitativa de la experiencia. Sin embargo, sostiene que estas funciones atribuidas a la inmediatez cualitativa en cuanto guía de todo pensamiento discursivo podrían ser tomadas como un fundacionalismo experiencial inefable. Frente a esta opción, Shusterman responde que las mismas funciones atribuidas a la inmediatez cualitativa pueden ser atribuidas a los hábitos, propósitos y necesidades del organismo, evitando así el fundacionalismo experiencial, y que la afirmación deweyana de la dimensión de inmediatez tiene el objetivo estético de realzar el valor de la experiencia, algo que puede hacerse reconociendo su dimensión somática (Shusterman, 1999). Pappas (2016) ofrece un detallado análisis de todos los sentidos en los que el aspecto cualitativo regula el proceso de investigación. Este punto será retomado al momento de reconstruir la pauta general de la investigación.
} 
Es interesante que Dewey reconozca como contexto de sus propias observaciones el hábito filosófico de omitir el contexto, hábito que para el pragmatista es la más recalcitrante falacia de la disciplina. En este marco, Dewey considera dos instancias y sus respectivas consecuencias de esta virtual negación: (i) la falacia analítica, es decir, la omisión del contexto en la práctica del análisis filosófico, por la cual los elementos surgidos de las distinciones son tratados como si fueran auto-suficientes y finales y derivan en un atomismo particularista; y (ii) la falacia de la extensión ilimitada o universalización, resultado de no considerar las condiciones limitantes puestas por el contexto/situación contextual, propia de la aspiración filosófica de hacer converger todas las cosas en una totalidad comprehensiva. Lo que ambas falacias ignoran es el contexto del investigador/experimentador, para el caso de la falacia analítica, y de la propia investigación, para el caso de la falacia de universalización. ${ }^{21}$

Más allá de estas observaciones críticas, Dewey aborda el costado positivo de la discusión para dar cuenta de qué entiende efectivamente por contexto. Para el autor, el contexto incluye al menos dos elementos: de un lado el trasfondo [background] y del otro el interés selectivo [selective interest]. El primero es, sin más, todo el ambiente [environment], tanto temporal como espacial, que la filosofía debería considerar en sus desarrollos. Por ambiente se entienden todas las cosas o temas que no entran como material directo en la reflexión, que permanecen estables hasta tanto no se sospeche que son causantes de la perplejidad que se busca aclarar o que ejercen cierto efecto diferencial sobre aquello que efectivamente es el objeto de la reflexión. Luego, ese material es tomado como objeto de pensamiento, aunque no deja de haber nunca material en el trasfondo -si ello sucediera, no habría nada tácito con lo cual relacionar aquellos factores que están en proceso de investigación y determinación.

\footnotetext{
${ }^{21}$ Vale recordar que ya en Experiencia y Naturaleza Dewey había advertido, con menos detalle analítico, que las tradiciones griega y moderna son claros exponentes del método no-empírico o no-contextual de filosofar, método que las conduce a un triple error: (i) no tienen instancias de puesta a prueba o comprobación; (ii) no enriquecen la experiencia primaria pues no aportan nuevas significaciones que se le apliquen; y (iii) vuelven a la filosofía una disciplina abstracta y arbitraria, cuyo objeto de reflexión se considera "real en sí y por sí", en otra versión alternativa de la falacia de la filosofía. En este sentido, filósofos tales como Platón, Descartes, Spinoza, Locke o Hegel toman para su filosofía conclusiones refinadas de las matemáticas, la lógica, las ciencias naturales o la estética pero no los vuelcan a la experiencia primaria; antes bien, adoptan un criterio arbitrario de preferencia selectiva respecto de lo real o del Ser por excelencia, ocultan la efectiva elección de tal criterio y finalmente desacreditan a la experiencia como fuente del conocimiento filosófico, la misma experiencia de la que lo obtuvieron (Cf. Dewey, 1948, p. 33-34. LW.1.37-38).
} 
Según se señaló, el trasfondo es tanto temporal como espacial, dimensiones que incluyen ciertas distinciones subsiguientes. El trasfondo temporal es tanto intelectual como existencial. En efecto, no hay pensamiento que no se presente sobre algún contexto de tradición con cualidades intelectuales, es decir, aquellas que la diferencian de la mera costumbre ciega. Una tradición implica, además, un modo de interpretar, de observar y de valorar todo lo que es explícitamente pensado. Es así que para Dewey la tradición puede ser denominada como órganos aperceptivos o hábitos mentales sin los cuales no podría haber pensamiento - más aún, es la atmósfera circundante en la que respira el pensamiento y fuera de la que nadie puede tener una sola idea. La filosofía, por su parte, debe reconocer la existencia de este contexto y, consecuentemente, debe aprender alguna lección de humildad que le impida elevar sus problemas y soluciones al rango de verdades eternas e inherentes a la naturaleza de las cosas, tal y como se había indicado al momento de evaluar la influencia metafilosófica del darwinismo. Por su parte, el trasfondo espacial implica todo el marco contemporáneo en el que emerge un curso de pensamiento y, en cuanto tal, es relativamente vago pero tiene una solidez y estabilidad de la que carece el objeto focal del pensamiento. Según el pragmatista, aquello que es objeto de investigación presenta un primer plano, una distancia media y un trasfondo [foreground, middle distance y background], y el hecho mismo de que haya demarcaciones de objetos tan estrictas que parezcan quedar aislados es un signo claro de algún tipo de selección realizada al interior de la escena objetiva, comentario que introduce entonces las observaciones acerca del interés selectivo (Cf. Dewey, LW.6.13).

A este respecto Dewey indica que todo caso particular de pensamiento es lo que es debido a cierta actitud que determina que se reflexione sobre un asunto u otro, sin ser ella misma una parte inmediata de dicho asunto. En este sentido, en toda operación de pensamiento hay selectividad o rechazo, cuidado y afección/preocupación [concern] pues todo sujeto tiene su propia afección o sensibilidad cualitativa diferencial respecto de las cosas, temas y problemas, y no puede dejarla atrás a la hora de reflexionar. En el ámbito filosófico, este aspecto del contexto denominado interés selectivo fue rotulado como "subjetivo" y en muchas oportunidades fue asociado al "subjetivismo", es decir, a una forma criticable de perjuicio vinculada a la constitución individual del sujeto de la 
reflexión. El punto es que para Dewey la objetividad o ser "objetivo" es también resultado de algún tipo de interés selectivo y operativo que permita identificar, ordenar y brindar una impronta cualitativa al material. El interés, en cuanto subjetivo, es después de todo equivalente a la individualidad y singularidad y no hay razón, según Dewey, para limitar su presencia en la actividad orgánica y mental en la medida en que es algo propio de todo pensamiento genuino. Frente a los que tienden a ver en esta posición algún tipo de solipsismo, Dewey señala que la individualidad no es el asunto del pensamiento sino un modo de selección que determina el asunto del pensamiento. Por otro lado, frente a los que tienden a tomar a los aspectos formales como auto-suficientes en su aislamiento, Dewey indica que esa variante de la falacia de la extensión ilimitada impide la aplicación de la investigación en futuras investigaciones pues los resultados aparecen como teniendo independencia del material existencial (Cf. Dewey, LW.6.14-17).

En este marco, si se acepta la tesis de la indispensabilidad del contexto entonces el lugar y la importancia que tiene un concepto como el de "experiencia" queda totalmente esclarecido. En palabras de Dewey, "[s]i el asunto último y significativo de la filosofía es la explicitación [disclosure] del contexto de creencias, entonces no podemos escapar a la conclusión de que 'experiencia' es el nombre para el contexto último y más inclusivo [last inclusive context]." (LW.6.20). La importancia de la experiencia para el método filosófico es, en suma, el reconocimiento del lugar del contexto en el pensamiento, el cual incide en tres niveles o esferas de profundidad y amplitud progresiva: (i) la escena inmediata, la experiencia vital y personal del propio filósofo, experiencia que sólo un análisis sesgado puede concebir como exclusivamente individual; (ii) la cultura, es decir las instituciones, tradiciones, intereses, aquello que previene a la filosofía de la falacia universalista, es decir de convertirse en una disciplina aislada y artificial; y (iii) la necesidad de una comprensión general de la naturaleza humana, de la construcción de la propia experiencia humana, con la ayuda de las ciencias experimentales, lo que haría trabajar a la filosofía con su contexto más inclusivo y permeante en el cual debe tomar su lugar y desarrollarse. ${ }^{22}$ Aún a riesgos

\footnotetext{
${ }^{22}$ Resulta muy interesante la lectura propuesta por Ramón del Castillo respecto de estos pasajes de "Context and Thought". En su opinión, Dewey mantiene una "doble actitud" pues oscila entre una sociología del conocimiento y una hermenéutica en la medida en que propone analizar por un lado las relaciones del conocimiento con las ideologías que lo enmarcan y por otro lado el carácter vital y constitutivo entre contexto y pensamiento. Más aún, del Castillo señala cierta tensión en la posición anti reduccionista de Dewey, toda
} 
de ser considerada no filosófica por parte de la tradición filosófica, esta es, para Dewey, la única manera de evitar que la filosofía se reduzca a un "mero batir de alas en el vacío" (LW.6.21).

\subsection{La necesidad de valorar}

Hasta el momento he recuperado ciertas aristas de la idea deweyana de experiencia que considero indispensables para comprender su perspectiva sobre los valores y sobre el vínculo entre valores e investigación. No obstante, poco he avanzado sobre el vínculo mismo entre experiencia y valores. A continuación me detendré en dos argumentos que en mi lectura permiten considerar que la concepción de experiencia propuesta por Dewey implica la necesidad de valorar.

El primer argumento se vincula con el carácter transactivo de la experiencia y se apoya en algunas consideraciones hechas por Dewey en sus Lectures on Ethics de 19001901. Según ha sido planteado, la categoría básica para comprender el concepto de experiencia es la categoría de transacción. Esta idea, señala Dewey, es consistente con algunas posiciones en psicología por las cuales toda aseveración proposicional o intelectual da lugar a un proceso motor. En este sentido, todo contenido modifica la conducta, por más mediaciones que pudiera haber. Luego, el contenido es el material que se aprecia o valora en un caso particular y la actitud es el punto de vista desde el cual se lo valora. Además, el marco teórico deweyano no permite considerar las categorías de objeto y sujeto como cerradas en sí mismas, puesto que se definen en la propia relación transaccional, ni permite considerar que haya contenido independientemente de la referencia a ambos. El ejemplo utilizado por Dewey es tan simple como elocuente: decir que el azúcar es dulce implica una referencia implícita al sujeto para quien el azúcar es dulce y que en cuanto objeto el azúcar demandará atención en la medida en que se vincula con la actitud expresada por el término “dulce”. A partir de aquí, y en términos más generales, se sigue que el contenido siempre es seleccionado e interpretado por referencia a la actitud. Luego, el proceso de valoración es inseparable de la experiencia y queda a la base de toda investigación incluyendo tanto a la moral como a la científica. De acuerdo con Dewey,

vez que sus argumentos parecen suponer la búsqueda de una universalización de las conclusiones del pensamiento -limitada, pero universalización al fin. (del Castillo, 1995, p. 424-425). 
"[...] si no hay tal cosa como una separación o aislamiento entre contenido y actitud, entonces todo y cada uno de los contenidos caen en [falls within] un proceso de valoración. [...] Esta relación que tiene [el contenido] con el sujeto demuestra que queda categorizado bajo el alcance de la idea de valor [come under the scope of the idea of value]. [...] Todo lo observado y pensado es observado y pensado como material a ser valorado, si no fue valorado antes." (Dewey \& Koch, 1991, pp. 22-23).

El segundo argumento remite a la concepción metafísica/ontológica de Dewey. Aun cuando me he detenido en analizar los distintos sentidos de continuidad de la experiencia, he dejado deliberadamente en reserva la controvertida tesis de la continuidad entre experiencia y naturaleza propuesta por Dewey en Experiencia y Naturaleza: "[...] la experiencia es de la naturaleza y figura en la naturaleza. No es la experiencia lo que es objeto de experiencia, sino la naturaleza." (Dewey, 1948, p. 6). ${ }^{23} \mathrm{Si}$ bien un análisis detallado de esta tesis conduciría a un terreno por fuera del alcance y objetivos de esta investigación, este punto también es crucial para comprender aquello que denomino la necesidad de valorar. En efecto, lo que atestigua la experiencia es que el mundo es un "teatro de mil riesgos" en donde se confunden peste, hambre, guerra, enfermedad, sequía y muerte con abundancia, fuerza, salud, victoria, fiesta y vida. Tal es la enseñanza de la experiencia primaria, de manera que en primer término son rasgos comunes a toda existencia una inextricable mezcla de lo inestable, azaroso e inseguro con lo estable, uniforme y seguro. Así, la contingencia y la necesidad, el movimiento y el reposo, lo aleatorio y lo cierto mantienen una combinación vital que no admite discriminación de jerarquías ontológicas. Siguiendo la definición de Dewey, si la metafísica es el conocimiento de los rasgos genéricos de lo existente, entonces lo incompleto e inestable debe estar a la misma altura que lo acabado y fijo (Cf. 1948, p. 47. LW.1.50).

La perspectiva metafísica/ontológica naturalista y procesual presentada por Dewey permite explicar la caracterización de la experiencia en términos de ritmo continuo de desequilibrios y ajustes que revierten en el curso primario de experiencia y la enriquecen.

\footnotetext{
${ }^{23}$ Una primera versión de esta idea puede encontrarse en "The Postulate of Immediate Empiricism" (1903), ensayo en el que Dewey afirma que las cosas, en el sentido más ordinario del término, son tal como son experienciadas (MW.3.158). Por otro lado, vale recordar que la tesis de la continuidad entre experiencia y naturaleza le ha valido a Dewey la ya mencionada crítica de panpsiquista hecha por Rorty (2000), es decir, la identificación de la naturaleza con la experiencia, entendida meramente como un contenido mental.
} 
En efecto, el carácter dinámico y contingente de la naturaleza en conjunción con el carácter transactivo de la experiencia hacen que no pueda pensarse una relación con el medio sin situaciones deficitarias o problemáticas. Siguiendo la lectura de Sleeper, bajo las condiciones ontológicas presentadas por Dewey, la experiencia -y la existencia misma, señala Sleeper- no puede sino ser intrínsecamente problemática (Cf. 1986, Capítulo 5). La misma idea es explicitada por Dewey en Lógica. Teoría de la Investigación, toda vez que

[e]l vivir puede considerarse como un ritmo continuo de desequilibrios y recuperaciones de equilibrios. [...] Por lo que se refiere al organismo humano, es particularmente cierto que las actividades llevadas a cabo para satisfacer cambian de tal suerte al ambiente que surgen nuevas necesidades que reclaman, a la vez, nuevos cambios en las actividades del organismo requeridas para su satisfacción, y así se procede en una cadena virtualmente ilimitada. (Dewey, 1950, p. 41-3. LW.12.35).

La cita precedente permite identificar con claridad el carácter transactivo y problemático de la experiencia, dado que no es sólo el ambiente el que da lugar a las situaciones problemáticas - de hecho, bajo el sentido deweyano de experiencia nunca se podría hacer mención "sólo" al ambiente- sino que aquellas advienen como resultado, efecto o consecuencia de la propia acción del organismo. Luego, la ontología procesual y el aspecto transactivo de la experiencia hacen que esta última no pueda eximirse de su carácter problemático $-\mathrm{y}$, en consecuencia, que el organismo no pueda eximirse de su carácter activo en favor del establecimiento de una nueva relación transaccional equilibrada.

En referencia específica al asunto de los valores, en un ensayo de 1933 titulado "Philosophy" Dewey advierte sobre la necesidad de definir a la filosofía desde el punto de vista del valor, pues los cambios de la filosofía están estrechamente vinculados a los nuevos énfasis y redistribuciones en el significado de los valores (LW.8.24). En este contexto surge la pregunta por la relación entre la existencia y el valor, pregunta que ha sido resuelta por la filosofía clásica apelando a dos posiciones radicalmente opuestas pero igualmente extremas: por un lado se ubican aquellas teorías que identifican Ser, Verdad y Bondad en sus significaciones más plenas, y por otro lado aquellas teorías que separan el reino de la 
existencia y de lo ideal en función de preservar cierta pureza de este último (Cf. Dewey, 1948, p. 337-338. LW.1.310).

Por el contrario, Dewey observa que la individualidad cualitativa, las relaciones constantes, la contingencia y el movimiento son al mismo tiempo la fuente de los valores y de su inestabilidad. En efecto, y de acuerdo con Eames (2003, p. 10), Dewey extiende en el plano de la teoría del valor aquellas observaciones acerca del carácter cualitativo de la experiencia al afirmar que "[...] los valores son valores, cosas que tienen directamente ciertas cualidades intrínsecas.” (1948, p. 323. LW.1.297), al tiempo que señala el rasgo cambiante de los valores, debido tanto a las contingencias de la naturaleza como a los cambios del propio organismo. ${ }^{24}$ De esta manera, el carácter efímero de los bienes directamente poseídos implica la necesidad de asegurar su obtención y apropiación duradera, movimiento que supone el paso de una primera experiencia sorda e informe de la cosa como un bien, es decir, de la estimación misma, a subsiguientes percepciones del bien informadas por el juicio crítico. De acuerdo con Fesmire, el carácter incierto y contingente del mundo, y con él de los valores en cuanto bienes, hace que todo sistema teórico que pretenda asentar de una vez y para siempre los límites y condiciones de la moral está condenado de antemano al fracaso (2003, p. 58). Así las cosas, la metafísica como "mapa catastral", esto es como observación, registro y definición de los rasgos genéricos de la existencia aparece como tarea preparatoria para una teoría del valor o, al decir de Philström (2011, p. 100), como una empresa profundamente valorativa, pues (i) permite ver que la inestabilidad de la naturaleza es la fuente de la inestabilidad de los valores; y (ii) se constituye como el único medio de apreciar en forma regulativa los valores, de darles origen y consolidarlos en virtud de una acción libre, dirigida, inteligente y responsable. En este marco, las palabras de Dewey en La Reconstrucción de la Filosofía resumen lo dicho y adelantan el rumbo de los próximos capítulos:

La moral [o cualquier otro conjunto de valores, me permito agregar] no es un catálogo de actos ni un conjunto de reglas que es preciso aplicar como recetas de farmacia o de libro de cocina. Lo que en la

\footnotetext{
24 "Pero ya una corta carrera de la experiencia refuerza la reflexión; no requiere sino breve tiempo el aprender que algunas cosas dulces al pronto son amargas poco más tarde y por sus consecuencias. La primitiva inocencia no dura. [...] Pero los valores son tan inestables como las formas de las nubes." (Dewey, 1948, p. 324-325. LW.1.298).
} 
moral se necesitan son métodos específicos de investigación e invención: métodos de investigación para localizar las dificultades y los males; métodos de invención para trazar los planes de los que nos serviremos como hipótesis de trabajo para afrontarlos. (1993, p. 180. MW.12.177).

\section{Conclusiones}

En el presente capítulo he avanzado sobre la concepción deweyana de experiencia en la medida en que esta última es para Dewey tanto el punto de partida como el punto de llegada de toda reflexión filosófica. A modo de primera aproximación he recuperado la definición de experiencia como una conexión orgánica de hacer y padecer entre organismo y ambiente, definición que ha permitido identificar algunos rasgos estructurales de la propuesta de Dewey, a saber: (i) el carácter vital de la experiencia, (ii) su interpretación en términos de transacción, (iii) las diferencias con las concepciones tradicionales de experiencia, (iv) la distinción entre experiencias primarias y secundarias, y (v) el carácter de consumación de las experiencias genuinas. Estos aspectos permiten afirmar que la teoría de la experiencia elaborada por Dewey es ciertamente novedosa.

Asimismo, me he detenido a analizar algunos elementos que estimo relevantes en función de la especificidad del tema de la presente investigación. En primer lugar, he señalado la influencia del darwinismo en la visión deweyana, influencia que se juega fundamentalmente en una reconfiguración de las aspiraciones de la propia filosofía en la medida en que ésta ya no se remite a verdades eternas, inmutables y trascendentes sino que debe concentrarse en el curso de experiencia concreta y constituirse como diagnosis y prognosis política y moral. En segundo lugar, he identificado los distintos modos en que Dewey comprende el principio de continuidad de la experiencia, enfatizando su idea de que la experiencia presente afecta la cualidad de las experiencias futuras o subsiguientes -sea enriqueciéndolas o empobreciéndolas, lo cual abre las puertas a considerar el rol del agente moral mismo. En tercer lugar, he abordado el aspecto de inmediatez cualitativa de la experiencia junto con las concomitantes nociones de situación y contexto, con el objetivo de señalar algunos rasgos teóricos básicos para posteriormente dar cuenta de las particularidades de la situación moral y evaluar el rol del contexto y de los intereses 
selectivos en el propio proceso de valoración. Finalmente, he presentado dos argumentos por los cuales la concepción deweyana de experiencia implica necesariamente la valoración. Así, por un lado, he señalado que la interpretación transaccional implica la imposibilidad de distinguir claramente entre contenido y actitud o entre material y valoración, de modo que todo material cae bajo proceso de valoración. Por otro lado, he identificado los rasgos centrales de la metafísica naturalista deweyana para señalar por qué vivir en un mundo signado por el azar, la contingencia y el riesgo implica la necesidad de asegurar los bienes y dirigir inteligentemente la acción, es decir, de valorar.

A partir de estas observaciones queda planteado el siguiente cuadro: dado el proceso de naturalización de los viejos respaldos metafísicos, la reflexión filosófica sobre los valores debe tomar un camino distinto al de las filosofías clásicas. Teniendo en cuenta lo señalado al momento, entiendo que la indagación filosófica debe, por un lado, inscribir y dar cuenta de la génesis de los valores en el curso de experiencia; por el otro, ofrecer una pauta general para la correcta formación de valores, dando cuenta en ambas tareas de sus líneas de continuidad con la experiencia primaria. En los siguientes capítulos, bajo sendas denominaciones de "perspectiva filosófica" y "perspectiva metodológica", abordaré este doble carácter de la tarea reflexiva sobre los valores. 


\section{CAPÍTULO 2: LA PERSPECTIVA FILOSÓFICA}

\section{Introducción}

En las últimas líneas del capítulo 1 he intentado señalar que, asumida la tesis naturalista, la reflexión filosófica debe inscribir a los valores en el continuo de la experiencia, dando cuenta de su génesis mediante un nuevo tipo de explicación. Ahora bien, la idea misma de génesis adopta, en mi lectura, dos sentidos distintos aunque ciertamente solidarios. Por un lado, habría que dar cuenta de la génesis cualitativa de los valores, vale decir, la continuidad entre la experiencia primaria, transactiva, apreciativa y los valores en cuanto resultado de un proceso de valoración. Por otro lado, habría que abordar la genealogía de los valores, esto es, el estudio de las condiciones históricas que explican nuestros valores efectivos, aquello que de hecho valoramos. En este capítulo me detendré en ambos aspectos, constitutivos de lo que propongo denominar la perspectiva filosófica respecto del asunto de los valores. Así, en la segunda sección me abocaré a analizar el diagnóstico que hace Dewey del tratamiento brindado por la historia de la filosofía a las cuestiones morales. En la tercera sección del capítulo abordaré en detalle el proceso de génesis de los valores, enfatizando su carácter cualitativo. En ese marco presentaré e intentaré dar respuesta a la crítica planteada por Eames según la cual Dewey no logra explicar las dos "junturas" que supone su posición -desde la experiencia primaria a la reflexiva y desde esta última a la experiencia primaria. Recuperar esta discusión permitirá, espero, enfatizar la idea central de este capítulo: que los valores en tanto resultado de la reflexión emergen de y se incorporan al curso de las transacciones entre el ser humano y su ambiente sin romper la mentada continuidad. Seguidamente, examinaré la perspectiva genealógica elaborada por Dewey en sus escritos de principios de siglo XX e intentaré señalar por qué su método genealógico no es una mera reconstrucción de condiciones históricas de las estimaciones sino un elemento de crítica prospectiva, toda vez que ofrece un principio de validez a las estimaciones de hecho. Finalmente me concentraré en la distinción entre moralidad habitual y moralidad reflexiva a fin de explicitar la continuidad propia del tránsito desde la experiencia primaria a la ética. 
Como puede advertirse, estas primeras observaciones suponen ya una cuestión central que iré desarrollando a lo largo del presente capítulo e incluso del siguiente: la diferencia entre estimación efectiva, de hecho, y valoración como resultado de un proceso deliberativo, reflexivo. La frecuente confusión entre ambos significados, señalada por el mismo Dewey en reiteradas oportunidades como uno de los problemas más acuciantes en la discusión respecto de los valores (Cf. MW.8.25, LW.7.262-65, LW.13.194-6, entre otros), tiene su raíz en la polisemia del término inglés "value", susceptible de ser utilizado como un sustantivo (valor) o como un verbo (valorar), y en particular en el doble sentido que admite este último uso, en cuanto "apreciar", "estimar" o disfrutar algo de modo inmediato, directo, sin reflexión mediante [prizing] o en cuanto "evaluar", "valorar", establecer un valor por vías de algún tipo de reflexión o ponderación que conduce a juicios prácticovalorativos [appraising]. Por mor de la claridad, reservaré el término apreciar para el “tener" cualitativo inmediato, estimar para aquellos casos en que se asume un valor por hábito, esto es, cuando no hay reflexión en el caso presente pero la hubo con anterioridad sentido que, según se indicará sobre el final del capítulo, tiene estrecha relación con lo que Dewey denomina moralidad habitual-, evaluar para el estudio de las relaciones entre cosas en términos de condiciones y consecuencias, y valorar para el proceso de evaluación de valores -vinculado a la moralidad reflexiva.

De aquí se sigue también otra diferencia de suma importancia, aquella entre valued y valuable, que en función de lo dicho podría leerse respectivamente como estimado y valioso, siendo este último un adjetivo adscripto a un objeto, situación, acción, etc. como resultado de un proceso de valoración. Lo importante es que estas categorías no mantienen una relación fija con aquello a lo que se les aplican sino que un objeto, situación, etc. puede ser estimado y tras ser valorado puede ser considerado no-valioso, o a la inversa -elemento que ya anticipa el rechazo deweyano a aceptar la idea de valores en sí mismos. Por supuesto, la distinción entre apreciaciones directas y valoraciones no implica una separación neta entre dos dimensiones independientes de la experiencia aunque sí da cuenta de la diferencia entre una decisión tomada sobre la base de la arbitrariedad o las meras costumbres y una decisión tomada a partir de una evaluación inteligente en términos de medios, fines y resultados. Dicho en pocas palabras, la diferencia central es la que existe entre apreciar algo como bueno o valorado y considerar si efectivamente es bueno y 
valioso, lo cual supone un punto clave: "[1]a función y el rango propio de algo que cumple con condiciones es diferente de la mera existencia." (Dewey, 1952, p. 227. LW.4.208). Las siguientes páginas se encuadran en estas distinciones iniciales e intentan aclararlas por vías de la explicitación y el desarrollo de los conceptos a ellas asociados, a fines de avanzar en la caracterización de la postura deweyana respecto del asunto de los valores.

\section{El diagnóstico de la filosofía moral}

Así como la idea de experiencia acuñada por Dewey puede comprenderse cabalmente si es comparada con las diferentes versiones elaboradas en la Modernidad, también su propuesta en el plano de la filosofía moral debe ser presentada haciendo referencia a la recapitulación histórica elaborada por el pragmatista. La interpretación de Dewey acerca de la modernidad resulta, en términos generales, ambivalente. Por un lado, en La reconstrucción de la filosofía subraya el valor del factor científico para la aparición de una nueva concepción de filosofía, en la medida en que aquél intenta llevar el interés por lo eterno y universal hacia las realidades mudables y concretas, al tiempo que remarca el carácter hipotético y falible del "nuevo" conocimiento experimental. Asimismo, el hecho de desterrar la teleología del ámbito de la naturaleza abre lugar a los designios deliberados de los hombres, quienes ahora pueden modificarla en función de sus propios intereses. En este sentido, Dewey identifica a Francis Bacon como "profeta del concepto pragmatista de saber" pues vincula método experimental de descubrimiento con control y progreso continuamente renovado, otorgando a la vez una notoria importancia al factor social en la búsqueda y finalidad de la investigación (Dewey, 1993, p. 71. MW.12.100).

Por otro lado, y más allá de esta elogiosa referencia a Bacon, en La búsqueda de la certeza Dewey observa que la filosofía moderna se construye sobre una "división intestina" producto del colapso entre los referidos avances de la revolución científico-experimental y la estructura conceptual heredada de la filosofía griega sobre la naturaleza del conocimiento

y de los valores. Tal estructura implica (i) que sólo en lo fijo e inmutable puede encontrarse certeza y seguridad; (ii) que el conocimiento teórico/contemplativo es único camino para llegar a lo intrínsecamente cierto; y (iii) que la actividad práctica es de tipo inferior y produce un conocimiento de "menor calidad". Asimismo, si bien la modernidad rechaza la 
concepción griega por la cual los objetos naturales y los valores son cognoscibles en la medida en que sus cambios están respaldados por esencias inmutables y perfectas, hereda por vía de la religión hebrea y cristiana la idea de que esas realidades que conforman el objeto de conocimiento por excelencia contienen a la vez los valores que corresponden a nuestras más altas aspiraciones y admiraciones, como la Verdad, el Bien y la Belleza. De este modo, "[1]as cualidades, excelencias y fines, desterrados de la naturaleza por la ciencia nueva, encontraron su sede y garantía exclusiva en el reino de lo espiritual, que estaba por encima de la naturaleza y era, sin embargo, su fuente y fundamento. [...] La tensión creada por la oposición y, sin embargo, conexión necesaria de naturaleza y espíritu, dio origen a todos los problemas de la filosofía moderna." (Dewey, 1952, p. 47. LW.4.43). En estas condiciones, el problema es claro: ¿cómo es posible aceptar el modelo experimental de la ciencia y conservar, a la vez, el reino inmutable de los valores? La filosofía moderna se dio la tarea de conciliar ambos componentes en tensión, so pena de relegar a la actividad práctica a un plano de escaso grado de realidad y certeza.

Desde la perspectiva de Dewey, la Ética de Spinoza es el más acabado esfuerzo por conciliar esos dos aspectos contradictorios, en tanto incluye un Ser último y autosuficiente como pauta de todo pensamiento o acción del hombre (tradición hebrea) junto con la exaltación del conocimiento teórico por sobre cualquier modalidad práctica (tradición griega), todo ello bajo el more geométrico (nueva ciencia). Ahora bien, a medida que el método experimental desplaza al more geométrico, los modos de conciliar esos aspectos contradictorios también se modifican. Kant, por ejemplo, opta por "dividir el territorio" para garantizar que no se generen conflictos entre el dominio de la ciencia y el de la moral. Así, con la pretensión de brindar una justificación filosófica a la ciencia newtoniana, Kant logra el anhelo de certeza cognoscitiva correspondiente al plano fenoménico; por otro lado, y con la autoridad categórica de la noción de deber, se asegura que ningún material concreto y empírico afecte las realidades morales últimas, justificadas por medios puramente racionales. En consecuencia, si no es la Revelación la que marca el criterio, lo será una Razón que también aparece por arriba de la experiencia. Finalmente, el idealismo post-kantiano (Fichte y Hegel) busca reintegrar aquello que Kant había separado. Más allá de las particularidades de cada uno de los planteos, Dewey resalta que ese idealismo procura resolver el problema básico de la filosofía moderna afirmando que, con 
independencia de las conclusiones puntuales que obtenga la ciencia experimental, la autoridad ideal de la verdad y del curso de la historia radica en un Ser último que poca atención presta a la experiencia y acciones humanas (Cf. Dewey, 1952, p. 51-6. MW.4.50).

Esta interpretación se apoya según Dewey en una asunción fatal, a saber, adscribir el carácter teórico tanto a la actitud del investigador como al objeto de estudio. Así se refuerza la exclusión del componente práctico del conocimiento y se elimina toda consideración intelectual por los valores que puedan guiar nuestra conducta efectiva e introducir modificaciones concretas en el curso de la experiencia. La filosofía contemporánea, entendiendo por ella al positivismo de la época, tampoco tiene mucho para aportar en esta empresa pues la alternativa de limitar las proposiciones con sentido a aquellas lógicamente posibles parece satisfacer la exigencia de certeza cognoscitiva -por vías de una rigurosa austeridad- pero tiene como consecuencia eliminar de la órbita de la filosofía los temas de moral, política o arte, vinculando a los valores con los sentimientos e impulsos humanos de modo tal que no puedan ser objeto de ninguna clase de conocimiento. ${ }^{25}$ La consecuencia más clara de la adhesión a los principios gnoseológicos clásicos es el apartamiento de la filosofía de los problemas de la vida contemporánea, de la cultura en la que de hecho viven los filósofos. Más aún, conlleva una confusión intelectual respecto de los criterios para establecer juicios y conclusiones respecto de las cosas de máxima importancia vital: cómo explicar el surgimiento de los valores y qué hacer para que los objetos valiosos sean más seguros en la existencia.

\section{La génesis de los valores}

Dewey busca responder a esta cuestión mediante otro camino distinto al de la filosofía moderna, marcado por la ya referida influencia del darwinismo en la filosofía. El vínculo entre darwinismo, valoración y ética capturó la atención de Dewey durante toda su carrera: ya en 1884 publica un ensayo titulado "Ethics and Physical Sciences" (EW.1) en el cual distingue entre una "ética teológica" y una "ética científica" en función de la aceptación o rechazo de los desarrollos científicos, particularmente de la teoría de la

\footnotetext{
${ }^{25}$ Recuperaré la discusión de Dewey con el positivismo y el emotivismo ético de Alfred Ayer y Charles Stevenson en el próximo capítulo, al momento de considerar el contexto de discusión y el contenido teórico de Teoría de la Valoración.
} 
evolución. Desde su perspectiva, la teoría de la evolución ha dejado en claro que los seres humanos no son genéricamente distintos de la naturaleza de modo que la ética en cuanto disciplina encargada de estudiar -al menos en parte- sus acciones, no debería ser diferente a las demás ciencias, al menos en cuanto a sus métodos y concepciones. Más aún, al adoptar esta perspectiva la ética deviene libre de asunciones teológicas o metafísicas (Cf. EW.1.210). Asimismo, en 1898 Dewey publica "Evolution and Ethics" (EW.5), texto en el que discute la posición de Thomas Huxley según la cual no pueden derivarse deberes morales a partir de hechos, tal como indica la versión clásica de la falacia naturalista. En opinión de Dewey, no se debería oponer el proceso natural al proceso ético ni se debería considerar que no hacerlo implica cometer la falacia naturalista pues no se derivan deberes morales a partir de meros hechos sino con la mediación de la deliberación en cuanto resultado del mismo proceso evolutivo (EW.5.53). ${ }^{26}$

Como queda claro, la impronta naturalista informa notablemente la perspectiva deweyana sobre los valores y sobre la ética como disciplina filosófica. Respecto de este mismo tema, en el ya citado y seguramente más reconocido "La influencia del darwinismo en la filosofía" Dewey afirma que "[1]a filosofía renuncia a inquirir por los orígenes absolutos y las finalidades absolutas para así poder explorar valores específicos y las condiciones específicas particulares” (Dewey, 2000, p. 56. MW.4.10). En estas pocas palabras Dewey plantea un enorme desafío a toda la tradición filosófica y reclama un cambio radical en su perspectiva, sentando las bases de lo que posteriormente será denominado ética pragmatista evolucionaria (Fletcher, 2011), moral naturalizada (Popp, 2010) o, como señala Jennifer Welchman sin ahorrar elogios, "la más original y sistemática teoría moral naturalista” del Siglo XX (1995, p. 4). Estas observaciones iniciales ofrecen el marco para la explicación de la génesis de los valores, explicación que según interpreto debe incluir el vínculo entre inmediatez cualitativa de la experiencia y valoración, por un

\footnotetext{
${ }^{26}$ En 1893 Huxley dicta sus Romanes Lectures, luego publicadas bajo el título "Evolution and Ethics" mismo título que empleará Dewey para su ensayo referido. Allí Huxley discute explícitamente con el darwinismo social de Spencer, lo cual permite entender su estrategia de distinguir el plano natural evolutivo del plano moral en función de evitar las interpretaciones reaccionarias a las que dio lugar el enfoque de Spencer. Sobre el texto de Huxley y el intercambio con Dewey, Cf. Teehan (2002). Respecto del pensamiento ético temprano de Dewey, Welchman propone una periodización entre (i) idealismo ético temprano, 18841894; (ii) período de transición, 1894-1903; y (iii) ciencia ética pragmática, 1908-1922, bajo la hipótesis de que, aún con cambios y reconsideraciones, las elaboraciones posteriores de Dewey sobre ética mantuvieron las bases presentadas en Naturaleza Humana y Conducta (Welchman, 1995).
} 
lado, y el método genealógico deweyano, por el otro. A continuación, avanzaré con la primera de las tareas.

\subsection{La génesis en cuanto continuidad cualitativa}

\subsubsection{Inmediatez cualitativa y apreciación}

Para comenzar, vale aclarar que el sentido de génesis aquí propuesto no es el único que admite el marco teórico deweyano. Hans Joas, por ejemplo, se concentra en dar cuenta de la fenomenología de las experiencias valorativas, especialmente en aquellos casos de reorientación profunda de valores - casos para los que reserva la expresión "génesis de los valores" (Joas, 2000, Capítulo 7). En su lectura, estas reorientaciones emergen o son producto de experiencias de auto-transformación y auto-trascendencia en el marco de la fase religiosa de la experiencia, según la presenta Dewey en Una fe común (2005 [1934]. LW.9). Si bien en principio no parecería haber contradicciones entre el análisis propuesto por Joas y el que ofrezco aquí, sí hay una diferencia en cómo se comprende la idea misma de génesis, sea como aparición novedosa, disruptiva e incluso radical, en el caso de Joas, o como la referida identificación de continuidad entre el nivel primario y reflexivo de la experiencia, en mi propuesta. ${ }^{27}$

A fines analíticos parece fructífero distinguir dos "momentos" en el marco de la referida continuidad: la relación entre el carácter apreciativo de la experiencia y el goce directo o apreciación, por un lado, y la relación entre lo apreciado y lo valioso, por el otro. Respecto del primer momento vale recordar que la inmediatez cualitativa, en cuanto apreciada o tenida, es una característica central de la concepción deweyana de experiencia. Dicho de otra manera, la relación transactiva entre organismo y ambiente puede comprenderse en términos de gusto o disgusto, aceptación o rechazo de la situación que los incluye. Esta aceptación o rechazo es expresión de deseos, preferencias e intereses de primer orden orientado a objetos o acciones que se aprecian, en principio, como un bien directo. Más aún, y en clara referencia al carácter naturalista de su propuesta, Dewey

\footnotetext{
${ }^{27}$ La posición de Joas respecto de este asunto cobra mayor sentido si se tiene en cuenta la rica y compleja interpretación previamente presentada por el autor en relación al pragmatismo en general y al pragmatismo deweyano en particular como una teoría de la acción creativa, anclada en la idea de reconstrucción inteligente de la experiencia (Joas, 1996, Capítulo 2.5).
} 
considera que directa o indirectamente todos los deseos se apoyan en carencias, apetitos y necesidades orgánicas tales como la alimentación o la protección, que no emergen de la reflexión sino que la anteceden (Cf. MW.5.307). En consecuencia, parecería haber una vinculación inicial entre los deseos como expresión de funciones orgánicas primarias y la apreciación en términos de aceptación o rechazo de una situación particular caracterizada por su cualidad permeante específica -en principio, según permitan o no satisfacer las referidas funciones orgánicas. En palabras de Dewey, "[1]lamar a una cosa buena o mala es establecer el hecho [...] de que efectivamente estuvo envuelta en una situación de aceptación o rechazo orgánico, cuales fueran las cualidades que específicamente caractericen al acto." (MW.8.26). En este sentido, y más allá de las diferencias señaladas anteriormente, la siguiente observación de Joas parece muy acertada: "En orden a entender qué son los valores, debemos comenzar desde el comportamiento orgánico mismo." (2000, p. 106). La referencia a los procesos vitales y la subsiguiente cualificación de la aceptación o rechazo como los procesos básicos que mantienen el desarrollo de la vida son, por tanto, datos observacionales a partir de los que se debe avanzar para evitar el riesgo del reduccionismo. Tal y como afirma Dewey en "The Field of 'Value", uno de sus últimos textos, "[1]os procesos de la vida tienen un aspecto físico, y ninguna consideración sobre ellos será adecuada si no se apoya en el conocimiento físico disponible. Pero este es un asunto radicalmente distinto de la reducción a términos físicos.” (LW.16.344). ${ }^{28}$

Desde las consideraciones precedentes puede comprenderse por qué Dewey se refiere a "lo intrínseco o natural de la cualidad valiosa [value-quality]" en estrecha relación con las apreciaciones inmediatas (1948, p. 232. LW.1.297). En este sentido Eames sugiere que la primera descripción de valor en el sentido de apreciación debe ser encontrada en la inmediatez cualitativa de la experiencia (2003, p. 43). Este carácter de apreciación es tal que según Dewey no puede haber teoría acerca de las cualidades pues éstas se tienen y se gozan de manera directa, al tiempo que solamente pueden ser señaladas o denotadas (1948, p. 328. LW.1.301). Ahora bien, teniendo en cuenta las observaciones deweyanas respecto

\footnotetext{
${ }^{28}$ En este mismo artículo Dewey indica que la primera modificación cualitativa de los procesos de aceptación o rechazo se da en el propio mundo animal con la actitud del cuidado [caring-for]. Esa actitud se especifica y diferencia enormemente en el caso de los seres humanos dada su capacidad para anticipar resultados y obrar en base a esa anticipación. No obstante, y más allá de las complejidades que adquiere la experiencia de valoración, me interesa destacar que el propio Dewey traza la línea entre función orgánica, actitud animal y comportamiento humano, en sintonía con su naturalismo no reduccionista (LW.16.346-348).
} 
de la sensibilidad cualitativa diferencial en términos de trasfondo temporal y espacial, intereses selectivos, hábitos de estima y tradiciones intelectuales dadas por el contexto, huelga decir que estas apreciaciones cualitativas, inmediatas e irreflexivas no tienen que ser confundidas con algún tipo de intuición "pura" o captaciones similares sino que siempre son situadas y relativas a su contexto particular -aun cuando el propio Dewey llega a referirse a ellas como intuiciones, aunque con todas las aclaraciones precedentes (1965b, p. 150. LW.7.266). En suma, las apreciaciones directas son resultado del carácter cualitativo y apreciativo de la experiencia, al tiempo que están relativamente al margen tanto de cualquier reflexión acerca de las condiciones que los generan y las consecuencias que de ellas se siguen. Luego, la génesis de las apreciaciones es cualitativa en cuanto está enraizada en la igualmente cualitativa experiencia primaria.

\subsubsection{La especificidad de la situación moral}

Una vez señalado el vínculo entre inmediatez cualitativa y apreciación -el primer momento de la génesis- es tiempo de avanzar en el argumento para dar cuenta de otro vínculo crucial, aquél entre apreciación y valor -el segundo momento. En este sentido, hay un pasaje en "Teoría de la Vida Moral" (Parte 2 del libro Ética escrito por Dewey y Tufts en 1908 y reeditado con considerables modificaciones en 1932) que no sólo da cuenta de la distinción entre el primer y el segundo momento del proceso de génesis de los valores sino que también permite comenzar a considerar el tránsito desde las apreciaciones hacia las valoraciones. Así, escribe Dewey, "[a]l principio, nuestras afecciones van hacia algo con atracción o repulsión, nos agrada o desagrada. Luego, la experiencia plantea la cuestión de si el objeto que se trata es lo que nuestra estima o desestima [apreciación, por utilizar los términos en el sentido propuesto] ha considerado, de si es tal que justifique nuestra reacción hacia él." (1965b, p. 148. LW.7.264. Traducción levemente modificada).

Respecto de la primera afirmación de la cita es importante señalar no sólo la explicitación de la apreciación "inicial" en términos de aceptación o rechazo sino también la incorporación de la noción de afectividad en cuanto aspecto inescindible de la relación transactiva que supone la experiencia. En efecto, parece que ya en el nivel primario, directo e irreflexivo de la experiencia, en el que se anclan las apreciaciones, hay una relación 
afectiva entre organismo y ambiente. La segunda afirmación introduce un nuevo elemento: en determinadas situaciones aparece la pregunta por el carácter efectivamente valioso de aquello apreciado. ${ }^{29}$

Resulta interesante complementar estas observaciones con la lectura de algunos pasajes de Experiencia y Naturaleza como el siguiente, explicando cómo el goce inmediato deja de ser un dato y se vuelve un problema y cómo, a su tiempo, “[...] la subsiguiente percepción del bien encierra por lo menos un germen de reflexión crítica" (Dewey, 1948, p. 324 y 326. LW.1.298 y 300, respectivamente). En efecto, aquí habría otro modo de explicitar el paso desde las apreciaciones hacia las valoraciones, desde el disfrute directo a la reflexión, por vías de la crítica entendida en términos de indagación de las condiciones causales de producción y consecuencias del objeto en cuestión. Más aún, Dewey indica que la crítica desenvuelve algún aspecto reflexivo implícito en la apreciación misma de tal forma que ensancha y ahonda aquellos factores de inteligencia inherentes al gusto y goce directos de la experiencia primaria. ${ }^{30}$ En este sentido, la experiencia misma se constituye como una sucesión de apreciaciones y críticas, que no presentan diferencias de naturaleza sino sólo de grado o intensidad.

29 Dewey reconoce explícitamente el valor de las teorías utilitaristas clásicas de Jeremy Bentham y especialmente de John Stuart Mill en la medida en que se orientan a una posición ética naturalista. No obstante, según Dewey el utilitarismo presenta dos grandes problemas. Por un lado, tanto Bentham como Mill tienen dificultades para articular preferencias individuales y felicidad general. Por otro lado, y aquí radica el cuestionamiento más profundo, ambos toman a la felicidad (en términos de placer y dolor) como determinante directo de las acciones (Bentham) o como una razón de peso, sumada a la tesis de la maximización de felicidad o minimización de su contrario, de las acciones (Mill), de modo que no llegan a dar cuenta de la complejidad de las situaciones morales ni conciben la instancia de deliberación para resolver dichas situaciones. Parecería entonces que el utilitarismo clásico plantea el problema en el terreno correcto pero no logra desenvolver su posición de forma adecuada. En consecuencia, no solo fracasa al momento de dar cuenta del modo en que podrían elaborarse deseos inteligentes sino que consagran las condiciones de la experiencia social actual, siendo así una filosofía estructuralmente conservadora (Cf. Dewey, 1965b, p. 112-124. LW.7.237-245 y 1952, p. 249. LW.4.227). Welchman propone una muy interesante recuperación de las críticas de Dewey al utilitarismo en vistas a describir el tipo de agente moral que supone la posición pragmatista (Cf. 1995, pp. 157-168).

${ }^{30}$ La idea de "germen de reflexión crítica" habilita a preguntarse si, en la experiencia primaria, hay distintos niveles de inmediatez según presenten instancias de diferenciación progresiva. Sobre este punto, Eames argumenta que en el nivel más bajo habría algo como una "sensación indiferenciada" [undifferentiated feeling] de la cual emerge la inmediatez cualitativa. En un segundo nivel podrían identificarse las "conexiones entre las cosas" [existential involvement Dewey, 1950, p. 71. LW.12.61]. Allí, finalmente, parece ubicarse el "germen de la reflexión crítica", en la medida en que emerge la función de las cualidades como signos en el proceso de significación, dando lugar a la inferencia y a la función evidencial. La pregunta es, entonces, cuánto de este último nivel de principio de reflexión puede ser tomado como experiencia primaria y si la experiencia de sentido común, en tanto primaria, es aquella que contiene ese principio de reflexión (Cf. Eames, 2003, p. 36). 
Ambos modos de introducir la cuestión de si lo apreciado es valioso suponen algún tipo de insatisfacción, tensión, problema. Recuperando aquí la interpretación de la situación como unidad de experiencia caracterizada e individualizada por una cualidad permeante pero, a la vez, inscripta en un curso continuo de experiencia, parece que una tarea fundamental es definir qué se entiende por situación de valoración, es decir, por el tipo de situación que requiere o conduce a un trabajo reflexivo de valoración.

Propongo comenzar el análisis mediante un primer acercamiento a lo que Dewey denomina juicios prácticos, un tipo de juicio en el que se inscriben los juicios de valor. $\mathrm{Si}$ bien abordaré de cerca la pauta de este tipo de juicios en los próximos capítulos, echar un vistazo al planteo de Dewey permitirá abstraer las características centrales de la situación de valoración. En "The Logic of Judgments of Practice" (1915. MW.8) Dewey señala que un juicio práctico tiene lugar frente a una situación incompleta. Además, el juicio práctico es él mismo un factor en el proceso de compleción [completion] de la situación e intenta ser un factor diferencial en el modo en que se completa esa situación, es decir, en asegurar que ese proceso arroje mejores resultados que otros alternativos. De este modo un juicio práctico es una resolución respecto de qué es conveniente o mejor hacer. En consecuencia, el tipo de situación que da lugar a un juicio práctico es una situación cuya característica central es la de demandar acción [demanding action] (MW.8.14). En línea con lo planteado anteriormente respecto del locus de las situaciones, ese carácter incompleto no radica ni en el ambiente u objeto ni en el sujeto sino en la propia situación transaccional. En efecto, la situación de valoración es ante todo práctica y problemática, en la medida en que toda valoración tiene que ver con la determinación de un curso de acción (MW.8.33).

Ahora bien, si el juicio valorativo es un tipo de juicio práctico, a su vez el juicio moral es un tipo de juicio valorativo, determinado por las cualidades de la situación particular que lo reclama, es decir, por la situación moral. En la edición de 1908 de "Teoría de la Vida Moral" Dewey dedica un parágrafo completo a determinar las "marcas definitorias" de la situación moral -parágrafo que no aparecerá en la edición de 1932. En sus palabras, una situación moral es "[...] una situación en la que se presentan y se emplean consideraciones acerca de lo bueno y lo malo, lo correcto y lo incorrecto.” (MW.5.185). Este tipo de situaciones surgen cuando interviene lo que Dewey llama factor moral, cuando 
el valor de un fin o una acción propuestos resulta incompatible con otro fin que apela a un modo distinto de disposición y agencia. En una situación moral, los fines son tan heterogéneos y discrepantes que se debe tomar una decisión acerca de qué es lo valioso. En este sentido, una situación moral es aquella que demanda al agente una decisión sobre qué hacer frente a los factores morales en conflicto. En consecuencia, es una situación eminentemente práctica porque su sentido no es evidente por sí mismo sino que reclama una búsqueda, una investigación, una decisión y una acción por parte del agente -e implica, además, el carácter que quiere asumir el agente, el tipo de persona que quiere ser.

Teniendo en cuenta que en la versión de 1908 de "Teoría de la Vida Moral" Dewey observa que la marca cualitativa de las situaciones morales es precisamente el conflicto de factores morales, el ensayo "Three Independent Factors in Moral” de 1930 también parece una pieza de suma relevancia para detallar la perspectiva del pragmatista respecto de este asunto (LW.5). Además, tener en cuenta este tipo de ensayos de Dewey permite comprender que sus reflexiones en el campo de la ética no se reducen al plano de la teoría de la valoración, esto es, al análisis de la lógica de los juicios de valor, sino que involucra otra serie de elementos de suma importancia. En este sentido, Pappas considera que una mirada a la posición deweyana sobre la ética que no contemple este ensayo en cuanto muestra clara del carácter situacional y pluralista de la perspectiva deweyana es, sin más, una mirada equivocada (Pappas, 2008, p. 111).

El planteo inicial de Dewey es tan claro como crítico respecto de la tradición pues en su opinión la filosofía no ha prestado suficiente atención a un elemento central, a saber, el elemento de incertidumbre y conflicto en toda situación que pueda llamarse propiamente moral. La actitud convencional identifica solamente conflicto entre bien y mal, conflicto en el que sencillamente no hay ningún tipo de incertidumbre pues el agente moral conoce el bien como bien y el mal como mal y elige entre uno u otro de acuerdo al conocimiento que tiene de ellos. Según Dewey, esta versión ideal no da cuenta de lo que efectivamente sucede, a saber, que cuanto más cuidado pone el agente en cuidar la cualidad moral de sus actos, más consciente es de la complejidad del problema de identificar el bien. Más aún, cualesquiera sean las diferencias entre teorías morales, todas proponen un único principio como explicación de la vida moral. Bajo tales condiciones, no es posible tener conflicto o incertidumbre, éstos son meramente aparentes. Las distinciones morales emanan de una 
única fuente y son aportadas de antemano por la teoría; por su parte, el conflicto no está en el agente sino en la naturaleza de las cosas, que ponen al agente en lugar de decidir entre bien o mal, deseo o deber, virtud o vicio.

Bajo estas líneas generales, Dewey identifica tres grandes sistemas de teoría moral: moralidad de los fines, de las leyes y de las virtudes. Para el primer caso, hay un fin único, supremo y universal al cual se reducen distintos fines intermedios; la idea de lo correcto es dependiente y aparece como un medio para lograr el fin o bien supremo. En la moralidad de las leyes es a la inversa, la ley prescribe lo obligatorio y los bienes morales devienen tales en cuanto están de acuerdo con el imperativo. En este marco la hipótesis central de Dewey indica que hay al menos tres factores independientes en la acción moral, cada uno de los cuales tiene un fundamento sólido, y que, debido a su origen y modo de operación diferente, pueden tener objetivos cruzados y ejercer fuerzas divergentes en la formación del juicio. Desde este punto de vista, la incertidumbre y el conflicto son inherentes a la moral pues lo característico de la situación denominada propiamente moral es que el agente ignore el fin y las buenas consecuencias, la recta y justa estrategia y la dirección virtuosa de la conducta. Así, la característica de la situación moral es el conflicto interno e intrínseco: la necesidad de elaborar un juicio y de actuar proviene del hecho de tener que manejar factores sin un denominador común.

El punto que Dewey propone analizar es el del origen y fuente en la experiencia concreta de lo que ha denominado factores o variables independientes. ¿Qué razones hay entonces para aceptar la existencia de estos tres factores? En primer lugar, como ya se ha señalado, Dewey afirma que no se puede negar que los deseos y apetitos son rasgos constantes de la acción humana y que tienen un rol importante a la hora de determinarla. Cuando el deseo opera sin previsión, no hay comparación o juicios de valor. Sin embargo, cuando se prevén las consecuencias de lo que puede resultar a partir del cumplimiento del deseo, la situación se modifica: los impulsos devienen objeto de análisis, se comparan las posibles consecuencias y los juicios resultantes pueden ser sucesivamente examinados y mejorados mediante juicios de situaciones ulteriores.

El análisis del origen y fuente del bien y de lo correcto es presentado por Dewey en términos históricos. En su lectura, los pensadores griegos fueron quienes dieron expresión 
articulada a la primera de las alternativas y dejaron como su legado filosófico-moral permanente la concepción de los fines como el mayor bien de la vida moral. No obstante, más allá de que la herencia griega sea indiscutible, Dewey observa que ella misma no llega a explicar la conducta en su alcance inclusivo; tal es el caso del fracaso para dar cuenta de la ley y de la obligación como bases de las relaciones sociales. Los romanos, por su parte, establecieron otro sentido de la razón y la ley, en virtud del orden social y la estabilidad gubernamental. Así, los deberes y las obligaciones no fueron tomados como medios para fines en sí mismos sino para la adaptación social y la armonía a partir de las expectativas de comportamiento por parte de los otros. Para Dewey es entonces obvio que esta demanda sobre el comportamiento de los demás conforma una variable con origen independiente respecto del principio teleológico racional de fines y bienes. En efecto, que una persona haga un reclamo sobre otra en favor de la satisfacción de algo que desea no implica que el reclamo sea justo; no tiene autoridad moral por sí. Para ser justo debe tener el reconocimiento intelectual y emocional de la comunidad, de modo que lo que es bueno no toma el sentido de aquello a lo que el deseo tiende sino de aquello que es correcto. Con el tiempo, el objeto en cuestión puede, por vía del hábito, devenir objeto de deseo, pero cuando esto sucede, pierde su cualidad de ser correcto y deviene simplemente un bien. En consecuencia, queda claro que hay una diferencia intrínseca tanto en su origen como en su modo de operar, entre los objetos que se presentan como objetos de deseo y consecuentemente como bienes y objetos que son demandas ajenas sobre la conducta.

Empíricamente hay una tercera variable independiente en la moral. Los individuos evalúan la conducta de los demás. Los actos y disposiciones aprobados conforman las virtudes; los desaprobados conforman los vicios. Ambos son para Dewey espontáneos, "instintivos" y no dependen de ningún otro tipo de consideraciones; carecen del carácter racional y calculado de los fines y de la presión social de lo correcto/justo. Éstos pueden operar como imputaciones reflexivas de virtudes y vicios, pero tienen un origen completamente distinto. En consecuencia, en tanto categorías o principios, el bien tiene que ver con la deliberación sobre deseos e intenciones; lo correcto o justo con las demandas que están socialmente autorizadas y respaldadas; y las virtudes con la aprobación generalizada.

Estos comentarios terminan de delinear la especificidad de la situación moral en cuanto tipo de situación cualitativamente única, dada la complejidad de los elementos que 
la componen. En efecto, los problemas morales existen porque tenemos que adaptar entre sí factores provenientes de distintas fuentes que, a primera vista, parecen irreconciliables. Si cada principio fuera separado y supremo, no habría forma de que se sucedieran dificultades e incertidumbres morales. Sin embargo, las distintas variables se cruzan entre sí y lo que está bien desde el punto de vista de un principio está mal desde el punto de vista del otro. Cada conflicto es genuino, agudo, y una de las causas de la ineficacia de las filosofías morales es justamente su intención de elaborar una teoría unitaria y simplificada de la vida moral. El resultado es una distancia entre las realidades entrecruzadas de las prácticas y las formas abstractas de la teoría. Es por ello que dejar de confiar en teorías unitarias sería una ganancia antes que una pérdida, toda vez que retirar la atención de las reglas rígidas conducirá a prestar más atención a los elementos concretos que intervienen en las situaciones morales -situaciones que en todos los casos demandan acción.

La concepción de la situación moral como aquella que reclama una resolución supone también una modificación del modo en que se comprenden los propios fines de la acción. Considerando que los errores ya no son aplicaciones equivocadas de criterios fijos ni pecados que se deben expiar sino indicaciones de lo que se deba revisar y modificar en el marco de las situaciones concretas, se siguen dos conclusiones: por un lado, el agente moral -siempre inscripto en un entramado de relaciones sociales- es quien lleva por sí mismo el desarrollo de normas e ideales, evitando así que la vida moral devenga formalismo o mera repetición y favoreciendo su carácter flexible, dinámico, vital; por otro lado, el carácter siempre cambiante de las situaciones hace que los fines estén continuamente bajo revisión, mejorando la dirección de los cambios a introducir en la cualidad de la experiencia. ${ }^{31}$

\footnotetext{
${ }^{31}$ Vale recordar que para Dewey el sujeto o agente moral no es autoconstitutivo sino que debe pensarse siempre en relación con sus distintos grupos sociales de pertenencia y con la comunidad en la que se inscribe. Según explica en Viejo y nuevo individualismo, "[1]a individualidad firme e integrada es producto de las relaciones sociales definidas y las funciones reconocidas socialmente" (Dewey, 2003, p. 86. LW.5.67). De esta manera, aun cuando en estas páginas el énfasis quede puesto en la deliberación a nivel individual, nunca hay que perder de vista el carácter comunitario de la valoración moral y política -tanto por lo dicho respecto del individuo como porque, según señalaré en el próximo capítulo, uno de los "materiales" de la valoración son las estimaciones habituales, consolidadas colectivamente. Por supuesto, Dewey sabe que las condiciones económicas y políticas de su tiempo, responsables de la consolidación de la "cultura pecuniaria", ejercen fuerzas centrífugas sobre el individuo, que tiende a una homogeneización, despersonalización y apatía política que conforman el carácter perdido del individuo. Este carácter perdido está dado, precisamente, por el modo en que se cortan las relaciones comunitarias y se pierde el núcleo de valores compartidos.
} 
Esta recapitulación sobre la especificidad de la situación moral permite subrayar la importancia del carácter cualitativo de la experiencia para dar cuenta del tránsito del nivel primario de apreciación al nivel reflexivo de deliberación o valoración. Así, en primera instancia una situación es moral debido a su cualidad permeante y definitoria. Ahora bien, el carácter contextual de las situaciones morales (histórico, cultural y de tradición) aporta una particularidad aún mayor a la situación. La intención de esta sección fue, por tanto, dar cuenta de estos aspectos y poner a disposición los elementos necesarios para analizar la propuesta deweyana sobre la deliberación moral.

\subsubsection{La dimensión cualitativa de la deliberación moral}

Teniendo en cuenta tanto las limitaciones de la apreciación inmediata del valor como la complejidad de las situaciones morales y la dinámica procesual de la metafísica deweyana, resulta evidente que en muchísimas oportunidades las estimaciones habituales ya no son suficientes para llevar adelante el curso de acción. Es necesario, por tanto, tomar una determinación y llegar a una elección en cuanto resultado de un proceso reflexivo. Este proceso es presentado por Dewey en "Teoría de la Vida Moral" como deliberación moral o ensayo imaginario de varios cursos de conducta posibles, cuya finalidad es anticipar las consecuencias que se seguirían de cada uno de ellos y optar por alguna alternativa en particular. Una característica fundamental del ensayo imaginario es que permite considerar varias opciones en poco tiempo y que al ser imaginario es renunciable, esto es, no carga con las consecuencias de probar efectivamente cada curso de acción (Cf. Dewey, 1965b, p. 160161. LW.7.274-5). ${ }^{32}$

Ahora bien, para avanzar en el análisis de la deliberación moral en el marco de la pregunta por la génesis de los valores resulta interesante tener en cuenta, a la vez, que la matriz cualitativa de la experiencia no se agota en el carácter ubicuo de las cualidades ni en que algunas de ellas se constituyan como las marcas definitorias de las distintas situaciones, incluyendo a las situaciones morales. En efecto, las cualidades cumplen también una función operativa: “[...] la existencia inmediata de las cualidades, y de una cualidad

\footnotetext{
${ }^{32}$ Para el análisis propuesto me concentraré en el pasaje según aparece en la segunda edición de "Teoría de la Vida Moral". No obstante, vale destacar que la presentación del ensayo imaginario ya puede encontrarse casi sin modificaciones en la edición de 1908 (MW.5.292-3) y también, con ciertos cambios en la presentación pero con un mismo sentido general en Naturaleza Humana y Conducta de 1922 (Dewey, 1964, p. 177-9. LW.14.132-3).
} 
dominante y permeante, es el trasfondo [background], el punto de partida y el principio regulativo de todo pensamiento." (Dewey, LW.5.261). ${ }^{33}$ Esta observación permite, en mi opinión, enriquecer la interpretación de la deliberación moral y complejizar el análisis del segundo "momento" del proceso de génesis de los valores:

(i) con respecto al punto de partida de la deliberación moral, y más allá de que la situación que la origina esté definida por su correspondiente cualidad permeante, Dewey indica que el ensayo imaginario mismo pone en juego "muchas y muy variadas sensaciones y apreciaciones directas" o, como indica en otros pasajes, “selecciones o preferencias espontáneas" (LW.7.275; LW.7.286). En relación a este punto y considerando también que para Dewey cualquier investigación comienza desde un "todo no analizado" [unanalyzed whole] y que las premisas de la misma emergen sólo cuando se ha llegado a alguna conclusión, parecería que la deliberación moral comienza con un juicio "directo y cualitativo" o "inmediato e irreflexivo" acerca de qué hacer, previo a las distinciones de aspectos o elementos particulares, y que esa "impresión inicial” guía todo el proceso subsiguiente (las expresiones entrecomilladas están tomadas de Pappas, 2008, p. 103). ${ }^{34}$

(ii) con respecto al trasfondo, y recordando que la dimensión cualitativa es aquello que permite al agente concentrarse en el problema sin necesidad de explicitarlo constantemente ni de vincularlo con el curso general de la experiencia, Dewey afirma que la deliberación es "activa y dramática" antes que matemática e impersonal justamente por mantener ese lazo con la situación que la origina mediante la dimensión cualitativa de la experiencia. Siguiendo la explicación de Dewey, “[p]ero si esas consecuencias se conciben meramente como remotas, si de su imaginación no surge un presente sentido de paz, de satisfacción o insatisfacción, de incompletitud e irritación, el proceso de prever las

\footnotetext{
${ }^{33}$ Propongo traducir background como "trasfondo" y context como "contexto" considerando que en "Context and Thought" el concepto de "contexto" es más amplio e incluye al background / "trasfondo" junto con el selective interest / "interés selectivo".

${ }^{34}$ Es importante no confundir estas observaciones con las características de los juicios prácticos, aquellos que comienzan con un juicio acerca de que algo debe ser hecho y termina con un juicio acerca de qué hacer. Los comentarios de este punto (i), en cuanto hacen "zoom" en una instancia particular de la deliberación, son ciertamente compatibles con las características generales de los juicios prácticos.
} 
consecuencias sigue siendo puramente intelectual" (Dewey, 1965b, p. 160. LW.7.274. Énfasis agregado). ${ }^{35}$

(iii) con respecto al principio regulativo y especialmente a la finalización del ensayo, Dewey indica que aquello que determina el valor del acto para el agente es algún sentido directo del valor: "[...] cada resultado previsto despierta inmediatamente nuestros afectos presentes, nuestras aficiones y repulsiones, nuestros deseos y aversiones. Hay un "comentario constante" [running commentary] que etiqueta a los objetos inmediatamente [at once] como buenos o malos. Es este sentido directo de valor, y no la conciencia de reglas generales o fines últimos, lo que finalmente determina el valor [worth] del acto para el agente.” (Dewey, 1965b, p. 161. Énfasis agregado, traducción levemente modificada. LW.7.274). De este modo, hay una nueva apreciación, inmediata y cualitativa, que es resultado del ensayo imaginario; justamente en este sentido Dewey reconoce el acierto de las teorías intuicionistas pero inmediatamente señala que esta apreciación resultante no excluye la reflexión sino que se sigue de ella.

En virtud de lo dicho, y como bien indica Joas, las preferencias, las apreciaciones directas y, más profundamente, las respuestas orgánicas son condiciones necesarias pero no suficientes para el sentido reflexivo del valor, esto es, en cuanto valioso (Cf. Joas, 2000, p. 107). En la misma línea, Welchman señala que la apreciación de los posibles cursos de conducta es genuinamente inmediata y que es dicha apreciación, en términos de satisfacción o insatisfacción, la que imprime valor a determinado curso de acción. No obstante, esto no implica que el juicio resultante sea inmediato: "[...] la decisión acerca de qué bienes tienen que ser perseguidos aún debe ser hecha. El 'ensayo imaginario', como lo describe Dewey, no es un método para elaborar juicios morales. El ensayo imaginario es un método para recolectar información necesaria para el juicio moral." (Welchman, 1995, p. 171. Cursivas en el original. Traducción propia). En pocas palabras, la resolución del conflicto moral -o valorativo, en general- implica más que el ensayo imaginario. ${ }^{36}$

\footnotetext{
${ }^{35}$ A diferencia de Rafael Castillo Dibildox, quien traduce "dramatic" por "espectacular", prefiero mantener la idea de "drama" bajo la hipótesis de que la estructura misma de la experiencia es, en cierto punto, dramática (Cf. Colapietro, 2018). Asimismo, la versión en español de Dibildox no incluye la frase que aquí enfatizo.

${ }^{36}$ La reelaboración del ensayo imaginario presentada por Dewey en Naturaleza Humana y conducta introduce una sutil pero importante diferencia porque el juicio moral ya no es tomado como una fase separada de la deliberación sino que ocurre en la deliberación mediante un proceso de unificación o integración de los
} 
Hasta aquí, la función primordial de la deliberación es prever consecuencias particulares, apreciar un curso de acción como bueno, adoptarlo conscientemente por deseo y convertirlo en propósito directivo, eje orientador o fin a la vista de la acción que se considere valiosa. Como se indicará con más detalle en el capítulo siguiente, un fin a la vista brinda unidad y continuidad a la acción; asimismo, se distingue de la mera previsión pues implica una necesidad y un deseo que la impulse, y se distingue también del mero hábito pues implica un elemento o factor intelectual.

Una vez que cierto fin previsto como valioso efectivamente se prueba como tal en el curso de experiencia, y a medida que aparecen elementos y valores comunes en las distintas deliberaciones, estos últimos adquieren paulatinamente un grado de alcance mayor y se presentan como principios, esto es, como generalizaciones empíricas de aquellas formas en que los juicios valorativos y las acciones resultantes han funcionado en la práctica. Los principios se presentan como factores de investigación y previsión, como hipótesis que requieren ser comprobadas y corregidas en/por los acontecimientos. Un aspecto fundamental de los principios es que no dictan cómo actuar en términos prácticos -tal sería, en todo caso, la función de las reglas- sino que son instrumentos intelectuales, puntos de vista para analizar una situación determinada, para juzgar los cursos de acción propuestos sobre la base de la generalización representada por el principio. En suma, los principios señalan consideraciones importantes que no tendrían que pasarse por alto en la deliberación, lineamientos centrales a tener en cuenta al momento de reflexionar sobre un conflicto moral específico sin pretensiones de determinar con anterioridad la resolución del mismo. ${ }^{37}$ Luego, lejos de instituirse como pautas fijas e inflexibles, tendientes a reducir a la vida moral a una mera conformidad legal o formal, los principios en cuanto

factores que constituyen el conflicto moral. Así el modelo es de "decisión en la deliberación". De acuerdo con Caspary, esta idea de unificación es reconceptualizada y ampliada en El Arte como Experiencia en términos de experiencia consumatoria (Cf. Caspary, 2003, sec. 2).

${ }^{37}$ El ejemplo que utiliza Dewey para ilustrar la función de los principios es la "Regla de Oro" (no sin antes aclarar que en este caso no es una regla sino un principio). En efecto, la Regla de Oro orienta las deliberaciones particulares señalando ciertos puntos a considerar: evaluar cómo nuestros actos afectarían los intereses de los demás, evitar consideraciones parciales, evitar la inclinación a exagerar placeres o dolores sólo porque nos afecta, etc. Es claro que estos "consejos" no resuelven por sí solos un conflicto moral con su particularidad e integridad, pero permiten analizarlo bajo una perspectiva determinada -que, como he señalado, no deja de ser una hipótesis a corroborar cada vez. El ejemplo de Dewey permite recordar, además, el carácter comunitario de la moral: los principios son tales en la medida en que sean empleados por la comunidad (Cf. Dewey, 1965b, p. 168. LW.7.280). 
generalizaciones permiten e incluso requieren la libre búsqueda de ideas y fines para dirigir la conducta. Así, "[...] las situaciones en que el cambio y lo inesperado intervienen, son un desafío a la inteligencia para que formule nuevos principios" (Dewey, 1964, p. 220. MW.14.164). Dicho de otro modo, la moral es o debería ser dinámica porque las condiciones sociales, políticas, y la vida misma lo son. En este sentido, el significado primario del carácter específico, contextual y, a fin de cuentas, único de cada situación moral implica transferir la atención de las concepciones generales hacia los actos particulares, localizar allí la responsabilidad y darle paso a la acción inteligente y creativa. En palabras de Dewey,

[s]i el hábito fracasa, la única alternativa para no obrar a capricho y al azar es la reflexión. Y la reflexión acerca de lo que debe hacerse es idéntica a la formación de fines. Más aún, cuando el cambio social es grande y sugiere una gran variedad de objetivos contradictorios, la reflexión no puede limitarse a escoger uno de ellos de entre el conjunto que le sugieren las condiciones. El pensamiento tiene que operar creativamente para formar nuevos fines. (1965b, p. 50. LW.7.185).

Esta lectura del ensayo imaginario y de la formulación de valores y principios permite delinear algunas conclusiones preliminares. En primer lugar, y haciendo referencia a una afirmación de la primera edición de "Teoría de la Vida Moral" según la cual el reconocimiento inmediato de la cualidad del valor y el cálculo indirecto de las consecuencias de una acción son complementarios (MW.5.292), parece que la apreciación directa de algo como valioso y la reflexión se nutren en una relación reciproca, debido a que dado el carácter contextual de todo proceso de pensamiento, cada apreciación se vuelve más cualificada en la medida en que se complejizan las deliberaciones. Las explicaciones ofrecidas en "Valuation and Empirical Knowledge" pueden ser de ayuda en este punto. En efecto, luego de distinguir entre juicios que meramente indican $[$ record $]$ apreciaciones y juicios que buscan establecer el valor de una situación, Dewey afirma que ambos tipos de juicios no pueden separarse taxativamente porque el objetivo del segundo tipo de juicios es (re)establecer [instate] un tipo de apreciación inmediata, propia del primer tipo de juicios. Sin embargo, advierte Dewey, hay una diferencia radical dada por la deliberación que resulta en el segundo tipo de juicios -diferencia que Bernstein, por ejemplo, denomina "el 
eslabón perdido" de la deliberación (2010, pp. 156-7). En palabras del propio Dewey, “[e]1 nuevo valor, dependiente del juicio, es, cuando surge, tan inmediatamente un bien o un mal como puede serlo cualquier otra cosa. Pero también es un valor inmediato con un plus [of a plus sort]. El juicio precedente ha afectado al nuevo valor no meramente en su condición causal sino entrando en su cualidad. El nuevo bien tiene una dimensión de valor agregada." (MW.13.6. Al respecto, Cf. Teehan \& di Carlo, 2004).

Para finalizar la sección me interesa recuperar una observación crítica del ya citado Eames acerca de las "junturas" que supone el recorrido señalado: (i) el pasaje de la inmediatez a la mediación, es decir, la emergencia de la investigación a partir del curso de experiencia primario; y (ii) el pasaje de la mediación a la inmediatez, de lo cognitivo a lo no cognitivo, es decir, cuando la investigación vuelve a la experiencia cualitativa primaria (Eames, 2003, Capítulo 3). Ensayar una respuesta en clave deweyana a esas críticas permitirá acentuar los aspectos centrales de la perspectiva del pragmatista y las afirmaciones principales de estas páginas.

Respecto del primer punto, la pregunta que plantea Eames es, en última instancia, si las apreciaciones son de un tipo diferente al de los valores en tanto resultado de valoraciones. De acuerdo con Eames, a partir de aquí se siguen dos alternativas: o bien los valores son discretos y completamente recortables de su correspondiente deliberación o investigación, de modo que Dewey parece caer en una posición realista, o bien la relación entre lo inmediato y lo mediato es tomada como una cuestión de grado o énfasis, de modo que Dewey queda en una encrucijada entre considerar que todas las apreciaciones y valoraciones son inmediatas, colapsando en alguna forma de subjetivismo (en tanto y en cuanto la apreciación está centrada en el organismo), o considerar que la investigación agota toda la realidad, colapsando en una suerte de idealismo. Para Eames, es posible leer la teoría del valor de Dewey en cualquiera de los dos sentidos, motivo por el cual es una teoría "vaga e incompleta" (Eames, 2003, p. 46). Respecto del segundo punto, la pregunta es si un valor instituido después de una deliberación es intrínsecamente diferente a sus antecedentes en la experiencia primaria, pregunta que sirve de antesala a la cuestión de cómo se relaciona o inserta el valor producto de la deliberación en el curso de experiencia primario. 
Frente a estos cuestionamientos considero que podría ofrecerse otra interpretación del planteo deweyano, anclada en varios de los elementos mencionados al momento. En primer lugar, tanto la acusación realista como la pregunta por la inserción del valor en el curso de experiencia primario pueden responderse apelando a la reiterada indicación deweyana de que la deliberación tiene como objetivo último la resolución de una situación moralmente conflictiva, esto es, que el valor es siempre un plan de acción. Respecto de este punto, en el ya referido "The Field of "Value"” (LW.16) Dewey señala una vez más que el campo de los valores es el comportamiento en referencia a los procesos vitales [lifeprocesses] en términos de selección-rechazo de algún objeto, evento o situación particular, de modo que "[...] no hay una clase peculiar de cosas (mucho menos de 'entidades') a las que se le puedan o deban atribuir la calificación de valor. [...] 'valor' es una palabra adjetival, denominando aquello que es un rasgo, propiedad o calificación de determinada cosa." (LW.16.346). Parece entonces que no hay lugar para que los valores puedan ser tomados como entidades abstractas sino que su ámbito es siempre la acción del individuo en el curso de experiencia -y allí radica, justamente, su inserción.

En segundo lugar, con respecto a los posibles colapsos en posiciones subjetivistas, si bien hay algún tipo de apreciación directa en el proceso de deliberación, tal y como sugiero en el análisis previamente elaborado, esa apreciación es "en situación”, de modo que aún cuando está centrada en el organismo nunca puede ser tomada como subjetivista porque la situación en cuanto tal es la propia transacción-siempre informada por el contexto, que incluye formas de interpretar y valorar socialmente aceptadas- y porque el valor que surge de la deliberación está precisamente respaldado por ese proceso reflexivo. El mismo hecho de ser deliberación "en situación” también permite explicar por qué Dewey no recae en una posición idealista, en tanto y en cuanto la idea misma de situación supone relación transactiva entre individuo y ambiente. Así, la referencia al carácter eminentemente práctico y situacional de la deliberación relativa a valores permite resolver las tensiones señaladas por Eames y enfatizar un rasgo central de la perspectiva aquí desarrollada: el campo de origen y aplicación del valor es siempre la experiencia en su carácter cualitativo y transaccional. Tal y como sugiere Thomas Smith en una de las primeras recepciones de la ética deweyana, “[1]os juicios morales no descubren ningún 
valor por fuera de la experiencia sino que reconstruyen y crean valores en [within] la experiencia” (Smith, 1922, p. 343. Traducción propia).

\subsection{La génesis en cuanto genealogía}

De acuerdo con la interpretación ofrecida y la terminología propuesta, el sentido amplio de génesis de los valores incluye tanto a la continuidad entre las apreciaciones primarias y las valoraciones reflexivas como a la genealogía de los valores entendidos en su carácter de estimaciones habituales, esto es, al estudio de las condiciones históricas que permiten explicar aquello que de hecho valoramos. Una de las presentaciones más claras de esta perspectiva aparece en "The Evolutionary Method as Applied to Morality" (MW.2), ensayo escrito por Dewey en 1902 sobre el que me concentraré a continuación.

La hipótesis principal de Dewey afirma que existe una "identidad exacta" entre lo que hace el método experimental para el conocimiento físico y lo que hace el método histórico o evolucionario para las ideas y prácticas morales. Para explicar esta afirmación inicial es importante tener en cuenta varios elementos. En primer lugar, el método experimental en ciencia es, en cierto sentido, un método genético, ya que su propósito principal es el [...] "control del análisis o la interpretación de cualquier fenómeno al revelar las condiciones exactas y las únicas condiciones, que están involucrados en su aparición.” (MW.2.4). Como resultado, se lo considera un método genético porque está relacionado con las condiciones por las cuales se llega a experienciar un objeto [comes to be experienced]. En segundo lugar, y aunque generalmente se presenta como carente de significado histórico debido a una abstracción intelectual de su contexto, tal método experimental es histórico y se refiere a casos individuales. En tercer lugar, y estrechamente relacionado con la posición metafísica de Dewey, tiene lugar en un mundo de cosas únicas y cambiantes, es decir, en un "universo evolutivo" (MW.2.8).

Siguiendo la analogía entre el método científico e histórico, si el primero se ocupa de las condiciones de aparición de un fenómeno particular, el segundo se ocupa de las condiciones en que se originan las ideas y prácticas morales. En otras palabras, el método evolutivo, histórico o genealógico intenta determinar cómo los valores morales, los ideales y posteriormente las estimaciones surgen en ciertas situaciones, cómo operan en estos 
contextos y cómo se convierten en un estímulo para provocar nuevos modos de acción. La ventaja de esta perspectiva es doble: por un lado, permite considerar una visión integral del lugar y las relaciones entre tales valores morales, ideales y prácticas. Por otra parte, prestar especial atención a las primeras etapas o períodos permite sustituir la operación artificial de un experimento porque durante estos primeros períodos, las partes constituyentes de nuestros valores morales son relativamente crudas y simples de desentrañar y explicar. ${ }^{38}$

El punto crucial aquí es que, de acuerdo con el planteo deweyano, "al ver de dónde vienen [las prácticas e ideas morales], en qué situaciones surgieron, vemos su importancia.” (MW.2.9). A diferencia de las posiciones materialistas y de las posiciones idealistas, el método genealógico revela el proceso, en términos de continuidad, en el que tienen lugar tanto la apreciación primaria como los valores reflexivos. Siguiendo a Dewey, “en [...] asuntos morales comprendemos tanto el instinto animal como el imperativo categórico humano cuando los ubicamos como términos limitantes de una sola historia continua." (MW.2.15). Por lo tanto, este método revela el lugar que ocupa nuestra cuestión moral particular en un contexto más amplio y, por extensión, revela el lugar de la moralidad. Además, permite una mejor comprensión del universo, marcado por la continuidad mencionada anteriormente (MW.2.16-20).

Hasta el momento, el método genealógico parece proporcionar algunas herramientas para interpretar y explicar nuestras estimaciones actuales a la luz de un contexto más amplio o línea de continuidad. Sin embargo, se mantiene la pregunta por si un método de este tipo afecta las cualidades morales y cuál es la influencia de su aplicación sobre la validez del juicio moral. En pocas palabras, se mantiene la pregunta por la relevancia de la historia para considerar la validez de un juicio moral. Según Dewey, si surge un valor o ideal moral, se desarrolla y opera en referencia a una situación dada. El método genealógico determinará si representan una mejor o peor respuesta a estas situaciones, considerando, por

\footnotetext{
${ }^{38}$ El planteo deweyano sugiere interesantes relaciones con las genealogías presentadas por Michael Foucault. Sobre esta línea de trabajo Koopman (2011) argumenta que la articulación entre ambos enfoques permite considerar una perspectiva filosófica capaz de explicar la normatividad sin necesidad de recurrir a fundamentaciones últimas, mientras que Colapietro (2012a, 2012b) ofrece un detallado estudio acerca de la convergencia entre el proyecto deweyano y el foucaultiano a favor de una comprensión de la filosofía no sólo como crítica del presente sino y especialmente como práctica de libertad. A la luz de estos estudios y teniendo en cuenta (i) la vinculación que puede generar el término "evolucionario" con una posición biologicistareduccionista en torno a los valores y (ii) la vinculación que puede generar el término "genético" con la falacia genética (asunto sobre el que me ocuparé en las próximas páginas), entiendo que el término "genealógico" es el más adecuado para referir a la propuesta de Dewey.
} 
ejemplo, si han desempeñado un papel en el mantenimiento de la integridad de la vida social o si han aportado nuevos valores a ella. En este caso, dicha referencia funcional constituye aquello que Dewey denomina "presunción de validez" (MW.2.26). En consecuencia, el método genealógico atribuye cierta validez moral positiva a todo valor, creencia o práctica que haya sido una respuesta persistente a una situación dada.

La observación deweyana sobre la presunción de validez introduce un punto importante, a saber, su distinción entre un tipo de validez moral que apunta a cuestiones como el Bien o la Justicia en sí, típica de las filosofías clásicas, y otro tipo de validez moral que apunta a juicios particulares y a sus respectivas acciones (MW.2.21). Por supuesto, Dewey desestima el primer tipo de validez y considera que preguntar por la validez moral es preguntar, al menos parcialmente, por las condiciones bajo las cuales surgieron esas valoraciones determinadas. De este modo, aducir que una perspectiva genealógica en ética -comprendida en los términos deweyanos- se reduce a una "historia de la moral" sin aportar elementos de relevancia para validar juicios morales determinados implica confundir ambos sentidos de validez y considerar, a contramano de todo el planteo precedente, que la ética debe ofrecer criterios de validez últimos.

Queda un último elemento: rastrear las condiciones de aparición de una determinada valoración (que luego puede devenir estimación por vías del hábito) impide adoptarla o rechazarla en su totalidad porque es necesario considerar las respuestas futuras de estos valores, creencias y prácticas a su situación particular. Luego, el método genealógico “[...] nos permite medir, a través del rastreo de su desarrollo y destino posteriores, el rango de valor que se le atribuye" (MW.2.28). Este desarrollo posterior de los valores es su factor operativo, su capacidad para modificar lo que ya está dado en lugar de repetir las cualidades existentes, los fines, etc. De lo contrario, estaríamos repitiendo las mismas respuestas habituales. Es precisamente en este sentido que el método genealógico no solo es justificativo de un valor dado -en la medida en que explica los ideales, creencias, prácticas en referencia a su situación particular- sino también un instrumento de investigación, de interpretación y de crítica. Dado que coloca estos elementos en perspectiva, con respecto a nuestros supuestos y estimaciones actuales, el método evolucionario tiene importancia moral porque ayuda a comprender nuestra situación actual de manera integral y porque 
mediante este análisis podemos modificar formas de actuar, hábitos para formar y fines para cultivar. En este sentido, la observación de Tiles es absolutamente apropiada:

La justificación fue su preocupación central [en referencia a Dewey] pero ella se apoya en cuánto el concepto o creencia nos ayuda a lidiar con problemas presentes y futuros. Los problemas, y los medios de los que disponemos para resolverlos, son productos históricos; no entenderemos ni el problema que enfrentamos ni los recursos que tenemos ni las modificaciones que se requiere hacer sobre esos recursos para solucionar el problema, a menos que estemos preparados para vincularlos con sus orígenes. [...] Ésta es la fuente de la preocupación de Dewey acerca de las consideraciones genéticas, pero hasta que no se logre comprender, el enfoque de Dewey aparecerá como aquél al que algunos denominan 'falacia genética'. (Tiles, 1988, p. 17. Traducción propia).

En suma, y lejos de cometer la falacia genética de sustituir el análisis lógico por el análisis histórico o sociológico para sustentar una justificación, lo que sugiere Dewey a fin de cuentas no es sólo un método histórico-genealógico sino también y ante todo un método crítico y prospectivo. Luego, el énfasis puesto en el estudio de las condiciones históricas no debería dar la imagen de una filosofía moral conservadora -mucho menos falaz- sino lo contrario. De acuerdo con Colapietro (2012b, p. 200), Dewey estuvo tan dedicado a contrarrestar las presiones del pasado como a fortalecer las insinuaciones del futuro, de modo que la definición de patrones de continuidad más amplios sólo podría lograrse junto con la implementación de estrategias efectivas de disrupción y reconstrucción de las condiciones de experiencia. En este sentido, y según intentaré explicar en el próximo capítulo, para Dewey genealogía y valoración necesariamente van de la mano.

Las observaciones precedentes permiten introducir la última fibra del capítulo, a saber, la concepción deweyana de teoría moral o ética. En efecto, la necesidad de reevaluar deseos y fines asumidos, vale decir, de considerar si aquello estimado es efectivamente valioso, da cuenta de la distinción propuesta por el pragmatista entre moralidad habitual y moralidad reflexiva. Mientras la primera se asienta en los usos y costumbres socialmente establecidos, la segunda apela a algún tipo de principio que implica pensamiento, reflexión, deliberación frente a una situación de perplejidad moral. Asimismo, la moral habitual ya tiene establecidas reglas y prohibiciones que no se ponen a discusión, mientras que la moralidad reflexiva surge precisamente cuando esas reglas ya no son suficientes para dar 
respuesta a nuevas situaciones que no pueden confrontarse adecuadamente con los viejos mandatos. La teoría moral, por su parte, es una extensión de lo que está involucrado en toda moralidad reflexiva, en todo intento de resolver un conflicto moral por medio de la reflexión. En cuanto tal, permite generalizar los tipos de conflictos morales para enmarcar las situaciones en contextos de reflexión más amplios, identificar los modos en los que se han resuelto intelectualmente esas situaciones y sistematizar las reflexiones del agente moral, sugiriendo alternativas que por sí solo no advertiría tan rápidamente (Dewey, 1965b, p. 26. LW.7.162).

En este marco Dewey señala un punto que deja en claro un aspecto central de su perspectiva: "[n]o existe diferencia fundamental entre la sistemática teoría moral [...] y la reflexión a que se dedica un individuo cuando intenta encontrar los principios generales de deban dirigir y justificar su conducta.” (1965b, p. 23. LW.7.163). De esta manera, también hay continuidad entre la moralidad reflexiva y la teoría ética en cuanto resultado de la sistematización de la primera. Recuperando las observaciones acerca presentadas en el capítulo 1, parece que el aspecto longitudinal de la experiencia en términos de continuidad entre experiencia primaria y experiencia reflexiva permite explicar el tránsito por la dimensión cualitativa de la experiencia (en cuanto tenida), las respuestas orgánicas, las apreciaciones directas, el germen de la reflexión, la deliberación frente a situaciones de conflicto moral y la teoría ética sistematizada. Dicho en pocas palabras, la continuidad longitudinal permite explicar el pasaje desde la experiencia primaria hacia la ética en cuanto experiencia secundaria. A la vez, y dado que el aspecto longitudinal remite en principio al carácter transactivo de la experiencia, permite también sostener que el carácter afectivo de la experiencia en cuanto necesidad del organismo de modificar el entorno hasta dar con una nueva integración dinámica con el ambiente es transversal a todo el tránsito referido pues la deliberación moral tiene como sentido último la dirección de la conducta y la resolución del conflicto -todo ello, por supuesto, en sintonía con el método empírico o denotativo propuesto por Dewey.

Bajo estas consideraciones también es posible incluir lo dicho respecto de la crítica genealógica de la moral. En efecto, entiendo que permiten incorporar el aspecto latitudinal o lateral de la experiencia, esto es, la continuidad entre experiencias, en la medida en que 
observar las condiciones de surgimiento de un valor, más allá de que luego devenga una estimación y decante hasta formar parte de la moralidad habitual, constituye una presunción de validez que también es tomada en cuenta al momento de preguntar por y determinar el carácter valioso de ese valor-estimación, motivo por el cual son un instrumento de investigación y tienen ellas mismas contenido moral.

\section{Conclusiones}

La intención general del capítulo ha sido ofrecer una explicación de la génesis de los valores en tanto resultados de un proceso deliberativo coherente con las asunciones naturalistas del pragmatismo deweyano. En este marco general, y tras haber señalado que según Dewey la fílosofía moderna no supo acompañar el desarrollo científico-experimental con una concepción coherente de los valores, en primer lugar he intentado dar cuenta de la génesis cualitativa de los valores, distinguiendo dos momentos signados por la tesis de la continuidad de la experiencia: por un lado el tránsito entre la experiencia primaria y las apreciaciones inmediatas de un objeto o situación como valioso, y por otro lado el tránsito entre esas apreciaciones y las deliberaciones propiamente dichas. En segundo lugar, he intentado recuperar el sentido de génesis en tanto genealogía, apelando al método genético, histórico o genealógico planteado por Dewey en algunos de sus textos tempranos.

Las conclusiones que se siguen del primer punto conducen a afirmar que la génesis de los valores está inextricablemente relacionada con el aspecto cualitativo de la experiencia. Respecto del primer momento Dewey indica que las apreciaciones directas de aceptación o rechazo remiten a funciones orgánicas primarias y dependen de las cualidades que caractericen a cada situación. En este sentido, la génesis de las apreciaciones es ella misma cualitativa pues está enraizada en la igualmente cualitativa experiencia primaria. Respecto del segundo momento el análisis permitió determinar que se torna más complejo pues requiere determinar cuáles son las características cualitativas propias de una situación de valoración moral para recién después avanzar en la consideración de la deliberación propiamente dicha. Aquí también la dimensión cualitativa de la experiencia tiene un rol fundamental, por dos razones. En primer lugar, el análisis de la situación moral y de los factores que en ella intervienen permite señalar que el conflicto moral es un conflicto cualitativo. En segundo lugar, la deliberación en cuanto ensayo imaginario de cursos de 
acción alternativos también está definida por la dimensión cualitativa de la experiencia pues tanto su punto de partida como su trasfondo y su principio regulativo se juegan en términos cualitativos, de modo que la apreciación del valor de cada curso de acción es genuinamente inmediata. Por supuesto, esto no quiere decir que la deliberación moral meramente replique las apreciaciones primarias sino que el "material" que obtiene del ensayo imaginario es predominantemente cualitativo pero adquiere, además, una determinación de valor agregada, dada por el juicio correspondiente. En palabras de Dewey, "[e]l juicio de valor, en suma, es el desarrollo deliberado de un aspecto constitutivo de las apreciaciones más directas que el ser humano en cuanto criatura viviente está y debe estar continuamente involucrado." (LW.16.354). En suma, cada uno de los momentos identificados en el análisis tiene una impronta cualitativa determinante: (i) en cuanto enraizado en la experiencia primaria y expresión de una respuesta orgánica en términos de aceptación o rechazo de una situación cualitativamente "tenida"; (ii) en cuanto situación moral problemática también cualitativamente definida; y (iii) en cuanto resultado de un tipo de reflexión principalmente cualitativo como lo es el ensayo imaginario. Estos elementos, vinculados entre sí por la tesis de continuidad de la experiencia y por el carácter afectivo de la transacción entre organismo y ambiente, permiten comprender a la génesis de los valores como un proceso intrínsecamente cualitativo.

En relación a la génesis en cuanto genealogía, he recuperado la propuesta del pragmatista acerca de la necesidad de estudiar las condiciones históricas de aparición y consolidación de un valor para explicar las estimaciones actuales respecto de cada situación u objeto particular. Ahora bien, el método genealógico no sólo permite dar cuenta en términos históricos de una estimación habitual dada sino que también aporta un principio de validez de dicha estimación y permite ponerla en perspectiva para considerar cómo se respondería a determinadas situaciones en base a esas mismas estimaciones. En este sentido, el método genealógico no es meramente retrospectivo sino y ante todo un instrumento de investigación y crítica prospectiva.

Tanto la génesis cualitativa de los valores como la genealogía en cuanto estudio a la vez histórico y prospectivo son elementos necesarios para comprender tanto el tránsito de la experiencia primaria y directa a la experiencia secundaria y reflexiva como el tránsito de la 
moralidad habitual a la moralidad reflexiva. En este marco, una clave de lectura cara a todo el capítulo ha sido la interpretación integral de la tesis de la continuidad de la experiencia. Sostengo entonces que observar ambos elementos en simultáneo abona la "interpretación integral" de los principios de continuidad y transacción ofrecida en el capítulo 1. Por un lado, en todo momento del desarrollo continuo desde las apreciaciones iniciales hasta la deliberación hay transacción con el ambiente, vale decir, hay una relación de afectividad con el ambiente. De esta manera el tránsito de la ética a la experiencia queda caracterizado por ambos elementos, continuidad y transacción. Por otro lado, afirmar que experiencias sucesivas tienen impacto unas en otras, como es el caso de las experiencias de valoración pasadas y el contenido moral que reportan para las valoraciones presentes o futuras, implica afirmar que hay continuidad entre ellas, tal que sea posible su vinculación y que cobre sentido aquella hipótesis respecto de la presunción de validez de las valoraciones pasadas a partir del estudio de sus condiciones de surgimiento.

Todas estas consideraciones ofrecen una explicación de los valores en cuanto inscriptos en las múltiples dimensiones del continuo de la experiencia, esto es, en las complejas transacciones que envuelven al ser humano con su propio ambiente. Ahora bien, el análisis de la génesis y de la genealogía de los valores no da acabada cuenta de la perspectiva deweyana sobre el tema. En efecto, en muchos pasajes del capítulo he sugerido que Dewey considera a la deliberación como una indagación inteligente o investigación. En el próximo capítulo examinaré esta segunda perspectiva, centrándome especialmente en la teoría de la valoración y perfilando ya algunos vínculos entre valoración e investigación científica, núcleo temático de la segunda parte del estudio. 


\section{CAPÍTULO 3: LA PERSPECTIVA METODOLÓGICA}

\section{Introducción}

Si el naturalismo adoptado por Dewey implica, por un lado, inscribir a los valores en el curso de la experiencia y ofrecer una explicación filosófica de su génesis en términos predominantemente cualitativos, también implica, por el otro, ofrecer alguna pauta o patrón general para la correcta formación de valores, en términos predominantemente metodológicos -sin que ello traiga consigo, por supuesto, una distinción estricta entre ambas tareas. El tema central del presente capítulo es el análisis del segundo punto mencionado, análisis que conduce a tratar aquello que Dewey denomina juicios prácticos y, más precisamente, juicios valorativos en cuanto evaluación de valores. En la medida en que, según mi interpretación, la teoría de la valoración de Dewey articula su concepción de la experiencia y la dimensión cualitativa de la deliberación, por un lado, y su teoría de la investigación, por el otro, entiendo que un análisis detallado de su propuesta permitirá completar el estudio de su perspectiva sobre los valores y, especialmente, plantear algunas cuestiones que serán retomadas más adelante, al momento de considerar la dimensión valorativa de la investigación científica. En este sentido, dado que una de las hipótesis que presentaré en los capítulos subsiguientes estipula la continuidad entre la valoración y la investigación, este capítulo se inserta en el argumento general de la tesis con la intención de señalar en qué puntos hay investigación en la valoración y de asentar algunos elementos teóricos para señalar en qué puntos hay valoración en la investigación, ya en la segunda parte de esta tesis.

La propuesta deweyana en clave metodológica acerca del tratamiento de los valores puede rastrearse prácticamente a lo largo de toda su obra. En efecto, entre 1903 y 1922 Dewey elabora un ciclo de investigaciones preliminares, según las denomina Martin Jay (2002, p. 432), en el que perfila algunas tesis centrales respecto del tema del capítulo: (i) la continuidad entre los juicios científicos y los juicios valorativos; (ii) la consideración de los juicios prácticos como juicios relativos a qué hacer frente a una situación problemática o indeterminada; y (iii) la idea de que los juicios relativos a valores no se agotan en reportar o describir valores en cuanto estimaciones de hecho sino que hay otro tipo de juicio dedicado 
tanto a considerar si un valor dado es valioso como a dar lugar a nuevos valores en la experiencia. $^{39}$

Más allá de estas referencias, en lo que sigue examinaré específicamente la posición de Dewey desarrollada en "Teoría de la Valoración” de 1939, pieza que tal vez constituya su formulación más madura y acabada acerca del tema de indagación. "Teoría de la Valoración" fue publicada como parte de la Enciclopedia de la Ciencia Unificada, bajo edición y a pedido expreso de Otto von Neurath. Como señala George Reisch (2009, p. 10) la participación de Dewey en ese proyecto colectivo puede parecer intrigante en la medida en que la perspectiva deweyana sobre los valores presenta muy pocas afinidades con la perspectiva del empirismo lógico standard. No obstante, vale aclarar que Neurath es una figura atípica en el contexto del positivismo lógico, dado el lugar que reserva a los valores políticos en la aceptación o rechazo de hipótesis científicas, y que aún con sus diferencias teóricas tanto Dewey como Neurath entienden al programa de unificación de la ciencia como parte de un programa social que se llevaría adelante por vías de la educación, visión común que permite explicar la cooperación entre ambos toda vez que, cada uno a su forma, se desmarcan de una concepción de conocimiento limitada al plano epistémico y avanzan sobre el plano socio-político (al respecto, Cf. Esteban, 2003; Gómez, 2011). ${ }^{40}$

En términos teóricos, el vínculo entre positivismo y pragmatismo podría explicarse por el rechazo común a las filosofías "anti-científicas" y "anti-modernas" antes que por la confluencia de perspectivas filosóficas concretas. Ahora bien, si la respuesta del positivismo pasa por distinguir y separar taxativamente el ámbito de los hechos y el ámbito

39 En "Logical Conditions of a Scientific Treatment of Morality" (1903) Dewey aclara que el sentido de "científico" se vincula con la capacidad de establecer métodos de control para la formación de juicios, de modo que bien podría ser adoptado para las reflexiones en el campo de la moral sin que ello suponga algún tipo de problema lógico ni de reduccionismo cientificista. Asimismo, observa que negar la relación entre investigación en ciencia y en moral supone negar la continuidad de la experiencia y afirmar que los principios de los juicios éticos se apoyan en concepciones trascendentales independientes del curso de experiencia. (MW.3.35). Por otro lado, en "The Logic of Judgments of Practice" (1915) Dewey plantea la idea de que el juicio incide en el modo de resolución de la situación inicial asegurando, tanto como se pueda, el mejor curso de acción, sea en moral, tecnología o investigación científica (MW.8.15-17). Finalmente, en "Valuation and Experimental Knowlegde" (1922) introduce la distinción analítica entre valores intrínsecos en tanto inmediatamente estimados y valores contributorios o instrumentales y advierte que no es posible separarlos en términos existenciales dado que cualquier valor inmediato es, después de todo, parte del curso de experiencia, mientras que los valores contributorios pueden tornarse medios indispensables y, consecuentemente, devienen valiosos en cuanto parte integral del fin o bien. De esta manera, Dewey presenta una versión de su argumento en contra de la distinción férrea entre medios y fines que, con algunas variantes, será recuperada en sus escritos posteriores (Cf. MW.13.5-6).

${ }^{40}$ Sobre el vínculo entre Dewey y Neurath también son muy interesantes las lecturas de Reisch (2009, pp. 112-117), da Cunha (2012) y di Berardino (2016). 
de los valores, bajo la premisa de que los primeros pueden ser objeto del estudio científico, mas no así los segundos, la posición deweyana, en cambio, apuesta a mostrar que los juicios de valor pueden someterse a las mismas pruebas de validez que los juicios de hecho porque los primeros se sustentan en estos últimos. ${ }^{41}$ En este sentido, los interlocutores de “Teoría de la Valoración" son dos: la versión clásica del positivismo expresada bajo la idea del significado emotivo de los términos valorativos (elaborada por Alfred Ayer en su Language, Truth and Logic de 1936) y el apriorismo racionalista respecto de los valores, esto es, el planteo según el cual existen valores racionales en cuanto entidades independientes del sujeto, susceptibles de algún tipo de aprehensión intelectual. Así, Dewey discute con el enfoque naturalista y no cognitivista del emotivismo, por un lado, y con el enfoque no-naturalista y cognitivista del apriorismo, por el otro, en vistas a ofrecer una teoría de la valoración naturalista y cognitivista (Di Berardino y Faerna, 2008b, p. 13). ${ }^{42}$

En este marco propongo entonces ubicar el análisis de "Teoría de la Valoración" ofrecido en las páginas siguientes. En la segunda sección del capítulo abordaré en detalle el contenido teórico, haciendo especial hincapié en el concepto de fin a la vista, la tesis del continuo entre medios y fines, sobre la que propongo una distinción analítica entre continuidad "en situación" y continuidad "en sentido amplio", y la concepción deweyana de la valoración en sentido distintivo. Finalmente, y ampliando el contexto de análisis tal que incluya los argumentos presentados por Dewey en el capítulo "La Construcción del Bien" de La Búsqueda de la Certeza, en la tercera sección recuperaré algunas críticas y discusiones que permitirán echar luz sobre un aspecto crucial: el sentido de normatividad enraizado en la experiencia y fundado en la investigación que se sigue del planteo de Dewey. Así, abordaré las objeciones presentadas por Clarence Irving Lewis y Morton White e intentaré elaborar algunas respuestas desde el punto de vista deweyano, apoyado en argumentos de Gail Kennedy (1955), Ralph Sleeper (1960), Gertrude Ezorsky (1958) y el

\footnotetext{
${ }^{41}$ Según la presentación del propio Dewey al comienzo de "Teoría de la Valoración", la idea básica del emotivismo consiste en considerar a los juicios de valor como calificativos emocionales o simples exclamaciones sin contenido cognitivo. Así, aun cuando Dewey prefirió no incluir las referencias bibliográficas para evitar polémicas en tono personal, en su texto aparecen distintas citas de Ayer que serían fuertemente criticadas.

42 De acuerdo con Faerna $(2006,2011)$ el carácter polémico de "Teoría de la Valoración" es una de sus marcas distintivas. Además, el hecho de que Dewey entre en discusión con la filosofía positivista explica la impronta más analítica del texto, poco usual en la obra del pragmatista.
} 
propio Dewey. El conjunto de estas elaboraciones permitirá, espero, ofrecer una reconstrucción integral del planteo deweyano acerca de los valores y del vínculo indisoluble de estos últimos con el curso continuo de la experiencia.

\section{El programa de "Teoría de la Valoración"}

\subsection{Fines a la vista y valores}

Según he adelantado, en términos generales el interés de Dewey es establecer un programa metodológico que permita afirmar el carácter de "digno de valor" de un objeto o situación. La premisa necesaria para llevar adelante esa tarea es que la lógica de la investigación sobre las proposiciones de hecho y sobre las proposiciones de valor es del mismo tipo genérico, lo cual habilita el interés deweyano por aplicar el método empírico o denotativo a los asuntos de la moral, tanto por referencia al carácter científicamente respaldado de las proposiciones valorativas como a la exigencia filosófica de partir del nivel primario de experiencia, iniciar una reflexión y "regresar" a la experiencia primaria, modificándola y enriqueciéndola con sus resultados. Esta descripción, aun cuando introductoria, permite ya observar una característica crucial del proyecto deweyano, según lo describe Tiles: "[1]a posición sobre los valores de Dewey trata de combinar tres características que son generalmente pensadas como empujando hacia direcciones diferentes. Su posición es racionalista [en el sentido de inteligencia, aclara inmediatamente después el autor], constructivista [en cuanto la consigna es traer a la existencia la cualidad de valor allí donde no estaba] y experimentalista.” (Tiles, 1988, p. 167).

Aun teniendo en cuenta las aclaraciones realizadas en el epígrafe anterior respecto del objeto puntual del texto, las proposiciones valorativas, es interesante destacar que Dewey comienza su análisis señalando la fuerte conexión entre el gustar y el disgustar con la valoración -conexión que remite a algunos de los puntos presentados en el capítulo precedente y que responde, claro está, a la dinámica de dar inicio a las reflexiones, del tipo que sean, a partir del nivel primario de la experiencia. Por supuesto, aquí "valoración" adquiere el referido sentido de estimación o hecho efectivo de la experiencia y debe considerarse en términos de comportamientos observables e identificables. Este tipo de estimaciones generalmente se lleva adelante por tendencia habitual, vale decir, ejecutando una conducta directa sin genuina valoración intermedia, de modo que en tanto no se 
produzca en la situación una conmoción o perturbación efectiva hay vía libre para pasar de inmediato al acto, a la acción abierta.

La observación de las acciones guiadas por el gusto o disgusto y de los efectos que ellas producen permite elaborar proposiciones sobre estimaciones, esto es, proposiciones sobre cuestiones de hecho. En efecto, aclara Dewey, "[e]l que los hechos [sobre los que tratan las proposiciones] resulten ser valoraciones no convierte a las proposiciones en valorativas en ningún sentido distintivo". (Dewey, 2008b, p. 101. LW.13.208. Cursivas en el original). ${ }^{43}$ Sin embargo, las estimaciones, analizadas especialmente en términos de sus condiciones y consecuencias, esto es, en términos evaluativos, habilita dos puntos cruciales para el planteo deweyano: por un lado, la posibilidad de evaluar estimaciones para determinar si ciertos actos de estima son mejores que otros; por el otro, considerar si esa evaluación puede modificar actos de estima ulteriores. En este contexto, según Dewey hay sólo dos alternativas: o bien se ejerce una conducta sin valoración intermedia, o bien la actividad está mediada por la anticipación de sus consecuencias en relación con los medios disponibles que intervienen en la configuración del deseo en cuanto deseo elegido. En el primer caso se estaría siguiendo algún tipo de norma en cuanto condición o regla de acción "a la que hay que plegarse", orientada a indicar las mejores formas de cumplir con los fines asignados y generalmente asentada en costumbres, convenciones o tradiciones. En el segundo caso, se apuesta por una evaluación de las relaciones empíricamente comprobadas entre ciertas cosas tomadas en su relación de medios o consecuencias y fines.

El punto de partida de las evaluaciones -e incluso de las valoraciones, como intentaré aclarar en las páginas siguientes- es la identificación de algún déficit, carencia o conflicto en una situación particular, sea o bien porque los hábitos de conducta no son suficientes para resolverla, de modo que quedan puestos en cuestión, o bien porque la resolución de la situación no es inmediatamente aparente. Esa condición deficitaria habilita la aparición de un deseo que podrá dar lugar a una valoración, en ese contexto determinado: “[...] los deseos brotan únicamente cuando 'hay algún pero', cuando se da algún problema

\footnotetext{
${ }^{43}$ En la traducción de Di Berardino y Faerna la expresión que Dewey efectivamente utiliza, "propositions about valuations" (LW.13.208), es traducida por "proposiciones sobre valoraciones". Sin embargo, considero más claro mantener la distinción estimación-valoración incluso para el caso de las proposiciones, de modo que propongo trocar la expresión del propio Dewey y de la traducción por "proposiciones sobre estimaciones".
} 
en una situación existente. [...] esos 'peros' nacen del hecho de que algo está ausente o se echa en falta en la situación tal como está, una carencia que genera conflictos en los elementos que sí están presentes.” (Dewey, 2008b, p. 113. LW.13.220).

En esta primera aparición los deseos son, de acuerdo con George Geiger, candidatos al estatuto de valor. No obstante, señala a continuación Geiger, los deseos alcanzarán ese estatuto cuando devienen significativos respecto del problema en cuestión y son útiles en su resolución (Geiger, 1978, p. 48). El contenido y el objeto del deseo son dependientes del contexto particular en el que surge y su función por referencia a ese mismo contexto es la resolución de la carencia o déficit tenido. De este modo, el deseo presenta un aspecto afectivo, ciertamente cualitativo, en cuanto aversión por una situación existente y atracción por una posible situación distinta. No obstante, y a diferencia de los meros anhelos, los deseos presentan también un aspecto motor en la medida en que entrañan de modo consustancial un esfuerzo, una relación activa entre organismo y ambiente en favor a resolver el conflicto inicial. Más aún, el deseo implica un aspecto ideacional o intelectual que se juega en el planteo de los fines de la acción en términos de los medios disponibles. En consecuencia, el deseo como emergente de una situación de déficit, conflicto o carencia, y siempre que no se limite a un mero anhelo o impulso, es el punto de partida para la proyección de fines a la vista, de aquello que dirija la acción de tal forma que se instituya un estado de cosas unificado en función de que se resuelva el conflicto inicial. En este sentido, el componente ideacional del deseo es preeminentemente práctico, orientado a la proyección situada de distintos fines de la vista.

Así, un fin a la vista es una consecuencia particular prevista que funciona como vínculo anticipado entre las condiciones y consecuencias pretendidas y como coordinación de las actividades para dar lugar a una nueva situación unificada o, dicho más sencillamente, como guía o plan hipotético de acción. En este sentido el fin a la vista se diferencia de la mera previsión de resultados por su cualidad motora y a la vez se diferencia del simple hábito por su factor intelectual o ideacional. Tal y como explica Dewey, “[...] allí donde hay un fin a la vista del género que sea, hay actividad afectivo-ideacionalmotora; o, dicho en los términos del significado dual de valorar, estima y evaluación se dan unidas." (2008b, p. 111. LW.13.218). 
El factor intelectual de los fines a la vista garantiza la posibilidad de elaborar proposiciones valorativas en sentido distintivo, apoyadas estas últimas en proposiciones evaluativas. En efecto, la característica central de las proposiciones evaluativas es la consideración de las cosas en su relación condiciones-consecuencias, relación empíricamente comprobable. Dado que, para Dewey, “[...] las cosas sólo pueden anticiparse o preverse como fines o resultados en términos de las condiciones por las cuales se traen a la existencia", entonces las proposiciones evaluativas jugarán un rol central en la elaboración de los fines a la vista (2008b, p. 114. LW.13.222). Precisamente aquí radica la diferencia central entre lo deseado y lo deseable pues esto último implica una evaluación de las condiciones que determinarán el resultado en el seno de la propia formación de deseos e intereses. Valga una nueva cita in extenso para dar cuenta de este punto:

Lo 'deseable', o el objeto de debe desearse (valorarse), no es algo caído de un cielo apriorístico ni que descienda desde un Sinaí moral. Se nos presenta porque la experiencia pasada ha mostrado que actuar apresuradamente sobre la base de deseos no criticados previamente conduce al fracaso, y posiblemente a la catástrofe. Así que lo 'deseable', en tanto que distinto de lo 'deseado', no designa nada genérico o apriorístico, sino que indica la diferencia entre las operaciones y consecuencias de impulsos no examinados y las de deseos e intereses que resultan de investigar condiciones y consecuencias (Dewey, 2008b, p. 111. LW.13.219).

Por el momento, el análisis deweyano acerca de los fines a la vista parece circunscripto a situaciones particulares. No obstante, y sin perjuicio del carácter único de toda situación dada su dimensión cualitativa, el curso de experiencia permite identificar ciertos tipos recurrentes de problemas o carencias. Concordantemente, los fines a la vista orientados a su resolución tienden a consolidarse progresivamente y a instituirse como un conjunto de pautas o condiciones que guían la acción y como un criterio que se aplica a los nuevos casos, conforme se van presentando. En este contexto, los valores son una descripción generalizada de relaciones entre medios y fines, prácticas y deberes, disposiciones y aprobaciones o, más sencillamente, fines a la vista generalizados, marcos 
de referencia relativamente abstractos que describen y definen determinados deseos o intereses como deseables, buenos o apropiados en situaciones similares. Dichos marcos se apoyan en proposiciones empíricas, se comprueban en cada caso -pues nunca dejan de ser hipotéticos, al igual que todo fin a la vista- y fungen como criterio de formación y evaluación de nuevos deseos y propósitos.

\subsection{La tesis de la continuidad medios-fines en el continuo de valoración}

Ahora bien, así como Dewey observa que la previsión de resultados sólo puede hacerse mediante la consideración de las condiciones, de igual manera plantea que " [...] los fines se evalúan dentro de las mismas valoraciones en las que se sopesan las cosas en tanto que medios" (2008b, p. 103. LW.13.212). La observación precedente permite señalar un punto apenas delineado en los textos sobre deliberación moral pero que ahora adquiere una centralidad insoslayable: la tesis de la continuidad entre medios y fines.

La tesis de la continuidad entre medios y fines es uno de los aportes más interesantes y complejos de la perspectiva deweyana. A lo ya señalado acerca de que las consideraciones de los fines deben hacerse en términos de sus medios o condiciones debe añadirse que un fin a la vista sólo es "final" en la medida en que representa la conclusión de un proceso de evaluaciones sobre las condiciones que operan en la situación determinada, esto es, en una relación medios-fines temporal y especificable, pero una vez alcanzado será condición o medio para fines subsiguientes. Ambas facetas de la tesis de la continuidad permiten sugerir una distinción entre continuidad "en situación" y continuidad "en sentido amplio", y permiten indicar de qué manera Dewey no sólo habilita sino alienta a la revisión de fines y valores, frente a la reiterada acusación al pragmatismo como filosofía instrumentalista u orientada a la mera consideración de los medios.

Respecto del primer sentido, y en cuanto circunscripto a una relación medios-fines determinada, el fin a la vista siempre es evaluado y reevaluado en función de la disponibilidad o el costo de sus medios, de la apreciación de los propios medios, incluso en el curso mismo de la acción. De este modo, el fin a la vista no está completamente definido de antemano sino que es, ante todo, un plan hipotético pues la relación entre condiciones y consecuencias resignifica las condiciones de posibilidad de los fines y permite ampliar el conjunto de fines a la vista inicialmente identificados. En este sentido, la continuidad e 
interpenetración de medios y fines es tal que la modificación de los primeros representa, en esa misma medida, la constitución de un nuevo fin. Por su parte, el fin a la vista está presente en cada etapa del proceso en cuanto significado [meaning] de los medios empleados y actos realizados. Sin la presencia directiva del fin a la vista, los medios son meras condiciones extrínsecas a la acción. En cambio, en su función constitutiva los medios dotan de contenido o forman parte del propio fin. A su vez, el fin a la vista hace que las condiciones obtengan su sentido como medios, de modo que ambas categorías son interdependientes y que, en una situación determinada, los medios y los fines son (o deban ser) ser recíprocos, vale decir, concordantes. Dicho de otro modo, los medios están internamente relacionados con el fin a la vista, mientras que en las versiones típicamente instrumentales tienen una relación de exterioridad. Puesto en términos negativos, la discrepancia entre los valores y fines nominalmente sostenidos y los medios efectivamente empleados debería ser un llamado de atención para considerar si el fin que se dice perseguir es el que de hecho se persigue.

En este marco puede comprenderse, finalmente, por qué Dewey está en franca oposición a cualquier concepción de fin en sí mismo, es decir, de algún tipo de fin que tenga valor independientemente de todas sus relaciones existenciales y que en base a su pretendido valor absoluto justifique cualquier medio para su obtención. En su opinión, la idea de fin en sí mismo no es más que una selección arbitraria de las consecuencias totales de la acción, que en cuanto tal deja sin contemplar tanto la evaluación sobre los medios conducentes como otras consecuencias posibles y no queridas (Cf. Catalán, 1993).

Por otro lado, el valor de los diferentes fines a la vista se pondera en virtud de su capacidad para resolver la situación inicial, esto es, en su función como medios directivos, mediante la observación de las consecuencias generadas en comparación con las previstas por el referido fin a la vista. En otros términos, la ponderación se lleva adelante mediante el contraste entre el contenido intelectual o ideacional del fin a la vista, la previsión, y el contenido existencial del resultado alcanzado o del fin en tanto que consecuencia. En este sentido, el fin es evaluado en su rol instrumental. ${ }^{44}$ Luego, plantea Dewey, "el valor de los

\footnotetext{
${ }^{44}$ Por supuesto, este análisis no se desentiende de las consideraciones respecto de la inmediatez cualitativa de la experiencia ni del rol que juega en la definición de las situaciones. En efecto, tal y como señala Gail Kennedy, la evaluación del fin a la vista en cuanto medio para resolver la situación de carencia o conflicto se
} 
diferentes fines que se insinúan se calcula o se mide por la capacidad que demuestren para guiar las acciones que subsanarán, que satisfarán, literalmente, las carencias existentes. He ahí el factor que detiene el proceso de prever y sopesar fines a la vista en su función de medios." (2008b, p. 124. LW.13.232).

El sentido "amplio" de la tesis de la continuidad remite a la idea de continuo de valoración: todo medio presente ha sido un fin alcanzado con anterioridad y todo fin de hecho alcanzado será un medio para futuros fines, formará parte de las condiciones existenciales que deberán ser tenidas en cuenta en las subsiguientes formaciones de deseos e intereses y será evaluado como recurso o como obstáculo para la ocurrencia de nuevas valoraciones. La identificación de esta continuidad permitirá, en opinión de Dewey, concebir fines a la vista y formar deseos sobre la base de proposiciones empíricamente fundadas respecto de la relación condición-consecuencia de unos sucesos con otros. De esta manera, aquello que se identifique como medio o fin será tal dentro de una relación particular pero no de modo independiente. Tal y como explica Ernest Nagel, se debe aplicar aquí -tanto como en el análisis de la lógica de la investigación, según detallaré en el próximo capítulo- el "principio general de análisis contextual", aquél que recuerda comprender a los fines de una acción o a las conclusiones de una investigación siempre en términos de sus medios o procesos para obtenerlos/as, respectivamente (Nagel, 1986. LW.12.xi). Dicho de otro modo, la distinción medios-fines es para Dewey temporal y relacional antes que ontológica (Cf. 2008b, p. 121. LW.13.229).

El primer sentido de continuidad representa, además, una de las razones por las que Hilary y Ruth Anna Putnam sostienen la reconocida tesis del colapso de la dicotomía hecho-valor. En efecto, un fin a la vista en determinada situación es evaluado tanto en función de los medios necesarios para su realización como en función de las consecuencias previstas, y todas esas evaluaciones son objeto de investigación. Si esta consideración sobre la continuidad entre medios y fines se lee a la luz de la definición deweyana de racionalidad en tanto "[...] cuestión de relación entre medios y consecuencias y no de principios fijos"

realiza justamente sobre la base de la unidad cualitativa de la situación (Kennedy, 1955). En el mismo sentido López señala que los fines en su función de medios resolutivos mantienen la dimensión cualitativa que permite apreciarlos inmediatamente (López, 2014, p. 229). Más aún, Dewey mismo sugiere que la tesis de la continuidad entre medios y fines tiene ella misma un sustento cualitativo, pues "[...] siempre que medios y fines son externos recíprocamente, son no-estéticos. Esta exterioridad puede aún ser considerada como una definición de lo no-estético.” (2008a, p. 223. LW.10.202). 
(Dewey, 1950, p. 22. LW.12.17), entonces todas estas evaluaciones son racionales y, consecuentemente, el criterio de demarcación entre hechos y valores basado en el modo de fundamentar sus respectivos juicios se desdibuja. Luego, señalan Hilary y Ruth Anna Putnam, “[...] cuando se vincula la concepción de racionalidad de Dewey con su idea de que los medios y los fines forman un continuo, se sigue su rechazo de la dicotomía hechovalor" (Putnam \& Conant, 1994, p. 205). ${ }^{45}$

Por supuesto, el sentido de la continuidad recién indicado no solamente implica este doble estatuto de las cosas en tanto medio-fin sino también la ubicación de la evaluación en contexto. Toman lugar aquí las consideraciones realizadas en el capítulo 1: todo pensamiento tiene un contexto particular que incluye, entre otros elementos, un modo determinado de observar, interpretar y valorar todo lo que es explícitamente pensado, esto es, un trasfondo cultural o tradición, que resulta inextricable del trasfondo existencial o material sobre el que se apoya el material directo de la reflexión. En cuanto caso particular de pensamiento o de investigación, las elaboraciones de fines a la vista y subsiguientes consolidaciones de valores no quedan eximidas de la influencia del trasfondo. En efecto, explica Dewey, “[1]as circunstancias y presiones sociales son parte de las condiciones que afectan a la ejecución de los deseos. Por tanto, hay que tenerlas en cuenta a la hora de planear fines en términos de los medios disponibles." (2008b, 111. LW.13.219). Ahora bien, y dada la tesis de la continuidad de la experiencia, así como una evaluación determinada no puede recortarse de su contexto, esto es, no puede ser considerada sin referencia al trasfondo en el sentido recién señalado, tampoco puede considerarse por fuera de las consecuencias que pueda generar en el propio contexto. De esta manera, la consideración de un valor se inscribe en un contexto determinado que lo afecta pero a su vez debe contemplar el modo en que puede afectar a dicho contexto, incluyendo por supuesto otros valores ya establecidos.

Estas observaciones sobre el sentido amplio de la tesis de la continuidad permiten, finalmente, recuperar el propósito central del texto deweyano. En efecto, la valoración en su sentido más pleno es justamente una evaluación de valores. En palabras de Dewey, “[e]n

\footnotetext{
${ }^{45}$ Este es uno de los argumentos en favor de la tesis del desplome de la dicotomía hecho-valor de Putnam. El segundo argumento señala que los juicios de hecho están entrelazados o imbricados [intertwined] con juicios de valor. Detallaré este punto en el Capítulo 5.
} 
caso de que, a resultas de ello [de comparar y contrastar diferentes tipos de estima], se demuestre que ciertos actos de estima son mejores que otros, los actos de valoración habrán sido ellos mismos evaluados y esa evaluación podrá modificar actos directos de estima ulteriores." (Dewey, 2008b, p. 101. LW.13.208-9).

De modo análogo a lo sucedido para las evaluaciones, las valoraciones en sentido distintivo también comienzan con una situación problemática o deficitaria. Si se acepta que los hábitos representan, de alguna manera, la puesta en práctica de valores en cuanto estimaciones, las situaciones de valoración surgen cuando o bien hay algún impedimento para la ejecución satisfactoria del hábito de estimación, o bien cuando dos hábitos de estimación entran en conflicto o se muestran incompatibles al momento de resolver la situación. La primera posibilidad parece implicar algún tipo de reconsideración de los medios de resolución, reconsideración que incluye al propio fin dada la tesis de la configuración mutua entre medios y fines. La segunda posibilidad parece implicar la ponderación de las valoraciones habituales puestas sobre el continuo de valoración. Ambas posibilidades, en suma, traen consigo una consideración respecto de si aquello valorado es efectivamente valioso. En este sentido, pues, Dewey insiste en que los valores no son entidades sino cualidades que las cosas adquieren como consecuencia de nuestra transacción con ellas.

¿Cómo se llevan adelante, pues, las valoraciones? Teniendo en cuenta que el eje de las proposiciones valorativas es la evaluación de los valores en términos de condiciones y consecuencias, el primer elemento es el estudio de las valoraciones pasadas en cuanto estimaciones o normas. Ellas aportan la materia prima y su conocimiento es condición indispensable para formular proposiciones valorativas. El segundo elemento es el estudio empírico de las consecuencias de los deseos e intereses presentes sobre la base del conocimiento de sus condiciones. A partir de aquí los valores sometidos a evaluación podrán ser rechazados o reforzados, según se observe que carecen del respaldo previamente supuesto o que disparan potencialidades individuales y contribuyen al refuerzo mutuo de deseos e intereses de los miembros de un grupo (Cf. Dewey, 2008b, p. 136. LW.13.244). Todo esto implica, sin excepción, inscribir a los valores en el continuo de valoración y por referencia a su contexto. En otras palabras, por fuera del trasfondo de los casos pasados de valoración, de los que son continuos, no es posible establecer de forma válida las 
valoraciones presentes ni definir aquello que Dewey denomina perspectiva de futuro, esto es, la proyección de consecuencias de las valoraciones actuales. En suma, por fuera del continuo de valoración no hay valoración genuina posible.

Llegado este punto surgen algunas observaciones de importancia. En primer lugar, el planteo deweyano acerca del método genealógico en la moralidad en cuanto estudio histórico de las condiciones que permiten dar cuenta de estimaciones actuales confluye con la propuesta señalada en "Teoría de la Valoración" en la medida en que proveerá conocimiento indispensable para llevar adelante genuinas valoraciones. Es el mismo Dewey quien habilita esta observación al plantear, en "Teoría de la Valoración”, que el conocimiento de las valoraciones pasadas es de tipo histórico y antropológico-cultural y que, si bien no es condición suficiente para una valoración genuina - del mismo modo que el método evolucionario aplicado a la moralidad no aporta validez sino una presunción de validez-, sí constituye una condición necesaria, como he indicado recién. Al poner en perspectiva de continuidad $\mathrm{y}$, además, ser resultado de investigación empírica, este conocimiento histórico-antropológico incrementa el carácter cognitivo de los juicios valorativos. Me permito citar nuevamente in extenso para dar cuenta de lo dicho:

Supongamos, por ejemplo, que se comprueba que una determinada serie de valoraciones hoy vigentes tiene como condición histórica antecedente el interés de un pequeño grupo o de una clase particular en mantener en exclusiva ciertos privilegios y ventajas, y que ello tiene el efecto de limitar el radio de los deseos de otros y su capacidad para materializarlos. ¿Acaso no es obvio que semejante conocimiento de condiciones y consecuencias [provisto por el método genealógico, evolucionario o histórico-antropológico] llevará con toda seguridad a una reevaluación de los deseos y fines a los que se había conferido autoridad como fuentes de valoración? (Dewey, 2008b, 136. LW.13.244). ${ }^{46}$

\footnotetext{
46 Teehan propone un ejemplo muy claro para contraponer los dos tipos de validez y señalar el acierto de la perspectiva deweyana: la subordinación política, moral, social y sexual de la mujer al hombre. Mientras que a fines del siglo XIX esta práctica era aceptada por los hombres y por muchas mujeres como una expresión de un orden moral natural, a principios del siglo XXI parece haber un consenso por el cual esa subordinación es moralmente injustificable. Frente a esto, Teehan plantea lo siguiente: “¿Hubo algún descubrimiento acerca de la fundamentación última de la ética durante esos años? ¿Identificaron los filósofos la teoría de Justicia? Por
} 
En segundo lugar, no debería sorprender que Dewey considere a la teoría de la valoración como un programa metodológico para la formación inteligente de deseos e intereses. En efecto, y tal como había planteado Dewey en reiteradas oportunidades frente a las concepciones de la moral como un "recetario" de farmacia o cocina, esta perspectiva metodológica no busca resolver problemas de valoración concretos ni ofrecer alguna lista de valores específicos -al menos en lo que a la moralidad respecta, a diferencia del campo de la política con el valor de la democracia- sino, antes bien, establecer condiciones respecto del conocimiento de las valoraciones pasadas y presentes que cualquier investigación sobre este tipo de asuntos debería cumplir. Además, en cuanto método la teoría no está completa puesto que “[...] sólo se podrá completar una vez se haya emprendido de modo sistemático la investigación de las cosas que mantienen entre sí la relación fines-medios, y cuando sus resultados se hayan hecho notar en la formación de deseos y fines." (Dewey, 2008b, p. 131. LW.13.239). No obstante, señala Dewey, el uso del método en situaciones concretas lo que permitirá su desarrollo y perfeccionamiento. ${ }^{47}$

En tercer lugar, y a diferencia de la postura positivista, la propuesta deweyana no busca meramente "importar" la metodología científica al ámbito de los valores pues en ese caso caería en un reduccionismo y se anularía la propia posibilidad de una discusión racional respecto de los fines, tanto individuales como colectivos. Al respecto, en “Intelligence and Power" Dewey señala que no se trata de copiar literalmente las técnicas de las ciencias sino ante todo de adoptar su actitud experimental ejemplificada en el avance sistemático de las ciencias naturales: “¿Cuáles son sus alternativas? -se pregunta el pragmatista- El dogmatismo reforzado por el peso de las costumbres y tradiciones no cuestionadas, el juego oculto o abierto de los intereses de clase, la dependencia de la fuerza bruta y la violencia." (LW.9.108). Por el contrario, el acento del programa está puesto en la evaluación empírica de los fines a la vista y en la deliberación activa y reflexiva para elegir

supuesto que no. Lo que ocurrió es una creciente comprensión de los orígenes y funciones sociales de la subyugación femenina. El reconocimiento de que la justificación de la dominación masculina no estaba basada en un orden moral natural sino en los intereses de los hombres en controlar la sexualidad femenina permitió modificar la validez de nuestros juicios morales respecto de esa práctica.” (Teehan, 2002, p. 236).

47 De acuerdo con Gertrude Ezorsky hay otro sentido en el que la teoría de la valoración podría ser comprendida como un programa metodológico: en la medida en que el deseo está enraizado en actividades vitales y en que la valoración es un tipo de investigación que intenta determinar si lo deseado (factual o hipotéticamente) es deseable, la valoración se instituye como "la original y más primaria forma de investigación de los seres humanos" y como "modelo para toda otra investigación” (Ezorsky, 1958, p. 124). 
un curso de acción entre varios posibles (curso de acción que funciona como un test para señalar la existencia de una valoración). Es así que, como ha sido indicado, la consideración de un objeto como deseable no proviene de un a priori o de un imperativo ni constituye una mera expresión emocional sin contenido cognitivo sino que resulta de la revisión empírica y crítica de los fines a la vista, según las consecuencias de la acción a las que da lugar. Dicho de otro modo, el auxilio del conocimiento científico no implica, de ninguna manera, la evasión de la decisión valorativa (moral, política, etc.) sino un intento de que esa decisión sea lo mejor informada posible.

Por supuesto, la posición desarrollada por Dewey en torno al tema de los valores no ha quedado al margen de cuestionamientos y objeciones. Una de las líneas más críticas para con los argumentos aquí señalados es presentada por algunos exponentes de la Escuela de Frankfurt. Así, por ejemplo, en su Crítica de la Razón Instrumental Max Horkheimer acusa al pragmatismo de filosofía cientificista y apologética del capitalismo más crudo (2007, pp. 57 y siguientes). Por su parte, en una reseña de “Teoría de la Valoración” Herbert Marcuse (1941) observa que, más allá de los avances que supone la posición de Dewey respecto del positivismo en su versión cientificista, aún queda limitada al ajuste a partir de los recursos y obstáculos dados, algo que en contextos como el fascista resulta profundamente legitimador del status quo. ${ }^{48}$ Desde otra perspectiva, Charles Stevenson arguye que la predicción de consecuencias de un deseo o fin, en cuanto atribución de cualidades, no es suficiente para darle fuerza normativa. Si bien parecería que hay aquí un mínimo acercamiento, en la medida en que se acepta que los enunciados de la ética, aun cuando fueran imperativos, pueden contener una dimensión descriptiva, Stevenson considera que aquella insuficiencia refuerza la necesidad de considerar el significado emotivo de los términos éticos (1944, pp. 253-264).

No obstante el interés que revisten estos cuestionamientos, en lo que sigue me detendré en otras dos críticas, presentadas por Clarence Irving Lewis y Morton White, respectivamente. El trabajo sobre ambos puntos y la sugerencia de algunas respuestas tienen como intención aclarar, en la medida de lo posible, el sentido de normatividad que se desprende del enfoque deweyano, teniendo en cuenta que este último aspira a dar cuenta

${ }^{48}$ Para un detallado análisis de ambas críticas y sus respectivas respuestas en clave deweyana, Cf. López, 2014, p. 240-257. 
del modo más inteligente de elaborar una valoración y de darle fuerza normativa al valor resultante justamente en virtud de este procedimiento. En este sentido, pues, la normatividad deweyana podría entenderse a nivel procedimental antes que de contenido aun cuando, según intentaré argumentar más adelante, el valor específico de la democracia pueda ser tomado como una prescripción con contenido.

\section{Críticas y aclaraciones sobre el sentido deweyano de normatividad}

Dado que tanto las críticas de Lewis como las de White se dirigen especialmente al capítulo 10 de La Búsqueda de la Certeza de Dewey, parece oportuno reconstruir en términos generales la propuesta allí presentada y luego dar paso a las objeciones. Recuérdese lo dicho acerca de la "división intestina" de la filosofía moderna producto del colapso entre los avances de la revolución científico-experimental y la estructura conceptual heredada sobre la naturaleza del conocimiento y de los valores (Cf. capítulo 2.2 de esta tesis). Dewey señala al respecto que las creencias acerca de los valores están en una situación muy similar a las creencias acerca del mundo antes de la revolución científica, situación que conduce a una bifurcación: o bien hay una desconfianza de la capacidad de la experiencia para desenvolver sus propios criterios reguladores y por ello se apela a valores eternos que guíen la acción, o bien se aceptan los goces inmediatamente experimentados, sin incidencia de ningún método u operación.

En este marco, la filosofía debe enfrentarse con lo que Dewey considera su problema más apremiante, a saber: cómo integrar las creencias acerca del mundo y las creencias acerca de los valores y fines que deben dirigir su conducta. Así las cosas, la indicación deweyana es clara: "Para salir al encuentro de las condiciones de la situación presente, es menester el empirismo experimental en el campo de las ideas de lo bueno y lo malo." (Dewey, 1952, p. 226. LW.4.206).

El empirismo experimental implica afirmar la consecuencia que la cosa satisfactoria establecerá activamente, vale decir, implica una predicción que contempla que en el futuro esa cosa satisfactoria seguirá siéndolo. De esta manera, se trata de examinar las consecuencias efectivamente atribuibles a nuestros deseos (y más aún, a nuestras costumbres e instituciones morales, políticas y económicas) para considerar inteligentemente el modo de modificarlas a favor de la generación de consecuencias 
diferentes, todo ello en base a la evaluación en su relación de medios a fines y con el auxilio de los hallazgos de las propias ciencias naturales. A partir de aquí queda claro que una perspectiva como la deweyana tiene por interés final la modificación activa de condiciones objetivas. Sin lugar a dudas, señala Dewey, uno de los efectos de llevar adelante tal propuesta se vería en el importante cambio en la significación de los criterios, principios y reglas, pues como ha sido indicado con anterioridad ya no serán reconocidos como estándares rígidos o fijos sino como hipótesis, es decir, como “[...] instrumentos intelectuales que tienen que ser puestos a prueba, y modificados en su caso, según qué consecuencias acarrea el ponerlos en práctica." (Dewey, 1952, p. 242. LW.4.221). Puede verse entonces que la posición presentada por Dewey en La Búsqueda de la Certeza no difiere con lo que una década después presentaría en "Teoría de la Valoración”, toda vez que ambas exhortan al empleo de los desarrollos científico-experimentales para estudiar las relaciones condición-consecuencia de las cosas en cuanto bienes o valores surgidos del curso de experiencia.

Como he adelantado, la recepción inmediata por parte de Lewis respecto del planteo trae consigo una crítica aguda acerca de las nociones de "bueno" y "correcto" -crítica a la que, hasta donde puedo rastrear, Dewey nunca respondió de modo directo. White, por su parte, señala la incapacidad del planteo de Dewey (e incluso del propio Lewis) para fundamentar la obligación moral. En lo que sigue propongo, pues, reconstruir ambas críticas y aventurar algún tipo de respuesta desde el punto de vista de Dewey.

\subsection{Las objeciones de Lewis y White}

Lewis comienza su “Review of John Dewey's The Quest for Certainty" (1970) señalando una serie de tesis centrales que estructuran a toda la obra y con las que, en su carácter de pragmatista, está completamente de acuerdo: (i) la continuidad entre conocimiento y acción, (ii) la función de los conceptos empíricos como prescripción de operaciones a ser ejecutadas y (iii) la consideración del conocimiento como predicción de nuestros propios modos de acción inteligentemente dirigidos. ${ }^{49} \mathrm{Sin}$ embargo, Lewis

\footnotetext{
${ }^{49}$ La publicación original apareció en 1930 en The Journal of Philosophy, Vol. 27, N 1, p. 14-25. Aquí utilizo la referencia de Collected Papers of Clarence Irving Lewis (1970) y una traducción preliminar cedida por Victoria Sánchez García.
} 
considera que la teoría del conocimiento deweyana dejaría algo importante sin decir acerca del fundamento [ground] y la validez del conocimiento, a tal punto que desde esa perspectiva lo único que podría concebirse como conocimiento es a posteriori [hindsight]. Más aún, Lewis indica que incluso si se conserva la interpretación del conocimiento como hipotético, se debería responder a la pregunta por su validez pues o bien se entiende que refiere a una proposición hipotética y en ese caso se tendría que validar la proposición en su conjunto (y más precisamente el consecuente), o bien se entiende que hipotético refiere a "tentativo" o "probable", en cuyo caso se tendría que responder a la pregunta por qué es lo que lo vuelve más o menos probable.

De acuerdo con Lewis, interpretar la situación cognitiva como una investigación experimental guiada por hipótesis que no son sino predicciones de consecuencias a obtener por medio de las operaciones que prescribe la propia investigación no es motivo suficiente para dejar de lado la distinción entre el fundamento y el contenido del conocimiento. En este sentido, hay incluso un aspecto temporal que diferencia a ambos factores pues si el contenido del conocimiento remite a la predicción del futuro en tanto condicionado por la acción, el fundamento de nuestro conocimiento descansa en algún factor antecedente, sin perjuicio de que el conocimiento implique cierta continuidad que se extiende desde el pasado hacia el futuro. Si bien Lewis considera que elevar esa trans-temporalidad al status de objetos trascendentes es un procedimiento ilícito, aun así estima que para resolver el problema de la validez de las creencias empíricas es necesario algún tipo de fundamento.

El segundo punto que observa Lewis refiere al instrumentalismo deweyano según el cual la correcta aprehensión de un objeto descansaría en las operaciones que prescribe y las anticipaciones que hace el concepto de ese objeto, al tiempo que el conocimiento efectivo del objeto dependería del uso [test $]$ que de él se haga. Según esta lectura, Dewey propondría un instrumentalismo que iría más allá de su versión clásica pues el fin del conocimiento se debe interpretar en términos prácticos y ya no teóricos o intelectuales tesis que de acuerdo con Lewis constituye el eje subyacente a toda la pieza de Dewey. Esta "subordinación ontológica" de lo abstracto a lo concreto representa, de acuerdo con Lewis, el corolario del principio ético según el cual la actividad intelectual que conduce a los objetos abstractos no debe concluir en ellos sino antes bien ser instrumentos para una función práctica, aquello que Lewis denomina tesis ética del instrumentalismo. 
Los últimos pasajes de la reseña se concentran, pues, en el referido capítulo 10 de La búsqueda de la certeza. Lewis recupera la propuesta de tender continuidades entre el método experimental de una ciencia humanizada y la teoría de los valores, en la medida en que ello nos permitiría superar la distancia entre la aprehensión teórica y práctica del mundo. Ahora bien, frente a la expresión deweyana que afirma que los juicios de valor son juicios sobre las condiciones y los resultados de los objetos experienciados que regularían la formación de nuestros deseos e intereses, es decir, frente a la idea de que la experiencia puede desenvolver sus propios estándares regulativos, Lewis observa que si bien la experiencia nos puede indicar qué cosas, situaciones o eventos son buenos, no puede ella misma determinar el criterio de lo bueno sino que éste debe ser "traído" [bring to] a la experiencia. En sus términos,

El sentido en que "la experiencia puede desarrollar sus propios estándares regulativos" no es claro. Se observará, por supuesto, que "experiencia" no significa aquí algo meramente dado; para el Profesor Dewey, el sujeto de experiencia y sus actitudes y actos están en la experiencia. [...] ¿Pero no es el caso que nosotros mismos debemos traer a la experiencia el criterio último y la piedra de toque de lo bueno; que de otro modo la experiencia no podría enseñarnos lo que es bueno tanto más que al hombre ciego qué cosas son rojas? La experiencia -la sola experiencia- puede enseñarnos lo que es bueno, si por ello queremos decir qué situaciones, cosas, eventos son buenos; esto es, sólo la sabiduría de la experiencia puede mostrarnos dónde ha de encontrarse lo bueno. Por lo tanto, si por "ideales" queremos decir objetivos concretos tales como democracia o salud o cortesía internacional, entonces la experiencia debe desarrollar sus propios ideales -aunque si se puede confiar en ello es, quizás, otra cuestión. ¿Pero puede la experiencia determinar la naturaleza, la esencia, los criterios de lo bueno? Antes de embarcarse en el problema práctico y empírico de realizar lo valioso o de construir lo bueno, ¿no es esencial que uno pudiera reconocerlo cuando se le revela; que uno supiera, no qué objetos o qué situaciones concretas, sino qué calidad de vida -ya sea el placer o el autocontrol, la actividad en concordancia con la virtud o el amor intelectual de Dioses la que se ha de realizar o 
construir? Frente a este problema, difícilmente podemos adoptar actitudes hipotéticas, dejando que la respuesta justa la determine el proceso social e histórico, porque la cuestión de si la historia humana es progreso o decadencia dependerá de ello. (Lewis, 1970, pp. 75-76).

La extensa cita anterior trae consigo una serie de consideraciones centrales. En primer lugar, la crítica de Lewis apunta a señalar que Dewey no distinguiría entre el criterio o esencia de lo bueno y su "darse" en la experiencia. Dada su apuesta por el desarrollo de criterios a partir de la experiencia, Dewey omitiría completamente la cuestión de lo correcto. Dicho de otra manera, Dewey disolvería lo correcto como criterio en lo bueno como experienciado. En segundo lugar, Lewis parece introducir una diferencia entre objetivos concretos y objetivos abstractos, afirmando que respecto de los primeros la experiencia puede desarrollar sus propios ideales de carácter hipotético sobre la base de los procesos sociales e históricos, mientras que para los segundos no, toda vez que de ellos depende el progreso o decadencia de la historia humana.

A partir de lo presentado parece posible trazar una analogía entre la crítica lewisiana a la teoría del conocimiento de Dewey y la consideración respecto de los bienes y valores. Desde el punto de vista de Lewis, Dewey no abordaría la pregunta por los fundamentos del conocimiento y la valoración. A diferencia de la postura atribuida a Dewey, Lewis considera que el análisis de la experiencia es una tarea necesaria pero no suficiente para dar cuenta del criterio de corrección y en especial de los fundamentos que lo legitiman, esto es, de los elementos que operan pragmáticamente a priori. ${ }^{50}$

\footnotetext{
${ }^{50}$ En "Practical and Moral Imperatives" (1949) Lewis intenta probar que su posición naturalista y pragmática es compatible con el reconocimiento de algún tipo de fundamento de la obligación para con los demás o de imperativo moral válido. Si bien el artículo está escrito en respuesta a las observaciones de Browning y White acerca de la imposibilidad del pragmatismo de dar solución al problema del escepticismo moral, entiendo que la referencia es pertinente porque allí Lewis afirma, por una parte -y frente a la expresión humeana según la cual no es válido derivar un debe de un es- que no puede haber un es sin un debe, vale decir, que no hay justificación o corrección sin presuponer la validez de los principios normativos antecedentes; y, por otra parte, que la obligatoriedad del imperativo descansa en un a priori pragmático. En "Pragmatism and the Roots of Morals" de 1956 Lewis retoma la asunción de que todo conocimiento implica normatividad y afirma que no es el resultado exitoso lo que prueba que el juicio está justificado, del mismo modo que el carácter normativo de las creencias garantizadas no es su buen funcionamiento sino cómo representan lo que es correcto en el modo del creer. Lewis integra a esta observación una segunda tesis de notoria relevancia: "[...] lo bueno solicita, pero lo correcto ordena. Es deseable adherir a lo que es bueno, es imperativo conformarse a lo que es correcto" (Lewis, 1969, p. 106). En este contexto, Lewis entiende por bueno a aquello que constituye una experiencia satisfactoria y por correcto aquello que creemos justificadamente que conducirá a
} 
Por su parte, las críticas de White, dirigidas tanto a Dewey como al propio Lewis, son de corte más analítico y apuntan a señalar que ninguno de los dos -ni, generaliza White, el pragmatismo en su conjunto- ha logrado solucionar el problema más acuciante de la ética, a saber, cómo pasar de un "hecho positivo" a una norma que guíe las acciones. De acuerdo con White, Dewey no habría sido capaz de ofrecer una concepción naturalista de la obligación mientras que Lewis, más allá de las notorias diferencias con el planteo deweyano, terminaría por asumir que las aseveraciones éticas no son empíricas y que, en consecuencia, requieren otro tipo de fundamentación. ${ }^{51}$

La afirmación central de White respecto de la propuesta deweyana es que el pragmatista no lograría distinguir cabalmente entre lo deseado y lo deseable en tanto afirmaciones de facto y de jure, respectivamente, dado que toda su posición se construye sobre una vinculación entre ambos. En consecuencia, Dewey no brindaría una explicación clara de "x debería ser deseado" [ought to be desired] como derivado de "x es deseable" y su naturalismo ético queda sujeto a una dificultad seria. En términos argumentativos White se apoya en ciertos pasajes en los que Dewey diferencia entre el reporte de una sensación inmediata y una afirmación acerca de una propiedad objetiva de las cosas. A partir de aquí, elabora una analogía que se desprendería de la perspectiva deweyana y luego busca una reducción al absurdo. ${ }^{52}$ El primer elemento de la analogía es la siguiente derivación: (i) " $\mathrm{x}$ se me presenta rojo ahora" es un reporte de sensación inmediata distinto a (ii) "x es objetivamente rojo"; sin embargo, "x es objetivamente rojo" puede contener reporte de sensación inmediata pues Dewey también parecería aceptar-siempre en la interpretación de White- que "x es objetivamente rojo" es equivalente a (iii) "para toda persona normal y, si y mira a x bajo condiciones normales, entonces x se le presenta rojo". Si se acepta esto, el segundo elemento de la analogía es la siguiente derivación: (i') "x es deseado por mí ahora"; (ii') "x es deseable"; "x es deseable" es equivalente a (iii') "para toda persona $y$, si

resultados buenos de experiencia, más allá de que las consecuencias efectivas de la acción resulten buenas o no (sobre este punto, Cf. Sánchez García, 2015, p. 171 y siguientes).

${ }^{51}$ La publicación original del artículo de White es de 1949: "Value and Obligation in Dewey and Lewis", The Philosophical Review, Vol. 58, p. 321-329. Aquí trabajo con una versión modificada y publicada en la compilación de artículos John Dewey. Critical Assessments, Vol. 3 [J. E. Tiles (Ed.), 1992]. Para un detallado análisis crítico de las objeciones de White a Lewis, Cf. Sánchez García (2017).

52 Posteriormente White aclara que la analogía propuesta se apoya en la idea de Peirce por la cual que una rosa sea roja significa, y sólo puede significar, que puesta frente a un ojo normal, a la luz del día, la rosa aparecerá roja (White, 1996, p. 240). 
y mira a x bajo condiciones normales, entonces x es deseado por y". En suma, White entiende que para Dewey la relación entre "deseable" y "deseado" sería análoga a la relación entre "objetivamente rojo" y "se aparece rojo".

El punto crítico es que, si la analogía es adecuada, "x es deseable" no tendría más cualidad de jure que "x es objetivamente rojo", de modo que "x es deseable" no tendría más fuerza normativa que "x es deseado". Puesto de modo inverso, si se acepta (iii') entonces (iii) sería "x debería aparecer rojo". Ahora bien, plantea retóricamente White, "[...] ¿queremos decir con esto que hay una obligación moral de ver x rojo? Yo no pienso eso. Esa afirmación no expresa ninguna pretensión moral y por esa razón cuando decimos que ' $x$ es deseado' por cualquier persona normal que lo mira bajo condiciones normales, no parece que estemos aseverando ninguna obligación moral.” (White, 1992, p. 31). En consecuencia, no hay un análisis adecuado de "x es deseable" en el sentido de "x debería ser deseado" sin que "x aparece rojo" conduzca a "x debería aparecer rojo" en sentido moral, conclusión “[...] absurda y por lo tanto fatal para la visión de Dewey." (White, 1992, p. 32. Traducción propia). ${ }^{53}$ En este sentido, y sigo aquí la interpretación de Sinclair (2014, pp. 41-44), la objeción de White no reproduce el típico cargo de falacia naturalista, es decir el intento de derivar un debe de un es, sino que cuestiona la premisa deweyana por la cual los juicios valorativos en cuanto tipo especial de juicios prácticos revistan la misma forma lógica que los juicios de hecho -y, con ello, cuestiona la posibilidad de que esa lógica de los juicios prácticos fuera suficiente para dar cuenta de la obligación moral.

White incorpora una segunda interpretación o "variante" del modo en que Dewey comprendería la relación entre deseado y deseable en su Social Thought in America (White, 1949). Esta lectura plantea que, según Dewey, una cosa sería deseable sólo cuando conocemos sus condiciones y consecuencias. No obstante, señala White, conocer las condiciones antecedentes y las consecuencias de una acción no implica ningún tipo de obligación moral respecto de ella. En ese sentido, ejemplifica White, conocer las

\footnotetext{
${ }^{53}$ Según aclara White en "Postscript on Dewey and Mill", la crítica que hace a Dewey no es la clásica crítica hecha a John Stuart Mill respecto de la confusión del sentido disposicional y normativo de "visible" y "deseable", respectivamente. En otras palabras, White no considera que Dewey cometa la falacia naturalista. En efecto, argumenta que Dewey no se ve forzado a sostener que cualquiera sea la cosa deseada, entonces es deseable, del mismo modo que cualquier cosa que se aparece roja no es necesariamente roja, dado que en ambos casos interviene la "observación de personas normales bajo circunstancias normales". Justamente esa condición es lo que impide derivar " $\mathrm{x}$ es deseable" de "x es deseado por mí ahora" tanto como impide derivar "x es rojo" de "x se me aparece rojo ahora" (White, 1992, p. 34-36).
} 
condiciones antecedentes del deseo de fumar opio y las consecuencias de hacerlo no imprime ninguna obligación moral al deseo de no fumar opio.

Desde aquí White elabora una "definición abierta" de deseable derivada del planteo deweyano, del siguiente modo: "yo debería desear no fumar opio sólo en caso de conocer los antecedentes causales de mi deseo de no fumar y también conocer que las consecuencias de ese deseo serían...". Dada esta definición las alternativas posibles son o bien (i) las consecuencias de ese deseo serían ellas mismas deseables, lo cual conduciría a una definición circular, o bien (ii) las consecuencias de ese deseo serían ellas mismas deseadas, con lo cual (a) la proposición "no fumar opio es deseable" se torna falsa si la persona involucrada no desea las consecuencias de desear no fumar (por ejemplo, la abstinencia), o (b) el deseo de no fumar opio debe ser reconsiderado si tiene consecuencias que la persona involucrada no desea (por ejemplo, el insomnio). La conclusión de White, entonces, es que no tiene sentido incluir lo deseado en el análisis de lo deseable porque eso implica incluir la consideración de cada persona particularmente involucrada y no la de cualquier persona bajo condiciones normales (White, 1949, pp. 216-217).

\subsection{Respuestas y aclaraciones}

Si bien los cuestionamientos de Lewis y White no apuntan precisamente al mismo tema, a mi juicio admiten respuestas que se fundamenta en un aspecto en común, a saber, una concepción de la normatividad naturalizada y deudora del proceso de deliberación metódica que supone toda valoración (valga por ahora esta descripción, en el próximo capítulo buscaré aclarar, a la luz de la pauta general de la investigación, por qué la valoración es ella misma un tipo de investigación). Intentaré a partir de aquí brindar respuestas a ambas objeciones. Para eso invertiré el orden de la discusión: inicialmente reconstruiré los argumentos de Kennedy y Sleeper frente a White junto con la devolución

del propio Dewey (escrita en 1950 pero publicada recién en 1990) y luego consideraré algunas respuestas a ambas críticas.

Las críticas de White a Dewey han tenido una notoria recepción en la literatura especializada sobre pragmatismo. Una de las primeras respuestas, si bien implícita, puede encontrarse en el artículo de 1955 de Gail Kennedy, "The Hidden Link in Dewey’s Theory 
of Evaluation". Como indica su título, el tema del texto es el "eslabón escondido" mas no "perdido" de la teoría de la valoración deweyana, aquel que permite vincular proposiciones descriptivas con proposiciones prescriptivas. El planteo de Kennedy es el siguiente: frente a una situación de valoración, sea tanto porque el valor en cuanto estimación habitual se muestra insuficiente para resolver la situación deficitaria o porque la situación es tal que pone en tensión algunas estimaciones habituales, el proceso de valoración apoyado en el conocimiento de los elementos intervinientes en términos de condiciones y consecuencias termina por aconsejar un determinado curso de acción en detrimento de otros posibles. La pregunta crucial es, de acuerdo con el autor, por qué se debe seguir ese curso de acción, vale decir, por qué un conjunto de afirmaciones descriptivas se torna prescriptivo. La respuesta constituye el mentado "eslabón escondido" de la perspectiva deweyana: se debe seguir ese curso de acción porque es la solución más adecuada al problema en el sentido de que la alternativa sugerida es el mejor medio que se puede diagramar por referencia al conocimiento empíricamente testeado del que se dispone. "En consecuencia -escribe Kennedy-, las bases sobre las que se apoya toda afirmación prescriptiva son afirmaciones derivadas de la observación y experimentación.” (1955, p. 94. Traducción propia).

La conclusión de Kennedy es, a mi juicio, un buen preludio de la explícita respuesta a White elaborada por Ralph Sleeper en 1960. El argumento de Sleeper se orienta a señalar que la reducción al absurdo de White no está bien construida porque se apoya en dos incomprensiones básicas. En primer lugar, White toma al capítulo 10 de La Búsqueda de la Certeza como una pieza de análisis lingüístico en vez de considerarlo como una investigación respecto de las implicancias de la investigación científica para la moral de modo que, siempre en opinión de Sleeper, White no contempla la preocupación constante de la obra, esto es, la exhortación a considerar problemas específicos, remitidos a la experiencia. A la inversa, según Sleeper -y permítaseme expresar mi acuerdo en este punto- cuando Dewey se enfoca en las proposiciones de facto y de jure "[...] éstas deben ser entendidas en referencia a situaciones concretas de 'tener' [en el sentido explicitado durante el primer capítulo de esta tesis] y 'conocer' antes que en relaciones lingüísticas abstractas." (Sleeper, 1960, p. 104 Traducción propia. Cursivas en el original).

En segundo lugar, White no reconstruye adecuadamente la teoría del conocimiento de Dewey pues considera que la ciencia importa algún tipo de obligación dado el estatus 
"verdadero" u "objetivo" de sus conclusiones. Frente a esta interpretación del conocimiento científico como fuente de la obligación, Sleeper sostiene que la fuerza normativa en cada situación proviene de la situación misma, de sus características, de los deseos e intereses de los agentes involucrados en ella. Dicho en términos negativos, en la medida en que el conocimiento es llamado a informar a la deliberación en situaciones inicialmente deficitarias y en que el objetivo de todo el proceso de valoración es la reconstitución de una nueva situación unificada, dicho conocimiento científico aislado de las condiciones existenciales concretas de cada situación no es suficiente para dictar ningún tipo de obligación o normatividad, esto es, ninguna proposición de jure. Estas observaciones permiten comprender por qué Sleeper estima que el error estructural de White es haber desvinculado la teoría del conocimiento de la metafísica (o, mejor dicho, de la dimensión cualitativa de la experiencia, según se desprende del capítulo 1) e intentar demostrar que la obligación moral se adscribiría a toda proposición científica cuando, en rigor, las proposiciones científicas acerca de condiciones y consecuencias de cursos de acción alternativos adquieren carácter de jure solamente frente a situaciones indeterminadas, habida cuenta de la "[...] creencia empíricamente testeada de que la inteligencia sirve más adecuadamente que otras agencias para alcanzar soluciones satisfactorias a los problemas reales de las personas." (Sleeper, 1960, p. 108. Traducción propia).

Ahora bien, como he indicado, la discusión entre White y Dewey tiene otro capítulo. En 1950 Dewey efectivamente escribe "Comment on Recent Criticisms of Some Points in Moral and Logical Theory" en respuesta a White pero esas páginas no ven la luz sino en 1990, gracias a su publicación póstuma en el último volumen de los Collected Works of John Dewey (LW.17). En lo que sigue recuperaré los puntos centrales de la devolución hecha por Dewey en función de identificar algunos elementos que permitirán terminar de delinear su noción de normatividad.

El primer elemento a considerar de la respuesta de Dewey es el modo en que describe los términos del problema -y orienta, desde el comienzo mismo de su argumento, toda la respuesta ulterior. Según el pragmatista, el tema general de discusión concierne al método de conocer y de obtener conclusiones. Con esta definición inicial Dewey apunta a señalar una diferencia de supuestos filosóficos entre su posición y la de White: mientras 
este último depende de alguna noción de "deseable en sí mismo", correlativa con el intuicionismo en ética y el apriorismo en epistemología, Dewey afirma que esa dependencia no hace sino reforzar su "[...] énfasis en la investigación de condiciones y consecuencias como el único camino por el que se pueden alcanzar afirmaciones válidas sobre lo deseable.” (LW.17.481-2). Este énfasis supone el movimiento contrario al hecho por White, vale decir, supone retirar [bring out] el conocimiento ético del plano de los absolutos e incluirlo en el método de la investigación filosófica en general y de la investigación moral en particular en cuanto análogo al método de la ciencia y la tecnología en cuanto investigación sistemática de condiciones y consecuencias.

El segundo punto relevante de la respuesta de Dewey es el modo en que pretende desmarcarse de la estrategia de reducción al absurdo planteada por White. Frente a la reconstrucción de White por la cual Dewey "genera una proposición normativa o de jure mediante una operación adecuada sobre proposiciones meramente de facto" -algo que, dice Dewey, parece acusarlo de depender de "una variedad de magia intelectual"-, el pragmatista señala tres puntos cruciales: (i) la operación es hecha por medio de las proposiciones [by means of them] y no sobre ellas [on them], cuestionando así la pretensión de reducir la proposición "x es deseable" a "x es deseado"; (ii) las proposiciones con las que lo deseable es determinado como normativo son resultado de la investigación sistemáticamente conducida y no de proposiciones tomadas casual o azarosamente; y (iii) las condiciones y consecuencias consideradas tampoco son una mera recolección de datos o proposiciones de facto sino que están existencialmente vinculadas a la situación que reclama resolución (en este punto la defensa de Dewey es similar a la de Sleeper, quien por supuesto no conocía este artículo al momento de escribir el suyo).

El tercer elemento apuntado por Dewey es el sentido de "bajo condiciones normales", sobre el que descansa el argumento de White. En efecto, señala Dewey, el calificativo "normal” es ambivalente y White no se encarga de aclarar esta cuestión. Así, "normal" puede remitir a aquello que sucede con frecuencia o a algún valor promedio, o bien puede remitir a las condiciones instituidas por la investigación continuada y en vistas a un fin, en cuyo caso lo "normal" es intrínsecamente normativo o de jure. Luego, Dewey le da la bienvenida a la identificación de White pero sólo si su dirección es "completamente revertida": "x es objetivamente rojo" es análogo a "x es deseable" porque ambos son 
proposiciones empíricas en el sentido de experimentalmente determinadas bajo condiciones normales/normativas. ${ }^{54}$

Crucialmente interesante es, en mi opinión, la frase con que Dewey cierra el texto: “Ellas [las condiciones 'normales'] son obtenidas llevando adelante el tipo de actividades que según el mejor conocimiento disponible en el momento deben ser intentadas en orden a identificar sus consecuencias específicas en y para futuro conocimiento.” (LW.17.484). Si las condiciones normales son normativas en el sentido de sentar referencias para los casos particulares y si ellas se obtienen mediante la acción aconsejada por la investigación, entonces esta última parece ser la fuente de la normatividad. Por lo tanto, "x es deseable" no puede derivarse solamente de "x es deseado", tal y como parece exigir White, aunque "x es deseado" siempre será parte de la evaluación para concluir si "x es deseable", toda vez que, como indica reiteradamente Dewey en "Teoría de la Valoración", los deseos o estimaciones actuales son condición necesaria pero no suficiente para una valoración en sentido genuino. El eslabón intermedio (ni escondido ni perdido, pace Kennedy) es, sin más, la investigación empírica sistemática.

En esta misma línea corren los recientes aportes de Robert Sinclair (2014). En su análisis, Sinclair enfatiza el carácter práctico de los juicios valorativos en general y morales en particular, cuya corrección queda definida, en última instancia, por el ajuste entre las consecuencias previstas y las consecuencias efectivamente obtenidas. De esta manera Sinclair señala que Dewey no está discutiendo el asunto de la obligación moral sino el asunto de la investigación valorativa y del modo de asegurar ciertas consecuencias elegidas luego de un proceso de deliberación. En sus términos, "[u]na vez que la evaluación

\footnotetext{
${ }^{54}$ El intercambio incluye dos piezas más. Por un lado, el texto "The Desirable and Emotive in Dewey's Ethics" de Sidney Hook (1950), escrito en respuesta a White. Allí Hook se concentra en la "segunda variante" de argumento de White. Por el otro, una réplica del propio White (1996) en la que (i) reconstruye su posición, (ii) responde a la interpretación que presenta Alan Ryan en John Dewey and the High Tide of Liberalism, según la cual White acusa a Dewey de cometer la falacia naturalista y finalmente (iii) responde a Dewey. Si bien no detallaré los argumentos de White - poco agregan, en mi opinión, a lo ya dicho por él mismo con anterioridad-, sí considero importante señalar que aun cuando reconoce y adhiere a los esfuerzos de Dewey frente a las distinciones agudas entre los modos de testear proposiciones empíricas y morales, finalmente termina por definir a la posición del pragmatista en términos de "naturalismo reduccionista", a diferencia de su propio "naturalismo ético corporativo". (White, 1996, p. 241). Queda pendiente la pregunta por el tipo de elemento que exige White para superar el reduccionismo deweyano, habida cuenta de que (i) no debería apelar a ningún tipo de a priori en virtud de mantener el carácter naturalista de su posición, y (ii) la investigación acumulada de condiciones y consecuencias no parece ser suficiente, desde su punto de vista, para dar cuenta de la fuente de la obligación moral.
} 
normativa es entendida como juicio práctico, puede verse nuevamente que los juicios acerca de qué deberíamos [should] hacer están pensados como directivas falibles para la solución de un problema moral antes que como prescripciones morales que debemos [must] seguir.” (Sinclair, 2014, p. 47. Traducción propia). Esta lectura es ciertamente consistente con lo afirmado al momento: el valor en cuanto fin a la vista generalizado cuenta con el respaldo de la investigación, respaldo que se apoya en dos puntos claves y mal interpretados por White: la imposibilidad de asumir una separación lógica estricta entre la dimensión descriptiva y la dimensión normativa, por una parte, y el carácter metodológico y no semántico de la analogía entre los juicios de hecho y los juicios de valor (Sinclair, 2014, p. 53). A estas razones deberían agregarse un punto más, no considerado por Sinclair: el papel del método genealógico, no sólo en su aspecto retrospectivo sino especialmente en su aspecto prospectivo, es decir, en tanto provee un principio o presunción de validez y aporta elementos importantes para dar cuenta del juicio valorativo, especialmente moral, en un marco naturalista.

Estas últimas observaciones son, a su vez, el punto de retorno a la crítica de Lewis. Según he señalado con anterioridad, Dewey entiende a los valores como fines a la vista generalizados que, por un lado, cuentan con el respaldo de las proposiciones evaluativas en tanto análisis empírico de las cosas en su relación condición-consecuencia y, por el otro, mantienen su carácter hipotético, vale decir, son puestos a prueba en la experiencia cada vez. En la medida en que estos valores se consolidan como respuestas satisfactorias a un tipo general de situaciones problemáticas se tornan normativos en el sentido de constituirse como referencia para aplicar operativamente en los nuevos casos y fungir como criterio de corrección para la formación de deseos e intereses ulteriores -o para "reconocer lo bueno", según se sigue de la observación de Lewis. Más aún, al referirse a los marcos de condiciones Dewey observa que "[...p]odemos decir incluso que funcionan como un principio 'a priori', pero exactamente en el mismo sentido en que las reglas para ejercitar un arte tecnológico anteceden y a la vez controlan en un caso dado de ese arte." (2008b, p. 125. LW.13.233). No obstante, el carácter normativo viene dado por la investigación empírica acumulada y la superación, una y otra vez, de esos valores en su rol de medios directivos para resolver la situación. Luego, y a riesgos de resultar insistente, la teoría de la valoración de Dewey supone una normatividad enraizada en la experiencia pues su material 
proviene sólo de allí, fundada en la investigación acumulada y empíricamente regulativa. La normatividad no está dada por cuánto se acomode un principio o norma a un standard previo, dado a priori (cualquiera sea su fuente) sino porque la experiencia ha mostrado al momento que son los mejores principios disponibles para resolver las situaciones problemáticas y la abstracción de esos mismos principios ofrece un criterio para próximas resoluciones -criterio que no es idealmente perfecto sino siempre pasible de reformulación (Cf. Dewey, 1950, pp. 122. LW.12.107-108).

La explicación reciente está en sintonía con las observaciones de Kennedy, Sleeper y Dewey. En efecto, los puntos en común son (i) subrayar que los juicios valorativos son juicios prácticos, esto es, juicios en los que algo debe ser hecho [has to be done]; y (ii) enfatizar el rol de la investigación para dar cuenta del carácter normativo de esos juicios prácticos. No obstante, hay un punto clave que en mi opinión no ha sido abordado por ninguna de estas tres respuestas y que es sugerido pero no desarrollado por Gertrude Ezorsky (1958). En línea con el argumento antes referido Ezorsky plantea que todo resultado de una investigación es normativo pues conforma un standard al que se deben conformar las investigaciones subsiguientes. Y agrega la siguiente pregunta: “¿No se puede hacer ninguna distinción entre el tipo de investigación que conducimos en ciencia y el tipo de investigación que tiene lugar sobre lo que ordinariamente consideramos valores?" (Ezorsky, 1958, p. 122).

El criterio de identificación propuesto por la autora es el asunto de la investigación, su subject-matter. Así, las investigaciones sobre valores se distinguen de otro tipo de investigaciones porque su asunto es el deseo. Desde mi punto de vista, este argumento puede ser extremado y, junto con las consideraciones realizadas respecto de la dimensión cualitativa de la experiencia en general y de las situaciones morales en particular, permite esbozar otro tipo de respuesta a White: el carácter normativo que supone la proposición " $\mathrm{x}$ es real/objetivamente rojo", en cuanto derivado de una investigación, es cualitativamente distinto al carácter normativo de la proposición "x es deseable" porque las situaciones que originan ambos tipos de investigación y, consecuentemente, toda la investigación, son distintas en ese mismo respecto. Si se considera esta diferencia, la reducción al absurdo imputada por White pierde sentido porque la analogía planteada, si bien se sostiene por 
referencia a la perspectiva metodológica, no se sostiene por referencia a la dimensión cualitativa. Dicho de otra manera, dada la diferencia en términos cualitativos el absurdo de concluir "x debería verse rojo" en sentido moral es ciertamente esperable pero no hace mella en el planteo de Dewey sino, en todo caso, en la construcción del argumento del propio White, quien no tiene en cuenta todos los elementos necesarios para su elaboración y reduce la normatividad a la normatividad moral.

\section{Conclusiones}

El objetivo del capítulo ha sido avanzar en el estudio de la concepción deweyana sobre los valores, esta vez desde lo que he denominado perspectiva metodológica. El análisis estuvo signado por algunos elementos transversales al tratamiento que ofrece Dewey sobre este tema, a saber: (i) la consideración de los juicios valorativos como juicios prácticos; (ii) cierta continuidad entre los juicios valorativos y los juicios científicos; y (iii) la idea de que los juicios relativos a valores no se agotan en reportar o describir valores en cuanto estimaciones de hecho sino que consideran si un valor dado es valioso y a dar lugar a nuevos valores en la experiencia. Estas tres consideraciones sintetizan, en mi lectura, gran parte del planteo del pragmatista pues (i) dan cuenta del vínculo insoslayable entre experiencia y valoración, vínculo que fundamenta las críticas de Dewey a todo apriorismo en materia de valoración; (ii) dan cuenta del rol que juega el conocimiento científico en los juicios valorativos, particularmente en lo que Dewey denomina juicios evaluativos respecto de las relaciones condición-consecuencia, rol que a su tiempo permite comprender los cuestionamientos de Dewey al emotivismo en cuanto posición meta-valorativa (especialmente meta-ética) derivada de la versión standard del positivismo lógico; y (iii) dan cuenta del carácter prospectivo de la visión deweyana, toda vez que alienta a reconsiderar las estimaciones y a formar creativa e inteligentemente nuevos fines y valores cuando el acervo disponible no es suficiente para resolver la situación de valoración.

En este marco, el objeto central de análisis ha sido "Teoría de la Valoración", texto que ofrece la elaboración más madura de la posición deweyana respecto de la perspectiva metodológica -sin perjuicio del interés y las especificidades que puedan reportar otros textos como "Logical Conditions of a Scientific Treatment of Morality" o "The Logic of Judgments of Practice". El primer elemento tratado ha sido el concepto deweyano de fin a 
la vista y su triple constitución afectivo-ideacional-motora, constitución que por un lado enfatiza el estrecho vínculo entre fin a la vista y deseos y por el otro señala la indispensable consideración inteligente de los deseos e intereses en cuanto resultado de investigar condiciones y consecuencias y siempre orientados a la resolución de algún problema práctico. Esta consideración es una de las claves para comprender la diferencia entre proposiciones sobre estimaciones y proposiciones evaluativas respecto de la relación de las cosas en términos de condiciones-consecuencias. Asimismo, en la medida en que las proposiciones evaluativas están científicamente informadas $\mathrm{y}$, a su vez, están a la base de las proposiciones valorativas propiamente dichas, aquellas cuyo objeto de consideración son los propios valores, entonces se pone de manifiesto un primer sentido en que la investigación científica y la valoración aparecen estrechamente vinculados -sentido que se torna crucial para las consideraciones de la segunda parte de esta tesis.

El segundo elemento tratado ha sido la novedosa tesis de Dewey respecto de la continuidad entre medios y fines, cuyo estudio me ha permitido distinguir dos sentidos de continuidad. Por un lado, hay continuidad "en situación”, referida a una relación mediosfines determinada en la que el fin a la vista siempre es evaluado y reevaluado en función de la disponibilidad o el costo de sus medios y de la apreciación de los propios medios, cuya modificación, en esa misma medida, implica la modificación del fin, dando cuenta de la interdependencia e inextricabilidad de unos y otros. Por otro lado, hay continuidad "en sentido amplio", referida a que en el curso de experiencia todo medio presente ha sido un fin alcanzado con anterioridad y todo fin de hecho alcanzado será un medio para futuros fines. En consecuencia, formará parte de las condiciones existenciales que deberán ser tenidas en cuenta en las subsiguientes formaciones de deseos e intereses y será evaluado como recurso o como obstáculo para la ocurrencia de nuevas valoraciones. Además, este sentido amplio supone la incidencia del contexto en la valoración pero también de la valoración en el contexto, es decir, del modo en que ciertos valores obtenidos por un genuino proceso de valoración se tornan estimaciones conforme se establecen como instrumento de resolución de problemas y pasan a formar parte de ese mismo contexto. Supone también los aportes del método evolucionario o genealógico considerado en el capítulo precedente, teniendo en cuenta que aporta material respecto de la constitución de 
las estimaciones que es necesario (mas no suficiente) para las valoraciones.

Finalmente, me he concentrado en las objeciones de Lewis y White a la perspectiva de Dewey, objeciones que apuntan a cuestionar el sentido de normatividad que se desprende del planteo aquí estudiado. En efecto, Lewis señala que si bien la experiencia puede indicar qué situaciones, acciones o cosas son "buenas", no puede ella sola ofrecer un criterio de lo que fuera "correcto". Por su parte, White arguye que Dewey no distingue cabalmente entre deseado y deseable y que, en consecuencia, el naturalismo ético de Dewey queda comprometido pues no ofrece una solución al problema de la obligación -y específicamente de la obligación moral. Frente a estos cuestionamientos y apoyado en las lecturas de Kennedy, Sleeper y Ezorsky he intentado subrayar dos cuestiones: (i) desde el punto de vista deweyano la experiencia efectivamente permite desarrollar sus propios estándares regulativos si en ellos queda incluida la evaluación inteligente de cosas, deseos e intereses tal que permita guiar la acción particular mediante la previsión de sus consecuencias y obtener criterios de corrección naturalizados para acciones ulteriores, de forma que la normatividad es resultado de la investigación acumulada; y (ii) la diferencia entre las investigaciones científicas y las valoraciones es de índole cualitativa, punto que según mi lectura no ha sido tenido en cuenta por White al momento de plantear sus críticas. El tratamiento de estas objeciones permite señalar las limitaciones de aquellas lecturas que disocian la perspectiva filosófica-cualitativa de la perspectiva metodológica, y por oposición, permite subrayar la complementariedad de ambos enfoques para un abordaje integral de la concepción deweyana sobre los valores. 


\section{RECAPITULACIÓN Y CONCLUSIONES PARCIALES}

En la primera parte de esta tesis me he ocupado de abordar la relación entre la noción deweyana de experiencia, punto de partida necesario de todo estudio sobre la filosofía de Dewey, y su concepción del valor y la valoración. El análisis de la concepción de experiencia ha intentado poner en claro dos puntos centrales. En primer lugar, y teniendo en cuenta la impronta naturalista de toda la filosofía de Dewey, la experiencia en cuanto transacción entre organismo y ambiente se juega primaria e inmediatamente en términos cualitativos y afectivos, es decir, la experiencia es apreciativa e implica un organismo que actúa constantemente para mantener o restablecer el equilibrio dinámico con su ambiente carácter que he sugerido sintetizar bajo la idea de una lógica de la experiencia. En segundo lugar, la noción deweyana de experiencia no puede comprenderse cabalmente sin referencia a la tesis de la continuidad en la interpretación integral aquí sugerida, esto es, continuidad entre el nivel primario y el nivel reflexivo de experiencia y continuidad entre experiencias a nivel reflexivo cualitativamente distintas. Puesta a la luz de la noción deweyana de contexto, esta interpretación integral expresada bajo la idea de continuo multidimensional de la experiencia permite sostener por un lado que cualquier análisis de una experiencia a nivel reflexivo no puede prescindir de una consideración de su contexto dada la injerencia de este último, por otro lado que no hay escisiones o límites taxativos entre experiencias reflexivas particulares y finalmente que éstas se enriquecen y trans-actúan mutuamente.

Una vez establecidas las líneas teóricas básicas he intentado reconstruir la posición de Dewey respecto del asunto de los valores, tema transversal a toda su reflexión filosófica. Para ello he identificado dos perspectivas que considero solidarias: una perspectiva filosófica, que se concentra en analizar la génesis de los valores partiendo del nivel de experiencia primario, enfatizando así la continuidad cualitativa entre la experiencia apreciativa y la deliberación valorativa (particularmente moral), y una perspectiva metodológica, que se concentra en elucidar la pauta general de la valoración en cuanto evaluación de valores informada por el mejor conocimiento disponible y ubicada siempre en un continuo de valoración. El estudio de ambas perspectivas, entendidas como complementarias, ha permitido observar que el carácter continuo de la experiencia es una 
clave de lectura indispensable a la hora de abordar la propuesta deweyana sobre los valores -y, según intentaré señalar en la segunda parte, también sobre la investigación.

Ahora bien, si se tiene en cuenta lo dicho respecto de la noción de experiencia junto con las ideas de Dewey por las cuales (i) toda práctica supone deliberación acerca de lo que hay que hacer, vale decir, incluye un factor inteligente (1950, p. 182. LW.12.162); (ii) no hay conducta inteligente que no implique valoraciones (2008b, p. 85. LW.13.193); y (iii) toda investigación, incluyendo las científicas, es un modo de práctica (1950, p. 183. LW.12.163, entre otras), resulta claro que el vínculo entre las concepciones deweyana de valoración e investigación amerita una revisión teórica profunda. En la segunda parte de esta investigación me abocaré a dicha tarea, con los siguientes objetivos: identificar los sentidos en los que debe entenderse dicha relación entre valoración e investigación, señalar las razones por las que, según mi hipótesis, Dewey permite pensar que la investigación no es ni debería ser libre de valores tradicionalmente denominados no epistémicos y finalmente analizar el modo en que la visión deweyana de investigación se vincula ineludiblemente con su concepción de la política y en particular de la democracia, al punto que permite perfilar una filosofía política del conocimiento científico. 
SEGUNDA PARTE: INVESTIGACIÓN Y VALORES 


\section{CAPÍTULO 4: LA INVESTIGACIÓN CIENTÍFICA COMO PRÁCTICA}

\section{Introducción}

Una vez puestos de relieve el carácter eminentemente práctico y apreciativo de la experiencia primaria junto con las dos perspectivas de la tarea filosófica respecto del asunto de los valores, el siguiente punto del argumento general de este estudio pasa por establecer las vinculaciones entre conocimiento científico y valores. Para ello, es crucial avanzar en una caracterización de la investigación en general y de la investigación científica en particular como empresas de naturaleza práctica por sobre toda otra consideración. Esta caracterización permite, según intentaré señalar, enfatizar dos tipos de continuidades, retomando aquella distinción presentada en el capítulo inicial. Por un lado, la continuidad en sentido longitudinal entre experiencia primaria y conocimiento científico; por otro lado, la continuidad en sentido lateral entre las experiencias reflexivas particulares del conocimiento científico y la valoración. Ambos tipos de continuidad, cada uno respecto de alguna dimensión particular de la experiencia reflexiva de investigación, permiten explicar lo siguiente: si, como se ha planteado en el capítulo previo, hay continuidad entre valoración e investigación en la medida en que la valoración genuina depende del conocimiento de las cosas en sus relaciones de antecedentes y consecuencias, también hay continuidad entre investigación y valoración, pues en cuanto práctica la primera implica necesariamente la toma de decisiones sobre la base de valoraciones. Luego, investigación y valoración forman un par inescindible. Esta es la afirmación central de los siguientes tres capítulos, cuya tarea será el detallar y analizar alcances y límites de esa tesis central.

En virtud del objetivo trazado, la atención estará concentrada fundamentalmente sobre el texto Lógica. Teoría de la Investigación (1938 [1950]. LW.12). La Lógica, como suele abreviársela, constituye una de las grandes obras de madurez de Dewey, cuyas ideas habían sido anticipadas de modo sumario en Cómo pensamos (1910 [1998]. LW.8), de orientación más pedagógica, junto con los ya mencionados Studies in Logical Theory (1903. MW.2) y Essays in Experimental Logic (una compilación de artículos de Dewey sobre lógica, algunos de ellos escritos para el volumen de 1903, y editados en 1916. MW.10). Según Eugenio Imaz (1950, p. x), la Lógica representa nada menos que la decantación profunda de cuarenta años de pensamiento, sin perjuicio de que sea 
considerada por Dewey como un tratado de carácter introductorio que no alcanza el acabado ni la perfección teóricamente posibles.

La consideración que articula toda la obra es la de la investigación como un continuo, idea que Dewey remite a Peirce y que, en opinión de Dewey mismo, trae consigo la necesidad de aportar una explicación empírica o experiencial de las formas lógicas, esto es, principios y propiedades lógicas. Uno de los objetivos principales de Dewey en esta obra es denunciar la inconsistencia que hay entre sostener una concepción moderna de la ciencia a la vez que una lógica de herencia aristotélica, a tono con lo dicho sobre el "conflicto de autoridades" propio de la filosofía moderna. Para ello el autor repasa varios tópicos de la lógica tradicional aristotélica y los sitúa en el escenario ontológico de la filosofía griega, caracterizado por la distinción entre lo permanente o fijo, vale decir, el ámbito de las formas, y lo variable o cambiante, y por la consideración de que el conocimiento propiamente dicho es el conocimiento teórico, aquel que puede dar cuenta del plano de lo permanente o fijo en tanto expresiones de formas ontológicamente necesarias. El punto central, señala Dewey, es que en ese orden jerárquico de especies fijas y de conocimiento demostrativo y contemplativo, la lógica aristotélica es rigurosamente adecuada, existencial -antes que formal- y describe magistralmente bien los caracteres del conocimiento tal y como eran entendidos por la tradición griega. ${ }^{55}$

De forma análoga a lo sucedido para el caso de los valores, el problema surge cuando la concepción moderna de la ciencia posterior a la Revolución Científica concentra su trabajo en el aspecto cuantitativo de su objeto de conocimiento y deja atrás el trasfondo de esencias o formas fijas pero, a pesar de todos esos cambios, insiste en una lógica de tipo aristotélico, sin observar que dichos modos de entender la lógica son expresión de una metafísica, de una teoría del conocimiento e incluso de un orden social subyacentes. Esta relación incompatible entre concepción científica y lógica es responsable de que se entienda a la lógica aristotélica como una lógica meramente formal, desprovista de objeto de estudio e investigación. En palabras de Dewey, “[1]a confusión que caracteriza a la teoría lógica es

\footnotetext{
${ }^{55}$ Es interesante señalar que Dewey parece concentrar su análisis en los Primeros Analíticos y Segundos Analíticos de Aristóteles, sin dar lugar a los textos del estagirita sobre retórica y dialéctica. Parece entonces que Dewey toma la teoría aristotélica del silogismo deductivo sin dar lugar a otros aspectos de la perspectiva lógica de Aristóteles.
} 
consecuencia natural del intento de retener las formas de la teoría lógica clásica después que han sufrido un cambio radical los métodos de investigación con los que se obtiene el conocimiento y con los que se prueban las creencias.” (1950, p. 112. LW.12.99).

Frente a esta situación Dewey introduce la segunda gran tesis de la obra, a saber, que el objeto de estudio de la lógica debe ser el trabajo efectivo de la investigación en vistas a la obtención de formas lógicas no vacías, es decir, por referencia al curso de la investigación. En estos términos, la lógica es entonces una descripción del modo de trabajo de las investigaciones, una "investigación de la investigación”. Bajo esta idea, la exigencia de una reforma lógica deviene en la exigencia de una teoría unificada de la investigación que busque regular la experimentación operativa de la ciencia y los métodos habituales de investigación del sentido común, desde los que se obtienen conclusiones, juicios y guías de acción. En consecuencia, las formas lógicas tienen que ver con el control de la investigación, se originan en el curso mismo de las investigaciones y dejan de aparecer como sentidos prefijados y externos.

La nueva comprensión de la lógica permite dar cuenta del carácter auto-correctivo de la ciencia, en la medida en que ella misma origina los criterios y formas que mejoran o se descartan en y por el uso, de acuerdo con el éxito o fracaso de cumplir con los fines u objetivos. En este contexto, las formas lógicas son ejemplos de una determinada relación entre medios y consecuencias en la investigación adecuadamente controlada, vale decir, condiciones que en el proceso de investigación continua aseguran resultados exitosos. Estas pautas permiten introducir uno de los ejes transversales de toda la filosofía deweyana: el sentido genuino de lo "pragmático" se refiere a "[...] la función que incumbe a las consecuencias como pruebas necesarias de la validez de las proposiciones, siempre que estas consecuencias se hayan logrado operativamente y que resuelvan el problema que suscita las operaciones [...]" (Dewey, 1950, p. 4. LW.12.4. Primeras cursivas agregadas, segundas cursivas en el original).

Más allá de esta somera presentación de la Lógica, he adelantado ya que el eje de los próximos capítulos estará puesto en el vínculo que establece Dewey entre conocimiento científico y valoración. Por supuesto, esta primera formulación irá refinándose a lo largo del argumento aquí presentado, en la medida en que será necesario responder, entre otras cuestiones, en qué instancia de la investigación inciden valores, qué tipos de valores son y 
de qué forma lo hacen. A efectos de aclarar estos puntos, durante la segunda sección reconstruiré en términos bien generales la pauta o patrón general de la investigación, haciendo hincapié, por una parte, en aquello que Dewey denomina el seno biológico y el seno cultural de la investigación y, por la otra, en la estructura bi-dimensional de la investigación, según el estudio de Matthew J. Brown (2012). En la tercera sección me concentraré en un tema ya mencionado previamente: los juicios prácticos y el rol que juga allí la evaluación, con especial referencia a la investigación científica y a la caracterización del científico como un práctico. Sobre esta base, en el próximo capítulo intentaré identificar con precisión las continuidades entre investigación y valoración a fines de dar respuesta a los interrogantes recientemente asentados y de indicar por qué la perspectiva deweyana es un antecedente de relevancia para lo que años más tarde Hilary Putnam (2002) ha denominado el desplome de la dicotomía hecho-valor. Recorrer este camino permitirá, espero, dar cuenta de los sentidos en que la perspectiva de Dewey habilita a incluir de modo legítimo y deseable la dimensión valorativa en la práctica científica y reflexionar en torno a la ciencia en clave política.

\section{La investigación como forma de acción}

En el marco de las tesis generales de la Lógica y a tono con el compromiso naturalista de toda su filosofía, Dewey considera que toda investigación se inscribe en un seno o matriz existencial que es tanto biológico como cultural. Como he adelantado, según Dewey el método de una teoría naturalista de la lógica debe estar definido por el estudio de lo que ocurre efectivamente en una investigación, prescindiendo de cualquier causa, criterio o principio ajenos a la misma. Además, el pragmatista plantea que hay una responsabilidad intelectual en indicar de qué modo la lógica está conectada con lo biológico en un proceso de desarrollo continuo, condición necesaria para una explicación satisfactoria del carácter naturalista de la disciplina. En este sentido, y como ha sido adelantado en el capítulo 1, el primer postulado de su teoría "[...] se expresa como la continuidad de las actividades y formas superiores (menos complejas) y las superiores (más complejas).” (Dewey, 1950, p. 37. LW.12.30). A la luz de la concepción deweyana de experiencia, y en especial de la idea de la naturaleza como una serie de transacciones superpuestas y combinadas, este primer 
postulado no debería sorprender en absoluto. En efecto, la continuidad aquí referida excluye rupturas o hiatos completos tanto como la mera repetición de identidades, la aparición de fuerzas extrañas a la propia experiencia y, punto crucial, la mera reducción de lo superior a lo inferior, razón por la cual el compromiso deweyano es con un naturalismo no reduccionista.

El objetivo central de Dewey al momento de encuadrar a la investigación en el seno biológico es señalar que hay ciertas funciones y estructuras biológicas que preparan, prefiguran o anticipan el camino para la investigación deliberada. A este respecto es importante recordar que la propia concepción de experiencia deweyana supone que la transacción entre organismo y ambiente se lleva adelante en un ritmo sucesivo de desequilibrios, esfuerzos y nuevos equilibrios o integraciones uniformes con el ambiente equilibrios que, vale insistir, no restablecen las condiciones idénticas de la situación entre ambiente e individuo sino que implican la modificación cualitativa del ambiente $\mathrm{y}$, en consecuencia, del propio organismo y sus posteriores necesidades, dado el carácter transactivo del vínculo. Así, el estado de equilibrio perdido constituye la necesidad del organismo, el movimiento para restaurar el equilibrio es búsqueda y exploración, y finalmente la recuperación del equilibrio es logro, que supone reorganización de energías del lado del organismo y existencia de condiciones satisfactorias del lado del ambiente.

Desde aquí Dewey obtiene una conclusión de suma importancia: existe una fuerte similitud estructural entre el curso del comportamiento vital del individuo y el modo de conducir las investigaciones más elaboradas. Esto implica que la investigación, desde las formas más simples hasta las más complejas, surge de la perturbación de un estado previo de adaptación y que no hay investigación que no implique la realización de algún cambio en las condiciones del ambiente tal que establece nuevas condiciones. ${ }^{56}$ Así, queda claro

\footnotetext{
${ }^{56}$ Esta idea de Dewey es suficiente para alertar sobre la fuerte impronta que ha ejercido Charles Sanders Peirce sobre su propia concepción de investigación. De acuerdo con el planteo que hace Peirce en "La Fijación de la Creencia", "[1]a irritación de la duda [en cuanto estado de inquietud e insatisfacción] causa una lucha por alcanzar un estado de creencia [en cuanto estado de tranquilidad y satisfacción]. Llamaré a esa lucha investigación [...]" (CP.5.374). Lo interesante en este contexto es que para Peirce la creencia ya no es una representación del mundo sino que "[...] nos sitúa en condiciones de actuar de cierta manera, dada cierta ocasión.” (CP.5.374). Luego, el fin de la indagación es el establecimiento de una disposición a actuar de determinada manera en determinadas condiciones, esto es, el establecimiento de un hábito. En suma, Peirce presenta una nueva relación entre conocimiento y acción que será recuperada, elaborada y profundizada por el mismo Dewey. Para un estudio detallado del antecedente peirceano en la concepción deweyana de investigación, Cf. López (2014) y Colapietro (2002, pp. 43-71).
} 
que la investigación implica ante todo acción. Asimismo, el énfasis puesto por Dewey en la relación transaccional concreta como punto de partida de las investigaciones permite afirmar el carácter situado y contextual de toda investigación.

Ahora bien, para el caso de los seres humanos, el medio en que viven, actúan e investigan, es decir, su ámbito de experiencia, está conformado no sólo por aspectos biológicos sino también y distintivamente aquellos aspectos que conforman el seno cultural de la investigación. De acuerdo con Dewey, la clave para esa modificación profundamente cualitativa de la conducta es el desenvolvimiento del lenguaje, con su base en actividades biológicas previas y sus conexiones con fuerzas culturales más amplias. Aparece aquí una nueva vía de argumentación para sostener aquel principio de continuidad entre las funciones más simples y más complejas de la teoría naturalista de la lógica. El lenguaje resulta central para esta explicación pues por un lado es un modo de comportamiento estrictamente biológico que surge en continuidad con actividades orgánicas previas y por el otro lado permite al individuo adoptar un punto de vista compartido con otros y finalmente establecer una comunicación general y objetiva, en el sentido de común a todas las partes que en ella intervienen. Bajo esta idea, Dewey sostiene que si bien el lenguaje no origina por sí mismo la asociación entre los individuos y mucho menos la experiencia de éstos en un ambiente, una vez desarrollado repercute de tal manera que brinda una nueva dimensión de la que no se puede volver atrás. ${ }^{57}$

Aunque no haya mención directa en estos pasajes iniciales de la Lógica, me permito recordar aquí que todo pensamiento, incluyendo cualquier tipo de investigación de sentido común o científica, se asienta sobre un contexto. Si bien recuperaré esta idea con

\footnotetext{
${ }^{57}$ La visión deweyana sobre el lenguaje constituye un tema cuyo tratamiento queda por fuera del alcance de este capítulo. No obstante, es sumamente interesante recordar que Dewey caracteriza al lenguaje como un modo de comportamiento enraizado y en total continuidad con las formas orgánicas que presenta (i) una dimensión instrumental, por la cual el lenguaje es para Dewey "instrumento de instrumentos", medio maestro y pleno de significaciones para actuar con un objetivo o interés y llegar a ciertas consecuencias no directas sino potenciales; (ii) una dimensión social, es decir, la estructura comunicacional del lenguaje que posibilita que cada participante se ubique por fuera de sí mismo, de su propia acción, y pueda evaluar las posibles consecuencias tanto del comportamiento de su interlocutor como de sus propias respuestas; y (iii) una dimensión final, en la medida en que la comunicación realza y consolida la vida que se goza por su propio valor (Cf. Dewey, Experiencia y Naturaleza, Cap. 5; Black, 1962). En el marco de la extensa y compleja discusión entre "pragmatistas centrados en la experiencia" y "pragmatistas centrados en el lenguaje" -a la que no dedicaré más que estas breves palabras- Pappas (2014) resalta el carácter cualitativo de la experiencia para lograr una cabal comprensión del rol del lenguaje en las tres dimensiones aquí señaladas.
} 
posterioridad, entiendo que es importante tenerla en cuenta para elucidar el alcance del seno cultural de la investigación. Esto permite explicar por qué, para Dewey, el medio estrictamente físico se halla tan incorporado al cultural que las transacciones de los seres humanos están profundamente afectadas por la herencia cultural expresada justamente en tradiciones, instituciones, costumbres, creencias y finalidades. Dicha influencia define el ambiente pero a la vez parece tener una notoria incidencia al momento de hacer ciertas selecciones e incluso de llevar adelante las apreciaciones directas e inmediatas, pues configuran el marco de interpretación de la experiencia $-\mathrm{y}$ en ese sentido son regulativas de toda experiencia y todo juicio particular.

Otro punto para destacar en este acercamiento preliminar a la Lógica es la continuidad que proyecta Dewey entre la investigación de sentido común y la investigación científica, toda vez que ambas comparten una pauta general. Es por ello que el pragmatista utiliza el término investigación en un sentido general, tal que incluye desde las pesquisas de sentido común propias de la vida cotidiana hasta las más abstractas de la física o la matemática. Dicho de otro modo, puede haber (y muchas veces hay) investigación y consecuentemente acción inteligente en todos los ámbitos de la vida. En este continuo se ubica la investigación científica como un tipo particular de investigación, a la par de otro tipo de investigaciones -en el ámbito de la educación, del arte, etc. A partir de esta indicación, en lo que sigue utilizaré el término investigación para hacer referencia al sentido más amplio, al de la pauta general, e investigación científica o ciencia para dar cuenta del sentido más específico.

La investigación de sentido común es la que lleva adelante los ajustes requeridos por el comportamiento, ajustes que tienen relación con el uso y goce de materiales, actividades y productos. Las investigaciones de sentido común se vinculan entonces con la conducta de la vida, con materias y operaciones cualitativas, y tienen como objetivo determinar lo que significa un objeto o acaecer con respecto al modo en que habrá de abordarse la situación total en conexión con el ambiente existente, el todo contextual al que se refiere la investigación en cuestión.

No obstante la continuidad planteada por Dewey, la historia de la ciencia indica que las investigaciones científicas en el sentido tradicional han registrado un triple movimiento que parece ir en dirección opuesta a la investigación de sentido común pues aquéllas (i) 
reducen lo cualitativo a lo cuantitativo, (ii) eliminan las causas teleológicas e introducen la causalidad eficiente, y (iii) se enuncian en un lenguaje altamente técnico. Así, las diferencias centrales entre investigación de sentido común e investigación científica se resumen en sus distintos asuntos o problemas de trabajo, la distancia que mantengan con las necesidades inmediatas y su grado de precisión, control y sistematicidad. Dewey suma a este desplazamiento un punto clave: la ciencia "ha olvidado" que la génesis y producción del conocimiento incluye la dimensión cualitativa y los fines o propósitos de la investigación. Sucede entonces con la concepción filosófica tradicional de la ciencia algo similar a lo que se había indicado en Experiencia y Naturaleza para el caso de la metafísica: ambas se originan en la experiencia de sentido común pero luego se independizan y no retornan a ese nivel originario para aplicar la respuesta al contexto en que se inició la investigación, del tipo que sea. ${ }^{58}$

Estas características, brevemente enumeradas, generan la sensación de un hiato o diferencia completa entre las investigaciones de sentido común y las científicas. Sin embargo, Dewey considera que las distinciones entre ambos tipos de investigación radican en el tipo y en la escala de problemas que afrontan, toda vez que distintos tipos de problemas demandan distintos énfasis de investigación, y no en cuestiones de orden epistemológico ni ontológico. Desde aquí Dewey obtiene dos conclusiones importantes. Por un lado, y mediante el estudio de ejemplos concretos, afirma que "[...] los objetos y procedimientos científicos surgen de los problemas y métodos del sentido común, de los usos y goces prácticos". Por otro lado, y tomando en consideración la incorporación del método científico dentro del sentido común en tanto modificación de las condiciones en que los seres humanos conviven entre sí (entiéndase por ellas la alimentación, la vestimenta, la vivienda, los medios de comunicación, tecnologías de producción y distribución de bienes y servicios, etc.), Dewey sostiene que la investigación científica repercute o debería repercutir en el uso y goce de los objetos y materiales "[...] en una

\footnotetext{
${ }^{58}$ En lo que podría verse como una sociología del conocimiento, Dewey insiste mucho en señalar el peso que tienen las condiciones sociales en ese movimiento unilateral de la investigación filosófica o científica y en el posterior emplazamiento de una concepción dualista. En este sentido, indica que la diferencia entre el conocimiento teórico-racional y el conocimiento práctico-empírico radica en la distinción entre aquellos que pudieron dedicar su vida a la contemplación ociosa, debido a que no les resultó necesario trabajar ni empeñarse a ninguna actividad del estilo, y aquellos que debieron ser artesanos o prácticos (Cf., por ejemplo, 1950, pp. 88-94. LW.12.66-68 y 1995, pp. 125-137. MW.12.141-155).
} 
forma que refina, expande y libera enormemente los contenidos y los agentes a disposición del sentido común.” (1950, p. 82. LW.12.71-2, ambas citas). De este modo, si la investigación científica mantiene estas líneas de continuidad con la investigación de sentido común y, a la vez, si esta última está íntimamente vinculada con los usos, goces y padecimientos de los objetos y materiales, es decir que presenta un carácter eminentemente práctico, entonces la primera también lo presentará, en mayor o menor medida. Según he adelantado, el rasgo común a ambos tipos de investigación -rasgo que las vincula también con este aspecto práctico recién señalado- es su pauta general. A continuación, pues, me detendré brevemente en la reconstrucción de sus fases para avanzar en este primer acercamiento a la concepción deweyana de investigación.

\subsection{La pauta general de la investigación}

Para iniciar esta reconstrucción parece oportuno, en primer término, recuperar la definición de investigación ofrecida por el mismo Dewey en la Lógica "[1]a investigación es la transformación controlada o dirigida de una situación indeterminada en otra que es tan determinada en sus distinciones y relaciones constitutivas que convierte los elementos de la situación original en un todo unificado.” (Dewey, 1950 p. 123. LW.12.108). Así, el primer impulso hacia la investigación es el enfrentamiento con los hechos reales para hacer frente a las dificultades y conflictos concretos de la experiencia, en tanto que la investigación tiene como resultado una nueva situación determinada $-\mathrm{y}$ vale recordar, una vez más, el sentido en que Dewey toma el concepto de situación en cuanto unificada y distinguida por la presencia de una cualidad permeante que la constituye como tal. ${ }^{59}$

\footnotetext{
59 Por supuesto, la definición misma de investigación no queda exenta de tensiones o críticas. Browning señala que la definición de Dewey no caracteriza a toda investigación sino a las investigaciones exitosas, aquellas que efectivamente logran dar lugar a una situación unificada, dejando por fuera a los casos de investigación truncados o no controlados (Cf. Browning, 2002, p. 168-9). A partir de este comentario Burke intenta complementar la definición deweyana, distinguiendo investigación en cuanto transformación deliberada de una situación indeterminada; investigación propiamente controlada, aquella que emplea métodos testeados para obtener aquello que, en virtud de esos mismos métodos, será "asertible garantizadamente"; e investigación exitosa, aquella que efectivamente logra recomponer las distinciones y relaciones de la situación indeterminada en un todo integrado (Cf. Burke, 2009, p. 160). Brown, por su parte, considera que Dewey efectivamente utiliza el término "investigación" para señalar aquellas pesquisas satisfactorias y que no lo utilizaría para señalar aquellas otras que finalizaron insatisfactoriamente o se disolvieron de modo prematuro. En este sentido, pues, el término "investigación” es normativo (Cf. Brown, 2012, p. 276).
} 
De acuerdo con Matthew J. Brown (2012) es posible diagramar un esquema bidimensional para dar cuenta de la posición deweyana en torno a la investigación. La primera de sus dimensiones queda capturada por la definición recién presentada: en ella se evidencian tres etapas temporalmente sucesivas: situación indeterminada, investigación propiamente dicha y juicio de resolución de la situación inicial. En este sentido, me permito agregar, la definición deweyana de investigación es una definición amplia y consistente con la propuesta filosófica general del pragmatista de analizar las actividades reflexivas específicas en tanto inscriptas en el curso de experiencia primario. La segunda de sus dimensiones se vincula con el carácter de las fases de la investigación en cuanto "[...] set de instancias funcionalmente definidas en un proceso recíproco e iterativo", aquel que hace de la investigación una actividad controlada y dirigida (Brown, 2012, p. 280). En este sentido, lo que Dewey propone no son etapas linealmente sucesivas -tal y como parecen suponer Thayer (1969, p. 49) o Nagel (1986. LW.12), por mencionar dos interpretaciones clásicas sobre la cuestión- sino relaciones funcionales que deberían ser satisfechas en la investigación. Tales consideraciones preliminares permiten introducir los cinco momentos de la pauta general de la investigación presentados por Dewey en su Lógica

El primer momento es la condición antecedente de la investigación, en tanto situación indeterminada e intrínsecamente dudosa en la que el organismo está perplejo, pues la situación demanda respuesta pero sus hábitos no son suficientes para ello, de modo que es necesario elaborar un nuevo tipo de resolución. Dicha situación es indeterminada con respecto a su resultado pues implica consecuencias que no son transparentes y sugiere respuestas discordantes. Asimismo, es pre-reflexiva en el sentido de que precede a la investigación aunque es condición necesaria de las operaciones cognoscitivas ulteriores. Nuevamente, encuentra aquí su lugar el concepto de situación, central para el entramado teórico deweyano. Puesto a la luz de la pauta general de la investigación trae consigo dos consideraciones importantes. En primer lugar, la cualidad que impregna a la situación no es de "indeterminación general" sino de una indeterminación particular que hace que la situación sea ella en cuanto única $-\mathrm{y}$ no cualquier otra situación. Por supuesto, la indeterminación no es del organismo en cuanto estado mental sino de la propia transacción que caracteriza a la situación, a tono con aquel planteo respecto del locus de las cualidades. 
Según indica Thayer, suponer que la situación indeterminada es en algún sentido subjetiva implica una mala comprensión del concepto mismo de situación y, a su base, una mala comprensión de la insistencia deweyana en situar a la investigación en un marco naturalista y transaccional y de indicar, por ejemplo, que la necesidad como punto de partida de la investigación es el estado de desequilibrio del vínculo entre organismo y ambiente o que la satisfacción es la recuperación del equilibrio (Cf. 1969, pp. 50-52).

En segundo lugar, la cualidad permeante de la situación sugiere la investigación particular iniciada y ejerce el control sobre sus procedimientos, no sólo en su carácter indeterminado inicial sino a lo largo de todo el proceso. En efecto, ya ha sido señalado con anterioridad que para Dewey la existencia inmediata de la cualidad dominante y permeante de la situación es el trasfondo, el punto de partida y el principio regulativo de todo pensamiento, de modo que el pensamiento científico tampoco puede deshacerse de la existencia cualitativa. Así, la dimensión cualitativa unifica y demarca la situación en la que ocurre el pensamiento, aporta continuidad al pensamiento en el sentido de funcionar como un hilo y como una pista directriz de lo que es explícitamente pensado, al tiempo que motiva, da sentido inicial de dirección y material para la investigación, por lo cual es una condición para la emergencia del pensamiento genuino. Ya en el curso de la investigación, lo cualitativo permite determinar la relevancia y peso de las distinciones, hechos, conceptos y principios en la investigación, aporta una guía en la selección y rechazo del material de la investigación, incide en el control provisto por las fases de experimentación y síntesis de toda investigación experimental y funge como guía del juicio que surge de la investigación. En este punto se logra ver, de acuerdo con Pappas, el carácter radical del contextualismo -o situacionismo, me permito modificar-, porque lo que prima en el juicio no son los standards acordados por la comunidad de investigación ni reglas heredadas, por más útiles que ambos puedan ser, sino la individual y única situación cualitativa en la que se desenvuelve la investigación -sin que ello suponga desestimar los aspectos contextuales, también fundamentales al momento de considerar la situación particular y de resolver el problema en cuestión (Cf. Pappas, 2016, p. 459).

El segundo momento es la consideración de la situación antecedente como problemática, vale decir, el planteo en términos de problema y el reconocimiento de la necesidad de investigación. De acuerdo con Dewey, la situación indeterminada se convierte 
en un problema en virtud de un acto inteligente que la cualifica y que perfila los pasos de la posterior resolución: "problema" y "solución" mantienen una relación recíproca. Así, la adecuación de la estructura y resultados de la investigación dependerá de la formulación del problema, de modo que esta última cumple una función heurística (Cf. Dorstewitz, 2011, p. 209). Es interesante subrayar aquí que no toda situación indeterminada es considerada como un problema sino que este paso requiere cierta cualificación por parte de quien investiga: "El resultado primero de la intervención de la investigación es que se juzga que la situación es problemática [it is adjudged to be problematic].” (Dewey, 1950, p. 126. Traducción modificada. LW.12.111). Volveré sobre este punto en el próximo capítulo, cuando sea oportunidad de considerar qué elementos inciden al momento de instituir un problema a partir de una situación indeterminada.

El tercer momento es la determinación de la solución del problema en tanto objeto de una investigación progresiva. En principio, se buscan aquellos aspectos del problema que se hallan definidos o establecidos mediante operaciones observacionales, puesto que una situación totalmente indeterminada no ofrecería ninguna pauta o indicio para la investigación. Las condiciones observadas constituyen los hechos del caso y se tendrán en cuenta para cualquier solución que se proponga porque son las condiciones que deben ser reconocidas o consideradas en cualquier solución relevante del problema instituido. Esto permite vislumbrar la importancia de la institución del problema pues determinará que ciertas observaciones sean tomadas como hechos del caso por referencia a la solución prefigurada desde la formulación del problema y que otras sean rápidamente desestimadas. Aparece aquí una cuestión central: la observación sugiere posibles soluciones que deberán ser examinadas respecto de su capacidad para resolver el problema. Si superan ese análisis inicial, se considerarán como ideas, “[...] consecuencias anticipadas (previstas) de lo que habrá de ocurrir si se ejecutan ciertas operaciones bajo las condiciones observadas y con referencia a las mismas" (Dewey, 1950, p. 128. LW.12.113). Una idea es una hipótesis sobre la determinación de la situación inicialmente indeterminada, una conjetura cuya validez depende del cumplimiento efectivo de lo que proyecta. En este sentido una idea es, por sobre todo, un plan de acción -y ese plan de acción es el significado de la idea. 
El cuarto momento corresponde al razonamiento, raciocinio o discurso racional, es decir la comprensión de la idea y su relación con otros conceptos para los propósitos de la investigación. Así, la idea inicialmente vaga se desarrolla en su vínculo con diferentes estructuras conceptuales hasta que se torna significativa para el problema en cuestión, justamente por las relaciones que se establecen con otras ideas, y recibe una forma que le permita dirigir las operaciones de resolución. Dicho de otra forma, el razonamiento es un examen de los significados de las ideas en cuanto planes de acción. Sin esta instancia de razonamiento, cualquier conclusión inmediatamente aceptada no tendría fundamentación suficiente. En esta fase cobra especial relevancia la idea de control de la inferencia, una clave de lectura para toda la concepción deweyana de investigación. Según había quedado planteado en Cómo pensamos (1989 [1910]. LW.8.191), el pensamiento como hecho efectivo implica necesariamente o de modo "natural" algún tipo de inferencia, vale decir, el proceso por el cual se arriba a una idea de lo que está ausente a partir del material que se tiene a disposición. Este salto desde lo conocido a lo desconocido, siguiendo la expresión del mismo Dewey, no tiene aún ninguna propiedad lógica pero constituye las condiciones y la materia prima de dichas propiedades pues introduce una idea que debe ser testeada mediante el control de la propia inferencia por el razonamiento, entre otras cosas.

En esta instancia de examen del significado de una idea en relación a un sistema de significados más amplio radica una de las diferencias más importantes entre las investigaciones de sentido común y las investigaciones científicas. Las investigaciones científicas ponen en relación las nuevas ideas con complejos entramados conceptuales y significativos de forma tal que esa primera instancia de análisis puede derivar en el abandono de la idea, dadas algunas inconsistencias con otros significados. En este sentido, la fase de razonamiento analiza significados en su carácter de significados y por referencia a otros significados, a un nivel de abstracción alto en el que prima la consistencia semántica de las proposiciones y de sus relaciones. Por supuesto, la idea de continuidad entre investigación de sentido común e investigación científica impide concluir que las primeras llevan adelante un análisis de distinto tipo o que no tienen alguna instancia de análisis de los planes de acción a la luz de otros significados ya establecidos. En efecto, Dewey afirma explícitamente que la diferencia entre ambos está dada por sus finalidades antes que por sus formas lógicas o procedimientos básicos. No obstante, la investigación de sentido común se 
inscribe en un sistema práctico antes que intelectual y por lo tanto el análisis de los significados presenta un grado menor de abstracción.

El quinto momento es la experimentación (o el carácter operativo de hechos y sentidos o significados). En primer término, las ideas son operativas porque sugieren más observaciones que dan lugar a una nueva idea modificada, y así sucesivamente, hasta completar y unificar el orden existente. En segundo término, los hechos del caso siempre cargados de significado presentan el carácter de operación experimental en tanto realizada por el investigador, operación que modifica la situación existencial anterior para reordenar las condiciones y obtener una situación unificada. Así, afirmar que una experimentación es satisfactoria implica afirmar que una hipótesis dada, en cuanto plan de acción, debería ser aceptada en función de su capacidad para resolver el problema instituido a partir de la situación indeterminada inicial. Al respecto vale recordar que para Dewey los hechos no son recibidos pasivamente por la sensación sino que son resultado de la propia investigación o de investigaciones antecedentes de las cuales se nutre la investigación en consideración y, además, son revisables a la luz de los resultados de nuevas investigaciones y de las nuevas ideas sugeridas por esos mismos hechos. Acerca de este punto Brown sostiene que aun cuando el propio Dewey no haya utilizado el término, bien podría pensarse que la relación entre hechos e ideas, en su carácter operativo, es dialéctica, por cuanto los dos se desarrollan constantemente entre sí. Más aún, Brown indica que lejos de implicar una relación compleja, problemática o incluso misteriosa entre hechos e ideas, percepción y razón, la perspectiva deweyana permite incluirlos como actividades en el curso de experiencia sin necesidad de dar ulteriores explicaciones: "Este es el núcleo de la crítica de Dewey a la epistemología: una vez que se adopta la lógica funcional, aquellos problemas que la epistemología moderna había trabajado durante tanto tiempo, que surgen por los recurrentes y perniciosos dualismos de alma/cuerpo, interno/eterno, etc. se disuelven.” (Brown, 2012, p. 293. Traducción propia). ${ }^{60}$

\footnotetext{
${ }^{60}$ Brown no sólo plantea la consideración funcional y recíproca entre las fases de la pauta de la investigación sino que incluso propone algunas modificaciones en su denominación. Así, los puntos identificados por el autor son (i) observación o recolección de datos; (ii) institución de un problema; (iii) sugerencia de hipótesis o ideas; (iv) razonamiento, elaboración de las hipótesis, etc.; y (v) experimentación o test de las hipótesis. Brown ofrece dos tipos de razones para sostener esta denominación: por un lado, y hacia el "interior" de la posición deweyana, sostiene que esta imagen de la investigación logra una versión equilibrada entre hechos e
} 
Según se sigue de lo anterior, en una investigación se da una transacción entre hechos e ideas, en la que el carácter de cada uno resulta transformado por el otro. La investigación finaliza con un juicio respecto de qué se debe hacer en favor de la determinación de la situación inicialmente indeterminada -más aún, podría pensarse que la investigación finaliza con el juicio retrospectivo acerca de lo que se hizo para resolver el problema inicial. En este sentido, indica Dewey, “[e]1 juicio consiste en la transformación de una situación antecedente, existencialmente indeterminada o incierta, en una situación determinada" (1950, p. 246. LW.12.220). Así presentada, la definición del juicio parece fusionarse con la definición misma de investigación. Sin embargo, Dewey entiende al juicio como un instrumento para la transformación existencial del curso de experiencia en la medida en que dirige las operaciones mediante aquellas ideas a las que se arriba a partir del razonamiento de modo que todo juicio es individual pues se refiere a una situación cualitativamente determinada y única, al tiempo que presenta una dimensión espaciotemporal inextricable, aquella que lo ubica por referencia a su objeto existencial. Luego, la investigación finaliza con la puesta en práctica del juicio en el intento por resolver la situación problemática. ${ }^{61}$

Si bien no es tema de estas páginas, es importante mencionar que cuando todas las instancias de la investigación son debidamente llevadas adelante, el juicio que la concluye es caracterizado por Dewey como una "aserción garantizada", justamente dado el respaldo provisto por la propia investigación. Dicho de otro modo, la aserción estará garantizada sólo en la medida en que es un resultado [outcome] de la investigación. Además, esa aserción garantizada da lugar a otro subproducto de la investigación sumamente relevante, el de la "asertabilidad garantizada" de ese conocimiento obtenido, capaz de ser utilizado en futuras investigaciones -hasta tanto continúe superando las puestas a prueba experimental cada vez que sea empleado. Luego, la investigación es instrumental no sólo en cuanto resolución del problema particular que la origina sino también en cuanto que da lugar a

ideas; por otro lado, y hacia el "exterior" de la posición deweyana, enfatizar el rol de la observación y de la experimentación hace que la pauta ofrecida por Dewey se torne más relevante para la filosofía de la ciencia (M. J. Brown, 2012, pp. 286-287).

${ }^{61}$ Intérpretes como Hook (2000, p. 78) y Thayer (1969, p. 63) incluyen a la finalización o término de la investigación como una sexta fase de la pauta general. Por mi parte, prefiero conservar la identificación de las instancias presentada por el propio Dewey en su Lógica. 
instrumentos o recursos que pueden ser empleados en investigaciones subsiguientes (al respecto, Cf. López, 2014, Capítulo 5).

Como puede vislumbrarse, las ideas de aserción y asertabilidad garantizada introducen, entre sus múltiples aristas, la ardua pregunta por el lugar que mantiene el concepto de verdad en el entramado teórico deweyano -si es que en definitiva mantiene alguno. ${ }^{62}$ Si bien no avanzaré en la discusión respecto de si la aserción garantizada debería ser interpretada como un "reemplazo" de la idea clásica de verdad -sobre este punto gira el complejo intercambio teórico entre Russell y el propio Dewey de la década de $1940^{63}$-, encuentro interesante la oportunidad para introducir el siguiente comentario: de acuerdo con Dewey, en el marco de una investigación, sea de sentido común como científica, la correspondencia ya no es pensada en términos del realismo epistemológico clásico, esto es, de adecuación entre el juicio y alguna entidad "externa", sino en términos de resolución o respuesta al problema instituido, vale decir, en términos de reconstrucción de la corespondencia en sentido operacional entre organismo y ambiente. En este contexto no debería sorprender que para Dewey la verdad cumpla la función de un adverbio, según indica en La Reconstrucción de la Filosofia:

\begin{abstract}
Lo que nos guía verdaderamente es verdadero; se entiende precisamente por verdad la capacidad probada de esa clase de guía. El adverbio 'verdaderamente' es más fundamental que el adjetivo 'verdadero' y que el sustantivo 'la verdad'. El adverbio expresa un modo, una forma de obrar. (Dewey, 1996, p. 168. MW.12.169).
\end{abstract}

\footnotetext{
${ }^{62}$ El rol que tiene la noción clásica de verdad en la teoría de la investigación deweyana es uno de los temas más trabajados por los intérpretes (Cf. Geiger, 1978, Capítulo 5; Sleeper, 1986, Capítulo 6; Tiles, 1988, Capítulo 5, entre otros). Al respecto, resulta de sumo interés la crítica planteada por Gertrude Ezorsky, quien considera que la ruptura de Dewey con la tradición no es lo suficientemente radical pues nunca deja de considerar a la verdad como una propiedad y no distingue, en la práctica de investigación, entre verdadero y verificado - con la diferencia de que las proposiciones ya no son verdaderas sino que devienen verdaderas mediante la investigación, esto es, devienen garantizadas por la evidencia adecuada. En opinión de la autora, Dewey opta por una versión "espacio-temporal dependiente" de la verdad pero, en definitiva, queda entrampado en el problema de fondo (Ezorsky, 1992).

${ }^{63}$ En 1940 Russell imparte las William James Lectures en Harvard y a partir de allí publica Investigación sobre la Verdad y el Significado, texto en el que critica la perspectiva deweyana presentada en la Lógica de 1938 (Russell, 2003). Dewey responde con un artículo titulado "Proposiciones, asertabilidad garantizada y verdad", originalmente publicado en The Journal of Philosophy, 38, 1941, pp. 169-186 (Dewey, 2000, p. 133156. LW.14.168-188).
} 
Así, una hipótesis puede guiar falsa o verdaderamente hacia el fin a la vista de la investigación, sin que ello suponga algún tipo de correspondencia en su sentido tradicional. Por el contrario, Dewey es explícito al dar cuenta de los constituyentes y del tipo de relación que busca enfatizar con su idea de investigación. Sobre el final de su respuesta a Russell dice lo siguiente, ya con cierto hastío: "Y espero que a estas alturas ya no sea necesario repetir que, según mi teoría, los acontecimientos relevantes son aquellas consecuencias existenciales que, en virtud de operaciones existencialmente realizadas, satisfacen (atienden, cumplen) las condiciones fijadas por los acontecimientos que constituyen un problema." (Dewey, 2000, p. 19. LW.14.183).

Estas breves observaciones dejan sentado un punto que constituye el eje de toda la concepción deweyana de la investigación: su carácter eminentemente práctico, continuo y sujeto a constante revisión. El investigador y entre ellos el científico no observa el mundo sino que toda investigación es dentro del mundo, dirigida y deliberada, con la intención de cambiar una situación confusa e insegura por otra clara y resuelta. En efecto, de acuerdo con el método empírico propuesto por Dewey, el conocimiento en tanto actividad reflexiva particular que tiene como punto de partida a la experiencia en su nivel primario vuelve o debería volver a ese nivel de la experiencia con fines de enriquecerla, ensancharla y profundizarla, esto es, brindarle nuevas condiciones o, para utilizar una frase cara al pragmatista, reconstruirla. Luego, lejos de ser una empresa orientada a la representación, el conocimiento en general y el conocimiento científico en particular se orienta a la modificación del curso de la experiencia, de acuerdo con los propósitos adelantados en el curso de la investigación. Más aún, implica también una transformación "de segundo orden", en la medida en que el conocimiento establece nuevas relaciones entre cosas, que se vuelven antecedentes o condiciones de otras, y entre el organismo y su ambiente pues aquél entra en nuevas relaciones con este último por el mero hecho de concebir nuevos vínculos potencialmente operativos, de forma tal que hay modificación aún antes de realizada la acción propiamente dicha.

En esta misma línea Anthony Quinton (1977, pp. 3-4) identifica algunos temas transversales a la posición deweyana que permiten sintetizar lo planteado hasta aquí -más allá de que, en mi opinión, la descripción de Dewey como anti-intelectualista propuesta por Quinton no es la más adecuada dado el énfasis constante del pragmatista en la idea de 
acción inteligente. En la medida en que Dewey hereda el anti-cartesianismo peirceano, su concepción podría estructurarse en cuatro ejes: (i) el carácter falible y corregible de la investigación, que en tanto orientada a la acción es fundamentalmente prospectiva [forward-looking]; (ii) la consideración del sujeto de conocimiento [knower] como activo, experimentador; (iii) el énfasis en el carácter situado, inteligente y encarnado [embodied] del sujeto de conocimiento en cuanto organismo inmerso en el ambiente; y (iv) la concepción de la investigación como una empresa social y colaborativa antes que como una tarea realizada por un sujeto aislado. Según Quinton, estas cuatro características dan cuenta del lugar preponderante que tiene la práctica en todo el entramado teórico deweyano, razón que explica por qué Dewey no suele referir a su posición como una teoría del conocimiento sino de la investigación -y por qué, me permito sugerir, Dewey considera a la lógica como una investigación sobre la investigación.

Asimismo, he señalado ya que el resultado o producto de la investigación tiene una doble función: por un lado, constituye el fin de la investigación específica, tanto en el sentido de culminación como de objetivo, y por otro lado, ya respecto de otras situaciones, puede servir como medio para una investigación posterior. Así es que el conocimiento se define por el efecto acumulativo de la investigación continua y que lo que se tiene como asentado es aquello que puede ser empleado como un recurso en la investigación ulterior. Tomar el ejemplo de la investigación científica resulta útil para señalar que la experiencia general, en cuanto experimental, no carece de fines sino que depende de éstos en todo momento. Dewey indica en La Búsqueda de la Certeza que la práctica científica representa “[...] la más seria posibilidad de la experiencia humana en todas sus fases, experiencia en la cual se apreciarán y serán continuamente engendrados y utilizados las ideas y los sentidos. Pero formarán parte integrante del curso de la experiencia misma y no serán importados de la fuente externa de una realidad situada más allá.” (1952, p. 121. LW.4.111).

Desde aquí surgen dos comentarios finales. En primer lugar, la afirmación precedente permite identificar la continuidad longitudinal entre experiencia primaria y conocimiento, dada precisamente por el referido carácter transactivo, esto es, de la concepción de la experiencia y de la investigación en términos de acción, práctica y transformación recíproca entre organismo y ambiente. En segundo lugar, permite 
comprender el llamado deweyano a sustituir el clásico concepto de razón (nous griego, intellectus escolástico o ratio moderna), externo, fijo e impuesto a la experiencia, por una noción de inteligencia en la experiencia, es decir, por la selección de fines y la disposición de los medios para obtener las consecuencias deseadas a partir del análisis de la experiencia pasada en tanto esta sugiere nuevos objetivos y métodos para desarrollar una mejor experiencia futura. De este modo, la inteligencia no es algo que se posea o se obtenga de una vez y para siempre sino que está en constante proceso de formación y su fortalecimiento requiere una permanente atención a las situaciones en favor del reajuste continuo entre organismo y ambiente, es decir, de la expansión y enriquecimiento progresivo de la experiencia misma (Cf. Dewey, 1996, pp. 115-121. MW.12.134-138).

Finalmente, resulta claro que el énfasis puesto por Dewey en entender a la investigación como actividad inteligente que recualifica el material existencial previo y al juicio como la transformación resultante están en fuerte contraste con la concepción contemplativa del conocimiento, la cual sostiene que todas las modificaciones que puedan ocurrir, hasta en la investigación mejor controlada, se limitan a mejorar las representaciones, estados y procesos del sujeto de conocimiento, es decir, a cambios subjetivos, mentales o psicológicos. Por el contrario, el pragmatista observa que no puede ocurrir cambio mental alguno sin que operaciones existenciales comporten una modificación del material existencial. Es por ello que, siguiendo una expresión de Martin Jay, Dewey insta a '[...] abandonar la actitud 'espectatorial' de la comprensión científica [...] a favor de una intervención activa y participativa en el mundo", cuyo fin a la vista es "[...] el mutuo ajuste entre el plan propuesto y la respuesta del entorno; en este sentido la experiencia era un concepto transaccional." (Jay, 2009, p. 331 y 333, respectivamente).

Tal vez la mejor forma de sintetizar las consideraciones precedentes sea utilizando una frase del propio Dewey, para quien "[...] toda investigación controlada y todo establecimiento de aserciones fundadas contiene, necesariamente, un factor práctico; una actividad de hacer y rehacer que transforma el material existencial previo que planteó el problema de la investigación" (1950, p 182. LW.12.162). Esta observación introduce, además, el asunto de los juicios prácticos en la investigación, sobre el que me detendré en los próximos párrafos. 


\section{Investigación y juicios prácticos}

Según el planteo deweyano, las investigaciones y sus juicios resultantes tienen estrecha relación con consideraciones acerca de qué es lo que conviene hacer y cómo ha de ser tratada la situación incierta. El modo de definir qué acción se lleva adelante está dado por la pauta de la investigación, es decir por las operaciones de observación, recolección de datos e inferencias dirigidas por ideas puestas en relación tanto con estructuras conceptuales previas como con la dimensión valorativa, que representa una fase inherente al juzgar mismo. En este contexto, reconociendo la identidad del juicio valorativo con los juicios prácticos en la experimentación, Dewey observa que "[c]uanto más problemática sea la situación y más penetrante la investigación con que hay que abordarla, tanto más explícita resulta la etapa valorativa". (Dewey, 1950, p. 203. LW.12.181).

Si bien estos problemas prácticos remiten en primer lugar a los oficios y las artes, Dewey asegura que el científico también toma decisiones continuamente dado que, según he enfatizado una y otra vez, las investigaciones son un modo de la práctica. Por supuesto, esta primera presentación en términos de decisiones debe ser refinada pues hay distintas dimensiones de la práctica científica en las que efectivamente se toman decisiones. En lo que resta del capítulo avanzaré sobre algunas consideraciones iniciales en virtud de afinar el análisis sobre el rol de los juicios prácticos y el lugar de los valores en la pauta de la investigación propuesta por Dewey.

Una primera consecuencia del acento deweyano en la dimensión práctica de la investigación es que los contenidos de las proposiciones acerca de cuestiones de hecho y acerca de cursos alternativos de acción no son autosuficientes ni están determinados por sí mismos sino por referencia al fin a la vista de la investigación y a las consecuencias que surgen mediante su operación. A diferencia de la concepción tradicional que elabora ex post facto algún silogismo para explicar las acciones llevadas a cabo durante la investigación, Dewey considera que si efectivamente interviene la deliberación en función de tomar una decisión (y no la mera respuesta por vías del hábito), entonces el juicio práctico representa un factor en la determinación del material existencial. En este sentido Dewey afirma que “[...] la conducción de una investigación científica, ya sea física o matemática, es un modo de práctica. El científico es un práctico por encima de todo y se halla constantemente 
embarcado en la emisión de juicios prácticos, es decir, en obtener decisiones acerca de lo que conviene hacer y de los medios a emplear para hacerlo.” (Dewey, 1950, p. 183. LW.12.163. Cursivas en el original). Esta insistencia en que la investigación se encuentra en el dominio de la práctica no rebaja su valor sino que realza el carácter experimental del conocimiento como instrumento de desarrollo y control de nuevas prácticas con el objetivo de volverlas prácticas inteligentes.

En virtud de las observaciones precedentes es posible afirmar que la investigación científica, en cuanto forma de la práctica, implica una ineludible toma de decisiones por parte de quien la ejerce. Las preguntas que surgen inmediatamente son qué tipo de decisiones toma el científico y en base a qué criterios lo hace. Dewey introduce aquí un punto importante, que cobrará más relevancia aún al momento de analizar la posición teórica de Heather Douglas: de acuerdo con el pragmatista, el investigador científico pondera constantemente la información recibida de investigaciones previas o ajenas y la información recolectada por él mismo, sopesa su significación por referencia al problema determinado y a las observaciones, experimentaciones y cálculos que deberán realizarse y define su sentido respecto de la investigación particular que se lleve adelante -siempre en referencia a la dimensión cualitativa de la situación particular, principio regulativo de cualquier tipo de investigación.

Este repertorio de acciones, aun cuando no es exhaustivo, permite identificar un punto crucial: el científico generalmente organiza y dispone del material en términos de las condiciones existenciales y sus consecuencias fundadamente proyectadas. Dicho de otro modo, y recuperando una categorización presentada en el capítulo precedente, el científico se apoya continuamente en juicios evaluativos sobre la relación medios-consecuencias de las cosas en función de determinar su relevancia y peso en la situación presente. De este modo, señala Dewey, "[n]o hay investigación que no suponga juicios prácticos”, teniendo en cuenta que estos últimos "[...] constituyen evaluaciones [evaluations], puesto que les atañe juzgar sobre lo que hay que hacer a base de las ponderadas consecuencias de condiciones que, por ser existenciales, serán operantes en cualquier caso.” (1950, p. 197, ambas citas, traducción modificada. LW.12.176 y 175, respectivamente). ${ }^{64}$

\footnotetext{
${ }^{64}$ En este punto me permito disentir con la traducción al español de Eugenio Imaz. En su versión, el término inglés evaluation aparece traducido por "valoración". Así, por ejemplo, el título mismo del capítulo al que estoy aludiendo en estas páginas queda traducido como "Juicios prácticos: valoración" -y lo mismo sucede
} 
Una vez organizada la información en términos de condiciones-consecuencias, el científico también delibera en la medida en que proyecta planes o cursos alternativos de acción y considera sus respectivas e hipotéticas consecuencias. En este punto aparece una cuestión central: tras concluir que las evaluaciones son una fase inherente al juzgar mismo -y téngase presente siempre la pauta general de la investigación y la interpretación no lineal sino recíproca de sus respectivas fases propuesta por Brown-, Dewey hace el siguiente comentario, que cito in extenso:

\begin{abstract}
En algunos casos el problema inmediato puede referirse tan directamente a la apreciación [appraisal] de las existencias en su capacidad de medios, positivos o negativos (recursos y obstáculos), y tan directamente también a la apreciación de la importancia relativa de consecuencias posibles que se nos ofrecen como fines a la vista, que el aspecto evaluativo [evaluative] resulta dominante. En tal caso, tendríamos juicios que, en un sentido relativo, podrían llamarse de valor, a diferencia de otros juicios en que tal aspecto sería subordinado. Pero como en todo juzgar nos encontramos con la selección de existencias para que sirvan como datos para el asunto y de ideas para que sirvan como posibilidades de predicación (o fines a la vista), resulta que la operación de valorar [valuational operation] es inherente al juzgar como tal. Cuanto más problemática sea la situación y más penetrante la investigación con que hay que abordarla, tanto más explícita resulta la fase valorativa [valuational phase]. La investigación científica reconoce implícitamente la identidad del juicio valorativo [valuational judgment] con los juicios prácticos en su necesidad de experimentar para la determinación de los datos y para el uso de ideas y conceptos -incluyendo principios y leyes- como hipótesis directivas. (Dewey, 1950, pp. 202-203. Traducción modificada, cursivas agregadas aunque presentes en la versión original en inglés. LW.12.180-181).
\end{abstract}

todas las veces que aparece el término en el parágrafo titulado justamente "Evaluation" (Cf. Dewey, 1950, p. 195-197. LW.12.174-176). En mi opinión, y si bien el mismo Dewey comienza el referido parágrafo recuperando la distinción entre la estimación en cuanto directa y la valoración en cuanto resultado de la reflexión, esta traducción puede generar una confusión relevante entre evaluación y valoración [valuation], dos tipos de juicios prácticos estrechamente relacionados pero a fin de cuentas distintos. En efecto, según se ha visto en el capítulo anterior, la primera remite a la relación de condiciones-consecuencias de las cosas y la segunda al caso particular de los valores en cuanto evaluados, ellos mismos, en términos de condicionesconsecuencias. Si aparte del análisis textual se tiene en cuenta que "Teoría de la Valoración" fue publicado en 1939, apenas un año después de la Lógica, parece plausible suponer que Dewey considera esta diferencia con el suficiente cuidado como para no pasarla por alto. 
En este fragmento Dewey explicita la distinción entre resoluciones guiadas por el hábito, incluso a nivel científico, y respuestas no habituales, supuesta a lo largo de todo su argumento. En el primer caso el investigador de sentido común y/o el científico sólo necesitan apelar a juicios evaluativos de condiciones-consecuencias porque sus hábitos de estimación están lo suficientemente arraigados como para no necesitar ningún tipo de reflexión subsiguiente. Más aún, parecería que, en definitiva, la situación inicial no es efectivamente problemática, es decir, no reporta la necesidad de una investigación tal y como la concibe Dewey. En un lenguaje menos apegado al deweyano, podría decirse que las resoluciones de este tipo son meramente técnicas o instrumentales en el sentido más lato del término, sin mucha intervención de algún tipo de reflexión ulterior respecto de la propia práctica de reunificación. Es por ello que los juicios resultantes son juicios de valor sólo en un sentido relativo y no predominante.

El segundo tipo de resolución presenta una diferencia cualitativa respecto del primero, diferencia que en mi opinión queda clara en el sutil pero vital cambio de términos hecho por Dewey, desde evaluativo [evaluative] a valorativo [valuational]. De acuerdo con el autor, la fase valorativa de la investigación es directamente proporcional a la dificultad de la situación inicialmente indeterminada y genuinamente concebida como problemática. En este tipo de situaciones los hábitos ya no son suficientes para la resolución y por lo tanto es necesario iniciar una investigación que permita obtener un juicio y finalmente una nueva situación determinada y unificada. Ahora bien, el fragmento referido incluye una consideración extra: todo juzgar propiamente dicho implica selección de material que servirá como datos para la investigación y selección de ideas que servirán para la elaboración del juicio resultante, al tiempo que toda selección y toda decisión implican una dimensión valorativa inherente en la medida en que dichas selecciones y decisiones se llevarán adelante por referencia a criterios y valores específicos. En otras palabras, la investigación propiamente dicha se desarrolla a partir de un problema genuino y la complejidad de este último torna indispensable a la fase valorativa del juzgar mismo. La valoración conforma el enlace entre la experiencia, las ideas o hipótesis que guiaron la investigación y la acción resultante, de modo que las consideraciones valorativas intervendrán en todas aquellas situaciones que requieren ajustar inteligentemente la conducta y la experiencia, es decir que la valoración está presente en todas las 
investigaciones del individuo. Luego, y si bien aquí el sentido de valoración no remite estrictamente a la evaluación de valores, como ha sido analizado en el capítulo previo, es posible afirmar que no hay genuina investigación sin valoración.

\section{Conclusiones}

En este capítulo he intentado subrayar el aspecto eminentemente práctico de la investigación, tal y como la concibe Dewey. En efecto, si bien la investigación es una experiencia de orden reflexivo o secundario, mantiene el carácter activo propio de la experiencia primaria. Esta conclusión se sigue con claridad si se tiene en cuenta de manera conjunta tanto las observaciones acerca del seno natural y cultural de la investigación como las observaciones acerca de la pauta general de la propia investigación, todas ellas orientadas a señalar que cualquier investigación, sea de sentido común o científica, necesariamente implica modificar el material existencial del ambiente en función del progresivo ajuste entre organismo y medio. Estas consideraciones han permitido, además, poner en juego muchos de los elementos presentado en el primer capítulo, en particular respecto del carácter transaccional de la experiencia y de su dimensión cualitativa explícitamente presente en la propia definición de investigación en cuanto tránsito de una situación inicialmente indeterminada a otra determinada y unificada e implícitamente presente a lo largo de toda la pauta general de la investigación.

El carácter práctico de la investigación supone, por supuesto, el carácter práctico de quien la lleva adelante. En este sentido, he remarcado junto con Dewey que el investigador, entre ellos el científico, es un práctico por sobre toda otra descripción y que continuamente debe tomar decisiones de esa índole. Dada la naturaleza de la investigación y del investigador, advertir el rol de los juicios prácticos es vital para una cabal comprensión del planteo deweyano pues aquí se juega un punto clave de la argumentación. Según he sugerido, cuando no hay un genuino problema y consecuentemente no hay una genuina investigación el científico se maneja por hábito, apelando principalmente a juicios de tipo evaluativo. Por el contrario, la investigación en sentido pleno no sólo implica juicios evaluativos sino también otro tipo de reflexión, presentada por Dewey en términos de valoración, que será tanto más necesaria conforme se complejiza el problema a resolver. 
Tomando en consideración estos elementos, la conclusión central del capítulo es que no hay investigación sin valoración.

Ahora bien, el reconocimiento de la dimensión valorativa como constitutiva de toda investigación propiamente dicha es una de las fibras del argumento general que me interesa elaborar. En efecto, aquellas visiones que distinguen taxativamente entre valores epistémicos y extra-epistémicos bien podrían acordar con la conclusión preliminar antedicha pues las selecciones realizadas por el científico no sólo remiten a operaciones "al interior" de la investigación sino que, y sobre todo, pueden realizarse por referencia a los valores tradicionalmente denominados epistémicos. Dicho de otro modo, el material que servirá como dato para la investigación o las ideas que conformarán el juicio resultante podrían ser seleccionados en razón de su capacidad explicativa y/o predictiva, de su simplicidad, etc. Por lo tanto, para poder sostener la hipótesis de lectura que aquí propongo hace falta explicar que la concepción deweyana de investigación implica legítimamente otro tipo de valores, apelando al sentido lateral de la continuidad de las experiencias reflexivas particulares de investigación y valoración.

En este contexto, el análisis propuesto permitirá considerar dos conjuntos de cuestiones, distintas pero estrechamente vinculadas en términos históricos y teóricos. Si se recuerda que la llegada del positivismo lógico a la costa este de Estados Unidos implicó la ulterior consolidación de la versión standard de la filosofía de la ciencia, fue causa del ocaso temporal del pragmatismo en la escena académica norteamericana y constituyó el punto de partida del value-free science ideal, la lectura que intento sostener permitirá, por un lado, discutir muchas de las dicotomías propias de la visión standard de la ciencia y reconocer que Dewey las cuestionó en tiempos del auge del positivismo lógico y, por el otro, ofrecer un marco filosófico elaborado para los desarrollos teóricos contemporáneos que ponen en cuestión el referido ideal de ciencia. Los primeros dos puntos serán tema del próximo capítulo mientras que el último quedará para la tercera parte de este estudio, no sin antes analizar las consideraciones deweyanas respecto del vínculo entre ciencia y democracia. 


\section{CAPÍTULO 5: LA RECONSTRUCCIÓN DE LAS CONTINUIDADES}

\section{Introducción}

De acuerdo con las conclusiones del capítulo precedente, toda investigación propiamente dicha, entre ellas la científica, implica la resolución de situaciones indeterminadas ya no siguiendo hábitos sino mediante genuinas instancias de decisión y consecuentemente de valoración. En este sentido, la valoración es una fase inherente al juzgar mismo y se torna más importante cuanto más compleja sea la situación a resolver. Sin embargo, y como también ha sido señalado, esta conclusión preliminar podría ser aceptada por quienes defienden la versión standard de la filosofía de la ciencia y abogan por una férrea distinción entre valores epistémicos y extra-epistémicos (inescindible de aquella otra entre contextos de justificación y de descubrimiento), afirmando que el científico valora y toma decisiones pero lo hace siempre y exclusivamente sobre la base de valores epistémicos. ${ }^{65}$ Dada esta posible interpretación, el objetivo central del presente capítulo es argumentar que en la perspectiva deweyana hay distintos sentidos de continuidad entre investigación y valoración, que estos sentidos son complementarios y que en su conjunto dan una sólida respuesta a las referidas distinciones taxativas -distinciones que, valga la insistencia, son el antecedente teórico del ideal de ciencia libre de valores. Por supuesto, aquí se mantiene la aclaración hecha en el capítulo 1: el continuo de la experiencia es multidimensional e integral, de forma que las distinciones ofrecidas son analíticas y no implican que efectivamente haya sentidos o dimensiones de la continuidad que puedan entenderse sin relación o como si no estuviesen también ellas atravesadas por las demás dimensiones. Sin embargo, entiendo que esas mismas distinciones, con las precauciones del caso, pueden ayudar a esclarecer algunos aspectos cruciales para sostener la hipótesis de lectura del presente estudio.

En este marco, la primera tarea del capítulo será señalar cuál es la incidencia del contexto en la investigación científica. Para ello en la segunda sección recuperaré

\footnotetext{
${ }^{65}$ Vale recordar que en el contexto de la filosofía de la ciencia del siglo XX la denominación de estos criterios en términos de "valores" es propuesta por Kuhn, bajo la intención de enfatizar que en cuanto tales su prioridad es intercambiable. Volveré sobre este punto en los comentarios preliminares a la tercera parte del estudio.
} 
brevemente el sentido deweyano de tradición y de interés selectivo para luego indicar en qué puntos específicos de la pauta general de la investigación se pueden identificar elementos contextuales y en qué sentido estos elementos contextuales implican, al menos en un primer acercamiento, que la investigación esté permeada por valores tradicionalmente denominados extra-epistémicos -aquellos que son parte del contexto.

La segunda tarea del capítulo será precisar algunos sentidos de la continuidad entre investigación científica y valoración. Por tanto, en la tercera sección retomaré la idea de continuidad lateral entre experiencias reflexivas y señalaré dos dimensiones de la misma. La primera ya ha sido anticipada durante el análisis de la perspectiva metodológica de la valoración: en tanto y en cuanto esta última implica la resolución de una situación conflictiva o indeterminada respecto de valores, es ella misma una investigación llevada a cabo bajo los lineamientos de la pauta general. De este modo, investigación y valoración presentan una continuidad estructural o "metodológica", siguiendo la denominación propuesta por López (2018). La segunda dimensión también ha sido sugerida anteriormente: si el proceso de valoración depende de juicios evaluativos respecto de las relaciones de las cosas en términos de condiciones y consecuencias, el conocimiento provisto por la investigación respecto de esas relaciones resulta un elemento necesario para la propia valoración. Dicho de otro modo, la genuina valoración debe estar debidamente informada por el mejor conocimiento disponible -carácter que, de acuerdo con López (2018), puede entenderse en términos de continuidad "material". Sin embargo, estas dos dimensiones o facetas de la continuidad lateral entre ciencia y valoración no son suficientes para sostener la hipótesis del capítulo dado que podría argumentarse que la ciencia informa a la valoración sin que ello implique el movimiento contrario. Es por eso que, bajo la idea del carácter bidireccional de la continuidad intentaré señalar que así como el conocimiento científico es recurso y condicionante para el procedimiento de valoración, los valores en cuanto resultados reflexivos también serán recurso y condicionante para las investigaciones científicas pues, como señala Dewey, la prueba completa de estas últimas debe considerar un amplio espectro de consecuencias que exceden el ámbito científico propiamente dicho.

Una vez aclarados estos sentidos, en la cuarta sección abordaré una última dimensión de la continuidad planteada por Dewey, aquella entre génesis y validez del conocimiento científico. Considerar esta faceta de la continuidad permitirá atacar el último 
reducto de la versión standard de la filosofía de la ciencia, esto es, la postulación de un ámbito de validez o justificación que esté exento de toda intromisión contextual o extraepistémica. Para ello, recuperaré algunas discusiones puntuales que Dewey mantuvo a principios de la década de 1910 para vislumbrar en qué sentido hay continuidad entre génesis y validez y por qué el sentido amplio de investigación científica propuesto por Dewey inhabilita la posibilidad de trazar una línea entre investigación como proceso y conocimiento como resultado válido. Además, intentaré indicar que el pragmatista discutió en su propio tiempo las ideas centrales de la versión standard de la filosofía de la ciencia-e incluso antes de que esta última se consolidara como tal- y que su perspectiva ofrece un marco teórico más integral para el análisis de la práctica científica.

Finalmente, y a partir de las conclusiones obtenidas, en la quinta sección retomaré la conocida tesis de Hilary Putnam (2004) respecto del desplome de la dicotomía hechovalor, ciertamente heredera del pensamiento de Dewey. Si bien no me detendré en un análisis exhaustivo de la interpretación de Putnam, su perspectiva es de sumo interés para los fines de estas páginas porque permite introducir un tema central: el vínculo entre investigación científica y democracia, tanto respecto de la organización de la investigación -asunto sobre el que me ocuparé en el cierre del capítulo- como de la inscripción de la investigación en un contexto social y político más amplio -tema que abordaré en el capítulo siguiente.

\section{El carácter contextual de la investigación}

Como ya he señalado previamente, para Dewey no hay pensamiento que no se sitúe ni se desenvuelva en un contexto. Uno de los elementos que conforman el contexto, en su aspecto temporal, es aquello que Dewey llama tradición, es decir, modos de observar, de interpretar y de valorar culturalmente consolidados - que en tanto constituyen la cualidad intelectual de la tradición permiten diferenciarla de la costumbre ciega. Puesto en otras palabras, la tradición está compuesta, en parte, por hábitos de estimación, valores que alguna vez fueron producto de la deliberación inteligente pero que ahora se asumen como dados porque no entran en conflicto en esa investigación particular. Por otro lado, el contexto incluye un sentido espacial, constituido por todos los pensamientos 
contemporáneos a aquel que se está considerando -por todas las investigaciones contemporáneas, para el caso de una investigación científica particular. En este sentido espacial, el contexto es al pensamiento o investigación lo que la banquina y "los costados" del camino son al propio camino: no representan el foco de atención pero lo contienen, lo enmarcan y le brindan solidez y estabilidad (Dewey, LW.6.13).

Habida cuenta de que para Dewey "[e]l hábito no excluye el uso del pensamiento pero determina los canales en los que éste opera [... y que] el pensamiento opera en los intersticios de los hábitos", entonces esas estimaciones o canales efectivamente cumplen un papel importante al momento de analizar cualquier tipo de pensamiento, incluyendo a las investigaciones científicas (Dewey, 2004, p. 144. LW.2.335). Advertir esto es fundamental para no cometer dos falacias identificadas por Dewey y adelantadas en el capítulo 1: la falacia analítica, cuya característica central es omitir el contexto de quien investiga, considerar que los elementos identificados son auto-suficientes y finalmente conducir al inevitable resultado de "diseccionar y atomizar" el mundo en que vivimos; y la falacia de extensión ilimitada o universalización, generada por la omisión de las condiciones limitantes puestas por el contexto a la propia investigación (LW.6.7. Cf. Supra, p. 50).

¿Cómo influye, pues, el contexto en la investigación científica? De acuerdo con Dewey, toda investigación comienza con un problema por referencia a una situación inicialmente indeterminada pero no toda situación inicialmente indeterminada se instituye como un problema. Esto explica que la formulación del problema de investigación sea una fase específica de la pauta general, según aclara en la Lógica de 1938. En este marco, un aspecto clave es identificar los distintos criterios de relevancia empleados para definir que una situación indeterminada es problemática y, hecho eso, para definir los términos del problema, siempre teniendo en cuenta que la formulación del problema ya es un primer paso hacia la resolución.

Sobre este punto hay que considerar dos aspectos. Por un lado ya se ha visto que la tradición en cuanto "modo de ver y valorar" determina los canales en los que opera el pensamiento reflexivo situado y que la incidencia de esas estimaciones no puede ser desestimada en la investigación. Por otro lado, todo individuo ejerce operaciones de selección mediante aquello que Dewey denomina interés selectivo en referencia a la selectividad o rechazo, cuidado y preocupación en cuanto afección o sensibilidad 
cualitativa diferencial de cada persona que investiga -siempre con incidencia del contexto cultural y estrechamente vinculadas con el carácter valorativo y cualitativamente apreciativo de la experiencia. Para el caso de las investigaciones científicas el contexto adquiere una mayor densidad pues incluye no solamente un conjunto de hábitos de observación, interpretación o valoración en términos generales sino también específicos. En efecto, hay tradiciones científicas que definen los referidos canales de investigación, entendiendo por tradición científica a la física aristotélica, a la astronomía ptolemaica, a la física newtoniana o al darwinismo, y hay múltiples investigaciones contemporáneas que conforman el sentido espacial del contexto de cada investigación en particular. ${ }^{66}$

El investigador científico no es la excepción: su contexto incluye tanto los antecedentes teóricos específicos que han permitido constituir a la situación indeterminada como un problema y el conocimiento técnico que permite controlar la investigación como los hábitos y disposiciones del sujeto, su atención a determinados elementos, etc. En suma, “[s]in la fase del contexto encontrada del lado del investigador no habría ningún resultado científico sino accidentes sin interés teórico." (Dewey, LW.6.8). Es así que el hecho de que una situación indeterminada particular sea lo suficientemente interesante, importante o relevante como para dar lugar a una investigación dependerá tanto de la incidencia de esta selectividad como de las estimaciones asentadas. ${ }^{67}$

En segundo lugar, si la determinación del problema es ya parte de su solución en la medida en que orienta la selección de hechos del caso significativos, la recolección de datos, etc., entonces la incidencia de esta instancia de valoración es fundamental para dar

\footnotetext{
${ }^{66}$ Aun cuando Dewey no la llame explícitamente así ni desarrolle el tema, esta idea de "tradición científica" en cuanto tradiciones regulativas, órganos de apercepción o hábitos mentales parece adelantar la idea de paradigma de Kuhn (LW.6.13). Al respecto, Cf. López, 2014, p. 236.

${ }^{67}$ Bajo la hipótesis de que la complejidad de la teoría de la investigación de Dewey sólo puede entenderse a la luz de las categorías aristotélicas de epistèmè, phronèsis y technè, Melvin Rogers argumenta que la sensibilidad del individuo (en cuanto capacidad de responder a aquello que la situación demanda) juega un rol fundamental en la determinación del problema. Según indica el propio Rogers, "[i]nterpreto a Dewey como expandiendo el alcance de la phronèsis vía Darwin. [...] la phronèsis, para Aristóteles, es a las virtudes morales lo que la investigación, para Dewey, es a la acción humana in toto. [...] La investigación, por tanto, es un proceso ejercido en referencia a un contexto particular y encarnado en acciones." (Cf. Rogers, 2007, p. 103. Traducción propia). En este punto es importante hacer la siguiente aclaración: el interés selectivo no carga de subjetividad a la investigación porque lo que prima en esta última es su carácter instrumental, tanto en referencia al problema a resolver como a la posibilidad de emplear el resultado de esa investigación como recurso para investigaciones subsiguientes. En esta línea, Dewey afirma que una de las notas características de la ciencia es precisamente el modo en que elimina la conexión entre la individualidad de quien investiga y los usos de esa investigación, en especial cuando esos usos se hacen a mediano y largo plazo (LW.6.15-16).
} 
cuenta de todo el proceso de investigación. Dewey es claro respecto de esta cuestión cuando afirma que "[t]oda investigación competente y genuina exige que, del embrollo del material existencial y potencialmente observable y recordable, se seleccione y pondere alguna parte de él en calidad de datos o hechos pertinentes. Este proceso es de adjudicación, apreciación o valoración.” (1950, p. 545. LW.12.491). A este respecto resulta interesante la propuesta de Geiger acerca de sustituir la idea de data como dado por la de capta como tomado, a fines de sostener que los hechos son aquellos objetos y eventos sobre los cuales el investigador ha definido su importancia (Geiger, 1978, p. 110). Aparece aquí una nueva instancia en que las estimaciones y valoraciones tienen un rol importante en la investigación, en la medida en que determinan que cierta línea de trabajo es relevante y cierta otra no. Si bien volveré sobre la cuestión más adelante, vale señalar que este punto es central pues para Dewey la comunidad científica es un grupo que tiende a cohesionarse en torno al interés y beneficio privado, valores que devienen estimaciones habituales asumidas acríticamente y que por supuesto incidirán al momento de decidir si cierta situación indeterminada se instituye como un problema, qué aspectos son los problemáticos y en qué términos se plantea la propia investigación. Dewey es elocuente acerca de la influencia de la dimensión contextual, que en ciertos casos es notoriamente negativa: "Es patente el impacto de las condiciones culturales sobre la investigación física. Los prejuicios de raza, de nacionalidad, de clase y de secta desempeñan un papel tan importante que su influencia no escapa a ningún observador.” (1950, p. 535. LW.12.482). En este sentido, las condiciones culturales y los prejuicios, todos ellos apoyados en hábitos de estimación, tienen un rol insoslayable que se explica por el carácter contextual de la investigación.

Por otro lado, y retomo aquí algunos puntos del argumento de Putnam sobre el desplome de la dicotomía hecho-valor, la selección del material aportado por dichas investigaciones fácticas se hace bajo la consideración del fin a la vista en cuestión. En consecuencia, la determinación de qué rasgos son relevantes, qué información puede ayudar, cuánto grado de precisión se aceptará son todos resultados del interés selectivo dado por el fin/valor guía, de modo que las aserciones factuales resultantes están imbricadas o entrelazadas [intertwined] con juicios de valor. En esta misma línea se ubica el comentario del ya citado Geiger, quien extrema la tesis de Putnam (o la adelanta, atendiendo a las fechas de las respectivas publicaciones) y sostiene que "[1]os hechos 
mismos devienen un tipo de valor debido a ese acto de preferencia, un acto que efectivamente previene al lego o al científico de ser completamente neutral, mucho menos indiferente." (Geiger, 1978, p. 111).

Ahora bien, aun cuando el establecimiento del problema y la determinación de los hechos del caso incluya elementos contextuales entre los que efectivamente hay valores, no toda incidencia valorativa en esos puntos es legítima. Al respecto, y en el marco de sus reflexiones en torno a la investigación social, Dewey reconstruye una objeción clásica según la cual habría que excluir las valoraciones para poder respaldar las conclusiones en hechos -movimiento que, según he intentado indicar en el cierre del capítulo previo, no encuentra lugar en la idea de investigación deweyana- porque la formación de juicios científicos basados en valores previos, sobre todo morales, daña a la propia investigación. Dewey mismo señala que este planteo se apoya, en principio, en una intención "sana" pues efectivamente sería un error conducir y condicionar la investigación hacia resultados prefijados por ese tipo de asunciones. Sin embargo, continúa el pragmatista, ese planteo descansa en dos errores: por un lado, supone que las valoraciones morales agotan todo el campo de valoración; por el otro, y entiendo que este es el punto más interesante, en la medida en que esos valores son previos no son valoraciones en el sentido lógico distintivo pues excluyen la consideración de las consecuencias y reducen a la investigación a un mero plano instrumental (en el sentido llano del término). En suma,

\footnotetext{
"[s]e requieren juicios de valor, juicios de mejor y peor acerca de los medios a emplear, tanto materiales como de procedimiento. [...] El daño surge porque los valores empleados no se hallan determinados dentro y por el proceso de investigación. [...] La investigación social, para satisfacer las condiciones del método científico, debe juzgar que ciertas condiciones objetivas constituyen un fin que vale la pena alcanzar en las condiciones dadas. Pero, una vez más, esta afirmación no quiere decir lo que tantas veces se pretende que quiera decir, a saber, que se puedan recoger los fines y los valores fuera de la investigación científica, de modo que esta última se limite a determinar los medios más conducentes a la realización de tales valores." (Dewey, 1950, p. 551. LW.12.496).
}

Las afirmaciones precedentes recuperan muchos de los puntos señalados en el análisis de la teoría deweyana de la valoración respecto de la cuestión metodológica o 
procedimental y adelantan un asunto clave: la legitimidad de la incorporación de consideraciones valorativas en la investigación está dada, en buena medida, por el modo en que se obtienen esos mismos valores, es decir, por el hecho de que fueran resultado de una investigación y deliberación informada y no el mero reflejo de tendencias subjetivas, preconceptos, tradición o dogmatismos. En lo que sigue avanzaré sobre las facetas procedimentales y materiales de la continuidad entre investigación científica y valoración a efectos de aclarar y ahondar en estas ideas.

\section{Continuidad procedimental y continuidad material}

Una vez identificados los principales puntos en los que hay incidencia del contexto es momento de avanzar en torno a las dimensiones o facetas de la continuidad entre ciencia y valoración, teniendo siempre en cuenta lo dicho acerca del carácter integral de la continuidad y del carácter analítico de estas distinciones. En esta sección me detendré en el sentido lateral de la continuidad de la experiencia, aquella que se da principalmente entre experiencias reflexivas, e indicaré por qué la definición deweyana de investigación es tal que no permite marcar una línea divisoria abrupta entre ciencia y valores tradicionalmente denominados no epistémicos.

En primer lugar, y teniendo en cuenta que para Dewey tanto la investigación científica como la valoración son experiencias reflexivas, ambas comparten la pauta general de la investigación y en consecuencia mantienen una relación de continuidad metodológica. En este sentido, no hay diferencias lógicas relevantes entre los juicios valorativos y los juicios propios de la ciencia, sin perjuicio de su especificidad cualitativa, contextual y situada. Según indica el propio pragmatista en su autobiografía intelectual, esta relación entre ciencia y valoración constituye uno de los temas de mayor preocupación: "[...] a medida que mi estudio y mi pensamiento avanzaban, yo estaba más y más preocupado por el escándalo intelectual que me parecía reportar el actual (y tradicional) dualismo desde el punto de vista lógico y metodológico entre algo llamado 'ciencia' por un lado y algo llamado 'moral' por el otro." (LW.5.156). Así, la elaboración de una lógica entendida como pauta general de la investigación que pudiera emplearse sin brechas abruptas en la continuidad entre ambos ámbitos constituye, en opinión de Dewey, la respuesta a la mayor necesidad práctica de su tiempo. 
De acuerdo con Caspary (2003) es posible identificar dos formas en las que Dewey da cuenta de la importancia de esta continuidad metodológica y con ello de la relación entre ciencia y valoración. En primer lugar, la utiliza para criticar a aquellas perspectivas morales "pre-darwinianas", es decir, aquellas perspectivas que aún consideran que hay fines dados, fijos e independientes de toda experiencia y los oponen al desarrollo de las ciencias naturales. En segundo lugar, permite relacionar las hipótesis surgidas durante el proceso de deliberación moral llevado adelante por los agentes morales con cierta información obtenida mediante el auxilio de la ciencia, clave para la elaboración de los juicios evaluativos. En el marco de esta propuesta, la resolución inteligente de una situación problemática tanto en el ámbito de la ciencia como de los valores se obtiene en tanto resultado de una investigación reflexiva y produce ciertas modificaciones existenciales guiadas y respaldadas por esa misma investigación.

Estas correlaciones entre investigación científica y valoración se observan prácticamente en todas las fases de la pauta general presentada por Dewey en su Lógica:

(i) el punto de partida de las investigaciones científicas y de los procesos de valoración es una situación deficitaria o conflictiva, es decir una situación inicialmente indeterminada que posteriormente se instituye como problemática;

(ii) tanto las investigaciones científicas como las valoraciones deben recopilar los hechos del caso relevantes respecto de la situación, como el material provisto por investigaciones previas, el estudio de las condiciones-consecuencias de las cosas o procesos en ella involucrados y los deseos, fines, valores, principios potencialmente afectados por la investigación o valoración;

(iii) así como en el caso de la valoración los fines a la vista adquieren un carácter hipotético por referencia a su función como guías o planes de la acción, en cuyo curso se pondrán a prueba y eventualmente se modificarán, en las investigaciones científicas las ideas fungen como consecuencias anticipadas de lo que habrá de ocurrir en el proceso de resolución del problema y pueden ser reconsideradas conforme avanza la instancia de puesta a prueba experimental;

(iv) aquello que en la pauta general de la investigación se denomina razonamiento en cuanto comprensión de la idea y "juego libre" con otros conceptos vinculados 
encuentra su correlato en la deliberación y sobre todo en el ensayo imaginario, para el caso de los juicios morales;

(v) los resultados alcanzados en las investigaciones científicas y en las valoraciones modifican el curso de experiencia en virtud de resolver el estado previo de necesidad o carencia, enfatizando así su carácter práctico;

(vi) tal y como sucede con los principios lógicos en general y con las hipótesis para el caso de las investigaciones científicas, los valores se instituyen en el mismo proceso por el que se responde a situaciones problemáticas similares y reiteradas, en la medida en que aquellos se definen como fines a la vista generalizados;

(vii) tanto en el campo de la ciencia como en el campo de las valoraciones, los resultados obtenidos devienen abstractos en el sentido de no quedar directamente vinculados con alguna experiencia particular -aunque por supuesto no en el sentido de ser independientes y ajenos a la experiencia- y serán utilizados como herramientas o instrumentos para el tratamiento de problemas similares (recuérdese aquí lo señalado respecto de los principios morales en el capítulo 2 y de la asertabilidad garantizada de los juicios en cuanto subproducto de la investigación particular en el capítulo 4). Así, dichos resultados también dejan planteadas ciertas condiciones que deberán ser tenidas en cuenta en investigaciones o valoraciones posteriores. ${ }^{68}$

En estos términos, la idea de continuidad procedimental entre investigación científica y valoración permite aventurar una interpretación de la pauta general de la investigación como una "lógica de la experiencia reflexiva" consistente y articulada con la idea de una "lógica de la experiencia" indicada en el capítulo 1. Además, habilita la

\footnotetext{
${ }^{68}$ Caspary (2003, sec. 3 y 4) plantea un análisis similar al ofrecido aquí pero modifica la comparación pues toma por un lado una caracterización de la ciencia aplicada menos apegada a la pauta general de la investigación y por el otro la deliberación moral tal y como aparece explicitada en Naturaleza Humana y Conducta y en la Ética de 1932. Así, destaca que ambas refieren a problemas concretos, tratan con situaciones cualitativamente únicas, implican un sentido de la creatividad situada, suponen una continuidad entre descubrimiento/justificación para el caso de la ciencia y deliberación/decisión para el caso de la moral, consideran a las consecuencias de las acciones como forma de confirmar o rechazar las hipótesis en tanto planes de conducta, presentan una fuerte dimensión comunal, dan lugar a formas lógicas/valores desde el curso de experiencia e implican una transformación del propio agente. En definitiva, si bien la mayoría de los puntos de contacto identificados por Caspary difieren de los aquí señalados, entiendo que esa diferencia se debe sobre todo a que los términos de comparación no son los mismos y entiendo también que el sentido general de la exposición sí coincide, de modo que ambos análisis pueden complementarse para ofrecer una imagen más completa de la propuesta de Dewey.
} 
posibilidad de que el procedimiento valorativo pueda enseñarse tan ampliamente como la metodología de la investigación científica, todo ello en el marco del proyecto políticoeducativo de Dewey (Caspary, 2003, p. 463).

Al momento esta continuidad no parece ir más allá de un isomorfismo estructural, sin necesidad de que haya algún tipo de contenido en común. Puesto de otra manera, si este tipo de continuidad fuera el único, tanto las investigaciones científicas como las valoraciones podrían interpretarse como "cerradas en sí mismas", es decir, apelando a hechos del caso, resultados previos, formas lógicas o principios exclusivos de cada práctica específica. Sin embargo, se ha indicado ya que la perspectiva metodológica respecto de los valores implica necesariamente que los juicios evaluativos en términos de condiciones y consecuencias de las relaciones entre cosas o procesos estén científicamente informados. De esta manera, las consideraciones valorativas acerca de los fines están influidas por el conocimiento científico de los medios y también de los fines, habida cuenta de la tesis de la continuidad medios-fines. Tal y como señalan Hilary y Ruth Anna Putnam, la única forma de superar la "esquizofrenia" que implica la visión exclusivamente instrumental de la ciencia según la cual esta última provee conocimiento sobre los medios pero no sobre los fines es tomar cada problema valorativo como una invitación a investigar, abandonar las demandas de fines que estén más allá de toda valoración e incorporar el conocimiento científico para los juicios evaluativos no sólo sobre los medios sino también sobre los fines a la vista (Putnam \& Conant, 1994, p. 199). En palabras de Dewey, “[...] una moral que establezca sus juicios de valor a base de las consecuencias, ha de depender íntimamente de las conclusiones de la ciencia. Porque el conocimiento de las relaciones entre los cambios que nos permiten conectar las cosas como antecedentes y consecuencias es, precisamente, ciencia.” (1952, p. 239. LW.4.219). Esta afirmación, entre tantas otras de similar sentido que pueden encontrarse a lo largo de la obra deweyana, deja en claro el importante lugar que reserva el pragmatista al conocimiento científico en la resolución de situaciones morales y permite introducir el segundo sentido de continuidad entre ciencia y valoración, ahora respecto del material o contenido.

Teniendo en cuenta los argumentos presentados en los capítulos 2 y 3, la valoración debería estar científicamente informada en al menos tres instancias -más allá del siempre 
presente trasfondo naturalista inspirado en la biología y particularmente en la teoría de la evolución. Por un lado, se cuenta con el aporte del método genealógico o históricoantropológico para la valoración y moralidad. ${ }^{69}$ En este marco, el conocimiento científico constituye una pieza clave para rastrear, comprender, obtener una presunción de validez de las estimaciones habituales actuales e incluso influir en la elaboración de nuevos principios o doctrinas morales, en la medida en que el método genealógico es también críticoprospectivo y confluye con la propuesta metodológica de la valoración.

Por otro lado, Dewey también otorga un rol a la psicología como disciplina científica que ayuda a comprender el proceso de valoración. Aquí resulta interesante pensar una distinción entre el nivel de análisis filosófico y el nivel de acción del agente envuelto en una situación de valoración, es decir, entre el estudio filosófico de cómo se valora y la acción de aquel que tiene que resolver. En este orden, si los conocimientos aportados por el método genealógico ofrecen un principio de validez al juicio valorativo y en esa misma medida son material de interés para el agente, los aportes de la psicología parecerían brindar material al estudio filosófico del proceso de valoración -sin desconocer que cierto conocimiento ofrecido por esta disciplina pueda ser de utilidad para el propio agente, especialmente respecto de las actitudes y disposiciones.

Una de las primeras referencias aparece en el ya citado "Logical Conditions of a Scientific Treatment of Morality” (1903. MW.3.26-30). Allí Dewey observa que si el contenido del juicio moral y el carácter del agente se determinan recíprocamente (idea que luego retoma en "Teoría de la Vida Moral”), entonces una pieza clave para una teoría sobre el control de los juicios morales será el estudio de las disposiciones o del carácter en cuanto acción afectiva que se pone de manifiesto [set forth] en el juicio. En efecto, el análisis aportado por la psicología permite determinar ciertas condiciones genéricas de experiencia (hábitos, emociones, motivos, etc.) y sobre todo permite determinar de qué modo el agente transita desde su "absorción" en las apreciaciones a nivel de la experiencia primaria hacia la

\footnotetext{
${ }^{69}$ Algunos intérpretes como Goldman (2012) o Ryan (1995) consideran que respecto del asunto señalado la posición de Dewey presenta un giro cultural o antropológico, es decir, que presta cada vez más atención al impacto de la esfera social en la moral y se desentiende progresivamente de la influencia de la teoría de la evolución. Frente a esta lectura, López (2018) sostiene que no habría tal giro cultural porque por un lado Dewey tiene contacto con la antropología desde al menos fines del siglo XIX, durante su estancia en Michigan, y especialmente porque el planteo de los textos tardíos no presenta diferencias relevantes en torno al rol del conocimiento científico en la deliberación valorativa o moral. Esta última interpretación es la que tomo de referencia para enmarcar los comentarios respecto del lugar que ocupa el método históricoantropológico en la visión deweyana de la valoración.
} 
instancia reflexiva. En consecuencia, los aportes de la ciencia de la psicología [psychological science] en cuanto clarificación de procesos conscientes tales como abstraer y formar un principio o ideal moral a partir del curso de experiencia se instituyen como una condición necesaria para el análisis de los juicios morales particulares.

Similares consideraciones aparecen en Naturaleza Humana y Conducta. Allí Dewey dedica un parágrafo completo al análisis de la "psicología del pensamiento" a efectos de "[...] precisar el lugar del conocimiento y el juicio en la conducta [...]" (1964, p. 170. MW.14.127). Echar mano al conocimiento provisto por la psicología permite, en primer lugar, dar cuenta del vínculo entre percepciones, recuerdos y previsiones, del rol de los impulsos en la conducta humana, de la conformación progresiva de los hábitos y de la modificación de estos últimos, siempre en vistas a comprender y propiciar la acción inteligente (tanto en términos generales como, y especialmente, en el ámbito de la moral). ${ }^{70}$ En segundo lugar, los resultados de las investigaciones en psicología permiten discutir con aquellas posiciones filosóficas ortodoxas que suponen la existencia independiente de valores y principios morales y que consecuentemente deben postular que existe alguna facultad o función intelectual "separada y no natural" capaz de aprehender dichas existencias. Puesto de modo inverso -y en esto consiste el aporte de la psicología-, si se aceptan los resultados de las investigaciones según las cuales el conocimiento se efectúa por medio de factores naturales, entonces la postulación de facultades especiales para el conocimiento moral ya no es aceptable pues se apoya en presupuestos que desconocen la continuidad entre naturaleza y mente o entre el mundo material y el mundo moral. Estas observaciones apuntan, en definitiva, a determinar " [...] si los valores, normas, principios y objetos morales forman un dominio separado e independiente, o si son parte integrante del curso normal del proceso de la vida." (Dewey, 1964, p. 74. MW.14.129). En tercer lugar, en la medida en que la psicología se constituye como un estudio científico de la naturaleza

\footnotetext{
70 De acuerdo con Dalton, Dewey no sólo apela al conocimiento de la psicología sino también a investigaciones en las áreas de paleo-antropología, paleo-neurología y zoología, disciplinas que no sólo abonan los términos generales de la perspectiva naturalista y de la continuidad naturaleza-mente sino que especialmente aportan evidencia respecto de la relación proporcional entre el crecimiento del cerebro y la posibilidad de anticipar y controlar las consecuencias del comportamiento individual, aspecto clave en la propuesta del pragmatista (Cf. Dalton, 2002, p. 124).
} 
humana, permite también relacionar o "eslabonar" a la moral con otras disciplinas científicas:

[u]na moral basada en el estudio de la naturaleza humana y no en el menosprecio de ella, encontraría que los hechos reales del hombre se concatenan con los del resto de la naturaleza y podría aliar la ética con la física y la biología; observaría que la naturaleza y las actividades de un persona tienen las mismas finalidades que las de otros seres humanos y podría, por tanto, eslabonar la ética con el estudio de la historia, de la sociología, de las leyes y de la economía. (Dewey, 1964, p. 23. MW.14.11).

Ahora bien, los aportes del método histórico-genealógico y de la psicología podrían considerarse como genéricos en el sentido de que deberían ser tenidos en cuenta en toda reflexión valorativa. Si bien las consideraciones ofrecidas por ambas perspectivas mantienen siempre una referencia a la situación específica y tienen un carácter prospectivo, la propia valoración demandará además algún tipo de conocimiento particular respecto de los elementos que intervienen en dicha situación tal que permita esclarecer sus relaciones en términos de condiciones-consecuencias y llevar a cabo una resolución inteligente. Aquí radica la tercera dimensión de la continuidad de contenido o material entre valoración y conocimiento científico, ajustada a cada valoración particular.

Para ejemplificar este punto podrían compararse dos tipos de situaciones que demandan valoración como la decisión de realizar o no realizar un aborto y la decisión de comer o no comer carne animal. Ambas valoraciones deberían tener en cuenta las condiciones históricas del surgimiento de las estimaciones habituales al respecto (en términos bien generales podrían mencionarse las condiciones sociales, políticas y económicas del patriarcado o de la idea de que la "mujer" se realiza sólo si es madre, por un lado, y del especismo y antropocentrismo, por el otro). Además, ambas valoraciones deberían tener en cuenta el rol de los hábitos, disposiciones, voliciones, etc. en las conductas propias de cada caso. Finalmente, y aquí aparece el aspecto diferencial, cada valoración apelará a la información provista por disciplinas científicas determinadas según lo demande la situación específica. De esta manera, el primer caso podría emplear conocimientos aportados por la embriología, la filosofía, la psicología, el derecho, la sociología, etc., mientras que el segundo podrá emplear conocimientos aportados por la 
zoología, la nutrición, la filosofía, etc. Dado que la especificidad de las situaciones se impone a las consideraciones generales y prescriptas de antemano, y en línea con aquella idea según la cual las valoraciones genuinas no pueden limitarse a un mero ajuste de la conducta a criterios fijos e impuestos desde fuera del curso de experiencia, el planteo de Dewey no pretende adelantar con exactitud qué tipo de conocimiento sería necesario para informar las valoraciones sin referencia a cada situación determinada. Lo que sí permite es afirmar que de cumplirse sistemáticamente estas condiciones se superaría una de las formas del divorcio entre la moralidad y la ciencia, sin que ello implique que el agente descargue su responsabilidad moral de decidir. Más aún, teniendo en cuenta que para Dewey "[p]reguntar si la ciencia es capaz de influir en la formación de los fines por los que luchan los hombres [sea aportando material para las evaluaciones o difundiendo aquello que Dewey llama actitud científica, de orden procedimental] [...] equivale a preguntar si la ciencia tiene una intrínseca potencialidad moral", entonces esta dimensión de la continuidad material parece tener cierta repercusión en la propia cualidad moral de la ciencia. (Dewey, 1965, p. 153. LW.13.171).

\subsection{El carácter bidireccional de la continuidad material}

El sentido de continuidad material recién presentado aún admite una interpretación por la cual el conocimiento científico sería un "informante neutral" de la valoración. Dicho de otra manera, aún podría considerarse que entre ciencia y valoración hay una relación de exterioridad y que ese vínculo no propicia ningún cambio en el conocimiento científico. Ahora bien, esta lectura sólo se sostiene bajo la hipótesis de que la continuidad material es unidireccional, vale decir, que la ciencia informa a las consideraciones valorativas pero que estas últimas no inciden en la primera. Sin embargo, el hecho de que tanto la investigación científica como la valoración se asienten en una base experiencial común y compartan con esta última el carácter transactivo, afectivo, apreciativo y continuo impediría establecer barreras infranqueables entre una y otra e impediría también considerar que el sentido lateral de la continuidad de la experiencia quede o bien confinado a un tipo de experiencia reflexiva en particular o bien limitado a dicha forma unidireccional. 
De acuerdo con Dewey ninguna investigación finaliza con la elaboración de un juicio sino que éste es un instrumento para guiar la acción, reunificar la situación y obtener un nuevo equilibrio dinámico con el ambiente. De este modo, la idea deweyana de investigación es lo suficientemente amplia para incluir una instancia de instrumentación, de "regreso" a la experiencia. Esta instancia da cuenta de la doble puesta a prueba del juicio en su dimensión instrumental, a saber: cuando guía la acción para resolver el problema y cada vez que es tomado como un dato para investigaciones subsiguientes o es empleado en la resolución de un problema similar a aquel que le dio origen. Si la investigación científica incluye a la instrumentación y si se tiene en cuenta lo dicho respecto del carácter iterativo y recíproco de las fases de la pauta general de la investigación (Cf. Supra, p. 133), entonces esos ámbitos no sólo no pueden escindirse sino que, por el contrario, se alimentan y modifican mutuamente. Este movimiento de retorno a la experiencia orientado a la dirección de los cambios que deben operarse para resolver el problema inicial tiene su apoyo en el principio de continuidad de la experiencia y otorga una nueva impronta valorativa a la investigación:

\footnotetext{
"[...] toda determinación de los objetos en cuanto objetos (incluyendo las ciencias que construyen los objetos físicos) tienen referencia al cambio de la experiencia, o a la experiencia en cuanto actividad; y, cuando esta referencia pasa de la abstracción a la aplicación (de negativo a positivo), tiene referencia al control consciente de la naturaleza de los cambios (i.e. cambio consciente) y así obtiene significación ética. Este principio podría llamarse el postulado de continuidad de la experiencia" (MW.3.39).
}

Por otra parte, si la instrumentación se vincula con la reunificación de la situación y la consideración respecto de esta última se efectúa en términos valorativos, dado que en todas las situaciones que requieren ajustar inteligentemente la conducta y la experiencia hay instancias de valoración, entonces la investigación está permeada por consideraciones valorativas no sólo por referencia a la instancia de problematización y selección de datos relevantes sino también a la instancia de instrumentación, todo ello sobre la base del continuo de la experiencia. Así,

\footnotetext{
“[d]el mismo modo como no es posible determinar la validez de una proposición en el raciocinio o, en general, del material conceptual, prescindiendo de las consecuencias a
} 
que da origen su empleo funcional, tampoco se puede determinar la garantía suficiente de un juicio que pretende ser conocimiento (en su sentido laudatorio) con independencia de su conexión con un amplio círculo de consecuencias. [...] Aunque la concordancia entre las actividades científicas y las consecuencias que provocan en el público en general (técnicamente no científico) se hallan en un plano diferente, sin embargo, esa concordancia constituye una parte integrante de la prueba completa de las conclusiones físicas, siempre que sus repercusiones públicas son de significación" (Dewey, 1950, p. 537. LW.12.483-484. Cursivas en el original). ${ }^{71}$

Resulta claro, entonces, que la valoración del ámbito de instrumentación tiene una influencia notoria en la investigación científica. El punto clave es que el referido "amplio círculo de consecuencias" se halla en un plano diferente al plano científico, según indica Dewey, de modo que no se pondera sólo a partir de valores tradicionalmente denominados epistémicos sino que incluye también otro tipo de valores: morales, políticos, sociales, etc., es decir, los que fueran necesarios para considerar la situación. En otros términos, esa valoración implica tener en cuenta qué ámbitos de experiencia se verían afectados por la investigación específica y forma parte de la prueba completa de las conclusiones de la investigación, de la validación del conocimiento. Si bien este punto es más claro para el caso de las ciencias sociales que las ciencias naturales, Dewey inmediatamente señala que “[...] no es un hecho que constituya una diferencia lógica o teórica intrínseca entre los dos tipos de investigación" precisamente porque ellos son ante todo formas de la práctica inteligente orientada a la reunificación de situaciones inicialmente indeterminadas y reconocidas como problemáticas (Dewey, 1950, p. 538. LW.12.485).

Esta continuidad tiene otras implicancias. Por un lado, al momento de formular hipótesis en cuanto cursos de acción el investigador debe anticipar sus consecuencias y debe prever qué valores se afectarían, de forma que estos últimos devienen un elemento que no puede ser excluido de la propia investigación porque la consideración de las consecuencias amplias es parte constitutiva de dicha investigación. Dicho en términos críticos por el propio Dewey, "[1]a idea de la separación completa de la ciencia respecto del

\footnotetext{
${ }^{71}$ Según indica el pragmatista, esto es claro en las investigaciones sociales, pues cuando sus conclusiones intensifican los conflictos sociales, estos últimos "[...] suministran la prueba presuntiva de la insuficiencia o parcialidad y carácter incompleto de las conclusiones tal como se presentan." (Dewey, 1950, p. 538. LW.12.484).
} 
ambiente social es una falacia que fomenta la irresponsabilidad en los científicos por lo que respecta a las consecuencias sociales de su trabajo.” (1950, p. 536. LW.12.489). Por otro lado, la ampliación de la noción de investigación y la inclusión de las consecuencias en el plano extra-científico exige ampliar y articular en esa misma medida las incumbencias de la institución científica con otras instituciones de orden político. Si bien dedicaré el próximo capítulo al análisis de esta cuestión, el ejemplo de Hilary y Ruth Anna Putnam es por demás claro: "[e]sta afirmación [de Dewey, citada anteriormente] es extremadamente radical. Implica, por ejemplo, que no podemos quedarnos contentos con el descubrimiento de técnicas para la maternidad subrogada sino que debemos desarrollar legislación que proteja a la mujer de ser explotada como resultado de esa nueva técnica." (Putnam \& Conant, 1994, p. 207).

En este punto resulta interesante recuperar los términos de la distinción planteada por Helen Longino entre valores constitutivos y valores contextuales de la ciencia (1990, pp. 4 y ss.). De acuerdo con la autora, los valores constitutivos son aquellos que determinan qué es y cómo está compuesta una práctica científica aceptable, mientras que los valores contextuales pertenecen al ambiente social y cultural en el que se inscribe la práctica científica. Desde mi punto de vista, esta distinción abre un camino valioso porque permite pensar que el conjunto de los valores constitutivos no está dado exclusivamente por los valores epistémicos sino que admite otro tipo de valores, generalmente relegados al plano de lo extra-epistémico. ${ }^{72}$ Retomando el planteo de Dewey, la tesis de continuidad no pretende desdibujar las diferencias y especificidades de los distintos tipos de valores que serán considerados en cada investigación sino que permite "reubicarlos" en esta nueva categorización de valor constitutivo - a sabiendas de que esa reubicación tal vez no coincida con el planteo de la propia Longino. Dicho de otra forma, la perspectiva deweyana habilita a considerar que hay valores morales, sociales o políticos tan constitutivos de la práctica científica como su contrastación experimental rigurosa o su predictibilidad, desarticulando así una de las distinciones más persistentes de la versión standard de la filosofía de la

\footnotetext{
${ }^{72}$ Ha sido señalado que el desarrollo del argumento de Longino presenta una tensión entre plantear que los valores constitutivos no explican por sí solos el desarrollo de la ciencia y que por ello se deben considerar también los valores contextuales, por un lado, y proponer deshacerse de la distinción misma entre valores constitutivos y contextuales, por el otro (Rooney, 1992, pp. 17-19). A los fines de la argumentación aquí presentada mantendré la distinción aun cuando sugiera algunas diferencias interpretativas respecto de la posición de Longino.
} 
ciencia y una de las bases del ideal de ciencia libre de valores. Por supuesto, no es posible afirmar de antemano cuáles serían esos valores morales, sociales o políticos pues eso depende del amplio círculo de consecuencias de cada investigación científica particular.

Finalmente, el ámbito de instrumentación "revierte” sobre la práctica científica en otro sentido, ya no relacionado específicamente con la instancia de validación sino a la cualidad moral de toda la investigación. En efecto, si se acepta que la instancia de instrumentación es parte de la investigación - del mismo modo que lo es la determinación del problema- entonces la investigación es ubicada en una perspectiva más amplia y puede ponerse en relación con los asuntos y problemas de la experiencia humana. Introduzco una nueva cita de La Reconstrucción de la Filosofía para dar cuenta de este punto:

\footnotetext{
Ahora bien, la lógica experimental aplicada a la moral nos impone que consideremos buena a cualquier cualidad en cuanto ella contribuye al mejoramiento [ameliorent] de los males existentes. Y, al hacerlo, establece el sentido moral de la ciencia natural. [...] Cuando la física, la química, la biología, la medicina, contribuyen a poner al descubierto los males concretos que sufre la humanidad, y al desarrollo de proyectos encaminados a ponerles remedio, se convierten en ética; entran a formar parte del mecanismo de investigación moral, o ciencia. [...] Pero esa ganancia no queda limitada a la faceta moral. Desde ese momento, las ciencias naturales dejan de estar divorciadas de lo humano, adquieren la cualidad de lo humano. Eso es algo que es preciso alcanzar, pero no buscando de manera técnica y especializada lo que se llama la verdad por la verdad, sino con la conciencia de su alcance social, de su obligatoriedad intelectual. Esa búsqueda es técnica únicamente en el sentido de que nos proporciona la técnica para las construcciones prácticas en lo social y en lo moral. (Dewey, 1993, pp. 182-3. MW.12.178-9. Cursivas agregadas).
}

Estos comentarios invitan a reflexionar en torno a los fines de la ciencia, en términos fundamentalmente políticos, tarea que quedará reservada para el próximo capítulo. No obstante, antes de avanzar en esa dirección, es fundamental dar cuenta de un último sentido de continuidad a efectos de desarticular una estrategia argumentativa frecuentemente empleada, a saber: la demarcación de una estricta diferencia entre el plano o ámbito de la génesis del conocimiento, reducida a lo subjetivo, y el plano o ámbito de su 
justificación o validez, vinculado a la objetividad, todo ello para conservar un último reducto exento de componentes experienciales, valorativos o extra-epistémicos.

\section{La continuidad entre génesis y validación}

Hacia comienzos del siglo XX Dewey fue parte de un amplio conjunto de filósofos que cuestionaron el idealismo absoluto de Josiah Royce. Una de las reacciones más fuertes al idealismo de Royce fue la de los denominados "nuevos realistas", de la mano de Perry y Montague. Dewey, en su recurrente estrategia de superar las alternativas dicotómicas, entabla una discusión con los nuevos realistas acerca del presunto carácter independiente de los objetos de conocimiento y ofrece allí algunas consideraciones de notorio interés para los propósitos de este estudio. ${ }^{73}$ En este marco, me detendré a analizar "Valid Knowledge and the Subjectivity of Experience", escrito por Dewey en 1910 y poco atendido por la bibliografía crítica (MW.6). El trabajo con los argumentos allí presentados permitirá señalar el modo en que Dewey analiza el proceso de validación del conocimiento a la luz de la tesis de la continuidad de la experiencia. Por otro lado, permitirá mostrar que el pragmatista discute la distinción entre contexto de descubrimiento o génesis del conocimiento y contexto de justificación o validez casi 20 años antes de que Hans Reichenbach la explicitara en su Experience and Prediction de 1938.

La pregunta que estructura todo el artículo de Dewey es la pregunta por la relación del conocimiento válido con la experiencia, habida cuenta de que los idealistas pero también algunos realistas como Moore y Russell o neo-realistas como Perry tienden a tachar a la experiencia de "meramente subjetiva" (lectura que no encuentra sustento en la concepción transaccional de la experiencia) y consecuentemente tienden a no considerarla al momento de dar cuenta de las condiciones de validez de los objetos de conocimiento. Puesto de modo inverso, idealistas y realistas por igual tienden a considerar a los objetos de conocimiento por fuera de sus relaciones de condiciones y consecuencias con otros objetos o procesos de la experiencia, como si la experiencia no estuviera allí. La primera respuesta que ensaya Dewey frente a esa tendencia se apoya en aquello que las ciencias

\footnotetext{
${ }^{73}$ En el período 1909-1910 Dewey escribe una gran cantidad de artículos dedicados a la discusión con el realismo, entre ellos "The Short-Cut to Realism Examined" y "Brief Studies in Realism" (MW.6, ambos textos). Para un detallado estudio de la discusión entre Dewey y los "nuevos realistas", Cf. Hildebrand, 2003, Cap. 2.
} 
experimentales efectivamente consideran como objeto de conocimiento válido. A diferencia de la tradición intelectualista del siglo XVII, que busca algún aspecto del objeto que por sí solo pueda garantizar su validez (y aquí nuevamente Dewey incluye a racionalistas y empiristas por igual), las ciencias experimentales indican que no hay ninguna cualidad del objeto de conocimiento que por sí misma pueda dar cuenta de su validez sino que ésta es determinada por el modo en que se conduce la investigación y por las conexiones que se establecen entre el objeto y otros objetos, en el futuro. Según Dewey, estas observaciones deberían ser suficientes para dejar de considerar a la experiencia como meramente subjetiva y excluirla del procedimiento de validación del conocimiento, al tiempo que la tendencia de los nuevos realistas de excluir al sujeto en sus análisis del conocimiento debería quedar descartada.

Sin embargo, parece que remitirse al modo de trabajo de las ciencias experimentales no es suficiente para resolver el problema. En efecto, Dewey recupera una objeción de los realistas según la cual habría que diferenciar entre la aparición del objeto de conocimiento y las condiciones de su validez. Siguiendo la reconstrucción deweyana, el realista señalaría que no deben confundirse las condiciones de génesis y las condiciones de validez del objeto de conocimiento sino que ellas deben quedar bien diferenciadas (MW.6.84). La respuesta del pragmatista no se hace esperar y sugiere al realista que considere

[...] las conexiones altamente íntimas y permeantes que existen entre las condiciones empíricas de génesis y consecuencias y el status de validez de un objeto. [...] La continuidad entre "experiencia" y "validez" es a la vez tan inquebrantable y tan importante como para volver increíble la noción de que la génesis y consecuencias estén en un ámbito -el subjetivo- y la validez en otro, el objetivo. En vistas de los hechos del procedimiento científico, difícilmente sea excesivo decir que, en cierto sentido, el status de validez es un tipo de experiencia. Aun si considerásemos a la experiencia como subjetiva [If it can be made out that experience is subjective] no deberíamos pensar que hemos logrado nada con una distinción entre génesis y validez. [...] Deshacerse de la dificultad [de explicar la validez del conocimiento] mediante el trazado de una fuerte y tajante línea entre génesis y validez - o entre lo psicológico y lo lógico- es creer que ponerle nombres a los términos del problema resuelve el problema que aquellos términos nombran. (MW.6.84). 
Este fragmento introduce algunas cuestiones de vital relevancia para el asunto aquí estudiado. En primer lugar, resulta claro que la posición de Dewey encuentra apoyo en la tesis de la continuidad de la experiencia. En efecto, el pragmatista señala que la distinción entre génesis y validez es en cierto sentido arbitraria y opera un corte en un proceso que es continuo, desde la aparición de una idea hasta el momento de aceptarla como válida, en cuanto resultado de la investigación. Como señala Hildebrand $(2009$, p. 21), si la investigación controlada es lo que respalda a la validación y a la asertabilidad de determinada idea y si esa asertabilidad es puesta a prueba cada vez que el juicio resultante conduce la acción a fin de resolver un problema, entonces los nuevos realistas no tienen buenas razones para pensar que la investigación como proceso o el objeto de conocimiento como su resultado transaccional implica algún tipo de subjetivismo pues ese conocimiento tiene un sustento en la experiencia.

En segundo lugar, si la continuidad de la experiencia es inquebrantable y no se ve afectada por una simple línea de demarcación entre un ámbito y otro, entonces tampoco hay razones para excluir a priori aquellos elementos que forman parte de la génesis del conocimiento. Además, si la investigación se inscribe en un seno o matriz cultural que incluye al contexto y si no es posible establecer un límite estricto entre ese ámbito y un supuesto ámbito de lo objetivo, de la validación, entonces esta última traerá consigo algunos elementos propios del contexto que son, entre otros, valores morales y políticos, cuya presencia no puede negarse ni aislarse. De aquí que, como señalan Di Gregori y López, “[...] la explicación científica resulta pragmáticamente cargada, aunque su formulación en términos de razonamiento no lo muestre, por las decisiones, valoraciones y apreciaciones que no pueden separarse como si fueran reinos absolutamente distintos entre sí, puesto que todas ellas se hallan involucradas en el hacer ciencia." (2013, p. 8). Más aún, si se tiene en cuenta que una de las apuestas de Dewey pasa por revisar los valores y fines de las acciones cada vez que fuera necesario y que esa revisión está también apoyada en la investigación y deliberación, entonces tampoco habría lugar para pensar que los componentes del contexto son subjetivos en el sentido de tendenciosos o individuales.

En tercer lugar, la respuesta de Dewey interpela explícitamente a quienes buscan diferenciar de modo taxativo entre ámbito de génesis y ámbito de validez o, como serán 
generalmente denominados desde mitad del siglo XX y por referencia al planteo de Reichenbach, contexto de descubrimiento y contexto de justificación. Este último punto es de suma importancia porque habilita a discutir desde un nuevo ángulo con aquellas visiones dicotómicas propias de la versión standard de la filosofía de las ciencias (además de demostrar que Dewey puso en cuestión algunas ideas básicas del positivismo lógico que, si bien parecería que ya circulaban en el ámbito intelectual, aún no estaba establecida en los términos antedichos). En efecto, y teniendo en cuenta que la pauta general de la investigación incluye como primera instancia a una situación inicialmente indeterminada a partir de la cual se instituye un problema, la propuesta deweyana es incompatible con las visiones filosóficas de la ciencia que excluyen la reflexión sobre el origen de los problemas o de las hipótesis elaboradas y que intentan circunscribir el análisis a la justificación lógica de las teorías. Según indica Dorstewitz, "Dewey incluye todas las fases de su 'pauta de investigación' en su 'lógica', que define como 'teoría de la investigación', y consecuentemente rechaza tratar al 'descubrimiento' y a la ‘justificación' como contextos separados." (Dorstewitz, 2011, p. 215).

Poner en discusión la dicotomía entre contexto de justificación y contexto de descubrimiento es un punto de partida para avanzar en diversos cuestionamientos. Esa distinción radical entre ambos tipos de contextos tiene estrecha vinculación con otras dicotomías fuertes como teoría/práctica o hechos/valores y a su vez funciona como punto de apoyo para otras distinciones subsiguientes como valores epistémicos/extra-epistémicos o lógica de justificación/no-lógica de descubrimiento. Dados los argumentos que explícitamente ofrece Dewey en contra de una distinción tajante entre génesis y validez y dada la posibilidad de reconstruir distintas facetas o dimensiones de la continuidad entre ciencia y valoración, es posible afirmar que la férrea distinción entre valores epistémicos y extra-epistémicos debe ser profundamente revisada o, tal vez, dejada de lado en favor de otro tipo de categorizaciones. La distinción ofrecida por Longino sugiere una novedosa forma de considerar los valores intervinientes en la investigación científica, permite afirmar que hay valores tradicionalmente denominados extra-epistémicos que son parte constitutiva de la investigación científica en términos generales y es lo suficientemente flexible para que cada investigación científica tenga un conjunto específico de valores constitutivos, de 
acuerdo con la particularidad de la situación en la que se desarrolle y de las consecuencias a las que dé lugar.

Hasta aquí he analizado los distintos modos en que valoración e investigación forman un continuo y he ofrecido razones por las que la ciencia está efectivamente cargada de valores tradicionalmente denominados extra-epistémicos, siempre en referencia a la pauta general de la investigación. Resta tratar un último sentido de la carga valorativa de la ciencia, vinculado en este caso a la organización de la propia investigación. En lo que sigue me interesa recuperar explícitamente la interpretación de Hilary Putnam acerca del desplome de la dicotomía hecho/valor a efectos de abordar el planteo del propio Putnam en favor de una organización democrática de la ciencia - planteo que, a mi juicio, añade una nueva dimensión valorativa moral y política intrínseca a la investigación científica.

\section{Del desplome de la dicotomía hecho/valor a la organización de la investigación}

Es bien sabido que una de las lecturas contemporáneas más relevantes del pragmatismo clásico es la que elabora Hilary Putnam, tanto en el ámbito de la epistemología como en el ámbito de la moral. ${ }^{74}$ En este marco, una de sus tesis más reconocidas es la del desplome de la dicotomía hecho/valor, de notoria resonancia deweyana. De acuerdo con la teoría de la valoración de Dewey, hay un sentido inicial en el que los valores pueden ser tomados como hechos: en cuanto estimaciones, los valores "se expresan" en acciones habituales, en comportamientos observables e identificables. Puesto a la inversa, las acciones de una persona responden a sus estimaciones respecto de la situación particular. La consideración de las estimaciones como comportamientos es precisamente lo que permite elaborar proposiciones sobre estimaciones, es decir sobre cuestiones de hecho analizables en términos de condiciones y consecuencias. Sin embargo, este primer sentido no resulta suficiente para sostener la interpretación de Putnam respecto del colapso de la dicotomía entre hechos y valores pues bien podría replicarse que el caso de las estimaciones no es un caso genuino de valor. El mismo Dewey reconoce que aun

\footnotetext{
${ }^{74}$ Respecto del acercamiento de Putnam al pragmatismo clásico, David Hildebrand distingue entre razones culturales (o académico-culturales, me permito aclarar), vinculadas a las disputas de legitimidad entre las ciencias naturales y las humanidades/ciencias sociales y ancladas en el viejo debate entre realismo y antirealismo, por un lado, y razones filosóficas (o técnico-filosóficas), vinculadas al problema del realismo metafísico, la verdad y la verificación. De acuerdo con Hildebrand, Putnam encuentra referencias interesantes en el pragmatismo clásico, especialmente de Dewey, para dar respuesta a ambas cuestiones (Hildebrand, 2000, pp. 109-112).
} 
cuando constituyan un punto de partida, las proposiciones sobre estimaciones no son valorativas en ningún sentido distintivo.

Frente a esta posibilidad, una clave en la que podría apoyarse la interpretación de Putnam es la tesis de la reciprocidad entre medios y fines planteada por Dewey. Vale repetir que desde el punto de vista deweyano la relación entre medios y fines a la vista o valores en cuanto fines a la vista generalizados no puede pensarse como una relación de exterioridad o mero instrumentalismo sino, antes bien, como una relación de mutua configuración. En ese sentido, la deliberación no debe escindir el tratamiento de los medios y de los fines porque los fines cobran forma y valor en el curso de su realización y porque los medios siempre expresan el valor del fin al que conducen. Es por ello que según Dewey un fin declarado no es auténtico si para su realización requiere medios que lo contradigan. Ahora bien, si no hay decisión sobre los fines o valores sin decisión sobre los medios y si las evaluaciones respecto de los medios se hacen con el apoyo o el informe de investigaciones fácticas, entonces una primera conclusión es que no hay decisión sobre los fines y valores que no implique consideraciones fácticas. De acuerdo con Faerna, "[1]os fines y los valores se descubren conjuntamente con los hechos", de forma tal que en principio no es posible pensar a los valores sin referencia al ámbito factual (1996, p. 197. Cursivas en el original). Luego, los valores deben ser considerados como "constructos" y no como captaciones directas del tipo de las apreciaciones inmediatas -más allá de que éstas representen un punto de partida para las valoraciones-, del mismo modo que los hechos no son considerados como percepciones sino como resultado de una serie de procesos intelectuales (Cf. Welchman, 1995, p. 187).

En esta línea, Putnam identifica como elemento común al pragmatismo clásico la idea según la cual el valor y la normatividad permean la totalidad de la experiencia. Esta "matriz valorativa" de la experiencia, si se me permite reformular la expresión de Robert Innis citada en el primer capítulo, habilita a Putnam a concluir que los juicios normativos son igualmente imprescindibles para el caso de la práctica científica en tanto experiencia reflexiva específica. Consecuentemente, arguye Putnam, se debe aceptar que la coherencia, la precisión o la predictibilidad son valores y que -tesis compleja sobre la que no ahondaré en estas páginas- si esos valores permiten describir correctamente el mundo es algo que se 
afirma a través del cristal de esos mismos valores (Cf. Putnam, 2004, pp. 45-48). ${ }^{75}$ Considerados bajo esta perspectiva, Putnam sostiene que este tipo de valores deberían ser tomados como máximas y que en cuanto tales siempre requieren interpretación contextual. Más aún, Putnam sostiene que el argumento elaborado por Dewey en su Lógica demuestra que hay cierta superposición [overlap] entre valores científicos y valores éticos, dado que los valores científicos son relativos al contexto de adquisición del conocimiento y este último proceso es susceptible de crítica ética. (Cf. Putnam \& Conant, 1994, p. 174).

A partir de aquí el argumento de Putnam presenta dos grandes bifurcaciones: por un lado el planteo del carácter específico de los valores científicos - planteo que no abordaré en detalle- y por otro lado la explicitación de la dimensión cooperativa de la investigación como elemento fundamental para explicar por qué el modelo deweyano no se ajusta en lo absoluto al modelo algorítmico de decisión. ${ }^{76}$ Las razones que ofrece el propio Putnam son dos: por un lado, el carácter de intervención y manipulación activa del ambiente es constitutivo de la investigación e impide considerar a quienes la llevan adelante como simples espectadores pasivos que registran y comparan observaciones a partir de ciertos parámetros. Por otro lado, la investigación es fundamentalmente una empresa colectiva que, a tono con lo analizado en capítulos previos, no admite la concepción del investigador como una entidad aislada y solitaria sino que toma como modelo a un grupo de

\footnotetext{
${ }^{75}$ Putnam identifica otro sentido más amplio en el que hecho y valor aparecen entrelazados, sentido que se observa en los conceptos éticos "densos" tales como "cruel" o "crimen" en tanto son susceptibles de ser utilizados con propósitos fundamentalmente descriptivos o fundamentalmente normativos. Si bien no me detendré en este sentido de imbricación o entrelazamiento, merece al menos ser mencionado en el marco del tratamiento de la perspectiva de Putnam respecto de la dicotomía hechos-valores (Putnam, 2004, pp. 49-50).

${ }^{76}$ Respecto de la primera cuestión, y si bien hasta el momento parece que la lectura de Putnam concuerda con el tono general de este capítulo, hay un punto importante que merece ser mencionado. Inmediatamente después de señalar que la posición de Dewey supone cierta superposición entre valores científicos y valores éticos, Putnam aclara que aun cuando se superponen, permanecen [remain] distintos (Putnam \& Conant, 1994, p. 174). Entiendo que la clave para interpretar esta observación radica en el sentido en que los valores permanecen distintos. El argumento de Putnam asocia la especificidad de los valores científicos a algún sentido de conocimiento puro en cuanto fin terminal: "[...] nosotros no estamos -ni hemos estado nuncainteresados en el conocimiento sólo por sus beneficios prácticos; la curiosidad es coetánea con la propia especie, y el conocimiento puro es siempre, en algún punto y en algunas áreas, un valor terminal aún para el menos curioso de nosotros." (Putnam \& Conant, 1994, p. 173). A diferencia de esta lectura, considero que el énfasis puesto por Dewey en el carácter práctico de toda investigación impide trazar distinciones férreas entre ambos tipos de conocimiento $\mathrm{y}$, consecuentemente, impide pensar que la especificidad de los valores científicos o epistémicos se apoya en esa distinción. En este sentido retomo la interpretación de Hildebrand (2000, p. 119) para sostener que el hecho de que un conjunto de valores tenga una función particularmente importante en las prácticas científicas no permite inferir que Dewey los hubiera considerado "científicos" si ello implica asumir que hay una diferencia categórica con otro tipo de valores, sean morales, políticos o estéticos.
} 
investigadores tratando de producir buenas ideas y de testearlas para determinar cuál de ellas es más valiosa. Si, a su vez, se recuerda que los parámetros o valores epistémicos requieren interpretación contextual, es decir que no son algoritmos "cerrados" que se aplican en cada caso, entonces el carácter grupal de la investigación tiene un impacto clave en aquello que se entienda por los valores (en principio epistémicos) que guían a la investigación. Putnam explica este punto señalando que "[n]ociones como la 'simplicidad', por ejemplo, no tienen significado claro hasta que investigadores que hayan probado su competencia en la práctica de investigación sean capaces de acordar, al menos en cierta medida, acerca de qué teorías poseen y qué teorías no poseen 'simplicidad"' (Putnam \& Conant, 1994, p. 171).

En virtud de lo dicho, parecería que los argumentos teóricos respecto del desplome de la dicotomía hecho/valor introducen una nueva dimensión de análisis de la investigación, estrechamente vinculada a su organización política. Para ser efectiva en cuanto a la formación de ideas y su testeo racional, Putnam sostiene que la investigación debe estar organizada de forma cooperativa. Son muchísimos los fragmentos de la obra de Dewey que podrían citarse para respaldar esta lectura, como por ejemplo la afirmación de que "[e]stá en la naturaleza de la ciencia no tanto tolerar como acoger gustosamente la diversidad de opiniones" o también la idea de que "[...] la inteligencia es un haber social cuya función es pública y cuyo origen se concreta en la cooperación interpersonal” (Dewey, 1965, p. 101. LW.13.135 y 1996, p. 101. LW.11.48, respectivamente). Retomando aquí algunos aspectos de la "ética del discurso" elaborada por Jürgen Habermas, Putnam sostiene que sin cuestionar hipótesis aceptadas mediante la crítica de la evidencia que las sostiene, sin proponer hipótesis alternativas y sin superar las relaciones de jerarquía y dependencia, la investigación científica nunca podrá alcanzar el criterio deweyano de libre y sistemática comunicación del conocimiento. ${ }^{77}$ Así, “[...] tanto para su pleno desarrollo como para su completa aplicación a los problemas humanos, la ciencia requiere la democratización de la investigación." (1994, p. 173).

\footnotetext{
77 Putnam y Habermas mantienen una extensa y profunda discusión en torno al problema de la fundamentación de las normas y valores, defendiendo el primero una concepción de corte pragmatista y el segundo la necesidad de emplear algunos criterios trascendentales como condiciones de posibilidad de todo diálogo racional (Putnam \& Habermas, 2008).
} 
En estos términos se presenta la justificación instrumental en favor de la democratización de la investigación científica, según la caracteriza el propio Putnam, pues en cuanto actividad cooperativa que pone en discusión sus parámetros o valores, la apertura al criticismo tanto en la generación y evaluación de teorías como en la interpretación contextual de los parámetros es un pre-requisito para el correcto desarrollo de la investigación. Además, si el ejercicio de la inteligencia, es decir la investigación, descansa en ciertos presupuestos valorativos respecto de la democracia, entonces hay aquí una nueva razón por la que la propia investigación no puede ser tomada como valorativamente neutral. Por supuesto, Putnam reconoce que la ciencia no necesariamente está organizada bajo este modelo no-jerárquico y de apertura. Una vez más, el planteo deweyano es un antecedente de referencia: "Dewey no era ingenuo. Fue consciente de que hubo 'juegos de poder' en la historia de la ciencia, tal y como los hay en la historia de toda institución humana. Él no se habría sorprendido por los hallazgos de los historiadores y sociólogos de la ciencia. Pero difiere de ellos (y de algunos de nuestros contemporáneos) en afirmar que tiene sentido postular una dimensión normativa de la ciencia.” (Putnam \& Conant, 1994, p. 173).

El argumento de Putnam a partir de la concepción deweyana de investigación torna necesario considerar una nueva instancia de la incidencia de valores tradicionalmente denominados no epistémicos al interior de la propia práctica científica porque la democratización de la investigación es parte de su definición normativa. Luego, la práctica científica en tanto actividad grupal o colectiva queda atravesada por consideraciones de índole política, todo ello en vistas a garantizar su organización cooperativa y la plena aplicación de la inteligencia en la resolución de problemas.

\section{Conclusiones}

En este capítulo he abordado los distintos sentidos en que el marco teórico deweyano permite pensar la continuidad entre investigación, particularmente científica, y valoración, siempre bajo la idea de que esos sentidos constituyen facetas del continuo multidimensional de la experiencia. En primer lugar, he prestado atención al carácter contextual de toda investigación, estrechamente vinculado a aquello que Dewey denomina tradición e interés selectivo. En este sentido, si la investigación se inscribe en un seno o matriz cultural que incluye al contexto y si no es posible establecer un límite estricto entre 
ese ámbito y el ámbito de la validación, entonces toda investigación incorporará algunos elementos propios del contexto. Uno de los puntos en los que más clara se torna la incidencia de la instancia valorativa permeada por estimaciones de orden contextual es en la determinación del problema, instancia clave en toda la investigación pues los términos en que se plantea el problema prefiguran sus posibles soluciones. De este modo, considerar el rol del contexto es un punto fundamental al momento de reflexionar en torno a la dimensión valorativa de la investigación.

Ahora bien, las continuidades entre ciencia y valores no se agotan en la incidencia contextual. Una lectura más precisa de las teorías deweyanas de la investigación y de la valoración permite identificar la continuidad metodológica o procedimental, habida cuenta de que tanto la investigación científica como la valoración propiamente dicha se rigen por la pauta general de la investigación. A su vez, permite identificar la continuidad material dado el carácter científicamente informado del proceso de valoración. Más aún, teniendo en cuenta que la idea misma de investigación supone una instancia de instrumentación, es decir la resolución del problema con la guía del juicio, y que esa instancia de instrumentación genera un amplio círculo de consecuencias que repercute en un plano distinto del científico, esas consecuencias no son valoradas exclusivamente en términos epistémicos sino que hay otros valores intervinientes, aquellos relativos a la ponderación de la reunificación de la situación. Esa valoración constituye una parte integrante de la prueba completa de las conclusiones y otorga sentido valorativo moral y político a toda la investigación. Además, si la investigación repercute en un plano no científico, el investigador debe tener en cuenta esas consecuencias al momento de elaborar las hipótesis y los valores que emplee para ello tienen legítimo lugar en el seno de la investigación. Así, retomando la distinción hecha por Longino entre valores constitutivos y no constitutivos de la práctica científica, la perspectiva deweyana permite afirmar que hay valores tradicionalmente denominados no epistémicos que son constitutivos de la ciencia.

Esta reconstrucción de las continuidades entre investigación y valoración puede tener todavía una última objeción, sostenida mediante la estrategia de postular un ámbito de validez del conocimiento en el que no intervenga ningún elemento propio del ámbito de génesis, es decir, ningún elemento de orden experiencial. Frente a esta alternativa, en su 
discusión con los realistas y neorrealistas (e incluso con idealistas) Dewey afirma que el carácter continuo de la experiencia es tan inquebrantable que el ámbito de validación no puede recortarse del proceso de investigación del cual es resultado y todo lo que ese proceso implica. Esta discusión permite observar un elemento más, de notoria relevancia al momento de pensar en términos históricos las relaciones entre Dewey y algunas afirmaciones del positivismo lógico: parecería que Dewey logró prever la estrategia argumentativa antedicha y discutió la distinción entre contexto de descubrimiento y contexto de justificación incluso antes de que fuera consolidada por Reichenbach en 1938.

Por último, he recuperado la lectura de Putnam respecto del desplome de la dicotomía hecho/valor. A partir de allí, y apoyado especialmente en su tesis según la cual los valores requieren interpretación contextual, he abordado sus argumentos acerca de la necesidad de democratizar la práctica científica. En efecto, si esta última aspira a la plena aplicación de la inteligencia en la resolución de problemas, según explica Putnam tomando de referencia el planteo deweyano, entonces es necesario que haya libre y plena posibilidad de aportar y cuestionar hipótesis, interpretaciones, etc. Dicho de otra forma, la práctica científica en cuanto actividad conjunta cooperativa incluye en su dimensión normativa un modo de organización democrático, incorporando una dimensión política inextricable a la idea misma de investigación.

No obstante, este sentido de democratización de la práctica científica planteado por Putnam vía Dewey no agota el vínculo de la ciencia con la política -y especialmente con la democracia. La tarea del próximo capítulo, por tanto, será ampliar las razones por las que este carácter político es constitutivo de la definición normativa de la práctica científica, ya no acerca de su carácter de actividad conjunta cooperativa sino de su consideración como práctica eminentemente pública. 


\section{CAPÍTULO 6: FILOSOFÍA POLÍTICA DE LA CIENCIA EN CLAVE DEWEYANA}

\section{Introducción}

El capítulo precedente ha dejado una línea de indagación abierta a partir de dos elementos centrales: por un lado, las referencias de Dewey respecto del carácter moral que puede adoptar cualquier investigación científica según el tipo de problemas al que se dirija; por el otro, las advertencias del pragmatista acerca del desenvolvimiento efectivo de la ciencia, orientada muchas veces al lucro de una minoría y ordenada bajo el supuesto de la neutralidad valorativa de la investigación en cuanto instrumento. La consideración conjunta de ambos aspectos permite concluir que es necesario dar lugar a la reflexión acerca de los criterios que definen los objetivos de la ciencia, es decir, a la reflexión acerca de sus fines y valores, todo ello en un sentido político. Como es bien sabido, en el marco de la filosofía de Dewey, pensar en clave política es pensar en términos de democracia. Así las cosas, el objetivo central de este capítulo es abordar los argumentos planteados por Dewey acerca de las diferentes relaciones que pueden establecerse entre investigación científica y democracia, tanto en relación a los fines de la investigación como en los aportes que ésta pudiera hacer para la construcción de una genuina democracia o Gran Comunidad.

Por supuesto, abordar todas las dimensiones de la concepción política deweyana excede el recorte temático del presente estudio pues se debería abordar la pregunta por sus fundamentos filosóficos y su impacto en los distintos temas de reflexión del pragmatista (política, educación, arte, etc.). Sin embargo, teniendo en cuenta el interés del capítulo, resulta necesario avanzar en una serie de aclaraciones preliminares que permiten, espero, encuadrar las observaciones subsiguientes. De esta forma, en la siguiente sección haré un pequeño excurso hacia la elaboración del concepto de democracia ofrecida por Dewey, identificando una serie de condiciones que permiten comprender por qué el sentido pleno de la democracia se comprende en términos de forma de vida orientado hacia el ideal de Gran Comunidad y recuperando, además, la justificación epistémica de la democracia planteada por Axel Honneth y el ya citado Putnam.

Una vez reconstruido este marco general me concentraré especialmente en los argumentos elaborados por Dewey en La opinión pública y sus problemas (1927. LW.2). 
Así, buscaré señalar por qué la distinción establecida por Dewey entre las transacciones privadas y públicas es relevante para analizar el lugar que adopta la ciencia en el entramado social y para justificar la necesidad de algún tipo de control institucional sobre su actividad. Posteriormente abordaré la pregunta por el lugar que ocupa la opinión pública en la discusión respecto de la orientación de las investigaciones y el lugar que, a su vez, ocupan las investigaciones en el enriquecimiento de la propia opinión pública. En el marco de estas consideraciones, y para contextualizar los argumentos de Dewey, repondré la discusión que mantuvo con Walter Lippmann durante la década de 1920 respecto de la posibilidad de una democracia popular y de una opinión pública informada, competente y activa. Esta discusión incluye muchas observaciones acerca del rol de los expertos en la conducción de las instituciones públicas y de los medios de comunicación en la divulgación del conocimiento científico, elementos de suma importancia para los intereses del capítulo pues para Dewey el fortalecimiento de la opinión pública y consecuentemente de la democracia como forma de vida se obtiene, entre otras cosas, mediante la plena y sistemática comunicación de los resultados de las investigaciones que atañen al público.

Una vez planteados estos argumentos consideraré la crítica de George Metz al enfoque de Dewey, crítica que señala una posible tensión entre el supuesto carácter valorativamente neutral de la investigación y el proyecto político sustantivo del pragmatista (Metz, 1969). Este cuestionamiento es ciertamente relevante porque su respuesta reclama una articulación de los argumentos elaborados durante toda la segunda parte de este estudio. Abordar el conjunto de estos planteos permitirá señalar las razones por las que, a mi juicio, el marco teórico de Dewey plantea explícitamente la necesidad de la reflexión política acerca del conocimiento científico.

\section{La democracia como forma de vida y su justificación epistémica}

De acuerdo con Honneth (1999), y considerando que la preocupación de Dewey por la democracia es transversal a toda su obra, es posible identificar al menos dos períodos diferentes en el tratamiento del tema por parte del pragmatista. Mientras el primero se basa en el individualismo de la libertad, la responsabilidad y la iniciativa, el segundo se centra principalmente en la esfera pública. Así, durante el período inicial Dewey escribe "The Ethics of Democracy" (1888), ensayo en el que, profundamente influenciado por el 
hegelianismo y por sus antecedentes religiosos, afirma que la democracia es una forma ética de vida, una forma de asociación moral y espiritual que no puede reducirse a la "regla de la mayoría" ni al supuesto subyacente de la sociedad como la suma de individuos aislados (EW.1.240). En este primer período Dewey también escribe "Philosophy and Democracy" (1918), en el que elabora una defensa de la democracia teniendo en cuenta el mundo de la existencia accesible a la investigación verificable (MW.11.41-53). Estos escritos ofrecen distintos argumentos para justificar filosóficamente a la democracia y prefiguran varias de las ideas centrales del segundo período, en particular la de cooperación social en base a la división del trabajo, todo ello en favor de la realización de fines comunitariamente elegidos y perseguidos. ${ }^{78}$ No obstante el interés que reporta el análisis de estas piezas y de las razones que condujeron a modificar su punto de vista (por ejemplo, haber advertido que su hegelianismo inicial implicaba una teleología de la naturaleza humana que era difícilmente conciliable con la nueva perspectiva darwiniana), dado el objetivo del capítulo propongo concentrar el análisis en el segundo periodo de los señalados por Honneth y, más precisamente, en la idea de democracia como forma de vida, estrechamente vinculada a la noción deweyana de Gran Comunidad. ${ }^{79}$

Según he adelantado, durante el segundo período Dewey se concentra en la dimensión pública de la democracia, sin perjuicio de sus consideraciones respecto del individuo. Tal y como el pragmatista reconoce, los conceptos propios de la filosofía social

${ }^{78}$ Bernstein (2010, p. 294) afirma que estos ensayos son programáticos pues definen la agenda de los principales problemas teóricos que abordará Dewey a lo largo de toda su trayectoria filosófica, a saber: la relación entre las democracias existentes y algún sentido ideal o normativo de democracia, los medios para aproximarse a dicho ideal y el rol del conflicto en las sociedades democráticas.

${ }^{79}$ Honneth también reconstruye algunos elementos de la transición que hace Dewey entre los períodos señalados. Así, en sus estudios de psicología experimental y aún bajo cierta influencia del hegelianismo, Dewey inicialmente hipotetiza que la realización humana tiende a aceptar las responsabilidades sociales y a convertirse espontáneamente en un buen compañero de cooperación en la división del trabajo. Tras haber advertido la inconsistencia de estas lecturas con el marco teórico darwiniano, Dewey modifica esa hipótesis inicial y elabora una teoría intersubjetiva de la socialización humana orientada a enfatizar la importancia del reconocimiento de los pares y del libre intercambio entre grupos sociales. Según indica Honneth, esta última tesis será central en las subsiguientes reconsideraciones de la idea de democracia hechas por Dewey (Honneth, 1999, p. 94). En su enorme trabajo dedicado al desarrollo del concepto de democracia a lo largo de toda la obra de Dewey, Westbrook señala que las conferencias dictadas por el pragmatista en 1918, material que luego sería retomado en Naturaleza Humana y Conducta, constituyen un esfuerzo por hallar un fundamento psicológico a su propia posición política. Allí Dewey arguye que si los hábitos son funciones sociales entonces pueden fungir como punto de partida para la extensión de la acción inteligente, todo ello orientado por la hipótesis según la cual "[b]ajo las condiciones adecuadas, la inteligencia podría devenir habitual." (Westbrook, 1993, p. 293). 
y política suelen tener dos sentidos, uno descriptivo o de facto y uno normativo o de jure. Si bien en principio parecen contrapuestos, esos sentidos adquieren una relación de complementación pues el estudio de las formas de vida en comunidad realmente existentes permite identificar sus rasgos deseables, emplearlos en la crítica de sus rasgos indeseables y sugerir su mejora, a fin de evitar tanto el riesgo de proponer una sociedad ideal impracticable como el riesgo de simplemente replicar rasgos efectivamente observados (Dewey, 1998, p. 78. MW.9.88). El concepto de democracia no escapa a estas observaciones sino todo lo contrario: para Dewey "[1]a democracia es una palabra de múltiples significados", entre ellos y como mínimo (i) la democracia como forma de gobierno; (ii) la democracia como forma de vida; y (iii) la democracia como ideal de vida comunitaria (2004, p. 101. LW.2.286).

El primer significado está constituido por las condiciones formales de la práctica política de selección de funcionarios y reglamentación de su conducta. En definitiva, se corresponde con una versión de la democracia sintetizada en los modos ordinarios de elección, sufragio y representación que dan cuerpo a la regla de la mayoría. En términos históricos, la democracia así entendida representa para Dewey la desarticulación de distintas formas de gobierno ordenadas en torno a factores irrelevantes e independientes de consideraciones políticas - dinastías de herencia familiar, gerontocracia, victorias militarespor un lado, y la posibilidad de contrarrestar las tendencias a utilizar el poder político para fines privados antes que al servicio público, por el otro.

Ahora bien, Dewey no demora en advertir que "[u]na democracia es más que una forma de gobierno; es primariamente un modo de vivir asociado, de experiencia conjunta comunicada." (Dewey, 1998, p. 82. MW.9.93. Traducción levemente modificada). Esta afirmación, una de las más citadas de toda la obra deweyana, introduce la pregunta por las condiciones que debe cumplir un modo de vivir genuinamente democrático. Una primera condición para el advenimiento de la democracia como modo de vida radica en el reconocimiento por parte de los distintos grupos sociales de un núcleo de valores comunes y estables. Para que ello suceda Dewey estipula (i) que al interior del grupo debe haber numerosos y variados intereses y valores conscientemente compartidos y libremente comunicados; y (ii) que entre los grupos debe haber una interacción plena que propicie el enriquecimiento recíproco de sus intereses, en lugar de un estancamiento de ideales rígidos 
y egoístas, y que conduzca a un reajuste continuo debido a las nuevas situaciones producidas por el múltiple intercambio (Dewey, 1998, pp. 80-81. MW.9.89-92). Así, la idea de democracia o el ideal democrático en su sentido más profundo implica, desde el punto de vista de los grupos sociales, una liberación de las potencialidades de cada miembro, en armonía con los intereses y valores comunes; y desde el punto de vista del individuo, una participación responsable según la capacidad para formar y dirigir las actividades de los grupos a los que pertenece (Dewey, 2004, p. 137. LW.2.237-8).

Una segunda condición se vincula con la continuidad e interdependencia medios/fines y el concepto de fin a la vista. En este marco se encuadra la afirmación por la cual todos los fines democráticos demandan métodos democráticos para su realización. Y no sólo eso, sino que una genuina defensa de la democracia supone hacer el máximo énfasis en los medios democráticos concordantes con y necesariamente conducentes a fines democráticos. Tal adecuación aseguraría la obtención de consensos por vías de la organización inteligente, sin ningún tipo de imposición externa, verticalista y arbitraria (Dewey, 1996, p. 173-4. LW.11.298). Es por ello que para Dewey la democracia como modo de vida se construye diariamente, conforme a la elección de medios y fines, que por supuesto responde a ciertos valores a los que adherimos o rechazamos. José Miguel Esteban (1996, p. 15) ofrece una excelente síntesis de este punto al afirmar que el liberalismo deweyano es un "pragmatismo consecuente" en tanto y en cuanto sigue una lógica experimental, meliorista y transformativa, se aleja de cualquier punto de apoyo trascendental o a priori y toma a las ideas políticas como planes de acción, es decir, como fines a la vista revisables en función de sus consecuencias respecto de los valores de libertad, justicia e igualdad -enumeración a la que me permito sumar los compromisos políticos concretos de Dewey como parte central de su perspectiva política.

Una tercera condición remite a la necesidad de comunicación libre, plena y sistemática de todos los asuntos que conciernen a la esfera política porque la evaluación pública de los problemas comunes, sus posibles consecuencias y sus respectivos planes hipotéticos de resolución constituyen, sin más, "inteligencia cooperativa organizada". Retomaré este punto en la sección siguiente, al momento de analizar la distinción deweyana entre público y privado. 
Por supuesto, las condiciones mencionadas no implican que el sentido deweyano de democracia aspire a eliminar el conflicto social producto de aspiraciones o intereses incompatibles sino más bien a encontrar la mejor forma de resolverlo. En eso consiste precisamente aquello que Dewey denomina "método de la democracia" (1996, p. 109. LW.11.56). En pocas palabras, Dewey apuesta por situar los conflictos, razones y argumentos en la esfera pública a los fines de observar y estimar las pretensiones en el contexto de intereses más amplios que los representados por cada parte. Esto permite analizarlos abiertamente, recopilar hechos y observaciones relevantes, considerarlos a la luz de principios políticos y morales pertinentes, proyectar hipótesis de resolución, etc. En suma, señala Dewey, el método de la democracia se funda en la convicción de que cuanto más se avanza en la evaluación pública y científica de las pretensiones de cada grupo en conflicto, tanto más probable es identificar el interés público y obrar en consecuencia. ${ }^{80}$

Esta interpretación de la democracia como forma de vida es lo que permite conectarla con la noción de comunidad y de ideal de vida comunitaria. En efecto, "[1]a democracia, contemplada como una idea, no es una alternativa a otros principios de la vida asociada. Es la idea misma de vida comunitaria. [...] La clara conciencia de una vida comunitaria, con todas sus implicaciones, constituye la idea de democracia." (Dewey, 2004, p. 138). En este sentido la democracia genuina excede al modo político y refiere a un tipo de actividad conjunta que, como se adelantó, debería reconocer un núcleo de valores compartidos y estables, identificar sus problemas comunes, deliberar para la promoción de consecuencias deseables bajo el modo de la acción inteligente y, en suma, dar lugar a lo que Dewey denomina Gran Comunidad, "una sociedad en la que las consecuencias en expansión constante y complejamente ramificadas de las actividades asociadas se conozcan en el pleno sentido de esta palabra, de manera que surja un Público organizado y articulado." (2004, p. 156).

\footnotetext{
${ }^{80}$ Entre 1916 y 1923 Dewey trabajó activamente para desarrollar una filosofía social pragmatista que incluya una teoría del conflicto entre grupos sociales. Una primera referencia de este proyecto es el último capítulo de La Reconstrucción de la Filosofía, en donde argumenta que la filosofía social debería estar guiada por la investigación experimental inteligente aplicada a dificultades concretas en vez de apelar a teorías generales de pretendido significado universal. Dewey elabora su teoría del conflicto en las "Lectures in Social and Political Philosophy", conferencias dictadas durante su estadía en China entre 1919 y 1921 aunque hacia 1926 parece haber abandonado el proyecto completamente. Al respecto, Cf. Frega, (2015), Midtgarden (2012) y Wang (2007), entre otros.
} 
Respecto de este último punto es importante aclarar, siguiendo a del Castillo, que Dewey no apunta a un retorno a la vida comunal sino que defiende una reconstrucción de la forma de vida comunal (del Castillo, 2004, p. 46). En el mismo sentido puede leerse la afirmación de Bernstein respecto del llamado de Dewey a una revitalización de la vida pública en favor de una "comunidad de comunidades" que, si bien comienza por la vida comunal como el primer espacio en donde desarrollar este nuevo modo de integración individual y social, no se mantiene aislada de las otras sino que permite reinsertar al público en el contexto complejo y de escala planetaria al que está sometido (Bernstein, 2010b, p. 234). Así, y en la medida en que se trata de un fin que requiere cambios estructurales en todas las instituciones (sociales, económicas, educativas, culturales) y en todas las dimensiones de la vida compartida, la idea de comunidad está lejos de constituir un principio regulativo kantiano o un horizonte utópico sino que es un fin a la vista radical. (1996, p. 174. LW.11.299. Bernstein, 2010b, p. 295). ${ }^{81}$

Una de las preguntas más importantes al momento de analizar la idea deweyana de democracia remite a su justificación normativa, es decir, a identificar por qué se debería querer vivir en una sociedad democrática. Dentro de los distintos enfoques posibles para dar respuesta a esta cuestión hay uno que es particularmente relevante para el interés de este estudio y está dado por la justificación epistémica de la democracia, según la llaman Putnam y el mismo Honneth. ${ }^{82}$ En el capítulo previo he señalado que para Putnam el flujo

${ }^{81}$ Las condiciones referidas podrían agruparse bajo un sentido "filosófico". A mi juicio, Dewey plantea también una serie de condiciones "políticas", generalmente poco consideradas en la literatura sobre el asunto. Por ejemplo, inmediatamente después de introducir su definición de democracia como experiencia conjunta comunicada Dewey afirma que el aumento del número de individuos con intereses comunes con referencia recíproca de sus acciones y su concomitante extensión en el espacio "[...] equivale a la supresión de aquellas barreras de clase, raza y territorio nacional que impiden que el hombre perciba la plena significación de su actividad." (Dewey, 1998, p. 82. MW.9.93). Por otro lado, y teniendo en cuenta que para Dewey el sistema económico competitivo producto de una errada comprensión del liberalismo es "un estado de guerra apenas encubierto" pues aquellos que están instalados en el poder tienen a la violencia como recurso habitual, no sorprende advertir que un capítulo de Viejo y Nuevo Individualismo se titule "Estados Unidos, S. A." o leer que "[d]onde quizá haya que insistir es en el control de los medios de producción por parte de una minoría que los posee legalmente y que los emplea como un potente instrumento para reprimir a la mayoría" o que si "[...] una minoría obstaculiza por la fuerza el desarrollo consecuente de la inteligencia como método de actuación, [entonces] cabe un uso inteligente de la fuerza que neutralice y desarme a la minoría recalcitrante" (Dewey, 1996, p. 98 y 114. LW.11.56 y 61, respectivamente). En este sentido, pues, las condiciones de tipo filosófico señaladas encuentran un complemento en estas condiciones de índole política.

${ }^{82}$ La idea de una justificación epistémica de la democracia es cuestionada, entre otras, por Cheryl Misak (2013, pp. 136-138). Para un detallado estado de la cuestión, Cf. Festenstein (2019, sec. 1). Además, la justificación epistémica no es el único argumento con el que Dewey fundamenta a la democracia. En este 
de información y la libertad para ofrecer y desafiar hipótesis son una necesidad de la investigación. Asimismo, Putnam afirma que el carácter libre y abierto de la investigación no solo se aplica al ámbito científico en general sino también a la indagación social y ética. Si ese es el caso, y si la filosofía tiene que utilizar el mejor conocimiento disponible para mejorar creencias, instituciones y políticas al criticar los bienes comunes y naturales, entonces las fuentes de la investigación ética y social tampoco deben definirse o limitarse de antemano. Además, si no hay un fin teleológico o una respuesta preconcebida a la pregunta de cómo se debe vivir, entonces es indispensable garantizar la apertura para discutir una y otra vez sobre las instituciones y las prácticas -y esta es precisamente la razón por la cual necesitamos democracia. De esta manera, argumenta Putnam, la necesidad de asegurar la libertad de pensamiento y de expresión en tanto valores democráticos fundamentales es una consecuencia de los requisitos generales de toda investigación. Puesto a la inversa, el orden jerárquico y los privilegios de un grupo por sobre otros en el marco de la investigación tiene costos epistémicos indeseables pues limita las posibilidades de los no-privilegiados y reduce la amplitud de perspectiva de los privilegiados, dos resultados que confluyen en detrimento de la propia investigación (sobre este punto, Cf. Festenstein, 2019). En suma, a partir del marco teórico deweyano Putnam sostiene que “[...] la democracia no es solo una forma de vida social entre otras formas de vida social

sentido, entiendo que el marco teórico deweyano permite identificar una "justificación experiencial" de la democracia. En efecto, si se analizan los argumentos de Dewey respecto del "público eclipsado" (en Opinión pública y sus problemas, Cap. 4) y del "individuo perdido" (en Viejo y nuevo individualismo, Cap. 4) a la luz de su teoría de la experiencia, es posible concluir que el cuadro allí presentado da cuenta de una experiencia, sea a nivel colectivo o a nivel individual, que nunca puede ser genuinamente tal sino que se encuentra truncada. De hecho, Dewey remarca el carácter contradictorio en el que vive el individuo y en el que se desarrolla su vida social, cada vez más permeable a interferencias que fragmentan la continuidad de su experiencia y que por lo tanto le impiden que se constituya como una experiencia. Si, además, la experiencia genuina surge como resultado de la transformación de interacción en participación y comunicación, y el panorama que plantea es el de una apatía política, un desinterés por lo público y una comunicación que no logra colmar en contenido aquellas potencialidades que ofrece la tecnología, el problema del individuo y del público es que no llevan adelante una genuina experiencia primaria. En efecto, para Dewey "[...] la democracia es el único [modo de vivir] inspirado y sostenido por la firme creencia en el proceso de la experiencia en cuanto fin y en cuanto medio. [...] todo modo de vida carente de democracia limita los contactos, los intercambios, las comunicaciones, las interacciones que estabilizan, amplían y enriquecen la experiencia" (1996, p. 205. LW.14.229). Esta observación, junto con los argumentos elaborados por Fott (1991, sec. 1) acerca del fundamento metafísico-naturalista de la democracia y los argumentos ofrecidos por Pappas (2008, p. 219 y ss.) según los cuales la democracia como estricto sistema político conduce a un modo no-estético y no-inteligente de vivir, abren las puertas a considerar el reverso del diagnóstico deweyano y a elaborar un "argumento experiencial" en favor de la democracia, es decir, a sostener que la democracia es la única forma de vida que permite un pleno desarrollo de la experiencia genuina, en todas sus dimensiones. Volveré sobre este punto en el capítulo 8, al momento de considerar el enfoque de Philip Kitcher. 
factible; es la condición previa para la plena aplicación de la inteligencia a la solución de problemas sociales" (1992, p. 180. Traducción propia). Estas afirmaciones encuentran apoyo en las palabras de Dewey: "[...] la democracia debería ser un medio de estimular el pensamiento original y de provocar una acción deliberada y previamente ajustada para enfrentarse a nuevas fuerzas." (1964, p. 69. MW.14.48).

El argumento de Honneth corre en el mismo sentido que el de Putnam. En efecto, Honneth toma la idea de que las posibilidades de resolver inteligentemente los problemas se incrementan conforme se extienden y profundizan los vínculos cooperativos en la investigación. A partir de aquí, y siempre en la interpretación de Honneth, Dewey trasladaría esa conclusión inicialmente referida a la investigación científica hacia investigaciones no científicas, de modo que la resolución inteligente de los problemas sociales también es función de la cooperación y del libre intercambio de hipótesis, informaciones y materiales de los participantes. Así, la democracia constituye "[...] una condición para el aumento de la racionalidad en las soluciones sociales de los problemas" $\mathrm{y}$, consecuentemente, se define como [...] la forma de organización política en la cual la inteligencia humana alcanza el desarrollo íntegro.” (Honneth, 1999, p. 96, ambas citas).

Ahora bien, Honneth extrema el punto y señala que en el planteo de Dewey esta transposición desde las investigaciones científicas a las investigaciones sociales debe también llegar a todas las relaciones sociales, de modo que la justificación epistemológica lo conduce, a diferencia de su concepción orgánica inicial, a enfatizar el valor racional de los procedimientos democráticos en toda la esfera pública. En definitiva, el núcleo del ideal democrático de Dewey es inseparable de su teoría de la investigación activa y cooperativa $\mathrm{y}$, en este sentido, la democracia como proceso de toma de decisiones adquiere legitimidad mediante la apertura y la discusión. En definitiva, así como una comunidad de investigadores intenta cooperativamente elaborar teorías para resolver situaciones definidas como problemáticas, una genuina comunidad democrática podría verse como una comunidad que intenta cooperativamente constituir las mejores formas de vida. Según indica el pragmatista en Libertad y Cultura, "[...] la libertad de investigación, la tolerancia de diversos puntos de vista, la libertad de comunicación y la distribución a cada individuo como último consumidor intelectual de lo que se ha descubierto, están comprendidas en el 
método democrático, así como en el científico.” (Dewey, 1965a, p. 102. LW.13.135). Bajo estas consideraciones, la lógica vuelve a adoptar su sentido primigenio de diálogo, se aleja de la interpretación del investigador/ciudadano como espectador y reivindica una actitud plenamente participante (Cf. Dewey, 2004, pp. 173-174. LW.2.371-372).

Todas estas consideraciones se enmarcan en el llamado de Dewey a expandir la "actitud científica", según la denomina en distintos textos. Dicha actitud implica deshacerse del control de la rutina, el prejuicio, los hábitos no examinados y el interés egoísta. Puesto en términos positivos, supone voluntad para investigar, examinar y obtener conclusiones. Así, la actitud científica en tanto cualidad no sólo implica que las personas elijan deliberadamente sus deseos, fines y valores apoyados en conclusiones obtenidas mediante los mejores conocimientos disponibles al momento y dejen atrás las estimaciones influidas por hábitos, circunstancias accidentales, propaganda o prejuicios, sino también que adopten la dinámica cooperativa de la investigación para garantizar la resolución inteligente de los problemas de índole social.

Asimismo, la expansión de la actitud científica implica también que el aspecto cooperativo se extienda a la relación entre los distintos campos de investigación. Como arguye Dewey en "Unity of Science as a Social Problem" (1939. LW.13), su segunda contribución al proyecto de la Enciclopedia llevado adelante por Neurath, antes que la búsqueda de un lenguaje unificado que permita una unidad especializada de contenido, tal y como planteaban algunos positivistas lógicos, a lo que se debe aspirar es al sentido cultural y humano de la unidad dado por la expansión de la actitud científica, por la convergencia de quienes la cultivan y por el intercambio recíproco producto de un genuino esfuerzo en común. En este sentido, generar la unidad de la actitud científica es, entonces, vincular a aquellos que la aceptan y que actúan por ella en cooperación activa de unos con otros. Este problema trasciende en importancia al problema técnico de la unificación de los resultados de las ciencias especiales: de acuerdo con Dewey, la ciencia en cuanto cuerpo de conocimiento está en un momento crítico tal que, si no se supera, “[...] ella [la ciencia] quedará confinada a un ámbito en el que habrá obtenido victorias pero mirará cómo los frutos de esas victorias son apropiados por aquellos que los utilizan con métodos anticientíficos para fines no humanos.” (LW.13.275). 
El proyecto deweyano de unificación de la ciencia adquiere su dimensión política en la medida en que aspira a la expansión de una actitud tendiente a reemplazar los intereses de clase, prejuicios sociales, raciales, nacionales o incluso el peso de la tradición (en el sentido más simple y rancio del término) por la investigación controlada y la deliberación informada por los mejores conocimientos disponibles. Este punto es ciertamente importante: "[...] el futuro de la democracia -indica Dewey- está aliado con la difusión de la actitud científica. Es la única garantía contra la desorientación general por medio de la propaganda. Más importante aún, es la única manera de asegurar la posibilidad de formar una opinión pública lo bastante inteligente para enfrentarse a los problemas sociales." (1965, p. 149. LW.13.168).

La cita anterior introduce un concepto crucial, el de opinión pública. De acuerdo con Honneth, Dewey toma a la opinión pública como el elemento para articular la orientación epistemológica del procedimiento democrático con la concepción de una comunidad constituida en torno a ciertos valores compartidos. Es precisamente mediante el concepto de opinión pública que Dewey podría superar algunos de los problemas de su concepción organicista inicial asentada en un supuesto individualismo atomista, es decir, la idea de que la sociedad es la suma de sus individuos (Honneth, 1999, p. 97). Con el paso de los años Dewey irá criticando este supuesto metodológico, a la base de las concepciones meramente formales de la democracia, y tomará como punto de partida dado el hecho de que los individuos se relacionan con el ambiente y con otros individuos de forma tal que no es posible pensarlos como una unidad aislada (sobre ontología social deweyana, Cf. Testa, 2017). Por otro lado, queda claro que para Dewey el conocimiento científico tiene un papel de absoluta importancia en la propia conformación de la opinión pública, aspecto fundamental para comprender todo el pensamiento político del pragmatista. De este modo, indagar en esa relación es vital para comprender en qué medida y bajo qué condiciones el conocimiento científico puede contribuir para consolidar el ideal de Gran Comunidad propuesto por Dewey -y en qué medida y bajo qué condiciones, consecuentemente, tiene una dimensión política propia. 


\section{Ciencia, expertos y constitución de la opinión pública}

Considerar el asunto de la opinión pública en clave deweyana implica, sin excepción, focalizar el análisis en los argumentos de La opinión pública y sus problemas (1927. LW.2). Esta obra puede leerse como una respuesta doble. Por una parte, Dewey hace frente a la primera gran crisis de la sociedad capitalista estadounidense y a los riesgos que conllevan la expansión de un desarrollo científico y tecnológico que no contemple las condiciones para la transformación de una Gran Sociedad en una Gran Comunidad. Por otra parte, la obra se concibe como respuesta a los planteos de Walter Lippmann en Public Opinion, libro publicado en 1922 (1998). ${ }^{83}$

En términos generales Lippmann sostiene que el sujeto de conocimiento y las teorías políticas clásicas deben enfrentar el mismo problema: tratar con un ambiente al que no acceden sino indirectamente. Así, Lippmann arguye que el público general no es capaz de aprehender la complejidad del ambiente en el que se desarrolla la vida política debido a algunas limitaciones cognitivas a la base y que debe elaborar imágenes estereotipadas [pictures, fictions o stereotypes] para regular las acciones individuales y colectivas que impactan sobre el ambiente real (Cf. Lippmann, 1998, Capítulo 1). Lippmann es un exponente del realismo democrático, según lo denomina Westbrook (1993, p. 296), y su planteo está orientado a legitimar la necesidad de que los gobiernos estén asesorados exclusivamente por expertos, habida cuenta de las referidas limitaciones del público general. Teniendo en cuenta que La opinión pública y sus problemas discute explícita o implícitamente con la visión de Lippmann, en algunos pasajes de la sección introduciré referencias puntuales a este último autor para contextualizar los argumentos de Dewey.

Al momento de analizar el vínculo que establece Dewey entre opinión pública y conocimiento científico es importante tener en cuenta que aquél adquiere, cuanto menos, dos dimensiones, en la medida en que (i) la ciencia es una actividad pública y por lo tanto

\footnotetext{
${ }^{83}$ Las referencias explícitas e implícitas a la obra de Lippmann junto con la reseña de Public Opinion que publica Dewey en The New Republic (1922. MW.13) son algunas de las fuentes del denominado "Debate Lippmann-Dewey". Éste incluye también The Phantom Public, libro que Lippmann publica en 1925, y la respectiva reseña de Dewey publicada el mismo año en The New Republic, bajo el título de "Practical Democracy" (LW.2). No obstante, de acuerdo con Michael Schudson (2008), el "Debate Lippmann-Dewey" no fue tal sino se construyó de manera unilateral pues Dewey responde a Lippmann pero no hay registros de una devolución por parte de este último. En opinión de Schudson, lo que reavivó la lectura de los citados textos de Lippmann y Dewey, presentándolos en términos de "debate", fue la discusión entre intelectuales liberales en Estados Unidos sobre los medios masivos de comunicación durante las décadas de 1980 y 1990 , particularmente bajo la influencia de James Carey.
} 
es objeto de regulación por parte de la opinión pública pero a la vez (ii) la ciencia informa y en ese sentido constituye a la opinión pública. Como señala del Castillo, cuando Dewey establece la relación entre ciencia e investigación social libre [free social inquiry] quiere decir que los intereses y necesidades del público son los elementos últimos de trabajo de la ciencia y al mismo tiempo que la opinión pública deberá nutrirse del conocimiento científico especializado: "[1]a ciencia sin opinión pública es ideología; la opinión pública sin ciencia o es una masa, o un fantasma." (del Castillo, 2004, p. 27). Queda claro entonces que ambos sentidos de la relación opinión pública-ciencia están estrechamente enlazados. En lo que sigue intentaré explicitar algunas consideraciones particulares de cada una de ellas con la intención de aclarar mi interpretación del planteo deweyano.

Respecto del primer asunto, el punto de partida es la distinción señalada por Dewey entre público y privado. En línea con su perspectiva filosófica general, el pragmatista propone que en vez de buscar definiciones del ser humano que expliquen su conducta política (por ejemplo, la idea del ser humano como un animal político es para Dewey un mero rodeo verbal y conduce a la mitología antes que a un tratamiento riguroso) se deben considerar los actos que efectivamente se realizan y observar las consecuencias de esos mismos actos. De esa observación, señala Dewey, es posible identificar dos grandes tipos de consecuencias: aquellas que afectan sólo a las personas directamente involucradas en la transacción inicial y aquellas que afectan a otras personas distintas de las directamente involucradas en la transacción inicial. Así, la amplitud y el alcance de las consecuencias de las transacciones definirán si las mismas son privadas, en el primer caso, o públicas, en el segundo. En este sentido, la distinción entre privado y público no puede asociarse directamente a la distinción entre individual y social porque una acción individual bien puede tener alcance público, dadas sus consecuencias, y tampoco puede asociarse una acción pública con lo socialmente útil o beneficioso (el ejemplo de la guerra en cuanto actividad organizada basta para señalar que lo público y lo socialmente beneficioso pueden desarrollarse por caminos separados).

Desde aquí se siguen dos cuestiones de suma relevancia. En primer lugar, Dewey considera que el alcance de las consecuencias de las acciones determina si estas últimas son tan importantes como para ser controladas y reguladas, mediante su restricción o 
promoción. En segundo lugar, aquellas personas que logran reconocerse como afectadas, para bien o para mal, por las consecuencias indirectas de determinadas acciones públicas y que consecuentemente tienen un interés conjunto en controlar esas consecuencias conforman lo que Dewey denomina un público. Por supuesto, estos públicos no son organizaciones estancas sino que varían con la misma dinámica de las acciones públicas y de los intereses y necesidades que éstas originen, al tiempo que una misma persona puede estar involucrada en distintos públicos en función de las formas en que se vea afectada por distintas acciones públicas. La conjunción de estos puntos permite finalmente definir al público como aquellas personas afectadas por las consecuencias indirectas de actividades públicas que son lo suficientemente importantes como para ser controladas sistemáticamente. Luego, la opinión pública es el juicio que forman quienes componen el público respecto de los asuntos públicos. Así, de acuerdo con la explicación de Honneth, “[...] 'público' es en cada caso aquella esfera del actuar social, de la cual un grupo puede comprobar con éxito que, por razón del surgimiento de consecuencias que se hacen extensivas, precisa de una regulación”, de forma que “[...] una 'opinión pública' se compone del círculo de aquellos ciudadanos que, al verse afectados conjuntamente, comparten la convicción de que deben dirigirse al resto de la sociedad con el fin de lograr el control administrativo de la respectiva interacción.” (Honneth, 1999, pp. 97 y 98).

Como corolario de las consideraciones previas Dewey sostiene que el reconocimiento y organización de los distintos públicos junto con el esfuerzo por regular las consecuencias indirectas es un punto de partida para la conformación de los Estados. En efecto, la propia organización del público supone, en el mediano plazo, la aparición de funcionarios e instituciones que tratan con las referidas consecuencias indirectas de las acciones públicas y que buscan defender los intereses de aquel público al que representan: "Las consecuencias duraderas, extensivas y graves de la actividad asociada -indica Deweydan origen al púbico. [...] El Estado es, pues, un público articulado que opera a través de los funcionarios representativos; no existe el Estado sin un gobierno, pero tampoco existe sin un público.” (2004, p. 92. LW.2.277). De este modo, según señala Westbrook, lejos de asumir una idea de Estado como árbitro neutral que debe saldar conflictos entre distintos grupos sociales, Dewey propone una idea de Estado en cuanto organización del público (Westbrook, 1993, pp. 304-305). Más allá de las especificidades de la teoría deweyana 
sobre el origen del Estado e incluso más allá de algunas ambigüedades o imprecisiones que pueden identificarse rápidamente, como por ejemplo la relación entre los públicos y el público o la idea de interés público, la conjunción de las consideraciones precedentes permite afirmar que el Estado se constituye como una institución que controla las consecuencias indirectas de amplio alcance de determinadas actividades públicas y concordantemente las regula mediante su promoción o restricción (sobre las ambigüedades, Cf. Westbrook, 1993, pp. 305-306).

Puesta a la luz de la distinción entre actividades privadas y públicas, la referencia hecha en el capítulo previo a la inscripción en el continuo de experiencia propia de la pauta general de la investigación y, por ende, de la investigación científica, permite concluir que esta última es una actividad eminentemente pública pues sus consecuencias afectan a otras personas distintas de las directamente involucradas en la investigación particular. En la historia de la ciencia hay sobrados ejemplos que confirman la amplitud y duración de las consecuencias de las investigaciones, desde la medicina o la genética hasta las investigaciones en economía o planificación urbana, por citar sólo algunas. Si, además, hay un reconocimiento de dicho alcance a mediano y largo plazo de las investigaciones científicas tal que permita la constitución de su respectivo público, entonces la actividad científica tiene que ser regulada por el Estado en cuanto público organizado institucionalmente. Esta conclusión también alcanza a las investigaciones científicas llevadas a cabo con financiamiento privado pues bajo el criterio deweyano de evaluar las consecuencias de sus acciones no dejan de ser ellas mismas acciones públicas. Así, la categorización público/privado ofrecida por Dewey rebasa la visión tradicional que los distingue en función de la proveniencia del financiamiento (estatal o de particulares) y permite analizar desde otra perspectiva la actividad científica.

Una de las primeras preguntas que surgen tras obtener la conclusión antedicha es la pregunta por el rol del experto. Este último es tema central de discusión entre Lippmann y Dewey. De acuerdo con Lippmann la principal necesidad de la teoría política clásica en general y de la democracia en particular es sortear la "distancia" entre las representaciones del pseudo-ambiente y el ambiente real para que los ciudadanos adquieran el conocimiento suficiente para gobernar. Esta necesidad se profundiza, claro está, a medida que se 
extienden y complejizan las relaciones económicas, sociales y políticas durante las primeras décadas del siglo XX (sobre el problema del conocimiento en la teoría política de Lippmann, Cf. DeCesare, 2012, sec. 2). En principio Lippmann plantea la posibilidad de que la prensa fuera la encargada de resolver ese problema. Sin embargo, señala el autor, la prensa no puede cumplir con las expectativas de convertirse en un instrumento para la práctica política democrática sino que se limita a repetir los mismos estereotipos con los que los hombres constituyen su imagen del mundo pues ha quedado encerrada en la lógica del mercado, organiza su producción en "episodios, incidentes, erupciones" tal que satisfagan las demandas de consumo inmediato de los lectores y consecuentemente no puede registrar de forma metódica las fuerzas políticas ni encabezar las instituciones públicas. (Cf. Lippmann, 1998, Capítulos 21-24). ${ }^{84}$

Una vez que Lippmann establece esta última conclusión debe entonces proponer una alternativa que pueda aportar más y mejores datos a la hora de conformar la imagen del mundo y actuar en consecuencia. El autor plantea entonces la posibilidad de organizar un cuerpo de expertos que tenga como función primordial representar de modo inteligible la complejidad del ambiente real para que los funcionarios políticos y el público en general puedan tomar decisiones de manera racional, informada y despojada de estereotipos (Lippmann, Cf. 1998, Capítulos 25-28). En otros términos, la tarea de este grupo de expertos pasa por mejorar los registros de los fenómenos sociales, precisar aquellos conceptos vagos o acríticos y desarrollar métodos de análisis y comparación de la información registrada. Esta tarea de organizar una maquinaria de conocimiento es para Lippmann una propuesta con la finalidad política de mejorar la relación sujeto-ambiente y

\footnotetext{
${ }^{84}$ De acuerdo con Lippmann hay dos situaciones distintas que conducen al referido encierro de la prensa en la lógica mercantil y en los estereotipos asentados. Por un lado, el lector no paga lo que debería pagar por el trabajo del reportero, de manera que el editor encuentra el dinero que necesita para mantener su diario a través de las publicidades. En consecuencia, (i) el lector deviene un potencial comprador de la mercancía publicitada, (ii) la circulación del diario se vuelve un medio para el fin del vendedor y (iii) la noticia queda supeditada a la venta del producto y debe conformarse al punto de vista del lector-cliente (buying public). Por otro lado, si bien Lippmann reconoce un tipo de lector que en principio se diferencia del lector-cliente, denominado constant reader, el problema es que éste juzga al diario en relación con aquellas noticias en las que se ve involucrado y según se correspondan éstas con su sentido común; por ende, aquellas noticias que no refieren directamente a la experiencia del constant reader son tratadas como si fueran ficciones, de modo que el canon de la verdad queda inaplicable y el editor se limita a presentar la noticia de tal forma que capte el interés del lector. En definitiva, sea para satisfacer las expectativas comerciales del publicista y del buying public o para mantener la atención del constant reader el editor debe hacer corresponder las noticias con los prejuicios del lector, hacer que éste se involucre e identifique personalmente con lo que lee y para ello no puede sino apelar a aquellos estereotipos e imágenes estandarizadas que debía dejar atrás.
} 
conforma según el autor una de las pocas soluciones que apuntan al núcleo del problema de la teoría política. En este sentido, los expertos funcionan como mediadores entre la política profesional y la opinión pública, favoreciendo si no un consenso racional, al menos la toma de decisiones efectivas. No obstante esta descripción del trabajo de los expertos es importante aclarar dos cuestiones centrales: (i) el intercambio de materiales, investigaciones y resultados queda restringido al ámbito de los expertos, y (ii) los resultados quedan destinados en primera instancia a los miembros del gobierno representativo, sea en política o en las industrias, y recién de manera secundaria ese trabajo apunta al público en general (en caso de estar interesado por algún evento o actividad, el lugar del ciudadano privado se circunscribe a asociaciones voluntarias que podrían contar con material provisto por el intelligence work, pero nunca es él mismo destinatario primario de las investigaciones de los expertos). En conclusión, siguiendo a del Castillo, “[...] para Lippmann 'información' y 'opinión', 'conocimiento objetivo' y 'debate' [y agregaría ‘investigación’ y ‘comunicación’] eran cosas incompatibles.” (del Castillo, 2004, p. 13).

Estas consideraciones sobre la posición de Lippmann permiten encuadrar la posición del propio Dewey acerca de los expertos y del lugar que tiene la investigación en la conformación de la opinión pública. De acuerdo con Dewey, la obra de Lippmann sabe señalar con claridad algunos de los problemas más profundos de la teoría política aunque las soluciones que allí se proponen no son adecuadas para el tipo de dificultades identificadas. Por el contrario, Dewey cuestiona fuertemente la idea de que el destinatario del conocimiento fuera la cúpula administrativa de las instituciones públicas y apuesta por vincular al público en general con el trabajo de los expertos y las decisiones que se tomen. Bajo esta premisa, en la propia reseña de Public Opinion señala que la democracia demanda una educación más profunda que la educación de los oficiales, administradores o directores y que dirigir la tarea de formación sólo a las cúpulas de las instituciones es perder una gran parte de la amplitud y del desafío que supone la apuesta por la democracia -entendida no sólo como un sistema de gobierno, como parece hacer Lippmann, sino como una forma de vida (MW.13.344).

Ahora bien, Dewey cuestiona tanto la solución ofrecida por Lippmann como la idea misma de un cuerpo de expertos. Su diagnóstico es el siguiente: por un lado existe una 
clase económica fuerte que se erige como dominante y por otro lado existe una clase intelectual que se arroga una supuesta inteligencia como atributo personal. Visto que las condiciones que permiten a esa clase dominante mantener su poder económico dependen en gran parte de invenciones tecnológicas y que estas últimas escapan de sus manos, esa oligarquía necesita aliarse con el grupo de expertos para mantener su posición. Por otro lado, la noción de cuerpo de expertos (que Dewey entiende como una actualización de la consigna platónica del rey filósofo) resultaría impracticable porque una aristocracia intelectual sería imposible de ocultar y porque el público, pese a todas las limitaciones intelectuales y a la subsiguiente incapacidad política que se le pueda atribuir, no aceptaría una sumisión pasiva a la intervención directa del referido cuerpo de expertos. De esta manera, y teniendo en cuenta que para Dewey lo que sí es factible es el ocultamiento del dominio político de una clase económica poderosa, la clase intelectual tiene dos alternativas: o bien se alía con la clase dominante y se convierte en instrumentos de esta última, o bien se aproxima al público general, lo cual implica algún tipo de participación de este último en las decisiones que se tomen respecto del conocimiento producido por el cuerpo de expertos (Cf. Dewey, 2004, pp. 166-170. LW.2.362-367).

El factor de la especialización del trabajo del experto es para Dewey un asunto de "doble filo" porque si bien es lo que garantizaría una mayor pericia y precisión de cualquier investigación que se lleve adelante, al mismo tiempo agranda la brecha entre dichas investigaciones y las necesidades que debería atender pues pierden el contacto con los asuntos comunes. En cuanto a este segundo punto, y retomo aquí algunas observaciones de Festenstein (2008), una posición como la de Lippmann respecto del gobierno de expertos incurre en una auto-contradicción pragmática. En efecto, esa distancia implícita en la propia idea y función de un cuerpo de expertos conduce a Dewey a afirmar que "[1]a clase de expertos se encuentra tan inevitablemente alejada de los intereses comunes que se convierte en una clase con unos intereses privados y un conocimiento privado que en cuestiones sociales no es conocimiento en modo alguno.” (2004, p. 168. LW.2.364).

En razón de lo señalado, el gobierno de expertos es una alternativa que obtura el surgimiento y crecimiento de cualquier idea proveniente de otro campo porque no permite instancias de debate, consulta y persuasión y evita que se conviertan en ideas de dominio público, a los fines de mantener el monopolio de la posesión del conocimiento y de la toma 
de decisiones. A su vez, limita la posibilidad de que el interés público juegue algún papel a la hora de juzgar la importancia de las investigaciones de ese mismo cuerpo de expertos. En definitiva, si no hay posibilidad de que el público general pueda informar sobre sus necesidades y sobre los intereses comunes, el gobierno de expertos deviene una oligarquía que protege los intereses de unos pocos y que se posiciona de tal manera que obliga al cuadro administrativo y ejecutivo a tener en cuenta su asesoramiento. Desde este punto de vista, el ideal de objetividad que dicen defender las élites intelectuales y políticas no asegura, e incluso entorpece, la formación de una opinión pública plena. Finalmente, y teniendo en cuenta que la definición de democracia como modo de vida implica la articulación de los fines e intereses de los distintos grupos, un cuerpo de expertos con fines desvinculados del resto de los grupos sociales es contrario al sentido más amplio y profundo de la democracia (en este punto, y a riesgos de extremar la comparación, el grupo de expertos sería asimilable con el grupo de ladrones tantas veces referido por Dewey, en tanto y en cuanto sus fines no pueden congeniarse con el de otros grupos sociales). ${ }^{85}$

Las críticas recién presentadas de ninguna manera implican que Dewey desestime el valor de la experticia de quienes investigan. Por el contrario, cuanto más precisas sean las investigaciones, más precisos serán los juicios evaluativos en términos de condiciones y consecuencias de los que dependen las valoraciones propiamente dichas, consideradas

\footnotetext{
${ }^{85}$ Hacia fines de la década de 1920 la mayor parte de los proyectos de investigación y de los contratos de investigadores estaba en manos de grandes empresas como General Electric, DuPont, American Telephone y Telegraph o Kodak, al tiempo que la investigación en universidades o institutos también dependía fuertemente de inversores privados, cuyas donaciones se suponían desinteresadas pero, en la práctica, incidían en la organización de la investigación, en la elaboración de planes de estudio, etc. Esta coyuntura también explica, en parte, la crítica deweyana a la regulación privada de la ciencia (Cf. del Castillo, 2004, p. 25). Otro elemento de suma importancia, explicitado por el pragmatista en "Liberalismo y acción social" y en Libertad y Cultura, remite a los efectos perjudiciales de una tan incorrecta como expandida interpretación del liberalismo: en cuanto exacerbación del individualismo y la competencia, el liberalismo en su mera acepción económica, es decir, el capitalismo, es para Dewey responsable del fracaso en la extensión de las conquistas de las ciencias experimentales a las condiciones efectivas de vida, a fines sociales. Los frutos de la revolución industrial quedaron concentrados en manos de una clase cuantitativamente pequeña, que contaba también con el amparo de las instituciones morales y legales vigentes. Como resultado, los empresarios industriales consiguieron la propiedad de los medios de producción e intercambio, desviaron los resultados de la productividad a sus propias arcas y fundamentalmente impidieron que la ciencia y la tecnología adquieran su sentido humano (Dewey, 1996, p. 106. LW.11.53). Luego, y citando nuevamente a del Castillo, “[...] cuando Dewey defiende una ciencia libre, está defendiendo, entre otras cosas, una ciencia liberada de intereses privados, una ciencia con medios y resultados controlados y difundidos públicamente." (del Castillo, 2004, p. 25). Si bien una indagación detallada de estos elementos excede las posibilidades de la presente investigación, entiendo que vale al menos su mención y que permiten, además, vislumbrar en la perspectiva deweyana una sociología del conocimiento.
} 
ahora en términos de intereses públicos, vale decir, políticos. Además, señala Dewey, la necesidad de investigaciones rigurosas es tanto más apremiante cuanto más afianzados están el prejuicio, el secreto, la tergiversación y la propaganda, todos ellos aspectos determinantes para explicar las dificultades del público para identificarse como sujeto activo y el consecuente clima de apatía política denunciado por el pragmatista a fines de la década de 1920 (y que aún hoy sigue siendo acertado).

Teniendo en cuenta este punto y los comentarios de la sección anterior, puede comprenderse la distinción que traza Dewey entre ciencia pura y aplicada. En términos generales, la ciencia pura (y todo lo que se vincule a la "pureza" del conocimiento) se caracteriza por ser demasiado especializada al punto que se vuelve comunicable sólo para los expertos, es decir que se vuelve una ciencia ajena que no se concibe desde el punto de vista de su relación con los intereses compartidos y con la conducción de los asuntos públicos. La consecuencia directa de enfatizar el pretendido valor de la ciencia pura es el abandono de la responsabilidad por parte de los investigadores, siempre asentados en una idea de neutralidad valorativa de la investigación que, según he sugerido en el capítulo anterior, no tiene lugar en la concepción deweyana. Por el contrario, indica Dewey, “[c]omo 'aplicación' significa una conexión marcada con la experiencia y el bienestar humanos [...] la ciencia se convierte en conocimiento en su sentido honorable y categórico sólo en la aplicación.” (2004, p. 151. LW.2.344. Cursivas en el original).

La condición de la aplicación de una investigación reside, de acuerdo con Dewey, en la absorción y distribución de los conocimientos producidos por la ciencia, en la comprensión común y en una comunicación libre y sistemática que garantice la divulgación de las conclusiones científicas necesarias para la toma de decisiones respecto de asuntos públicos. En un contexto en el que las investigaciones científicas se refugian en una especialización académica comparable al escolasticismo, en el que las propagandas adquieren un carácter sensacionalista que fragmenta la continuidad vital de la experiencia y en el que los agentes publicitarios son los principales formadores de opinión, queda claro por qué la necesidad de investigaciones rigurosas se combina con la necesidad de mejorar los métodos y condiciones para ampliar las bases y fines sociales de la investigación científica y emplearlos para la elaboración de políticas. Luego, la diferencia entre aplicación para [to] y aplicación en [in] los intereses humanos resulta fundamental pues 
mientras la primera marca una relación de exterioridad entre un conocimiento ya cristalizado y un curso de experiencia ajeno -relación que explica el sentido lucrativo de "aplicación"-, la segunda da cuenta de la integridad entre ambos elementos, a tono con toda la teoría del conocimiento deweyana.

Así, no obstante la necesidad de la experticia técnica de los investigadores, debe tenerse en cuenta la necesidad de mejorar los métodos y condiciones de comunicación de los resultados de las investigaciones para que fueran empleados en la resolución de asuntos públicos. De manera esquemática, si para Dewey el público son todas aquellas personas que se ven afectadas por las consecuencias indirectas de las transacciones y la forma de garantizar el conocimiento de esas consecuencias indirectas es la plena publicidad y la comunicación libre y sistemática de todos los asuntos referentes al público, entonces la comunicación es condición para la constitución del público que se organiza políticamente y regula las consecuencias indirectas de las diversas acciones. Si, además, se asume que la ciencia es una actividad pública pues genera consecuencias que afectan a más personas que las inicialmente involucradas, entonces la comunicación también es una condición que se aplica a la investigación científica:

En todo lo dicho queda implícito que el conocimiento es comunicación además de comprensión. [...] Un hecho de la vida en comunidad que no se difunda hasta ser un dominio común es una contradicción en los términos. [...] La comunicación de los resultados de la investigación social es lo mismo que la formación de la opinión pública [...] [p]orque la opinión pública es el juicio que se forman y mantienen quienes componen el público, y se refiere a los asuntos públicos. [...] Sólo la investigación continua, o sea, una investigación interconectada y reiterada, puede proporcionar el material de una opinión duradera sobre los asuntos. [...] Desde luego, puede darse una honesta divergencia en cuanto a las políticas que hay que emprender, incluso cuando los planes surgen del conocimiento de los mismos hechos. Pero la política auténticamente pública no se puede generar a menos que esté informada por el conocimiento, y este conocimiento no existe excepto cuando hay investigación e información sistemática, exhaustiva y bien provista. (Dewey, 2004, pp. 152-153. LW.2.345-346).

A partir de estas consideraciones queda claro el rol de la investigación respecto de la formación de la opinión pública. Retomando nuevamente el análisis ofrecido por 
DeCesare (2012, p. 113), una diferencia central entre los planteos de Lippmann y Dewey está dada por los modelos de sujeto político supuestos por cada uno. En efecto, Lippmann supone un sujeto de conocimiento y un sujeto político que, para ser idóneo, debe ser omnicompetente. Dadas las limitaciones cognitivas que tendría ese sujeto, vale decir, dado que no es un sujeto omnipotente, entonces la intervención del cuerpo de expertos se torna necesaria y el público queda consecuentemente reducido a un mero espectador sin intervención en la toma de decisiones públicas. Por el contrario, Dewey supone un sujeto político ya no omnipotente sino con competencias democráticas que, siempre según DeCesare, consisten en emplear crítica, reflexiva e inteligentemente los datos ofrecidos por las investigaciones para resolver o dirimir asuntos públicos. En este sentido, la investigación científica adquiere un valor político deseable y por derecho propio dentro del proyecto deweyano porque permite hacer del ciudadano en particular y de la opinión pública en general actores competentes para participar en la esfera pública. Luego, hay aquí nuevas razones por las que la investigación científica no puede verse como un instrumento valorativamente neutral. Por un lado, es un elemento necesario para el reconocimiento de los intereses comunes y consecuentemente para la conformación del público; por el otro, ofrece los conocimientos necesarios para formar a la opinión pública y hacer de las personas ciudadanos capaces de intervenir colectivamente en la resolución de los asuntos comunes; y finalmente propicia una actitud inteligente y cooperativa para la resolución de los problemas públicos. En virtud de lo señalado, la investigación científica tiene un sentido político propio que se juega en el proyecto de la Gran Comunidad.

Por supuesto, Dewey es plenamente consciente de que la ciencia no siempre se orienta al fortalecimiento del modo de vida democrático sino más bien al beneficio privado o de clase, como ocurre en la guerra o el comercio, todo ello producto de seguir considerando que la investigación es una especialidad técnica instrumental disociada del fin al que apunta (Cf. Dewey, 1952, p. 239. LW.4.219). Tales derivas de las investigaciones científicas se ven reforzadas, precisamente, “[...] por la actitud que con gran frecuencia asumen los mismos hombres de ciencia, pues comúnmente se dice y se cree que la ciencia es por completo neutral e indiferente en lo que respecta a los fines y valores que mueven a los hombres $[\mathrm{y}]$ que, a lo sumo, sólo les proporciona medios más eficientes para la realización de fines que tienen su ser y son debidos a necesidades y deseos completamente 
ajenos a la ciencia." (Dewey, 1965, p. 137. LW.13.160). En este marco, es importante retomar la pregunta por el pretendido carácter valorativamente neutral de las investigaciones científicas y por sus fines en cuanto constitutivos de las mismas

\section{Dewey, en camino a una filosofía política de la ciencia}

Para abordar este asunto propongo, en primer término, retomar e intentar dar respuesta a algunas críticas planteadas por George Metz, críticas que se tornan relevantes pues permiten discutir la idea de la neutralidad de la ciencia por referencia a la política (1969, sec. 3-5). Según indica Metz, la interrelación necesaria entre instrumentalismo, ciencia y democracia representa la clave para interpretar el pensamiento político de Dewey. El autor identifica, además, algunas condiciones o pre-requisitos para el advenimiento de la democracia, que en gran medida coinciden con los que he enumerado en la segunda sección de este mismo capítulo. No obstante, Metz argumenta que la posición de Dewey presentaría una contradicción interna: por un lado sostendría que la ciencia política [political science] debe ser independiente de la filosofía política sustantiva pues el método científico sería por sí solo significativo y suficiente para resolver los problemas políticos y que, en cuanto método, es intrínsecamente neutral respecto de cualquier propósito político específico; por otro lado, ofrecería su propia filosofía sobre la que considera que debe basarse una genuina democracia (Metz, 1969, pp. 258-260).

Si bien Metz señala que Dewey tiende a resolver esta contradicción en favor de su filosofía (entendiendo por esto último el contenido político de su defensa de la democracia), quisiera cuestionar el planteo acerca de la supuesta tensión en el pensamiento del pragmatista. Ante todo, vale señalar que si bien no son citadas por Metz, su lectura acerca de la supuesta neutralidad de la investigación encuentra respaldo en algunas afirmaciones del propio Dewey, como por ejemplo la siguiente: "[1]a neutralidad de la ciencia respecto de los usos que de ella se hace vuelve tonto hablar de su quiebre [bankruptcy] o adorarla como la guía de una nueva era." Sin embargo, el pragmatista rápidamente aclara que "[e]n la medida en que nos damos cuenta de este hecho, debemos dirigir nuestra atención a los propósitos y motivos humanos que controlan su aplicación." De esta manera, 
[m]ientras que [la ciencia] es un fin para quienes están involucrados en esa actividad, en un amplio sentido humano es un medio, una herramienta. ¿Para qué fines debería ser utilizada? ¿Debería ser utilizada deliberadamente, sistemáticamente, para la promoción del bienestar social, o debería ser empleada principalmente para la expansión privada, dejando los resultados sociales librados al azar? [...] Nos vemos obligados a considerar la relación de las ideas e ideales humanos con las consecuencias producidas por la ciencia en tanto instrumento. ("Science and Society". LW.6.54-55, todas las citas).

Desde mi punto de vista, las observaciones acerca de los fines de la investigación son lo suficientemente relevantes como para reconsiderar los comentarios sobre la neutralidad del instrumento. En primer lugar, y retomo aquí un comentario del propio Metz, "[d]e acuerdo con Dewey el método científico no tiene sentido cuando es apartado del continuo de la "experiencia"' (Metz, 1969, p. 262). En esa línea, no tiene sentido apartar a la investigación de sus propósitos o fines, enmarcados en la referida continuidad de la experiencia. Por el contrario, argumentar en favor de la neutralidad de la investigación qua instrumento requiere abstraerla del curso de experiencia, movimiento que en la interpretación aquí ofrecida resulta inaceptable. Dicho de otra manera, el carácter contextual de toda investigación, en su seno biológico y cultural, impide considerarla como un instrumento abstracto, en sí mismo. Lo mismo sucede con los instrumentos surgidos como subproductos de la investigación, cuya asertabilidad garantizada los vuelve aplicables a distintas investigaciones pero siempre con un propósito y una finalidad determinada, con toda la carga valorativa que eso supone. Por supuesto, no debe ignorarse que la investigación científica en su dimensión instrumental puede utilizarse para distintos fines orientados por distintos valores o que algunos de los instrumentos desarrollados en una investigación particular puedan ser empleados en otras investigaciones y con otros fines, pero eso es precisamente lo que torna más urgente la discusión por sus fines.

Aceptada esta conclusión preliminar, la idea de neutralidad de la investigación también pierde sentido cuando es puesta a la luz de la tesis de la continuidad y reciprocidad de medios y fines. En efecto, la investigación en cuanto medio debería ser concordante con los fines a los que se orienta y expresar los valores que guían esos propios fines. Dado que de acuerdo con la pauta general de la investigación no hay investigación sin fines y que estos últimos dan cuenta de valores entonces no hay investigación/medio que fuera 
valorativamente neutral respecto de su fin/valor. En suma, si la investigación no puede desligarse del curso de experiencia y si en cuanto instrumento adquiere determinado valor por los fines que persigue (vale recordar lo dicho en el capítulo previo acerca de la cualidad moral de la investigación), la pregunta urgente es la pregunta por los fines de la investigación. En la medida en que la ciencia es una actividad pública, entonces la pregunta por sus fines es una pregunta de orden político $-\mathrm{y}$ consecuentemente la crítica de la supuesta disociación entre método y política que plantea Metz pierde su sentido.

Permítaseme recuperar algunas ideas a la base de todo el argumento precedente en favor de avanzar sobre esta última tesis. Por un lado, y a tono con su idea de experiencia como transacción, Dewey considera que el desarrollo de la ciencia ha creado un nuevo ambiente que reacciona sobre las actividades de las personas de una forma tan rápida e intensa que no puede detenerse pero que tampoco puede continuar tal y como lo viene haciendo hasta su momento, dado el tipo de efectos indeseables producidos. Por otro lado, el pragmatista sostiene que el avance del conocimiento científico en cuanto conjunto de técnicas e instrumentos no ha sido lo suficientemente acompañado por consideraciones inteligentes, deliberadas y sistemáticas respecto de sus resultados planificados y potenciales consecuencias. Teniendo en cuenta ambas cuestiones, Dewey concluye que la ciencia representa el desafío más grande al que se ha enfrentado la humanidad y que la forma de asumirlo es planificar inteligentemente sus efectos sociales con el mismo cuidado con que se planifican sus operaciones físicas o materiales (LW.6.57-58).

Un claro ejemplo de la radicalidad de este desafío está dado por los sucesos de la Segunda Guerra Mundial. Dewey introduce algunas observaciones al respecto en el Epílogo a La opinión pública y sus problemas, escrito en 1946. En términos generales, el pragmatista interpreta los acontecimientos que condujeron a la guerra como una suerte de confirmación de sus ideas respecto de la necesidad de identificar y poner en práctica intereses comunes y recíprocos, sea a nivel local, nacional o internacional. Bajo estas consideraciones se detiene a comentar la situación de la ciencia y sus notorias consecuencias indirectas y a mediano plazo, todo ello a partir del caso del desarrollo de la fisión del átomo conducente a la bomba atómica. Cito nuevamente in extenso: 
La importancia relativa de las consecuencias de sucesos de naturaleza teórica, y de acontecimientos tan patentes como para convertirse en objetos de la atención general, ha quedado perfectamente demostrada con el caso de la fisión del átomo. [...] Distintos aspectos del problema moral del estatus de la ciencia física llevan coleando desde hace mucho tiempo. Pero las consecuencias de las ciencias físicas, aunque sean enormemente importantes para la industria $y$, a través de esta, para la sociedad en general, no han recibido el tipo de observación que hubiera llevado a la acción y el estado de la ciencia al campo específicamente político. El uso de estas ciencias para incrementar la capacidad destructora de la guerra se convirtió con la división del átomo en un tema tan sensacional que hoy, queramos o no, nos enfrentamos con su dimensión política. (Dewey, 2004, p. 179. LW.2.380. Cursivas en el original).

El alcance de los sucesos de la guerra, así como lo hicieran años antes el avance de la máquina a vapor o el uso de la energía eléctrica (si bien, posiblemente, con otra impronta respecto de sus consecuencias), ponen de relieve la dimensión política de la ciencia y nuevamente dan lugar a la sugerencia deweyana acerca de la necesidad de que el público organizado en instituciones estatales tenga algún tipo de control sobre los fines de la propia actividad científica. En sus palabras, “[n]o es necesario que la mayoría tenga los conocimientos y la destreza para realizar las investigaciones necesarias; lo que se requiere es que tenga capacidad para juzgar la importancia de los conocimientos que otros proporcionen sobre los intereses comunes" (Dewey, 2004, p. 169. LW.2.365).

Varios son los elementos que se deben tener en cuenta para comprender cabalmente este planteo, muchos de ellos ya presentados en las páginas precedentes. Primero, en cuanto actividad pública, la actividad científica debería ser objeto de regulación de sus consecuencias indirectas de reconocido amplio alcance, tanto para promover algunas como para evitar otras, todo ello en función del interés público y compartido. Segundo, los resultados de las investigaciones, cuando son correctamente comunicados, aportan material de relevancia para conformar la opinión pública y volverla políticamente competente. Tercero, el grupo de expertos tiende a priorizar el beneficio privado, de modo que no puede ser depositario de la conducción de la actividad científica en tanto pública. Por último, aunque no menos importante, los fines de la investigación y los valores que la orientan son determinantes pues definen el valor de la investigación como medio o instrumento. 
Teniendo todo esto en consideración, resulta claro que Dewey habilita una reflexión sobre el conocimiento científico que no se debe entender en términos moralizantes que supongan a la ciencia como un instrumento abstraído del curso de experiencia sino que debe centrarse en sus fines y valores, considerando siempre su carácter público y contextual.

En virtud de lo dicho surge una cuestión central, a saber: cómo planificar el ejercicio de regulación de la opinión pública sobre la actividad científica. A partir de la lectura de la obra deweyana es posible identificar algunos lineamientos generales sobre este punto. En términos institucionales, habrá un auto-reconocimiento del público en cuanto afectado, se identificarán necesidades e interés en común y se organizarán dependencias en el seno del Estado para ejercer la regulación de la actividad. En términos filosóficopolíticos, y según se desprende de la posición de Dewey, los fines generales de cualquier investigación científica deben articularse con los fines compartidos por los distintos grupos que conforman la comunidad, habida cuenta de la condición de integración de intereses propia de la democracia como forma de vida. Dicho de otra manera, los fines generales de la ciencia no pueden entrar en colisión con el núcleo de intereses y valores compartidos por la comunidad, intereses y valores que en términos normativos deberían ser democráticos.

Asimismo, al igual que todos los asuntos comunes, la regulación debe ser democrática, es decir abierta a la consulta y discusión pública, pues aún con todos sus defectos, indica Dewey, es la mejor forma para identificar y clarificar los intereses comunes -y precisamente en eso consiste la cualidad educativa del método de la democracia señalado anteriormente. Así, frente a la tendencia de la clase de expertos de priorizar sus intereses, de los empresarios industriales a usufructuar los avances del conocimiento científico y desviar los resultados del incremento de productividad e incluso de los Estados totalitarios de emplear los recursos de la ciencia para controlar y dirigir la opinión mediante la propaganda, la ciencia debería estar guiada por fines resultantes de un genuino proceso de valoración, de deliberación crítica, abierta, libre, llevada a cabo con la referida "actitud científica" e informada, como toda valoración, por el mejor conocimiento a disposición. Esto último permite comprender por qué, en la perspectiva de Dewey, la investigación científica, la opinión pública y consecuentemente la democracia como forma de vida se configuran mutuamente. 
Por supuesto, estos son apenas algunos lineamientos generales que entiendo se desprenden de la posición de Dewey. De hecho, ha sido frecuentemente señalado que la cuestión del diseño institucional no es objeto de elaboraciones detalladas por parte del pragmatista. Frente a este diagnóstico, recientes e interesantes investigaciones agrupadas bajo el título de "experimentalismo democrático" parten de la concepción deweyana de democracia y de Estado para considerar alternativas de organización de instituciones que respeten las condiciones filosófico-políticas propuestas por Dewey y que fomenten la organización y articulación de distintos públicos (Cf. Butler, 2013). Las reflexiones en torno a la filosofía política de la ciencia y el incipiente experimentalismo democrático en clave deweyana abren una promisoria línea de investigación acerca del diseño institucional que podría adoptar la referida relación entre ciencia, opinión pública y democracia. ${ }^{86}$

\section{Conclusiones}

De acuerdo con la interpretación ofrecida, el marco filosófico deweyano y especialmente su concepción de la experiencia, de la valoración y de la investigación permiten elaborar una visión de la ciencia que, lejos de constituirse como libre de valores o valorativamente neutral, presenta una dimensión valorativa de hecho y de derecho. Esta dimensión incide tanto en el ámbito de validez o justificación del conocimiento, según he intentado argumentar en el capítulo previo, como en la consideración de los fines y valores de la ciencia, de acuerdo con lo argumentado en el presente capítulo.

El punto de partida de este capítulo ha sido una presentación general de la perspectiva política deweyana, identificando algunas condiciones filosóficas para la constitución de la democracia en cuanto forma de vida. En este marco, me he detenido en la justificación epistémica de la democracia elaborada por Honneth y Putnam, justificación según la cual la democracia es el pre-requisito para la aplicación de la inteligencia en la resolución de los conflictos sociales, de la misma forma que el carácter cooperativo y la libre propuesta y discusión de hipótesis en el contexto de una investigación científica propicia la mejor resolución posible del problema en cuestión. Así, en la medida en que

\footnotetext{
${ }^{86}$ Cuevas (2008) parte de la respuesta de Dewey a Lippmann y analiza el modelo de "comisiones de consenso" para la participación ciudadana en asuntos de política científica, llevada adelante inicialmente en Dinamarca y luego en Japón y algunos lugares de Estados Unidos. Más allá de las dificultades identificadas por la autora, tal vez fuera un modelo para tener en cuenta al momento de reflexionar en torno al diseño institucional antedicho.
} 
descansa sobre presupuestos respecto del valor de la organización democrática-cooperativa, es posible identificar un primer sentido de la dimensión política de la ciencia.

Una vez planteado el contexto de la reflexión, he recuperado el contrapunto entre Dewey y Lippmann a propósito del rol de los expertos en la democracia con el objetivo de contextualizar dos cuestiones que han estructurado el argumento general del capítulo. Así, he referido a la consideración de la ciencia como actividad eminentemente pública, dado el amplio alcance de sus consecuencias y de la consecuente constitución de un público organizado en instituciones para regular dicha actividad. También he referido a la consideración de la ciencia en cuanto constitutiva de la opinión pública, en cuanto condición para la adquisición de competencias democráticas por parte de los individuos y de los distintos públicos. En este marco, he intentado señalar que la relación entre ciencia y opinión pública es cuanto menos doble pues en cuanto actividad pública la ciencia es objeto de regulación por parte del público pero, a su vez, informa al público para nutrir las deliberaciones acerca de los asuntos comunes. Todo esto ha permitido identificar un segundo sentido de la dimensión política de la ciencia, dado el rol que juega en el proyecto deweyano de Gran Comunidad.

Ahora bien, la consideración de la carga valorativa política de la ciencia no se agota allí. Por el contrario, en la medida en que la investigación es un medio en el sentido de instrumento para la resolución de determinados problemas, siempre es un medio por referencia a un fin. Por tanto, la pregunta que urge es la pregunta por los fines de la investigación pues, por un lado, sobradas muestras hay de que la ciencia en cuanto instrumento ha sido utilizada con múltiples propósitos (benéficos, lucrativos, destructivos) y, por otro lado, el valor de esos propósitos dotan de valor a toda la investigación en cuanto medio, de modo que en principio no es posible pensar la idea de neutralidad valorativa de la investigación -a menos que se la considere en abstracto o por fuera del curso de experiencia, operando un recorte contrario al sentido filosófico general deweyano. $\mathrm{Si}$, al mismo tiempo, se considera que la ciencia es una actividad eminentemente pública, la pregunta por sus fines es una pregunta de interés común, es decir, una pregunta política. En cuanto tal, debería quedar en manos de una opinión pública organizada, cuyas resoluciones deberían contemplar las condiciones de una democracia como forma de vida. De este 
modo, el entramado conceptual deweyano reclama una reflexión política en torno a la investigación científica y, más aún, deja abiertas promisorias líneas de investigación y puesta en práctica de esas mismas consideraciones. 


\section{RECAPITULACIÓN Y CONCLUSIONES PARCIALES}

En la segunda parte de este estudio he analizado las relaciones entre valoración e investigación científica y a partir de ellas he avanzado en consideraciones de índole política respecto de la ciencia, siempre desde el marco teórico de Dewey. En este sentido, durante los tres capítulos precedentes he intentado dar cuenta de ciertos elementos fundamentales para el desarrollo argumentativo de esta tesis: (i) el carácter eminentemente práctico de la investigación, carácter que - una vez más- pone de manifiesto que la noción de experiencia como transacción está a la base de toda elaboración filosófica del pragmatista; (ii) las continuidades entre valoración e investigación científica, haciendo empleo de la clave de lectura forjada en la primera parte del presente estudio; y (iii) el proyecto político para la ciencia de Dewey, inextricable de su idea de democracia como forma de vida comunitaria.

En relación a (i) el elemento más significativo de la noción de investigación es el modo en que se desmarca de cualquier versión especular o contemplativa del conocimiento en general y del conocimiento científico en particular mediante la reconstrucción de una pauta de investigación que, si bien reconoce instancias de reflexión teórica o raciocinio, toma como eje la situación - con todas sus particularidades, según he sugerido en el capítulo inicial. En este sentido, la visión deweyana de la investigación en cuanto modo de la práctica es absolutamente consistente con su concepción de experiencia y con el método denotativo reclamado para toda actividad reflexiva, entre ellas la filosofía. Asimismo, dicha concepción de la investigación implica necesariamente alguna instancia valorativa pues toda la pauta general cobra dirección por referencia al fin a la vista de la investigación y a las consecuencias que surgen mediante su operación. En suma, el carácter amplio de la investigación en general y de la investigación científica en particular implica necesariamente una dimensión valorativa inherente a su propio juzgar.

Esta última afirmación es lo que ha permitido avanzar sobre (ii), punto sobre el que he sugerido distintos sentidos en los que hay continuidad entre valoración e investigación científica. En esta línea, he señalado que no es posible aislar a la investigación del contexto en cuanto estimaciones asentadas y desapercibidas pero presentes en toda forma de pensamiento y reflexión, razón por la cual no es posible concebir que valores de todo tipo 
no tengan injerencia en la investigación -en particular si se tiene en cuenta que los hechos de la investigación y esta última en cuanto medio o instrumento cobran sentido por referencia a un fin y al valor que este último pueda tener. Asimismo, he indicado dos dimensiones o facetas de la continuidad lateral entre la investigación científica y la valoración, en términos metodológicos o procedimentales y en términos de contenido o material, y he señalado que esas facetas de continuidad son bidireccionales. Luego, así como hay investigación en la valoración, también hay valoración en la investigación, y ello en dos sentidos: por un lado, hay valoración de las decisiones de quien investiga; por otro lado, hay incidencia de valores ya no exclusivamente epistémicos sino morales, sociales y político tanto por la ineludible incidencia del contexto como por las valoraciones explícitas y legítimas al momento de ponderar las consecuencias amplias de la investigación científica -todo ello sin perjuicio de las diferencias cualitativas entre ciencia y valoración. En suma, la investigación no puede desmarcarse de la "matriz valorativa" de la experiencia que está a su base. Por otro lado, apelando a la discusión entre Dewey y los "nuevos realistas" he sugerido que la posición del pragmatista pone en jaque uno de los fundamentos de la versión standard de la filosofía de las ciencias, heredada del positivismo lógico: la distinción entre contexto de descubrimiento o génesis y contexto de justificación o validez. Asimismo, he recuperado la lectura que hace Putnam sobre el desplome de la dicotomía hecho/valor, a la cual el propio Putnam añade una interpretación muy sugerente respecto de la necesidad de organizar la propia investigación de forma democrática en favor de propiciar la circulación de ideas, hipótesis, etc. y beneficiar la propia investigación, argumento que ofrece ya una primera consideración política de la ciencia.

Finalmente, con respecto a (iii) he indicado que la perspectiva de Dewey sobre la investigación científica no puede considerarse al margen de sus consideraciones políticas pues aquella constituye un elemento fundamental para la reconstrucción del público y el advenimiento, si alguna vez posible, de la democracia como forma de vida o Gran Comunidad. Esto supone una discusión de índole política con aquellas posiciones expertocráticas y una apuesta a rediseñar la participación colectiva en aquellos asuntos que conciernen a la esfera pública -sin que ello implique desestimar el aporte técnico y especializado que puedan hacer los investigadores, uno de los eslabones indispensables para la construcción de una democracia genuina. Es por eso que, en mi interpretación, la 
postura de Dewey enfatiza la necesidad de la ciencia para una buena política, tanto porque la deliberación inteligente permite identificar y/o dar lugar a intereses comunes como porque esa misma deliberación debe estar informada por el mejor conocimiento científico disponible, pero también implica la necesidad de la política para una buena ciencia, aquella cuyos fines y valores no son inmunes a la crítica sino que pueden ser puestos en discusión y modificado. Así, lejos de un reduccionismo cientificista, la pregunta por los fines de la investigación científica debe incluir una deliberación acerca de la consistencia de esos mismos fines con la democracia y con el núcleo de valores e intereses compartidos por la comunidad.

En todo este contexto, entiendo que el recorrido por el entramado teórico deweyano realizado hasta aquí permite sostener las siguientes dos afirmaciones: en primer lugar, la investigación científica no puede concebirse como valorativamente neutral o libre de valores dada su inscripción en el curso de experiencia; en segundo lugar, la investigación científica no puede concebirse al margen de la política dado su carácter distintivamente público. En virtud de lo dicho, la filosofía de Dewey -desde su novedosa y estructural noción de experiencia hasta sus argumentos más refinados respecto de la necesidad de libre comunicación de los resultados de las investigaciones, pasando por su perspectiva respecto de la valoración y la investigación- ofrece un encuadre sólido y consistente para la reflexión política sobre el conocimiento científico. En lo que sigue me detendré a evaluar algunas intervenciones en el debate actual sobre el ideal de ciencia libre de valores con el objetivo de señalar qué aportes se podrían hacer desde la perspectiva deweyana. 
TERCERA PARTE: APORTES AL DEBATE SOBRE EL IDEAL DE CIENCIA LIBRE DE VALORES 


\section{COMENTARIOS PRELIMINARES: UN MAPA DEL DEBATE}

De acuerdo con lo indicado en la introducción general, la tercera parte del estudio queda reservada al análisis de algunas posiciones intervinientes en el debate contemporáneo sobre el ideal de ciencia libre de valores [value-free ideal]. En efecto, la producción en materia de filosofía del conocimiento se ha interesado cada vez más en la relación entre el conocimiento (en especial el conocimiento científico) y la presencia o ausencia de valores tradicionalmente denominados no epistémicos. Así, como señalan Kincaid, Dupré y Wylie, “[e]n las últimas décadas es difícil haber estado involucrado en debates sobre filosofía de la ciencia sin confrontar el lugar de los valores en ciencia.” (2007, p. iii. Traducción propia).

En este contexto se da un amplio espectro de argumentaciones cuya identificación permitirá dar cuenta del estado del debate y del marco de discusión en el que se inscribe el presente tramo del trabajo. Dichas posiciones deben responder no sólo si es posible una ciencia libre de valores sino también cómo se interpreta el ideal, qué se entiende por valores y sobre qué tipo de valores se concentra la discusión, en qué instancia, momento o fase del proceso de producción de conocimiento inciden y/o deberían incidir, qué legitimidad y qué consecuencias teóricas y prácticas tiene dicha incidencia, si el ideal es deseable o puede elaborarse alguna alternativa filosófica al mismo y finalmente qué consecuencias se siguen de asumir estas distintas perspectivas en términos de la objetividad y racionalidad de la empresa científica. En suma, la pregunta “¿la ciencia está libre de valores?” incluye muchas preguntas distintas (Kincaid et al., 2007, p. 14). En lo que sigue presentaré una breve reconstrucción histórica de la conformación del ideal y de algunas posiciones representativas del debate. Así, pretendo preparar la arena de discusión de los próximos capítulos, dedicados especialmente a las propuestas de Heather Douglas, Philip Kitcher y, en el ámbito iberoamericano, de León Olivé y Javier Echeverría.

En términos bien generales, el ideal de ciencia libre de valores considera que las afirmaciones científicas son verdaderas o falsas y que esa atribución depende de la evidencia disponible y de una correcta derivación lógica, sin referencia a las perspectivas morales, políticas o sociales de quien investiga. En este sentido, la tarea de la ciencia se remite a los hechos, un dominio autónomo y totalmente independiente del plano de los 
valores o preferencias (Kincaid et al., 2007, p. 4). De acuerdo con la propia Douglas (2009, Capítulo 3, 2016) y también con Reisch (2009, Capítulos 8, 9, 14), y más allá de que sus raíces históricas puedan rastrearse siglos atrás, la formulación contemporánea del ideal de ciencia libre de valores se origina durante la Guerra Fría. En efecto, ya ha sido señalado en la introducción que una de las razones relevantes para explicar la forma profesional apolítica, individual y técnica adoptada por la filosofía de la ciencia estadounidense de la segunda mitad del siglo XX es la presión anticomunista y anticolectivista ejercida por Joseph McCarthy, todo ello en favor de elaborar una legitimación filosófica de las pretensiones científico-militares del gobierno de Estados Unidos. Para completar este cuadro debe hacerse mención a Science: The Endless Frontier, el célebre informe de Vannevar Bush encargado por el presidente de Estados Unidos Franklin Roosvelt en 1944, informe que ciertamente constituyó un punto de partida para la notoria expansión del sistema científico estadounidense. No obstante el evidente vínculo entre ciencia y política que supone y al que dio lugar este informe, los temores respecto de la posible corrupción de la ciencia por parte de la política o de la excesiva intromisión de la ciencia en la política estaban disipados precisamente gracias al ideal filosófico de ciencia libre de valores: “[d]ado que los científicos tenían experticia científica y dado que la ciencia estaba libre de valores sociales y políticos, entonces el consejo de los científicos estaba igualmente libre de esos valores. Esta 'neutralidad valorativa' era tomada como una característica inherente a la mayoría de los científicos y crucial para la continuidad de un consejo científico sólido.” (Douglas, 2004, p. 226).

En este punto es importante hacer la siguiente aclaración: la filosofía no ha sido la única disciplina ocupada en reflexionar en torno al vínculo entre ciencia y política, o en términos más amplios, entre ciencia y sociedad. En efecto, a partir de la década de 1930 y especialmente de 1940 se fue conformando el campo de estudio de la sociología de la ciencia, cuyo objetivo inicial fue analizar a la ciencia en cuanto producto de la sociedad y también elaborar otra estrategia argumentativa frente al riesgo de la utilización de la ciencia y sus productos por parte de regímenes caracterizados como autoritarios (como fue el famoso caso Lysenko en la Unión Soviética). En este marco, los trabajos pioneros de Robert Merton, inicialmente basados en la escuela estructural-funcionalista estadounidense, han sentado las bases de los estudios sociales de la ciencia hasta, al menos, las lecturas 
sociológicas de La Estructura de las Revoluciones Científicas de Kuhn. Entre las valiosas contribuciones de Merton se destacan sus trabajos sobre el ethos de la ciencia y sobre la estructura de la institución de la actividad científica (por ejemplo, la dinámica de reconocimiento de prestigio), trabajos signados por una notoria impronta normativa (Merton, 1938 y 1942). Ya para la década de 1970 ganan terreno las corrientes postmertonianas de sociología de la ciencia, entre ellas el Programa Fuerte iniciado con la publicación de Knowledge and Social Imagery de David Bloor (1976), y hacia la década de 1980 se desarrollan los estudios de laboratorio de la mano de los ya citados Karin KnorrCetina (2005 [1981], entre otros) o Bruno Latour (2008 [1983] o 1988, este último con Steve Woolgar). No obstante el valioso aporte de la sociología de la ciencia, de su carácter en buena medida solidario con el enfoque filosófico y de los fecundos lazos teóricos que pueden esbozarse entre dichos aportes y el marco teórico deweyano, en lo que sigue avanzaré en una perspectiva sobre la relación entre ciencia y valores sociales, morales y políticos que permita reflexionar en torno a las propias nociones de investigación, de valores y de política -especialmente democrática- en clave primordialmente filosófica. ${ }^{87}$

El debate entre programas rivales para la filosofía de la ciencia de posguerra, según lo denomina Reisch, se juega en el control del nuevo Instituto para la Unidad de la Ciencia establecido en Boston, en la revista Philosophy of Science y en la Asociación de Filosofía de la Ciencia de Estados Unidos, y se extiende durante aproximadamente una década. Recién hacia comienzos de 1960 los tópicos de discusión académica eran aquellos impulsados por Feigl, Reichenbach y Carnap en función de distinguir a la filosofía de la ciencia propiamente dicha de otros estudios del ámbito de la ética o la política, mientras que las líneas interpretativas defendidas por Frank, Neurath y Morris -y también aquellas ideas de Dewey que confluían con la visión general del conocimiento científico sostenida por el Movimiento de Unidad de la Ciencia- quedaron progresivamente desestimadas. ${ }^{88}$ En

\footnotetext{
${ }^{87}$ Para una reconstrucción general del derrotero de la sociología de la ciencia, Cf. Kreimer, 1999. Para un análisis detallado del caso Lysenko, Cf. Gómez, 2014, Capitulo 12. Finalmente, para un estudio de las vinculaciones teóricas entre la perspectiva deweyana y los aportes de la sociología de la ciencia contemporánea, Cf. López, 2014, Capítulos 8-10.

${ }^{88}$ Paradójicamente, señala Reisch, uno de los motivos más importantes para dar cuenta del eclipse intelectual de Charles Morris es la fuerte crítica esgrimida por Dewey respecto de la interpretación de la teoría semiótica presentada por el propio Morris en sus contribuciones a la Enciclopedia y respecto de la idea de transacción elaborada por Dewey y Bentley (Reisch, 2009, pp. 399-403).
} 
este punto Reisch plantea una muy interesante tesis que vale la pena mencionar, aun cuando no fuera objeto de análisis de estas páginas: “[e]n el escenario político maniqueo de la Guerra Fría, se pensaba que los valores que dividían a Occidente de los soviéticos eran absolutos e inmodificables a un nivel que los depositaba fuera de los límites para el tratamiento por parte de la filosofía de la ciencia.” (2009, p. 413). Reisch concluye que el triunfo de la versión logicista de la filosofía de la ciencia es un movimiento de repolitización antes que de despolitización pues quita del ámbito de reflexión filosófica una serie de valores funcionales a la posición política estadounidense y los legitima "por default", es decir, por no ponerlos en discusión (2009, p. 413). ${ }^{89}$

En este marco general Douglas recupera algunas de las intervenciones teóricas que dieron cuerpo al debate durante la década de 1950 (Cf. 2009, pp. 49-65). Así, por un lado, se encuentran posiciones como las de Richard Rudner (1953) o C. West Churchman (1956). Según Rudner, se requieren valores, incluso sociales y éticos para definir cuándo la evidencia es suficiente, según la importancia de cada caso y habida cuenta del carácter inductivo de la investigación y de la posibilidad de error. En sus palabras, "[c]uán seguros necesitamos estar antes de aceptar una hipótesis dependerá de cuán grave sería cometer un error." (Rudner, 1953, p. 2). De acuerdo con Douglas, concepciones como las de Rudner llevan a los valores tradicionalmente denominados no epistémicos hacia el centro mismo de la actividad científica. Frente a argumentos como el de Rudner se encuentran posiciones como las de Isaac Levi (1962), quien introduce la concepción de "canon de evidencia" para suplantar la apelación a valores a la hora de decidir si determinada evidencia es suficiente para afirmar la hipótesis. En esa línea se fue conformando el ideal de ciencia libre de valores pues el canon de evidencia incluye aspectos típicamente epistémicos como la simplicidad, la capacidad explicativa y predictiva, etc., y excluye explícitamente cualquier otra consideración. De este modo, en el núcleo de la ciencia sólo regirían los cánones de

\footnotetext{
${ }^{89}$ Douglas propone una interpretación similar cuando afirma que la Guerra Fría demandaba una dicotomía estricta y primigenia: o bien se está con Estados Unidos, su capitalismo y su democracia, o bien se está con la Unión soviética, su comunismo y su totalitarismo. En este contexto y desde el punto de vista de la filosofía norteamericana, argumentar en favor de las relaciones entre ciencia y valores era una tarea delicada porque quienes lo intentaran podrían ser acusados rápidamente de marxistas, dado que el marxismo efectivamente establece relaciones entre ambos elementos; porque no había un suelo de discusión teórica común y, sobre todo, porque cierto sentido de prudencia indicaba que el mejor camino era el pretendidamente apolítico (Douglas, 2009, p. 47).
} 
inferencia y no se aceptarían valores sociales o éticos pues éstos quedan en el plano de los aspectos "externos" a la ciencia.

A diferencia de ciertas ambivalencias respecto del ideal promovido por Levi que, de acuerdo con Douglas, pueden encontrarse en algunos textos de Carl Hempel o de Ernest Nagel, es Thomas Kuhn quien establece claramente la especificidad, alcance y competencia de las comunidades científicas. Estas comunidades se rigen por sus propios criterios y en su forma idealizada aparecen desvinculadas del resto de la sociedad: "[...] el aislamiento de la comunidad científica con respecto a la sociedad permite que el científico individual concentre su atención en problemas sobre los que tiene buenas razones para creer que es capaz de resolver." (Kuhn, 2004, p. 253). Asimismo, Kuhn es uno de los primeros en denominar "valores" a los criterios de inferencia, todo ello bajo su idea de que, si bien no es posible establecer un algoritmo para las decisiones porque en muchos casos la evidencia empírica y la lógica deductiva no son suficientes para elegir entre teorías alternativas, sí es posible establecer un conjunto de valores utilizados para informar en la decisión entre teorías, en cuya apelación aunque sea parcial radica la objetividad de la ciencia. En efecto, los científicos pueden no acordar acerca de qué valores deben priorizarse para elegir entre teorías, pero no pueden salirse del conjunto de valores epistémicos establecidos por Kuhn. Así surge la versión más difundida de los valores epistémicos en cuanto criterios o factores tomados por legítimos para orientar las decisiones al interior de la ciencia. De esta manera, el ideal de ciencia libre de valores incluye aquellos valores cuya consideración se considera legítima o permitida a la hora de decidir entre distintas teorías.

En suma, para la década de 1980 una "ciencia libre de valores" era equivalente a una ciencia libre de valores no epistémicos. Más aún, la reformulación progresiva de la distinción entre contextos de justificación/descubrimiento y la elaboración de una visión más precisa de lo que implica la práctica científica generó que los límites del ideal de ciencia libre de valores se volvieran más definidos pues si bien se reconoció ampliamente que la ciencia apela a valores no epistémicos en su dimensión "externa”, se restringió aún más su fortaleza "interna”. Así lo explica Douglas cuando indica que "[...] la expresión "ciencia libre de valores" realmente refiere a la norma [de apelar a] valores epistémicos sólo en las instancias internas de la ciencia. Es esta forma cualificada de 'ciencia libre de 
valores' la que es postulada como un ideal para la ciencia." (Douglas en Kincaid et al., 2007, pp. 120-121). Es por ello que, y remito nuevamente a Douglas, la denominación "ideal de ciencia libre de valores" es una etiqueta inadecuada para expresar un "ideal de emplear sólo valores epistémicos en la inferencia científica" (2016, p. 3). Dicho de otra forma, el ideal de ciencia libre de valores se expresa en términos de valores aceptados y no aceptados en la actividad científica, especialmente en el contexto de justificación y en la elección entre teorías alternativas o rivales. Así, los valores aceptados son los valores epistémicos mientras que los no aceptados quedan referenciados con el grupo de los valores extra o no-epistémicos (incluyendo valores sociales, morales, etc.).

En la contemporaneidad, uno de los defensores más reconocidos del ideal de ciencia libre de valores es Hugh Lacey (1999). De acuerdo con Lacey, aun cuando haya presencia efectiva de valores en la investigación científica, aquella debería circunscribirse de modo que no afecte las tres características constitutivas del ideal, a saber:

(i) neutralidad. Relacionada con fundamentos metafísicos y metaéticos de resonancia galileana y humeana respecto del estatuto de los objetos de la ciencia y de los objetos de valor, la neutralidad señala que el propósito de la ciencia es representar un mundo de "hechos" y dar cuenta de su orden mediante teorías que no necesitan apelar a contenidos evaluativos. Así, ninguna teoría científica tiene juicios de valor en sus implicaciones lógicas, la aceptación de una teoría u otra no produce consecuencias en los juicios de valor que cada quien asume y una teoría puede ser empleada en proyectos vinculados a cualquier conjunto de valores;

(ii) imparcialidad. Relacionada con fundamentos epistemológico-metodológicos de inspiración baconiana, la imparcialidad indica que la inferencia científica puede ser reconstruida exclusivamente en términos de reglas que median entre la observación empírica, la experimentación o replicación y la propia teoría. La aplicación de estas reglas evitaría toda incidencia de deseos o perspectivas valorativas personales, institucionales y/o culturales, todo eso a efectos de garantizar elecciones no ambiguas respecto de qué teoría elegir; y

(iii) autonomía. Relacionada con fundamentos práctico-institucionales, la autonomía afirma que la ciencia tiene una dinámica interna propia que responde sólo a valores epistémicos. Luego, la autonomía es condición para la neutralidad y la 
imparcialidad y en cierto sentido se constituye, al decir de Lacey, en un mecanismo para proteger los valores e intereses de la dinámica interna de la ciencia, Es, en definitiva, una propuesta política: "dejar la ciencia a los científicos pero también proveerlos con los recursos para llevar adelante sus investigaciones sin ataduras." (Lacey, 1999, p. 9. Traducción propia).

En este marco, y si bien Lacey afirma que los valores sociales y morales juegan un rol al momento de considerar la significación o aplicación de una teoría y de definir ciertas estrategias de investigación, el punto irrenunciable de todo su argumento es el siguiente: "Que la ciencia está libre de valor, repito, no significa que no haya un interjuego entre ciencia y valores; sólo que [no importa] cuál interjuego haya, deja intactos los tres componentes.” (1999, p. 17. Traducción propia). Ese núcleo del ideal se corresponde, según el autor, con la instancia de aceptación o rechazo de teorías, en la que no hay lugar para juicios personales, morales, sociales, estéticos, etc. Dicho de otra forma, aun cuando haya algún tipo de interacción entre ciencia y valores tradicionalmente denominados no epistémicos, los tres componentes estructurales del ideal planteado por Lacey no deberían verse afectados y la elección de teorías debería dirimirse exclusivamente en los clásicos términos de evidencia empírica, "buena" lógica deductiva y valores epistémicos.

De acuerdo con Lacey, la idea de imparcialidad adquiere cierto tipo de prioridad por sobre las otras dos. El autor reconoce que la autonomía ha sido sistemáticamente violada por las instituciones científicas y políticas y reconoce también que la neutralidad es difícil de sostener dada la práctica científica efectiva. Por tanto, la imparcialidad se constituye como el eje central de su posición. Más aún, a pesar de las dificultades para poner en práctica los componentes del ideal, ellos tienen fuerza precisamente porque son tesis respecto de la aceptación efectiva o concreta [actual] de teorías, que en cuanto tal se cumplen en mayor o menor grado, y no tesis lógicas acerca de una ciencia idealizada. No obstante, y en la medida en que siempre son susceptibles de mayor cumplimiento, pueden servir como valor-guía o ideal regulativo, de modo que la propia afirmación "la ciencia está libre de valores" representa un valor, meta o aspiración de las prácticas científicas y un criterio para evaluar sus resultados y consecuencias (Cf. Lacey, 1999, pp. 2, 17-18). 
La posición de Lacey ha dado lugar a numerosos análisis críticos, entre ellos el de Elizabeth Anderson (2004). Anderson señala que la tesis de la neutralidad se articula en dos sub-tesis, a saber: que las teorías sólidas (i) no presuponen y (ii) no sostienen ningún juicio de valor no epistémico. Estos dos aspectos se apoyan, a su tiempo, en sus respectivos argumentos. El primero es de orden psicológico y señala que los investigadores que dan lugar a juicios de valor respecto de los asuntos de su investigación no podrían evaluar las distintas teorías vinculadas a ese asunto de manera imparcial y que por tanto serían presas del wishful thinking o de una actitud mental poco abierta. Dicho de otra manera, para garantizar una actitud neutral u objetiva los científicos deberían poner sus valores a un lado. El segundo es de orden lógico, se apoya en la tesis por la cual no hay inferencia válida de "es" a "debe" y señala entonces que los juicios factuales no pueden tener una relación de fundamentación con los juicios de valor, en particular acerca de los fines a los que se oriente la acción. Ahora bien, si se sigue el planteo antedicho, los juicios de valor también deberían ser science-free y por eso mismo deberían quedar por fuera del ámbito de justificación. Luego, señala Anderson, el ideal de ciencia libre de valores depende del supuesto de que los valores no cuentan con respaldo empírico y consecuentemente son elementos que entorpecen e incluso enceguecen a quienes investigan, razón por la cual la cláusula de neutralidad es, en definitiva, una cláusula frente al dogmatismo. Así, la discusión sobre el ideal de ciencia libre de valores es deudora de la concepción misma de valor y de cómo se interpreta el vínculo entre juicios científicos y juicios valorativos, mucho más de lo que en general se acepta, de modo que la tarea más urgente debería orientarse a señalar el carácter no dogmático de esos juicios de valor para garantizar que esas mismas asunciones valorativas no conducirán la investigación hacia conclusiones prefijadas. Este es, además, el criterio propuesto por Anderson para distinguir entre usos legítimos e ilegítimos de valores en ciencia.

Junto con planteos críticos como el de Anderson pueden encontrarse distintas posiciones que rechazan el ideal de ciencia libre de valores, partiendo del reconocimiento de su presencia efectiva y permitiendo una comprensión más adecuada de cómo efectivamente se desarrolla la empresa científica. ${ }^{90}$ Entre las contribuciones más destacadas

\footnotetext{
${ }^{90}$ Aquí sigo y complemento una reconstrucción del estado de la cuestión ofrecida por Douglas (2016). Kincaid, Dupré y Wylie (2007, pp. 5-12) también ofrecen una muy interesante reconstrucción del ideal,
} 
en la línea de rechazo al ideal aparece la epistemología feminista, responsable de denunciar que la ciencia, tanto en sus investigaciones como en su práctica institucional, fortalece, reproduce e invisibiliza las inequidades entre hombres y mujeres (y géneros disidentes, se podría agregar). Tal vez la filósofa pionera en esta perspectiva es Helen Longino (1990 y 2002), quien diseña un ideal de "valor social" de la ciencia [social value management] por el cual todos los valores sociales pueden ser incluidos en ciencia en la medida en que sean sujetos al criticismo transformativo. En ese ideal quedarían incluidos, precisamente, los valores de equidad entre géneros pues la práctica científica debería estar informada por los valores socio-históricos más relevantes.

En el mismo sentido, Janet Kourany (2010, Capítulo 3) elabora un ideal de ciencia socialmente responsable, es decir, aquella que cumple conjuntamente con standards y valores tanto epistémicos como sociales que afectan aspectos internos y externos de la ciencia. A partir de esta formulación, la pregunta importante es la pregunta por los valores que guiarán ese ideal de ciencia responsable, todo ello bajo la intención general de eliminar el sexismo y el androcentrismo en la práctica científica. Así, a diferencia del ideal de ciencia libre de valores, el ideal de ciencia socialmente responsable sostiene que quitar de raíz el sexismo y el androcentrismo de la ciencia es equivalente a implantar valores sociales igualitarios en la ciencia; a diferencia del ideal de social value management, el ideal de ciencia socialmente responsable considera que puede hacer aportes sustantivos acerca de cuáles serían los valores sociales que deberían entrar en la ciencia (precisamente aquellos tendientes a la equidad); y a diferencia del ideal empirista de la ciencia, el ideal de ciencia socialmente responsable afirma que el éxito científico [scientific success] tiene que ser definido en términos empíricos así como sociales, atendiendo al valor del "florecimiento humano, aquel que hace a una sociedad buena." (Kourany, 2010, p. 68. Traducción propia).

Aparte de la epistemología feminista es posible identificar otras perspectivas que discuten el ideal de ciencia libre de valores. Por ejemplo, Daniel Hicks (2014) arguye que la filosofía de la ciencia debería tener un compromiso profundo con la ética en favor de elaborar un diagnóstico más complejo y detallado tanto de los objetivos de la ciencia como de los objetivos de otras acciones de las que la ciencia es parte. Hicks sostiene que se debe

remontada hasta la filosofía de Hume, y de cómo se fueron elaborando las críticas, desde Quine hasta la filosofía del lenguaje ordinario. 
considerar si ciertos valores no-epistémicos podrían y/o deberían tener prioridad en contextos particulares y por referencia a los objetivos específicos de esa investigación. Por su parte, el ya citado Matthew Brown (2012) intenta rehabilitar la concepción deweyana de investigación y sostiene que la incorporación de valores en ciencia es un aspecto necesario de la misma. Más aún, Brown advierte los riesgos de aceptar sin análisis la prioridad léxica de la evidencia tanto porque la idea misma de evidencia y los criterios utilizados son cargados de valor [value-laden] como porque los juicios de valor son también resultado de la investigación cuidadosa, detallada y metódica, a diferencia de la idea general que los suele asociar con meras preferencias subjetivas, tal y como quedó explicado en los capítulos previos. Por lo tanto, en la investigación debería haber una coordinación entre la evidencia, los valores y la teoría, que todos estos elementos deberían conciliarse en vistas a resolver el problema que dio lugar a la investigación y que es precisamente la valoración que se hace de la situación reunificada la que permite determinar si una investigación cumplió su objetivo de manera adecuada.

Más allá de la importancia que revisten todos estos argumentos, los próximos tres capítulos estarán centrados en las figuras de Douglas, Kitcher y Echeverría/Olivé, respectivamente. A modo de presentación vale decir que Douglas (2004, 2009, 2014, 2016) fundamenta su posición a partir de la estrecha relación existente entre la ciencia y el diseño de políticas públicas [policymaking] en sus dos sentidos, esto es, ciencia para la política y política para la ciencia. Así, la autora sostiene que “[...] en muchas áreas de la ciencia, particularmente en aquéllas que son utilizadas para asesorar en decisiones de políticas públicas, la ciencia no debería ser libre de valores [...]. En esas áreas, la ciencia libre de valores no es ni un ideal ni una ilusión. Es una ciencia inaceptable.” (Douglas en Kincaid et al., 2007, p. 121). En términos generales, Douglas sostiene que rechazar el ideal de ciencia libre de valores no sólo no atenta contra la objetividad del conocimiento científico sino que constituye una condición necesaria para las normas básicas de responsabilidad de los científicos, en la medida en que deben considerar las consecuencias tanto epistémicas como éticas y sociales de sus investigaciones durante el desarrollo de las mismas (y no una vez finalizadas) para tomar decisiones al respecto. Más aún, la explicitación de todos los valores que intervienen en el proceso de producción de conocimiento permitiría identificar en qué puntos se toman decisiones claves, por qué hay desacuerdos entre los científicos y 
fundamentalmente por qué es importante la intervención del público en general en los debates acerca de cuáles deberían ser los valores que fundamentan tales decisiones (Douglas, 2007, p. 126-136).

Por su parte, Kitcher (1993, 2001, 2011b) propone una nueva unidad de análisis de las investigaciones, a saber: las prácticas científicas. Apoyado en esta nueva perspectiva cuestiona profundamente el denominado "mito de la pureza" de la versión clásica de la ciencia e introduce la tesis de que la ciencia no busca la verdad sino la verdad significativa, de modo que la pregunta central pasa a ser la pregunta por cómo y quiénes definen el sentido de significatividad de la verdad (y consecuentemente de la investigación). En este marco, y explícitamente apoyado en ideas deweyanas, Kitcher propone un ideal de ciencia bien ordenada vinculado desde su misma definición con la democracia y ofrece una alternativa que se pretende en línea con lo analizado acerca del vínculo entre opinión pública e investigación científica. Así, Kitcher avanza en algún tipo de diseño institucional para dar cuenta del vínculo que deberían mantener las prácticas científicas y la sociedad en la que se inscriben. En este marco, la tarea de investigación será analizar los alcances y límites de la propuesta de Kitcher a la luz del marco teórico deweyano.

Finalmente, Echeverría $(1995,2002,2003,2011)$ y Olivé $(2000,2007)$ recuperan la discusión respecto del ideal de ciencia libre de valores y avanzan en la elaboración de un sentido axiológico de la racionalidad que, a mi juicio, es ciertamente compatible con algunos rasgos centrales del modelo pragmatista de racionalidad, según lo describe José Miguel Esteban (2006). En este marco, la contribución más importante de la axiología de la ciencia y de la tecno-ciencia es vincular de modo integral los valores relativos a la producción de conocimiento con los valores que rigen la actividad económica, política o social, es decir, iniciar la discusión por los valores y fines de la actividad (tecno)científica en un sentido práctico y por ello mismo político. Al respecto Olivé afirma que "[p]ara comprender la dimensión política en la ciencia, entonces, es necesario no reducir la ciencia a sus productos, los conocimientos científicos, sino entenderla como un complejo sistema de prácticas y de instituciones que tienen una estructura normativo-valorativa cuyo objetivo principal es la producción de conocimiento y donde los agentes intencionales que generan ese conocimiento son centrales." (2007, p. 128). 
Dado este breve estado de la cuestión, resulta importante observar que los estudios sobre filosofía política del conocimiento suponen algunas revisiones teóricas en relación a la estructura conceptual de la versión standard de la filosofía de la ciencia: (i) modificar la unidad de análisis, vale decir, dejar de pensar a la ciencia en términos de enunciados y teorías para pensarla como actividad o práctica, la cual incluye no sólo la consideración del científico como un agente que toma decisiones en el curso de la investigación sino también a las instituciones científicas; (ii) modificar la distinción dicotómica entre contexto de justificación y contexto de descubrimiento; y (iii) desarticular la diferenciación entre valores epistémicos propios del contexto de justificación y valores extra-epistémicos propios del contexto de descubrimiento, aplicación y enseñanza. De acuerdo con la lectura que aquí sugiero, tales reconsideraciones teóricas se hacen sobre la base de algunas "jugadas filosóficas" de fondo: (i) modificar la interpretación del conocimiento como contemplación y entenderlo como una forma de la acción para la resolución progresiva de problemas, siempre inscripta en un contexto o ámbito mayor; (ii) desmontar los dualismos teoría y práctica, hecho y valor, justificación y descubrimiento, validez y génesis o epistémico-extra-epistémico; (iii) ofrecer una concepción de los valores que no los reduzca a una mera preferencia subjetiva ni los asocie al dogmatismo sino que los considere como resultado de una elaboración reflexiva o deliberación debidamente fundamentada; y (iv) dar lugar a un modelo de investigación que contemple la dimensión valorativa como constitutiva y que habilite la discusión por los fines de la práctica científica y por los valores que la orientan. Según he intentado mostrar en las primeras dos partes del estudio, la filosofia de Dewey efectivamente realiza esos movimientos y, por tanto, puede aportar herramientas teóricas muy interesantes para dar cuenta de estos puntos y para sustentar algunas posiciones que forman parte del debate en torno a la dimensión valorativa y especialmente política de la práctica científica. A continuación, pues, avanzaré sobre estas consideraciones. 


\section{CAPÍTULO 7: HEATHER DOUGLAS Y SU RECHAZO AL IDEAL}

\section{Introducción}

Siguiendo el mapa presentado en los comentarios precedentes, una de las partícipes más activas en la discusión sobre el ideal de ciencia libre de valores es Heather Douglas. El punto de partida de Douglas es el reconocimiento de la centralidad de las investigaciones científicas para el diseño de políticas públicas y la pregunta por la confianza que puede inspirar la ciencia para el asesoramiento en dicho diseño. Frente a la respuesta más “intuitiva" según la cual el mejor modo de asegurar esa confianza pasa por alejar a la ciencia de las cuestiones políticas, sociales y/o morales y conservar una pretendida neutralidad valorativa, el objetivo de la autora es articular una nueva visión para la ciencia capaz de incluir la dimensión ética y social y, a su vez, de preservar la legitimidad del conocimiento científico al momento de asesorar en política pública.

La postura de Douglas frente al ideal de ciencia libre de valores no se restringe a señalar que es inalcanzable [unattainable] o insostenible [untenable] sino también a calificarlo como un ideal malo que en ciertos casos conduce a una visión inaceptable de la ciencia. La autora también afirma que los valores tradicionalmente denominados no epistémicos son necesarios para un buen razonamiento en ciencia (Cf. Douglas en Kincaid et al., 2007, pp. 121-122). A la luz de esta declaración inicial y teniendo en cuenta el planteo de Lacey por el cual aún en su incumplimiento efectivo el ideal funge como valorguía de las prácticas científicas (1999, p. 18. Cf. Supra), parecería que Douglas tiene una tarea triple: (i) explicar por qué el ideal es inalcanzable o insostenible; (ii) explicar por qué es un ideal malo, es decir, por qué debería rechazarse; y finalmente (iii) explicar por qué el buen razonamiento en ciencia requiere de valores tradicionalmente denominados no epistémicos en su desarrollo. El argumento general de Douglas se apoya en algunas consideraciones de índole netamente epistémicas: por un lado, toda investigación tiene un margen de incertidumbre e implica un vacío inductivo que debe ser saldado; por otro lado, toda investigación empleada para el diseño de políticas públicas supone, por definición, consecuencias que exceden al ámbito propiamente epistémico. En este marco, si la investigación incluye riesgo de consecuencias no epistémicas entonces debe incluir 
legítimamente valores no epistémicos, vale decir, éticos y sociales, para la ponderación de esas mismas consecuencias.

Esta consideración conduce a dos cuestiones ulteriores. En primer lugar, es necesario determinar qué tipo de incidencia valorativa resulta admisible o legítima en el curso de la investigación. Para ello la autora distingue entre instancias externas e internas de la investigación y entre roles directo e indirecto de los valores, al tiempo que arguye que las instancias externas (entre ellas, la definición del tema o problema de la investigación y la metodología a emplear) admiten un rol directo de valores cognitivos, éticos y sociales mientras que las instancias internas sólo admiten un rol indirecto. En segundo lugar, es necesario considerar el impacto de este nuevo ideal sobre la concepción de objetividad científica, cara a las versiones standard de la filosofía de la ciencia. Así, Douglas identifica hasta siete sentidos de objetividad compatibles con la admisión de la dimensión valorativa en la propia investigación.

En este contexto, en el presente capítulo busco analizar el planteo de Douglas a la luz del marco teórico deweyano. En las secciones 2-4 propongo reconstruir los argumentos centrales de Douglas: su desafío al ideal, su noción de "terreno moral" de la ciencia y su posición en torno a la estructura y los roles de los valores en la investigación junto con los diversos sentidos de objetividad. Por su parte, en la sección 5 intento identificar las continuidades y divergencias entre su perspectiva y la de Dewey. A ese respecto me interesa señalar que Douglas recupera explícitamente el concepto deweyano de público y que sus propuestas de diseño institucional para alentar la participación ciudadana en algunas esferas de la investigación científica bien pueden leerse en continuidad con la posición del propio Dewey elaborada en La opinión pública y sus problemas y analizada en el capítulo precedente. No obstante, entiendo que hay algunas tensiones en el argumento de Douglas generadas por su concepción de valor en cuanto expresión de deseos y por su concepción estrecha de investigación en cuanto explicación empírica del mundo, visiones ambas que parecen arrojarla a alguna forma de dualismo hecho/valor que se torna contradictoria con algunas de sus afirmaciones centrales -entre ellas, que los valores y la evidencia aparecen inextricablemente entremezclados- y que la obligan a introducir las restricciones del rol indirecto de los valores para salvaguardar una pretendida integridad de 
la ciencia, de modo que reeditaría posiciones generalmente asociadas al ideal de ciencia libre de valores.

Frente a esto, arguyo que adoptar la visión deweyana de los valores en cuanto fin a la vista generalizado resultante de un proceso de investigación exime de la necesidad de introducir roles directos e indirectos pues se supera la dicotomía entre hechos "objetivos" y valores "subjetivos", al tiempo que da lugar a la propuesta de Douglas de que los científicos efectivamente pongan en discusión pública qué valores emplearon para tomar determinadas decisiones a lo largo de la investigación. Asimismo, sostengo la visión deweyana de la investigación como resolución de problemas, cuya lógica incluye por igual aquello que Douglas denomina aspectos externos e internos de la ciencia, supera la necesidad de preservar algún ámbito de la investigación de la incidencia de valores, explica por qué las consecuencias extra-epistémicas de la investigación son ellas mismas asunto de quienes investigan, da cuenta cabalmente de las continuidades entre ciencia y política, eje central del planteo de Douglas y, finalmente, muestra la vigencia de los aportes deweyanos.

\section{El triple desafío al ideal}

Siguiendo el análisis de Longino (1990, pp. 83-86) Douglas reconoce un sentido de exterioridad de la ciencia para el cual los valores no epistémicos operan legítimamente cuando es el momento de decidir sobre (i) la selección de problemas a perseguir, (ii) el uso directo del conocimiento científico en la sociedad y (iii) las limitaciones en las opciones metodológicas, como por ejemplo la experimentación en seres humanos o en animales. Cada una de estas tres etapas involucra valores no epistémicos porque incluye consideraciones sobre las consecuencias directas e intencionales de cualquier curso de acción en particular. Sin embargo, Douglas apunta que este modelo no es suficiente para desafiar las suposiciones clásicas sobre el papel de los valores en la ciencia pues se limita a su "periferia" y no incluye valores no epistémicos en el nivel de razonamiento científico aquel al que refiere el ideal de ciencia libre de valores, según quedó indicado en los comentarios preliminares (Cf. Douglas, 2000, pp. 563-564).

La tarea inicial de Douglas es explicar por qué el ideal de ciencia libre de valores es insostenible y, más aún, un mal ideal. Estas afirmaciones encuentran su punto de partida en 
lo que Douglas denomina "el triple desafío" al ideal: a su juicio, el ideal puede ser cuestionado desde varias perspectivas que, lejos de concebirse como estrictamente separadas, deberían verse como solidarias - sin perjuicio de que cada una de ellas apunte hacia direcciones diferentes (Cf. Douglas, 2016, pp. 3-8). El primer desafío es el desafío descriptivo. Como he adelantado, hacia la década de 1980 filósofas feministas de la ciencia señalaron que incluso las investigaciones tomadas como ejemplo de "buena ciencia" están cargadas de valores en aspectos centrales de modo que muchas de ellas cumplen con los requisitos epistémicos respecto de la recopilación de evidencia o el procedimiento de inferencia pero continúan arrojando resultados abierta e incluso "descaradamente" [blatantly] sexistas. Estos resultados dan la pauta de que hay muchos presupuestos que imposibilitan concebir explicaciones alternativas de ciertos fenómenos y, consecuentemente, que tienden a dar por comprobadas hipótesis que luego se muestran inadecuadas. El punto central de Douglas es señalar la dificultad transversal para eliminar los valores del proceso científico y los resultados obtenidos: sólo se pueden testear aquellas teorías que se tienen a disposición utilizando asunciones contextuales y ambos elementos, en opinión de Douglas, reflejan los valores de quienes investigan.

Esta línea de argumento también está vinculada a la tesis de la subdeterminación de la teoría por la evidencia disponible, vale decir, a la tesis por la cual la evidencia no es suficiente para definir qué afirmaciones son adecuadas, para garantizar que las alternativas dispuestas son todas las alternativas plausibles ni para dar cuenta de las asunciones contextuales de la investigación. No obstante, señala Douglas, efectivamente se hacen afirmaciones con pretensión científica, de modo que el vacío [gap] entre teoría y evidencia ha de ser saldado de alguna u otra forma. El reconocimiento de ese vacío y de que aun así hay afirmaciones científicas permite advertir que aquel es "completado" o saldado por ciertos valores. Esta es precisamente la idea que condujo a las epistemólogas feministas a señalar que si las asunciones contextuales generalmente encubren valores sociales muchas veces utilizados para sortear el vacío entre teoría y evidencia, entonces es fundamental descubrir esos valores y generar asunciones contextuales con mejores valores -que en la perspectiva feminista incluye necesariamente valores relativos a la diversidad, tanto respecto de la estructura de las comunidades científicas como de las condiciones sociales amplias del conocimiento científico. Dicho de manera simple, cualquier inferencia cuyas 
premisas están cargadas de prejuicios sólo puede arrojar conclusiones igualmente cargadas de prejuicios, por lo cual una revisión crítica de estos últimos se torna indispensable. En razón de lo dicho el desafío descriptivo queda formulado de la siguiente manera: la ciencia, aun si fuera guiada por una "buena" lógica deductiva (y en ese sentido fuera well-done science) no está libre de valores. Luego, el ideal se torna irrelevante.

Estrechamente vinculado al cuestionamiento descriptivo aparece el segundo desafío, denominado el desafío de los límites [boundary challenge]. El punto de apoyo de esta crítica es la dificultad de hacer una distinción clara entre valores epistémicos y no epistémicos, esto es, entre los valores que se permiten y no se permiten en la instancia de justificación o validación y de elección de teorías. De acuerdo con Douglas, si esta distinción no logra mantenerse con claridad, el ideal de ciencia libre de valores colapsaría pues no se podría sostener su asunción principal, a saber, la identificación de los valores aceptables con los valores epistémicos. En esta línea la autora señala dos elementos relevantes: en primer lugar, afirma que hay cierta porosidad entre los valores epistémicos y no epistémicos. En efecto, en incontables ocasiones los primeros terminan reflejando a los segundos de forma que éstos tienen cierta incidencia "codificada" en el ámbito constitutivo o epistémico en tanto sirven como guías o marcos para las elecciones epistémicas. Así sucede, por ejemplo, con la influencia de algunos presupuestos teológicos respecto del rol del azar en el universo que subyacen al debate entre Niels Bohr y Albert Einstein acerca de la física cuántica. ${ }^{91}$ Teniendo en cuenta esta suerte de mediación, es plausible considerar que algunos valores no epistémicos adquieren roles epistémicos. Luego, si los valores no epistémicos moldean a los valores epistémicos e influyen en la ciencia, entonces la demarcación estricta entre ambos parece desdibujarse y por lo tanto también parece desdibujarse el planteo acerca de valores aceptables e inaceptables en ciencia, piedra de toque del ideal. Aquí podría tomar lugar el argumento elaborado en clave deweyana acerca del contexto y particularmente de la tradición pues la incidencia de valores no epistémicos

\footnotetext{
${ }^{91}$ Douglas recupera la expresión "codificado" [encoded] y el análisis del debate entre Bohr y Einsten de Rooney (1992, pp. 15-16), quien a su vez se apoya en la tesis de Ernan McMullin acerca de que ciertas creencias o asunciones metafísicas pueden servir como "valores epistémicos no-standard" en determinados contextos.
} 
o la porosidad, en términos de Douglas, queda explicada precisamente por la continuidad entre contexto e investigación (Cf. Douglas, 2009, pp. 90-91).

En segundo lugar, Douglas sostiene que otro de los límites más difíciles de mantener, aún si se quisiera, es aquel entre ciencia y política, especialmente cuando se trata de asuntos de asesoramiento científico para el diseño de políticas públicas [policymaking]. Permítaseme recordar que uno de los puntos de inflexión para la constitución del ideal de ciencia libre de valores fue la presión gubernamental estadounidense para elaborar un perfil de científico apolítico tal que permita legitimar, por omisión, las pretensiones militares y expansivas basadas precisamente en investigaciones científicas. A esta estrategia debe agregársele el reconocimiento de la enorme utilidad que tiene la ciencia, especialmente en épocas de guerra (ya se ha hecho referencia a la bomba atómica como ejemplo paradigmático pero también se deben mencionar el radar de onda corta o la penicilina, entre otros). En este marco, y sumada la influencia del ya referido informe de Bush, la política estadounidense del período 1945-1965 estuvo considerablemente apoyada en el consejo científico y este último resguardado siempre por el ideal de ciencia libre de valores.

Ahora bien, la aparición de disputas entre científicos en torno al financiamiento, la ampliación de los temas sobre los que resultaría necesario el consejo científico y el clima de descreimiento en la política durante la década de 1960 (que incluyó a la ciencia como su consejera) pusieron sobre la mesa la necesidad de restablecer algunos límites fuertes. Así cobró forma la distinción procedimental entre "evaluación del riesgo" y "manejo del riesgo", pensada para defender cierta integridad de la ciencia y distinguir las funciones de la ciencia y la política en algunas decisiones. No obstante, como indicaré más adelante, la dificultad para mantener esa distinción y para separar taxativamente los ámbitos de incumbencia de la ciencia y de la política permiten concluir que establecer y mantener los límites entre valores tradicionalmente denominados epistémicos y no epistémicos es cuanto menos una tarea compleja (Cf. Douglas, 2004).

El tercer desafío es el desafío normativo, referido al ideal en cuanto ideal. Según Douglas, si los cuestionamientos normativos resultan acertados, el ideal debería quedar definitivamente descartado. Douglas identifica tres bases distintas para sostener su crítica. Por un lado, la incertidumbre endémica del conocimiento científico, que da lugar a un vacío inductivo en cada afirmación científica y a un riesgo inductivo que acompaña todas las 
decisiones. Por otro lado, la responsabilidad de los científicos, habida cuenta de que la autoridad epistémica de la ciencia para la sociedad es generalmente reconocida y a la vez normativamente deseada. En este sentido, dado que los científicos no hacen ciencia para ellos solos sino para la sociedad en la que se inscriben y de la que, en muchos casos, reciben fondos públicos, y dado que tienen autoridad epistémica prima facie sobre sus áreas de investigación, adquieren un tipo particular de responsabilidad y deben ponderar las consecuencias de sus errores -errores de los que nunca estarán absolutamente exentos, dado el riesgo inductivo endémico de la propia práctica científica. La tercera base es la poca adaptabilidad del ideal de ciencia libre de valores a situaciones distintas. En efecto, si en ciertas oportunidades el ideal es demasiado restrictivo al excluir consideraciones valorativas, especialmente en aquellos casos complejos en los que no se contempla la incidencia de otros valores más que los tradicionalmente denominados epistémicos, en otras oportunidades es demasiado flexible pues habilita que ciertos valores epistémicos adquieran un rol preeminente y directo en distintas instancias en las que no deberían hacerlo, por ejemplo durante la interpretación de evidencia: "no queremos -señala Douglas- que los científicos rechacen teorías sólo porque no son simples, o no tan amplias como sus competidoras, o porque parecen tener menos capacidad explicativa.” (2009, p. 103).

Como puede advertirse, la segunda y tercera dimensión del desafío al ideal requiere algunas explicaciones ulteriores. En la próxima sección detallaré esas cuestiones y señalaré por qué Douglas rechaza el ideal de ciencia libre de valores, mientras que en una sección subsiguiente analizaré la propuesta de Douglas respecto de la estructura de los valores en ciencia, intentando trazar algunos vínculos con el marco teórico de Dewey.

\section{Rechazando el ideal: riesgo inductivo y terreno moral de la ciencia}

En virtud de avanzar en la discusión sobre los valores no epistémicos dentro del razonamiento científico y de explicitar las razones por las que el ideal de ciencia libre de valores es un mal ideal resulta interesante recuperar las referencias hechas por Douglas a la noción de riesgo inductivo formulada por Carl Hempel (1965). En pocas palabras, el riesgo inductivo es la posibilidad de equivocarse o, más precisamente, el riesgo de error al aceptar o rechazar una hipótesis científica. Cuando los científicos aplican reglas de aceptación a 
hipótesis específicas se encuentran frente a cuatro posibilidades principales: (i) aceptar una hipótesis verdadera, (ii) rechazar una hipótesis falsa, (iii) aceptar una hipótesis falsa y (iv) rechazar una hipótesis verdadera. Luego, es absolutamente importante formular reglas o criterios adecuados para sopesar las consecuencias de los errores al aceptar o rechazar la hipótesis, es decir, para considerar los casos (iii) y (iv).

Según Douglas, es posible implementar esta noción de riesgo inductivo en las tres etapas principales del procedimiento científico: elección de la metodología, recopilación y caracterización de la evidencia e interpretación de los datos. En la medida en que los científicos podrían tomar decisiones equivocadas y propiciar consecuencias indeseables en cada nivel, el concepto de riesgo inductivo podría considerarse no solo con respecto a las hipótesis sino también con respecto a las etapas mencionadas anteriormente. Un ejemplo claro de este tipo de ponderaciones es la decisión respecto de qué niveles de error se tolerará o qué tipo de errores se permitirán, es decir, cómo balancear los falsos positivos y falsos negativos, todo ello en vistas a la subsiguiente elaboración de un criterio de significancia estadística. Obtener un equilibrio apropiado depende de cómo se valoren los efectos de ambas consecuencias y cuál se considere más importante de evitar (Cf. Douglas, 2000, p. 565-569). Asimismo, las consecuencias del error deben ser ellas mismas sopesadas mediante la asignación de determinado valor, de modo que si el riesgo inductivo es intrínseco a la práctica científica, entonces esta primera dimensión valorativa también lo será. Sólo después de esa evaluación sobre las posibilidades y riesgos del error, arguye Douglas, una decisión es ciertamente apropiada. Luego, si bien no son determinantes, los valores adquieren un rol de suma importancia en las decisiones científicas relativas a las instancias previamente señaladas (Cf. Douglas, 2007, p. 123).

A partir de aquí Douglas afirma que "[...] expandiendo lo que consideramos como riesgo inductivo relevante, el rol potencial de los valores no epistémicos también se expande" (2000, p. 565). De hecho, el punto crucial es que cuando la ponderación del riesgo inductivo requiere la consideración de las consecuencias no epistémicas de la investigación, dicha ponderación incluye legítimamente valores no epistémicos en cada uno de los niveles internos de la ciencia en función de determinar los riesgos que se asumen o las decisiones que se toman. Luego, los valores no epistémicos se tornan necesarios para el 
buen razonamiento científico, de modo que ocupan un lugar por derecho y su inclusión es parte de la definición normativa de ciencia. La tesis de Douglas es absolutamente clara:

"[...] los valores no epistémicos son una parte necesaria de los aspectos internos del razonamiento científico para casos en los que el riesgo inductivo incluye el riesgo de consecuencias no epistémicas. En estos casos, la ciencia libre de valores es una ciencia inadecuada; el razonamiento es defectuoso e incompleto. Por lo tanto, el standard normativo debe ser reconsiderado. Para la ciencia que tiene claros impactos no epistémicos, ser 'libre de valores' no es un objetivo loable" (Douglas, 2000, pp. 559-560).

Por supuesto, semejante afirmación no queda exenta de cuestionamientos, algunos de ellos retomados por la propia autora. En primer lugar, bien podría argumentarse que los científicos no deben considerar más que los aspectos internos de la práctica científica y deben desentenderse, por ejemplo, de evaluar las consecuencias de aceptar una teoría inadecuada, conservando así una instancia valorativamente neutral en ciencia (precisamente esa fue la idea de distinguir entre "evaluación del riesgo" y "manejo del riesgo"). En este sentido, el argumento del riesgo inductivo podría incluso reforzar el ideal de ciencia libre de valores no epistémicos: dado que hay posibilidad de error en las instancias de justificación o validación, el científico apela a valores epistémicos para saldar los saltos inductivos y evaluar los riesgos correspondientes, siempre en ese plano. No obstante, señala Douglas, dado que los científicos tienen autoridad en los ámbitos no científicos sobre los que se aplicarán sus investigaciones, suponer que no deberían evaluar las consecuencias de posibles errores es atribuirles cierta a-moralidad que los exime de sus responsabilidades (atribución que es cuestionada por Douglas, según examinaré más adelante). En segundo lugar, podría objetarse el planteo apelando a aquellos casos en los que las consideraciones respecto de las consecuencias del error son menores, inexistentes o triviales, bien porque la incertidumbre es tan baja que apenas puede vislumbrarse la posibilidad del error, bien porque las consecuencias del error son opacas (y no podría pedírsele a quien investiga que las pueda prever con claridad). Sin embargo, estos casos son dos extremos poco representativos de la práctica científica frecuente, en la que hay grados considerables de incertidumbre y en la que es plausible prever las consecuencias del error (Cf. Douglas 2007, p. 123-124). 
Todas estas observaciones dan cuenta del "terreno moral de la ciencia", según lo denomina Douglas (2014). La necesidad de reconsiderar las obligaciones morales de los científicos es una de las consecuencias de haber rechazado el ideal de ciencia libre de valores. Frente al standard clásico de conducta responsable en la investigación (que advierte contra la falsificación, el plagio, las pruebas no consentidas con seres humanos, etc.), la autora recupera el concepto de responsabilidad incluido en la cita precedente e identifica cuatro dimensiones principales para elaborar un análisis completo del tema: (i) las bases de la responsabilidad, (ii) la distinción entre las responsabilidades generales y de rol, (iii) la distinción entre el comportamiento mínimamente aceptable y el ideal, y (iv) la distinción entre responsabilidad individual y colectiva o institucional (Cf. Douglas, 2014, p. 962). Según se sigue de todo el argumento del rechazo al ideal de ciencia libre de valores, quienes hacen ciencia son responsables ante el buen razonamiento científico, ante la comunidad científica y ante la sociedad en un sentido amplio. ${ }^{92}$

Más allá de las consideraciones de cada uno de los puntos, me interesa señalar que las bases de la responsabilidad de quienes hacen ciencia surgen de reconocer el valor de la ciencia para la sociedad pero al mismo tiempo de reconocer que la sociedad presenta otras fuentes de valor que siempre se deben tener en cuenta -tanto por la ciencia como, y fundamentalmente, por la sociedad. En cuanto a la relación entre la ciencia y la sociedad en general, Douglas afirma que es importante respetar tanto los valores generales en la sociedad como el valor de la ciencia, incluyendo, por ejemplo, la posibilidad de restringir cierto tipo de investigaciones si se oponen a los valores políticos o morales de la sociedad en la que se desarrolla o si pueden sentar bases para posteriores desarrollos dañinos (como sucede con las investigaciones dual-use), bajo condición de no dañar el valor general de la ciencia en la sociedad. En suma, las obligaciones y las responsabilidades ante la sociedad en la que se inscribe toda investigación pueden legítimamente generarle restricciones.

La distinción entre responsabilidades generales y responsabilidades de rol también aparece estrechamente ligada con el punto anterior pues intenta aportar claridad a la discusión respecto del rol de quienes hacen ciencia en el marco de sociedades más amplias

\footnotetext{
${ }^{92}$ En su versión original Douglas dice lo siguiente: "I focus on what scientists are resposible to rather than responsable for." (2014, p. 962. Cursivas en el original). He optado por traducir responsable to por "responsable ante" pues eso involucra a otra parte además de quien fuera responsable, y también para diferenciarla de "responsable por o de", expresión más frecuente en español pero que, entiendo, invisibiliza las relaciones entre la investigación y la sociedad que Douglas busca enfatizar.
} 
y en su papel de frecuentes asesores de políticas públicas. Teniendo en cuenta el carácter falible de toda investigación, Douglas considera que la pregunta central al momento de reflexionar respecto de las responsabilidades de los investigadores es la pregunta por si deben tener en cuenta las consecuencias del error de sus consejos. Esta pregunta incluye, en opinión de Douglas, dos aspectos relacionados pero distintos. Por un lado, hay un nivel de responsabilidades generales y comunes a toda persona respecto de prever las consecuencias del error que toda elección deliberada puede generar. En la medida en que esa elección es intencional, la responsabilidad por sus efectos previsibles e incluso por algunos efectos colaterales es, para Douglas, de tipo moral. Por otro lado, las responsabilidades de rol son las que refieren al trabajo del investigador en función del cumplimiento de los objetivos centrales de cualquier investigación, como puede ser la responsabilidad respecto del reporte honesto de datos, de la discusión abierta con pares, de la consideración y evaluación justa de pares, etc. -todas ellas incluidas en lo que Douglas denomina "ética básica de la investigación" (2009, p. 72).

En este contexto, la pregunta crucial es si las responsabilidades de rol tienen algún tipo de prioridad por sobre las responsabilidades generales o si por algún motivo quienes llevan adelante las investigaciones deberían quedar exentos de las responsabilidades generales. Douglas (2009, pp. 71-79) articula dos argumentos. En primer lugar, hay muchos casos en los que la pretendida excepción moral hubiera sido (aún más) dañina para la sociedad en su conjunto. Por ejemplo, en el "test Trinity" de la bomba atómica (Nueva México, 1945) se consideró el riesgo de que se sucediera una reacción en cadena con los elementos constitutivos de la atmósfera tal que acabara con toda vida humana en el planeta. Este riesgo sólo pudo haber sido previsto y su probabilidad sólo pudo haber sido calculada por los científicos que están inmersos en la investigación y que a la vez tienen en consideración los alcances más amplios de las consecuencias del error. En segundo lugar, no parece haber argumentos convincentes para ofrecerles a los científicos algún tipo de excepción moral acerca de la consideración de las consecuencias de su trabajo, en particular si el fundamento del argumento es la supuesta distinción entre emitir juicios empíricos (con todas las salvedades de la expresión) y emitir juicios respecto de la seguridad del procedimiento científico, porque los segundos aparecen con el transcurso mismo de la 
investigación, a la luz de los primeros. En ese sentido las ponderaciones de las consecuencias de los errores no se realizan al final sino durante la investigación, a medida que sus avances abren distintos escenarios con sus respectivos márgenes de tolerancia al riesgo de error. Retomando el ejemplo del "test Trinity", los distintos grados de seguridad que se fueron evaluando en función de los juicios empíricos son ellos mismos la ponderación del riesgo del error, de modo que allí no es posible trazar diferencias netas entre ambos tipos de juicios (más allá de lo que se pudiera postular acerca de cuán deseable es que los investigadores hagan esas evaluaciones, según indica el primer argumento).

En virtud de estos dos argumentos resulta claro que las responsabilidades de rol no reducen, suplantan o anulan sino más amplían las responsabilidades generales, integrándolas en evaluaciones más específicas. En suma, si la responsabilidad moral general se vincula con la ponderación del riesgo de error de nuestras elecciones deliberadas, si el riesgo de error es endémico a la práctica científica y si a niveles de complejidad altos el riesgo sólo puede ser identificado por los propios científicos, entonces tanto las responsabilidades generales como las de rol son necesarias para llevar adelante la investigación de forma correcta (Cf. Douglas, 2014, p. 971).

Por el momento he recuperado las razones por las que Douglas plantea que el ideal de ciencia libre de valores es un mal ideal y que quienes investigan deben legítimamente incluir consideraciones morales y sociales en el propio razonamiento científico. Sin embargo, indica Douglas, esta conclusión parcial no es suficiente para saldar el debate sino que es necesario elaborar otro ideal de ciencia que contemple cómo inciden esos valores sociales y morales sin que ello implique parcialidad o pérdida de objetividad. El próximo apartado estará dedicado, entonces, a examinar el nuevo ideal y las consideraciones de la autora acerca del renovado sentido de objetividad científica.

\section{La estructura de los valores en ciencia}

\subsection{Roles directo e indirecto de los valores}

Según he indicado con anterioridad, Douglas reinterpreta el ideal de ciencia libre de valores en términos de valores aceptados o no aceptados en el contexto de justificación de las teorías. Ahora bien, el argumento de la porosidad de los límites entre valores epistémicos y extra-epistémicos lleva a una "comprensión fluida de las categorías", según 
refiere Douglas, y por tanto es necesario elaborar un criterio distinto apelando ya no al tipo de valores que se acepta en la práctica científica sino al rol que juegan en las distintas instancias de la investigación (2009, p. 92).

En este punto vale una aclaración preliminar: si bien el énfasis queda efectivamente puesto en la diferenciación de roles, Douglas también hace ciertas observaciones respecto del tipo de valores cuando señala que prefiere dejar de lado la categoría de valores epistémicos en favor de valores cognitivos. Según arguye la autora, los valores epistémicos no son valores sino más bien criterios básicos que cualquier investigador debe cumplir, de modo que no intervienen al momento de decidir. Los valores cognitivos son aquellos que ayudan o asisten al proceso de cognición en ciencia y precisamente por su rol de guía actúan como valores. Por su parte, los valores morales o éticos son los que refieren a lo bueno o correcto al momento de considerar las consecuencias del error, mientras que los valores sociales se vinculan con lo que cierta sociedad valora de hecho, como por ejemplo la justicia, la privacidad, la libertad, la innovación, etc. (Cf. Douglas, 2009, pp. 92-95).

El nuevo criterio propuesto por Douglas se apoya en la distinción entre rol directo e indirecto de los valores en ciencia. En su rol directo, los valores actúan como razones que determinan por sí mismos las decisiones en el curso de la investigación. En su rol indirecto, los valores actúan para sopesar la importancia de la incertidumbre en relación a la afirmación que se analiza o a la decisión que se toma pero no determinan la decisión por sí solos. Lo particularmente interesante es que los tres tipos de valores -cognitivos, morales y sociales- pueden tener incidencia directa o indirecta en todas las instancias de la investigación, de modo que el desafío central pasa por mantener cierto tipo de límites, en especial acerca del rol directo de los valores en ciencia.

Las etapas iniciales de la investigación, incluyendo la decisión de qué tema o problema abordar, qué investigación financiar con recursos públicos o qué metodología aplicar admiten una incidencia directa de valores. Por citar dos ejemplos, la decisión de financiar un proyecto que estudie y busque ampliar la eficacia de las células fotovoltaicas bien puede estar apoyada en consideraciones respecto de la importancia económica, social y política de mejorar la capacidad de producción energética de un país, o la decisión de no experimentar con pesticidas en seres humanos, aun cuando voluntarios, más allá de los 
posibles avances cognitivos que ello podría generar, puede estar apoyada en consideraciones de índole moral. En este sentido, más allá de los conflictos que puede haber entre los tres tipos de valores -el segundo ejemplo es un caso citado con frecuencia para señalar esta cuestión- la decisión es finalmente tomada a partir de las razones ofrecidas por esos valores, es decir a partir de su incidencia directa.

Por supuesto, esto no implica que toda incidencia directa de valores en las etapas iniciales de la investigación sea aceptable. Por ejemplo, seleccionar un problema y una metodología determinados cuya combinación predetermine el resultado de la propia investigación o permitir que presupuestos sexistas definan el criterio de inclusión o exclusión en las comunidades científicas son algunas de las restricciones que deberían tenerse en cuenta al momento de considerar la incidencia directa de valores en la etapa inicial de la investigación. En suma, resulta claro que algún tipo de rol directo es aceptable, que todo el espectro de valores es relevante y que permitir su incidencia directa no debe socavar el valor de la propia ciencia en cuanto producción de conocimiento confiable. Esto último se evidencia aún más si se considera el rol directo en el núcleo de la actividad, v. g. la caracterización de los datos, la interpretación de la evidencia y la aceptación o rechazo de teorías. En estas instancias la autora es taxativa: "Si permitimos que los valores tengan un rol directo en estas decisiones científicas, estaríamos causando daño al propio valor de la ciencia, a la razón por la que hacemos ciencia [...] Si nos importa el conocimiento confiable, entonces los valores no pueden tener un rol directo en aquellas decisiones que surgen una vez que el estudio está en desarrollo.” (Douglas, 2009, p. 102).

El rol indirecto de los valores busca entonces morigerar esta incidencia directa en el desarrollo de la investigación, incidencia que según Douglas minaría el valor mismo de la práctica científica. La apelación a valores cognitivos, morales y sociales se vincula con el análisis respecto de la suficiencia de la evidencia, de la evaluación de la incertidumbre y de las consecuencias del error pero siempre circunscripto a su rol indirecto, particularmente en lo que refiere a las afirmaciones empíricas [empirical claims] en base a la evidencia disponible. Douglas prueba sus argumentaciones analizando distintas investigaciones científicas, en su mayoría relacionadas al ámbito de la medicina, con el objetivo de señalar la importancia de las evaluaciones sobre el posible error tanto a nivel de caracterización de la evidencia como de interpretación de resultados y de señalar, además, cuán necesaria y 
legítima se torna la incorporación de valores tradicionalmente denominados no epistémicos en esas mismas ponderaciones, dadas las consecuencias no epistémicas de la investigación. $\mathrm{Al}$ respecto, me interesa recuperar el estudio sobre desarrollo de tumores cancerígenos en ratas desarrollado hacia 1978 y empleado para establecer políticas de regulación de dioxinas en Estados Unidos (Cf. Douglas, 2000, pp. 569-572; 2007, pp. 124-125). Brevemente explicada, la investigación consistió en exponer ratas de laboratorio a distintos niveles de dioxinas durante dos años, practicar disecciones, hacer autopsias para analizar los tejidos del hígado, determinar si contenían tumores y, en tal caso, si eran benignos o malignos. El punto es que durante los siguientes 14 años esos mismos tejidos fueron evaluados sucesivamente por distintos grupos de científicos, cuyas conclusiones fueron notoriamente distintas. Estas discrepancias ofrecen ya un primer elemento relevante: no hay consenso respecto de qué cuenta como cáncer de hígado en las ratas, vale decir, no hay consenso respecto de cómo caracterizar la evidencia e interpretar sus resultados.

Asimismo, de esa caracterización de evidencia e interpretación de los resultados se siguen determinadas actitudes de tolerancia del error y sus respectivas regulaciones. Respecto de esa investigación particular, el falso negativo, es decir no caracterizar un caso de cáncer cuando efectivamente lo es, implica considerar que las dioxinas no son potenciales cancerígenos y proponer regulaciones más flexibles sobre la calidad del agua. El falso positivo, por su parte, implica reconocer a las dioxinas como potenciales cancerígenos y proponer regulaciones más estrictas, caras y difíciles de emplear. Además, se debe tener en consideración la correlación entre toxicidad y aparición de cáncer, que en muchos casos no aparece como una causación necesaria. Bajo todas estas consideraciones, elaborar un nivel de significancia estadística permitirá establecer el balance entre falsos positivos y negativos en función de cómo se valoren cada una de estas alternativas. Finalmente, y atendiendo a que la pregunta por qué consecuencias o errores es preferible evitar implica consideraciones no epistémicas, pues muchas de sus consecuencias son relevantes en otros ámbitos más allá de la propia investigación, queda claro que sopesar todas las posibles consecuencias de error y cursos de acción alternativos supone incluir valores extra-epistémicos morales y sociales, siguiendo la clasificación de Douglas. En la medida en que la caracterización e interpretación de la evidencia y la decisión respecto de 
la suficiencia de la evidencia para sostener una hipótesis incluye la incidencia indirecta de valores sociales o morales, entonces la instancia de elección entre hipótesis o teorías alternativas también la incluirá.

Sin embargo, aun cuando la ponderación valorativa sea necesaria, en todos estos casos la incidencia de valores debe seguir siendo indirecta pues tienen un rol que cumplir sólo en razón de la incertidumbre endémica del conocimiento científico. Esta suerte de cláusula se aplica también a los valores cognitivos (recuérdese que Douglas los diferencia de los valores epistémicos) pues por sí solos ellos tampoco son razones para caracterizar de determinada manera a la evidencia o para aceptar una teoría sino que son de ayuda para mitigar la incertidumbre en el largo plazo de la investigación. En términos concretos, la simplicidad, el alcance, la capacidad explicativa, la precisión o la capacidad predictiva no alcanzan para definir la aceptación o rechazo de una teoría pero ayudan a trabajar con esa teoría, a desarrollarla y eventualmente a identificar sus aspectos más deficitarios. Luego, los científicos deben considerarlos no por ellos mismos sino por las incertidumbres propias del conocimiento científico, todo ello en favor de mitigar dichas incertidumbres en el mediano o largo plazo de la investigación (Cf. Douglas, 2009, pp. 103-108).

Este tipo de casos también ilustra las dificultades para distinguir cabalmente entre "evaluación del riesgo" como prerrogativa exclusivamente científica y valorativamente neutral y "manejo del riesgo" como cuestión exclusivamente política -argumento propio de quienes aún replican que los científicos no tienen que involucrarse en juicios de valor no epistémicos y que se los debe dispensar de la obligación de considerar el manejo de las consecuencias, dejando ese análisis en manos de la política. La estrecha relación entre cómo se caracteriza e interpreta la evidencia y los cursos de acción alternativos subsiguientes hace que los límites entre ambas incumbencias se difuminen y que se torne necesaria la incorporación de valores no epistémicos en la consideración del riesgo. Más aún, las investigaciones pocas veces remiten sólo a "hechos" sino que generalmente ofrecen interpretaciones igualmente cargada de valores y asunciones contextuales. En estos términos, Douglas afirma que

\footnotetext{
“[...] si queremos que los científicos tengan las mismas responsabilidades que tenemos el resto de nosotros, los juicios necesarios para hacer ciencia no pueden escapar de la consideración de consecuencias potenciales, tanto previstas como imprevistas, tanto
} 
epistémicamente relevantes como socialmente relevantes. [...] Evidencia y valores son

cosas diferentes, pero se vuelven inextricablemente entremezcladas en nuestras explicaciones del mundo." (2007, p. 126. Cursivas en el original).

De esta manera, no es posible eximir a los científicos de las consideraciones valorativas en las afirmaciones empíricas porque (i) la aplicación de sus investigaciones requiere de sus interpretaciones, siempre atravesadas por valores y asunciones contextuales; (ii) la ponderación de las consecuencias no se realiza una vez finalizada la investigación sino que son parte integral de todo el proceso pues en todo el proceso se toman decisiones, según puede verse con el ejemplo sobre la aparición de tumores en ratas; y especialmente (iii) delegar las valoraciones significaría atentar seriamente contra la autonomía de los científicos y contra la actividad reflexiva respecto de las consecuencias de la investigación. No obstante, Douglas indica que una vez iniciado el curso de investigación, esa valoración debe apelar a un rol indirecto de los valores cognitivos, éticos y sociales pues el rol directo violaría las prácticas de buen razonamiento orientadas a la obtención de conocimiento confiables acerca del mundo y daría lugar a una "ciencia politizada". En consecuencia, "[t]oda ciencia está cargada de valores. Pero la ciencia politizada, inaceptable, ocurre cuando se permite que los valores dirijan las afirmaciones empíricas hechas por los científicos. [...] Distinguiendo entre roles directo e indirecto para los valores, la integridad fundamental de la ciencia se mantiene protegida." (Douglas, 2009, p. 113).

\subsection{Implicaciones para el sentido de objetividad cientifica}

La cita precedente permite introducir una última cuestión relevante, a saber: las consecuencias que tiene rechazar el ideal de ciencia libre de valores en el concepto de objetividad científica, habida cuenta de que la versión standard de la filosofía de la ciencia busca equiparar objetividad con libertad valorativa en ciencia. El objetivo de Douglas es sostener que no hay relación necesaria entre objetividad y libertad valorativa. Para ello la autora reformula el concepto de objetividad de forma que mantenga un rol central a la hora de analizar las prácticas científicas, que no pierda densidad teórica y que observe las conclusiones obtenidas respecto de la responsabilidad moral de los científicos y de los roles directo e indirecto de los valores cognitivos, morales y sociales en la investigación. Así, 
Douglas ofrece siete sentidos distintos de objetividad en los que aquella relación planteada por la versión standard no aparece como una relación necesaria y en los que se incluyen sus indicaciones acerca de la estructura de los valores en la práctica científica (Cf. Douglas en Kincaid et al., 2007, pp. 131-135). ${ }^{93}$

Remitiendo a algunas observaciones de Daston (1992, p. 597-598), Douglas señala que el concepto de objetividad parece referir a la vez al plano metafísico de la "verdad objetiva" de una afirmación, al plano metodológico de los "procedimientos objetivos" que garantizan las conclusiones y al plano valorativo de las "formas o modos objetivos" [objective manner] que cualifican a quienes investigan. Así, "objetivo" puede ser empleado como un sinónimo relativamente vago de factual, confiable, imparcial, racional e incluso real. Frente al carácter multívoco del término, la tarea de precisar sus diferentes matices, alcances y limitaciones se torna urgente. En este contexto Douglas se concentra solamente en aquellos sentidos cuyas definiciones permiten definir operativamente si la existencia de una entidad o la conclusión de una investigación son objetivas, es decir, en las afirmaciones cognitivas. De acuerdo con los términos empleados por Daston, Douglas ubica su análisis en los planos metodológico y valorativo, dejando de lado el plano metafísico, esto es, dejando de lado todas aquellas versiones de la objetividad definidas como independientes de la consideración del sujeto, entre ellas la idea de "ojo de dios" (Cf. Douglas en Kincaid Dupré, \& Wylie, 2007, p. 131.) Los dos primeros sentidos de objetividad se vinculan con las distintas interacciones entre investigador y ambiente durante la propia investigación, vale decir, con los procesos que dan lugar a afirmaciones científicas con pretensión de objetividad. Así, (i) la objetividad manipulable remite a la suficiente aprehensión [sufficiently gotten] de un objeto para emplearlo como instrumento e intervenir exitosamente en el mundo, como el caso de la manipulación genética de ADN para crear animales experimentales -por ejemplo, los ratones fluorescentes producto de la manipulación genética que permite la inserción de proteínas encontradas en cierta especie de medusas en el tejido de los roedores. Por su parte, (ii) la objetividad convergente remite a la aproximación a cierto objeto de conocimiento con distintos métodos independientes a los fines de asegurar la objetividad respecto de las creencias acerca de la existencia del

\footnotetext{
${ }^{93}$ La misma Douglas (en Kincaid et al., 2007, p. 130) señala que desde la década de 1990 se han elaborado múltiples reelaboraciones del concepto de objetividad, señalando que de ninguna manera es un concepto unívoco sino que contiene múltiples sentidos.
} 
objeto o de la confiabilidad de las conclusiones de la investigación (más allá de la posibilidad de cierta convergencia azarosa o de las discusiones en torno a la pretendida independencia de los distintos métodos empleados en cada caso). Ahora bien, en la medida en que estos dos sentidos de objetividad dependen de la confiabilidad de los resultados obtenidos mediante la intervención en los distintos contextos o de la independencia y especificidad de los métodos que convergen en una afirmación, Douglas señala que en ambos casos la objetividad es una cuestión de grados (2009, p. 121).

Los siguientes sentidos de objetividad se concentran en los procesos de investigación o pensamiento principalmente individual. En este espectro podría ubicarse entonces la restricción al empleo directo de valores cognitivos, éticos y sociales como razones en sí mismas para sostener una afirmación empírica. En efecto, (iii) la objetividad distanciada o separada [detached, sigo aquí la traducción de Sánchez García, 2014, p. 194) refiere a la prohibición de utilizar valores en lugar de evidencia, sean personales o grupales, y a la necesidad de reservar el rol indirecto en el análisis general de evidencia en pos de sostener o rechazar afirmaciones empíricas. Lamentablemente, señala Douglas, la concepción de objetividad distanciada aparece estrechamente vinculada con la de libertad valorativa, razón que explica por ejemplo que en las publicaciones científicas no haya menciones a los procesos de toma de decisiones como si eso volviera más objetiva a la investigación, cuando lo que efectivamente sucede es que se ocultan las alternativas y los valores que ayudaron a tomar cada decisión, haciendo que la propia investigación se torne imposible de examinar por sus pares.

En virtud de mantener esa diferencia crucial entre objetividad distanciada y libertad valorativa Douglas añade entonces un nuevo sentido, (iv) la objetividad como neutralidad valorativa, bajo la idea de que la neutralidad no apunta a anular la incidencia de los valores en la investigación sino a mantener una posición inicialmente equidistante entre los valores que puedan entrar en conflicto al momento de decidir qué se debe hacer. Por supuesto, este sentido no es deseable en todos los casos: adoptar un lugar inicialmente imparcial respecto de la incidencia de valores sexistas o racistas en la producción de conocimiento científico no es aceptable, toda vez que ese tipo de posiciones encuentra fuerte rechazo a nivel moral y político. No sucede lo mismo en ciertas discusiones al interior de la investigación que 
reflejan debates sociales no saldados. Para esos casos Douglas considera pertinente mantener este sentido de objetividad como imparcialidad. Estos sentidos (iii) y (iv) de objetividad proveen ciertas bases confiables para el resultado de la investigación sin caer en la afirmación de la libertad valorativa de la ciencia ni en lo que Douglas denomina ciencia politizada, según he mencionado al cierre de la sección precedente.

Los tres sentidos restantes de objetividad se vinculan con asuntos o procesos sociales de la investigación, es decir con el trabajo de los grupos de investigación y particularmente con los procesos empleados para obtener acuerdos respecto de las afirmaciones empíricas. En esta línea, (v) la objetividad procedimental ocurre cuando un proceso es dirimido de tal manera que siempre produce el mismo resultado o que no requiere juicio individual al momento de considerar su corrección, más allá de quien lleve adelante el proceso - este es el caso de los multiple choice tests, en los que por supuesto hay toma de decisiones cuando se los elabora (los valores aparecen codificados en el propio proceso, señala Douglas) pero ya no cuando se corrigen los resultados. Junto con el aspecto procedimental Douglas identifica (vi) la objetividad concordante, cuyo sentido remite a los acuerdos intersubjetivos, sin discusión previa, respecto de una descripción de una experimentación o de un juicio respecto de un evento. Huelga aclarar que esta objetividad concordante sin discusión ocurre en muy pocas oportunidades, de modo que es importante considerar también (vii) la objetividad interactiva, que surge a partir de una discusión llevada adelante por grupos con formación pertinente y apropiadamente constituidos. La discusión aquí es, por supuesto, qué cuenta como formación pertinente, por constitución apropiada y por acuerdo. No obstante la necesidad de aclaraciones ulteriores, hay dos cuestiones que me interesa señalar: en primer término, y retomo aquí un comentario de Gómez, este sentido de objetividad interactiva tal vez sea el más referido por la fílosofía de la ciencia (Cf. 2014, p. 140); en segundo término, Douglas indica que garantizar este último sentido de objetividad implica garantizar la circulación de datos y evidencia, la replicación de experimentación, etc. En sus palabras, de clara resonancia deweyana, "[1]a comunidad abierta de discusión ha sido durante mucho tiempo considerada como crucial para la ciencia.” (Douglas, 2009, p. 128). La misma dirección habían tomado ya las expresiones de Helen Longino (1990, p. 62), para quien “[1]a objetividad de la ciencia está asegurada por el carácter social de la investigación." 


\section{Continuidades, críticas y aportes desde Dewey}

Una vez presentados los argumentos de Douglas respecto de la necesidad de incluir consideraciones valorativas me interesa hacer una lectura a la luz del marco teórico elaborado en las primeras dos partes de la investigación, a efectos de señalar los puntos en común y de indicar las razones por las que el entramado deweyano permitiría superar algunas limitaciones que encuentro en el planteo de Douglas. Desde mi punto de vista, la posición de Douglas acerca de la legitimidad de incluir consideraciones valorativas tradicionalmente denominados no epistémicas en la propia de investigación podría encontrar apoyo en dos puntos centrales desarrollados por Dewey. En primer lugar, si se toma como referencia la distinción entre privado y público ofrecida por el pragmatista, podría señalarse que todo el argumento de Douglas supone que la ciencia es una actividad eminentemente pública dado que sus consecuencias van más allá de la propia investigación. En efecto, el alcance público y a largo plazo de las consecuencias de las investigaciones es precisamente lo que lleva a Douglas a plantear que la valoración de esas consecuencias no se agota en la dimensión epistémica y que es necesario incorporar valores sociales, morales y políticos como componentes legítimos de dichas investigaciones.

En segundo lugar, y estrechamente vinculado con lo anterior, parece haber alguna comprensión compartida respecto del vínculo entre ciencia y política, en el sentido de que tanto Dewey como Douglas entienden que las políticas públicas deben estar informadas por el conocimiento científico porque éste representa el tipo de conocimiento más fiable del que se dispone. Como ha sido señalado, el conocimiento científico es un elemento central para la concepción deweyana de valoración y deliberación (tanto a nivel moral como político) dado que aporta información confiable para la elaboración de juicios evaluativos, base de los juicios valorativos. En efecto, basta recordar que una de las condiciones para el advenimiento de la Gran Comunidad es la plena y libre comunicación de los resultados de las investigaciones para que estas últimas devengan conocimiento en el sentido honorífico del término e informen al público respecto de los asuntos sobre los que se debe expedir. Los argumentos de Douglas corren en esa misma dirección pues asumen que el conocimiento científico es el mejor consejero para la elaboración de políticas públicas y que, consecuentemente, no debería estar libre de valores. Más aún, la autora remite a una 
idea de impronta deweyana, a saber, la continuidad entre los distintos ámbitos de la experiencia dada por su carácter intrínsecamente valorativo. En palabras de Douglas, “[c]ualquier límite, ontológico, procedimental, u otro, que aspire a separar a la ciencia de la política sobre la base de la presencia de valores en la política o la ausencia de valores en ciencia está condenado a fracasar." (Douglas, 2004, p. 240). Esa “condena al fracaso" no es meramente descriptiva sino normativa: en la medida en que esas investigaciones sean empleadas para el diseño de políticas públicas, sus consecuencias indefectiblemente serán de orden no epistémico, hecho que reclama una ponderación mediante valores morales y sociales $-\mathrm{y}$ no solo mediante valores cognitivos.

Entre las escasas menciones de Douglas a Dewey hay dos que vale destacar y que abonan las continuidades identificadas. La primera de ellas es la caracterización que ofrece Douglas de La Opinión Pública y sus Problemas de Dewey como una valiosa excepción frente a la tendencia filosófica de negar o cuanto menos desatender a la reflexión respecto del rol de los expertos en el diseño de políticas públicas. En efecto, Douglas reconoce al pragmatista como un antecedente relevante para su propio argumento acerca de las responsabilidades generales y de rol de los expertos (Cf. 2008, p. 1). La segunda, a mi juicio más significativa que la anterior, se vincula con la relación que propone Douglas entre expertos y público. En un comentario casi marginal Douglas indica que efectivamente retoma el concepto deweyano de público en cuanto conjunto de individuos capaz de organizarse en torno a un interés común tras reconocer que ciertas acciones tendrán consecuencias que lo afectarán de forma indirecta (Douglas, 2005, p. 168, nota 1). El hecho de retomar el concepto deweyano resulta interesante no sólo por el lugar central que le otorga Douglas (de hecho el título del texto que estoy considerando aquí es "Inserting the Public into Science") sino porque la autora articula algunos argumentos que, en mi interpretación, siguen la línea iniciada por Dewey: si se acepta que la actividad científica incluye de forma legítima valores éticos para el análisis de las consecuencias de las investigaciones, entonces surge la pregunta por cuáles y de quiénes [whose] son los valores empleados para ese análisis, pregunta que según la propia autora "invoca el espectro [raises the specter] de la democracia". En sus palabras,

\footnotetext{
“[m]ás allá del ideal teórico de democracia que uno pudiera sostener, no es aceptable que una élite minoritaria imponga sus valores a la población general. Si los científicos pueden
} 
hacer esos juicios en privado, sin explicitarlos en sus publicaciones, y así dar forma a una política pública sin lugar para la rendición de cuentas pública, todo standard de democracia habrá sido violado. Luego, mínimamente, los científicos necesitan ser más explícitos en sus trabajos respecto de los puntos en los que hay juicios valorativos y cómo estos se llevan adelante, incluyendo una discusión de los valores empleados." (Douglas, 2005, p. 156, ambas citas).

Estas demandas de Douglas cuadran muy bien con el argumento de Dewey respecto de tornar públicas a las investigaciones pues, me permito recordar una vez más, hay una conformación recíproca entre ciencia y opinión pública mediada precisamente por una comunicación libre -no sólo en cuanto libre de trabas para hacer circular ideas y valores tenidos de antemano sino en cuanto condición para la elaboración conjunta de ideas y valores. Más aún, Douglas sugiere un punto de notoria impronta deweyana y de gran importancia para la filosofía de la ciencia: quienes hacen ciencia, quienes obtienen datos y caracterizan evidencia, quienes determinan criterios o niveles de aceptabilidad estadística tienen que poner públicamente en discusión sus valores y analizar cuán compatibles son con los valores e intereses compartidos por la comunidad. En este marco, y frente al ideal de objetividad defendido por las élites científicas, intelectuales (y gobernantes, por qué no) que aspira a aislar a las investigaciones de las consideraciones valorativas sociales, morales y políticas, el último sentido de objetividad elaborado por Douglas admitiría una apertura aún mayor: la comunidad abierta de discusión no debe reducirse a la comunidad científica sino a la comunidad política. En esta misma línea Douglas indica que "[...] la ciencia será un lugar de debate y crítica en la medida en que sus implicancias sean relevantes para el público y para el diseño de políticas. La ciencia no es un mecanismo para producir acuerdos o unanimidad en el público. La ciencia es un recurso para el debate y un recurso para imaginar nuestro futuro en el ya complejo ámbito público.” (2017, p. 94).

Por supuesto, abrir la discusión es un primer paso pero no resuelve la cuestión respecto de cuáles y de quiénes son los valores que deberían guiar a la ciencia y a la política basada en la ciencia. En términos ideales habría que detenerse en una deliberación abierta, libre, pública y científicamente informada tal que permita identificar e incluso dar lugar a valores e intereses compartidos que luego serán observados en las investigaciones que dan 
forma a las políticas. No obstante, arguye Douglas, el tiempo y las dificultades que eso implica junto con la urgencia por resolver algunas cuestiones específicas invitan a considerar y proponer modelos de participación del público en los asuntos que conciernen a la dirección de la actividad científica y al empleo de la ciencia para políticas públicas: “[s]i la deliberación es ciertamente necesaria para informar el análisis y el análisis para informar a la deliberación, expertos y ciudadanos necesitan trabajar en contacto directo para afrontar las más complejas preguntas sobre políticas basadas en ciencia. [...] Los elementos analíticos y deliberativos deben estar interconectados.” (Douglas, 2005, p. 157-158).

El objetivo rector es, siempre según Douglas, maximizar la interacción entre expertos y ciudadanos o público. Para ello se debe idear un modelo distinto de aquel en que el público es políticamente activo mediante procesos deliberativos pero no interactúa con ni tiene impacto en el trabajo de los expertos sino que este último aparece ya cerrado de antemano, y también distinto de aquel en que el público apenas delibera y el trabajo de los expertos se lleva delante de forma independiente y no incluye ningún elemento propio de la esfera pública. La propuesta de Douglas es un modelo de "investigación participatoria [participatory]" o "análisis colaborativo", diseño institucional en el que el público pueda orientar las investigaciones en virtud de asegurar que los valores que guían a los análisis técnicos son los apropiados. En estos términos, las ventajas identificadas por Douglas son tres: (i) el público puede ayudar a definir y encuadrar mejor el problema de investigación; (ii) el público puede aportar conocimiento relevante acerca de las condiciones y prácticas específicas y/o locales de la investigación; y especialmente (iii) el público puede incidir en la consideración de qué valores deben orientar o dar forma al análisis, a la luz de todos los argumentos precedentes acerca de la necesidad de incorporar la dimensión ética y social en la actividad científica (Cf. Douglas, 2005, p. 158). Teniendo en cuenta lo afirmado por la propia autora sobre la adopción del concepto de público elaborado por Dewey, la sugerencia de investigación participatoria podría verse como una continuidad del proyecto deweyano para ampliar las bases y fines democráticos de la investigación científica.

Más allá de estas líneas comunes y del reconocimiento explícito de Douglas, desde un punto de vista deweyano considero que hay aspectos de su posición que pueden ser complementados y otros ciertamente cuestionados. En primer lugar, Douglas introduce el concepto de democracia (más aún, el de "espectro de la democracia") sin ninguna precisión 
o consideración ulterior, esto es, asumiendo el valor que pudiera tener la democracia y dando por sentado que la única alternativa a la imposición de valores y decisiones por parte de una élite minoritaria de expertos es precisamente la democracia. Sin embargo, ha sido señalado que la idea misma de democracia presenta una complejidad considerable y que esa complejidad se profundiza todavía más al momento de evaluar sus relaciones con el conocimiento científico. Teniendo en cuenta los puntos comunes ya presentados, podría pensarse que la fundamentación epistémica de la democracia y la fundamentación democrática para la aplicación de la inteligencia a la resolución de los problemas públicos elaborada por Dewey constituye un marco filosófico sólido a partir del cual comprender las elaboraciones de la propia Douglas. En efecto, la centralidad que otorga el pragmatista a la comunicación de las conclusiones de las investigaciones públicamente relevantes tanto para informar como para ser objeto de regulación por parte del público cuadra con el planteo de Douglas acerca de la ciencia como lugar y recurso para el debate más amplio, siempre en favor de fortalecer una relación y constitución bidireccional entre público y expertos (Cf. Douglas, 2017, pp. 85-86).

Ahora bien, hay dos cuestiones centrales del planteo de Douglas que parecen más difíciles de conciliar con el marco deweyano y que, a mi juicio, resultan problemáticas para su propio argumento: (i) qué entiende por valores y (ii) qué entiende por investigación científica. Con respecto al primer punto, una de las pocas definiciones explícitas ofrecidas por la autora reza lo siguiente: "Los valores son declaraciones de normas, objetivos, deseos [...] La prohibición de Hume se mantiene en su efecto: no se puede derivar un debe de un es." (Douglas en Kincaid et al., 2007, p. 126). Aquí aparecen algunos puntos a considerar. Primero, el referido espectro de "normas, objetivos, deseos" es demasiado amplio, de forma que si se pone el énfasis en los valores como declaraciones de deseos sin cualificación ulterior parecería arribarse a una posición subjetivista, mientras que si se pone el énfasis en los valores como declaraciones de normas aquellos parecerían ser una mera repetición de lo dado, sea a nivel institucional o habitual (puesto en términos deweyanos, parecerían ser estimaciones). Segundo, la aclaración posterior sobre la vigencia del planteo de Hume respecto de la incorrección de derivar un debe ser de un es -planteo apoyado en la férrea 
distinción entre cuestiones de hecho y cuestiones de valor, base del denominado "tenedor de Hume"- aleja a Douglas de cualquier posición cognitivista respecto de los valores.

Según mi lectura, esta asunción se evidencia con claridad a lo largo del argumento respecto de los roles directo e indirecto de los valores. Teniendo en cuenta que la idea de limitar la incidencia de valores a un rol indirecto es evitar que los valores dirijan afirmaciones empíricas y así proteger la pretendida integridad de la ciencia, entonces los valores quedan arrojados a un plano cuanto menos no-empírico -llámese subjetivo, en referencia a la definición de valor como declaración de deseos. El punto sería el siguiente: el intento de preservar la integridad de la ciencia parece suponer un "fondo" de hechos que idealmente sería suficiente para determinar todas las cuestiones que fueran necesarias en la dimensión interna de la investigación y que debería ser preservado de la incidencia directa de aspectos subjetivos como parecen ser los valores, so pena de dar lugar a una ciencia politizada (en el sentido negativo del término empleado por la autora). En este marco, queda abierta la pregunta por si la incorporación de la dimensión ética y social en esos aspectos internos de la investigación es sólo por defecto, esto es, por el riesgo inductivo de toda investigación -0 , puesto a la inversa, la pregunta por si Douglas aceptaría la incidencia de valores éticos y sociales en el hipotético caso de absoluta certeza.

Ahora bien, si a la vez se considera que para Douglas valores y evidencia están inextricablemente entremezclados -observación de impronta pragmatista- entonces ese "fondo" de hechos o evidencia no parece tal y el rol de la dimensión valorativa no es tan indirecto como quisiera la autora. Como contrapartida, en las instancias de definición de los objetivos y de la metodología de la investigación el rol de los valores tampoco es tan directo como parece indicar Douglas, toda vez que esas mismas decisiones también están informadas por investigaciones previas, por proyecciones, esto es, por "hechos". Si esto es así, entonces no resulta claro por qué en esta instancia se admite el rol directo de valores y en las instancias internas no. En definitiva, Douglas parece suponer un dualismo hecho/valor que la conduce a preservar a los primeros de los últimos en determinadas instancias de la investigación, movimiento que parece generar ciertas tensiones en su distinción entre rol directo e indirecto de los valores.

Este último comentario se vincula con el segundo punto señalado: qué entiende la autora por investigación científica. En sus palabras, "[1]a ciencia es una empresa basada en 
la evidencia que busca construir un conocimiento empírico del mundo. Lo hace mediante la propuesta de teorías explicativas que incluyen evidencia disponible y el subsiguiente testeo de esas teorías para potenciar su capacidad [to the best of its ability]." (Douglas, 2017, p. 86). Esta definición parece vincularse con las concepciones más clásicas del conocimiento, en términos de explicación empírica del mundo, y reproduce una visión estrecha de la investigación como elaboración de teorías. Asimismo, esta definición de investigación deja por fuera las dimensiones "externas", esto es, las instancias de definición del objeto de la investigación y de la metodología. En este marco resulta más comprensible que Douglas intente preservar la integridad de la ciencia limitando el rol de los valores y dándole preponderancia a la evidencia factual (más allá de las tensiones anteriormente señaladas). Sin embargo, este movimiento parece conducirla a una posición que aísla a la investigación de su contexto, que privilegia ciertas instancias por sobre otras y que, en suma, busca conservar algún núcleo objetivo e idealmente basado sólo en hechos o evidencia.

¿Qué puede aportar una perspectiva como la de Dewey frente a las tensiones identificadas? Vale recordar aquí el planteo de Anderson (2004, Cf. Supra p. 219), quien señala que el ideal de ciencia libre de valores sólo se sostiene a partir de una noción de valores libres de ciencia (es decir, una noción de valores emparentada al dogmatismo, a la mera preferencia sin razones) y que, entonces, una forma de discutir el propio ideal es reconsiderando la noción misma de valor. ${ }^{94}$ En este marco, la perspectiva deweyana ofrece una concepción del valor y una teoría de la valoración que busca alejarse del dogmatismo, que se muestra muy próxima a lo que reclama Anderson y que, finalmente, podría resolver las tensiones identificadas en el planteo de Douglas. En efecto, la noción de los valores como fines a la vista generalizados e informados por el mejor conocimiento disponible hace caer la contraposición entre esos mismos valores y la evidencia o los hechos. Desde esta perspectiva no habría "hechos" que debieran ser preservados de los valores, como parece suponer la posición de Douglas, de la misma forma que la incorporación de valores no

\footnotetext{
${ }^{94}$ Anderson (1995) elabora una teoría del valor a la que define como "teoría de actitud racional". La autora intenta dar cuenta de su carácter históricamente contingente, socialmente fundado, pluralista y basado en ideales. Si bien un estudio detallado de esta posición queda por fuera del alcance de estas páginas, parece posible afirmar que esa elaboración difiere en algunos puntos de lo que posteriormente planteara acerca del vínculo entre ciencia y valores -en buena medida porque la preocupación de Anderson al momento de proponer una teoría del valor en términos de actitud racional se posa sobre las relaciones entre ética y economía, en el marco de la discusión sobre teorías de elección racional.
} 
deviene un elemento a limitar o resguardar pues estos últimos no son mera expresión de deseos ni vectores del dogmatismo sino resultado de un proceso de investigación o deliberación cuya lógica es estructuralmente análoga a la lógica de la investigación científica. Además, la concepción deweyana es perfectamente compatible con la propuesta de Douglas respecto de hacer públicos y de discutir los propios valores que asumen los científicos al momento de decidir respecto de la suficiencia de la evidencia o de cualquier otro asunto - propuesta difícil de concretar bajo una concepción subjetivista de los valores.

A este punto debe sumarse una visión de la investigación más amplia, en términos de resolución de problemas, que incluye tanto a la determinación del problema como a la recopilación de hechos del caso, a las inferencias controladas y a la resolución efectiva del problema en el curso de experiencia primario. Como he señalado con anterioridad, apoyado en la lectura de Dorstewitz (2011) y de Brown (2012), esta perspectiva más amplia de la investigación permite dejar atrás la idea de que hay instancias de la investigación que deben preservarse más que otras o que hay instancias internas y externas. Además, a diferencia de la idea de investigación como explicación del mundo, esta concepción amplia de investigación como resolución de problemas afirmada sobre la tesis de la continuidad de la experiencia ofrece respaldo a un argumento central para el planteo de Douglas: la dimensión de las consecuencias extra-epistémicas de la ciencia, aquella que justifica la incorporación de valores éticos y sociales. En efecto, inscribir a la investigación en un continuo más amplio permite considerar que sus consecuencias no son externas sino propias de la investigación y que la ponderación de esas mismas consecuencias, con los valores correspondientes, corresponde -también- a quienes la llevan adelante. Dicho de otra forma, una visión deweyana de investigación permite enmarcar mejor los argumentos de Douglas respecto de la responsabilidad de los científicos y de la imposibilidad de establecer límites o fronteras infranqueables entre ciencia y política.

\section{Conclusiones}

A modo de conclusión de lo dicho me interesa señalar tres grandes cuestiones. En primer lugar, considero que el planteo de Douglas incluye aspectos ciertamente loables y de suma relevancia tanto para discutir el ideal de ciencia libre de valores como, y especialmente, para proponer alternativas que den cuenta del funcionamiento de la 
investigación y corran por la senda de la filosofía política de la ciencia. En este sentido, entiendo que el triple desafío al ideal es un punto de partida sólido para señalar las limitaciones de la pretendida libertad valorativa de la ciencia, tanto en términos descriptivos como normativos. Asimismo, la consideración de las consecuencias no epistémicas de las investigaciones científicas contribuye a inscribirlas en contextos de análisis más amplios y a complejizar las consideraciones filosóficas sobre esas mismas investigaciones. Finalmente, el esfuerzo de distinguir distintos sentidos de objetividad y de proponer diseños institucionales en línea con el desarrollo teórico antedicho y con el concepto deweyano de público hacen que la perspectiva de Douglas contemple distintos frentes de argumentación y que se instituya como interlocutora ineludible en el debate sobre el ideal de ciencia libre de valores.

No obstante, también hay ciertas tensiones o limitaciones en la posición de Douglas, enraizadas en su concepción de valor y de investigación. En efecto, y aun cuando la propia autora afirme que la evidencia y los valores están inextricablemente mezclados y que la reflexión sobre la investigación científica admite alguna consideración de su dimensión externa, su argumentación parece suponer un dualismo entre hechos y valores que, sumado a una visión estrecha de la investigación como explicación empírica del mundo, vuelve necesaria la cláusula del rol indirecto de los valores para preservar cierta integridad de la propia ciencia. Si a ello se le agrega que Douglas condiciona la presencia de valores morales y sociales al riesgo inductivo, de forma que aquellos parecen tener un lugar legítimo sólo por defecto, entonces el modelo propuesto por la autora parecería reeditar algunas posiciones cercanas a las que pretende cuestionar.

Ante estos cuestionamientos, entiendo que el marco teórico deweyano podría ofrecer algunos puntos a considerar. En primer lugar, la concepción de valor como fin a la vista generalizado resultante de una investigación o deliberación científicamente informada supera el dualismo hecho/valor y consecuentemente permite incluir a los valores en las investigaciones científicas sin ningún reparo extra. Dicho de otra forma, la perspectiva deweyana de valor no tiene el problema del subjetivismo y por tanto no reclama ningún tipo de consideración sobre su incidencia o rol porque es la propia pauta general de la investigación la que le ofrece respaldo. Por otro lado, entiendo que la visión amplia de 
investigación ofrecida por Dewey permite dar cuenta de la vinculación entre ciencia y su contexto, de la necesidad de incluir las consecuencias extra-epistémicas en las evaluaciones hechas por la propia investigación y de la imposibilidad de establecer límites entre ciencia y política, sobre la base de la tesis de la continuidad de la experiencia. De esta forma, a los aportes deweyanos sobre ciencia, expertos, público y democracia señalados por Douglas podrían agregarse estos otros elementos teóricos que, según mi punto de vista, ayudan a superar algunas dificultades identificadas en el planteo general de la autora y, en esa misma medida, dan cuenta de la vigencia del enfoque elaborado por el pragmatista. 


\section{CAPÍTULO 8: PHILIP KITCHER, CIENCIA BIEN ORDENADA Y \\ DEMOCRACIA}

\section{Introducción}

De acuerdo con la elaboración del capítulo previo, la intervención de Heather Douglas en el debate sobre el ideal de ciencia libre de valores se orienta especial (aunque no exclusivamente) a dar cuenta de la legitimidad de la presencia de valores morales y sociales en la tarea de investigación -entendiendo por esto el trabajo con evidencia, la ponderación de riesgos, la elaboración de niveles de significancia estadística y también las decisiones respecto de qué investigar y con qué metodología hacerlo. Por supuesto, esta estrategia no es la única seguida por quienes discuten el ideal de ciencia libre de valores. Philip Kitcher, una de las figuras más representativas del debate, ha optado por concentrarse en la relación que tiene la ciencia con la sociedad en la que se inscribe, relación que a su juicio implica sostener que los valores sociales y morales son intrínsecos a la práctica científica (Cf. Kitcher, 2001, p. 65). En este marco, Kitcher presenta el concepto de ciencia bien ordenada, una ciencia que "[...] debería satisfacer las preferencias de los ciudadanos en la sociedad en la que se practica" (2001, p. 117). Dicho de manera más precisa, “[...] la ciencia está bien ordenada cuando la especificación de los problemas que debe resolver estaría respaldada por una conversación ideal, incluyendo todos los puntos de vista humanos, bajo condiciones de compromiso mutuo." (Kitcher, 2011b, p. 106).

En este capítulo me detendré a analizar la propuesta de Kitcher con la intención de evaluar sus implicancias, alcances y limitaciones filosóficas, particularmente en lo que refiere al vínculo que traza el autor entre ciencia y democracia. Bajo este propósito general, en la sección 2 buscaré reconstruir los fundamentos epistemológicos que sostienen la propuesta de Kitcher, a saber: la crítica a la leyenda de la ciencia como búsqueda de la verdad y al mito de la pureza de la ciencia, por un lado, y la idea de significatividad científica, por el otro. Como bien señala Longino (2002a, p. 561), la noción de significatividad es el pivote del planteo de Kitcher pues articula argumentos de índole epistemológica con argumentos de índole política en la medida en que habilita la pregunta

por quiénes, de qué manera, bajo qué condiciones y con qué restricciones pueden tomar 
decisiones respecto de las investigaciones que deben llevarse a cabo -si es que, como indica la cita del párrafo previo, su propósito es satisfacer las preferencias de los ciudadanos. En este sentido, el objetivo central de Kitcher es evaluar qué lugar ocupa la ciencia en una sociedad democrática y cómo debería organizarse el sistema de conocimiento público.

Ya en la sección 3 recuperaré los fundamentos políticos de la propuesta de Kitcher, orientándome especialmente a ponderar el modelo de deliberadores ideales bajo condiciones de mutuo reconocimiento - modelo de cuya conversación deberían surgir los criterios de significatividad científica. Respecto de este modelo, es importante observar una diferencia crucial entre Science, Truth and Democracy (2001) y Science in a Democratic Society (2011b), dada por el intento de Kitcher de superar algunas limitaciones de la visión sobre los deliberadores ideales inspirada en la posición teórica de John Rawls mediante un giro al pragmatismo deweyano, todo ello en virtud de ofrecer algún sostén teórico de su idea de democracia y subsanar algunas deficiencias de la primera formulación del ideal de ciencia bien ordenada. ${ }^{95}$ Atento a este desplazamiento, la sección presentará dos parágrafos: en el primero reconstruiré la primera versión del ideal de ciencia bien ordenada en clave rawlsiana, junto con las críticas realizadas por Mark Brown (2004), mientras que en el segundo me concentraré en la reformulación de Kitcher de los fundamentos políticos y meta-éticos del ideal de ciencia bien ordenada, en perspectiva deweyana.

Esta primera aproximación resulta suficiente para observar que la relación establecida por Kitcher entre ciencia bien ordenada y democracia es promisoria pero no queda exenta de dificultades. En efecto, y más allá del referido desplazamiento, considero que Kitcher no logra reformular su concepción de democracia en línea con la perspectiva de Dewey sino que, por el contrario, su planteo evidencia ciertas tensiones dadas por la dificultad de superar una visión meramente formal o mecánica de la democracia y una

\footnotetext{
${ }^{95}$ El giro al pragmatismo de Kitcher no se expresa solamente en sus referencias a la noción deweyana de democracia sino que progresivamente incorpora elementos de la filosofía de Dewey para dar cuenta de su posición naturalista y de su posición en meta-ética. Así es que Kitcher pasa de hacer una única mención a Dewey en Science, Truth and Democracy, a propósito de un trabajo de Peter Godfrey-Smith (2001, p. 206), a otorgarle considerable importancia en Science in a Democratic Society y a darle un lugar de suma relevancia en The Ethical Project (2011c), texto conmás de 30 referencias a Dewey, incluyendo el epígrafe de la obra. Finalmente, Kitcher publica una compilación de artículos titulada Preludes to Pragmatism: Toward a Reconstruction of Philosophy, cuyo texto de apertura es una reconsideración del valor del enfoque deweyano sobre filosofía, educación e investigación, todo ello con la intención de señalar que su ideal de ciencia bien ordenada estaría en línea con la perspectiva de Dewey (Kitcher, 2012).
} 
visión objetivista de sus valores estructurales - dos puntos que en principio Kitcher cuestiona e intenta superar. En la sección 4 me detendré a analizar estos elementos a la luz del marco teórico de Dewey con el objetivo de señalar que, en mi interpretación, Kitcher no termina de deshacerse de una visión procedimental de la democracia ni de una visión objetivista de los valores y que su mera referencia a Dewey no es suficiente para la reformulación de los fundamentos meta-éticos y políticos del ideal de ciencia bien ordenada. Finalmente, en la sección 5 propongo reconsiderar algunos elementos del planteo de Kitcher desde lo que entiendo es un planteo deweyano consecuente, capaz de ofrecer resoluciones consistentes a las dificultades identificadas apelando al concepto de público como alternativa a los deliberadores ideales, a una concepción "experiencial" de la democracia y a la interpretación de los valores en cuanto fin a la vista generalizado y respaldado por la investigación o deliberación reflexiva.

\section{El ideal de ciencia bien ordenada: fundamentos epistémicos}

Si bien el capítulo está concentrado en la idea de ciencia bien ordenada, es importante señalar que la reflexión filosófica de Kitcher sobre la ciencia aparece inicialmente vinculada con algunos asuntos más "tradicionales" de la disciplina, si se me permite la expresión. En efecto, la preocupación central en The Advancement of Science, su primera gran obra, es analizar y reformular nociones como progreso y racionalidad científica, todo ello bajo la influencia del trabajo de Darwin y guiado por la intención de desplazar a la física y ubicar a la biología como disciplina de referencia para la indagación filosófica sobre el conocimiento científico (Kitcher, 1993). Una de las ideas más interesantes del autor es modificar la unidad de análisis, esto es, dejar atrás las teorías, los paradigmas y los programas de investigación y analizar a las investigaciones en términos de prácticas científicas, inicialmente individuales o compartidas por pocas personas y progresivamente devenidas en prácticas científicas consensuadas.

La propuesta de Kitcher respecto de esta nueva unidad de análisis tiene una elaboración teórica notoria. Por un lado, el autor identifica siete componentes definitorios de las prácticas científicas consensuadas, desde el lenguaje utilizado hasta las muestras de razonamiento científico aceptado, pasando por las preguntas y problemas centrales, los 
enunciados comunes, los patrones explicativos, los informantes confiables y los paradigmas de experimentación y observación. Esto le permite al autor sostener que la ciencia no es una sucesión de teorías monolíticas (ni estas últimas como un conjunto de afirmaciones) sino más bien una actividad multifacética orientada a la conformación de esquemas explicativos. Por otro lado, Kitcher complejiza la noción misma de progreso científico pues bajo esta perspectiva es posible evaluar si hay progreso tanto al interior de una práctica como entre prácticas sucesivas e incluso por referencia a uno o varios componentes de una misma práctica (Cf. Kitcher, 1993, Capítulos 3 y 4).

Más allá de la riqueza filosófica de este planteo -cuyo análisis detallado queda por fuera del alcance de estas páginas- me interesa señalar lo siguiente: Kitcher propone su nueva unidad de análisis en explícita discusión con la leyenda de la ciencia, aquella imagen por la cual "[1]os nobles objetivos de la ciencia tienen algo que ver con la consecución de la verdad" (Kitcher, 1993, p. 3). Huelga decir que la leyenda admite distintas versiones, desde las más exigentes que plantean que la ciencia busca la verdad por la verdad misma hasta las más modestas que plantean que la ciencia busca la verdad en aquellos asuntos que nos afectan directamente. Como fuera, la leyenda se elabora sobre dos pilares prácticamente innegociables, a saber: (i) el acercamiento progresivo a la verdad, a una visión completa y verdadera del mundo - $\mathrm{o}$, cuanto menos, el alejamiento progresivo del error, como podría seguirse del modelo falsacionista; y (ii) la confianza en el método científico como guía para corregir los eventuales errores y orientar dicha tendencia progresiva -cualesquiera fueran las diferentes versiones del propio método.

Uno de los aspectos que vinculan estrechamente esta imagen legendaria con la nueva unidad de análisis presentada por Kitcher y, finalmente, con el argumento general de este capítulo es el asunto de los objetivos de la investigación. En efecto, si bien la leyenda de la ciencia supone que el trabajo científico estaría dirigido a objetivos cognitivos y guiado por valores del mismo tipo, Kitcher señala que por detrás de ese enunciado general hay una diversidad de motivos, intereses y objetivos sumamente relevantes para la labor de investigación, desde la satisfacción en el trabajo hasta el reconocimiento por colegas y/o por la sociedad en general, de modo que "[1]as consideraciones epistémicas y noepistémicas se confunden [blur] fácilmente.” (Kitcher, 1993, p. 72). En este marco Kitcher sostiene que los objetivos a largo plazo de un investigador pueden ser de cuatro tipos: 
epistémico y no epistémico, personal e impersonal, en todas sus combinaciones. El punto crítico es que frente a esta constatación de hecho, la demanda tradicional de suprimir los objetivos no-epistémicos en favor de los epistémicos o cognitivos debe responder (i) si la supresión es posible, esto es, si una investigación larga y compleja puede prescindir de las motivaciones, intereses y valores no epistémicos, y ante todo (ii) si la supresión es deseable, cuya respuesta queda supeditada a definir si todo elemento no epistémico es necesariamente una interferencia en el curso de la investigación.

Ahora bien, si la búsqueda de la verdad y la orientación de la investigación en términos de objetivos y valores cognitivos es parte de una imagen legendaria, ¿qué le queda a la ciencia? De acuerdo con Kitcher, las prácticas científicas ya no aspiran a la verdad sino a la verdad significativa (Cf. 2001, p. 65). Las implicaciones inmediatas de esta afirmación son absolutamente importantes. En primer lugar, la noción de significatividad implica reconocer la centralidad del contexto en la práctica científica pues lo que resulta significativo para un contexto no resulta para otro. Puesto en términos más concretos, para Kitcher no hay una noción de significatividad independiente del contexto. En segundo lugar, y dado que no se puede separar significatividad de contexto, los valores sociales y morales propios de este último son parte intrínseca de las prácticas científicas y deberán ser considerados al momento de definir la referida significatividad. En tercer lugar, y como corolario de las dos observaciones previas, resulta evidente que la noción de significatividad está cargada de valores y que los juicios respectivos involucran un "balance multidimensional" entre las condiciones contextuales, los intereses y los bienes e ideales intervinientes, difícilmente reductibles a un denominador común. Luego, "[e]n los juicios sobre significatividad científica aparecen todo tipo de consideraciones, incluyendo ideales morales, sociales y políticos." (Kitcher, 2001, p. 86). Si bien volveré sobre este punto en la sección siguiente, queda de manifiesto ya que la relación entre significatividad científica y ciencia bien ordenada es un eje central del planteo de Kitcher, toda vez que "[1]a significatividad científica corresponde a aquellos problemas que serían seleccionados bajo las condiciones de la ciencia bien ordenada." (Kitcher, 2011b, p. 106).

Para analizar en detalle el argumento es interesante recordar que Kitcher distingue entre significatividad teórica o epistémica, relacionada con aquellas verdades cuyo 
conocimiento es intrínsecamente valioso, y significatividad práctica, vinculada con aquellas verdades cuyo conocimiento incrementa la posibilidad de cumplir objetivos prácticos. Esta podría ser la base para distinguir entre ciencia pura o básica, ciencia aplicada y tecnología: mientras la primera tendría metas cuya significatividad es exclusivamente epistémica, la segunda tendría metas con ambos tipos de significatividad y la última se orientaría a metas cuya significatividad es exclusivamente práctica. ${ }^{96}$ Sin embargo, estas caracterizaciones no aplican al modo en que efectivamente se procede en las prácticas científicas pues la significatividad epistémica y práctica suelen estar íntimamente vinculadas. Por otra parte, las distinciones entre ciencia pura, aplicada y tecnología no son claras ni definitivas porque no pueden distinguirse por el lugar en el que se practican o por si se orientan a la producción de instrumentos o de conocimiento teórico. Además, una vez que se acepta que el objetivo de la práctica científica es la verdad significativa, con sus dimensiones epistémica y práctica, todo proyecto debe ser analizado por relación a su significatividad, a la significatividad de los proyectos alternativos y al contexto en el que se inscribe la investigación. En consecuencia, la distinción se torna difusa y la pureza no es más que un mito constitutivo de la leyenda anteriormente señalada.

Más aún, el mito de la pureza es funcional al ideal de ciencia libre de valores pues asume que la ausencia de cualquier objetivo práctico es suficiente para aislar a la investigación de cualquier crítica moral, social o política. Por el contrario, señalar que las delimitaciones entre ciencia básica, aplicada y tecnología son difusas permite reconsiderar la incidencia de la dimensión valorativa en cualquier tipo de investigación. Al respecto, Gómez señala un punto de relevancia mayor: "[s]i la distinción [entre ciencia básica, aplicada y tecnología] no es clara, no puede afirmarse que lo político y lo social afecten solamente a la ciencia aplicada y a la tecnología.” (2014, p. 127).

También resulta importante advertir que en Science in a Democratic Society (2011) Kitcher prácticamente no menciona la idea de verdad significativa (lo hace sólo tres veces en todo el texto) y su referencia a la significatividad científica implica ahora una idea de investigación bastante más cercana a la deweyana que la noción de práctica científica

\footnotetext{
${ }^{96}$ En principio Kitcher propone utilizar las categorías de ciencia pura y ciencia básica, por un lado, y ciencia aplicada y tecnología, por el otro, como sinónimos (incluso las utiliza alternativamente). Sin embargo, en el curso de su argumento refina la distinción entre ciencia aplicada y tecnología al tiempo que deja de apelar a la categoría de ciencia pura y sólo remite a la de ciencia básica, sin aclarar si aún se mantienen como sinónimas -algo que efectivamente no sucede para el otro par de categorías (Cf. Kitcher, 2001, Capítulo 7).
} 
abocada a las verdades significativas.$^{97}$ En efecto, uno de los componentes determinantes de la significatividad científica son los problemas significativos, aquellos que se considera merecen tiempo y esfuerzo -y que han sido generalmente relegados de las consideraciones filosóficas sobre la ciencia como resultado de intentar eliminar los juicios de valor en la identificación de los objetivos de la investigación. Otros elementos que otorgan significatividad a la investigación son el valor potencial en tanto forja herramientas para futuras investigaciones (recuérdese aquí la noción de asertabilidad garantizada de Dewey en cuanto subproducto de la investigación pasible de ser empleado en subsiguientes investigaciones) y la posibilidad de mejoras relativamente directas en la calidad de vida. El punto crucial es que todas estas ponderaciones requieren juicios de valor pues todas suponen objetivos dignos de ser cumplidos. Asimismo, en coincidencia con el planteo de Douglas y en franca crítica a la distinción entre contexto de descubrimiento y justificación como maniobra para sostener el ideal de ciencia libre de valores, Kitcher señala que el análisis de las dificultades no anticipadas, típicas de toda investigación, y del nivel de evidencia aceptado para aceptar una hipótesis o para seguir adelante con la investigación, entre otras decisiones, también requieren juicios de valor (Cf. 2011b, pp. 33-35).

Por supuesto, este argumento aún requiere precisar qué tipo de valores son los que intervienen en la decisión respecto de la significatividad científica. Para ello Kitcher identifica tres esquemas de valores distintos aunque todos parte de la investigación: (i) el esquema amplio, es decir el conjunto de compromisos de índole general en torno a los que se organiza la vida de cualquier ciudadano y que atraviesa distintos ámbitos de la misma; (ii) el esquema cognitivo, relacionado con las razones por las que cierto tipo de conocimiento es especialmente importante tanto por sí mismo como por la posibilidad de resolver algunos de los problemas que el esquema amplio señala como prioritarios; y (iii) el esquema probativo, propio de las prácticas científicas específicas -y foco de disputa durante los períodos de transición de una práctica científica a otra. En la sección siguiente

\footnotetext{
${ }^{97}$ En Science, Truth and Democracy (2001, Capítulo 6) Kitcher ya introduce la idea de significatividad científica pero la asocia casi con exclusividad a la búsqueda de verdades significativas sobre la base de un realismo modesto, aquel que lidia con el mundo tal y como lo encontramos, sin involucrarse en disquisiciones metafísicas. Esto le permite encontrar un término medio entre el objetivismo científico, base del ideal de ciencia libre de valores, los constructivistas radicales, quienes cuestionan la idea de un mundo independiente de nuestras categorías, y los críticos de la ciencia, quienes consideran que esta última no hace sino representar grupos de poder e intereses (Cf. Kitcher, 2001, Capítulo 2 y Brown, 2004, p. 79).
} 
intentaré explicar por qué los tres esquemas forman parte del ideal de ciencia bien ordenada. Por el momento, basta señalar que dada la complejidad de las prácticas científicas, los esquemas de valores aparecen ciertamente imbricados: quienes investigan confían en su esquema probativo para decidir si pueden avanzar con la siguiente etapa de la investigación pero ajustan sus objetivos sobre la base de su esquema cognitivo y muchas veces de su esquema amplio (esquemas que, a su tiempo, se modifican a la luz de las nuevas creencias factuales). Si estas observaciones son correctas, prosigue Kitcher, entonces no hay posibilidad de defender a la ciencia como una práctica libre de valores. Por el contrario, cualquier consideración de la ciencia debe estar antecedida por un análisis sobre los valores y la valoración (Cf. Kitcher, 2011b, pp. 38-40).

En lo que sigue me detendré a considerar este último planteo. En función de organizar la reconstrucción de la propuesta de Kitcher y teniendo en cuenta que entre la primera y la segunda versión del ideal de ciencia bien ordenada (2001, 2011b, respectivamente) hay ciertos cambios pero por sobre todas las cosas hay una ampliación y reformulación de sus fundamentos éticos y políticos (por ejemplo, la necesidad de un análisis sobre los valores y la valoración, tal como indica la referencia previa, es un elemento que Kitcher plantea en su segunda versión del ideal) en primer lugar abordaré la presentación inicial del ideal y recuperaré las críticas de Brown (2004) mientras que en segundo lugar me detendré en las referidas modificaciones, signadas por la referencia al marco teórico de Dewey, para posteriormente señalar nuevas críticas, ya en la sección 4.

\section{El ideal de ciencia bien ordenada: fundamentos políticos y meta-éticos}

\subsection{En tono rawlsiano: la primera versión del ideal}

Según he adelantado en la introducción, la ciencia bien ordenada es aquella que satisface las preferencias de los ciudadanos de la sociedad en la que se inscribe. Ahora bien, dado que el objetivo de las prácticas científicas es la verdad significativa (en una primera versión del ideal) o la significatividad científica (en una segunda versión) y que la definición de este criterio es contextual y colectiva, entonces el foco debe estar puesto en lograr que esa investigación no presente tensiones con los valores subyacentes de los ciudadanos o, mejor aún, que promueva los valores colectivos de los esquemas amplios, en el más abarcativo de los sentidos (Cf. Kitcher, 2001, p. 108 y 111). Una primera opción 
para garantizar la relación entre las mentadas preferencias y las investigaciones científicas sería llevar adelante los proyectos favorecidos por la representación de una porción mayoritaria de la sociedad. Kitcher denomina a esto "democracia vulgar", cuya deficiencia central se sintetiza en la idea de "tiranía de la ignorancia", es decir, en el hecho de que las preferencias de los ciudadanos muchas veces están basadas en impulsos, carecen de los conocimientos necesarios para juzgar sobre la significatividad científica y son fácilmente manipulables por quienes tienen intereses privados sobre las investigaciones. ${ }^{98}$

Dadas las limitaciones de la democracia vulgar, especialmente de cara a asuntos técnicamente complejos como puede ser la práctica científica, Kitcher considera que la noción de significatividad científica emergería de una conversación ideal entre agentes o deliberadores ideales, aquellos que representan la distribución de los puntos de vista y/o preferencias distintas en una sociedad, con la posibilidad de intervención de algún tipo de árbitro ante posibles desacuerdos o incomprensiones (Cf. Kitcher, 2001, pp. 117-123). En este marco, la ciencia estaría bien ordenada si hubiera instituciones gubernamentales que conduzcan a los investigadores a coincidir con las conclusiones de los deliberadores ideales en las tres instancias centrales de toda investigación: (i) la determinación de la agenda y la asignación de recursos en función de las elecciones hechas en la instancia de deliberación ideal; (ii) el desarrollo de las investigaciones, tanto respecto de las posibilidades disponibles como de su eficacia y de sus reparos sociales o morales; y (iii) la aplicación de los resultados de la investigación y sus consecuencias prácticas, sobre la base de aquellas políticas recomendadas por la propia deliberación ideal. Tal y como señala Dijstelbloem (2014, p. 41), la propuesta de Kitcher “[...] busca combinar una idea epistémicamente

\footnotetext{
${ }^{98}$ Para este último caso Kitcher reserva el nombre de "elitismo externo", un mecanismo para tomar decisiones que sólo contempla la opinión de los científicos y de aquellos que financian las investigaciones. Debido a las presiones de las comunidades científicas este mecanismo externo muchas veces deviene "elitismo interno", esto es, la pretensión de que fueran únicamente los especialistas quienes definan el criterio de significatividad científica (Kitcher, 2001, pp. 133-135). El ideal de ciencia bien ordenada descartaría de inmediato ambas opciones. No obstante, Kitcher dedica numerosas páginas a argumentar por qué su propuesta es preferible a cualquiera de las dos variantes de elitismo (2001, Capítulo 11). Helen Longino (2002a) retoma el asunto de las investigaciones privadas para señalar que el ideal de Kitcher encuentra ciertas limitaciones en un contexto en el que la ciencia financiada por sectores privados es parasitaria de los laboratorios e instituciones públicas pues no ofrece bases suficientes para incluir a ese tipo de investigación en el ideal de ciencia bien ordenada. La idea deweyana de público podría ser una buena alternativa para dar respuesta al planteo de Longino, dado que las consecuencias a mediano o largo plazo de una investigación no dejan de ser tales en función de quién financie la investigación. Por lo tanto, aun cuando privada, la investigación científica es siempre una actividad pública y como tal requiere algún tipo de control público.
} 
realista de la ciencia con una visión deliberativa de la democracia que se apoya fuertemente en la noción de 'razón pública' de Rawls, en el hecho común de dar razones por parte de los ciudadanos en una sociedad pluralista." 99

La idea de deliberación ideal requiere algunas precisiones ulteriores. Con respecto a (i), los deliberadores serían informados de todo aquello que fuera necesario y pertinente a la discusión por la significatividad epistémica o teórica y práctica de la(s) investigación(es) objeto de análisis. De este modo, la deliberación no se apoya en meras preferencias sino en preferencias asesoradas [tutored] que deberían ponerse en consideración junto con los resultados que cada deliberador haya adoptado previamente. Luego del proceso de deliberación propiamente dicho, apoyado en algunos criterios básicos de respeto y de cuidado para que los consensos no impliquen sub-representaciones, se espera que cada deliberador ideal haya modificado sus preferencias iniciales como resultado del intercambio y del reconocimiento de las preferencias ajenas, y se espera también que haya cierto consenso en torno a la significatividad científica de una investigación, esto es, en torno a los asuntos, las modalidades, las previsiones y los reparos generales que debería observar la investigación en cuestión. ${ }^{100}$ Esas conclusiones son elevadas a los grupos o subgrupos de especialistas, quienes ofrecen estimaciones respecto de la factibilidad técnica de la investigación, y recién después el propio grupo de deliberadores ideales considera el asunto presupuestario y la formación de agenda, cuyo resultado de máxima sería dar cuenta de las preferencias e intereses de las comunidad representada por los deliberadores ideales. ${ }^{101}$

En cuanto a (ii), los deliberadores ideales deben garantizar que la prosecución de la investigación no vaya en detrimento de derechos y compromisos morales individuales o grupales. Al igual que Douglas, Kitcher recupera dos ejemplos clásicos sobre este punto: la discusión respecto de experimentar con animales (si nunca debe hacerse, si puede hacerse

\footnotetext{
99 Todas las traducciones de Dijstelbloem (2014) son propias.

${ }^{100}$ Las opciones podrían ser las siguientes: consenso total, acuerdo en una visión como la más representativa de los diferentes puntos de vista/preferencias o falta de acuerdo en una visión representativa. En este último caso, Kitcher propone votación directa entre los deliberadores ideales (Kitcher, 2001, p. 122).

${ }^{101}$ Vale señalar que, apoyado en la concepción negativa de la libertad de John Stuart Mill y a contramano de los liberales que se apoyan en el mismo Mill para sostener el derecho inalienable a la investigación libre, Kitcher plantea que es posible considerar limitaciones al referido derecho cuando ello va en contra de otros derechos determinados (por ejemplo, que la investigación no refuerce estereotipos incorrectos). En estos casos, si bien no habría lugar a prohibiciones institucionales formales, Kitcher sostiene que sería deseable algún tipo de imperativo moral tal que los propios investigadores decidan no llevar adelante esa línea de trabajo particular (Cf. Kitcher, 2001, Capítulo 8).
} 
con algunos tipos de animales mientras que con otros no, etc.) o de experimentar con seres humanos que aceptan hacerlo bajo todas las debidas condiciones del consentimiento informado. Finalmente, en cuanto a (iii) y dado que el desarrollo de la investigación puede habilitar aplicaciones prácticas no previstas, Kitcher propone reeditar la discusión dada al momento de establecer la agenda de investigación con el énfasis puesto en la revisión de la significatividad práctica orientada por una política que debería dar cuenta de las nuevas preferencias asesoradas. En este sentido, Kitcher (2001, p. 121) señala que "[e]1 resultado [...] es el curso de investigación que mejor refleja los deseos de la comunidad representada por los deliberadores ideales", construido sobre la base de lo que denomina "democracia informada" [enlightened].

El cumplimiento absoluto de estas instancias daría lugar a una ciencia perfectamente bien ordenada, aquella en la que las actividades de quienes investigan, orientadas por y desde instituciones gubernamentales, coincidan exactamente con los resultados de la deliberación ideal en las tres instancias recientemente señaladas, esto es, que satisfaga las preferencias y puntos de vista de los grupos representados por los deliberadores ideales. Por supuesto, esta formulación es un ideal y Kitcher es absolutamente consciente de ello, razón por la cual su intención, en definitiva, es propiciar una aproximación factible a dicho ideal mediante un diseño institucional que, sin instituir de hecho el esquema de deliberación ideal recientemente presentado, pueda al menos garantizar la incorporación de todos los puntos de vista y los valores del esquema amplio pertinentes a la discusión sobre la base de la inclusión, la discusión racional y el respeto mutuo entre deliberadores ideales.

Si bien esta versión inicial de Kitcher ha sido ampliamente recibida y discutida durante los años inmediatamente posteriores a la publicación de Science, Truth and Democracy, (Cf. Longino 2002a 2002b, Bunge 2005, Simon 2006, Weber 2009, entre otros), la fundamentación filosófico-política del ideal de ciencia bien ordenada no ha sido muy tematizada en la bibliografía especializada. Una interesante excepción es la reseña crítica de Mark Brown (2004), cuyo planteo central es que el objetivo central de Kitcher queda finalmente frustrado por una concepción equivocada de la relación entre filosofía y política. Más allá de identificar algunos puntos ciertamente valiosos del ideal de ciencia 
bien ordenada (por ejemplo, las intenciones de revertir la frecuente sobre-representación de los grupos sociales privilegiados, de enfatizar la necesidad de que los dirigentes políticos estén debidamente informados o de subrayar la necesidad de algún tipo de control público de las prácticas científicas), Brown cuestiona dos aspectos del planteo de Kitcher que en mi opinión merecen atención.

En primer lugar, Brown apunta que el interés de Kitcher no es tanto el procedimiento por el que se obtengan los resultados, es decir la calidad institucional de la democracia, sino más bien los propios resultados. En efecto, al momento de argumentar por qué la propuesta de ciencia bien ordenada no requiere una realización efectiva Kitcher plantea que "[...] el desafío es encontrar instituciones que generen aproximadamente los resultados correctos, aun cuando no tengan los deliberadores ideales para tomar las decisiones que se esperan sean replicadas.” (Kitcher, 2001, p. 123. Énfasis agregado). En esta línea, Kitcher parece más preocupado por lo que el gobierno pueda hacer por el público antes que por lo que el público pueda hacer mediante el gobierno. Más aún, la aspiración del ideal de ciencia bien ordenada parece ser conformar una política científica a tono con lo que los ciudadanos aprobarían antes que una política científica elaborada por los propios ciudadanos. Así, queda clara la herencia rawlsiana en el planteo de Kitcher, habida cuenta de que el planteo de Rawls supone representaciones ideales en un encuentro igualmente ideal sin necesidad de actualizar las condiciones de compromiso público (Brown, 2004, p. 83). Sin embargo Brown entiende que la idea de ciencia bien ordenada privilegia el standard sustantivo o el resultado antes que el standard procedimental o la deliberación.

Por otro lado, Brown señala que Kitcher no ofrece explicaciones respecto de (i) cómo la deliberación ideal se relaciona con el ideal de representación democrática; (ii) de qué forma los deliberadores reflejan los intereses de los grupos sociales, esto es, si sólo los representan, si los promueven o si buscan que prevalezcan; y (iii) cómo alentar la participación mediante un esquema de deliberación ideal que incluso podría no ensayarse pues lo primordial son los resultados. A esta serie de puntos confusos podría agregársele algunos más: Arnon Keren (2013, p. 240) pregunta (iv) si no es deseable que aquellas personas cuyo bienestar aparece más directamente comprometido por la investigación en cuestión tengan mayor representación en la deliberación, incluidos los científicos al momento de discutir la significatividad epistémica. El ya mencionado Gómez (2014, p. 
130) también pregunta (v) cómo establecer en cada contexto el bien común de referencia para la investigación, si por una deliberación ideal previa o por otro mecanismo y (vi) para qué fines es funcional una ciencia bien ordenada. Finalmente, me permito a sumar a lista algunos interrogantes más: (vi) qué debería tenerse en cuenta para definir el perfil de deliberador ideal (clase social, perspectiva política, locación geográfica, representación por género, intersección de criterios, etc.); (vii) quién/cómo ilustraría a los deliberadores ideales y (viii) cómo se define y cómo operaría el árbitro imparcial.

En segundo lugar, Brown señala que Kitcher no logra explicitar cómo el ideal de ciencia bien ordenada permitiría mejorar el diseño efectivo de políticas científicas precisamente porque asume la existencia de un "resultado correcto" y no contempla que la deliberación es sólo un aspecto de la política en general y de la democracia en particular. Así, “[...] la deliberación hipotética bajo condiciones ideales -tales como la ciencia bien ordenada de Kitcher o la teoría de justicia de Rawls- no puede generar el aprendizaje colectivo generado por las deliberaciones reales entre ciudadanos", de forma que el enfoque de Kitcher no es simplemente abstracto sino que "[...] amenaza uno de los principios de la democracia moderna, a saber, que los ciudadanos vean a la política como algo que ellos mismos tienen que hacer." (Brown, 2004, p. 90 y 91, respectivamente). ${ }^{102}$

La segunda objeción de Brown tiene algunos elementos más que aparecen estrechamente vinculados con el planteo de esta tesis. En su lectura, Kitcher tiende a interpretar a la política como una cuestión de acción individual antes que colectiva. El individualismo metodológico asumido por Kitcher es claro, dado que su propuesta parte de una visión subjetivista (en el sentido de individual) de los valores e intenta "[...] relacionar el bien individual con el bien colectivo en un marco en el que los ideales democráticos se den por garantizados [taken for granted]." (2001, p. 116). De acuerdo con Brown, Kitcher no ofrece respuestas satisfactorias a cómo pasar del nivel individual al nivel colectivo de la acción política. Por el contrario, en todos los ejemplos elaborados por Kitcher la dimensión valorativa de la investigación se juega a nivel individual (Cf. Brown, 2004, p. 92). Asimismo, Kitcher disocia medios y fines, de forma que, si la filosofía postula los fines ideales, la política se ve reducida a arbitrar medios para esos fines predeterminados y la

\footnotetext{
${ }^{102}$ Todas las traducciones al texto de Brown (2004) son propias.
} 
propia elección de fines aparece sustraída de la decisión colectiva y la legitimación democrática - movimiento cuestionado por Brown mediante una apelación explícita a la tesis de la continuidad de medios y fines de Dewey (2004, p. 91). En este sentido, Brown sugiere que el marco teórico deweyano ofrece ideas relevantes para el asunto que ocupa a Kitcher:

\begin{abstract}
No puedo responder la pregunta por cuáles deberían ser los objetivos y métodos de una distintiva filosofía política de la política científica. Pero parece que sería ciertamente bueno [it could do worse than] sumarse a la búsqueda de Dewey de 'una filosofía que intervenga entre el ajuste a las reglas y la devoción a una sistemática subordinación de la inteligencia a fines preexistentes [...]'. Más que ofrecer un standard ideal por el que trabajar, una filosofía política de la política científica podría explorar ideas e ideales con los que el público podría trabajar. (Brown, 2004, p. 94. Cursivas en el original). ${ }^{103}$
\end{abstract}

Desde mi punto de vista los cuestionamientos de Brown son acertados y precisos. Me permito sumar una consideración final, relacionada con la última cita de Kitcher: resulta llamativo que si la noción de democracia es un componente crucial de la idea de ciencia bien ordenada, el autor no haya ofrecido algún tipo de justificación filosófica de aquella sino que, como indica el pasaje referido, la democracia es supuesta o tomada por garantizada. Reformulando una expresión del propio autor referida con anterioridad, podría afirmarse que cualquier consideración del ideal de ciencia bien ordenada debe estar antecedida por un análisis sobre los valores, la valoración y la democracia. Parece que el propio Kitcher advierte esta carencia argumentativa y en Science in a Democratic Society (2011b) efectivamente ofrece razones que soportan su idea de democracia y su interpretación meta-ética de los valores -interpretación que es desarrollada en profundidad en su libro The Ethical Project (2011c).

\title{
3.2. En tono deweyano: la segunda versión del ideal
}

Como ha sido indicado con anterioridad, uno de los cambios teóricos más interesantes de la segunda versión del ideal de ciencia bien ordenada es la referencia

\footnotetext{
${ }^{103}$ Brown remite la cita de Dewey a La Reconstrucción de la Filosofía pero en verdad la frase aparece en "The Need for a Recovery of Philosophy" (MW.10.20).
} 
explícita de Kitcher a la noción deweyana de democracia como forma de vida, esto es, como experiencia conjunta comunicada (Kitcher, 2011b, p. 68). ${ }^{104}$ En mi opinión, el objetivo de esta referencia es triple: por un lado Kitcher busca desmarcarse de las visiones formalistas o mecánicas de la democracia en favor de una comprensión de los valores que ella promueve; por el otro, busca desmarcarse de una visión objetivista de los valores según la cual habría fines objetivamente valiosos y con relaciones objetivas entre sí, más allá de las preferencias efectivas de las personas; finalmente, busca responder a una pregunta que, puesta a la luz de la filosofía de Dewey es ciertamente significativa, a saber: ¿por qué deberíamos querer vivir en democracia? En este contexto, la presente sección estará orientada a (i) reconstruir, en términos generales, el proyecto meta-ético de Kitcher; (ii) recuperar la imagen de la democracia y las consideraciones ofrecidas por el autor sobre sus dos valores centrales, a saber, libertad e igualdad; y (iii) señalar cómo ambos elementos son introducidos en la nueva versión del ideal de ciencia libre de valores.

Con respecto a (i) resulta interesante señalar que Kitcher define a su posición como un "naturalismo pragmático" bajo la intención de hacer honor al intento de Dewey de reconectar a la filosofía con la vida humana y de concebir a la ética en cuanto basada en la vida social humana (Cf. Kitcher, 2011b, p. 3). Más allá de las discusiones teóricas que introduce Kitcher durante la elaboración de su posición (entre ellas, la ardua pregunta por el progreso en ética, entendiendo a esta última como una suerte de tecnología social que intenta resolver problemas) me interesa señalar un aspecto central que será tomado como fundamento para el ideal de ciencia bien ordenada. ${ }^{105}$ Kitcher rechaza la idea de que la ética busca algún tipo de verdad previa o independiente y sostiene que la única forma asequible a los seres humanos para obtener juicios de valor es una conversación o discusión cuyo objetivo último es proveer iguales oportunidades de vida valiosa a todas las personas. Kitcher sugiere entonces un tipo de conversación en la que todos sus participantes lo hagan en condiciones de igualdad y de mutuo compromiso, tanto en términos epistémicos como

\footnotetext{
${ }^{104}$ Como bien indica Dijstelbloem (2014, p. 42) Kitcher no hace ninguna referencia a la sugerencia de Brown de acercarse al pragmatismo deweyano.

105 Con respecto a la impronta naturalista de su posición, Kitcher se apoya en trabajos antropológicos y biológicos para rastrear la historia de lo que él denomina "proyecto ético" hasta la aparición de las conductas altruistas de nuestros ancestros, estudiadas en el comportamiento de chimpancés y bonobos. Al respecto. Cf. Kitcher, 2011a, Parágrafos 5-5 y especialmente 2011b, Parte 1, Capítulos 1-4.
} 
(y especialmente) en términos afectivos, incluyendo la posibilidad de modificar deseos iniciales a partir de la consideración de deseos ajenos. Ahora bien, dado que en el ordenamiento social contemporáneo el intento de replicar ese tipo de discusiones es impensable, Kitcher afirma que "[...] en su lugar, las conclusiones éticas a ser apoyadas son aquellas que emergerían de una conversación ideal, una que satisfaga las condiciones de compromiso mutuo. Estas condiciones forman el núcleo de mi propuesta sobre el método para la investigación de valores.” (Kitcher, 2011b, p. 51).

En cuanto a (ii) Kitcher inicialmente observa que, aunque la democracia suele definirse por el gobierno de la mayoría, es decir, por la oportunidad de votar por aquellos representantes que tomarán decisiones políticas, tal concepción es bastante inadecuada ya que no proporciona razones para responder por qué la democracia es valiosa. Siguiendo a Dewey, Kitcher afirma que la tarea más importante pasa por entender los valores que la democracia promueve antes que limitarse a los meros mecanismos a los que estamos acostumbrados (entre ellos y principalmente la regla de la mayoría expresada en la votación directa), incluso si son una expresión adecuada de un "sentimiento popular" sobre el "control popular" -suponiendo, claro está, un escenario político en el que no reine la indiferencia o apatía política, algo que no suele suceder en las democracias contemporáneas (Cf. Kitcher, 2011b, pp. 63-5). Frente a esta (in)comprensión de la democracia, Kitcher ofrece algunas observaciones sobre sus valores estructurales y una imagen de la democracia que funcionaría como base para una teoría de la ciencia en una sociedad democrática (2011b, pp. 65-83).

Sobre el primer asunto Kitcher afirma que el atractivo de la democracia se basa en dos valores o ideales principales, la libertad y la igualdad. El autor presenta la clásica distinción de Isaiah Berlin sobre la libertad, presentando por un lado una concepción negativa, es decir, la libertad con respecto a las amenazas, limitaciones, restricciones, protección de derechos o la libertad de [freedom from]. Esta versión negativa es predominante en la tradición política liberal angloamericana, cuyo punto de partida es el individualismo metodológico, según puede rastrearse en las obras de Hobbes o Mill -y en el planteo del mismo Kitcher, como intentaré señalar más adelante. Por otro hay una concepción positiva de la libertad, orientada hacia las posibilidades que la libertad nos abre, o libertad para [freedom to]. Esta segunda versión suele ser considerada en términos de 
autodominio, como lo hace Rousseau o también el mismo Dewey y su idea del crecimiento individual en el contexto del crecimiento comunitario. Más aún, Kitcher recupera un elemento de la visión política de Dewey ya señalado en esta investigación, esto es, la necesidad de superar las barreras de clase, raza o nación para la plena participación de los individuos en las actividades conjuntas, en los intereses compartidos y en la formación de los valores que regularán la vida común. En virtud de estos elementos Kitcher entiende que el enfoque deweyano ofrece un sentido de libertad que constituye "[...] un componente crucial en una sociedad verdaderamente democrática.” (Kitcher, 2011b, p. 70). ${ }^{106}$

En cuanto a la igualdad, Kitcher también distingue dos sentidos o significados. El primero de ellos comprende a la igualdad en términos de igualdad de trato frente a las normas o la ley. Si bien Kitcher advierte que este primer sentido es un sentido "delgado" [thin], también observa que cualquier sociedad democrática requiere este tipo de igualdad porque garantiza que haya una igualdad en las libertades de los ciudadanos. Como fuera, Kitcher entiende que esta noción de igualdad es meramente formal y vacía, de modo que es importante considerar algún otro sentido de igualdad por referencia a las distinciones realizadas respecto de la libertad. En efecto, es posible considerar la igualdad en términos de disponibilidad equitativa de opciones de vida valiosas, lo que sin duda constituye un tipo de igualdad más exigente, a saber, la igualdad en libertad [equality in freedom]. ${ }^{107}$

A partir de las consideraciones precedentes Kitcher (2011b, p. 74) introduce una imagen o una forma básica de democracia dispuesta en tres niveles:

1. ideales de libertad e igualdad en libertad. promovido por la

2. implicación de los ciudadanos en las decisiones sobre los asuntos que les afectan. realizado en la

3. maquinaria estándar de elecciones, votos, la ley, etc.

\footnotetext{
${ }^{106}$ El punto señalado por Kitcher se corresponde con aquello que he denominado condiciones "políticas" de la democracia y es ciertamente un elemento poco considerado por los especialistas en la filosofía o teoría política del pragmatista (Cf. capítulo 6, nota 4 de esta tesis).

${ }^{107}$ En este punto Kitcher vuelve a referir a Rawls para sostener que en situaciones de gran inequidad se debe priorizar la ampliación de las oportunidades de los menos favorecidos, aún si eso implica una disminución de las oportunidades de los más favorecidos.
} 
Como he mencionado anteriormente, el principal desafío para Kitcher es responder por qué las personas están y deberían estar entusiasmadas con la democracia. Para lograr este objetivo, el autor primero identifica un patrón: en toda sociedad hay dos grupos, opresores y oprimidos (y, entre estos últimos, oprimidos con o sin recursos para resistir a la opresión). En segundo lugar, identifica dos tipos diferentes de opresión: la opresión identificable y la no identificable. Con respecto a la opresión identificable Kitcher explica que generalmente se caracteriza por interferencias o violaciones de derechos, es decir, en términos de limitaciones o restricciones a la concepción negativa de la libertad. En general, las posibilidades de los oprimidos con recursos les han permitido limitar la opresión e incluso involucrarse en los procesos de toma de decisiones para establecer sus propias protecciones. Sin embargo, Kitcher intenta enfocarse en el último problema, sobre la opresión no identificable. Para él, este es un problema típico de las sociedades grandes, modernas e industriales y se aplica a los casos en que las limitaciones no se sienten y/o son difíciles de rastrear debido a sus múltiples causas. De hecho, Kitcher explica que los problemas de opresión no identificable pueden tomar dos formas, ya sea porque el agente opresivo es bueno ocultando su responsabilidad, o porque no hay a quien atribuirle responsabilidades de forma directa (Cf. 2011b, p. 83).

¿Cómo, entonces, podemos explicar el éxito de la democracia? Para Kitcher, el factor principal es que la democracia ha sido "[...] una respuesta efectiva al problema de los opresores identificables" dado que promueve varias protecciones contra las formas más importantes de comportamiento opresivo de los representantes y líderes (Kitcher, 2011b, p. 82). En suma, la democracia es preferible a otros regímenes porque provee protecciones que garantizan la realización de los ideales precisados anteriormente, incluso cuando dichas protecciones no sean definitivas sino parciales y cuando, según reconoce el propio Kitcher, la democracia está continuamente en desarrollo (Cf. 2011b, p. 83).

Una vez recuperados los argumentos de Kitcher respecto de la conversación ideal y del concepto de democracia es tiempo de (iii) evaluar cómo se integran con el ideal de ciencia bien ordenada. Lo primero que ha de observarse es el paralelo entre el modelo de deliberación ideal con deliberadores ideales propio de la ciencia bien ordenada y el modelo de conversación ideal con conversadores ideales propio del proyecto ético. En efecto, si bien la deliberación ideal parece suponer algún tipo de especificidad o preparación 
particular producto de la complejidad de las cuestiones a considerar, ambos procedimientos presentan las mismas condiciones básicas: incluir todos los puntos de vista de la sociedad en la que se inscribe la conversación/deliberación, desarrollarse sobre la base del mutuo compromiso y orientarse a enriquecer las opciones de vida. Así, la segunda versión del ideal de ciencia bien ordenada sostiene que esta última lleva adelante líneas de investigación definidas a través de discusiones "[...] cuyas conclusiones son aquellas que serían alcanzadas mediante deliberación bajo compromiso mutuo y que exhibirían las bases que esa deliberación presentaría." (Kitcher, 2011b, p. 114). Esas bases son precisamente las que plantea el modelo de conversación ideal.

En segundo lugar, la propuesta de deliberación ideal intenta ubicarse como una alternativa a la democracia vulgar y a las concepciones formales o mecánicas, por un lado, y a las versiones elitistas de la conducción de expertos, por el otro. ${ }^{108}$ En este sentido, el intercambio entre deliberadores que asumen preferencias informadas parece dar lugar a la implicación de los ciudadanos en los asuntos que los afectan, como indica el segundo nivel de la imagen de la democracia, dado que pueden apelar a los valores de los esquemas amplios para asentar las preferencias al momento de iniciar la deliberación. El punto importante es que el esquema amplio podrá tener un rol legítimo en la práctica científica y en la deliberación siempre y cuando surgiera de una conversación ideal. Así, la aspiración democrática que permite introducir los esquemas amplios mediante el ideal de ciencia bien ordenada se vincula con la posición meta-ética y permite a Kitcher afirmar que "[e]l ideal de ciencia libre de valores se derrumba por la importancia de emplear esquemas amplios de valores bien fundados (esquemas que serían aprobados por una discusión ideal bajo condiciones de mutuo compromiso) para regir un programa de investigación." (2011b, p. 61). En consecuencia, el problema de muchas discusiones de la práctica científica no es la incorporación de valores del esquema amplio sino el fundamento de ese esquema.

\footnotetext{
${ }^{108}$ Una de las objeciones que Kitcher recoge es aquella que plantea que bajo el ideal de ciencia bien ordenada la ciencia perdería autonomía. A ello Kitcher responde (i) que al momento de discutir el reconocimiento de la significatividad epistémica los científicos tendrán su deliberador ideal que los represente; (ii) que el reconocimiento de la significatividad práctica de una investigación no implica que el mecanismo de deliberación proponga estrategias de investigación; y (iii) que la certificación del conocimiento queda en manos de los científicos, siempre y cuando cumplan los criterios de transparencia y se orienten a construir un conocimiento público lo suficientemente significativo y acorde con los cánones más amplios de la sociedad en la que se inscribe (Kitcher, 2011b, p. 120-121 y 147-153).
} 
Resta señalar un último punto: Kitcher explícitamente señala que su ideal de ciencia bien ordenada es una expresión del planteo deweyano sobre la investigación: "La visión de Dewey sobre la significación filosófica está integrado en un standard de investigación bien ordenada, que es plenamente democrático e igualitario." (Kitcher, 2012, p. 8). Más aún, indica que el ideal de ciencia bien ordenada parece implícito en los propios textos de Dewey, en particular en los que el pragmatista cuestiona que la investigación represente intereses privados o de clase (Kitcher, 2012, p. 9). De este modo, Dewey no sólo funge como referencia para encuadrar la concepción de democracia sino también de ciencia bien ordenada. En este sentido, revisar las referencias de Kitcher a Dewey en torno a la fundamentación meta-ética y política del ideal de ciencia bien ordenada supondrá también revisar el proyecto mismo de ciencia bien ordenada.

\section{Preguntas y tensiones}

Al igual que la primera versión del ideal de ciencia bien ordenada, la reformulación ofrecida por Kitcher aún es pasible de ciertas críticas desde el mismo punto de vista deweyano que pretende asumir, particularmente respecto de sus fundamentos meta-éticos y políticos. Comenzaré esta sección recuperando algunos planteos del ya citado Dijstelbloem (2014) a los que posteriormente añadiré otros cuestionamientos.

Según indica Dijstelbloem, si bien Kitcher no explica por qué en su segunda versión remite a Dewey y la idea de democracia como forma de vida ni en qué puntos esta nueva referencia es más coherente o fructífera que la anterior, la elección de Kitcher resulta ciertamente adecuada, en particular si se tiene en cuenta que el pragmatista pone de relieve la dimensión política de la ciencia y la tecnología, el valor de la democracia, el rol de la lógica o del método -tanto para la ciencia como para la política- y el carácter indisoluble del vínculo entre democracia y educación. Ahora bien, Djistelbloem (2014, pp. 42-43) plantea algunas preguntas ciertamente agudas: “¿Cuánto obtiene Kitcher de esto? ¿Queda satisfecho con algunas de las propuestas más modestas de Dewey para hacer 'más inteligente’ a la democracia? ¿O está preparado para leer a Dewey en un modo más radical y para ver en Dewey una oposición a muchas de las ideas predominantes [mainstream] respecto de qué es la democracia?" Puesto en términos más directos, el planteo de Djistelbloem apunta a considerar si Kitcher hace una lectura meramente procedimental de 
la idea de democracia de Dewey, es decir, como fundamento formal de las democracias deliberativas, o si asume una visión más comprehensiva del planteo deweyano, aquella vinculada con una interpretación de la democracia como la forma de vida que permite el enriquecimiento de la experiencia individual y comunal, según ha sido indicado en el capítulo 6 de esta investigación. ${ }^{109}$

Con respecto a las preguntas señaladas, Djistelbloem recuerda que Kitcher (2012, p. 9) se apoya en algunos pasajes del propio Dewey tales como "[...] estas personas [los científicos] representan una división social del trabajo y sólo puede otorgarse confianza a su especialización cuando cooperan sin ningún obstáculo con otras ocupaciones sociales, cuando demuestran sensibilidad hacia otros problemas y hacen partícipes de sus resultados para que les den una aplicación más amplia en la acción.” (Dewey, 1996, p. 11. MW.12.164). Estas referencias junto a la actitud general de Kitcher de no abordar explícitamente la pregunta sobre la interpretación procedimental o comprehensiva del enfoque político deweyano llevan a Djistelbloem a señalar que Kitcher parece suponer que el enfoque del pragmatista es valioso sólo en su dimensión procedimental. (Djistelbloem, 2014, p. 44) ${ }^{110}$ A partir de esta lectura me permito aventurar una observación ulterior: parece que Kitcher todavía mantiene ciertos reparos para dejar atrás la visión rawlsiana y asumir lo que, en mi visión, constituye una visión plenamente deweyana.

En esta línea se inscriben, además, las siguientes críticas que entiendo pueden plantearse frente al intento de respaldarse en una visión deweyana llevado adelante por Kitcher. En primer lugar, hay algunos puntos poco claros sobre el vínculo entre libertad y democracia. Con respecto a la concepción positiva de la libertad, Kitcher inicialmente

\footnotetext{
${ }^{109}$ Vale señalar que si bien Brown y Dijstelbloem utilizan la distinción entre la interpretación procedimental y sustantiva de la democracia y parecen coincidir en qué entienden por "procedimental", difieren en cuanto al aspecto sustantivo pues Brown lo vincula con los resultados de la deliberación (Cf. Supra, 3.1) mientras que Dijstelbloem lo vincula con la fundamentación filosófica de la democracia. En lo que sigue adoptaré la interpretación de Dijstelbloem (que en principio no es contradictoria con la de Brown sino que apunta a un aspecto diferente de la discusión).

${ }^{110}$ Según señala Dijstelbloem, Kitcher asumiría las conocidas críticas de Robert Talisse $(2007,2011)$ según las cuales la perspectiva de Dewey no es compatible con el hecho del pluralismo de visiones morales comprehensivas (punto de partida del argumento de Rawls) sino que supone una visión comprehensiva/normativa determina de modo que la visión de la democracia sostenida por el pragmatista no es viable en las condiciones político/sociales contemporáneas. Más aún, arguye Talisse, esa visión comprehensiva deweyana es la que justifica las políticas públicas particulares; en consecuencia, el programa político de Dewey no sólo es inviable sino ante todo opresivo (Talisse, 2011, p. 515).
} 
explica que los votos y las elecciones son condiciones necesarias para alcanzar ese ideal subyacente, ya que promueven la oportunidad de reunirse y debatir en términos políticos. No obstante, indica que algunas concepciones de democracia basadas en ideales positivos de libertad son simplemente imposibles bajo las condiciones de las sociedades contemporáneas, considerando, por ejemplo, la cantidad de ciudadanos y la complejidad de sus interacciones (Cf. Kitcher, 2011b, p 78-81). Con respecto a la concepción negativa de la libertad, Kitcher sostiene que la toma de decisiones públicas, los votos y las elecciones previenen ciertos tipos de interferencias y violaciones de derechos y de la esfera privada. Sin embargo, también afirma que "si se ha avanzado en la extensión del ideal de libertad negativa para abarcar a estos grupos [minoritarios], esto se debe a los esfuerzos adicionales realizados por algunos de sus miembros [...]" (2011b, p. 76), por lo que las elecciones y las votaciones ni siquiera parecen ser condiciones necesarias para lograr una libertad negativa. Como resultado, si la concepción formal de la democracia ya no es una condición necesaria tanto para la concepción positiva como negativa de la libertad (debido a las condiciones históricas y actuales), no está claro cómo y por qué estos valores o ideales podrían realizarse en ella. Por estas razones, el argumento no es exhaustivo y, en consecuencia, el cuadro de la democracia no es tan "obvio" como lo presenta el autor.

En segundo lugar, parece que Kitcher es demasiado optimista al afirmar que la democracia es una respuesta efectiva al problema de la opresión identificable. Basado en el mismo argumento "empírico" que presenta con respecto a la igualdad de trato real ante la ley (2011b, p. 82), es posible afirmar que después de pasar un poco de tiempo caminando y enfrentando a personas sin hogar, sin cobertura médica o sin acceso a la educación, la conclusión es que la democracia todavía tiene mucho que hacer en contra de estos límites ostensibles a la libertad positiva. En cuanto al problema de la opresión no identificable, Kitcher explica que es un problema ubicuo dados los defectos y limitaciones propios del conocimiento público - aspecto fundamental para la resolución de aquellos problemas de opresión no identificable (2011b, p. 83). Si, por un lado, es posible encontrar fácilmente contraejemplos de lo que Kitcher considera el factor más importante para explicar el éxito de la democracia con respecto al problema de la opresión identificable y, por otro lado, el argumento con respecto a la opresión no identificable se basa en un sistema de 
conocimiento público que según el autor es defectuoso, entonces los argumentos en favor de la democracia resultan débiles -y aquella parece ser solo una esperanza.

Aparte de las críticas antedichas, considero que toda la posición de Kitcher conduce a algunos puntos que no son consistentes con sus declaraciones iniciales. Como se indicó, Kitcher considera que la concepción mecánica no es constitutiva de la democracia porque aun cuando se entiendan por referencia a la idea de control popular muchas veces " [...] no son expresión de esa idea sino su traición” (Kitcher, 2011b, p. 65). Teniendo en cuenta esta observación, existe cierta tensión entre las críticas de Kitcher a las concepciones mecánicas o formales de la democracia y el tercer nivel de su imagen de la democracia. En efecto, he señalado que según Kitcher la participación de los ciudadanos y con ellos los ideales de libertad e igualdad se materializan en la maquinaria estándar de elecciones, votos, la ley, etc. de una manera claramente relacionada con esas concepciones mecánicas de la democracia. Esto podría ser aceptable solo bajo una perspectiva descriptiva, esto es, si Kitcher explicara cómo funcionan realmente las sociedades democráticas. Sin embargo, el autor está tratando de ofrecer argumentos a favor de la democracia a nivel normativo, para responder por qué podemos querer una sociedad democrática. En este sentido, resulta sorprendente encontrar que Kitcher incluye "la maquinaria estándar" a un nivel corolario de la imagen de la democracia después de argumentar en contra de "la urna y el gobierno de la mayoría" y después de citar la idea de Dewey de la democracia como una experiencia conjunta, cooperativa y comunicada.

En cuanto al ideal de libertad, Kitcher asume principalmente una concepción negativa de la libertad, cuando se considera que la democracia es buena (o la mejor opción entre otras) para evitar o limitar las opresiones externas, pero no presta atención a la concepción positiva de la libertad en términos de disponibilidad de opciones de vida. Además, la idea de que la democracia es valiosa porque limita la opresión externa parece considerar solo la situación de los oprimidos con recursos, aquellos que pueden lograr establecer algún tipo de protección y participar cuando es el momento de tomar decisiones, pero excluye a aquellos oprimidos sin recursos que no pueden establecer ningún tipo de límite para proteger su libertad, al menos en su concepción negativa. Tal concepción negativa de la libertad también está conectada a una concepción formal de la igualdad en 
términos de mera igualdad de trato con respecto a las reglas o la ley, caracterizada por Kitcher como formal o vacía. Como resultado, los argumentos de Kitcher conducen a una concepción formal de la democracia, a pesar de sus esfuerzos por evitarla y de su apelación a Dewey como marco teórico de referencia.

Resta un último punto que me interesa considerar. En el contexto de cómo integrar las preferencias individuales a nivel colectivo -que, según he indicado con anterioridad, es uno de los principales problemas del ideal de ciencia bien ordenada-, Kitcher rechaza la posición objetivista sobre los fines y valores, es decir, la suposición de que existen fines objetivamente dignos y relaciones objetivas entre ellos, sin importar las preferencias que tengan las personas. Desde su perspectiva, las preferencias individuales deben ser el punto de partida para nuestra comprensión del bien personal que la ciencia bien ordenada tiene que promover pues por un lado resulta difícil separar lo que es bueno para una persona de sus propias preferencias reflexivas y por otro lado resulta difícil integrar esos valores objetivos en una trama o jerarquía (Cf. Kitcher, 2001, pp. 115-116). No obstante el rechazo de Kitcher a la concepción objetivista de los valores, el autor afirma que el atractivo de la democracia se basa en los ideales de libertad e igualdad, pero no explica por qué particularmente esos valores y no algunos otros, situación que lo deja frente a dos alternativas: o bien (i) identifica esos ideales como una cuestión de hecho, es decir, como los ideales que realmente valoramos, de modo que los estaría apoyando solo por alguna tradición política, en una actitud bastante conservadora; o bien (ii) sostiene que deberíamos tomar estos valores como base normativa de la democracia por el valor que en sí mismos podrían tener, sin avanzar en más explicaciones relacionadas con las preferencias de los ciudadanos y la forma en que estas preferencias podrían volverse normativas, cayendo precisamente en la noción objetivista que quiere evitar.

\section{Algunas reconsideraciones -o qué aportaría un enfoque deweyano consecuente}

Una vez presentadas las críticas a los fundamentos meta-éticos y políticos de la segunda versión del ideal de ciencia bien ordenada es momento de volver a considerar la democracia, la libertad y la igualdad desde una perspectiva plenamente deweyana, esto es, naturalista y no objetivista, con el objetivo de señalar algunas líneas de resolución de las tensiones identificadas en el planteo de Kitcher. Para ello, haré referencia a algunos de los 
elementos teóricos que he desarrollado en las primeras dos partes de esta investigación. En primer lugar, y recupero otra vez la lectura de Dijstelbloem (2014, p. 45), un enfoque deweyano consecuente no se debería concentrar en restaurar una pretendida naturaleza procedimental del proyecto democrático (apelando a figuras ideales de las que nunca se sabe a quién, cómo ni por qué representan, me permito agregar) sino en reconstruir los públicos fragmentados por las condiciones políticas y sociales concretas de la Gran Sociedad, comunes a Dewey y a Kitcher. En este sentido, el planteo de Kitcher sería más consistente con su referencia a Dewey si dejara de lado la visión de los deliberadores ideales y en su lugar utilizara la categoría de público en cuanto conjunto de personas afectadas por las consecuencias indirectas de una acción y reconocidas como tales.

Asimismo, según plantea Ólafsson (2017), el vínculo que establece Dewey entre público y comunicación plena y libre es lo que permite establecer la confianza epistémica en las investigaciones, es decir, la confianza en que el conocimiento público aborda y soluciona los problemas públicos de la forma más inteligente posible. En efecto, mientras Kitcher considera que hay condiciones en las sociedades contemporáneas bajo las cuales la discusión pública amenaza la libertad de los ciudadanos y mina el valor más básico de la democracia, razón por la cual muchas veces es recomendable no abusar de la discusión libre para que los individuos no asuman posiciones quiméricas o pseudo-cientificas (Cf. Kitcher, 2011a, p. 121), Dewey se aleja del individualismo epistemológico y sostiene que la discusión pública sostenida es la que resuelve el problema del prejuicio epistémico de la ignorancia del ciudadano y la conducción tendenciosa de los representantes políticos. Así, indica Ólafsson, "[e]l punto no es crear un foro mínimo o un microcosmos deliberativo sino aprender mediante la acción -mediante el trabajo de mejorar las condiciones de comunicación e información.” (2017, p. 184). Por lo tanto, la categoría deweyana de público es más fructífera para dirimir la pregunta por la significatividad científica que el "microcosmos" de los deliberadores ideales pues ofrece una vía de resolución práctica, comunitaria y cooperativa al problema divisado por Kitcher (Cf. Ólafsson, 2017, p. 185). ${ }^{111}$

${ }^{111} \mathrm{Si}$ bien no es objetivo de estas páginas, el argumento de Ólafsson tiene como referencia la declaración de Kitcher por la cual los individuos tendrían cierto nivel de ignorancia irreductible o irremediable, razón que los vuelve maleables a las intenciones de los "retóricos habilidosos" con intereses parciales y perjudiciales para la sociedad -como puede ser, por ejemplo, en la discusión sobre cambio climático (Kitcher, 2011a, pp. 117121). Desde aquí, arguye Ólaffson (2014, p. 179), podría decirse que para Kitcher “[...] sólo unos pocos 
En segundo lugar, es importante notar que la democracia comparte con la experiencia primaria su carácter experimental. El ideal de democracia y, en particular, de "democracia radical", no es una utopía o un principio regulativo en un sentido kantiano, que no se puede realizar por definición. Por el contrario, las ideas e instituciones políticas son hipótesis y fines de vista que deben realizarse y juzgarse por sus consecuencias en la experiencia real. En este sentido, la idea de democracia funciona como un estándar crítico para evaluar las democracias actuales. Por otro lado, y de acuerdo con el enfoque teórico sobre el continuo medios-fines, la experiencia humana señala inequívocamente que los fines democráticos exigen métodos democráticos para su realización (Cf. Supra, Capítulo 6.2). Además, este proceso de toma de decisiones implica apertura y discusión, no solo en niveles institucionales o gubernamentales, sino particularmente en los hábitos cotidianos, que devienen cooperativos e inclusivos (Fesmire, 2015, p. 155 y siguientes; Mougan Rivero, 2016, pp. 94-96).

En esta línea vale recordar el planteo deweyano por el cual la democracia es el ideal de vida comunitario que tiene como punto de apoyo la dimensión de las consecuencias de las acciones concretas entre los individuos y grupos. Por otro lado, vale también recordar que para el pragmatista "[1]a democracia es la creencia en la capacidad de la naturaleza humana para generar objetivos y métodos que acrecienten y enriquezcan el curso de experiencia. [... y que f]rente a otros modos de vida, la democracia es el único inspirado y sostenido por la firme creencia en el proceso de la experiencia en cuanto fin y en cuanto medio [...]." Teniendo en cuenta lo dicho, queda claro por qué, lejos de adoptar una visión mecanicista o formal, Dewey enraíza su idea de democracia como forma de vida en la noción misma de experiencia (Dewey, 1996, pp. 204 y 205. LW.14.228). Para resumir, y como señala Westbrook, la democracia es "[1]a plena realización de las posibilidades de la sociedad humana como tal", considerada no como algo que ya hemos alcanzado, sino como un ideal "arraigado en los aspectos más esenciales de la experiencia humana." (1993, p. 365. Traducción propia). En este sentido, pues, Dewey ofrece una respuesta clara a la

poseen las habilidades necesarias para el conocimiento y la consecuente conducción de la opinión pública.” A este diagnóstico pesimista de Kitcher, basado en un fuerte individualismo epistemológico, Ólafsson le contrapone la idea deweyana de que las mejoras en las condiciones de comunicación y participación conducen a que el público se identifique como tal y devenga una fuerza más activa y competente. Esta diferencia hace que la propuesta de Dewey sea más realizable en la medida en que no tiene que (i) articular las condiciones de la deliberación ideal con la práctica política efectiva ni (ii) lidiar con ese fondo irreductible de ignorancia, tesis que rápidamente puede conducir a posiciones experto o epistocráticas à la Lippmann. 
pregunta de Kitcher acerca de por qué deberíamos querer vivir en una sociedad democrática mediante lo que propongo denominar fundamentación "experiencial" de la democracia: si hay compromiso efectivo con el crecimiento y el enriquecimiento de la experiencia actual, entonces también debería haber compromiso con la democracia como una forma de vida que se forja en el carácter cooperativo y que supera la dicotomía entre la interpretación meramente procedimental y la interpretación sustantiva a priori. Lamentablemente nada de esto aparece en la explicación de Kitcher, cuya referencia a Dewey no pasa de ser meramente eso, una referencia. ${ }^{112}$

En tercer lugar, los valores de libertad e igualdad también deben ser reconsiderados, desde dos puntos de vista. El primero tiene que ver con el enfoque metodológico reconstruido en la primera parte de esta investigación. Si Kitcher remite a Dewey para enmarcar su concepción de ciencia bien ordenada y democracia y a la vez busca desmarcarse de una concepción objetivista de los valores, resulta cuanto menos extraño que no atienda a las consideraciones de Ética y de "Teoría de la Valoración”, por mencionar sólo dos referencias, en favor de adoptar una visión de los valores como resultado de la investigación y de la deliberación acorde con el naturalismo, la idea de ciencia y de democracia que presuntamente adopta del pragmatismo deweyano. En efecto, Dewey insiste en que la postulación de fines o valores en sí mismos es resultado indeseado de fragmentar la continuidad medios-fines y que eso trae aparejada la peligrosa alternativa de quitar del ámbito de discusión a los propios fines y reducir la inteligencia a una mera consideración de medios - movimiento por el que, paradójicamente, él mismo ha sido acusado. Como fuera, la discusión de Dewey contra las posiciones objetivistas y aprioristas ha estado presente en todos sus textos sobre el juicio valorativo como tipo particular de juicio práctico y podría haber sido considerada por Kitcher para dar cuenta de su posición meta-ética -recordando, siempre, que es el propio Kitcher quien se adscribe a la línea deweyana.

\footnotetext{
${ }^{112}$ En este mismo sentido Honneth plantea que el modelo deweyano ofrece una alternativa a la interpretación meramente procedimental de la democracia (léase Rawls o Habermas) y a la interpretación supra-ética del liberalismo (Arendt, Sandel) pues permite "[...] concebir la eticidad democrática como resultado de aquella experiencia que pueden hacer todos los miembros de una sociedad entre sí, sólo si estuvieran relacionados cooperativamente unos con otros por medio de una organización justa de la división del trabajo." (Honneth, 1999, p. 105).
} 
El segundo punto se vincula con la interpretación conceptual de los valores de libertad e igualdad. Para Dewey, las concepciones tradicionales tienden a aislar la libertad y la igualdad de la vida comunitaria y a reducirlas como simples abstracciones sin esperanza. Como resultado, "[1]a la igualdad se convierte en un credo de identidad mecánica que se contradice con los hechos y es imposible de realizar" y la libertad "[...] se entiende entonces como la independencia de las ataduras sociales [...]" (Dewey, 2004, p. 138. LW.2.329). A diferencia de esto, Dewey sugiere que la libertad y la igualdad deben interpretarse como marcas y rasgos de la comunidad, tomando la forma dinámica de los fines a la vista. Por lo tanto, la mera ausencia de restricciones externas es una condición necesaria pero no suficiente para lograr un pleno desarrollo de la libertad. Por el contrario, esta concepción de la libertad solo podría tener lugar en un modo de vida democrático, promoviendo un equilibrio entre el punto de vista del individuo, el responsable de formar, dirigir y participar en las actividades de los grupos a los que pertenece, según sus valores, y el punto de vista del grupo, que debe propiciar la liberación de las potencialidades individuales antes mencionadas en armonía con los bienes e intereses comunes.

En suma, ni la reformulación de los fundamentos políticos ni la posición meta-ética a la base del ideal de ciencia bien ordenada presentadas por Kitcher parecen ir más allá de las referencias textuales a Dewey. En efecto, si el argumento de Kitcher se apoya en (i) una concepción de democracia informada que se torna igualmente ideal por asumir la interpretación procedimental -desconociendo que Dewey vincula indisociablemente su concepción de democracia con su concepción de experiencia- y en (ii) una concepción objetivista de los valores de libertad e igualdad y una interpretación que enfatiza la concepción negativa de dichos valores - desconociendo los aportes metodológicos y la interpretación deweyana- entonces no es consistente con las referencias al pragmatismo clásico. Como resultado, todo su planteo queda a medio camino pues busca apoyarse en una visión experiencial de la democracia pero en definitiva nunca logra despegarse de la visión procedimental-ideal. Y esto es fatal para las aspiraciones del ideal de ciencia bien ordenada porque a fin de cuentas no ofrece explicaciones convincentes acerca de qué investigaciones deben ser llevadas a cabo en una sociedad democrática.

\section{Conclusiones}


En este capítulo he analizado el ideal de ciencia bien ordenada propuesto por Kitcher en cuanto alternativa al ideal de ciencia libre de valores. En virtud de reconstruir el planteo de Kitcher he señalado sus críticas a la leyenda de la ciencia y al mito de la pureza, cuya conjunción arroja una imagen de la ciencia como búsqueda de la verdad orientada por criterios exclusivamente epistémicos. Frente a esta interpretación Kitcher supone un realismo moderado y sostiene que la ciencia busca la verdad significativa y que esta última comprende una dimensión epistémica o teórica y una dimensión práctica. Esta perspectiva constituye lo que he denominado la fundamentación epistemológica del ideal de ciencia bien ordenada, la cual se articula directamente con la consideración política pues introduce la pregunta por la significatividad de la investigación y habilita a echar mano a los esquemas amplios de valores para fundamentar la respuesta a esa cuestión. En este sentido, la noción de verdad significativa es un aporte muy interesante al momento de dar cuenta del aspecto moral y político de la investigación científica pues funciona como pivote entre su dimensión epistemológica y su dimensión valorativa (tradicionalmente considerada como extra-epistémica).

Dada la pregunta por la significatividad de la investigación y la intención de Kitcher de que la práctica científica se inscriba en y de cuenta del contexto en que se lleva adelante, aparece entonces la necesidad de fundamentar el ideal de ciencia bien ordenada ya no en términos epistemológicos sino meta-éticos y políticos. Para ello Kitcher diseña un modelo llevado adelante por deliberadores ideales que representan todos los puntos de vista de la sociedad. El resultado de esa deliberación sería una decisión respecto de la significatividad de la investigación en función de cuánto logre expresar las preferencias debidamente informadas de los deliberadores y sus hipotéticos representados. Esa fundamentación, y consecuentemente el ideal de ciencia bien ordenada, presenta dos versiones. La primera de ellas es de impronta rawlsiana, acentuando el carácter procedimental del modelo. Frente a las críticas recibidas respecto del funcionamiento de la deliberación ideal Kitcher elabora una segunda versión y se remite a la concepción deweyana de democracia como experiencia conjunta comunicada, en virtud de evitar una visión mecánica o formal de la democracia y una visión objetivista de los valores, al tiempo que explica que deberíamos 
querer vivir en democracia porque ésta es la mejor respuesta frente a la opresión identificable.

Ahora bien, esta segunda reformulación tampoco queda exenta de tensiones ni supera, en definitiva, una visión procedimental. Dicho de otra forma, teniendo en cuenta que es Kitcher quien remite a Dewey, sus explicaciones no adoptan una impronta deweyana. A mi juicio, esto queda claro tanto si se considera la imagen de la democracia ofrecida por el autor, cuyo nivel corolario está conformado por la "maquinaria de elecciones" - planteo difícil de conciliar con la pretendida crítica a las visiones formales de la democracia- como si se considera su adopción de las versiones negativas de los ideales de libertad e igualdad. En consecuencia, el pragmatismo de Kitcher no parece ir más allá de las referencias textuales y su ideal de ciencia bien ordenada no logra explicar de forma consistente con esas mismas referencias cómo y por qué se define el carácter significativo de una investigación para ser llevada a cabo en una sociedad democrática.

En este marco, he intentado señalar que, una vez asumido el marco teórico deweyano, Kitcher podría haber tenido en cuenta tres elementos fundamentales para resolver las tensiones de su planteo inicial. En primer lugar, el concepto deweyano de público puede ser una alternativa al modelo de deliberadores ideales, alternativa consistente tanto con la intención del ideal de ciencia bien ordenada como con la concepción de la democracia como forma de vida, según he señalado en el capítulo 6. En segundo lugar, la relación que plantea Dewey entre democracia y experiencia - por la cual la democracia es la forma de vida que permite la experiencia más plena y rica posible a nivel individual y comunal- le habría permitido a Kitcher desmarcarse definitivamente de una visión formal, procedimental o mecánica de la democracia, tal y como se propone en la segunda versión del ideal. Finalmente, el enfoque metodológico deweyano de los valores como fines a la vista generalizados y resultado de la investigación controlada junto con la interpretación sustantiva de la libertad y la igualdad como condición para el pleno desarrollo cualitativo del individuo y de la comunidad le habrían aportado a Kitcher un contexto consistente para superar las visiones objetivistas y vacías de ambos ideales. En definitiva, una perspectiva deweyana consecuente podría ofrecer respuestas a las dificultades indicadas y permitiría avanzar en algunas de las ciertamente interesantes líneas de reflexión abiertas por Kitcher. 


\section{CAPÍTULO 9: LA PERSPECTIVA IBEROAMERICANA}

\section{Introducción}

En la tercera parte de esta investigación he propuesto abordar ciertas visiones críticas del ideal de ciencia libre de valores con el objetivo de analizarlas y señalar en qué medida el marco teórico deweyano puede aportar argumentos a la discusión o algunas fundamentaciones filosóficas elaboradas y sólidas a esas posiciones intervinientes. El ámbito filosófico iberoamericano, especialmente México, Argentina y España, no ha sido ajeno al debate sobre la carga o neutralidad valorativa de la ciencia sino que ha avanzado en ricas discusiones. En este capítulo me ocuparé de recuperar y evaluar las propuestas del mexicano León Olivé y del español Javier Echeverría acerca de la ciencia, la tecnología y la tecno-ciencia en cuanto prácticas cognitivas atravesadas por múltiples valores y del modo en que su reconsideración implica una nueva formulación de la idea de racionalidad científica y, más aún, de racionalidad en sentido general.

Desde el punto de vista de los autores, la inclusión del análisis de los valores en la ciencia y la tecnología se sostiene en base a la consideración de que ambas están constituidas por agentes intencionales con capacidad de representar el mundo e intervenir en él. Al mismo tiempo, esos agentes asignan distintos valores a los estados de cosas. En este marco, los problemas éticos y políticos que plantean la ciencia y la tecnología no se reducen sólo al uso de los conocimientos o artefactos sino que en tanto sistemas intencionales, estos problemas surgen en torno a la intención de los agentes, los fines que persiguen y los resultados que de hecho producen. Puesto que dichos elementos son susceptibles de análisis en base a los valores que los sustentan (esto es, son pasibles de valoración, podría decirse desde el enfoque deweyano) entonces el propio sistema intencional es valorable, razón por la cual desde esta concepción la ciencia y la tecnología no pueden verse como valorativamente neutrales. A partir de estas consideraciones generales la segunda sección del capítulo estará dedicada a señalar por qué la ciencia y la tecnología son prácticas cognitivas y a recuperar el novedoso concepto de tecno-ciencia planteado por Echeverría -concepto que se elabora observando especialmente el tipo de valores que intervienen en la práctica cognitiva y las relaciones que se establecen entre 
ellos. Por su parte, la tercera sección quedará reservada a analizar y ponderar la noción de valor y sus fundamentos filosóficos, según los plantea el mismo Echeverría.

Ahora bien, en opinión de los autores la conclusión respecto del carácter valorativamente cargado de las prácticas cognitivas lleva a discutir y ampliar la idea misma de racionalidad epistémica en al menos dos sentidos. Por un lado, y a tono con las críticas al ideal de ciencia libre de valores, Olivé y Echeverría plantean que la racionalidad epistémica debe incluir un pluralismo de valores estrechamente vinculado con el pluralismo de fines que animan a las prácticas científicas. Por otro lado, en cuanto sistemas intencionales, la ciencia y la tecno-ciencia admiten (e incluso reclaman, desde el punto de vista que me interesa defender en esta investigación) un sentido de racionalidad que no se limita a su sentido instrumental sino que incluye la valoración de sus propios fines. Más aún, si la producción de conocimiento científico es una forma específica de la acción y la incorporación del aspecto valorativo conlleva una modificación en la concepción de racionalidad científica, entonces tenemos que proyectar esas mismas modificaciones para la racionalidad "en sentido general", entendida en los términos de racionalidad axiológica o valorativa. Bajo estas observaciones, en la cuarta sección reconstruiré estos argumentos antedichos e indicaré algunos rasgos del sentido deweyano de racionalidad que, en mi interpretación, permiten encuadrar los planteos de Olivé y Echeverría y ofrecen una fundamentación más elaborada a los novedosos y ricos planteos de ambos filósofos iberoamericanos.

\section{Ciencia y tecno-ciencia como prácticas cognitivas}

\subsection{Del "reduccionismo heredado" a la acción científica}

En línea con la reconstrucción histórico-filosófica planteada en los comentarios preliminares a la tercera parte de este estudio, Echeverría señala un lugar común a las visiones clásicas en filosofía de la ciencia: la identificación de los valores epistémicos como los únicos que pueden regir en ciencia y, como contrapartida, el rechazo de los valores tradicionalmente denominados extra-epistémicos. A su juicio, el origen de esta postura dicotómica radica en la filosofía empirista de John Locke y de David Hume: el

primero es responsable de la distinción entre Filosofía Natural, Filosofía Práctica y Semiótica, ámbitos de conocimiento completamente separados y diferenciados entre sí en 
razón de sus finalidades. Hume, en tanto ideólogo de la distinción entre juicios de hecho y juicios de valor, es quien marca la irreductibilidad entre el ser y el deber ser, dando pie a la posterior formulación de la falacia naturalista Esta línea abierta por Locke y Hume, que también es reforzada por Kant y los neo-kantianos, tiene un punto alto en la obra de Weber, para quien los juicios de valor deben estar ausentes en las obras que se precien de ser auténticamente científicas, las cuales, a su vez, se guían únicamente por el valor epistémico de la verdad (Cf. Echeverría, 1995, pp. 71-73). Así se consolida tanto la identificación de la racionalidad científica con la racionalidad pura como la separación entre ciencia y axiología o valoración, junto con el consiguiente precepto de la neutralidad valorativa de la ciencia y un fuerte monismo axiológico.

Según Echeverría, la concepción filosófica que mejor da cuenta de esta herencia es el empirismo lógico del Círculo de Viena y sus continuadores, hasta aproximadamente la década de 1960. Si hubiera que sintetizar en una sola palabra al conjunto de las críticas que Echeverría aplica al Círculo de Viena y a la "concepción heredada", esa palabra sería reduccionismo. Ese reduccionismo se juega en varios aspectos: reducir la ciencia a los contextos de descubrimiento y justificación; reducir la reflexión filosófica válida al segundo de ellos, reducir el objeto de estudio a las teorías, reducir al mínimo el impacto de cualquier valor ajeno al ámbito epistémico y finalmente reducir la racionalidad a su función teórica e instrumental. Una vez presentada la interpretación en clave axiológica de algunos autores fundamentales en la filosofía de la ciencia, se deben analizar dos aspectos fundamentales de la postura de Echeverría: (i) la distinción de cuatro contextos en la ciencia, y como consecuencia, (ii) la consideración de esta última en términos de acción que puede explicarse a partir de los valores compartidos por los científicos.

El primer movimiento de Echeverría pasa por objetar la distinción tradicional entre contexto de descubrimiento y contexto de justificación presentada por Reichenbach (1938) y presupuesta por Popper, Carnap e incluso el manifiesto del Círculo de Viena. ${ }^{113}$ Como he señalado en la introducción general de este estudio y también en los comentarios preliminares de su tercera parte, durante la segunda mitad del Siglo XX surgen críticas a la

${ }^{113}$ Echeverría indica que la misma distinción también se le puede atribuir a filósofos precedentes como Husserl o Frege e incluso menciona a Kant, Aristóteles y Euclides, de manera que estamos frente a "[...] uno de los grandes pilares de la reflexión filosófica de la ciencia." (Echeverría, 1995, p. 51). 
posición de Reichenbach, en varias líneas. Echeverría encuentra en el ya referido Robert Merton un punto de partida para esa discusión pues si bien Merton restringe su campo de estudio a las instituciones científicas, se encarga de analizar la estructura normativa de la ciencia y define el ethos de la ciencia como un complejo de valores y normas anclados en las instituciones. Esta interpretación de Merton, a pesar de restringir el objetivo de la ciencia a la extensión del conocimiento verificado (de modo que termina respondiendo a la tendencia reduccionista del monismo axiológico), ubica a los objetivos, valores y normas como una parte importante de la ciencia. Este es precisamente el punto que le permite a Echeverría sentar un primer precedente en la conformación de una interpretación de la ciencia que discute la neutralidad axiológica y la distinción entre juicios de hecho y juicios de valor, al tiempo que admite que los enunciados que formulan los científicos están cargados de valores, como mínimo epistémicos e institucionales -observación que a su tiempo incluye la dimensión intersubjetiva de la práctica científica, en la medida en que esta última requiere valores compartidos para ser llevada adelante (Cf. Echeverría, 1995, pp. $75-79$ y $2002 a$, pp. 58-60).

Más allá del antecedente de Merton, Echeverría coincide con la lectura generalmente aceptada por la cual una de las referencias ineludibles al momento de discutir la concepción heredada de la filosofía de las ciencias es Kuhn. En efecto, el español señala que Kuhn y los filósofos de la ciencia de tendencia historicista optan por añadir nuevos términos a la distinción entre contexto de descubrimiento y justificación. Finalmente, la sociología de la ciencia post-mertoniana, y especialmente los estudios de laboratorio, entre otros, avanzan de manera decidida frente al reduccionismo epistemológico de la postura positivista argumentando que los hechos, teorías y descubrimientos "se construyen" en los laboratorios. Ahora bien, Echeverría entiende que, así como el positivismo adolece de un reduccionismo epistemológico, también la sociología de la ciencia representa otro tipo de reduccionismo pues limita la evaluación y valoración de la actividad científica a los parámetros tradicionalmente epistémicos (hechos, teorías, descubrimientos). Frente a las dos clases de reduccionismo el español propone replantear la distinción entre contexto de descubrimiento y contexto de justificación en virtud de considerar la amplitud y variedad de la actividad científica, de manera que justificación o descubrimiento resulten uno más entre otros contextos de la ciencia. En razón de lo anterior, y bajo la consideración de la 
ciencia como una construcción social altamente especializada, Echeverría distingue cuatro contextos, sin intenciones de demarcar sino de señalar diferencias funcionales: (i) de educación, enseñanza y difusión, (ii) de innovación, (iii) de evaluación o valoración, y (iv) de aplicación (Cf. 1995, pp. 58-66).

Respecto del contexto de educación, enseñanza y difusión, Echeverría entiende que es el primer ámbito en el que la actividad científica tiene vigencia pues para entender un enunciado científico es menester manejar un sistema de complejos conocimientos teóricos y prácticos sin los cuales no hay posibilidad de descubrir, justificar o aplicar conocimiento alguno. La educación incluye para Echeverría dos acciones recíprocas básicas: enseñanza y aprendizaje tanto de sistemas conceptuales y lingüísticos como de representaciones mentales adecuadas de conocimientos científicos previos que prefiguran la adscripción del científico o profesional a un paradigma o comunidad científica y le permiten trabajar en la situación kuhniana de "ciencia normal". En el contexto de innovación, que reemplazaría al contexto de descubrimiento, Echeverría contempla no solo la elaboración teórica de la ciencia clásica sino fundamentalmente la labor de invención propia de la tecno-ciencia. Aquí prima la producción de conocimiento, lo cual incluye la construcción de nuevos artefactos técnicos, empíricos e incluso teóricos cuyo éxito o fracaso depende de su utilidad, de su funcionalidad, de la facilidad con la que puedan ser utilizadas, de su capacidad para plantear y resolver problemas.

Estas consideraciones aparecen estrechamente ligadas al contexto de evaluación o valoración, en tanto reelaboración del contexto de justificación tradicionalmente limitado a una buena fundamentación metodológica de la ciencia (cualquiera sea el modelo que se aplique). En efecto, si se amplía el ámbito de descubrimiento a la innovación entonces se debe ampliar el ámbito de justificación a la evaluación o valoración porque se incorporan nuevos elementos de evaluación que superan las herramientas lógico-formales de la versión algorítmica de la racionalidad. En pocas palabras, si los descubrimientos se justifican, las innovaciones se evalúan y se valoran. Finalmente, el contexto de aplicación se vincula con la idea de la ciencia como transformadora del mundo en la medida en que instrumentos, técnicas, métodos y resultados de la actividad científica sufren modificaciones según estén en uno u otro contexto. Nuevamente los criterios de aceptación trascienden a la comunidad 
científica y se remiten a la sociedad en general de manera tal que la política y la gestión científica devienen cuestiones fundamentales, tanto en el plano público como en el privado. También aquí Echeverría sostiene una tesis que puede leerse en clave pragmatista pues según ha sido subrayado en el Capítulo 6 Dewey sostiene que la ciencia se convierte en conocimiento "en sentido honorífico" sólo en la aplicación, que incluye asimismo la instancia de divulgación y valoración por parte de un público competente y activo. Sin lugar a dudas, todos los elementos mencionados amplían la concepción de ciencia y de racionalidad típicamente positivista $\mathrm{y}$, como se evaluará posteriormente, son centrales para la tesis que sostiene Echeverría sobre la racionalidad axiológica.

En las consideraciones precedentes se ha supuesto a la ciencia como acción, práctica o actividad científica, a diferencia del enfoque positivista que se concentra en la teoría o producto final del conocimiento científico. Echeverría (2002b) plantea la necesidad de pasar de las teorías científicas a las acciones científicas como unidad de análisis fundamental y la insuficiencia de las teorías atomistas de la acción o del modelo nomológico-deductivo de Hempel para dar cuenta de la práctica científica. En primer término es interesante destacar que para el autor

[...] se parte de la afirmación de que la ciencia es una actividad transformadora del mundo, que por tanto no se limita a la indagación de cómo es el mundo, sino que trata de modificarlo en función de valores y fines [...] Aquí consideraremos que la razón humana, y en concreto la razón científica, es una potencia activa que tiende a transformar lo dado para hacerlo mejor. Los científicos nunca son inactivos frente a la naturaleza o al mundo, al menos si nos referimos a la ciencia actual. [...] Frente a la separación estricta que postuló Hume entre lo que él llamaba filosofía especulativa y filosofía práctica, y por consiguiente entre conocimiento científico y moral, conviene insistir en que incluso la investigación en las ramas más puras de la ciencia tiende siempre a transformar algo que venía dado previamente (Echeverría, 1995, pp. 68-71. Comillas en el original).

Puede observarse cómo la extensa cita anterior condensa en algunas pocas líneas tres temas centrales, a saber: (i) una presentación de la ciencia y del científico como 
fundamentalmente activos y prácticos; (ii) una propuesta de revincular el ámbito teórico y especulativo con el práctico, en virtud de considerar a la razón como una potencia transformadora; y por último (iii) un concepto de racionalidad que ya no contempla verdades sino que modifica el mundo que le es dado en base a fines y valores. En este contexto la filosofía de la ciencia debe alejarse del prurito cientificista común al positivismo lógico y a la sociología de la ciencia, visto que ni la base empírica ni la base sociológica alcanzan para explicar a la actividad científica en toda su complejidad, y considerar atentamente que esta última adquiere su auténtico sentido no en sus orígenes sino en sus fines. En consecuencia, y como se irá analizando a lo largo del capítulo, ampliar la concepción de la ciencia en términos de actividad o práctica implica que la reflexión filosófica sobre el conocimiento, la ciencia y la racionalidad no se limite a una actividad metateórica que analiza lógica y metodológicamente las teorías científicas; desde ahora "[...] la filosofía de la ciencia ha dejado de ser únicamente una filosofía pura (o filosofía del conocimiento científico) para pasar a ser, además, una filosofía práctica, en el sentido de una filosofía de la actividad científica." (Echeverría, 1995, p. 41).

La interpretación de la ciencia como una actividad implica una serie de modificaciones respecto de las consideraciones más tradicionales -modificaciones que en principio no parecerían ajenas al planteo deweyano, en la medida en que el principal viraje teórico de Dewey es considerar que la acción es la categoría de análisis básica y, consecuentemente, que el conocimiento es una forma de actividad. Así, en el diseño de una concepción alternativa la ciencia y la tecnología deben concebirse como prácticas cognitivas constituidas por sistemas de acciones intencionales, esto es, sistemas que incluyen a agentes que deliberadamente buscan ciertos fines en función de determinados intereses, y para lo cual ponen en juego creencias, valores y normas.

A este respecto uno de los aportes más interesantes es el de León Olivé. En El bien, el mal y la razón Olivé considera que la ciencia es mucho más que un conjunto de conocimientos científicos: es una práctica dinámica llevada adelante en instituciones y orientada hacia el logro de fines en función de deseos, intereses y valores (2000, pp. 87-89). Las prácticas cognitivas incluyen (i) un conjunto de agentes, que se proponen actividades colectivas y coordinadas; (ii) un medio en el cual se desenvuelven esas prácticas; (iii) un 
conjunto de objetos; (iv) un conjunto estructurado de acciones que se planean, incluyendo (iv.i) representaciones del mundo, (iv.ii) intenciones, propósitos y fines, (iv.iii) supuestos básicos, (iv.iv) juicios sobre hechos y juicios de valor, y por último (iv.v) afectos y emociones.

Olivé indica que un rasgo constitutivo de las prácticas es su estructura axiológica y que la elección de creencias o de teorías necesariamente debe realizarse dentro de una práctica, donde se efectúan acciones sujetas a la referida estructura axiológica. En este sentido propone discutir con aquellas posiciones que consideran que la ciencia y la tecnología son valorativamente neutrales, es decir que no son buenas o malas en sí mismas sino que pueden ser juzgadas moralmente sólo sus usos y aplicaciones. Según el mexicano una concepción tal se sostiene bajo tres supuestos: (i) que la ciencia y la tecnología sólo son medios para la consecución de fines determinados; (ii) que los problemas éticos surgen en la elección de los fines; y finalmente (iii) que los científicos y los tecnólogos no son responsables por los fines que otros eligen, sino que esta elección compete a los políticos o militares. En definitiva, a la base de esta posición está funcionando la clásica distinción entre hecho y valor como supuesto general, siendo el objetivo de las teorías científicas el describir y explicar los hechos sin involucrarse en juicios de valor sobre esos hechos. Por el contrario, la concepción del mexicano ya no entiende a la ciencia como conjunto de teorías ni a la tecnología como conjunto de artefactos o técnicas sino que ambas con interpretadas bajo la noción de sistemas de acciones intencionales. De acuerdo con lo dicho anteriormente, estos sistemas incluyen a los agentes que deliberadamente orientan sus acciones a ciertos fines en función de intereses, normas y valores -elementos que también constituyen al sistema de acción intencional y que precisamente porque son susceptibles de evaluación moral y política, tornan evaluable al propio sistema.

Reconociendo explícitamente el aporte de Olivé, Echeverría distingue una pluralidad de componentes de la acción científica, distinción que tendrá una notable incidencia a la hora de evaluar las acciones científicas pues los valores relevantes son muy distintos según el componente al que se haga referencia. A los fines de reconstruir la postura del español basta indicar aquí que identifica doce componentes de una acción, a saber: (i) agente; (ii) acción (iii) complemento directo; (iv) complemento indirecto, (v) instrumentos o herramientas; (vi) lugar o contexto, que a su vez se diferencia en (vii) 
coordenadas espacio-temporales y (vii') condiciones iniciales; (viii) intenciones, objetivos o fines; (ix) reglas, normas y prescripciones; (x) resultados de la acción; (xi) consecuencias; y finalmente (xii) riesgos de la acción. Asimismo, Echeverría retoma dos ideas de Olivé centrales para dar cuenta de la posición de ambos filósofos: en primer lugar, ambos sostienen que la ciencia no tiene esencia constitutiva, fines prefijados ni reglas establecidas definitivamente sino que el desarrollo científico debe considerarse siempre a la luz de los criterios particulares del contexto en que estemos (Olivé, 2000, p. 135). Por otro lado, ambos afirman un pluralismo teleológico que se deriva del pluralismo axiológico: "De acuerdo con Olivé, afirmamos el pluralismo axiológico, metodológico y lo que podríamos denominar pluralismo teleológico, es decir: la tesis de que la actividad científica no tiene un único objetivo o fin, sino varios, precisamente porque está guiada por varios valores, no por uno principal." (Echeverría, 2002a, p. 95. Cursivas en el original). En este sentido el español reconoce hasta doce subsistemas de valores relevantes para evaluar las acciones científicas, junto con los diversos valores particulares de cada subsistema: valores básicos, epistemológicos, técnicos, económicos, militares, políticos, jurídicos, sociales, ecológicos, religiosos, morales y estéticos.

Estas dos listas de componentes y subsistemas dan cuenta de la complejidad que considera el autor a la hora de evaluar una acción científica, complejidad que lo conduce a afirmar que cuando pensamos en ciencia la ética no tiene la primacía en el campo de los valores relevantes, aunque por supuesto tiene lugar en la evaluación de las acciones científicas. Antes de abordar esta última cuestión, que llevará a analizar la propuesta del español respecto a cómo entender a los valores y en qué medida es posible considerar una valoración axiológica de las prácticas cognitivas, resulta interesante avanzar en la consideración de aquello que Echeverría denomina tecno-ciencia, una categorización a mi juicio novedosa que permite señalar distinciones con la práctica científica más tradicional pero que mantiene la tesis de la pluralidad axiológica y los conflictos de valores como sus aspectos constitutivos. 


\subsection{La revolución tecno-científica}

El concepto de tecno-ciencia es presentado por Echeverría (2003) desde dos perspectivas convergentes. Por un lado se encuentra la perspectiva histórica, en la que se diferencian tres etapas: (i) la emergencia de la Big Science (1940-1965), primera modalidad de tecnociencia caracterizada por una fuerte apuesta a la investigación básica, financiación estatal y orientación militar, impulsada por el ya referido informe de Vannevar Bush de 1945 y en cuyo contexto se desarrollaron proyectos como los "Radiation Laboratory" de Berkeley y del Massachusetts Institute of Technology o el Proyecto Manhattan de Los Álamos; (ii) una década de relativo estancamiento (1966-1976), producto de la desconfianza y contestación social frente a la macrociencia militarizada de Estados Unidos y Europa, de la subsiguiente caída de la financiación estatal a la investigación "básica” y sobre todo de la irrupción de nuevos sistemas de valores sociales, morales, jurídicos, etc. que deriva en la conformación de nuevos criterios de valoración para la tecno-ciencia y en el reclamo por un nuevo contrato social de la ciencia orientado a su democratización; y (iii) el auge de la tecnociencia propiamente dicha (1977-), en sus distintas ramas y especialidades, dado por lo que Echeverría denomina un nuevo contrato financiero de la investigación.

No obstante esta reconstrucción histórica, es la segunda perspectiva la que constituye el foco de atención de Echeverría y de estas páginas, denominada perspectiva axiológica -sin perjuicio de las estrechas relaciones con el derrotero histórico antes indicado. En principio Echeverría indica que el concepto mismo de tecnociencia proviene de una propuesta de Latour (2008 [1983]), quien criticó la distinción "interno/externo" frecuentemente utilizada a la hora de reflexionar sobre la producción de conocimiento científico. En línea con la idea de Latour, Echeverría considera que la tecnociencia ha surgido por un cambio profundo en la estructura de la acción científica y no por una revolución metodológica o epistemológica. Ahora bien, según el español la tesis de Latour tiende a desdibujar las diferencias entre ciencia, tecnología y tecnociencia, diferencias que Echeverría quiere mantener (si no taxativamente, al menos con distinciones graduales y notas distintivas de cada una de ellas), en base a una evaluación axiológica de los contextos de investigación y aplicación. En sus palabras, “[...] hay diferencias significativas entre los sistemas de valores que guían las acciones técnicas, científicas, tecnológicas y 
tecnocientíficas. Por ello, para distinguir entre la ciencia y la tecnociencia investigaremos sobre los valores subyacentes a estos dos tipos de actividad." (Echeverría, 2003, p. 49).

Una de las primeras diferencias entre ciencia y tecnociencia está dada por el peso relativo de los sistemas de valores epistémicos y técnicos. Como he señalado con anterioridad, el ideal de ciencia libre de valores se construye sobre la distinción entre valores permitidos y no permitidos en el pretendido núcleo de la ciencia, de tal modo que la prioridad de los valores epistémicos fuera total. Más aún, propuestas como la de Douglas y su argumento respecto de los roles directo e indirecto de los valores cognitivos, sociales y morales en el curso de la investigación científica todavía mantienen la prioridad de los valores epistémicos, cuanto menos en esa instancia de recolección, caracterización e interpretación de datos o evidencia. Por su parte, las interpretaciones más clásicas de la tecnología dan prioridad a los valores técnicos como la eficiencia, la efícacia o la funcionalidad -aún cuando los avances tecnológicos efectivamente incorporen valores tradicionalmente denominados epistémicos en su núcleo axiológico. En el caso de las investigaciones tecnocientíficas Echeverría observa una modificación sustancial dada por la interdependencia casi total entre ciencia y tecnología y por la consecuente reorganización de las prioridades relativas de los sistemas de valores epistémicos y técnicos. Es así que en el marco de la tecnociencia no es posible diseñar y llevar adelante investigaciones científicas sin apoyo tecnológico -todavía más, el propio proyecto es tecnológico en la medida en que se evalúa con criterios relativos a su relevancia y/o utilidad- así como tampoco es posible una innovación tecnológica sin apelar a conocimientos científicos. Luego, la hibridación entre ciencia y tecnología y entre los sistemas de valores epistémicos y técnicos es una marca distintiva de la tecnociencia. Asimismo, con el impulso del Informe Bush y posteriormente con el renovado auge de las investigaciones científico-tecnológicas a mediados de la década de 1960 se evidencia una creciente participación de investigadores en agencias, comités y otras instancias de asesoramiento del poder ejecutivo, especialmente en Estados Unidos. ${ }^{114}$ De este modo, no sólo se consolida la necesidad de atender

\footnotetext{
${ }^{114}$ Echeverría (2003, pp. 188-197) analiza con detenimiento el Informe Bush y a partir de las indicaciones que allí aparecen respecto del modelo lineal de progreso social basado en el desarrollo tecnológico y científico y de la conformación del capital científico concluye que ese informe sienta las bases de la futura economía política de la ciencia y la tecnología.
} 
específicamente al diseño de políticas de ciencia y tecnología sino que la propia práctica de investigación incorpora valores políticos y jurídicos dado que es precisamente en esos marcos en los que podrá desarrollarse.

No obstante, el aspecto que diferencia netamente a la tecnociencia de las instancias precedentes es económico, impulsado por el creciente reemplazo del rol de los Estados en la financiación de los desarrollos tecnológicos por parte de iniciativas privadas durante la década de 1980 y cristalizado en una lógica de competencia inherente a la actividad tecnocientífica. Por supuesto, esta modificación hizo que las empresas de $\mathrm{I}+\mathrm{D}$ devinieran empresas de $\mathrm{I}+\mathrm{D}+$ innovación con el objetivo de insertar y capitalizar las nuevas tecnologías en el mercado. En este sentido, los resultados tecnocientíficos se convirtieron en mercancías, vale decir, en propiedad privada, lo cual supone patentar el conocimiento incluso desde las primeras fases de la investigación. Dada esta mayor ponderación de los aspectos económicos (que a su vez otorga gran peso a los valores jurídicos que permitan asegurar la propiedad del conocimiento), desde el punto de vista axiológico Echeverría concluye que los valores más característicos del capitalismo integran el núcleo mismo de la actividad tecnocientífica y que esa mayor ponderación de valores como la rentabilidad o el logro potencial de patentes genera un cambio estructural o sistémico en el núcleo valorativo de la investigación. Tal es, desde su perspectiva, la diferencia central entre ciencia y tecnociencia: si en la etapa de la macrociencia los científicos se involucraban en grandes proyectos militares por convicciones epistémicas pero también políticas (a pesar de la estrategia filosófica de construir una imagen de ciencia valorativamente neutral, según he indicado en varios pasajes de este trabajo apoyado en la investigación e interpretación de Reisch), la etapa de la tecnociencia queda marcada por la adopción de los valores empresariales no sólo por parte de quienes financian la investigación -al fin y al cabo, sería esperable que eso fuera así- sino particularmente por los propios científicos. En palabras de Echeverría, "[l] tecnociencia siempre está guiada por valores económicos, cosa que sólo sucedía ocasionalmente en el caso de la ciencia” (2003, p. 70. Cursivas en el original).

Ahora bien, la tecnociencia no se distingue únicamente por la incidencia de valores económicos sino que, al igual que en la actividad científica, se reconoce una multiplicidad de sistemas de valores que entran en tensión e incluso hacen de esa tensión una de sus características principales. Un claro ejemplo de esta última caracterización es el Proyecto 
Genoma Humano puesto en marcha en la década de 1990. Las profundas transformaciones en biología y más específicamente en genética se iniciaron a mediados de la década de 1940, con la adopción de modelos matemático-computacionales para estudiar los procedimientos combinatorios y reproductivos de genes y virus y la posterior incorporación de la idea de código genético. Estos aportes - que para Echeverría conforman la aparición en biología de un nuevo paradigma, en el sentido kuhniano del término- sientan las bases para la investigación de Watson y Crick sobre la doble hélice del ADN, cuya metodología es de orden típicamente científica pero, a juicio del español, requirió una serie de conceptos que no podrían haber sido tratados sin el cambio de paradigma en la disciplina. No obstante la repercusión del trabajo de Watson y Crick, publicado en 1953, el primer gran proyecto de investigación sobre el tema tuvo comienzo recién en 1988, con la creación del National Center for Human Genome Research con Watson como director.

Resulta sumamente interesante advertir que una de las primeras decisiones de Watson fue dedicar un 5\% del millonario presupuesto a analizar las repercusiones morales, sociales y legales del proyecto, lo cual indica su relevancia para la propia investigación tecnocientífica, aún cuando sea de manera inicialmente periférica. En efecto, en 1992 el conflicto entre Watson y la directora del área política del proyecto respecto de la posibilidad de patentar fragmentos génicos sin ninguna función conocida derivó en la dimisión de Watson como director y el crecimiento de la figura del biólogo Craig Venter. Un nuevo conflicto jurídico sobre la posibilidad de patentar genes subyacentes aún sin terminar de identificar alejó a Venter de los proyectos estatales y lo condujo al Institute for Genomic Research, institución sin fines de lucro financiada por el mecenas Wallace Steinberg. Equipado con tecnología de punta que permitía multiplicar por 10 el ritmo de trabajo del NCHGR, este Instituto se concentraba únicamente en producir secuencias, es decir información. Ahora bien, Steinberg también fundó la empresa Human Genome Sciences, cuya estrategia fue vender el acceso a las bases de datos del Instituto a empresas farmacéuticas. Así, el conocimiento científico del Instituto se convirtió en una mercancía altamente rentable, al punto que el mismo Venter en 1998 creó su empresa propia: Celera Genomics. Con ello, la disputa tomó un cariz político que trascendió las fronteras de Estados Unidos: atentos a que el National Center for Human Genomic Research también 
contaba con recursos provenientes de Reino Unido, Francia, Alemania y Japón y a que la competencia generada por Celera Genomics obligaba a invertir cada vez más dinero en dicho Centro, el presidente Clinton tuvo que intervenir para lograr un pacto entre el equipo público y el privado y anunciar en 2002 que habían culminado las etapas iniciales del proyecto. Finalmente, la primera versión esencialmente completa del genoma humano fue presentada oficialmente el 14 de abril de 2003 -dos años antes de lo planificado-, cubriendo un total de $3.069 \mathrm{Mb}(92.3 \%$ del total estimado del genoma humano) con un 99.99\% de fiabilidad en cada posición secuenciada.

Esta breve reconstrucción deja en claro que efectivamente hay interdependencia de los sistemas de valores epistémicos y técnicos pues la secuenciación de los genes es tanto una investigación científica como una operación tecnológica, dado que requiere medios y habilidades técnicas de gran desarrollo y capacidad operativa. Sin embargo, la nota fundamental es la mercantilización y la orientación netamente empresarial de la actividad de investigación caracterizada por la reconversión de los resultados en bancos de conocimiento en favor de producir réditos comerciales. A esa nueva impronta se le añaden los litigios judiciales y las cuestiones, para nada menores, respecto del valor moral y político de patentar secuencias genéticas y ofrecerlas en el mercado para que empresas farmacéuticas obtengan aún más ganancias. En este sentido, los avatares que rodearon al PGH y la consecuente multiplicidad de sistemas de valores que se entrecruzan a todo nivel de la investigación dan cuenta de la tesis teórica de Echeverría y de Olivé respecto del pluralismo axiológico de las investigaciones en cuanto prácticas cognitivas -en este caso tecnocientíficas, apelando a la categoría propuesta por el español. Todos estos elementos permiten afirmar que "[d]esde una perspectiva axiológica la tecnociencia se distingue de la ciencia de la tecnología por la mayor pluralidad de sistemas de valores involucrados en los procesos de evaluación. [...] El mito de la neutralidad y de la ciencia value-free ha de ser eliminado de la reflexión sobre la tecnociencia.” (Echeverría, 2003 p. 233).

Por el momento he recuperado algunos aspectos fundamentales de la interpretación sobre la ciencia y la tecnociencia ofrecidas especialmente por Echeverría y he subrayado las razones por las que ambos están en franca oposición al ideal de ciencia libre de valores. No obstante, aún no he avanzado sobre un punto fundamental para su propuesta y para la presente tesis, a saber: qué entiende por valor. En lo que sigue me detendré a analizar el 
enfoque del español sobre esta cuestión para luego indicar algunos cuestionamientos que considero pueden realizarse a su propuesta. Finalmente, en la cuarta sección consideraré las implicancias que suponen propuestas como las de Echeverría y Olivé para la noción de racionalidad epistémica y de racionalidad en general, señalando algunos puntos de contacto con la perspectiva deweyana a ese mismo respecto.

\section{Concepción de valor y fundamentos filosóficos de la axiología}

Ninguna definición es, a juicio de Echeverría, inocua, y por supuesto esa apreciación general le cabe al concepto de "valor". Es así que el español reserva enormes esfuerzos a elucidar la naturaleza de los valores y a argumentar que respecto de aquellos no hay una primacía de la ontología en tanto ciencia primera ni se pueden aplicar los modelos aristotélicos de definición (género y especie) ni de predicación ( $\mathrm{S}$ es $\mathrm{P}$ ). Antes bien, hay una primacía axiológica y los valores se definen en términos de funciones. Bajo esta premisa, Echeverría retoma una idea del filósofo decimonónico Rudolf Lotze y afirma que "los valores no son, valen", en tanto y en cuanto el verbo "valer" no es reductible al ámbito del ser (Cf. Echeverría, 2002a, pp. 29-37).

Desde este punto de partida y frente al esquema aristotélico, Echeverría se inspira en los estudios de Gottlob Frege para caracterizar a los valores como "funciones aplicables a diversos argumentos." 115 Una de las ideas principales que recupera de Frege indica que los términos o palabras no tienen significado de manera aislada sino siempre dentro de un marco proposicional y en combinación con otros términos. Aplicando esta interpretación al campo de la axiología, Echeverría considera que un término axiológico no tiene significado en sí porque un valor sólo adquiere significado cuando está inserto en un sistema de valores y se aplica a una determinada cosa para generar una expresión valorativa. En este sentido, la estructura teórica de Frege le permite alejarse del esquema aristotélico y dejar de considerar a los valores como un predicado que se atribuye a un sujeto para entenderlos como aquello que surge de aplicar las funciones axiológicas a diversos tipos de argumentos. En consecuencia, una expresión valorativa (o, en el caso de expresiones lingüísticas, un enunciado valorativo) cobra la forma $V(x)$, donde $x$ es el argumento y $V$ la función, siempre

\footnotetext{
${ }^{115}$ Las referencias puntuales de Echeverría son al artículo de Frege de 1981, "Sobre concepto y función”.
} 
aplicada por algún agente individual o colectivo. Echeverría dedica varios pasajes para presentar los conceptos fregeanos de objeto y función, sobre los cuales no me detendré en estas páginas, aunque sí mencionaré dos ítems centrales, atento a que el español construirá su axiología formal de la ciencia para analizar los procesos de evaluación de la actividad científica sobre esta matriz. En palabras del mismo autor:

(i) "[1]os valores adquieren expresión, y en su caso sentido, cuando las funciones axiológicas y los objetos a valorar se imbrican mutuamente [...]", dando lugar a las ya mencionadas expresiones axiológicas (Echeverría, 2002a, p. 50), y

(ii) "[1]o importante es que la aplicación de un valor a un determinado argumento (acción científica, resultado científico, instrumento, persona, institución, etc.) tenga sentido, lo cual es una cuestión ante todo pragmática", afirmando que hay valores pertinentes para unos argumentos y no para otros y, en definitiva, dando cuenta del carácter empírico de la axiología, toda vez que ésta parte de los procesos efectivos de evaluación (Echeverría, 2002a, p. 52).

El análisis de estos fundamentos filosóficos conduce a Echeverría a la discusión respecto de la subjetividad u objetividad de los valores, introduciendo así un tema central para los intereses del capítulo. De modo similar a lo realizado en su libro previo Filosofía de la ciencia (1995) Echeverría elabora una breve reconstrucción histórica para diferenciar en términos generales a filósofos subjetivistas y objetivistas. Entre los primeros incluye a Russell, Ayer y Quine, cuyas posiciones remite a Hume y Locke. Por el lado de los objetivistas, el español vuelve a subrayar la figura de Merton y añade referencias a Bunge, Kuhn y Putnam.

En este marco, la referencia que más me interesa considerar es la de Putnam, especialmente en relación a la dicotomía hecho/valor. De acuerdo con la reconstrucción de Echeverría -y en línea con lo señalado en el Capítulo 5 de esta investigación- Putnam no sólo niega la dicotomía sino que afirma taxativamente que no hay hechos científicos (y ni siquiera mundo) sin valores, es decir que estos últimos son condiciones necesarias de aquéllos y que la axiología de la ciencia se convierte en una tarea previa a la filosofía de la ciencia propiamente dicha. En este sentido Putnam ofrece una perspectiva frente a las posiciones subjetivistas, en la medida en que afirma la objetividad de los valores 
epistémicos e incluso de algunos valores éticos, de los cuales dependen los procedimientos de investigación para decidir si algo es o no es un hecho.

Si se consideran los vínculos teóricos entre Putnam y Dewey y a la vez la referencia de Echeverría a Putnam, entonces parecería haber aquí algún nexo, aunque en principio no fuera robusto, entre el planteo de Echeverría acerca de la racionalidad axiológica y algunos aspectos de la posición deweyana -sin dejar de advertir todas las diferencias del caso, en particular acerca de qué entiende cada uno por valor. De hecho, el español cita a Dewey como antecedente filosófico de la posición de Putnam (Echeverría, 2002a, p. 69, n. 70). En razón de lo expuesto Echeverría afirma que sea acerca de instrumentos, datos, condiciones o resultados, la tarea de los científicos pasa por valorar alternativas posibles y tomar decisiones en base a tales valoraciones.

Ahora bien, esas decisiones no dependen de maximizar alguna función de utilidad, en este caso un valor, sino de la satisfacción gradual de los criterios de valoración. Aquí Echeverría recupera los argumentos de Ronald Giere, cuyo modelo de agente racional se diferencia del modelo propio de la economía clásica (vale decir, aquel agente que busca maximizar sus funciones de preferencia) y se asemeja más a un modelo de agente que funciona con condiciones de racionalidad acotada, en base a tres características centrales: (i) trabaja con un número limitado de opciones y estados de mundo, (ii) pocas veces es capaz de calcular la utilidad de cada opción y de mantener un orden de preferencias coherente, y (iii) es capaz de diferenciar entre opciones satisfactorias y opciones no satisfactorias. Luego, los agentes humanos son "satisfacedores" en un sentido acotado, modelo al que Echeverría acoplará su idea de criba axiológica que surge de la introducción sucesiva de nuevos criterios de valoración y que será el fundamento de la racionalidad valorativa. Desde la perspectiva de Echeverría, la noción de "gradualidad de satisfacción o cumplimiento de los valores" y la noción de "satisfacción mínima" se adecúan bien al comportamiento de los científicos durante los procesos de evaluación, entendidos éstos como procesos iterados de valoración y no como resoluciones algorítmicas fundadas en la maximización de utilidad. ${ }^{116}$

116 Respecto de la noción de satisfacción, Echeverría se basa en los estudios de Tarsky sobre Lógica y
Semántica y considera que es una noción axiológica primitiva, lo cual equivale a decir que la relación 301 
En base a estas consideraciones Echeverría elabora una matriz de evaluación que si bien no es propiamente un objeto algebraico muchas veces es representable numéricamente (o cuanto menos formalmente, según el propósito del autor). Esta matriz de evaluación, sumada a la distinción entre valores nucleares y orbitales de cada subsistema, arroja una criba axiológica que en su punto inferior establece un umbral de satisfacción (mas no de maximización) por debajo del cual la acción es inadmisible. De este modo Echeverría introduce su propuesta de formalización axiométrica para sostener que en cada situación hay una cota superior e inferior de satisfacción de cada valor y que la tesis es puramente formal, vale decir, es independiente del contenido de los valores que se consideren y de los agentes que evalúen. La idea del español pasa por transformar los juicios de valor o preferencia en una ecuación con la posibilidad de aplicar distintas técnicas matemáticas y estadísticas para procesar los datos obtenidos, en base al número determinable $n$ en relación a una unidad de medida que surge de la aplicación hecha por un sujeto $A$ de una función axiológica $V$ a un objeto $x$ : $(V A x=n)$. El objetivo ulterior es indicar que será racional aquella acción que se mantenga dentro del rango mínimo-máximo de satisfacción del valor considerado, también expresado con una fórmula: $1_{A, V}<V_{A}(x)<\mathrm{L}_{A, V}{ }^{117}$

Amén de los sucesivos modelos formales que presenta el autor tanto en Ciencia y valores como en trabajos posteriores, resulta importante destacar otra cuestión de la propuesta de Echeverría, a saber: su carácter meliorista. En efecto, se plantea que el modelo no se limita a describir, analizar o reconstruir los procesos de evaluación sino que tiene la capacidad de intervenir y mejorarlos en la misma sucesión de la investigación, tal y como sucede tanto con las formas lógicas de la investigación como con la deliberación de medios y fines en la filosofía de Dewey. En efecto, aquí aparece otro de los pocos pasajes en los que Echeverría menciona a Dewey, si bien entre paréntesis y casi "al pasar":

“[...] no optamos por la noción de preferencia, que tiene connotaciones subjetivistas, sino por un análisis meliorista (Dewey), donde la expresión 'una acción [tecno]científica A (o una de sus componentes) es mejor que otra acción $A^{\prime \prime}$ puede ser analizada en base a

semántica de satisfacción es lógicamente anterior a la de verdad y que siempre es gradual (Cf. Echeverría, 2002, p. 81-87).

117 Recuperamos estas últimas consideraciones de "Dos dogmas del racionalismo (y una propuesta alternativa)" pues allí Echeverría presenta de manera sintética todo el procedimiento de formalización elaborado en Ciencia y valores. 
valores: ser mejor equivale a satisfacer en mayor grado valores pertinentes para evaluar dichas acciones (o componentes). (Echeverría, 2002b, p. 134). ${ }^{118}$

Por todo lo dicho, las prácticas cognitivas (científicas y tecno-científicas) pueden ser explicadas, evaluadas y mejoradas en base al grado de satisfacción de un sistema de valores por parte de sus distintos componentes, valores que no se limitan a los tradicionalmente denominados epistémicos sino que incluyen diversos subsistemas. Luego, la evaluación axiológica de Echeverría, lejos de ser atomista o de caer en el reduccionismo de la "Concepción heredada", es sistémica y plural, tanto respecto de los componentes de la acción como de los valores que intervienen para su evaluación. Así, el autor propone concentrarse en aquellos valores que constituyen el núcleo axiológico de cada contexto de la actividad científica, pues en tanto la reflexión sobre las prácticas cognitivas incluye una axiología, la contribución filosófica pasa por identificar los valores generales de cada instancia y su interacción con cualquier otro criterio que pueda intervenir. En este sentido surgen dos líneas de trabajo para la axiología de la ciencia:

(i) en lo que constituye una vertiente descriptiva, la axiología puede estudiar los valores que efectivamente inciden en la producción, aplicación y enseñanza del conocimiento y de la ciencia, sea a nivel individual, grupal, institucional o social.

(ii) en una orientación normativa, la axiología puede evaluar y proponer cuáles deberían ser esos valores partícipes de la actividad científica. Si bien el aspecto normativo no se aplica al contenido de la ciencia, se pueden promover nuevos valores tanto epistémicos como prácticos que puedan funcionar cual innovación axiológica para los propios científicos.

Como se destacó anteriormente, los valores que intervienen no son exclusivamente éticos o morales sino que son valores (y sus correspondientes disvalores) de todo tipo, de manera que en este contexto de pluralismo axiológico el principal problema consiste en integrar los diversos subsistemas de valores en una sola valoración y consecuente decisión. En estos casos se co-valora, es decir se evalúa en base a varios valores y eventualmente se prioriza unos sobre otros. Dada la tesis de la pluralidad axiológica y la vertiente normativa

118 Casi las mismas palabras aparecen en Ciencia y valores, aunque menciona a Dewey en el Prólogo, cuando presenta el carácter meliorista de la racionalidad valorativa (Cf. Echeverría, 2002a, pp. 165 y 20). 
de la tarea antedicha, la pregunta por "lo bueno" en el caso de las prácticas cognitivas científicas, tecnológicas y tecnocientíficas debe incluir elementos valorativos de orden económico, jurídico, moral y político, entre otros. Desde mi punto de vista, el corolario de esta tesis es radical: los subsistemas de valores que atraviesan las distintas prácticas cognitivas identificadas por los autores ya no pueden ser considerados como contextuales sino más bien como constitutivos, retomando la categoría acuñada por Longino.

No obstante el interés de estas observaciones, entiendo que la propuesta de formalización elaborada por Echeverría es pasible de ciertos cuestionamientos. A pesar de todos los recaudos que toma el autor en su argumentación y de su insistencia en que la formalización no tiene carácter determinante, considero que su intención de brindar un modelo que se expresa en ecuaciones presenta resonancias a las versiones logicistas o algorítmicas de la racionalidad -cuestionadas por el propio español, según señalaré en el próximo parágrafo. Esto se debe a que brindar una fórmula mediante la cual podría decidirse entre dos acciones alternativas sugiere un procedimiento similar al que sucedía para la elección de teorías científicas rivales en base a fórmulas lógico-matemáticas de carácter deductivo. En este sentido Echeverría estaría frenando la discusión filosófica más interesante, esto es, la deliberación en base a valores respecto de las consecuencias de los diversos cursos de acción, y la limitaría a optar por aquella alternativa que permita la satisfacción del valor dentro de un rango racional fijado de manera previa -al menos en relación a la decisión particular que se tome como referencia.

En virtud de lo dicho parece entonces que la posición de Echeverría oscila entre la predilección por el modelo formal, que en el mejor de los casos puede finalmente definir "externamente" que una acción es preferible a otras, y el reconocimiento de la instancia deliberativa como insustituible en la decisión. Por mi parte, sostengo que esta segunda alternativa complejiza el análisis, ofrece una mejor idea de lo que efectivamente sucede al momento de ponderar cursos de acción y por tanto ofrece una visión más rica de la valoración. El propio Echeverría se acerca a esta posición al afirmar que "[1]as matrices de evaluación también pueden representar dichos conflictos [de valores], así como sus procesos de resolución (o enconamiento), siempre que añadamos formas de racionalidad deliberativa a la racionalidad valorativa." (2002a, p. 165. Cursivas agregadas).

\section{Hacia un nuevo modelo (pragmatista) de racionalidad}


Resta abordar un último eslabón en los planteos de Echeverría y Olivé que ha estado implícito en las páginas precedentes y que es puesto de relieve en la última cita: la noción de racionalidad. En efecto, una de las implicancias cruciales de la incorporación de la dimensión valorativa en las prácticas científicas y tecnocientíficas es la modificación de la clásica idea de racionalidad inferencial. El ejemplo más nítido de este sentido de racionalidad ha sido (o ha pretendido ser) la investigación científica, arguye Olivé, mediante la elaboración de un modelo tal que no permita el desacuerdo racional entre sujetos que partieran de la misma evidencia empírica y trabajaran con el mismo conjunto de reglas lógicas. Siguiendo a Harold Brown "[1]as reglas son el corazón de la concepción clásica de la racionalidad: si tenemos reglas que son aplicables universalmente, entonces todos los que comiencen con la misma información deben en efecto llegar a la misma conclusión, y esas reglas son las que proporcionan la conexión necesaria entre nuestro punto de partida y nuestra conclusión” (citado en Olivé, 1995, p. 97). De esta manera, la única forma de racionalidad considerada fue la racionalidad epistémica, algorítmica o logicista. Por otro lado, la idea de neutralidad valorativa de la ciencia ha consolidado una visión instrumental de la racionalidad que, me permito repetir, se ha concentrado en la evaluación de los medios adecuados para alcanzar un determinado fin pero ha excluido el problema de la elección racional de fines y valores (Olivé, 2000, p. 94).

En este punto resulta interesante incorporar el análisis de Ricardo Gómez respecto de los mitos de la racionalidad científica, mitos que persisten al menos desde el Siglo XVII y que juegan un papel importante al momento de ocultar la efectiva presencia de valores de diversos tipos en las decisiones de los científicos. El primer mito es la identificación de la racionalidad con la trilogía certeza-formalismo-necesidad, por el que las teorías debían ser formuladas como sistemas deductivos a partir de principios evidentes. Así, la racionalidad tuvo su expresión más alta con el método científico euclídeo-deductivo, de la mano de Descartes, Galileo o Newton, y quedó reducida al carácter lógico de las pruebas matemáticas. El segundo mito se relaciona con la creencia de un único método que garantice la racionalidad del procedimiento científico en cuestión, junto con la sobrevaloración consecuente de las ciencias duras. El principal motivo de la subordinación de las ciencias sociales a las ciencias exactas o naturales era que aquéllas carecían del rigor 
formal y la precisión de estas últimas, bajo el supuesto de que ambos componentes son necesarios para cualquier disciplina que aspire al carácter de científica. Por último, el tercer mito se vincula con la concepción dicotómica entre hecho y valor, habida cuenta de que filósofos como Carnap o Neurath admiten la presencia de valores o elementos "pragmáticos" bajo ciertas condiciones. De estos tres mitos se desprenden algunos rasgos fundamentales de la versión tradicional de la racionalidad, a saber: (i) es logicista o algorítmica, (ii) se atiene a un único método científico, (iii) trabaja con el principio de maximización de objetivos, (iv) tiene carácter instrumental, sin posibilidad de discusión racional de los fines, y finalmente (v) se mantiene en el campo teórico, sin discutir cuestiones de valores, pues los hechos y sólo los hechos garantizan la objetividad del conocimiento (Cf. Gómez, 2011, p. 461-466). ${ }^{119}$

Resulta muy sugerente que frente a los mitos o dogmas, los autores aquí considerados propongan una reconsideración de la dimensión valorativa. Según indica explícitamente Echeverría, “[...] la capacidad de razonar depende de la capacidad de valorar." (2011, p. 78). Ahora bien, la incorporación de los valores como elemento de análisis reporta un cambio profundo en las perspectivas clásicas de la racionalidad -en particular en la visión instrumental. En palabras de Echeverría, "[1]a idea básica es sencilla: en lugar de reducir la racionalidad a la relación medios-fines, introduciremos un tercer elemento, los valores, que permiten el análisis, la crítica y, en su caso, la justificación de la elección tanto de medios como de fines.” (Echeverría, 2002a, p. 114. Cursivas en el original). La incorporación de los valores permite, por tanto, introducir la idea de racionalidad valorativa: "[s]e ve así que la racionalidad valorativa no se limita a justificar los medios, sino que valora los fines. Es una racionalidad propiamente filosófica [...]” (Echeverría, 2002, p. 111). Teniendo en cuenta que Echeverría y Olivé enmarcan y comprenden la estructura axiológica de las prácticas tecnocientíficas en esta visión de la

\footnotetext{
${ }^{119}$ Es interesante destacar que los puntos (iii) y (iv) se vinculan con el surgimiento de la economía neoliberal y la utilización de modelos formales en los que las relaciones entre variables y fórmulas mantienen se analizan en base a los principios de la lógica formal deductiva. Este método supone que los agentes siempre actúan tratando de maximizar el logro de su objetivo, es decir la ganancia económica, y que ese objetivo no se pone en discusión, de manera que la racionalidad es meramente instrumental y maximizadora, características que serán puestas en cuestión por aquellas concepciones de la racionalidad que no se limitan al cálculo de costo-beneficio a favor de un objetivo predeterminado sino que incluyen la evaluación racional de los fines en base a valores (Gómez, 2011).
} 
racionalidad, en lo que sigue me detendré a considerar sus fundamentos filosóficos y a señalar algunas líneas compartidas con el enfoque deweyano.

En primer término vale señalar que tanto Echeverría como Olivé elaboran su concepción de racionalidad valorativa por oposición al racionalismo clásico, del cual también identifican dos dogmas: (i) la razón como diferencia específica de los seres humanos, es decir como capacidad privativa de la especie que se resume en la expresión "hombre = animal racional", y (ii) la razón como facultad trascendental y omniabarcativa que termina convirtiéndose en una entidad metafísica que cuenta con una serie de criterios absolutos para evaluar si creencias, acciones, medios y fines son apropiados, más allá del contexto específico. Por el contrario, de acuerdo con Echeverría la racionalidad no es exclusiva del ser humano sino que es común al conjunto de los animales, visto que todos distinguen entre lo que resulta bueno-valioso o malo-disvalioso y que todos actúan en consecuencia. Luego, no hay razón suprema o razón ínfima y, en el marco de una teoría evolutiva y evolucionista, la razón es una capacidad animal, tan animal como lo es el hombre. Desde aquí también queda claro que para Echeverría la racionalidad es una capacidad de actuar, que esa capacidad de actuar siempre se realiza en una situación determinada bajo condiciones internas o iniciales y externas o de contexto, y que esas acciones están guiadas por valores:

[s]upuesta la capacidad de discernir en el mundo lo que puede ser favorable o desfavorable para el sujeto que actúa, lo que presupone una capacidad de valorar, se eligen unos cursos de acción en lugar de otros teniendo en cuenta lo que puede resultar de las diversas acciones posibles y del beneficio o perjuicio correspondiente para el sujeto agente. El acto de deliberar antes de actuar, aunque sea instantáneo, siempre tiene en cuenta los bienes y males que se pueden obtener de las diversas acciones posibles. Un sujeto es tanto más racional cuanta mayor capacidad tiene de prever las consecuencias beneficiosas o perjudiciales de sus acciones. Éste es el núcleo conceptual de la racionalidad valorativa, que no es específica de los seres humanos, aunque éstos la hayan desarrollado en mayor grado que otras especies animales. (Echeverría, 2011, p. 79. Cursivas en el original). 
Olivé también considera que la racionalidad no es una característica única del ser humano sino que se comparte con otras especies. La tesis central de Olivé indica que la razón en tanto capacidad compleja está compuesta por otras capacidades básicas; así, la racionalidad permite tener representaciones del mundo, hacer conexiones entre dichas representaciones, tener creencias, proponernos fines, conectar creencias con otras creencias, elegir cursos de acción posibles, etc. Todas estas acciones son, en definitiva, estrategias para seleccionar conductas y patrones de acción en pos de adaptarse al entorno y sobrevivir. En el caso del ser humano, estas estrategias se han desarrollado de modo más amplio precisamente como consecuencia del proceso evolutivo y le permiten realizar operaciones más complejas como aprender un lenguaje proposicional, comunicarse, valorar objetos y estados de cosas, evaluar esos mismos valores, justificarlos y eventualmente modificarlos. Por tanto, si bien las acciones recientemente enumeradas están en el extremo más desarrollado del continuo evolutivo, lo cierto es que son parte de él y que, en consecuencia, la razón como capacidad y la racionalidad como ejercicio de dicha capacidad no distinguen radicalmente a los seres humanos de otros animales.

Otro aspecto destacable en el planteo de Olivé es el modo en que revincula las dimensiones teóricas y prácticas de la racionalidad en torno al problema de la justificación de las creencias. Al respecto el mexicano sostiene que incluso en el ámbito del conocimiento (aquella actividad que podría considerarse, en sentido estricto, ejercicio de la racionalidad teórica) sería irracional hacer elecciones de teorías y modelos sin realizar al mismo tiempo ciertas acciones y tomar decisiones (consideradas tradicionalmente como parte de la racionalidad práctica). Más allá de las distinciones que propone entre justificación débil y fuerte de las creencias, el punto que me interesa destacar es que estas últimas se entienden siempre como disposiciones a actuar, consideración que le permite sostener que "[1]a constatación de la objetividad de una creencia es, por tanto, un asunto de acciones que pueden tener éxito o fracaso" (Olivé, 2011, p. 36).

Por otro lado, según se indicó con anterioridad, el objetivo de la racionalidad axiológica es la satisfacción de los valores positivos o bienes y el rechazo de los disvalores negativos o males. Desde esta perspectiva el problema no pasa exclusivamente por la selección de los medios sino anteriormente por la elección de los valores que justifiquen los fines en razón de los cuales se arbitrarán tales medios. En consecuencia, otra de las notas 
sobresalientes de la racionalidad valorativa es que se constituye como crítica a la racionalidad instrumental y maximizadora, es decir, aquella que mantiene los fines fuera de discusión y sólo evalúa qué medios son los más adecuados para la consecución de tales fines. Por otra parte, el carácter situado y acotado de la racionalidad valorativa rompe con el segundo dogma del racionalismo tradicional, a saber, el de la razón como una capacidad omniabarcativa. Finalmente, la concepción axiológica o valorativa de la racionalidad considera que no hay fines últimos o previamente establecidos y por lo tanto avanza en la discusión sobre ellos. Más aún, atentos a que "[l]a racionalidad no está basada en fines, sino en valores", este modelo no se limita a la discusión de los fines de la acción sino que permite reflexionar sobre los valores que fundamentan esos fines (Echeverría, 2011, p. 80. Cursivas en el original). Así, la racionalidad valorativa da no sólo uno sino dos pasos adicionales: de la discusión de medios a la discusión de fines y de esta última a la discusión de los valores que fundamentan los fines de las acciones.

La misma dirección habían tomado ya algunas consideraciones de Olivé, especialmente cuando indica que el análisis racional de los fines en las prácticas cognitivas se hace en función de valores y principios que se aceptan como fundamentales. Los ejemplos de Olivé son claros:

A veces podemos percatarnos de que hemos estado persiguiendo algún objetivo que, después de todo, es irrealizable o muy impráctico, como ocurrió con la construcción de globos aerostáticos para el transporte masivo de pasajeros a principios de siglo XX. O bien podemos darnos cuenta de que algún fin que perseguimos es incompatible con creencias y valores que consideramos prioritarios. Por ejemplo, podemos querer aviones más veloces pero si nos convencemos de que eso es imposible sin aumentar el gasto de reservas energéticas y la contaminación ambiental, entonces podemos abandonar aquel fin por ser incompatible con dos valores importantes para nosotros: el ahorro de energía y una menor contaminación atmosférica. En tal caso hemos evaluado racionalmente nuestro fin y hemos tomado la decisión racional de abandonarlo. (Olivé, 2000, p. 94).

Las características de la racionalidad valorativa o de fines propuestas por Echeverría y Olivé pueden encontrar apoyo en el marco teórico deweyano elaborado en las primeras dos partes de esta investigación. En mi interpretación, el carácter naturalista de la filosofía 
de Dewey junto con sus argumentos respecto del carácter transactivo y apreciativo de la experiencia - punto de partida cualitativo para la concepción reflexiva de valor- y su teoría de la valoración ofrecen elementos filosóficos profundamente elaborados, sólidos y ciertamente coherentes con muchas de las ideas presentadas en este capítulo. Por supuesto, estas líneas son apenas un esbozo para reflexionar en torno a la racionalidad en clave pragmatista e intentan sumarse a una serie de valiosos aportes en el área (Esteban, 2006; López, 2016; Sánchez García, 2016).

Efectivamente Dewey considera que la racionalidad concierne a la relación medios y fines/consecuencias y que el sentido abstracto de racionalidad no es más que un fin a la vista generalizado relativo a la dirección de la conducta en lo concreto y por referencia a esa relación de las cosas como medios y fines (Cf. 1950, p. LW.12.17 y 2004, p. 118. LW.13.226). Sin embargo, y según he intentado argumentar durante el capítulo 3, la visión deweyana de la racionalidad no debe ser asimilada a una visión instrumental por dos razones principales. En primer lugar, la interdependencia entre medios y fines imposibilita abstraer el fin de la deliberación (a este punto concierne la referida crítica deweyana al dictum "el fin justifica los medios" y a toda idea de fin en sí mismo). En segundo lugar, la perspectiva deweyana permite e incluso demanda, en términos filosóficos, morales y políticos, la valoración de los fines y valores de las acciones. Así, Dewey afirma que no es racional adoptar un fin que no guarde conexión con los medios disponibles, ni adoptar un fin sin considerar los obstáculos que pudieran surgir en el camino de su obtención, ni emplear medios que entren en tensión con otros valores o que conducen a consecuencias tan distintas que a fin de cuentas excluyen el logro del fin inicialmente buscado. Como señala López (2016, p. 19), la racionalidad entendida en referencia a la relación mediosfines recorre ambos sentidos de esa relación y re-evalúa constantemente tanto los medios como los fines -apoyada también en el carácter contextual, afectivo y cualitativo de todo pensamiento. En este marco, la última cita de Olivé constituye un claro ejemplo de la tesis deweyana sobre la continuidad entre medios y fines -e incluso de la distinción elaborada en el capítulo 3 de esta investigación entre continuidad en situación (el caso de los globos aerostáticos, en donde el fin es analizado en relación al coste o disponibilidad de los medios y las dificultades encontradas a ese respecto condujo a que se descartara el propio fin) y continuidad en sentido amplio (el caso de los aviones más veloces, en donde se consideran 
distintos valores que pueden entrar en colisión con el valor que se intenta satisfacer mediante esa acción particular). Bajo estas consideraciones, la diferencia entre el enfoque instrumental y el enfoque deweyano de lo que significa "relación medios-fines" es radical. Con relación a este punto José Miguel Esteban (2006, p. 240) propone diferenciar entre instrumentalismo ingenuo e instrumentalismo pragmático (o pragmatista, me permito sugerir) deweyano. El primero se apoya en una nítida separación medios-fines y en la atribución a estos últimos de una existencia en algún sentido independiente y estática. Tal es el denominador común de las críticas elevadas a Dewey por parte de Marcuse, Horkheimer e incluso MacIntyre. Por su parte, el instrumentalismo pragmatista se opone por igual a un sentido categórico o "criteriológico" de la racionalidad como a la versión instrumental ingenua, siempre poniendo el acento en la posibilidad de valorar fines y valores de la acción.

Una segunda marca distintiva del modelo de racionalidad pragmatista presentado por Esteban es su carácter situado y contextual, en la acepción técnica atribuida por Dewey. En este marco, la visión pragmatista no debe entenderse como cálculo sino ante todo como deliberación acerca de medios y fines. También debe incluir la dimensión cualitativa de la valoración, en especial atendiendo a la continuidad entre experiencia primaria y experiencias reflexivas. Ambos puntos son de suma importancia pues explican desde un nuevo ángulo por qué la perspectiva deweyana no supone un reduccionismo cientificista sino todo lo contrario, en la medida en que enfatiza el carácter deliberativo y cualitativo de la racionalidad. En palabras de López, “[...] la abstracción de la dimensión valorativa [y cualitativa, agrego] de la racionalidad, de la que surge la idea de una racionalidad meramente instrumental [...] no es más que una operación analítica que, si se toma en serio, no arroja una caracterización instrumental de la racionalidad sino una caracterización de la irracionalidad de la mera instrumentalidad." (2016, p. 20. Cursivas en el original).

En virtud de lo dicho resulta claro que la concepción de racionalidad axiológica o valorativa tiene algunos puntos en común con la postura deweyana, especialmente porque (i) ambas se conciben como capacidad de actuar situada, producto de la evolución y orientada en pos de la resolución de problemas, de modo que racionalidad teórica y racionalidad práctica son dos aspectos de un mismo procedimiento que no pueden 
distinguirse en la investigación sino analíticamente; (ii) ambas permiten pensar una relación de complementariedad entre el sentido técnico-instrumental y el sentido deliberativo, contraponiéndose a cualquier forma de reduccionismo; y finalmente (iii) ambas consideran que es posible poner en discusión, modificar y re-crear los fines de la actividad en la que se esté involucrado, entre ellas la científica, y todo ello en base a valores.

\section{Conclusiones}

En las páginas precedentes he intentado recuperar los argumentos de León Olivé y Javier Echeverría en torno al carácter valorativo de la ciencia, la tecnología y la tecnociencia, todo ello con la intención de abordar algunos aportes iberoamericanos respecto a la discusión sobre el ideal de ciencia libre de valores. En este marco, el argumento general del capítulo tuvo como punto de partida la conceptualización de la ciencia y de la tecno-ciencia como prácticas cognitivas, conceptualización que conduce a reconocer que los juicios de valor aparecen en todos los contextos o ámbitos de la práctica (tecno)científica. Una de las conclusiones centrales a este respecto apunta a dejar atrás la asociación entre neutralidad valorativa y objetividad en la ciencia porque brinda una visión muy limitada de la actividad científica y a dar paso a la consideración de los subsistemas de valores que guían todos los momentos de dicha actividad. Esta lectura habilita a subrayar la dimensión prácticoevaluativa de la ciencia debido a la presencia ineludible de valores y destaca la importancia de la pregunta por los fines y valores de la (tecno)ciencia. Afirmadas estas conclusiones, he avanzado sobre la consideración filosófica de valor presentada por Echeverría, concepción a mi juicio ambivalente pues si por un lado enfatiza de sobremanera el aspecto formal derivado de la interpretación de los valores como funciones, por otro lado abre las puertas a un sentido de racionalidad axiológica valorativa sumamente promisorio.

En esa línea, finalmente he intentado vincular algunos aspectos de la racionalidad axiológica con el sentido de racionalidad que se desprende de la perspectiva deweyana, identificando ciertas afinidades dadas por sus visiones compartidas en torno al carácter evolutivo, activo situado/contextual, basado en valores y orientado a la discusión racional de los fines de las actividades, entre ellas la (tecno)científica. En este sentido, me permito decir una vez más que el modelo pragmatista de racionalidad, en buena medida basado en la investigación, no implica una reducción cientificista, es decir, no supone que las 
decisiones deban ser tomadas aplicando algún tipo de método particular que determine qué hacer -y que en definitiva exima al agente de tomar la decisión. Por el contrario, el énfasis de Dewey está puesto en la deliberación, en la consideración de la especificidad de la situación y sus dimensiones cualitativas y apreciativas.

Además de estas ricas observaciones acerca del concepto de racionalidad, los argumentos aquí señalados abonan una idea de filosofía política del conocimiento científico en total sintonía con lo planteado a lo largo de esta investigación. La noción de práctica cognitiva constituye un primer paso en esa dirección. De acuerdo con Olivé, la dimensión política de las ciencias se refleja, entre otras cosas, en una disputa por el sentido mismo de los conceptos, entre ellos y particularmente el de ciencia. Esto implica un legítimo lugar para la filosofía política del conocimiento científico, sostiene Olivé, entendido como el análisis de asuntos y problemas epistemológicos, morales y sociales que puedan surgir de los sistemas científico-tecnológicos e incluso como la discusión por ganar lugares de dominio (2007, p. 132). También implica entender a las prácticas cognitivas como resultado de la actividad humana, políticamente situada y atravesada por valores que operan de acuerdo con las condiciones contextuales económicas, políticas, sociales, etc. Finalmente, abre la posibilidad de reflexionar sobre la incidencia práctica de la ciencia y de valorar sus fines y valores, esto es, de reflexionar sobre la ciencia en clave política. 


\section{CONCLUSIONES GENERALES}

En esta tesis he abordado la pregunta por la dimensión valorativa de la investigación científica, tomando como referencia el pensamiento de John Dewey y guiado por el interés de señalar algunas de sus proyecciones en ciertos planteos críticos del ideal de ciencia libre de valores. En lo que sigue reconstruiré las conclusiones obtenidas en cada parte del estudio

y ofreceré, por último, algunos comentarios acerca de los aportes más relevantes del marco teórico deweyano respecto de la discusión indicada.

\section{Experiencia y valores}

El punto de partida ha sido un análisis de lo que se considera un elemento estructural de toda la filosofía deweyana: su concepto de experiencia. A este respecto he sugerido que una de las marcas distintivas y más novedosas de la noción deweyana de experiencia está dada por el énfasis en la categoría de acción o, más aún, de transacción. De acuerdo con la lectura del pragmatista, la experiencia se define entonces como transacción entre organismo y ambiente tal que los elementos y su unidad funcional obtienen su carácter específico en el papel que desempeñan dentro de esa misma relación transaccional. Puesto en términos más sencillos, la experiencia es un asunto activo-pasivo, esto es, incluye acción, ensayo, error, etc. (un sentido que explicita su vínculo con la idea de experimentación) pero también incluye el padecimiento de las consecuencias de esas mismas acciones, dando lugar a un continuo ritmo dinámico de equilibrio, desequilibrio y recomposición de un nuevo equilibrio.

Dado que la noción de experiencia es transversal al pensamiento deweyano y otorga fundamento a toda la variedad de temas abordados por el pragmatista en su extensa obra, el objetivo inicial ha sido ofrecer una reconstrucción de dicho concepto orientada al asunto de los valores. En ese marco, de acuerdo con las consideraciones realizadas a partir del análisis de la influencia del darwinismo en el enfoque deweyano, del principio de continuidad de la experiencia, de las nociones de situación, contexto e interés selectivo y de las condiciones de la metafísica naturalista deweyana, he sugerido (i) que la experiencia es cualitativamente afectiva; (ii) que dado el vínculo entre los niveles primario y secundario de la experiencia, ese carácter afectivo inmediato tiene un rol crucial al momento de analizar la cuestión de 
los valores; y (iii) que la fundamentación de los valores ya no puede remitir a teleologías sino al curso mismo de la experiencia, por referencia a sus condiciones y consecuencias. Asimismo, y de acuerdo con el llamado deweyano al método denotativo para la filosofía, la experiencia se constituye no sólo como el punto de partida sino como el punto de llegada de las transformaciones operadas por toda reflexión, dando así una nueva razón por la que cualquier concepción de los valores y de la valoración no puede desligarse del curso de experiencia. En este sentido, me he permitido reformular una expresión tomada de Robert Innis y he sugerido que la experiencia es de matriz valorativa. Asimismo, en estas primeras reflexiones he adelantado una de las tesis que articulan todo este estudio, a saber, que el principio de continuidad multidimensional de la experiencia, en la interpretación integral que he elaborado a partir de sus sentidos longitudinal y latitudinal, es un elemento crucial para una correcta comprensión de la filosofía deweyana y ofrece una clave de lectura indispensable para toda la argumentación acerca de los vínculos entre valoración e investigación.

En este marco he señalado que la reflexión filosófica sobre los valores debe afrontar una tarea con dos perspectivas pues por un lado debe inscribir y dar cuenta de la génesis de los valores en el curso mismo de la experiencia y por el otro debe ofrecer algún tipo de pauta general para la correcta formación de los valores, observando en ambos casos las continuidades con el curso de experiencia primaria. Respecto de la primera perspectiva, he intentado señalar las razones por las que la deliberación en términos generales y la deliberación valorativa, moral y política en términos particulares tiene una impronta cualitativa permeante, en tres sentidos: (i) en cuanto enraizada en la experiencia primaria y expresión de una respuesta orgánica en términos de aceptación o rechazo de una situación cualitativamente "tenida"; (ii) en cuanto situación moral problemática cualitativamente definida; y (iii) en cuanto resultado de un tipo de reflexión principalmente cualitativo como lo es el ensayo imaginario. Asimismo, he abordado con detenimiento aquello que Dewey denomina método genealógico para la moralidad, el cual abona la propuesta de inscribir a los valores en el curso continuo de la experiencia porque no sólo apunta la necesidad de elaborar una explicación histórica de las estimaciones habituales sino que esa explicación ya constituye un principio de validez de los valores en tanto resultado de la investigación 
inteligente. En este sentido, por tanto, he señalado que el método genealógico no es meramente retrospectivo sino, y en especial, prospectivo.

Con respecto a la segunda perspectiva, he intentado enfatizar el vínculo entre experiencia y valoración, en tanto permite enmarcar las críticas de Dewey a todo tipo de apriorismo, y el vínculo entre investigación y valoración, en la medida en que esta última se constituye a partir de juicios evaluativos en términos de condiciones y consecuencias y además permite dar una respuesta naturalista a las reiteradas críticas que retoman el problema de la normatividad. Especialmente importante ha resultado la tesis de la continuidad entre medios y fines, tanto en sentido situado, es decir entre medios y fines por referencia a una situación particular, como en sentido amplio, esto es, teniendo en cuenta que el fin de una acción devendrá medio para una acción subsiguiente y teniendo en cuenta también que es indispensable valorar las relaciones entre el fin de la acción particular y los fines y valores concomitantes, puestos sobre el mismo continuo de valoración. Dicha tesis de la continuidad medios-fines en el continuo de valoración permite considerar la posibilidad de evaluar los propios fines y valores tanto por relación a sus medios como por relación a los otros fines y valores que pudieran entrar en colisión o conflicto. De acuerdo con Dewey este es el genuino sentido de la valoración. En virtud de lo dicho, he sugerido que desde el punto de vista de Dewey no hay valoración sin investigación. Ahora bien, teniendo en cuenta que para el pragmatista toda práctica que no se limite a un mero hábito incluye un factor inteligente, que no hay conducta inteligente que no implique valoraciones y que toda investigación es un modo de práctica, entonces es posible afirmar que tampoco hay investigación sin valoración. Elucidar en qué medida la investigación científica puede caer bajo estas consideraciones y ponderar cuáles son las implicancias específicas de las mismas ha sido la tarea de la segunda parte del estudio.

\section{Investigación y valores}

La segunda parte de esta tesis ha quedado reservada al estudio de la noción deweyana de investigación, especialmente de investigación científica, a efectos de evaluar las continuidades entre ciencia y valoración y las estrechas relaciones que traza el pragmatista entre investigación científica, opinión pública y democracia. El objetivo central ha sido plantear que el pensamiento deweyano permite considerar que la dimensión política 
es propia de la investigación científica y que, en consecuencia, su marco teórico da lugar a una genuina filosofía política del conocimiento científico.

El primer punto de análisis ha sido la propia pauta o matriz general de la investigación. A este respecto he intentado poner de relieve la continuidad entre investigación de sentido común e investigación científica (sin perjuicio de las diferencias efectivamente existentes entre ambas) y el aspecto eminentemente práctico de toda investigación, entendida por Dewey como resolución de una situación inicialmente indeterminada y orientada siempre por referencia a esa resolución. En este marco ha cobrado vital relevancia la consideración de los juicios prácticos en cuanto juicios respecto de lo que se debe hacer y la idea de Dewey por la cual cuanto más compleja es la situación que se debe resolver y la decisión que se debe tomar, tanto más necesaria es la dimensión valorativa (y no meramente evaluativa) de la propia investigación.

Ahora bien, teniendo en cuenta que la conclusión antedicha bien podría ser sostenida por las versiones clásicas de la filosofía de la ciencia, bajo la idea de que dicho ideal acepta la presencia de valores epistémicos en ciencia y que, por tanto, las referidas decisiones podrían referir a ese tipo de valores, ha resultado fundamental elucidar otros sentidos en los que efectivamente hay continuidades entre investigación científica y valoración. En este contexto he enfatizado el carácter contextual de la investigación, focalizando en el rol que juega aquello que Dewey denomina tradición en cuanto modos culturalmente consolidados de observar, estimar e interpretar que impregnan en todo tipo de pensamiento y aquello que denomina interés selectivo, más asociado a ciertas preferencias de quien investiga. La influencia del contexto en la pauta general de la investigación es notoria pues incide en la consideración de la situación como problemática, en la subsiguiente formulación de los primeros pasos de la investigación y en la instrumentación de sus resultados.

Por otro lado, he señalado la continuidad metodológica o procedimental entre valoración e investigación científica, habida cuenta de que tanto la investigación como la valoración propiamente dicha se rigen por la pauta general de la investigación, y la continuidad material, dado el carácter científicamente informado de los juicios evaluativos a la base de toda valoración. Asimismo, visto que la instancia de instrumentación del juicio 
resultante de la investigación es ella misma parte de la investigación y obtiene su prueba completa por referencia al amplio círculo de consecuencias de la misma investigación y que se ubican en un plano distinto del plano científico, he indicado que los valores que intervienen en la ponderación de ese círculo de consecuencias (de carácter moral, social, político, etc.) deben ser legítimamente considerados en la propia investigación, de modo que esa continuidad material resulta bidireccional. También he recuperado la discusión entre Dewey y los "nuevos realistas" respecto de la continuidad entre génesis y validez a fines de señalar que la imposibilidad de hacer un recorte del ámbito de validación, como si fuera algo independiente de todo el proceso de investigación que precisamente permite afirmar la validez de una idea, supone también la imposibilidad de excluir de ese mismo ámbito de validez aquellos elementos constitutivos de la experiencia -esto es, su matriz cualitativa y valorativa. Al mismo tiempo, esta discusión documenta que Dewey cuestionó la distinción entre contexto de descubrimiento y contexto de justificación incluso antes de que fuera consolidada por Hans Reichenbach en 1938. Si se tiene en cuenta la tesis de Reisch recuperada al inicio mismo de esta investigación por la cual la noción de ciencia valorativamente neutral ha sido una estrategia para despolitizar aquello que efectivamente constituía un elemento político y si, además, se recuerda que para Douglas el punto de partida de las versiones contemporáneas del ideal de ciencia libre de valores es esa misma maniobra de despolitización de las ciencias, entonces la discusión que Dewey lleva adelante en ese tiempo adquiere aún mayor relieve. En este marco, y recuperando la distinción de Longino entre valores constitutivos y no constitutivos de la ciencia, he sostenido que en la perspectiva deweyana los valores sociales, morales y políticos deben efectivamente considerarse como constitutivos de la investigación científica -teniendo en consideración los recaudos planteados por el mismo Dewey acerca de la inconveniencia de conducir las investigaciones hacia fines pre-determinados.

Junto con estos señalamientos he analizado la lectura ofrecida por Ruth Putnam y especialmente por Hilary Putnam en torno a su interpretación del desplome de la dicotomía hecho/valor: en su opinión, dado que la investigación tiene como fin a la vista la resolución de una situación inicialmente indeterminada, la selección de los hechos del caso relevantes, la metodología y demás instancias de la investigación se hace siempre por referencia a ese fin a la vista tomado como valioso. Luego, las aseveraciones factuales resultantes están 
entrelazadas con juicios de valor y el dominio de la ciencia no puede concebirse como opuesto al dominio de la valoración pues, en definitiva, todo hecho se apoya en algún tipo de valoración de la experiencia. El otro elemento del análisis de Putnam subrayado ha sido su interpretación de la dimensión cooperativa de la investigación científica, característica señalada por Dewey en reiteradas oportunidades, como elemento fundamental para explicar por qué el modelo deweyano no se ajusta en lo absoluto al modelo algorítmico de decisión -ofreciendo así una nueva razón para señalar que la investigación no es neutral respecto de valores morales, sociales o político. La lectura de Putnam, además, me ha permitido iniciar la reflexión respecto del vínculo entre ciencia y política planteado por Dewey, reflexión que a su tiempo me ha conducido a otro punto nodal de la presente investigación.

En cuanto a este último tema, a partir de las reflexiones aquí propuestas he sostenido en primer lugar que la ciencia es una actividad eminentemente pública, de acuerdo con la distinción que plantea Dewey entre público y privado, distinción basada en el alcance de las consecuencias de las acciones. En cuanto pública, la ciencia debe quedar sujeta a algún tipo de regulación por parte del público por ella afectado, de modo que la pregunta por sus fines es una pregunta de interés común, político. En segundo lugar, he afirmado que la comunicación de los resultados de las investigaciones científicas es condición de posibilidad para la conformación de un público competente y activo, y por eso la propia ciencia adquiere una nueva dimensión política dado el rol que juega en el proyecto de Gran Comunidad. Siguiendo estas observaciones, así como no hay valoración sin ciencia ni ciencia sin valoración, tampoco hay política sin ciencia ni ciencia sin política. Asimismo, he identificado una última razón para dar cuenta del valor político de la ciencia y para discutir aquellas interpretaciones que hacen de la investigación científica un mero instrumento neutral que puede ser aplicado "indistintamente" a fines alternativos: dada la tesis de continuidad entre medios y fines, si se acepta que una investigación es un medio para un fin moral, social o políticamente valioso y que esa valoración es un elemento integrante de la prueba completa de la propia investigación, entonces esa misma investigación adopta ese valor en cuanto medio para dicho fin -a menos que se considere a la investigación por fuera del curso de experiencia, movimiento absolutamente contrario al sentido filosófico deweyano. En virtud de lo dicho, me he permitido señalar que el marco 
teórico de Dewey no sólo habilita sino que reclama una consideración seria y responsable de la dimensión política de la investigación científica pues ésta presenta una capacidad transformativa inmensa y, si no es tomada en manos públicas, vale decir, si sus valores no son resultado de una deliberación pública ni están orientados al enriquecimiento de la experiencia común, seguirá replicando los intereses de clase y el beneficio privado. Este último punto resulta crucial para habilitar la deliberación acerca de dichos valores y fines de la investigación científica y para considerar si son consistentes con los intereses y valores debidamente fundamentados de la comunidad.

\section{Aportes al debate sobre el ideal de ciencia libre de valores}

En la tercera parte de la investigación he abordado algunas posiciones que forman parte del debate sobre el ideal de ciencia libre de valores, a saber: Heather Douglas, Philip Kitcher y, en el ámbito iberoamericano, Javier Echeverría y León Olivé. Siguiendo la reconstrucción histórico-filosófica del ideal ofrecida por Douglas, éste debe interpretarse no tanto en términos de neutralidad valorativa sino de valores aceptados y no aceptados en el ámbito de justificación y/o al momento de elegir entre teorías alternativas. En este marco, uno de los filósofos más representativos del ideal de ciencia libre de valores es Hugh Lacey, para quien la investigación científica debería preservar un núcleo constitutivo que fuera neutral, imparcial y autónomo - o, al menos, debería tenerlo como meta regulativa.

Frente a estos planteos, una de las voces más críticas es precisamente la de Douglas. Como he intentado indicar, Douglas elabora su crítica al ideal de ciencia libre de valores mediante los desafíos descriptivo, de los límites y normativo, todo ello a efectos de afirmar que dicho ideal no sólo es irrealizable sino también un mal ideal. En efecto, tanto por el vacío inductivo como por las consecuencias no epistémicas de las investigaciones científicas, quienes investigan toman ciertas decisiones en el curso de la investigación (en materia de metodología, recolección e interpretación de datos, etc.) que incluyen o deberían incluir valores tradicionalmente denominados no epistémicos en un rol indirecto -so pena de perder autonomía en tanto científicos. Asimismo, la propuesta de la autora acerca de enfatizar el vínculo entre ciencia y políticas públicas -vínculo que en su opinión haría revertir, de forma legítima, ciertos valores políticos en la propia práctica científica-, y su apuesta por incorporar estas consideraciones a la fundamentación de diseños institucionales 
para la participación de la ciudadanía en asuntos relativos a la conducción política de la investigación científica resultan, en mi lectura, puntos de notorio interés. Sin embargo, he señalado también que Douglas no deja de tener una visión “estrecha” de la investigación, que algunos de sus argumentos presuponen un dualismo hecho/valor y, más aún, que los valores sociales y morales son elementos que parecería tener lugar por defecto, es decir, cuando hay incertidumbre epistémica - más allá de que esta última fuera inherente a toda investigación. A este respecto he indicado que la interpretación de Dewey en torno a la posibilidad de superar el dualismo hecho/valor en favor de afirmar que incluso el lenguaje relativo a la evidencia empírica es un híbrido entre descripción y valoración, por un lado, que su concepción "amplia” de investigación, es decir, en cuanto resolución de problemas, por el otro, y que su noción de valor en cuanto resultado de una investigación o deliberación debidamente informada, por último, ofrecen una mejor articulación y fundamento de varios de los puntos abordados por Douglas y que, en ese sentido, sus visiones podrían ser complementarias.

Con respecto a la posición de Kitcher, me he dedicado a reconstruir su ideal de ciencia bien ordenada en cuanto ciencia que contempla los intereses de la sociedad en la que se inscribe y desarrolla, y me he dedicado a señalar las fundamentaciones filosóficas de su noción de democracia, modelo político que sustenta al ideal referido. Este es precisamente el asunto sobre el que Kitcher refiere a Dewey como un antecedente de relevancia para su propia posición, sobre todo en su segunda formulación del ideal y en su intento de dejar atrás la impronta rawlsiana inicial. En términos generales he sostenido que Kitcher tiene puntos de partida y propósitos loables pues elabora su teoría sobre la base de considerar la dimensión moral, social y política como propias de la ciencia. Sin embargo, he afirmado que no logra articular una propuesta sólida y que su insistencia en apelar a un grupo de deliberadores ideales partícipes de una conversación ideal en la que se obtendrían los intereses sociales en torno a las investigaciones científicas no sólo lo aleja de la referencia al sentido deweyano de democracia como forma de vida, al que pretende remitir, sino que actúa en detrimento del propio ideal de ciencia bien ordenada. Al respecto, he señalado que la noción deweyana de público en cuanto categoría que en cierta medida funciona como mediadora entre la investigación científica, la democracia como forma de 
vida y especialmente como ideal de vida comunitaria es un elemento de suma relevancia para superar las tensiones señaladas y avanzar hacia el propio ideal de ciencia bien ordenada.

Finalmente, he abordado algunos aportes del ámbito iberoamericano mediante el análisis de las propuestas de Javier Echeverría y León Olivé. De acuerdo con las consideraciones de estos filósofos, la ciencia, la tecnología y la tecnociencia deben comprenderse como sistemas de acción intencional o prácticas cognitivas que en cuanto tales incluyen los intereses, fines y valores de los agentes involucrados. En este sentido, el cambio de unidad de análisis -también planteado, como he indicado oportunamente, por el mismo Kitcher- permite incluir una dimensión de reflexión no contemplada en las versiones más tradicionales de la filosofía de las ciencias. Asimismo, me he detenido en la concepción de los valores como funciones elaborada por Echeverría, sin dejar de señalar que su propuesta de formalización en cierto punto anula un aspecto crucial de todo el asunto, a saber, el aspecto deliberativo. Como fuera, las perspectivas de Echeverría y Olivé introducen una noción de racionalidad evolutiva, situada y basada en valores que, en mi interpretación, encuentra interesantes vínculos con la idea de racionalidad seguida del marco teórico deweyano en tanto y en cuanto se orienta a discutir los fines y valores de las acciones, es decir, se aleja del modelo de racionalidad instrumental y abre las puertas a considerar un sentido de racionalidad más amplio y pertinente respecto al planteo que he intentado llevar adelante en esta investigación.

Teniendo en cuenta la caracterización de los lineamientos generales de una filosofía política del conocimiento científico ofrecida por Gómez, entiendo que las consideraciones previas permiten afirmar que el pensamiento deweyano abona ese tipo de reflexión -entre otras, claro está. En efecto, Gómez señala que una filosofía política del conocimiento científico rechaza la idea de la ciencia como instrumento neutral para alcanzar fines políticos o sociales y, en consecuencia, la idea de que la ciencia está completamente divorciada de la política, dada la incidencia de valores al momento de definir sus fines, sus problemas, la aceptación o rechazo de hipótesis, etc. Este tipo de reflexión filosófica rechaza también el supuesto del individualismo liberal, es decir la idea de que el productor del conocimiento es un individuo valorativamente neutral. Por otra parte, Gómez sostiene que una filosofía de estas características no es fundacionalista, es decir que no pretende 
ofrecer fundamentos últimos del conocimiento científico, y tampoco puede reducirse a la epistemología pues no pretende elucidar al conocimiento científico en términos lógicos o cognitivos sino que implica múltiples dimensiones de la reflexión filosófica, como la ética y la política. Además, esta perspectiva es profundamente contextualista y situada porque asume que la investigación científica como práctica no puede escindirse de las instituciones que conforman su marco de referencia ni del contexto social en el que se desarrollan, vale decir, no pueden escindirse de la polis ni de sus estimaciones o valores sino que, por el contrario, "[...] considera a las ciencias como producto de la actividad humana, en contextos humanos, tomando en cuenta los valores de dichos contextos [por lo cual] es una filosofía de las ciencias con sujeto cognoscente y actuante, políticamente situado en su circunstancia histórica.” (Gómez, 2014b, p. 165). Finalmente, esta visión no implica el abandono de la objetividad y la racionalidad sino que ofrece una imagen más amplia e incluye la posibilidad de acuerdos consensuados acerca de asuntos cruciales como los valores, todo ello a efectos de integrar la dimensión epistémica con las dimensiones morales, sociales y políticas de toda investigación científica.

En este marco, en primer lugar considero que uno de los aportes más relevantes del pensamiento deweyano y en línea con una filosofía del conocimiento crítica del ideal de ciencia libre de valores está dado por la comprensión que ofrece el pragmatista acerca de qué son los valores y qué es la valoración. En efecto, afirmar que los valores son fines a la vista generalizados, resultados de una deliberación en términos de reflexión respecto de las condiciones y consecuencias de esos mismos valores informada por el mejor conocimiento disponible permite desarticular el argumento por el cual la dimensión valorativa introduciría algún grado de distorsión de la objetividad de la investigación pues significaría incorporar aspectos subjetivos o dogmáticos. En mi interpretación, la posición falibilista, anti-fundacionalista pero a la vez anti-escéptica de Dewey permite identificar un fructífero término entre las visiones objetivistas o aprioristas, que hacen abstracción del curso de experiencia, de su aspecto cualitativo y de su impronta naturalista, y las visiones emotivistas, que restan contenido cognitivo a los valores. Luego, la incorporación de la dimensión valorativa no atenta contra la investigación, no introduce elementos ajenos al curso de experiencia, no requiere algún tipo de facultad cognitiva especial para la captación 
de bienes o valores pretendidamente trascendentales o eternos y finalmente no deja sin resolución el problema de la normatividad. Antes bien, los valores están en continuidad con la dimensión primaria de la experiencia y son resultado de una investigación que comparte la pauta general y contenidos específicos con las investigaciones científicas. Además, Dewey advierte insistentemente acerca de la necesidad de reconsiderar e incluso inventar creativamente los valores necesarios para conducir la acción, en particular cuando la propia tradición cristaliza en hábitos de estimación discordantes con los intereses y valores compartidos por la comunidad. Por todo lo dicho, la incorporación de la dimensión valorativa en términos morales, sociales y políticos no sólo no atenta contra el buen desarrollo la investigación sino que, en mi lectura, resulta legítima y deseable.

En segundo lugar, entiendo que la noción de investigación elaborada por Dewey aporta otro elemento de suma importancia y vigencia. En efecto, la noción deweyana resulta lo suficientemente amplia como para incluir la instancia de problematización e instrumentación en cuanto fases de la propia investigación, toda vez que esta última es de carácter práctico y se orienta a la resolución de problemas. Es así que dicha idea de investigación se encuentra a tono con las argumentaciones contemporáneas acerca del cambio de unidad de análisis de la filosofía de la ciencia -vale decir, de las teorías a las prácticas científicas o cognitivas. Este sentido permite inscribir a la investigación científica en su contexto y trazar sus relaciones más amplias en términos de sus condiciones y consecuencias en planos que no se reducen a lo tradicionalmente comprendido por científico pero que, sin embargo, resultan constitutivos de esa misma investigación. Finalmente, el sentido amplio de la investigación y sus vínculos con la valoración es también un profundo llamado a reconsiderar el perfil de quienes investigan pues implica comprender que la investigación científica es siempre una investigación situada en la que intervienen elementos valorativos (que muchas veces son hábitos de estimación) y que, en consecuencia, demanda un sentido de responsabilidad de mayor alcance y profundidad.

En tercer lugar, estimo que la distinción entre público y privado señalada por Dewey y la idea de que el conjunto de individuos afectados por las consecuencias de las acciones públicas, entre las que se incluye la ciencia, debe constituirse como público competente y activo para regular esas mismas consecuencias es otro aporte de absoluto interés para la discusión de la ciencia en clave política. Por un lado, esta idea permite 
sostener la necesidad de articular algún tipo de control político sobre la práctica científica dado que esta última sin lugar a dudas transforma el espacio púbico, es decir, el espacio político. Por el otro, considero que la distinción ofrecida por Dewey permite analizar desde una renovada perspectiva algunas cuestiones recurrentes en torno a la regulación de las investigaciones realizadas con financiamiento privado porque habilita a afirmar que aun cuando fuera costeada por capitales privados, la investigación científica no deja de ser una acción pública y por tanto no deja de ser incumbencia del público, es decir, no deja o no debería dejar de estar sujeta a la deliberación informada, inteligente y pública respecto de los fines y valores que la sustentan.

Como he intentado señalar, la base o el punto de partida de la posición deweyana y de la reconstrucción que aquí he presentado es su teoría de la experiencia. Desde allí se desprenden los puntos centrales de la posición del pragmatista que he recuperado para articular el argumento de estas páginas: la valoración no es captación de bienes ni mera expresión de emociones y el conocimiento no es contemplación o representación sino que ambos son formas de investigación en favor del ajuste progresivo e inteligente con el ambiente, es decir formas de la acción reflexivas que hunden sus raíces en el nivel primario, cualitativo y afectivo de la experiencia. Junto con estos elementos, el carácter de continuidad multidimensional de la experiencia ha permitido dar cuenta de la relación inescindible y legítima entre valoración e investigación, en términos generales, y entre valores morales, sociales y políticos e investigación científica, en términos más puntuales. Así, además de mostrarse notoriamente fructífera al momento de reflexionar en torno a problemas contemporáneos como puede ser la discusión sobre el ideal de ciencia libre de valores -y tantos otros, en el plano de la educación, la política o el arte-, la perspectiva deweyana presenta un sustento filosófico de notable rigor, alcance y articulación del que muchas veces carecen las visiones que forman parte de esos debates actuales, generalmente más fragmentarias e hiper-especializadas.

Sobra decir que son muchas las líneas de investigación que se desprenden de este trabajo, desde un estudio ya no de la ciencia sino de la tecnología a partir de las ideas aquí sugeridas hasta la posibilidad de diseñar instancias de participación pública en las decisiones respecto de los fines de las investigaciones científicas teniendo en cuenta la 
perspectiva deweyana, pasando por un estudio profundo de las relaciones teóricas y prácticas entre ciencia y democracia que incluya las dimensiones del conflicto social, del poder y las aspiraciones tecno o expertocráticas. En sintonía con el planteo de Dewey sobre el continuo de la investigación, espero que estas páginas ofrezcan elementos para dichas tareas. Para finalizar, me permito recordar algunas palabras de la introducción: el diagnóstico deweyano sobre el desafío al que se enfrenta la humanidad dada la capacidad transformativa de la ciencia reporta, sin lugar a dudas, una notoria actualidad -basta mencionar los avances en tecnociencia y nanotecnología, las complejidades filosóficas del proyecto transhumanista o las discusiones morales y políticas respecto de la creciente capacidad de manipulación genética de especies no humanas. Luego, llevar adelante una reflexión filosófica en torno a los fines y valores de la ciencia en clave política (tanto los que intervienen de hecho como los que consideraríamos deseable que intervengan) no sólo permite enriquecer distintas discusiones teóricas sino que, ante todo, ofrece herramientas para afrontar uno de los problemas más urgentes de nuestros días. Espero, también, que lo planteado hasta aquí constituya un aporte en esa dirección. 


\section{REFERENCIAS BIBLIOGRÁFICAS}

Anderson, E. (1995). Value in Ethics and Economics. Cambridge, MA: Harvard University Press.

Anderson, E. (2004). Uses of Value Judgments in Science: A General Argument, with Lessons from a Case Study of Feminist Research on Divorce. Hypatia, 19(2), 2-24.

Bernstein, R. J. (1961). John Dewey's metaphysics of experience. The Journal of Philosophy, 58(1), 5-14.

Bernstein, Richard (1992). The resurgence of pragmatism. Social Research, 59(4), 813-840.

Bernstein, R. J. (2010a). Dewey's Vision of Radical Democracy en The Cambridge Companion to Dewey (pp. 288-308). Cambridge: Cambridge University Press.

Bernstein, R. J. (2010b). Filosofia y democracia: John Dewey (R. del Castillo, Ed.; A. García Ruiz, Trad.). Barcelona: Herder.

Black, M. (1962). Dewey's Philosophy of Language. The Journal of Philosophy, 59(19), 505-523.

Bloor, D. (1976). Knowledge and Social Imagery. Chicago: University of Chicago Press.

Brown, M. B. (2004). The Political Philosophy of Science Policy. Minerva, 42(1), 77-95.

Brown, M. J. (2012). John Dewey's Logic of Science. HOPOS: The Journal of the International Society for the History of Philosophy of Science, 2(2), 258-306.

Browning, D. (2002). Designation, Characterization, and Theory in Dewey's Logic. En Burke, F. T., Hester, D. M., \& Talisse, R. B. (Eds.). (2002).

Burke, F. T., Hester, D. M., \& Talisse, R. B. (Eds.). (2002). Dewey's logical theory: New studies and interpretations (1st ed). Nashville: Vanderbilt University Press.

Butler, B. E. (Ed.). (2013). Democratic Experimentalism. Rodopi.

Caspary, W. R. (2003). «One and the Same Method»: John Dewey's Thesis of Unity of Method in Ethics and Science. Transactions of the Charles S. Peirce Society, 39(3), 445-468.

Churchman, C. W. (1956). Science and Decision Making. Philosophy of Science, 23(3), $247-249$. 
Colapietro, V. (2002). Experimental Logic: Normative Theory or Natural History? En Burke, F. T., Hester, D. M., \& Talisse, R. B. (Eds.). (2002).

Colapietro, V. (2012a). Foucault's Pragmatism and Dewey's Genealogies [Part I]. Cognitio: Revista de Filosofia, 13(1), 61-97.

Colapietro, V. (2012b). Mapping Our Historical Situations and Locating Our Philosophical Maps [Part II]. Cognitio: Revista de Filosofia, 13(2), 187-218.

Colapietro, V. (2018). The Actuality of Philosophy Thought Over Once Again. The Speculative Journal of Philosophy, 32(1), 3-20.

Cometti, J. P. (2015). Le Naturalisme Pragmatiste. Expérience, langage et action sociale. Texto inédito.

Cruz, F. (1987). John Dewey's Theory of Community. New York: Peter Lang Publishing. da Cunha, I. F. (2012). John Dewey e a Unidade Lógico-Empirista da Ciência. Cognitio: Revista de Filosofia. ISSN 2316-5278, 13(2), 219-230.

Dalton, T. C. (2002). Becoming John Dewey: Dilemmas of a philosopher and naturalist. Bloomington, IN: Indiana University Press.

Daston, L. (1992). Objectivity and the Escape from Perspective. Social Studies of Science, $22,597-618$.

DeCesare, T. (2012). The Lippmann-Dewey "debate" revisited: the problem of knowledge and the role of experts in modern democratic theory. Philosophical Studies in Education, 43, 11.

del Castillo, R. (1995). Conocimiento y acción. El giro pragmático de la filosofía. Madrid: UNED.

del Castillo, R. (2004). Érase una vez en América. Estudio preliminar a John Dewey (2004).

Dewey, J. The Collected Works of John Dewey, 1882-1953 (1967-1987). The Early Works, 1882-1898 (1967-1972); The Middle Works, 1899-1924 (1976-1983); The Later Works, 1925-1953 (1981-1991). Carbondale: Southern Illinois Univesity Press.

Dewey, J. (1948). Experiencia y naturaleza (Primera edición: 1925. Segunda edición corregida: 1929). Prólogo y traducción de José Gaos. México: FCE.

Dewey, J. (1950). Lógica. Teoría de la Investigación (Primera edición: 1938). Prólogo y versión española de Eugenio Imaz. México: FCE. 
Dewey, J. (1964). Naturaleza humana y conducta. Introducción a la psicología social (Primera edición: 1922). Traducción de Rafael Castillo Dibildox. México: FCE.

Dewey, J. (1965a). Libertad y cultura (Primera edición: 1939). Traducción de Rafael Castillo Dibildox. México: Unión Tipográfica Editorial Hispano Americana.

Dewey, J. (1965b). Teoría de la vida moral (Segunda edición: 1932). Traducción de Rafael Castillo Dibildox. México: Herrero Hermanos.

Dewey, J. (1989). Cómo pensamos. Nueva exposición de la relación entre pensamiento y proceso educativo (Primera edición: 1931). Traducción de Marco Aurelio Galmarini, prólogo de Antonio Caparros. Barcelona: Paidos.

Dewey, J., \& Koch, D. F. (1991). Lectures on Ethics 1900-1901. Carbondale, IL: Southern Illinois University Press.

Dewey, J. (1993). La reconstrucción de la filosofía (Primera edición: 1920). Traducción de Amando Lázaro Ros. Barcelona: Editorial Planeta-De Agostini.

Dewey, J. (1996). Liberalismo y acción social y otros ensayos (Primera edición: 1935). Traducción y estudio introductorio de José Miguel Esteban. Valencia: Edicions Alfons el Magnànim.

Dewey, J. (1998). Democracia y Educación. Una introducción a la filosofía de la educación (Primera edición: 1816). Traducción de Lorenzo Luzuriaga. Madrid: Ediciones Morata.

Dewey, J. (2003). Viejo y nuevo individualismo (Primera edición: 1930). Traducción de Isabel Adánez, introducción de Ramón del Castillo. Barcelona: Paidós.

Dewey, J. (2004). La opinión pública y sus problemas (Primera edición: 1927). Traducción de Ramón del Castillo. Madrid: Ediciones Morata.

Dewey, J. (2005). Una fe común (Primera edición: 1934). Traducción de Josefina Martínez Alinari. Buenos Aires: Losada.

Dewey, J. (2008a). El arte como experiencia (Primera edición: 1934). Prólogo y traducción de Jordi Claramonte. Barcelona: Paidós.

Dewey, J. (2008b). Teoría de la valoración. Un debate con el positivismo sobre la dicotomía de hechos y valores. (Primera edición: 1934). Introducción, traducción y notas de María Aurelia Di Berardino y Ángel Faerna. Madrid: Biblioteca Nueva. 
Dewey, J. (2010). Experiencia y Educación (Primera edición: 1938). Traducción de Lorenzo Luzuriaga. Madrid: Biblioteca Nueva.

Dewey, J. (2012). Unmodern philosophy and modern philosophy (P. Deen, Ed.). Carbondale: Southern Illinois University Press.

Dewey, J.; Schilpp, P. A. \& Hahn, L. E. (Eds.) (1939). The Philosophy of John Dewey. Chicago: Open Court.

di Berardino, M. A. (2016). Acuerdos Enciclopédicos: Dewey y Neurath sobre ciencia y valores. Cuadernos Filosóficos. Segunda Época. XIII, 17-33. Disponible en http://cuadernosfilosoficos.unr.edu.ar/index.php/cf/article/view/20/16

Di Gregori, M. C. y Durán, C. (2008). Acerca del arte, la ciencia y la acción inteligente. Actas de las VII Jornadas de Investigación en Filosofía para Profesores, Graduados y Alumnos. FaHCE, UNLP. Disponible en http://www.memoria.fahce.unlp.edu.ar/trab_eventos/ev.453/ev.453.pdf

Di Gregori, M. C. y Duran, C. (2009). El valor epistémico y político de la opinión pública. Una variación deweyana. Borsani, M., Gende, C. y Padilla, E. (Coords.) (2009). La diversidad, signo del presente: ensayos sobre filosofia, crítica y cultura. Buenos Aires: Ediciones del Signo.

Di Gregori, M. C.; Hebrard, A. (Comps.) (2009). Peirce, Schiller, Dewey y Rorty: usos y revisiones del pragmatismo clásico. Buenos Aires: Ediciones del Signo.

Di Gregori, M. C. y Pérez Ransanz, A. R. (2010). Las emociones en la ciencia y en el arte. Castro, S. y Marcos, A. (Comps.) (2010). Arte y ciencia. Mundos convergentes. Madrid: Plaza y Valdés Editores.

Di Gregori, M. C.; López, F. (2013). Explicación, investigación y valoración en John Dewey. Miguel, Hernán (Comp.). Causación, explicación y contrafácticos. Buenos Aires: Prometeo.

Di Gregori, M. C. (2013). Creatividad y teoría de la acción. Hans Joas, recuperando a John Dewey. Actas de IX Jornadas de Investigación en Filosofía para Profesores, Graduados y Alumnos. FaHCE, UNLP. Disponible en http://www.memoria.fahce.unlp.edu.ar/trab_eventos/ev.2903/ev.2903.pdf

Di Gregori, M. C.; López, F. (Comps.) (2014). Regreso a la experiencia. Lecturas de Peirce, James, Dewey y Lewis. Buenos Aires: Biblos. 
Di Gregori, M. C.; Mattarollo, L.; Rueda, L. (Coords.) (2014). El conocimiento como práctica. Investigación, valoración, ciencia y difusión. Serie "Estudios / Investigaciones", Pro-Secretaría de Publicaciones, FaHCE-UNLP. Disponible en https://libros.fahce.unlp.edu.ar/index.php/libros/catalog/book/4

Dijstelbloem, H. (2014). Science in a not so well-ordered society. A pragmatic critique of procedural political theories of science and democracy. Krisis, 2014(1), 39-52.

Dorstewitz, P. (2011). Dewey's Science. A Transactive Model of Research Processes. En The Continuing Relevance of John Dewey: Reflections on Aesthetics, Morality, Science, and Society (pp. 205-224). Amsterdam \& New York: Rodopi Press.

Douglas, H. (2000). Inductive Risk and Values in Science. Philosophy of Science, 67(4), 559-579.

Douglas, H. (2004). Border Skirmishes Between Science and Policy: Autonomy, Responsibility, and Values. En P. Machamer \& G. Wolters (Eds.), Science, Values and Objectivity. Pittsburgh: Pittsburgh University Press.

Douglas, H. (2005). Inserting the Public into Science. S. Maasen \& P. Weingart (Eds.), Democratization of Expertise? Exploring Novel Forms of Scientific Advice in Political Decision-Making (pp. 153-169). Nederland: Springer.

Douglas, H. (2008). The Role of Values in Expert Reasoning. Public Affairs Quarterly, 22(1), 1-18.

Douglas, H. (2009). Science, Policy and the Free-Value Ideal. Pittsburgh: University of Pittsburgh Press.

Douglas, H. (2014). The Moral Terrain of Science. Erkenntnis, 79(S5), 961-979.

Douglas, H. (2016). Values in Science. The Oxford Handbook in the Philosophy of Science, 609-630.

Douglas, H. (2017). Science, Values and Citizens. Eppur si muove: Doing Historyand Philosophy of Science with Peter Machamer. A Collection of Essays in Honor of Peter Machamer (pp. 83-96). Springer.

Eames, S. M. (2003). Experience and value: Essays on John Dewey and pragmatic naturalism (E. R. Eames \& R. F. Field, Eds.). Carbondale, IL: Southern Illinois University Press. 
Echeverría, J. (1995). Filosofia de la Ciencia. Madrid: Akal.

Echeverría, J. (2002 a). Ciencia y valores. Barcelona: Ediciones Destino.

Echeverría, J. (2003). La revolución tecno-científica. Madrid: Fondo de Cultura Económica.

Echeverría, J. (2002 b). "Explicación axiológica de las acciones científicas" en Wenceslao González (2002). Diversidad de la explicación científica. Barcelona: Ariel.

Echeverría, J. (2011). "Dos dogmas del racionalismo (y una propuesta alternativa)" en Pérez Ransanz, Ana Rosa y Velasco Gómez, Ambrosio (Coords.) (2011).

Esteban, J. M. (2003). La Unificación de la Ciencia como Acción Social. Otto Neurath y John Dewey. Endoxa: Series Filosóficas, 17, 227-229.

Esteban, J. M. (2006). Variaciones del pragmatismo en la filosofía contemporánea. Morelos: Universidad Autónoma del Estado de Morelos.

Ezorsky, G. (1958). Inquiry as Appraisal: The Singularity of John Dewey's Theory of Valuation. The Journal of Philosophy, 55(3), 118-124.

Ezorsky, G. (1992). Truth in Context. John Dewey. Critical Assessments. Vol. 4. London \& New York: Routledge, 85-105.

Faerna, Á. M. (1996). Introducción a la teoría pragmatista del conocimiento. Madrid: Siglo XXI.

Faerna, Á. M. (2003). Creer en Darwin: sobre las relaciones entre marco científico e interpretación filosófica. Quaderns de filosofía i ciencia, 32-33. Valencia: Universitat de València, 21-27.

Faerna, Á. M. (2006). Significado y valor: La crítica pragmatista al emotivismo. Quaderns de filosofia i ciència, 36. Valencia: Universitat de València, 27-39.

Faerna, Á. M. (2011). Dewey's Value Theory and the Analytic Tradition of Moral Philosophy. L. A. Hickman, K. P. Skowronski, \& J. A. Rea (Eds.), The Continuing Relevance of John Dewey: Reflections on Aesthetics, Morality, Science, and Society Amsterdam \& New York: Rodopi Press.

Fesmire, S. (2003). John Dewey and moral imagination: Pragmatism in ethics. Bloomington, IN: Indiana University Press.

Fesmire, S. (2015). Dewey. London \& New York: Routledge. 
Festenstein, M. (2008). John Dewey: Inquiry, Ethics, and Democracy. Misak, Ch. (Ed.) The Oxford Companion to American Philosophy. Oxford: Oxford University Press.

Festenstein, M. I. (2019). Does Dewey have an "epistemic argument" for democracy? Pragmatism Today (2-3), 217-241.

Fletcher, A. (2011). Evolving Hamlet: Seventeenth-Century English Tragedy and the Ethics of Natural Nelection (1st ed). New York: Palgrave Macmillan.

Fott, D. (1991). John Dewey and the Philosophical Foundations of Democracy. The Social Science Journal, 28(1), 29-44.

Frega, R. (2015). John Dewey's Social Philosophy. A Restatement. European Journal of Pragmatism and American Philosophy, 7(VII-2). Disponible en https://journals.openedition.org/ejpap/410

Fuller, S. (1998). De cómo Kuhn quitó mordiente a la historia de la ciencia y algunos pasos para devolvérselo. Solís Santos (Comp.). Alta tensión: historia, filosofía y sociología de la ciencia: ensayos en memoria de Thomas Kuhn (pp. 145-174). Buenos Aires: Paidos,

Geiger, G. R. (1978). John Dewey in Perspective (2. ${ }^{a}$ ed.). New York: Oxford University Press.

Goldman, L. (2012). Dewey's Pragmatism from an Anthropological Point of View. Transactions of The Charles S. Peirce Society: A Quarterly Journal in American Philosophy, 48(1), 1-30.

Gómez, R. J. (2011). Otto Neurath: Lenguaje, ciencia y valores. La incidencia de lo político. Arbor, 187(747), 81-87.

Gómez, R. J. (2011b). “Hacia una racionalidad científica sin mitos”. En Pérez Ransanz, Ana Rosa y Velasco Gómez, Ambrosio (Coords.) (2011).

Gómez, R. J. (2014a). La dimensión valorativa de las ciencias. Hacia una filosofía política. Bernal: Universidad Nacional de Quilmes.

Gómez, Ricardo (2014b). "Hacia una filosofía política del conocimiento científico", en Di Gregori, María Cristina; Mattarollo, Livio y Rueda, Leopoldo (2014).

Hahn, L. E. (1980). Introduction. The Middle Works of John Dewey, Vol. 10. Carbondale: Southern Illinois Univesity Press. 
Hicks, D. J. (2014). “A New Direction for Science and Values." Synthese, 191(14), 32713295.

Hildebrand, D. L. (2000). Putnam, Pragmatism, and Dewey. Transactions of the Charles $S$. Peirce Society, 36(1), 109-132.

Honneth, A. (1999). Democracia como cooperación reflexiva (C. Rendón \& S. Muñoz, Trads.). Estudios Políticos, 15, 81-106.

Hook, S. (1950). "The Desirable and Emotive in Dewey's Ethics". John Dewey: Philosopher of Science and Freedom. New York: Dial. Pp. 194-216

Hook, S. (2000). John Dewey, semblanza intelectual. (Primera edición: 1939) Introducción de Richard Rorty, traducción de Luis Arenas Llopis. Barcelona: Paidós.

Jay, M. (2002). The education of John Dewey: A biography. New York: Columbia University Press.

Joas, H. (1996). The creativity of action. Cambridge: Polity Press.

Joas, H. (1998). El pragmatismo y la teoría de la sociedad (Primera edición: 1993). Ignacio Sánchez y Carlos Rodríguez Lluesma, Trad. Madrid: Siglo XXI.

Joas, H. (2000). The genesis of values. Chicago: University of Chicago Press.

Kennedy, G. (1955). The Hidden Link in Dewey's Theory of Evaluation. The Journal of Philosophy, 52(4), 85-94.

Keren, A. (2013). Kitcher on Well-Ordered Science: Should Science Be Measured against the Outcomes of Ideal Democratic Deliberation? THEORIA. Revista de Teoría, Historia y Fundamentos de la Ciencia, 28(2), 233-244.

Kincaid, H., Dupré, J., \& Wylie, A. (Eds.). (2007). Value-free science? Ideals and Illusions. Oxford; New York: Oxford University Press.

Kitcher, P. (1993). The Advancement of Science: Science without Legend, Objectivity without Illusions. Oxford; New York: Oxford University Press.

Kitcher, P. (2001). Science, Truth, and Democracy. Oxford ; New York: Oxford University Press.

Kitcher, P. (2011a). Public Knowledge and its Discontents. School Field, 9(2), 103-124.

Kitcher, P. (2011b). Science in a Democratic Society. Oxford: Oxford University Press.

Kitcher, P. (2011c). The Ethical Project. Cambridge, Mass: Harvard University Press. 
Kitcher, P. (2012). Preludes to Pragmatism: Toward a Reconstruction of Philosophy. Oxford; New York: Oxford University Press.

Knorr Cetina, K. (2005). La fabricación del conocimiento. Un ensayo sobre el carácter constructivista y contextual de la ciencia (Primera edición: 1981). M. I. Stratta, Trad. Bernal: Universidad Nacional de Quilmes.

Koopman, C. (2011). Genealogical Pragmatism: How History Matters for Foucault and Dewey. Journal of the Philosophy of History, 5(3), 533-561.

Kourany, J. A. (2010). Philosophy of science after feminism. Oxford ; New York: Oxford University Press.

Kreimer, P. (1999). De probetas, computadoras y ratones. La construcción de una mirada sociológica sobre la ciencia. Bernal: Universidad Nacional de Quilmes.

Kuhn, T. (2004). La Estructura de las Revoluciones Cientificas (A. Contin, Trad.). Buenos Aires: Fondo de Cultura Económica.

Lacey, H. (1999). Is Science Value Free? Values and Scientific Understanding. London \& New York: Routledge.

Latour, B. (2008). Dadme un laboratorio y conquistaré al mundo. (M. I. González García, Trad.). Ciencia, Tecnología y Sociedad, Organización de Estados Iberoamericanos. Disponible en https://www.oei.es/historico/salactsi/latour.htm

Latour, B.; Woolgar, S. (1986). Laboratory Life: The Construction of Scientific Facts. Princeton, NJ: Princeton University Press.

Levi, I. (1962). On the Seriousness of Mistakes. Philosophy of Science, 29(1), 47-65.

Lippmann, W. (1998). Public Opinion (2. ${ }^{\mathrm{a}}$ ed.). New Jersey: Transaction Publishers.

Longino, H. E. (1983). Beyond Bad Science. Skeptical Reflections on the Value-Freedom of Scientific Inquiry. Science, Technology and human Values, 8 (1), 7-17.

Longino, H. E. (1990). Science as Social Knowledge. Princeton, N.J: Princeton University Press.

Longino, H. E. (2002). Science and the Common Good: Thoughts on Philip Kitcher's Science, Truth, and Democracy. Philosophy of Science, 69(4), 560-568.

López, F. E. (2014). Una reconstrucción de la lógica de la investigación de John Dewey: antecedentes y derivaciones. Tesis de posgrado. Presentada en Facultad de 
Humanidades y Ciencias de la Educación, Universidad Nacional de La Plata, para optar al grado de Doctor en Filosofía. Disponible en: http://www.memoria.fahce.unlp.edu.ar/tesis/te.1105/te.1105.pdf

López, F. E. (2016). Hacia una caracterización pragmatista de la racionalidad: Los aportes de John Dewey en Sánchez García, V. P.; López, F. E.; Busdygan, D. (Comps). Conocimiento, arte y valoración: Perspectivas filosóficas actuales. Bernal: Universidad Nacional de Quilmes. Disponible en http://www.memoria.fahce.unlp.edu.ar/libros/pm.503/pm.503.pdf

López, F. E. (2018). The Place of Biology and Anthropology in Dewey's Ethical Project. Cognitio: Revista de Filosofia, 19(2), 270-281. Disponible en https://revistas.pucsp.br/cognitiofilosofia/article/view/40880

Merton, Robert K (1938): “Science and the Social Order" Philosophy of Science 5 (3): 321337. Traducción al español: "La ciencia y el orden social" en La Sociología de la Ciencia, Vol. II. Madrid: Alianza Editorial.

Merton, Robert K (1942): "Science and Technology in a Democratic Order" Journal of Legal and Political Sociology 1: 115-126. Traducción al español: "La estructura normativa de la ciencia" en La Sociología de la Ciencia, Vol. II. Madrid: Alianza Editorial.

Metz, J. G. (1969). Democracy and the Scientific Method in the Philosophy of John Dewey. The Review of Politics, 31(02), 242-262.

Midtgarden, T. (2012). Critical Pragmatism: Dewey's Social Philosophy Revisited. European Journal of Social Theory, 15(4), 505-521.

Miras Boronat, N. (2019). "Peace, Bread, and Ideas for a Cosmopolitan World: Addams' Unknown Pragmatist Legacy Today” en K. P. Skowronski; S. Philström (eds.), Pragmatism, Kant and Kantianism in the Twenty-first Century. Nordic Studies in Pragmatism 4, Helsinki, 2019, pp. 307-326.

Misak, C. J. (2013). The American Pragmatists (First edition). Oxford: Oxford University Press.

Mougan Rivero, J. C. (2016). Dewey: El significado democrático de la primacía de los hábitos. Daímon, (68), 85-100. 
Nagel, E. (1986). Introduction. The Later Works of John Dewey, Vol. 12. Carbondale: Southern Illinois Univesity Press.

Ólafsson, J. (2017). Skilled Rhetoricians, Experts, Intellectuals and Inventors: Kitcher and Dewey on Public Knowledge and Ignorance. Transactions of the Charles S. Peirce Society: A Quarterly Journal in American Philosophy, 53(2), 167-188.

Olivé, L. (1995). "Racionalidad, objetividad y verdad”. En Olivé, León (Ed.) Racionalidad epistémica. Enciclopedia IberoAmericana de Filosofía. Madrid: Trotta.

Olivé, L. (2000). El bien, el mal y la razón. Facetas de la ciencia y de la tecnología. México DF: Editorial Paidós.

Olivé L. (2007). La ciencia y la tecnología en la sociedad del conocimiento. Ética, política y epistemología. México DF: Fondo de Cultura Económica.

Olivé, L. (2011). "La razón naturalizada y la racionalidad plural”. En Pérez Ransanz, Ana Rosa y Velasco Gómez, Ambrosio (Coords.) (2011).

Pappas, G. (2008). John Dewey's Ethics: Democracy as Experience. Bloomington, IN: Indiana University Press.

Pappas, G. (2014). What Difference Can "Experience" Make to Pragmatism? European Journal of Pragmatism and American Philosophy, VI(VI-2), 200-227. Disponible en https://journals.openedition.org/ejpap/322

Pappas, G. (2016). John Dewey's Radical Logic: The Function of the Qualitative in Thinking. Transactions of the Charles S. Peirce Society: A Quarterly Journal in American Philosophy, 52(3), 435-468.

Pérez Ransanz, A. R. y Velasco Gómez, A. (Coords.) (2011). Racionalidad en ciencia y tecnología. Nuevas perspectivas iberoamericanas. México DF: Universidad Nacional Autónoma de México.

Popp, J. (2010). Evolution's First Philosopher: John Dewey and the Continuity of Nature (Vol. 26). New York: State University of New York Press.

Putnam, H. (2004). El desplome de la dicotomía hecho-valor y otros ensayos. Barcelona: Paidos.

Putnam, H., \& Conant, J. (1994). Words and life. Cambridge, Mass: Harvard University Press. 
Putnam, H., \& Habermas, J. (2008). Normas y Valores (J. Vega Encabo \& F. J. Gil Martin, Trads.). Madrid: Trotta.

Putnam, H., \& Putnam, R. A. (1992). Epistemology as Hypothesis. John Dewey. Critical Assessments. Vol. 4. London \& New York: Routledge. Pp. 40-59.

Putnam, H. (1992). A Reconsideration of Deweyan Democracy. Renewing Philosophy. Cambridge: Harvard University Press, pp. 180-202

Quinton, A. (1977). John Dewey's Theory of Knowledge. John Dewey Reconsidered. London, Henley \& Boston: Routledge \& Kegan Paul. Pp. 1-17.

Reisch, G. A. (2009). Cómo la Guerra Fría transformó la filosofía de la ciencia: Hacia las heladas laderas de la lógica (D. Blanco, Trad.). Bernal: Universidad Nacional de Quilmes.

Reichenbach, H. (1938). Experience and Prediction: an Analysis of the Foundations and the Structure of Knowledge. Chicago, Ill: University of Chicago Press.

Rogers, M. L. (2007). Action and Inquiry in Dewey's Philosophy. Transactions of the Charles S. Peirce Society: A Quarterly Journal in American Philosophy, 43(1), 90115.

Rooney, P. (1992). On Values in Science: Is the Epistemic/Non-Epistemic Distinction Useful? PSA: Proceedings of the Biennial Meeting of the Philosophy of Science Association, 1992(1), 13-22.

Rorty, R. (1984) The Historiography of Philosophy: Four Genres en Rorty, R., Schneewind, J. B. and Skinner, Q. (1984) (Eds.). Philosophy in History. Cambridge: Cambridge University Press.

Rorty, R. (2000). "Dewey, entre Hegel y Darwin” (Primera edición: 1992). Verdad y progreso. Escritos filosóficos 3. Traducción de Ángel Faerna. Barcelona: Paidós.

Rudner, R. (1953). The Scientist Qua Scientist Makes Value Judgments. Philosophy of Science, 20 (1), 1-6.

Russell, B. (1939). “Dewey’s New Logic” en Schilpp, P. A. y Hahn, L. E. (Eds.).

Russell, B. (2003). Investigación sobre el Significado y la Verdad (Rovira Armengol, Trad.). Buenos Aires: Losada.

Ryan, A. (1995). John Dewey and the High tide of American Liberalism. London and New York: W.W. Norton. 
Sánchez García, V. P. (2014). Filosofía del conocimiento y racionalidad: Lacey vs. Douglas en torno al ideal de ciencia libre de valores en Di Gregori, M. C., Mattarollo, L. y Rueda, L. (Comps.) (2014). Pp. 184-197.

Sánchez García, V. P. (2016). Una revisión del concepto de racionalidad en el pragmatismo lewisiano. Actas X Jornadas de Investigación del Departamento de Filosofia (2015). Ensenada: FaHCE, UNLP. Disponible en http://jornadasfilo.fahce.unlp.edu.ar/x-jornadas-2015/actas-2015/a69.pdf

Sánchez García, V. P. (2017). Uma revisão da crítica de Morton White referente à teoria da valoração e normatividade de Clarence Irving Lewis. Cognitio: Revista de Filosofia, 18(2), 259-272.

Disponible en https://revistas.pucsp.br/cognitiofilosofia/article/view/38082

Santa Cruz, M. I. (2003). Filosofía o historia de la filosofía. Una falsa disyuntiva. En Nudler, O. y Naishtat, F. (Eds.). El filosofar hoy. Buenos Aires: Biblos.

Shusterman, R. (1999). Dewey on Experience. Foundation or Reconstruction? En Dewey Reconsidered. Albany: State University of New York Press. Pp. 193-219.

Sinclair, R. (2014). Dewey and White on Value, Obligation and Practical Judgment. SATS, 15(1), 39-54.

Sleeper, R. W. (1960). Dewey's Metaphysical Perspective: A Note on White, Geiger and the Problem of Obligation. The Journal of Philosophy, 57(3), 100-115.

Sleeper, R. W. (1986). The Necessity of Pragmatism. John Dewey's Conception of Philosophy. New Haven \& London: Yale University Press.

Smith, T. (1922). Dewey's Theory of Value. The Monist, 3(32), 339-354.

Stevenson, C. (1944). Ethics and Language. New Haven: Yale University Press.

Stuhr, J. (1979). Dewey's notion of Qualitative Experience. Transactions of the Charles $S$. Peirce Society: A Quarterly Journal in American Philosophy, 15(1), 68-82.

Talisse, R. B. (2007). A Pragmatist Philosophy of Democracy. New York: Routledge.

Talisse, R. B. (2011). A Farewell to Deweyan Democracy. Political Studies, 59(3), 509526.

Teehan, J. (2002). Evolution and Ethics: The Huxley/Dewey Exchange. The Journal of Speculative Philosophy, 16.3, 225-238. 
Teehan, J., \& diCarlo, C. (2004). On the Naturalistic Fallacy: A Conceptual Basis for Evolutionary Ethics. Evolutionary Psychology, 2(1), 32-46.

Testa, I. (2017). Dewey's Social Ontology: A Pragmatist Alternative to Searle's Approach to Social Reality. International Journal of Philosophical Studies, 25(1), 40-62.

Thayer, H. S. (1969). The Logic of Pragmatism (2. ${ }^{\text {a }}$ ed.). New York: Greenwood Press.

Thayer, H. S. y Thayer, V. T. (1978). Introduction. The Middle Works of John Dewey, Vol. 6. Carbondale: Southern Illinois Univesity Press.

Tiles, J. E. (1988). Dewey. London \& New York: Routledge.

Wang, J. C.-S. (2007). John Dewey in China: To teach and to learn. Albany: State University of New York Press.

Welchman, J. (1995). Dewey's Ethical Thought. Ithaca: Cornell University Press.

Westbrook, R. B. (1993). John Dewey and American Democracy. Ithaca: Cornell University Press.

White, M. (1949). Social Thought in America. New York: Viking.

White, M. (1992). Value and Obligation in Dewey and Lewis. John Dewey. Critical Assessments. Vol. 3. London; New York: Routledge. Pp. 28-36.

White, M. (1996). Desire and Desirability: A Rejoinder to a Posthumous Reply by John Dewey. The Journal of Philosophy, 93(5), 229-242. 